\title{
The Distribution and History of Nuclear Weapons Related Contamination in Sediments from the Ob River, Siberia as Determined by Isotopic Ratios of Plutonium, Neptunium, and Cesium
}

\author{
by \\ Timothy Cope Kenna \\ B.A., Vassar College, 1988
}

Submitted in partial fulfillment of the requirements for the degree of

Doctor of Philosophy

at the

WOODS HOLE OCEANOGRAPHIC INSTITUTION

\section{MBL / WHOI LIBRARY \\ Woods Hole, MA}

Marine Biological Laboratory

Woods Hole Oceanographic Institution and the

MASSACHUSETTS INSTITUTE OF TECHNOLOGY

February 2002

(C) 2002 Timothy C. Kenna

All rights reserved

The author hereby grants MIT and WHOI permission to reproduce paper and electronic copies of this thesis in whole or in part and to distribute them publicly.

Signature of Author

Joint Program in Oceanography

Massachusetts Institute of Technology and Woods Hole Oceanographic Institution

Certified by 


\section{The Distribution and History of Nuclear Weapons Related Contamination in Sediments from the Ob River, Siberia as Determined by Isotopic Ratios of Plutonium, Neptunium, and Cesium}

by

Timothy Cope Kenna

\section{Abstract}

This thesis addresses the sources and transport of nuclear weapons related contamination in the Ob River region, Siberia. In addition to being one of the largest rivers flowing into the Arctic Ocean, the bulk of the former Soviet Union's nuclear fuel reprocessing and weapons testing facilities (i.e. Mayak, Tomsk-7, and Semipalitinsk) are located within the $\mathrm{Ob}$ drainage basin. The atom ratios ${ }^{240} \mathrm{Pu} /{ }^{239} \mathrm{Pu},{ }^{237} \mathrm{~Np} /{ }^{239} \mathrm{Pu}$, and ${ }^{137} \mathrm{Cs} /{ }^{240} \mathrm{Pu}$, measured by magnetic-sector ICP-MS, are used to distinguish between contamination derived from global fallout and contamination derived from local sources. Deposition chronologies estimated for sediment cores are used to construct a record of weapons related contamination at the sites sampled. Contaminant records indicate that in addition to debris from atmospheric weapons tests, materials derived from local sources have also played a role in nuclear weapons related contamination of the $\mathrm{Ob}$ region. Isotopic data presented in this study clearly demonstrate that non-fallout contamination has been transported the full length of the Tobol, Irtysh, and Ob Rivers (i.e. the tributaries draining Mayak, Semipalitinsk, and Tomsk-7, respectively).

In several instances, unique isotopic compositions are observed in sediments collected from tributaries draining each of the suspected non-fallout sources. In such cases, these materials and their deposition ages have been used to link contamination in the Ob delta to Mayak, Tomsk-7, or Semipalitinsk. Linear transport rate estimates (km $\left.\mathrm{yr}^{-1}\right)$ indicate that contaminated sediments transit between source tributaries and the $\mathrm{Ob}$ delta on time-scales of $\leq 1$ year. These estimates suggest that a catastrophic release of contamination due to dam failure at one of the many reservoirs located at both Mayak and Tomsk-7 that contain high levels of radioactive waste would result in measurable levels of contamination in the delta within as little as 1 year.

Isotopic concentrations in sequentially extracted sediments containing weapons related contamination reveal that the majority of plutonium and neptunium (80 to 90 
percent) behaves in a similar fashion regardless of the source and is removed by treating the sediments with citrate-dithionite. This indicates that plutonium and neptunium are not truly refractory and likely associate with redox sensitive sedimentary components. Isotopic ratios measured in extracted fractions suggest that only a minor fraction of contamination is associated with acid leachable or acid digestible sedimentary phases.

Thesis Supervisor: Frederick L. Sayles, Scientist Emeritus 


\section{Acknowledgements}

Conducting high quality scientific research and writing a doctoral dissertation is not a solitary endeavor; it requires collaboration of the finest kind. Six years ago Fred Sayles took a chance on me; thanks Fred. During our time together, I have learned much and relied heavily on your advice and guidance; you have my respect and deepest gratitude. I would also like to thank my committee members, Bill Jenkins, Greg Ravizza, Hugh Livingston, John Edmond, and Harry Hemond for their insight, encouragement, and patience as I went through this process. Special thanks to Bill Jenkins for traveling across the Atlantic to be at my defense and to Harry Hemond for stepping in on rather short notice. Thanks also to Ken Buesseler not only for chairing my defense, but also for taking the time to talk with me when I would wander into his office and making available to me both laboratory facilities and reference materials.

This work would not have been possible without the efforts of Gera Panteleyev and Steven Smith who were responsible for logistics and sample collection in the Ob. It is a sad note that a tragic accident on the Ob River in the summer of 1995 took Gera's life; he is sorely missed, and I would especially like to acknowledge his contribution to this research.

I also want to acknowledge and greatly appreciate the assistance of Joanne Goudreau for setting up and over-seeing many of the sample processing and radiochemical procedures as well as putting up with my tendency to sprawl and colonize any available space in the lab.

Scot Birdwhistell was also very helpful with sample processing and method development.

Outside of the Sayles group, there are numerous scientists and technical staff, who have been of great assistance. I want to say thanks to all those who have taken the time to listen and give advice over the years. Mark Kurz, who hired me as a research assistant in 1991, and is largely responsible for my interest in isotope geochemistry. He continues to act as both friend and confidant. Dave Glover has been a constant source of information and assistance with modeling and statistical analyses and never seemed to mind taking time to help me. Special thanks to Lary Ball, the ICP-MS master, for his patient assistance, sense of humor, and allowing me to independently operate the Element. Kathleen Ruttenberg was extremely helpful with advice and information concerning selective extraction. Conversations with Ed Sholkovitz, Eric Hintsa, John Andrews, Steve Pike, Steve Manganini and Pat Lohman were also very helpful. Special thanks to both Dempsey Lott and Josh Curtis for all their technical assistance over the years. They may notice that tools and supplies last a bit longer after I am gone. I also greatly appreciate the assistance of Sheila Clifford, Joanna Ireland, Susan Casso, and Donna Mortimer in the Department of Marine Chemistry and Geochemistry as well as Julia Westwater, Marsha Bissonette in the WHOI Education Department.

Outside of WHOI, I want to acknowledge Sherrod Maxwell, Wes Efurd, Tom Beasley, and Jim Kelley for their help with method development and measurements.

I would also like to thank the many friends that I have made over the years. Fellow students, especially Mak Saito, Carrie Tuit, Payel Parekh, Allegra Hosford, Jen 
Georgian, Robert Ackert, and Kirsten Laarkamp. All of my friends at the Sea Education Association, Penikese Island School, Chuch of the Messiah, and the Upper Cape Cod Tae Kwon Do Club. I especially want to acknowledge the friendship of Bill and Dori Mebane and thank them for all of the good times and adventures. I shall miss you all terribly.

But most importantly, I want to thank my family; my mother and father and especially my wife Laura and daughter Katie. Without their constant love, encouragement, and support, I never would have made it.

Funding for this research was provided by the Office of Naval Research under Grants N00014-93-1-1139, and N00014-1-95), and the National Science Foundation under Grant EAR-98-07590. 


\section{Table of Contents}

Title Page......................................................................

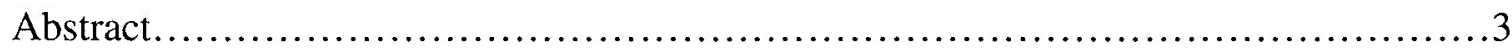

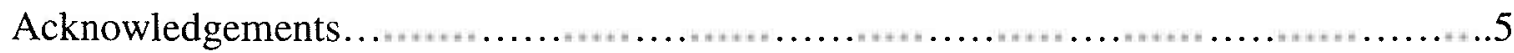

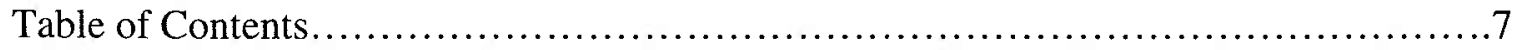

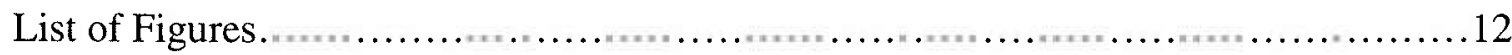

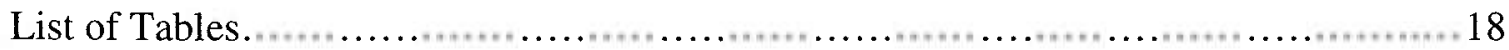

Chapter 1. Nuclear weapons related contamination in the Ob River: Introduction,

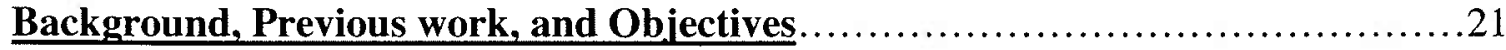

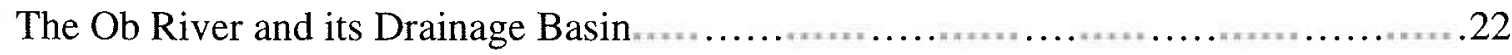

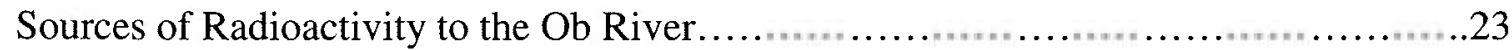

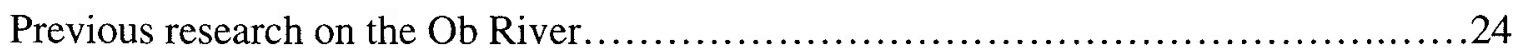

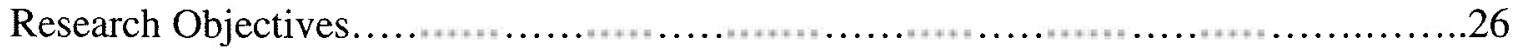

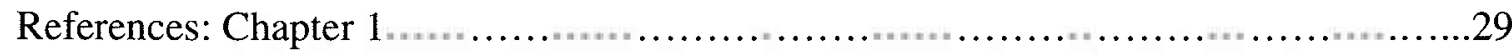

Chapter 2. Sources of Radioactive Contamination to the Ob Watershed............31

Radioactive Fallout from Nuclear Weapons Tests.................................. 31

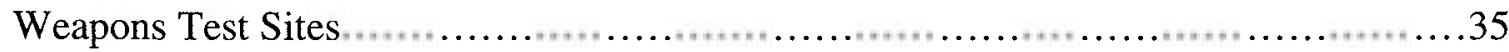

Weapons Production and Nuclear Fuel Reprocessing Facilities.......................40

Nuclear Accident at Chernobyl ..............................................44

Isotopic Composition of Different contaminant Sources..................................45

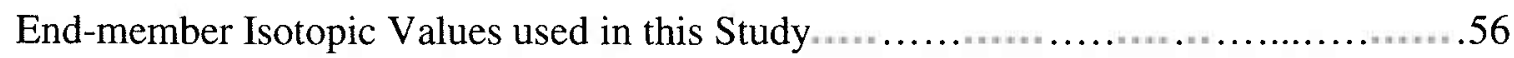

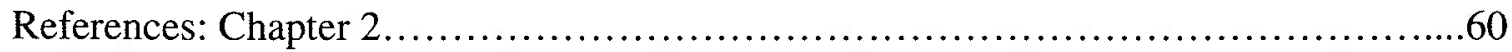


Chapter 3. Characteristics of the Ob River System.

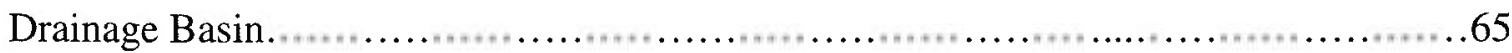

Hydrologic Regime and Sedimentation........................................65

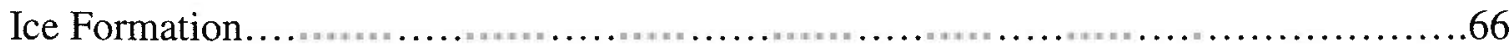

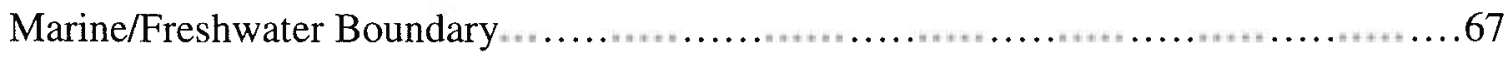

Water and Suspended Sediment Discharge ........................................67

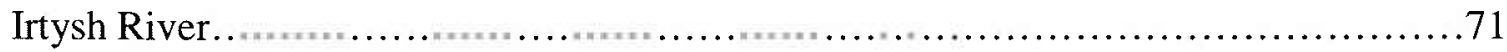

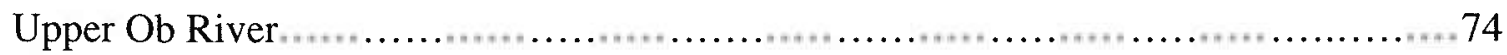

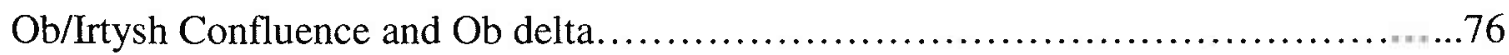

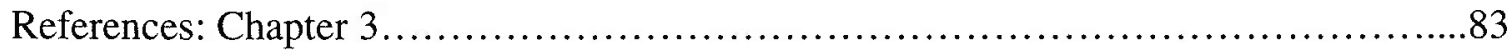

Chapter 4. Sampling, Analytical Methods, and Data .............................8 87

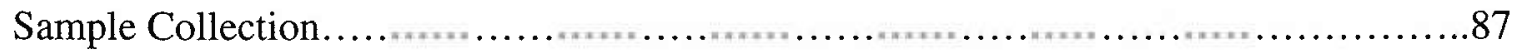

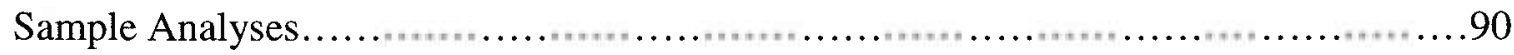

Isotope dilution and yield monitors............................................ 91

Instrumentation and mass spectrometer analysis method...........................91

Isotope ratio and concentration calculations and uncertainty estimates..................99

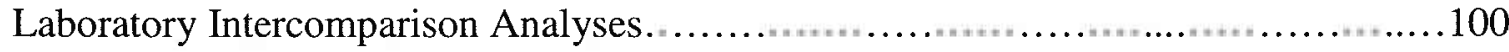

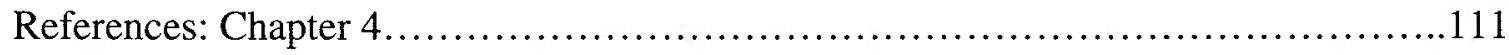

Chapter 5. Radionuclide Distributions, Sedimentation Rates, and Core

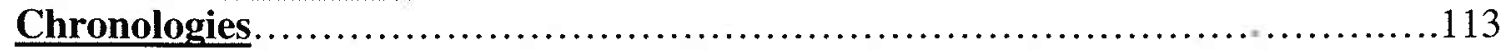

Radionuclide Distributions...................................................... 113 
Sedimentation Rates and Chore Chronologies.................................... 127

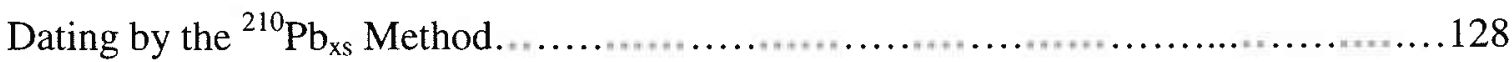

Dating by the Radionuclide Horizon Method........................................133

Initial Appearance of Weapons Related Contamination...............................134

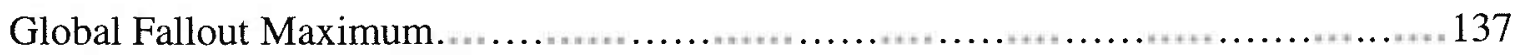

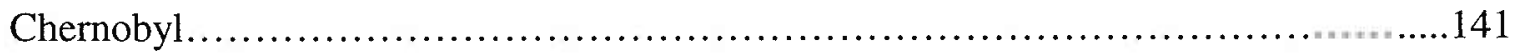

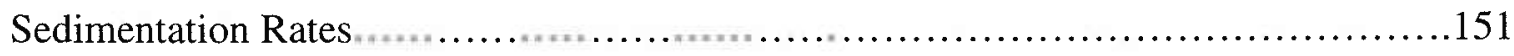

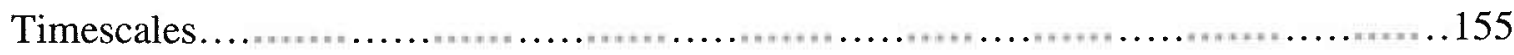

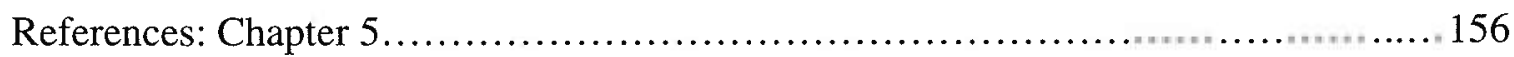

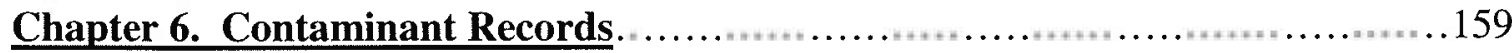

Characterization of Nuclear Weapons Related Contamination........................159

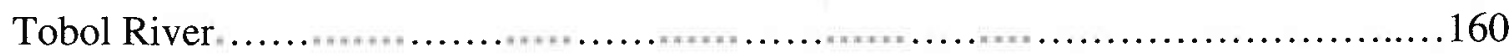

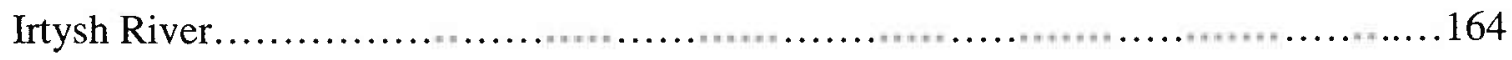

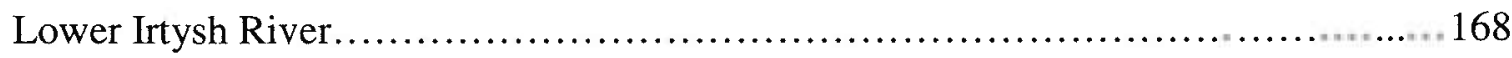

Upper Ob River .......................................................... 170

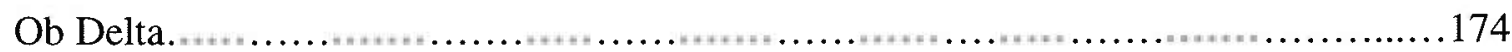

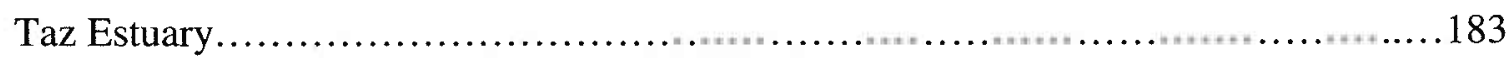

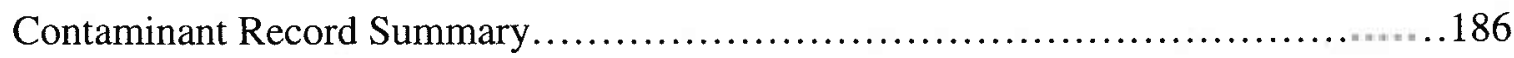

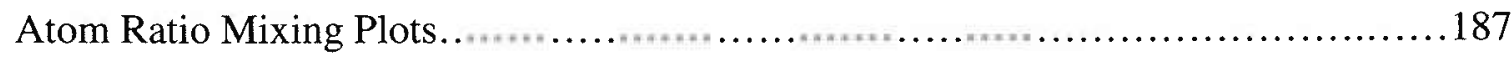

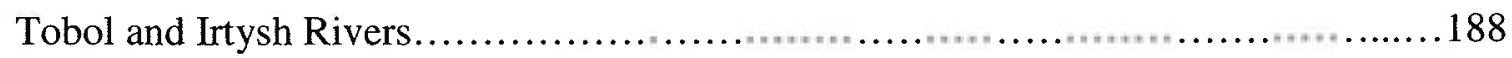

Lower Irtysh River, Upper Ob River, and Ob Delta from 1986 to $1995 \ldots \ldots \ldots \ldots \ldots \ldots . . . .193$ 
Tobol River, Irtysh River, Upper Ob River and Ob delta prior to the mid-1980s.

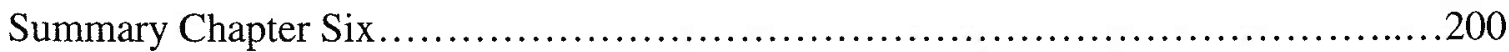

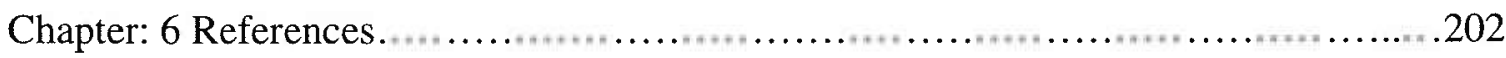

Chapter 7. The Distribution of ${ }^{239} \mathrm{Pu},{ }^{240} \mathrm{Pu}$, and ${ }^{237} \mathrm{~Np}$ among Chemically Defined

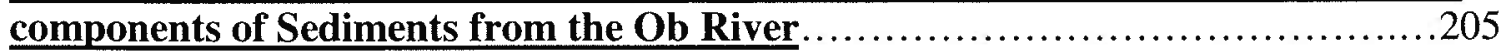

Overview of Selective Leach Fractions and Experimental Design.......................207

Results and Discussion..................................................... 215

Distributions of ${ }^{239} \mathrm{Pu},{ }^{240} \mathrm{Pu}$, and ${ }^{237} \mathrm{~Np}$ among Fractions.........................216

Comparison of ${ }^{239} \mathrm{Pu},{ }^{240} \mathrm{Pu}$, and ${ }^{237} \mathrm{~Np}$ measured in Bulk Sediments and Fraction

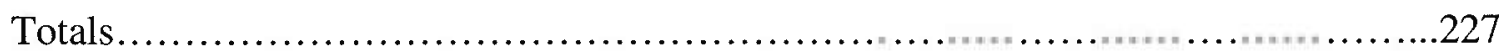

Comparison of $\mathrm{Pu}$ and $\mathrm{Np}$ Isotopic Composition of Bulk Sediments and Leached

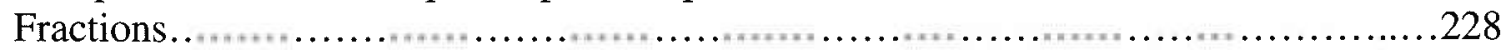

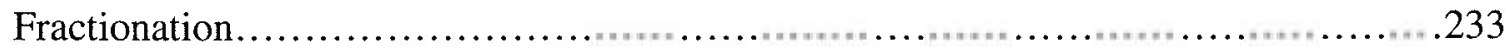

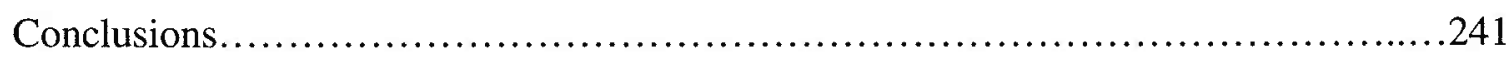

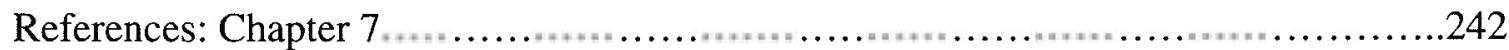

Chapter 8. Contaminated Sediment Transport Rates and Contribution Estimates

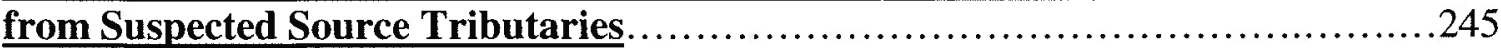

Contaminated Sediment Transport Rates.........................................245

Contaminated tributary sediment vs. global fallout contributions .....................258

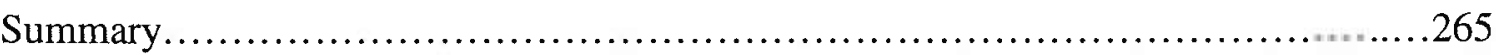

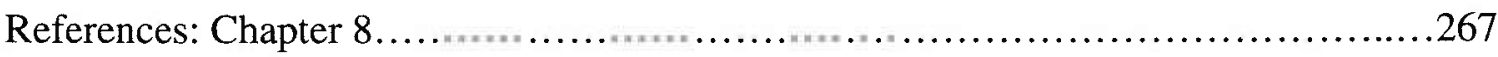


Chapter 9. Conclusions.

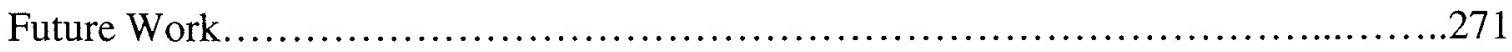

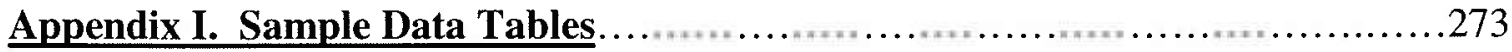

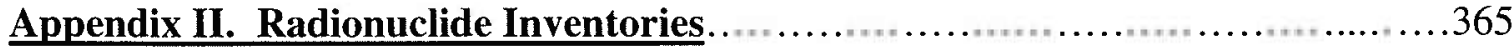




\section{List of Figures}

Chapter 1. Nuclear weapons related contamination in the Ob River: Introduction, Background, Previous work, and Objectives

Figure 1:1. Map showing Ob River drainage basin with sources of weapons related contamination and study region.................................................... 20

\section{Chapter 2. Sources of Radioactive Contamination to the Ob Watershed}

Figure 2:1. Summary of Nuclear Weapons tests by the 5 major Nuclear Powers.........30

Figure 2:2. Latitudinal distribution of ${ }^{90} \mathrm{Sr}$ Fallout Measured for the Period 1958 to 1967

Figure 2:3 Quarterly Deposition of 90Sr Measured at New York City between 1954 and 1970.

Figure 2:4. Percent of Total Activity initially injected into the Troposphere as a Function of Total Yield for Air Bursts in the Tropical Atmosphere..................................34

Figure 2:5. Summary of FSU Tests at Semipalitinsk and Novaya Zemlya................36

Figure 2:6. Summary of USA Aboveground Tests Conducted at Low Latitude Pacific

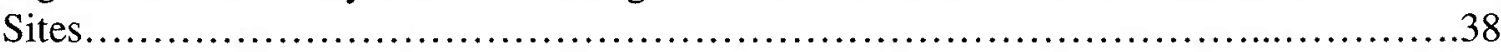

Figure 2:7. Summary of PRC aboveground tests conducted at Lop Nor.................38

Figure 2:8. The Range of Isotopic Composition of Different Contaminant Sources......57

\section{Chapter 3. Characteristics of the Ob River System}

Figure 3:1. Mean Monthly Water and Sediment Discharge observed at Salekhard

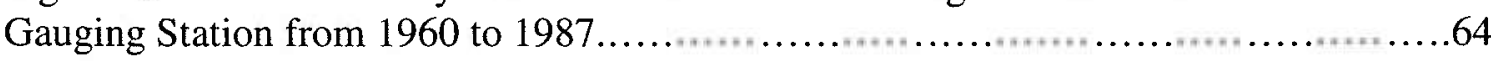

Figure 3:2. Map of Ob River Region with Hydrographic Stations and Potential Sources of Weapons Related Contamination...............................................69

Figure 3:3. Mean Annual Water and Sediment Discharge for Locations along the Iset, Tobol, and Irtysh River above its Confluence with the Ob River ...........................73 
Figure 3:4. Mean Annual Water and Sediment Discharge for Locations along the $\mathrm{Ob}$ River above its Confluence with the Irtysh River................................. 75

Figure 3:5. Mean Annual Water and Sediment Discharge for Locations along the $\mathrm{Ob}$ River Below its Confluence with the Irtysh River..................................77

Figure 3:6. Annual Water and Sediment Discharge Estimated for Khanty-Mansiysk and the Ob River above its Confluence with the Irtysh River ................................79

Figure 3:7. Estimated Contributions of Sediment from the Techa, Tom, and upper Irtysh River to the Suspended Sediment Load at Salekhard from 1960 to $1987 . \ldots \ldots \ldots \ldots \ldots \ldots . . .82$

\section{Chapter 4. Sampling, Analytical Methods, and Data}

Figure 4:1. Map Showing Study Region with Sample Station Locations................86

Figure 4:2a. Schematic Outlining the Combustion, Acid Digestion, and Co-precipitation techniques developed at WHOI for Pu and Np ICP-MS Isotopic Analyses...............94

Figure 4:2b. Schematic Outlining the Ion Exchange Clean-up and Purification and Sample Loading Techniques Developed at WHOI for Pu and Np ICP-MS Isotopic

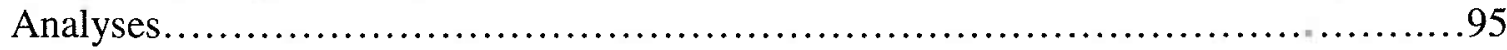

Figure 4:3. Radionuclide intercomparison analyses for OB94-07B..................101

Figure 4:4. Replicate radionuclide analyses by WHOI ICP-MS for $10 \mathrm{~g}$ aliquots from

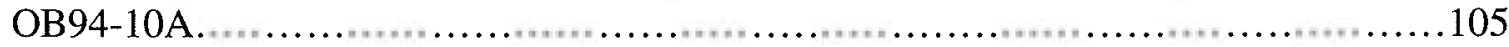

Figure 4:5. Replicate radionuclide analyses by WHOI ICP-MS for 10g aliquots from

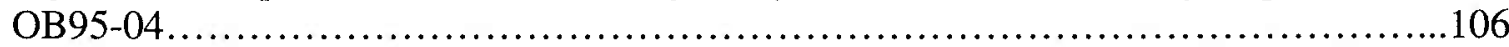

Figure 4:6. The ${ }^{240} \mathrm{Pu} /{ }^{239} \mathrm{Pu}$ isotopic ratio of excess plutonium detected in replicate analyses where concentration differences for both ${ }^{239} \mathrm{Pu}$ and ${ }^{240} \mathrm{Pu}$ were $>3 \sigma$ error.....110

\section{Chapter 5. Radionuclide Distributions, Sedimentation Rates, and Core Chronologies}

Figure 5:1a. Depth distributions of ${ }^{137} \mathrm{Cs}$ in sediment cores from the Ob delta and Taz estuary ........................................................................ 116 
Figure 5:1b. Depth distributions of ${ }^{137} \mathrm{Cs}$ in sediment cores from the upper reaches of the Ob, Irtysh, and Tobol Rivers.

Figure 5:2a. Depth distributions of ${ }^{239} \mathrm{Pu}$ in sediment cores from the Ob delta and Taz estuary

Figure 5:2b. Depth distributions of ${ }^{239} \mathrm{Pu}$ in sediment cores from the upper reaches of the Ob, Irtysh, and Tobol Rivers. 120

Figure 5:3a. Depth distributions of ${ }^{240} \mathrm{Pu}$ in sediment cores from the Ob delta and Taz estuary 122

Figure 5:3b. Depth distributions of ${ }^{240} \mathrm{Pu}$ in sediment cores from the upper reaches of the Ob, Irtysh, and Tobol Rivers.

Figure 5:4a. Depth distributions of ${ }^{237} \mathrm{~Np}$ in sediment cores from the Ob delta and Taz estuary 125

Figure 5:4b. Depth distributions of ${ }^{237} \mathrm{~Np}$ in sediment cores from the upper reaches of the $\mathrm{Ob}$, Irtysh, and Tobol Rivers.

Figure 5:5a. ${ }^{210} \mathrm{~Pb}_{\mathrm{xs}}$ with exponential fits for sediment cores from the Ob delta and Taz estuary.

Figure 5:5b. ${ }^{210} \mathrm{~Pb}_{\mathrm{xs}}$ with exponential fits for the upper reaches of the Ob, Irtysh and Tobol Rivers. 132

Figure 5:6. Estimated fractions of global fallout and non-fallout ${ }^{240} \mathrm{Pu}$ in OB94-07B...140 Figure 5:7a. ${ }^{137} \mathrm{Cs} / 240 \mathrm{Pu}$ profiles from sediment cores collected in the upper reaches of the $\mathrm{Ob}$, Irtysh, and Tobol Rivers from global fallout maximum (GFM) to surface......143

Figure 5:7b. ${ }^{137} \mathrm{Cs} /{ }^{240} \mathrm{Pu}$ profiles from sediment cores collected in the Ob delta and Taz estuary from global fallout maximum (GFM) to surface. 148

\section{Chapter 6. Contaminant Records}

Figure 6:1. Contaminant records in the Tobol River core, OB95-10 ..................161

Figure 6:2. Contaminant records in the Irtysh River core, OB95-13................ 165

Figure 6:3. Contaminant records in the Lower Irtysh River core, OB95-06...........169 
Figure 6:4a. Contaminant records in the upper Ob River core, OB95-04..............171

Figure 6:4b. Contaminant records in the upper Ob River core, OB95-05 $\ldots \ldots \ldots \ldots \ldots 172$

Figure 6:5a. ${ }^{240} \mathrm{Pu} /{ }^{239} \mathrm{Pu}$ records in Ob delta cores, OB94-07B and OB94-10A.........175

Figure 6:5b. ${ }^{240} \mathrm{Pu} /{ }^{239} \mathrm{Pu}$ records in Ob delta cores, OB94-09 and OB94-08............ 176

Figure 6:6a. ${ }^{237} \mathrm{~Np} /{ }^{239} \mathrm{Pu}$ records in Ob delta cores, OB94-07B and OB94-10A.........178

Figure 6:6b. ${ }^{237} \mathrm{~Np} /{ }^{239} \mathrm{Pu}$ records in Ob delta cores, OB94-09 and OB94-08...........179

Figure 6:7a. ${ }^{137} \mathrm{Cs} /{ }^{240} \mathrm{Pu}$ records in Ob delta cores, OB94-07B and OB94-10A..........181

Figure 6:7b. ${ }^{137} \mathrm{Cs} /{ }^{240} \mathrm{Pu}$ records in Ob delta cores, OB94-09 and OB94-08.............182

Figure 6:8. Contaminant records in the Taz estuary core, OB94-13 .................184

Figure 6:9. ${ }^{240} \mathrm{Pu} /{ }^{239} \mathrm{Pu}$ vs. ${ }^{237} \mathrm{~Np} /{ }^{239} \mathrm{Pu}$ atom ratio mixing plot; data from the Tobol and upper and lower Irtysh River with estimated deposition ages between 1986 and $\sim 1995$.

Figure 6:10. ${ }^{239} \mathrm{Pu} /{ }^{240} \mathrm{Pu}$ vs. ${ }^{137} \mathrm{Cs} /{ }^{240} \mathrm{Pu}$ atom ratio mixing plot; data from the Tobol and upper and lower Irtysh River with estimated deposition ages between $\sim 1986$ and $\sim 1995$.

Figure 6:11. ${ }^{240} \mathrm{Pu} /{ }^{239} \mathrm{Pu}$ vs. ${ }^{237} \mathrm{~Np} /{ }^{239} \mathrm{Pu}$ atom ratio mixing plot; data from lower Irtysh, upper $\mathrm{Ob}$, and $\mathrm{Ob}$ delta with estimated deposition ages between $\sim 1986$ and $\sim 1995$.

Figure 6:12. ${ }^{239} \mathrm{Pu} /{ }^{240} \mathrm{Pu}$ vs. ${ }^{137} \mathrm{Cs} /{ }^{240} \mathrm{Pu}$ atom ratio mixing plot; data from the upper $\mathrm{Ob}$, lower Irtysh, and $\mathrm{Ob}$ delta with estimated deposition ages between $\sim 1986$ and $\sim 1995$.

Figure 6:13. ${ }^{240} \mathrm{Pu} /{ }^{239} \mathrm{Pu}$ vs. ${ }^{237} \mathrm{~Np} /{ }^{239} \mathrm{Pu}$ atom ratio mixing plot; samples from the Tobol, upper Irtysh, and upper Ob Rivers, and the $\mathrm{Ob}$ delta with estimated deposition ages prior to $\sim 1985$. 198

Figure 6:14. ${ }^{137} \mathrm{Cs} /{ }^{240} \mathrm{Pu}$ vs. ${ }^{239} \mathrm{Pu} /{ }^{240} \mathrm{Pu}$ atom ratio mixing plot; samples from the Tobol, upper Irtysh, and upper Ob Rivers, and the Ob delta with estimated deposition ages prior to $\sim 1985$. 
Chapter 7. The Distribution of ${ }^{239} \mathrm{Pu},{ }^{240} \mathrm{Pu}$, and ${ }^{237} \mathrm{~Np}$ among Chemically Defined components of Sediments from the Ob River

Figure 7:1. Sequential Extraction Procedure

Figure 7:2. A comparison of ${ }^{240} \mathrm{Pu} /{ }^{239} \mathrm{Pu}$ atom ratios in Accessible and Refractory fractions.

Figure 7:3. A comparison of ${ }^{237} \mathrm{~Np} /{ }^{239} \mathrm{Pu}$ atom ratios in Accessible vs. Refractory fractions

Figure 7:4. Approximate positions of some natural environments as characterized by Eh and $\mathrm{pH}$

Chapter 8. Contaminated Sediment Transport Rates and Contribution Estimates from Suspected Source Tributaries

Figure 8:1 Yearly ${ }^{240} \mathrm{Pu} /{ }^{239} \mathrm{Pu}$ and ${ }^{237} \mathrm{~Np} /{ }^{239} \mathrm{Pu}$ isotopic ratios of source tributaries used in model. .250

Figure 8:2 Yearly ${ }^{137} \mathrm{Cs} /{ }^{240} \mathrm{Pu}$ isotopic ratios of source tributaries used in model shown at two different scales. 251

Figure 8:3. Model results for delta core OB94-07B..............................254

Figure 8:4. Model results for delta core OB94-10A.............................255

Figure 8:5. Model results for lower Irtysh core OB95-06 ............................256

Figure 8:6. Model results for delta core OB94-07B (1-year lag) ....................259

Figure 8:7. Model results for delta core OB94-10A (1-year lag, low ratio replicate

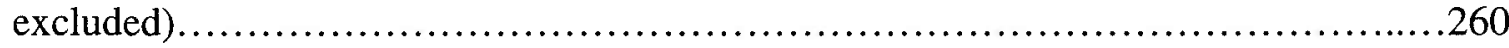

Figure 8:8. Model results for lower Irtysh core OB95-06 (0-year lag) $\ldots \ldots \ldots \ldots \ldots \ldots \ldots . \ldots 1$

\section{Appendix II Radionuclide Inventories}

Figure AII:1a. ${ }^{237} \mathrm{~Np}$ inventory comparison between sediment cores from the $\mathrm{Ob}$ region and soils from other northern latitude sites. 
Figure AII: 1 b. ${ }^{239} \mathrm{Pu}$ inventory comparison between sediment cores from the Ob region

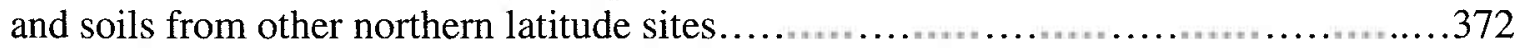

Figure AII:1c. ${ }^{240} \mathrm{Pu}$ inventory comparison between sediment cores from the $\mathrm{Ob}$ region

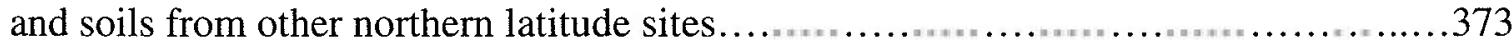

Figure AII:1d. ${ }^{137} \mathrm{Cs}$ inventory comparison between sediment cores from the Ob region and soils from other northern latitude sites..................................... 374 


\section{List of Tables}

\section{Chapter 2. Sources of Radioactive Contamination to the Ob Watershed}

Table 2:1. Summary of reactor operations at Mayak....................................41

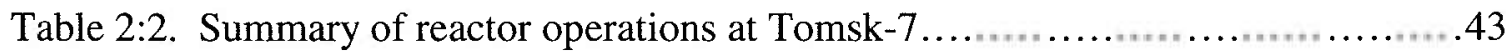

Table 2:3 Estimated isotope ratios of radioactivity sources in the Ob River watershed

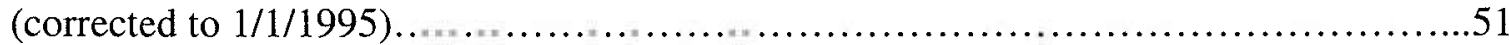

\section{Chapter 3. Characteristics of the Ob River System}

Table 3:1. Mean annual water and suspended sediment discharge at various locations along the $\mathrm{Ob}$ River and its tributaries............................................ 71

\section{Chapter 4. Sampling, Analytical Methods, and Data}

Table 4:1. Sampling locations, water depths, lengths, and suspected contaminant sources for sediment cores in the Ob River Drainage basin..................................8

Table 4:2 Example of instrumental operating conditions..............................93

Table 4:3. Data acquisition parameters for Pu/Np analysis.........................97

Table 4:4. Example of ${ }^{240} \mathrm{Pu} /{ }^{239} \mathrm{Pu}$ calculation and comparison of uncertainty estimates

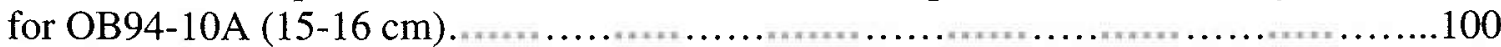

Table 4:5a. Replicate radionuclide analyses by WHOI ICP-MS for standard reference

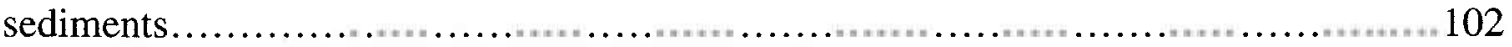

Table 4:5b. Comparison of WHOI results to recommended or informational values available for standard reference sediments....................................... 104

Chapter 5. Radionuclide Distributions, Sedimentation Rates, and Core Chronologies

Table 5:1. Selection of 1950 horizon for Ob River Sediment cores....................136

Table 5:2 Selection of 1963.5 horizon for Ob River Sediment cores.....................141 
Table 5:3 Selection of Chernobyl horizon (1986.5) for Ob River Sediment cores....... 150

Table 5:4 Comparison of deposition ages and sedimentation rates by ${ }^{210} \mathrm{~Pb}_{\mathrm{xs}}$ and the radionuclide horizon method.

\section{Chapter 6. Contaminant Records}

Table 6:1 Percentage of samples containing global fallout and non-fallout contamination as indicated by the different ratios used. .188

Chapter 7. The Distribution of ${ }^{239} \mathrm{Pu},{ }^{240} \mathrm{Pu}$, and ${ }^{237} \mathrm{~Np}$ among Chemically Defined components of Sediments from the Ob River

Table $7: 1$. Fractions and reagents used for sequential extraction....................209

Table 7:2. Bulk Sediment Samples Selected for Sequential Extraction.................216

Table 7:3 Distributions of ${ }^{239} \mathrm{Pu},{ }^{240} \mathrm{Pu}$ and ${ }^{237} \mathrm{~Np}$ among leached fractions............218

Table 7:4 Plutonium distributions among extracted fractions from previous work $\ldots . . .221$

Table 7:5. Weight percent organic material for selected samples....................225

Table 7:6 Concentrations of ${ }^{239} \mathrm{Pu},{ }^{240} \mathrm{Pu}$ and ${ }^{237} \mathrm{~Np}$ for Fraction Totals and Bulk

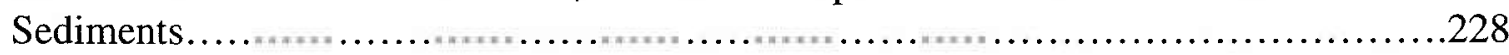

Chapter 8. Contaminated Sediment Transport Rates and Contribution Estimates from Suspected Source Tributaries

Table 8:1. Contaminated sediment transport rates based on measured isotopic ratios...238

Appendix I. Sample Data Tables.

\section{Appendix II. Radionuclide Inventories}

Table AII:1 Radionuclide Inventories. 367

Table AII:2. Comparison of selected radionuclide inventories measured in Ob sediments prior to 1971 to global fallout inventories measured in soils north of $58 \mathrm{~N}$ latitude......370 


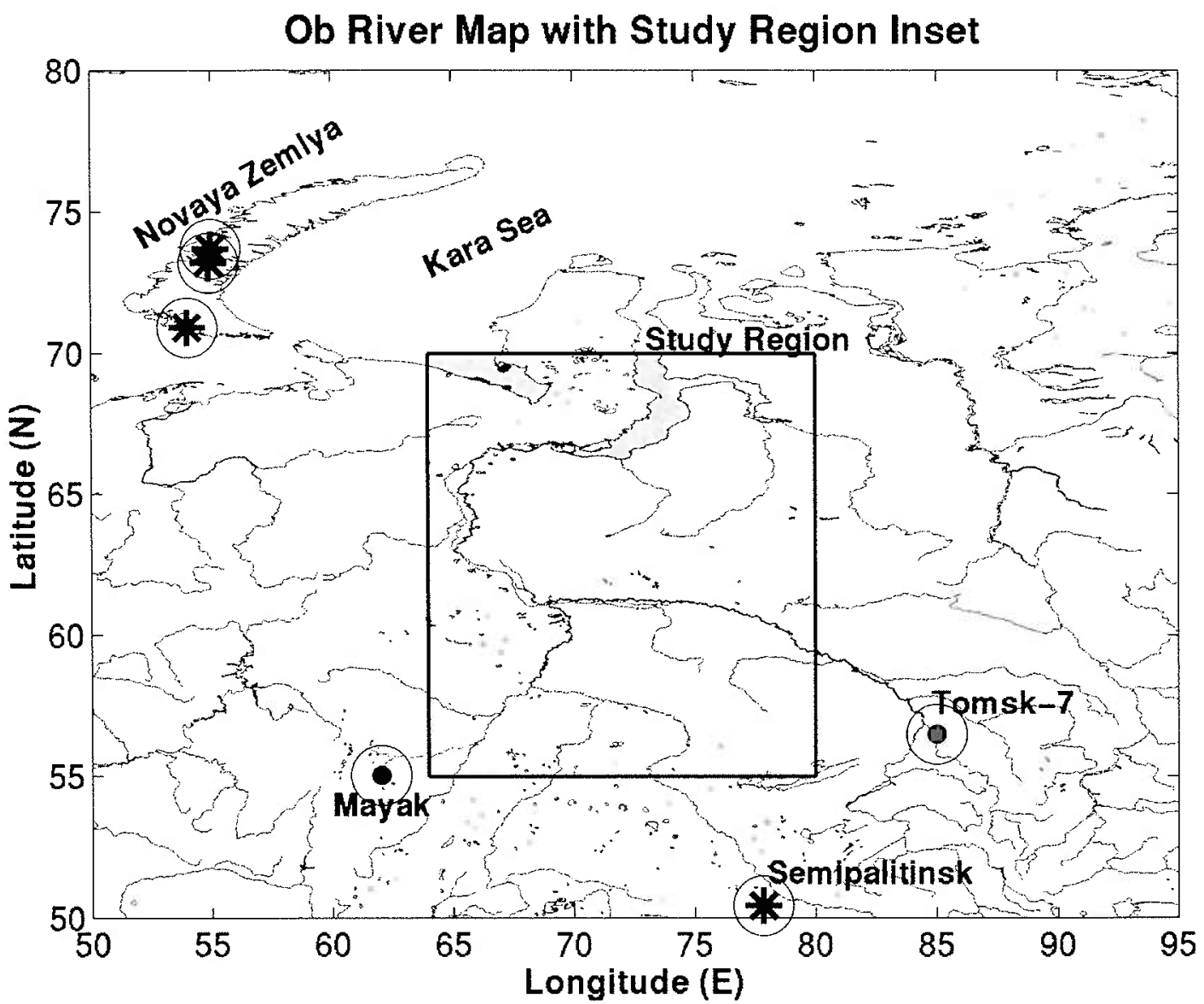

Figure 1:1. Map showing Ob River drainage basin with sources of weapons related contamination and study region. Filled circles within circles are nuclear weapons related facilities and stars within circles are nuclear weapons test sites. 


\section{Chapter 1}

\section{Nuclear weapons related contamination in the Ob River: Introduction, Background, Previous work, and Objectives}

\section{Introduction}

Nuclear contaminants have been introduced to the environment through a number of activities, primarily those related to nuclear weapons development, production, and testing. Contaminants such as plutonium and neptunium, and cesium are important in their own right as a human health concern due to their extreme toxicity. Long-lived radionuclides such as ${ }^{239} \mathrm{Pu},{ }^{240} \mathrm{Pu}$, and ${ }^{237} \mathrm{~Np}$ (half-lives of $2.41 \times 10^{4}, 6.56 \times 10^{3}$, and $2.14 \times 10^{6} \mathrm{y}$, respectively) present a long-term threat. Atmospheric weapons tests conducted primarily by the governments of the USA and former Soviet Union (FSU) have been the major source of contamination to date. However, the generation of large quantities of anthropogenic radionuclides in the form of weapons inventories and radioactive waste, without a safe and effective means of long-term storage, makes future contamination a concern. In this context, understanding the geochemistry and behavior of artificial radionuclides once they are released to the environment is imperative. In addition, human health concerns and environmental contamination notwithstanding, an unexpected benefit of these isotopes is that they also provide powerful tracers of natural processes.

This thesis addresses the issues of artificial radionuclide geochemistry and transport by examining the record of nuclear weapons related contamination contained in undisturbed sediments collected from the flood plains of the Ob River, Siberia and its 
major tributaries, as well as the Ob River delta. Particle reactive artificial radionuclides are used to characterize the composition and input timing of contamination derived from both global and local sources. Studies like this one are possible due to several important features of weapons related radionuclides. First, the specific isotopes used in this study are derived entirely from anthropogenic sources. Second, the release history of the primary source of contamination (i.e. aboveground testing of nuclear weapons) is well constrained. Finally, the isotopic composition of nuclear contamination is dependent upon its means of production, e.g. weapons testing, fuel reprocessing, power generation, etc. This last feature offers the ability to resolve contamination from sources other than global fallout, the release histories of which are not as well known. Uniqueness in nature, release information, and the ability to identify a particular source of contamination by its isotopic composition make these isotopes extremely useful for resolving different sources of contamination contributing to delta sediments as well as determining rates and mechanisms of transport. An additional quality of the elements of interest is their particle reactive nature. This not only allows their application to the problem of the fate and transport of other non-nuclear particle reactive contaminants (e.g. heavy metals and organic contaminants like PCBs) but also to the general problem of sediment transport in a large arctic river system.

\section{The Ob River and Drainage Basin}

Arguably, the region most heavily affected by weapons related activities is the $\mathrm{Ob}$ River located in the Siberian Arctic (Figure 1:1). The Ob River is over $2000 \mathrm{~km}$ long and 
flows north to northwest from the Sayan Mountains to its similarly named estuary, which feeds into the Kara Sea. It is the third largest river flowing into the Arctic Ocean and ranks among the largest in the world with respect to both drainage area and annual water discharge (Bobrovitskaya, Zubkova et al. 1996; Meade, Bobrovitskaya et al. 2000). Compared to other rivers of similar water discharge, the sediment discharge is small. Of those rivers draining into the Arctic Ocean however, it is estimated that the $\mathrm{Ob}$ contributes up to $25 \%$ of the total sediment load (Milliman and Meade 1983). The Ob drains an area of $2.5 \times 10^{6} \mathrm{~km}^{2}$, which is approximately $1 / 3$ of the Eurasian Arctic drainage (Milliman and Meade 1983). The Ob drainage basin can be described as generally low-lying terrain comprised of large areas of forest and swamp; these terrains are primarily flood plains which act as excellent sediment traps, limiting the delivery of sediment to the ocean (Bobrovitskaya, Zubkova et al. 1996).

\section{Sources of Radioactivity to the $\mathrm{Ob}$ River}

The Ob River is not only among the largest rivers emptying into the Arctic Ocean; its catchment houses the bulk of the facilities connected to the FSU's nuclear weapons program. The two main weapons production and fuel reprocessing facilities, Mayak and Tomsk-7, and atomic weapons test sites near Semipalitinsk, are situated on tributaries feeding the Ob River. Atomic weapons tests conducted on the nearby island of Novaya Zemlya are also a source of contamination to the region (see Figure 1:1). Incidents of serious environmental contamination at the FSU's weapons production facilities are well documented (Trapeznikov, Pozolotina et al. 1993; Makhijani, Hu et al. 1995; Aarkrog, 
Dahlgaard et al. 1997; Bradley and Payson 1997). Releases due to accidents and wastehandling practices include storage tank explosions, direct disposal onto land and into rivers, storage in lakes and open reservoirs, burial of radioactive scrap metal and solid waste, and deep well injection. The total amount of radioactivity released from sources located within the $\mathrm{Ob}$ drainage basin is estimated to be $1.25 \times 10^{9} \mathrm{Ci}\left(4.63 \times 10^{19} \mathrm{~Bq}\right)$ (Bradley and Payson 1997). The estimated radioactivity of storage inventories at Mayak and Tomsk-7 combined is nearly twice that amount (Bradley and Payson 1997).

\section{Previous Research on the Ob River}

In an effort to better understand the transport of anthropogenic radioactive materials and identify sources of contamination in the Ob River, several studies have been carried out. Panteleyev (1995) measured particle reactive ${ }^{137} \mathrm{Cs},{ }^{238} \mathrm{Pu}$, and ${ }^{239,240} \mathrm{Pu}$ in sediment cores from several small flood plain lakes at different locations in the $\mathrm{Ob}$ delta. The author concluded that sediments in shallow flood plain lakes are relatively unmixed, and thus preserve a clear record of transport and deposition of Pu and Cs. The stability of these environments also permits the use of ${ }^{210} \mathrm{~Pb}_{\mathrm{xs}}$ to establish independent chronologies; these matched the timing characteristics of global fallout deposition quite well as indicated by $\mathrm{Pu}$ and Cs. Using activity ratios of ${ }^{238} \mathrm{Pu} /{ }^{239,240} \mathrm{Pu}$ and ${ }^{239,240} \mathrm{Pu} / /^{137} \mathrm{Cs}$ to indicate sources of contamination to sediments, it was concluded that global fallout is the dominant source of these isotopes to the Ob Delta region; however, uncertainties in data would permit up to $25 \%$ from other sources. 
Sayles et al. (1998) employed a different approach to more definitively identify the sources of weapons related contamination to delta sediments. The plutonium and neptunium isotopic composition of a material corresponds to its means of production (i.e., type and duration of nuclear reactor fuel burn-up, fuel reprocessing, high and low yield weapon detonations). This allows $\mathrm{Pu}$ and $\mathrm{Np}$ isotope ratios to be used as indicators of a contaminant's source, which led to the measurement of ${ }^{239} \mathrm{Pu},{ }^{240} \mathrm{Pu}$ and ${ }^{237} \mathrm{~Np}$ isotopes by thermal ionization mass spectrometry (TIMS) in a sediment core from the $\mathrm{Ob}$ delta. Results from this study confirmed that global fallout was the dominant source of contamination over most of the nuclear age. However, they also provided clear evidence of three additional types of non-fallout contaminants to delta sediments. The presence of contamination by materials from the Chernobyl accident was indicated by measurable amounts of ${ }^{134} \mathrm{Cs}$ activity in a horizon well above the horizon associated with maximum global fallout deposition. Based on departures from published values reported for global fallout, atom ratios of ${ }^{240} \mathrm{Pu} /{ }^{239} \mathrm{Pu}$ and ${ }^{237} \mathrm{~Np} /{ }^{240} \mathrm{Pu}$ indicated two additional types of contamination, one enriched in ${ }^{239} \mathrm{Pu}$ and the other in ${ }^{237} \mathrm{~Np}$.

Using similar techniques to identify the origin of contamination in the Ob River, Cochran et al.(2000) measured Pu and Np isotopic ratios in suspended material collected throughout the Ob River system in 1994 and 1995, which included the tributaries where Mayak, Semipalitinsk, and Tomsk-7 are located. Relative to the average global fallout ${ }^{237} \mathrm{~Np} /{ }^{239} \mathrm{Pu}$ and ${ }^{240} \mathrm{Pu} /{ }^{239} \mathrm{Pu}$ atom ratios of 0.48 and 0.18 , respectively, the material suspended in the Tobol River exhibited a low ${ }^{237} \mathrm{~Np} /{ }^{239} \mathrm{Pu}$ ratio, which indicated contamination originating from Mayak. Suspended material from the Irtysh River 
exhibited low ${ }^{240} \mathrm{Pu} /{ }^{239} \mathrm{Pu}$ and high ${ }^{237} \mathrm{~Np} /{ }^{239} \mathrm{Pu}$ ratios when compared to global fallout, which indicated contamination from Semipalitinsk. Material from the upper Ob River exhibited a low ${ }^{240} \mathrm{Pu} /{ }^{239} \mathrm{Pu}$ ratio, which indicated contamination from Tomsk-7. The authors concluded that contamination observed in suspended particulate matter from the main portions of the $\mathrm{Ob}$ River and $\mathrm{Ob}$ delta was derived from a mixture of global fallout, close-in fallout from Semipalitinsk, and material originating from weapons reprocessing facilities.

\section{Research Objectives}

The research objectives of this thesis are to: 1) develop a history of nuclear weapons related contamination in the Ob River system, and 2) obtain better understanding of the transport and mobility of these materials in a large arctic river system. In pursuit of these goals, a rapid plutonium and neptunium measurement method was developed using recently available magnetic sector inductively coupled plasma mass spectrometer (MS-ICPMS) technologies. Down core distributions of the weapons related isotopes ${ }^{239} \mathrm{Pu},{ }^{240} \mathrm{Pu},{ }^{241} \mathrm{Pu},{ }^{237} \mathrm{~Np}$ and ${ }^{137} \mathrm{Cs}$ in sediment cores collected from flood plain lakes in $\mathrm{Ob}$ delta, the $\mathrm{Ob}$, Irtysh, and Tobol Rivers, and one core from the Taz estuary were measured. Similarities between model deposition ages suggested by unsupported ${ }^{210} \mathrm{~Pb}$ activity $\left({ }^{210} \mathrm{~Pb}_{\mathrm{xs}}\right)$, the timing of the deposition of radionuclides associated with global fallout, and atom ratios of the measured isotopes $\left({ }^{240} \mathrm{Pu} /{ }^{239} \mathrm{Pu},{ }^{237} \mathrm{~Np} /{ }^{239} \mathrm{Pu}\right.$, ${ }^{137} \mathrm{Cs} /{ }^{240} \mathrm{Pu}$ ) have been used to develop time scales for the down core isotope ratio profiles of these nuclear contaminants. Isotopic ratios have also been used to characterize 
contamination originating from the various weapons related sources in the Ob River basin as well as to differentiate between local sources and global fallout.

An important issue concerning the use of isotopic ratios of different elements (i.e. ${ }^{237} \mathrm{~Np} /{ }^{239} \mathrm{Pu}$ and ${ }^{137} \mathrm{Cs} /{ }^{240} \mathrm{Pu}$ ) is the possibility of fractionation of $\mathrm{Pu}, \mathrm{Np}$, and $\mathrm{Cs}$. Fractionation due to differences in geochemical properties could result in variable $\mathrm{Np} / \mathrm{Pu}$ and $\mathrm{Cs} / \mathrm{Pu}$ ratios, which would obscure source information. Since elemental ratios are used throughout this study, the reader is directed to Chapter 7, where experimental work has been conducted on this issue and where other data are discussed to suggest that fractionation does not impact the major trends in the sediment records.

In further support of the research objectives, sub-samples of sediments from the Ob River, delta, and major tributaries for which bulk Pu and Np isotopic composition revealed non-fallout contamination were sequentially leached with a series of different reagents. Each reagent was selected to isolate isotopes bound to different geochemical phases ranging from easily exchangeable to refractory. The distributions of ${ }^{239} \mathrm{Pu},{ }^{240} \mathrm{Pu}$, and ${ }^{237} \mathrm{~Np}$ among these chemically defined components are reported and implications for the mobility of nuclear weapons related contaminants originating from different sources are discussed.

Finally, first order radionuclide transport rates are estimated using the isotopic information obtained in this study. Due to their particle reactive nature, the elements studied can be used as proxies to arrive at contaminated sediment transport rates. Contaminated sediment transport rates are estimated in the Ob River using well-dated, isotopically distinct features that are observed at both upstream and downstream 
locations. The potential transport of contaminants from likely sources within the $\mathrm{Ob}$ watershed is discussed. 


\section{References Chapter 1}

Aarkrog, A., H. Dahlgaard, et al. (1997). "Radioactive inventories from the Kyshtym and Karachay accidents; estimates based on soil samples collected in the South Urals (1990-1995)." The Science of the Total Environment 201(2): 137-154.

Bobrovitskaya, N. N., C. Zubkova, et al. (1996). "Discharges and yields of suspended sediment in the $\mathrm{Ob}^{\prime}$ and Yenisey rivers of Siberia

Proceedings of an International symposium on Erosion and sediment yield; global and regional perspectives." International symposium on Erosion and sediment yield; global and regional perspectives 236: 115-123.

Bradley, D. J. and D. R. Payson (1997). Behind the nuclear curtain : radioactive waste management in the former Soviet Union. Columbus, Ohio, Battelle Press.

Cochran, J. K., S. B. Moran, et al. (2000). "Sources and transport of anthropogenic radionuclides in the Ob River system, Siberia." Earth and Planetary Science Letters 179(1): 125-137.

Makhijani, A., H. Hu, et al. (1995). Nuclear wastelands : a global guide to nuclear weapons production and its health and environmental effects. Cambridge, Mass., MIT Press.

Meade, R. H., N. N. Bobrovitskaya, et al. (2000). "Suspended-sediment and fresh-water discharges in the Ob and Yenisey rivers, 1960-1988." International journal of Earth Sciences 89: 461-469.

Milliman, J. D. and R. H. Meade (1983). "World-wide delivery of river sediments to the Oceans." Journal of Geology 91(1): 1-21.

Panteleyev, G. P. (1995). The history of plutonium and cesium-137 contamination of the Ob River delta sediments, Massachusetts Institute of Technology, Cambridge, MA, United States.

Sayles, F. L., T. C. Kenna, et al. (1998). Release and transport of artificial radionuclides from nuclear weapons related activities in the Ob River, Siberia ove the course of the nuclear age. International symposium on marine pollution, Monaco, IAEA.

Trapeznikov, A. V., V. N. Pozolotina, et al. (1993). "Radioaktivnoye zagryazneniye reki Techi na Urale; Techa River radioactive contamination in Urals." Ekologiya 1993(5): 72-77. 


\section{Summary of Nuclear Weapon Detonations}
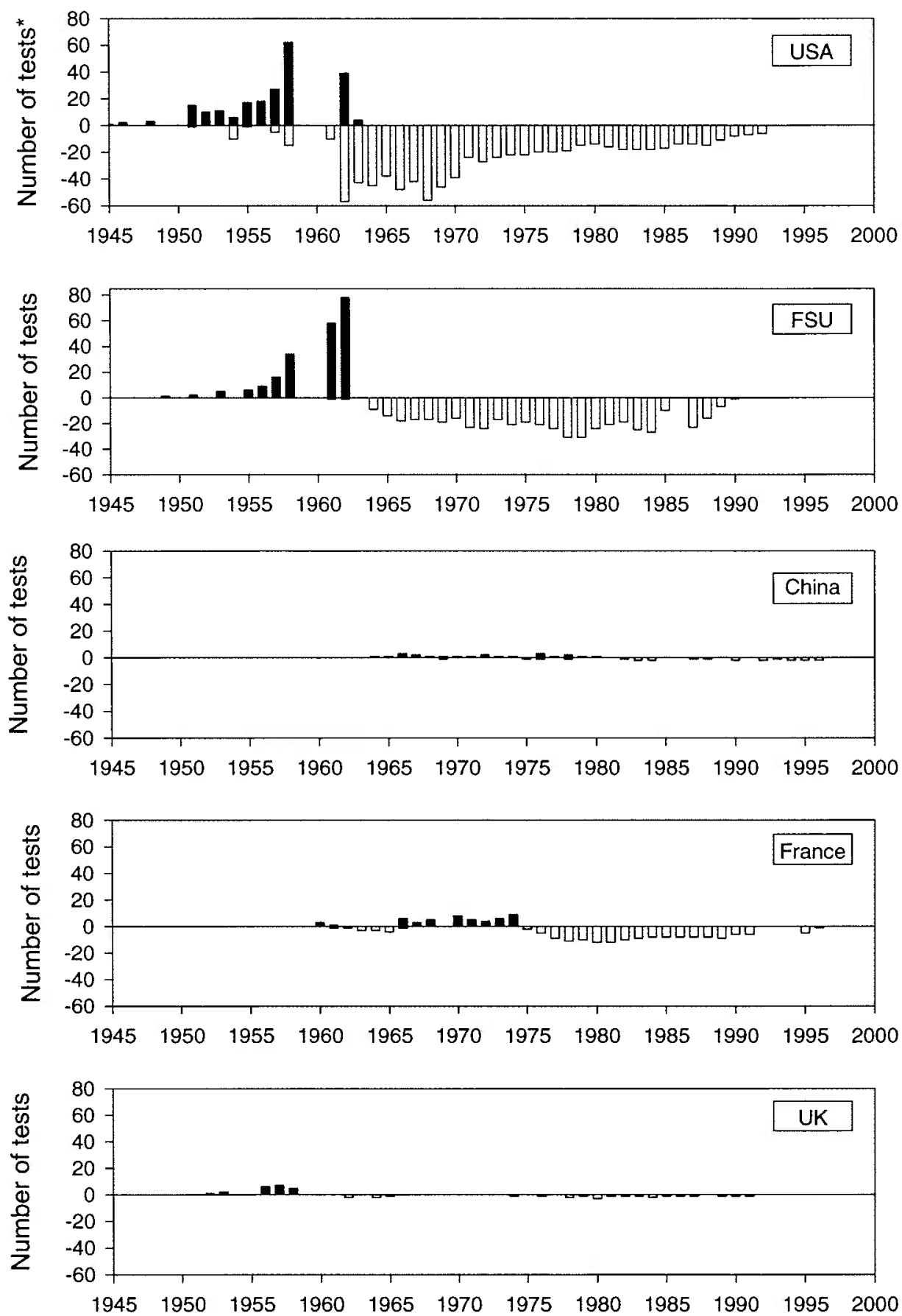

Figure 2:1. Summary of Nuclear weapons tests by the 5 major nuclear powers. ${ }^{*}$ Black and white bars indicate aboveground and underground tests, respectively. 


\section{Chapter 2}

\section{Sources of Radioactive Contamination to the Ob Watershed}

The major source of radioactive contamination to the Ob River region and to the environment in general has been global fallout from the atmospheric weapons tests, which were conducted primarily by the USA and FSU during the 1950s and early 1960s (Perkins and Thomas 1980). Local sources of radioactive contamination include two nuclear testing sites, and two of the FSU's largest nuclear fuel reprocessing facilities and weapons complexes. Additional sources potentially important in the Northern Hemisphere include the Chernobyl accident (April 1986) and aboveground weapons tests conducted by the government of the Peoples Republic of China (PRC) from the mid1960 s to the early $1980 \mathrm{~s}$.

\section{Radioactive Fallout from Nuclear Weapons Tests}

The first atmospheric nuclear weapons test occurred on July 16, 1945 at the Alamogordo, New Mexico test site. The FSU detonated its first atomic weapon at the Semipalitinsk test site on August 29, 1949. A summary of nuclear weapons tests conducted by the 5 major nuclear powers is shown in Figure 2:1. The USA and FSU conducted the majority of all atomic weapons tests. Testing increased during the 1950s until the November 1958 moratorium, which lasted until September 1961 when testing began again in earnest. The majority of the atmospheric tests occurred from this point 


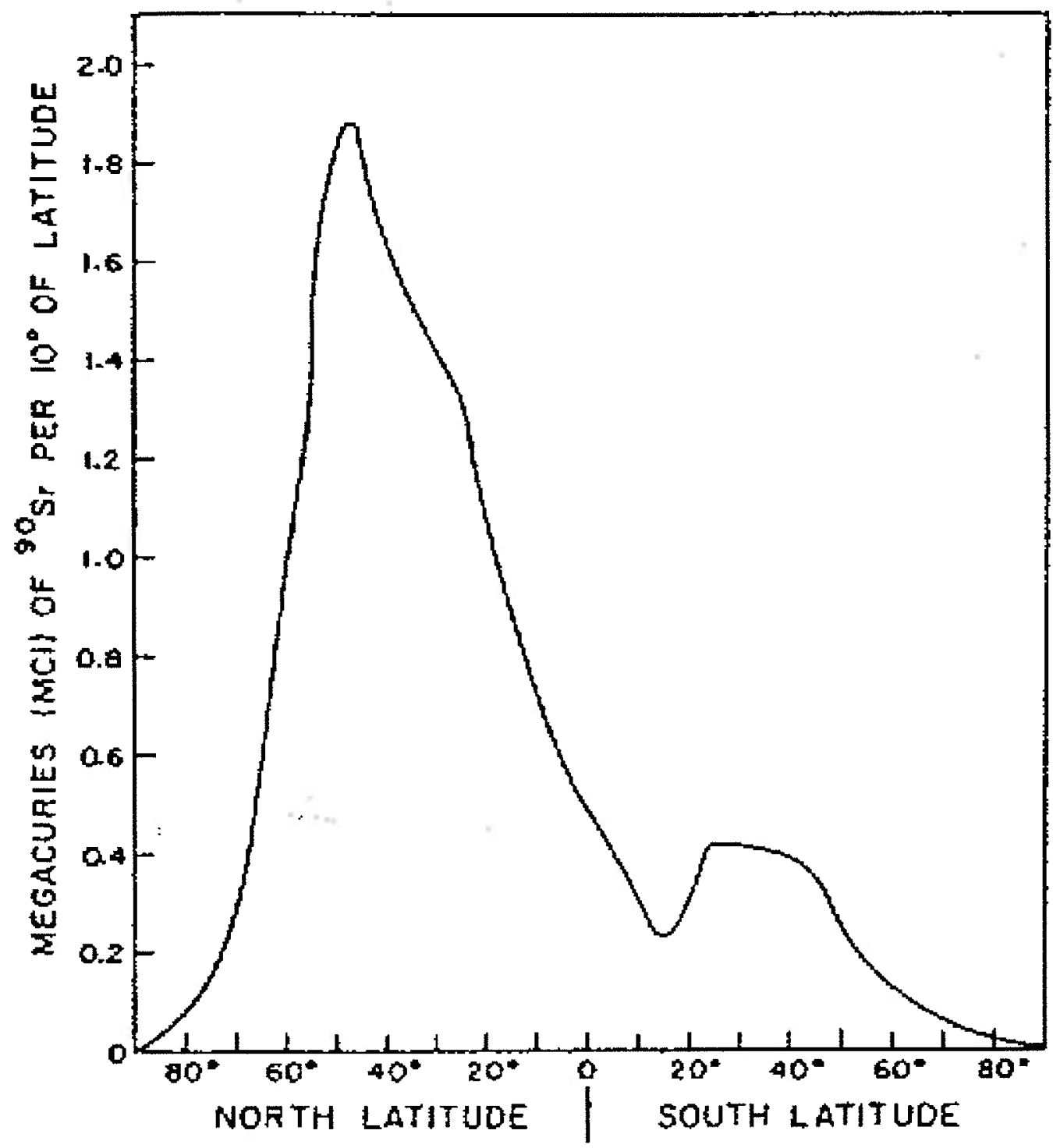

Figure 2:2. Latitudinal distribution of ${ }^{90} \mathrm{Sr}$ fallout measured for the period 1958-1967 (Joseph and Gustafson 1971). 
until the signing of the limited test-ban treaty in early 1963 , at which point both countries initiated substantial underground testing programs. Atmospheric testing continued on a much smaller scale by the governments of the PRC from 1963 to 1980 in the northern hemisphere and France from 1966 to 1974 in the southern hemisphere (DOE 1982).

Atmospheric and aboveground testing of nuclear weapons is significant because it results in the injection of radioactive material into the stratosphere and troposphere; the subsequent deposition of this material on the planet's surface is termed fallout. Fallout can generally be divided into two types: global fallout and local fallout. Global fallout occurs when an explosion of sufficient yield occurs, and the debris is injected into the stratosphere. The deposition pattern of global fallout exhibits a latitudinal dependence with maxima at mid-latitudes and minima at the poles and equator. This is due to the fact that material exits the stratosphere via the tropopause discontinuity. Since interhemispheric-stratospheric exchange of materials occurs on longer time scales than materials exchanged between the stratosphere and troposphere, most global fallout is deposited within its hemisphere of origin (Joseph and Gustafson 1971; Krishnaswami and Lal 1978; Perkins and Thomas 1980). This effect can be observed in Figure 2:2, which shows the latitudinal distribution of ${ }^{90} \mathrm{Sr}$ for the period 1958 through 1967. The large maximum $\sim 45^{\circ} \mathrm{N}$ is due to the fact that the majority of nuclear weapons testing occurred in the Northern Hemisphere (Joseph and Gustafson 1971).

Material injected into the stratosphere has a residence half-life of approximately one year (Junge 1963; Bhandari and Lal 1966; Lal and Rama 1966; Thomas and Young 1970). Figure $2: 3$ clearly illustrates the relationship between the timing of the two main 


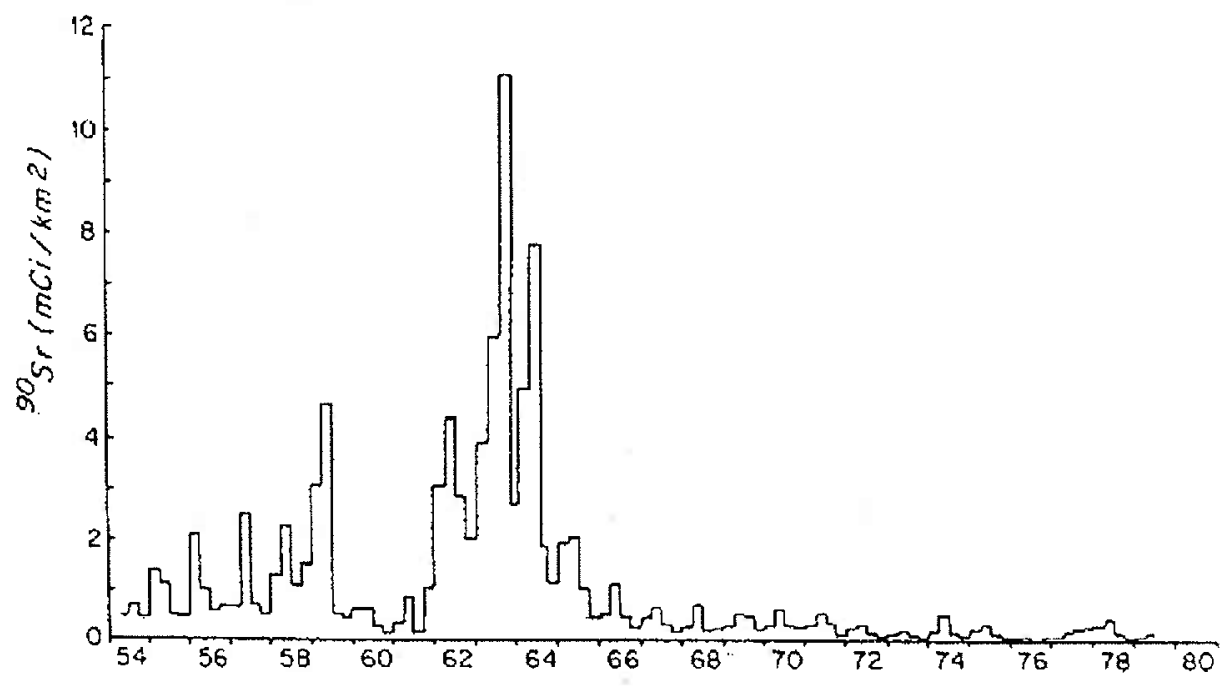

Figure 2:3. Quarterly deposition of ${ }^{90} \mathrm{Sr}$ measured at New York City between 1954 and 1970 (Larsen 1980)

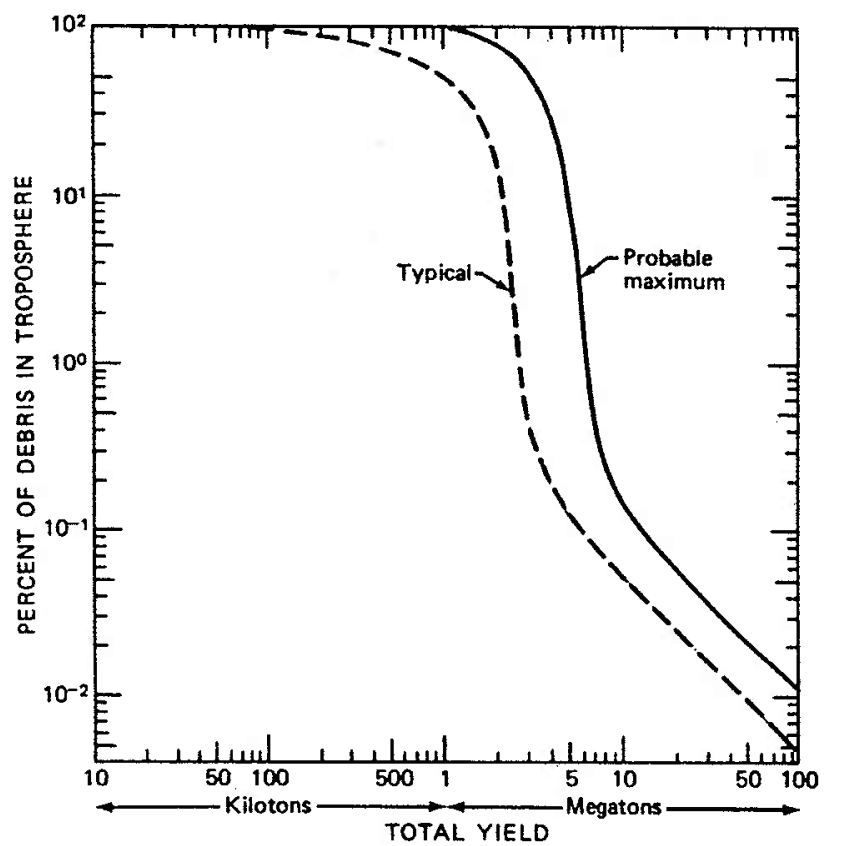

Figure 2:4. Percent of total activity initially injected into the troposphere as a function of total yield for air bursts in the tropical atmosphere (Ferber 1964) 
testing periods in 1958 and 1962 and the subsequent deposition of global fallout in 1959 and 1963-1964 (Larsen 1980).

Local or close-in fallout results from low-yield explosions with only enough energy to inject material into the troposphere. Figure 2:4 indicates that explosive yields of $\leq 100 \mathrm{kt}$ do not inject appreciable amounts of material into the stratosphere, however, explosive yields on the order of a few Mt are sufficient to inject nearly 100 percent of the test debris into the stratosphere. It must be kept in mind that these estimates are for tropical latitudes, and tests conducted at higher latitudes would shift the curve in Figure $2: 4$ to the left due to atmospheric attenuation. The deposition of material injected into the troposphere is controlled by weather and wind patterns, which can result in an uneven distribution on the earth's surface. Although residence times in the troposphere for this type of material can vary from seconds to months due to the size of debris created during an explosion, the typical residence time is between 20 - 40 days (Stewart, Crooks et al. 1955; UN 1964; Krey and Krajewski 1970).

\section{Weapons Test Sites}

Above ground weapons tests occurring in the Northern Hemisphere are of interest because of the possibility of both global and close-in fallout contributions to the $\mathrm{Ob}$ drainage basin. Of particular interest are the two FSU test sites, Novaya Zemlya and Semipalatinsk-21; the USA test sites in the tropical pacific (Enewetak, Bikini, and 
Summary of Aboveground tests at Semipalitinsk

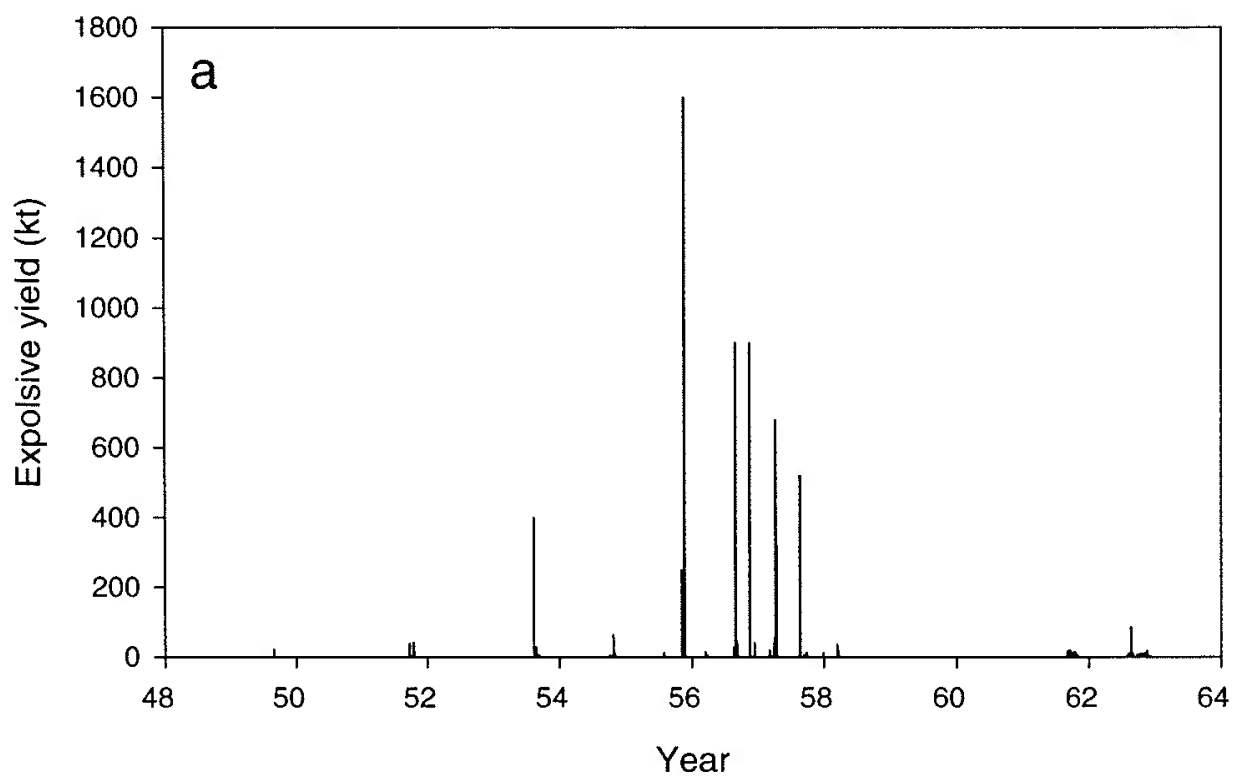

Summary of Aboveground tests at Novaya Zemlya

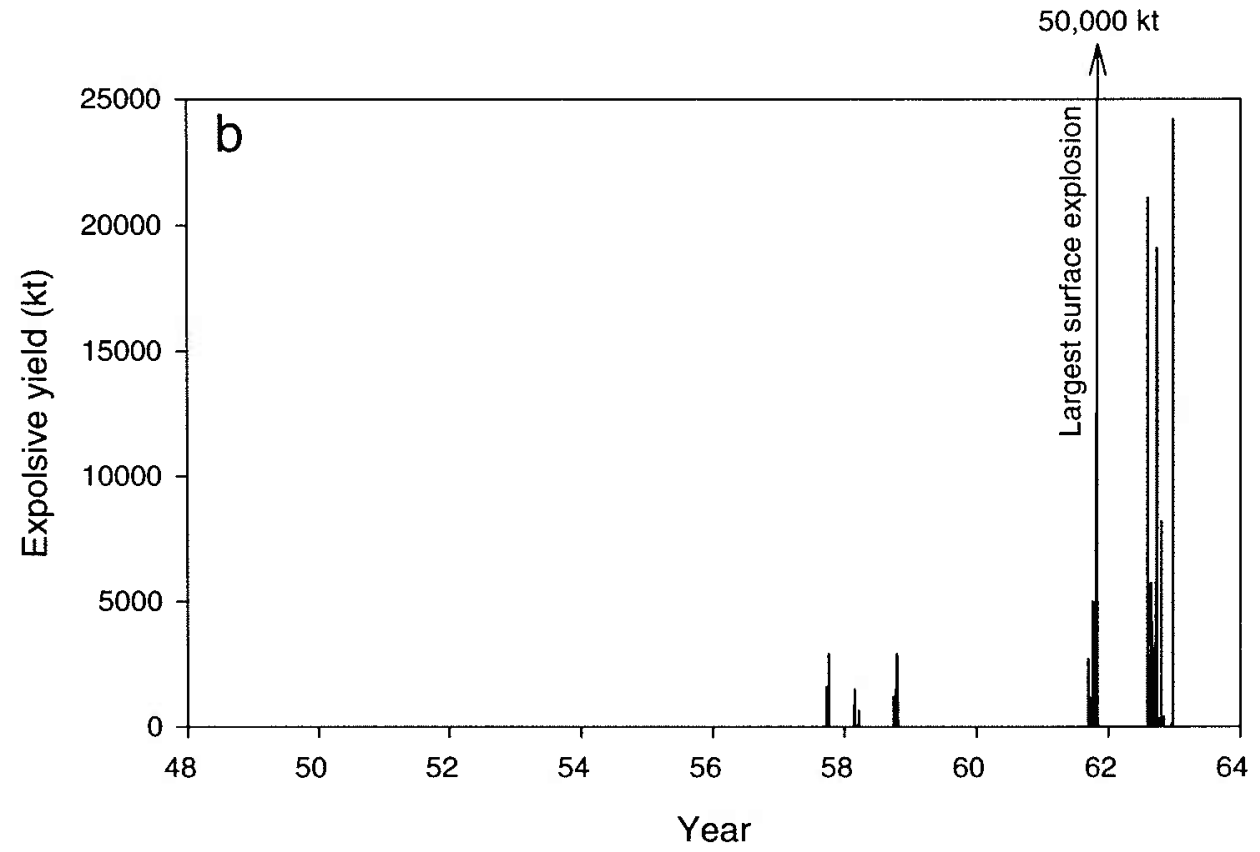

Figure 2:5. Summary of FSU aboveground tests at Semipalintinsk (a) and Novaya Zemlya (b). 
Johnson Atolls, and Christmas Islands), and to a lesser extent the Chinese test site at Lop Nor.

Semipalatinsk-21 is located in northeast Kazakhstan $\left(48^{\circ} \mathrm{N} \times 76^{\circ} \mathrm{E}\right.$ ) (c.f Figure 1:1). Approximately 124 atmospheric and above ground explosions occurred at this location (Figure 2:5a). The first test occurred on August 29, 1949, and the last aboveground test occurred on December 24, 1962. The majority of these tests had explosive yields that were $\leq 100 \mathrm{kt}$ with a concentration of relatively higher yield explosions occurring between 1956 and 1958. The tests at Semipalitinsk likely generated significant amounts of close-in fallout to the surrounding region but contributed little to the global fallout signal. Between February 2, 1962 and October 19, 1989, approximately 332 underground tests were conducted at various locations within the test site. Four of these tests were "cratering" explosions, which released radioactive debris to the environment. The most significant of these was the Chagan Lake explosion at the Balapan area on January 15,1965 , which was set off at $150 \mathrm{~m}$ depth and had an explosive yield of $140 \mathrm{kt}$. As a result, it ejected large amounts of fallout debris into the atmosphere as evidenced by the resulting $400 \mathrm{~m} \times 100 \mathrm{~m}$ deep crater (Bradley and Payson 1997). This test site is also important because it is located within the Ob drainage basin on the Irtysh River. Drainage of contaminated areas likely results in dispersal of materials by fluvial transport down the $\mathrm{Ob}$. There are also three research reactors located at Semipalitinsk that are potential sources of contaminants. 
Summary of USA Aboveground tests at low latitude sites

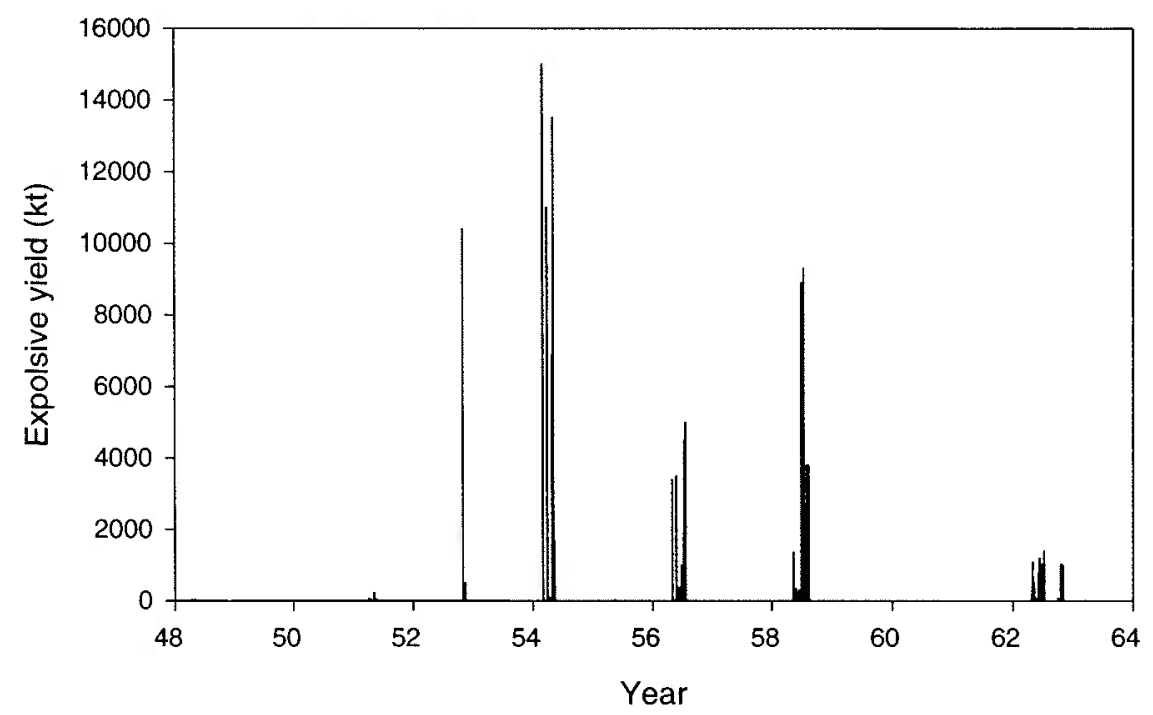

Figure 2:6. Summary of USA aboveground tests conducted at low latitude Pacific sites.

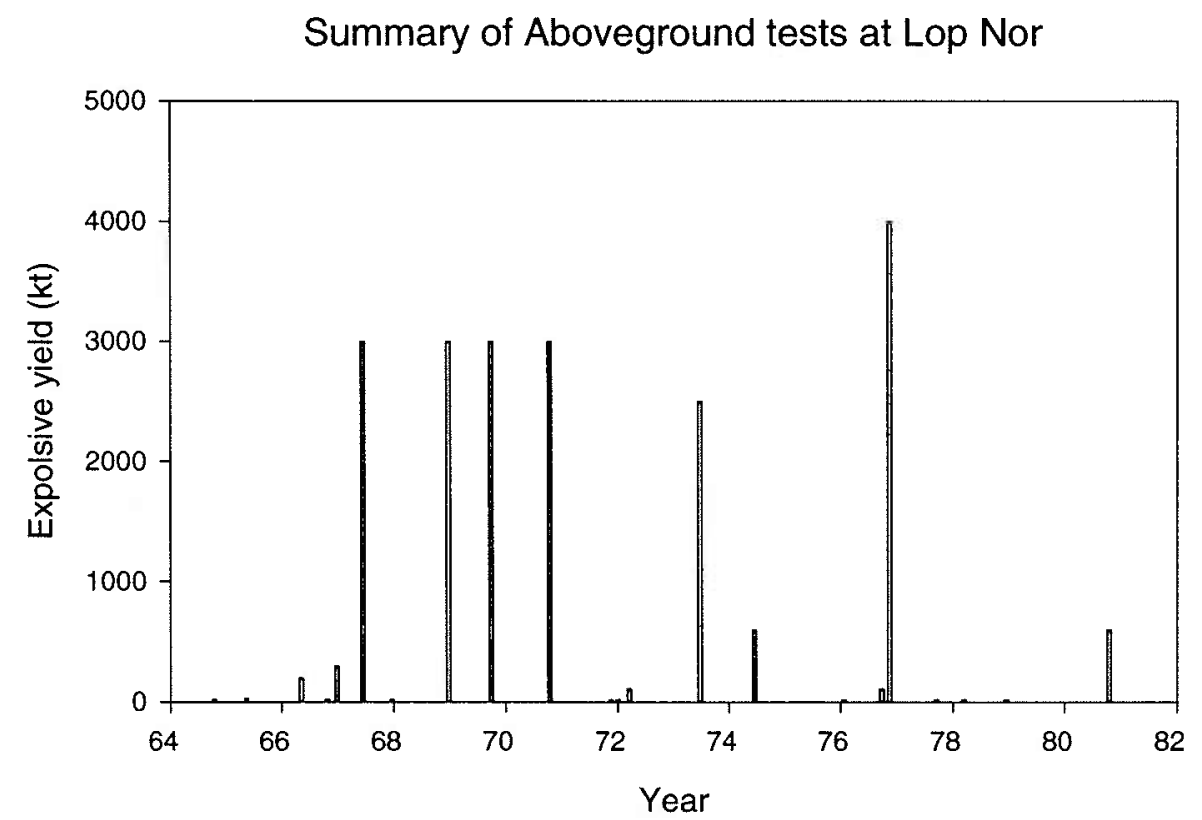

Figure 2:7. Summary of PRC aboveground tests conducted at Lop Nor. 
Novaya Zemlya is comprised of two islands above the Arctic Circle between the Kara and Barents Seas $\left(73^{\circ} \mathrm{N} \times 55^{\circ} \mathrm{E}\right)$ (see Figure 1:1). The first test occurred on August 21, 1955 and the last test occurred on December 25, 1962 (Figure 2:5b). The majority of tests conducted at this site were in the multi-megaton range; one test conducted on October 30, 1961 was estimated at $50 \mathrm{Mt}$, which is the largest nuclear weapons explosion to have ever taken place. The combination of high yields and high latitude caused the introduction of substantial amounts of material to the stratosphere. The 1963 maximum in global fallout deposition is attributed to the large number of highyield tests conducted at this site between 1961 and 1963 (Aarkrog, Tsaturov et al. 1993). Low yield tests $(\leq 200 \mathrm{kt})$ conducted at Novaya Zemlya may also have contributed closein fallout to the $\mathrm{Ob}$ watershed.

Tests conducted by the USA at low latitude Northern Hemisphere sites in the western Pacific are shown in Figure 2:6. Although the first test in this region occurred on June 30,1946 , the first test of sufficient yield to produce significant amounts of global fallout was the Ivy Mike test, which occurred on October 31, 1951. This was the first thermonuclear detonation, and it was significantly larger than any previous explosions (10.4 Mt). It was also the first test that injected appreciable amounts of material into the stratosphere, and it has been used to mark the onset of global fallout. The majority of tests after the Ivy Mike test were in the multi-megaton range, and they occurred in three distinct groups, in 1954, 1956, and 1958. The 1958 maximum in global fallout deposition is attributed to the large number of high-yield tests conducted at low latitude test sites that same year (Aarkrog, Tsaturov et al. 1993). 
Lop Nor is located in northwestern China $\left(41^{\circ} \mathrm{N} \times 91^{\circ} \mathrm{E}\right)$ approximately $800 \mathrm{mi}$. southeast of Semipalitinsk. Figure 2:7 summarizes aboveground tests conducted by the government of the Peoples Republic of China (PRC). By comparison, the number of nuclear weapons tested is substantially lower than those conducted by either the FSU or the USA. The timing, however, is important. The first above ground weapons test conducted by the PRC was on October 16, 1964 after the USA and FSU had signed the limited test-ban treaty. The PRC aboveground program continued until October 16, 1980, and included 6 multi-megaton above ground explosions (DOE 1982). As a result, the Northern Hemisphere global fallout signal from the late 1960s to the early 1980 s is comprised wholly of debris from PRC tests, some of which is likely present in the $\mathrm{Ob}$ Watershed.

Weapons Production and Nuclear Fuel Reprocessing Facilities

Of the two weapons production and fuel reprocessing facilities located within the region (i.e. Mayak and Tomsk-7), the Mayak Chemical Combine (also known as Mayak, Chelyabinsk-40, Chelyabinsk-65, and Ozersk) is the largest of the FSU's weapons production facilities. Recent reviews document considerable contaminant release at Mayak and give estimates of inventories (Aarkrog, Tsaturov et al. 1993; Donnay, Cherniack et al. 1995; Bradley and Payson 1997). The Mayak facility is located near the city of Chelyabinsk along the headwaters of the Techa River, which is a small tributary in the Iset-Tobol-Irtysh-Ob river system. Throughout its existence, Mayak has housed ten 
nuclear materials production reactors. Table 2:1 summarizes reactor operations at Mayak (Bradley and Payson 1997)

Table 2:1 Summary of reactor operations at Mayak

\begin{tabular}{lllcl}
\hline \hline \multicolumn{1}{c}{ Reactor Name } & Start Date & Shutdown & Type & Purpose \\
\hline A & $6 / 19 / 48$ & $6 / 16 / 87$ & open circuit GLWR & Weapons-Pu \\
AV-1 & $6 / 15 / 50$ & $8 / 12 / 89$ & open circuit GLWR & Weapons-Pu \\
AV-2 & $4 / 6 / 51$ & $7 / 14 / 90$ & open circuit GLWR & Weapons-Pu \\
OK-180 & $10 / 17 / 51$ & 1965 & Heavy Water & Weapons-Pu \\
IR & $12 / 22 / 51$ & $5 / 24 / 87$ & open circuit GLWR & Weapons-Pu \\
AV-3 & $9 / 15 / 52$ & $11 / 1 / 90$ & open circuit GLWR & Weapons-Pu \\
OK-190 & $12 / 27 / 55$ & $11 / 8 / 65$ & Heavy Water & Weapons-Pu \\
OK-190m & $4 / 1 / 66$ & 1986 & Heavy Water & Weapons-Pu \\
Ruslan & $6 / 16 / 79$ & Operating & Heavy Water & ${ }^{3} \mathrm{H},{ }^{238} \mathrm{Pu},{ }^{60} \mathrm{Co},{ }^{14} \mathrm{C},{ }^{192} \mathrm{Ir}{ }^{90} \mathrm{Sr}$ \\
Lyudmila & $6 / 16 / 79$ & Operating & Light Water & ${ }^{3} \mathrm{H},{ }^{238} \mathrm{Pu},{ }^{60} \mathrm{Co},{ }^{14} \mathrm{C},{ }^{192} \mathrm{Ir},{ }^{90} \mathrm{Sr}$ \\
\hline
\end{tabular}

Mayak's early operations were dedicated to the production and reprocessing of low burn-up fuels in order to produce weapons-grade plutonium $\left({ }^{239} \mathrm{Pu}\right),{ }^{238} \mathrm{Pu}$, tritium, and other special isotopes. In 1976, the processing of spent fuel for the production of weapons-grade plutonium ceased. Operations were converted to processing spent fuel from civilian power reactors, VVER-440 and BN (fast breeder-type); this included reprocessing spent fuel not only from reactors operating in Russia but also from Ukraine, Bulgaria, Hungary, and Czechoslovakia. Additionally, spent fuel from naval propulsion and research reactors is also processed (Donnay, Cherniack et al. 1995; Bradley and Payson 1997). Recently shipments of spent fuel have begun to arrive from Germany for reprocessing. Operations also include the storage of reactor-grade plutonium recovered from reprocessing operations since 1976 and vitrification of liquid radioactive waste.

Severe contamination of the environment has occurred as a result of activities at Mayak. Beginning with the installation of the first plutonium production reactor in 1948 , 
all liquid reprocessing wastes were discharged directly into the Techa River. In 1951, dam construction allowed containment of high-level wastes. The release of intermediate and low-level wastes continued until 1956 and 1964, respectively, while construction of additional dams was completed (Cochran and Norris 1992). It is estimated that a total of 2.75 million Ci was released to the river during this period (Bradley and Payson 1997). One of the most highly contaminated lakes in this system is Lake Karachai, which was used specifically as a repository for high-level radioactive waste after 1951. It is estimated that Lake Karachai contains $1.2 \times 10^{8} \mathrm{Ci}$ of radioactive wastes. Under drought conditions in 1967, winds dispersed approximately $600 \mathrm{Ci}$ of contaminated dust and sediment from the exposed shoreline downwind to a distance of $75 \mathrm{~km}$ (Donnay et al., 1995). In an effort to create a more secure repository for high-level waste, on-site storage tank construction began in 1953 . In 1957, due to poor maintenance practices, a tank containing approximately $2 \times 10^{7} \mathrm{Ci}$ overheated and exploded dispersing about $2 \times 10^{6} \mathrm{Ci}$ to the local environment (Cochran and Norris 1993). While current levels of operations at Mayak are significantly reduced, the threat of contamination has continued to increase. High-level wastes with an estimated inventory of between $5.46 \times 10^{8}$ and $9.76 \times 10^{8} \mathrm{Ci}$ reside in storage tanks, many of which are similar in age and construction to the one that exploded in 1957. In addition, seepage from Lake Karachai has also contaminated the groundwater with strontium and a number of other nuclides. A plume is migrating to the south at a rate of $\cong 63 \mathrm{~m} \mathrm{yr}^{-1}$. Wastes estimated at $1.22 \times 10^{8} \mathrm{Ci}$ reside in the open reservoirs and lakes. Rising water levels and aging dams create chronic contamination by allowing the escape of radioactive water through spills and seeps. Dam failure would 
result in a catastrophic release of radioactivity and massive levels of contamination (Donnay, Cherniack et al. 1995; Bradley and Payson 1997).

Tomsk-7 (also known as Siberian Chemical Combine and Seversk) is located near the cities of Seversk and Tomsk on the Tom River, which is a tributary to the Ob River. Due to the secrecy under which Tomsk-7 was operated, information concerning waste management practices and environmental releases is less reliable than information from Mayak. Reports and personal accounts indicate that operating conditions and disposal practices did not differ significantly from those at Mayak. Throughout its history Tomsk-7 has operated five reactors, two of which are still in operation today. The main purpose of facilities at Tomsk-7 was the production of weapons-grade plutonium. Reactors ADE-4 and ADE-5 are still in operation. These reactors are unique in that they serve a dual role, producing weapons-grade plutonium and providing power to the city as well. Table 2:2 summarizes reactor operations at Tomsk-7 (Bradley and Payson 1997).

Table 2:2 Summary of reactor operations at Tomsk-7

\begin{tabular}{lllll}
\hline \hline Reactor Name & Start Date & Shutdown & \multicolumn{1}{c}{ Type } & Purpose \\
\hline I-1 & $11 / 20 / 55$ & $8 / 21 / 90$ & Open circuit GLWR & Weapons-Pu \\
I-2 & 1959 & $1 / 1 / 91$ & Closed circuit GLWR & Weapons-Pu \\
ADE-3 & $7 / 14 / 61$ & $8 / 14 / 92$ & Closed circuit GLWR & Weapons-Pu \\
ADE-4 & 1962 & Operating & Closed circuit GLWR & Weapons-Pu/ Power \\
ADE-5 & 1963 & Operating & Closed circuit GLWR & Weapons-Pu/Power \\
\hline
\end{tabular}

Early operations at Tomsk-7 included the production and reprocessing of both weapons-grade plutonium and highly enriched uranium. Current operations include the production of low-enriched uranium for use in power reactors and weapons-grade $\mathrm{Pu}$ 
reprocessing operations. Plutonium production began at Tomsk-7 in 1955. In 1976, Tomsk-7 began receiving all spent fuel that was produced at Mayak for the purpose of weapons production. Similar to Mayak, a series of reservoirs were constructed to receive radioactive waste; it is estimated that $1.30 \times 10^{8} \mathrm{Ci}$ have been dumped into them. Other significant radioactivity has been released in the form of high level waste injected into deep wells; approximately 1 x $10^{9} \mathrm{Ci}$ has been injected since 1963. In 1993, a tank containing approximately $537 \mathrm{Ci}$ exploded. While heavier contamination occurred at the explosion site, it is estimated that over $40 \mathrm{Ci}$ were deposited in the surrounding area. Other reports describe the practice of waste disposal from the "once through" type of reactor directly into the Tom River as well as the underground burial of wastes and highly contaminated materials. The true extent of current contamination and the threat of future contamination resulting from activities at Tomsk-7 are not well known; however, it is likely to rival that of Mayak (Aarkrog, Tsaturov et al. 1993; Donnay, Cherniack et al. 1995; Bradley and Payson 1997).

\section{Nuclear Reactor Accident at Chernobyl}

On April 26, 1986, due to design flaws and operating errors, RMBK reactor 4 at the Chernobyl nuclear power station was severely damaged, causing considerable contamination to surrounding regions. The accident has been described as a runaway nuclear reaction. This caused at least one and possibly a second explosion within a few minutes of one another shortly after the accident began, resulting in the release of $\sim 50 \times$ 
$10^{6} \mathrm{Ci}$ to the environment (Bradley and Payson 1997). Releases of radioactive material also occurred days to weeks after the initial accident as a result of fires and heated reactor zones. Due to the extreme heat and prolonged nature of the accident, material released after the initial explosion(s) varied in its isotopic composition and may be characterized as being enriched in elements that are more easily volatilized such as $\mathrm{Cs}, \mathrm{I}, \mathrm{Te}, \mathrm{Ba}$, and $\mathrm{Sr}$ (Krey, Klusek et al. 1986). The most heavily contaminated regions were those in close proximity to the accident, which lead to a $30 \mathrm{~km}$ exclusion zone surrounding the nuclear power plant. While areas in the FSU and Europe received the majority of the contamination transported away from the reactor site, measurable radioactivity was detected as far away as Japan and North America (Krey, Klusek et al. 1986; Bradley and Payson 1997). Contamination derived from the Chernobyl accident has been observed in sediments from the Ob River (Sayles, Kenna et al. 1998).

\section{Isotopic Composition of Different Contaminant Sources}

Nuclear contaminants derived from various sources contain different proportions

of plutonium isotopes, ${ }^{237} \mathrm{~Np}$, and ${ }^{137} \mathrm{Cs}$. This is due to the fact that the isotopic composition of a nuclear contaminant is strongly linked to the means by which it is produced. Global fallout is derived from high yield weapons tests. Contamination originating from Mayak or Tomsk-7 is derived from the reprocessing of low burn-up fuel for the production of weapons-grade plutonium. Contamination derived from Semipalitinsk is derived from mainly low yield weapons tests. Contamination derived from Chernobyl is derived from high burn-up fuel as a result of nuclear power 
generation. Thus, the different production pathways, to a large extent, control the isotopic composition of a nuclear contaminant. If contaminants originating from suspected sources are well characterized with respect to their isotopic composition and release histories, it possible to confirm or rule out their presence in sediments collected from various locations within the $\mathrm{Ob}$ watershed, as well as the fractional contribution from each.

The mechanism by which these different sources obtain their isotopic signatures is essentially the same. As uranium and/or plutonium is bombarded with thermal neutrons, several nuclear reactions can occur. The primary reactions producing ${ }^{237} \mathrm{~Np}$, plutonium isotopes, and various fission products are as follows:

$$
\begin{aligned}
& { }_{4.47 \mathrm{e} 9 \mathrm{y}}^{238} \mathrm{\stackrel {( \textrm {n } , \gamma ) } { \longrightarrow }}{ }_{23.5 \mathrm{~m}}^{239} \mathrm{U} \stackrel{\beta-}{\longrightarrow}{ }_{2.35 \mathrm{~d}}^{239} \mathrm{~Np} \stackrel{\beta-}{\longrightarrow}{ }_{2.41 \mathrm{e} 4 \mathrm{y}}^{239} \mathrm{Pu} \stackrel{(\mathrm{n}, \gamma)}{\longrightarrow}{ }_{6.56 \mathrm{e} 3 \mathrm{y}}^{240} \mathrm{Pu} \stackrel{(\mathrm{n}, \gamma)}{\longrightarrow}{ }_{14.4 \mathrm{y}}^{241} \mathrm{Pu} \stackrel{(\mathrm{n}, \gamma)}{\longrightarrow}{ }^{242} \mathrm{Pu} \\
& { }_{4.47}^{238} \mathrm{U} \stackrel{(\mathrm{n}, 2 \mathrm{n})}{\longrightarrow}{ }_{2.14 \mathrm{yp}}^{237} \mathrm{yp} \\
& { }_{14.4 \mathrm{y}}^{241} \mathrm{Pu} \stackrel{\beta-}{\longrightarrow}{ }_{433 \mathrm{y}}^{241} \mathrm{Am} \stackrel{\alpha}{\longrightarrow}{ }_{2.14 \mathrm{e} y}^{237} \mathrm{~Np}
\end{aligned}
$$

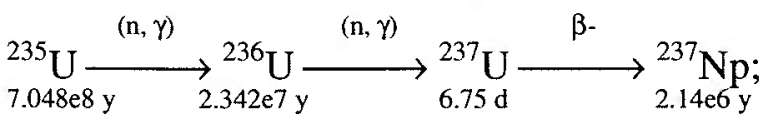

$$
\begin{gathered}
\downarrow \\
\text { Fission Products }\left(\mathrm{t}_{1 / 2}\right): \\
{ }^{90} \mathrm{Sr}(29.12 \mathrm{y}),{ }^{106} \mathrm{Ru}(368 \mathrm{~d}),{ }^{125} \mathrm{Sb}(2.77 \mathrm{y}),{ }^{137} \mathrm{Cs}(30.17 \mathrm{y}),{ }^{134} \mathrm{Cs}(2.07 \mathrm{y}),{ }^{144} \mathrm{Ce}(284 \mathrm{~d}),{ }^{99} \mathrm{Tc}(2.13 \mathrm{e} 5 \mathrm{y})
\end{gathered}
$$

Neutron bombardment of fissile or fissionable material can cause one of two important reactions: neutron capture or fission. Neutron-capture and beta decay cause the 
production of successively heavier isotopes of plutonium and other transuranics (i.e. americium and curium), and the fission reaction causes the target isotope to split producing any number of lower mass fission products, energy, and additional neutrons. The energy released by these reactions is the basis for both power generation and the destructive nature of nuclear weapons. In some cases, the energy created by the fission reactions is used to produce a fusion reaction, which results in a substantially higher explosive yield (i.e. a thermonuclear explosion).

${ }^{237} \mathrm{~Np}$ is produced when an atom of ${ }^{238} \mathrm{U}$ undergoes a neutron capture, then spontaneously loses two neutrons. ${ }^{237} \mathrm{~Np}$ is also produced via the beta decay of ${ }^{241} \mathrm{Pu}$ (half-life $=14.4$ years) to ${ }^{241} \mathrm{Am}$, which subsequently decays by alpha emission to ${ }^{237} \mathrm{~Np}$. The half-life of ${ }^{241} \mathrm{Am}$ is 433 years, which means that ${ }^{237} \mathrm{~Np}$ will continue to increase over the next $\sim 2000$ years. As a result of weapons related activities in the second half of the twentieth century, ${ }^{237} \mathrm{~Np}$ (half-life $=2.14 \mathrm{e} 6$ years), together with the fission product, ${ }^{99} \mathrm{Tc}$ (half-life $=2.13 \mathrm{e} 5$ years), will be present in the environment for millions of years.

Neutron production is the main factor in determining the isotopic composition of a nuclear contaminant. If production is controlled, a self-sustaining chain reaction will result, and each fission reaction will produce one additional fission reaction, as is the case in a nuclear reactor. If neutron production is not controlled, fission reactions will multiply quickly, causing a nuclear explosion or rapid disassembly to occur as is the case in a reactor "meltdown" or atomic weapon detonation. The transuranic composition and relative abundance of fission products produced are proportional to the duration and intensity of neutron irradiation as well as the isotopic composition of the initial material. 
The longer this material is irradiated or the more intense the neutron flux the further up the chain the production reaction will proceed and the higher the concentration of fission products in the irradiated material. Thus, low burn-up fuel for weapons Pu production can be characterized by low ${ }^{240} \mathrm{Pu} /{ }^{239} \mathrm{Pu}$ and high burn-up fuel for power production and high yield weapons can be characterized by relatively higher ${ }^{240} \mathrm{Pu} /{ }^{239} \mathrm{Pu}$ (Makhijani and Salesks 1995).

Numerous studies have used the source specific signature of nuclear contaminants to reconstruct radionuclide time histories and resolve input from multiple sources. Much of the available isotopic information documents the isotopic signatures of the various sources as they are recorded in different environmental samples (e.g. soils, sediments, ice and water). (HASL 1973; Koide, Goldberg et al. 1977; Koide, Michel et al. 1979; Perkins and Thomas 1980; Koide, Michel et al. 1982; Buesseler, Livingston et al. 1985; Koide, Bertine et al. 1985; Buesseler and Anonymous 1986; Buesseler and Sholkovitz 1987; Buesseler and Sholkovitz 1987; Trapeznikov, Pozolotina et al. 1993; Yamamoto, Tsukatani et al. 1996; Yamamoto, Tsumura et al. 1996; Buesseler 1997; Beasley, Kelley et al. 1998; Kelley, Bond et al. 1998; Yamamoto, Hoshi et al. 1999; Muramatsu, Ruhm et al. 2000; Oughton, Fifield et al. 2000). The available isotopic information for each potential source to Ob River sediments is discussed below.

The published values for sources of contamination to the Ob watershed are summarized in Table 2:3. Kelley, Bond et al. (1998) published the most comprehensive and globally representative data set documenting the global fallout inventories and composition of plutonium isotopes and ${ }^{237} \mathrm{~Np}$ in soils. These authors have shown that the 
atom ratios of ${ }^{240} \mathrm{Pu} /{ }^{239} \mathrm{Pu},{ }^{237} \mathrm{~Np} /{ }^{239} \mathrm{Pu}$, and ${ }^{241} \mathrm{Pu} /{ }^{239} \mathrm{Pu}$ exhibit relatively little variation in soils collected at locations around the world. This allows the characterization of global fallout and provides a means to detect the presence of contamination derived from sources other than fallout, which differ markedly in their isotopic composition. The average ${ }^{240} \mathrm{Pu} /{ }^{239} \mathrm{Pu},{ }^{237} \mathrm{~Np} /{ }^{239} \mathrm{Pu}$, and ${ }^{241} \mathrm{Pu} /{ }^{239} \mathrm{Pu}$ ratios in global fallout for the northern region of the Northern Hemisphere $\left(30^{\circ} \mathrm{N}\right.$ to $\left.71^{\circ} \mathrm{N}\right)$ are $0.180 \pm 0.014,0.480 \pm 0.070$, and $2.44 \mathrm{e}-3 \pm 3.5 \mathrm{e}-4$, respectively (see Table $2: 3$ ).

No ${ }^{137} \mathrm{Cs}$ data is available for the samples analyzed by Kelley, Bond et al. (1998), however, the average ${ }^{239,240} \mathrm{Pu} /{ }^{137} \mathrm{Cs}$ activity ratio of global fallout is well documented at $\sim 0.026$ (decay corrected to 1/1/1995) (Koide, Griffin et al. 1975; Krey, Hardy et al. 1976; Koide, Goldberg et al. 1977). Using this value and information published by Kelley, Bond et al. (1998), it is possible to calculate ${ }^{137} \mathrm{Cs} /{ }^{240} \mathrm{Pu}$ and ${ }^{137} \mathrm{Cs} /{ }^{237} \mathrm{~Np}$ atom ratios for global fallout (Table 2:3).

The samples analyzed by Kelley, Bond et al. (1998) consisted of homogenized 30 $\mathrm{cm}$ soil and sediment cores collected from a wide range of geographic locations in the early 1970s. Given the homogenization of the samples and the pattern of global fallout deposition (see Figure 2:3), the average values reported will be heavily weighted by the second and larger period of atmospheric testing (September 1961 to August 1963), which occurred after the November 1958 moratorium. It is reasonable to use the average isotopic values reported by Kelley, Bond et al. (1998) to characterize global fallout in samples with estimated deposition ages later than $\sim 1960$, since the majority of global fallout was delivered after the weapons testing moratorium. Isotopic data for pre- 
moratorium testing is limited, however, reported ${ }^{240} \mathrm{Pu} /{ }^{239} \mathrm{Pu}$ atom ratios and ${ }^{239,240} \mathrm{Pu}$ and ${ }^{137} \mathrm{Cs}$ activities measured in Arctic ice cores from 1954 to 1959 allow the average atom ratios ${ }^{240} \mathrm{Pu} /{ }^{239} \mathrm{Pu},{ }^{137} \mathrm{Cs} /{ }^{240} \mathrm{Pu}$, and the ${ }^{239,240} \mathrm{Pu} /{ }^{137} \mathrm{Cs}$ activity ratio of global fallout to be estimated for the pre-moratorium period (Koide and Goldberg 1981; Koide, Michel et al. 1982; Koide, Bertine et al. 1985). The average ${ }^{240} \mathrm{Pu} /{ }^{239} \mathrm{Pu}$ is $0.247 \pm 0.03(\mathrm{n}=7)$, the average ${ }^{137} \mathrm{Cs} /{ }^{240} \mathrm{Pu}$ is $0.267 \pm 0.082(\mathrm{n}=3$, decay corrected to $1 / 1 / 1995)$, and the average ${ }^{239,240} \mathrm{Pu} /{ }^{137} \mathrm{Cs}$ activity ratio is $0.0364 \pm 0.01(\mathrm{n}=3$, decay corrected to $1 / 1 / 1995)$. These results are also listed in Table 2:3.

Available data that document the isotopic composition of materials at Mayak consist of soils and sediments collected from the Techa River and the region contaminated by the 1957 Kyshtym explosion (the East Ural Trace or EURT) (Trapeznikov, Pozolotina et al. 1993; Beasley, Kelley et al. 1998; Oughton, Fifield et al. 2000). Where data overlap (see Table 2:3), there is good agreement (i.e. ${ }^{240} \mathrm{Pu} /{ }^{239} \mathrm{Pu}$ EURT). The lower ${ }^{240} \mathrm{Pu} /{ }^{239} \mathrm{Pu}$ ratios observed in the Asanov swamp, suggest that materials contaminating it are different from those in the EURT samples. The isotopic ratios observed at both locations are quite low and easily distinguishable from global fallout. Additionally, ${ }^{240} \mathrm{Pu} /{ }^{239} \mathrm{Pu}$ ratios provided by Oughton, Fifield et al. (2000) for soils and sediments proceeding downstream from Mayak to its confluence with the Iset River generally increase and approach a value $\sim 0.10$, suggesting the influence of global fallout. Interestingly, sediments collected in the Iset River $10 \mathrm{~km}$ upstream of its 


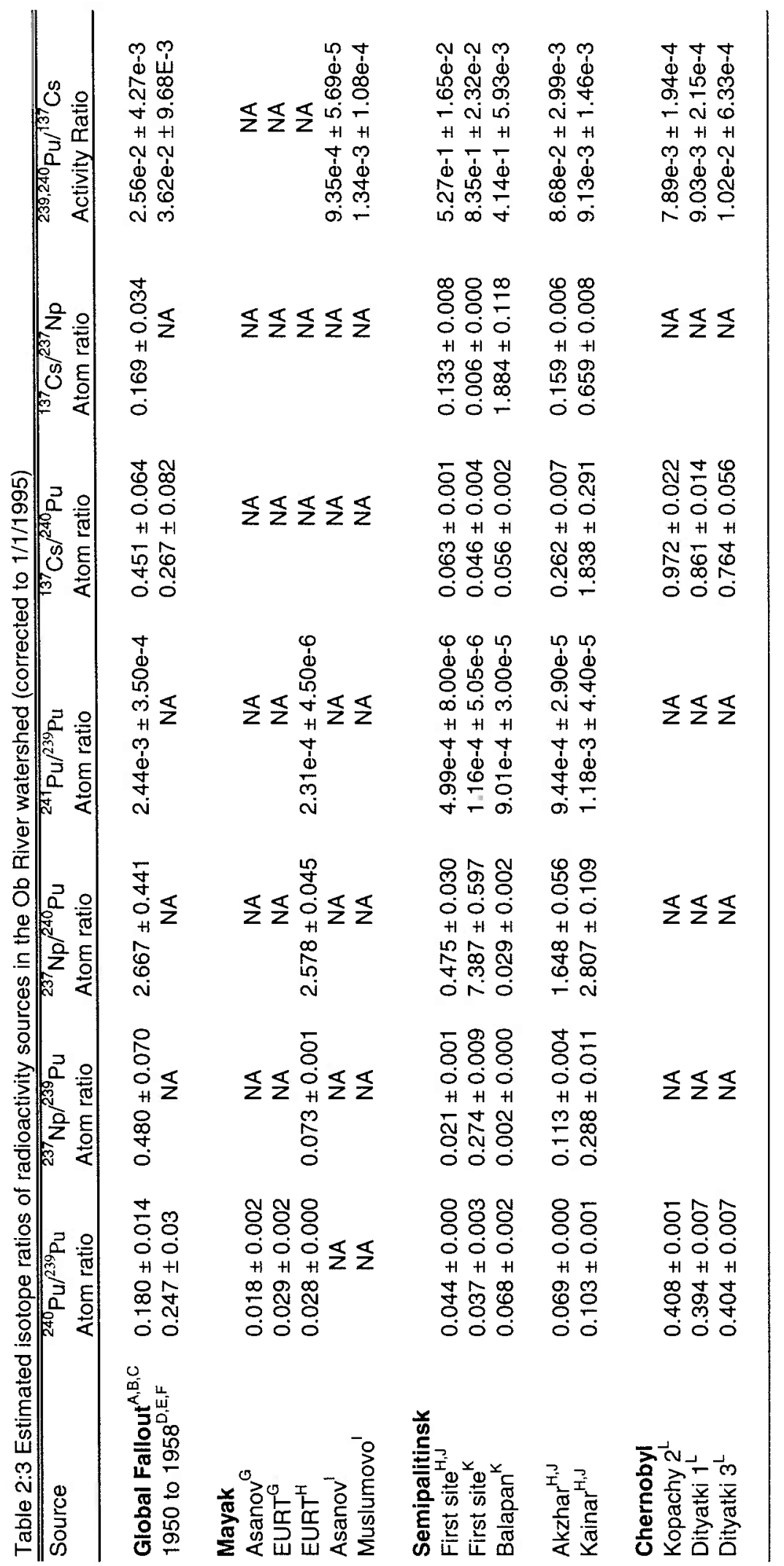




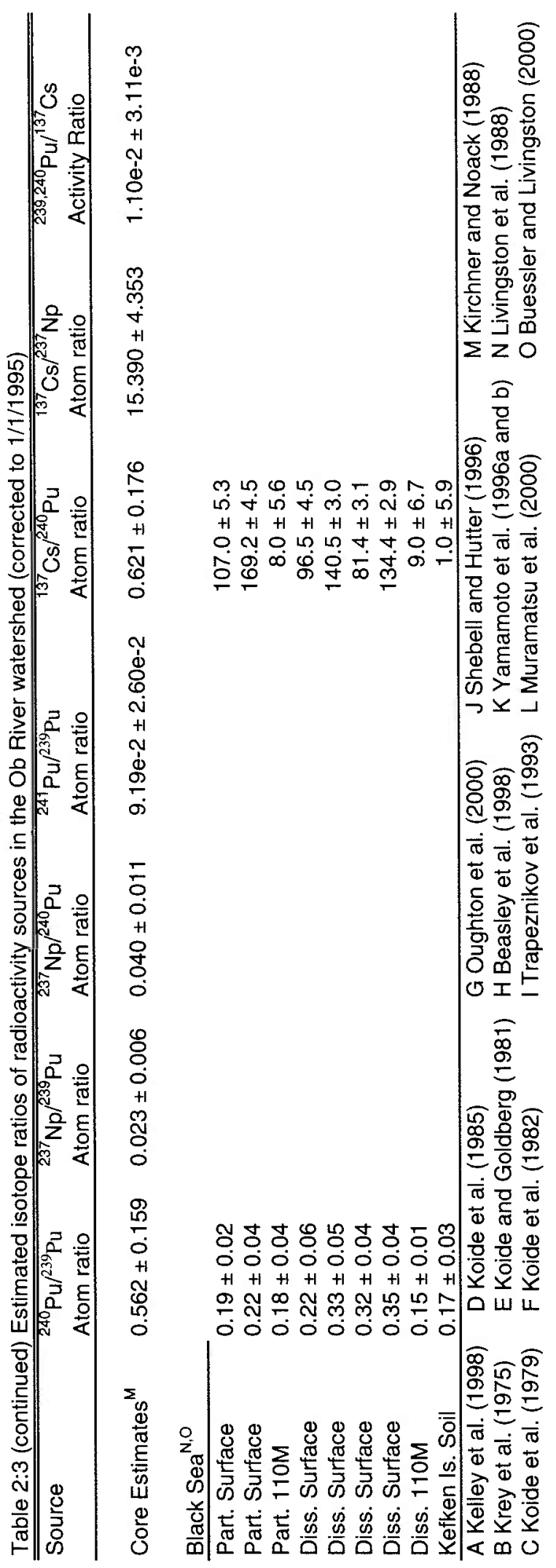


confluence with the Techa River yield a ${ }^{240} \mathrm{Pu} /{ }^{239} \mathrm{Pu}$ ratio of $.200 \pm .032$, a value not significantly different from global fallout.

The isotopic composition of materials originating from Semipalitinsk is documented by the isotopic analyses of soils collected at the two main test sites (the first experimental test site and the Chagan lake site). Additionally, samples collected from Akzhar and Kainar, two villages $40 \mathrm{~km}$ to the northeast and $75 \mathrm{~km}$ to the south, respectively are also listed in Table 2:3 (Shebell and Hutter 1996; Yamamoto, Tsukatani et al. 1996; Yamamoto, Tsumura et al. 1996; Beasley, Kelley et al. 1998). While the isotopic compositions reported for Semipalitinsk materials are substantially different from global fallout, they also demonstrate an extreme variability with respect to ${ }^{237} \mathrm{~Np}$. Beasley, Kelley et al. (1998) attribute this variability to differences in depositional inventories across the test site, differences in sampling techniques employed by Yamamoto et al. (1996) (i.e. homogenized soils to a depth of $5 \mathrm{~cm}$ vs. the top few millimeters), and radionuclide inhomogeneities in the soils. Additionally, soils from Kainar also exhibit elevated levels of ${ }^{237} \mathrm{~Np}$. Elevated levels of ${ }^{237} \mathrm{~Np}$ may be due to certain types of weapons tested at Semipalitinsk (Beasley, Kelley et al. 1998). Some of the variability may be due to different sampling techniques, however, as Beasley, Kelley et al. (1998) note, some of the variability is no doubt real, suggesting that the use of a single end-member of uniform isotopic composition to represent contamination originating from Semipalitinsk may not be entirely reasonable.

The reported isotopic composition of materials from the Chernobyl accident consist of isotopic analyses made on soils collected at sites 6,26 , and $28 \mathrm{~km}$ from the 
nuclear power plant. Estimates of the isotopic composition based on the nuclear reactor inventories at the time of the accident are also included (Kirchner and Noack 1988; Muramatsu, Ruhm et al. 2000). In general, the isotopic composition observed at all three sites is quite similar. Additionally, estimates made by Kirchner and Noack (1988) are not significantly different from actual measurements in the soils samples $\left({ }^{240} \mathrm{Pu} /{ }^{239} \mathrm{Pu}\right.$ and ${ }^{137} \mathrm{Cs} /{ }^{240} \mathrm{Pu}$ ), indicating that they are reasonable indicators of Chernobyl contamination deposited near the site of the accident.

There is, however, evidence that suggests more variability than the data presented for nearby locations indicate. Several studies of the Chernobyl accident have shown that the deposition pattern of radioactivity was highly variable throughout Europe and that the isotopic composition of this material varied throughout the period of the accident (Krey, Klusek et al. 1986; Livingston, Buesseler et al. 1988; Buesseler and Livingston 2000).

Krey, Klusek et al. (1986) observed that the proportions of refractory nuclides (i.e. ${ }^{103} \mathrm{Ru}$, ${ }^{140} \mathrm{Ba}$, and ${ }^{141} \mathrm{Ce}$ ) to volatile nuclides (i.e. ${ }^{131} \mathrm{I},{ }^{132} \mathrm{Te},{ }^{137} \mathrm{Cs}$, and ${ }^{134} \mathrm{Cs}$ ) from Chernobyl exhibited large differences with respect deposition location. Compared to soils from cities in central and southern Europe, soils measured from cities in Sweden were depleted with respect to refractory nuclides.

${ }^{240} \mathrm{Pu} /{ }^{239} \mathrm{Pu}$ ratios measured in surface particulate matter collected in the Black Sea show minimal elevation above global fallout values. The ${ }^{240} \mathrm{Pu} /{ }^{239} \mathrm{Pu}$ ratios in dissolved surface samples however, are uniformly and significantly higher than global fallout. While the distribution of plutonium between particulate and dissolved phases in the Black Sea suggest a relationship that is quite complex (see Table 2:3), the high ratios 
observed in the dissolved phase do indicate that some Chernobyl derived plutonium was distributed well away from the site of the accident. However, the ${ }^{137} \mathrm{Cs} /{ }^{240} \mathrm{Pu}$ ratios in both dissolved and particulate phases are extremely elevated over those observed near the site of the accident, indicating that substantially more cesium than plutonium is present in the Black Sea as a result of Chernobyl (Buessler and Livingston, 2000, Livingston, Buesseler et al., 1988). Due to its particle reactive nature, one would expect dissolved plutonium in the the Black Sea to decrease, while Cs would be conservative. This alone will cause $\mathrm{Cs} / \mathrm{Pu}$ ratios to increase with time in surface waters similar to $\mathrm{Ce} / \mathrm{Cs}$ and $\mathrm{Ru} / \mathrm{Cs}$ ratios (Buesseler and Livingston 2000). These observations further suggest that the isotopic composition of Chernobyl material is variable, but it may be generally characterized as depleted with respect to refractory nuclides as distance from the site increases. In the $\mathrm{Ob}$ region, large increases in ${ }^{137} \mathrm{Cs}$ after 1986, which are attributed to the Chernobyl accident, are not accompanied by increases in plutonium concentrations or elevated ${ }^{240} \mathrm{Pu} /{ }^{239} \mathrm{Pu}$ ratios (discussed in Chapters 5 and 6 ). This indicates that contamination reaching the $\mathrm{Ob}$ region as a result of Chernobyl was also depleted with respect to the refractory elements, including plutonium.

Isotopic values suggested by Kelley, Bond, et al (1998) for tropospheric fallout are not significantly different from values reported for Semipalitinsk; therefore, attempts are not made to differentiate between these two sources. Other potential sources of tropospheric fallout to the $\mathrm{Ob}$ region are tests conducted at Novaya Zemlya, and possibly Lop Nor. The isotopic composition of materials at these sites is unavailable, making it difficult to accurately assess their influence. 
End-member isotopic values used in this study

In some cases, available data documenting the isotopic composition of each of the suspected contaminant sources to the $\mathrm{Ob}$ watershed show a large amount of variability. Given this variability, some of the isotopic ratios listed are not as useful as others in resolving the source(s) of contamination (e.g. the ${ }^{237} \mathrm{~Np} /{ }^{240} \mathrm{Pu}$ ratios observed in soils from Semipalitinsk spans the range of values observed in global fallout and Mayak, as well as those estimated for Chernobyl). Figure 2:8 illustrates the range of isotopic composition observed in contamination originating from different sources and demonstrates that the ${ }^{240} \mathrm{Pu} /{ }^{239} \mathrm{Pu},{ }^{237} \mathrm{~Np} /{ }^{239} \mathrm{Pu}$, and ${ }^{137} \mathrm{Cs} /{ }^{240} \mathrm{Pu}$ isotopic ratios measured in global fallout are distinct from other sources. Furthermore, the isotopic compositions measured in materials originating from local/other sources are sufficiently distinct in some cases to allow identification of materials originating from each one (see Table 2:3 for references and further details).

To discern sources of observed nuclear materials, contaminant records in $\mathrm{Ob}$ River sediments are compared to the published isotopic information for the various sources of contamination discussed above. In the following discussion, the term 'global fallout' is used to denote global stratospheric fallout. In general, the values used to define global fallout are those defined by Kelley, Bond et al. (1998). The ${ }^{240} \mathrm{Pu} /{ }^{239} \mathrm{Pu}$ ratios listed in Table 2:3 for each source are different from one another. While these ratios are quite low compared to global fallout in samples from both Mayak and Semipalitinsk, those from Mayak are lower, and ${ }^{240} \mathrm{Pu} /{ }^{239} \mathrm{Pu}$ ratios lower than $\sim 0.03$ 


\section{${ }^{240} \mathrm{Pu} /{ }^{239} \mathrm{Pu}$}

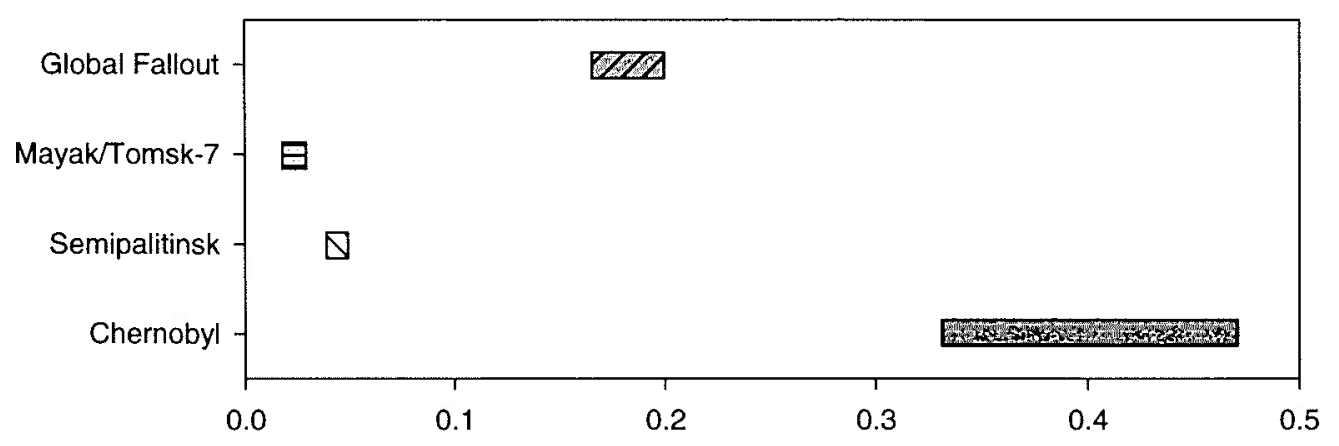

${ }^{237} \mathrm{~Np} /{ }^{239} \mathrm{Pu}$

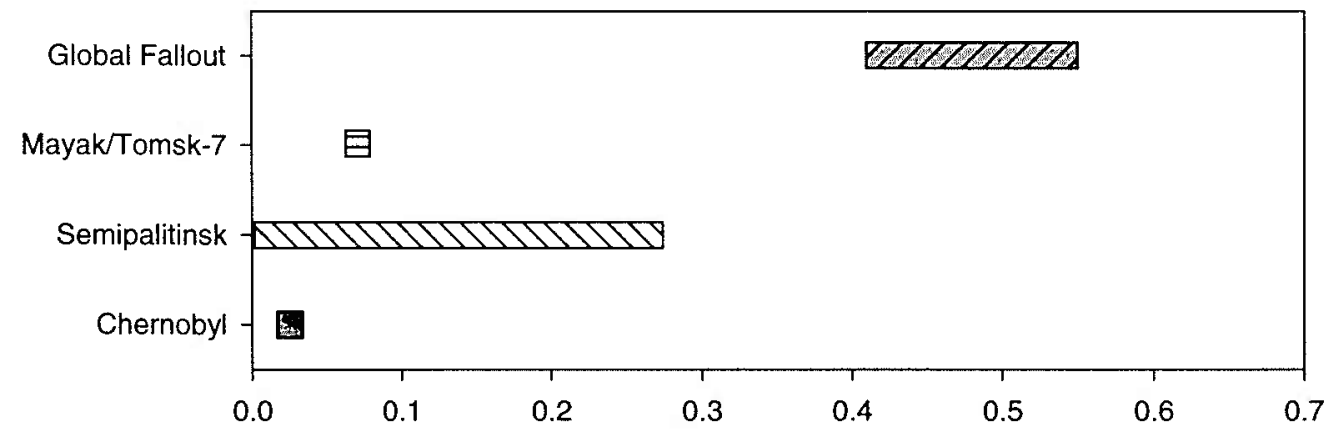

${ }^{137} \mathrm{Cs} /{ }^{240} \mathrm{Pu}$

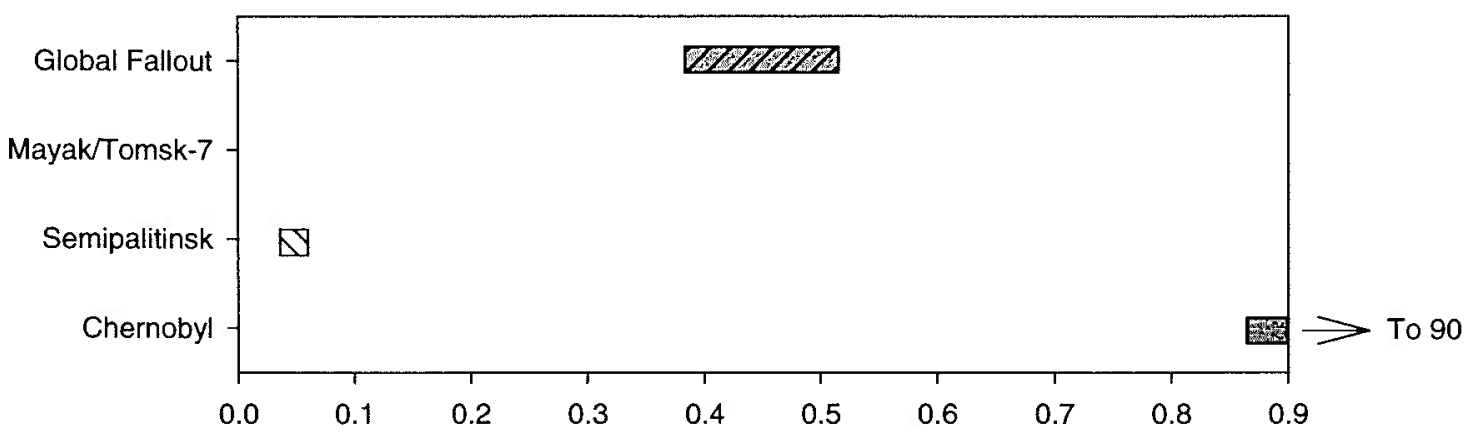

Figure 2:8. The range of isotopic composition of contamination originating from different sources (see Table 2:3 for references and further details). 
would likely indicate materials originating from that location. Based on the available data, ${ }^{240} \mathrm{Pu} /{ }^{239} \mathrm{Pu}$ ratios that are significantly elevated above global fallout with deposition ages later than $\sim 1986$ can be identified as being derived from Chernobyl, although the levels are likely to be insignificant compared to plutonium from other sources.

The ${ }^{237} \mathrm{~Np} /{ }^{239} \mathrm{Pu}$ ratios measured in samples collected from Semipalitinsk range from 0.002 to 0.274 . Due to the similar value measured in soils contaminated by the 1957 Kyshtym accident, this ratio is limited in its ability to distinguish between contamination originating these sources. All of the values measured at either Semipalitinsk or Mayak however, are significantly below the global fallout value. Thus, it does have some utility in resolving global fallout from non-fallout sources. The low ${ }^{237} \mathrm{~Np} /{ }^{239} \mathrm{Pu}$ ratio estimated for Chernobyl indicates that compared to plutonium, levels of neptunium present in the $\mathrm{Ob}$ watershed as a result of the accident will be substantially lower and likely below detection.

Data documenting the ${ }^{137} \mathrm{Cs} /{ }^{240} \mathrm{Pu}$ is not available for samples collected from Mayak. Samples collected at Semipalitinsk exhibit fairly uniform ${ }^{137} \mathrm{Cs} /{ }^{240} \mathrm{Pu}$ values that are significantly lower than the average global fallout value. All the data documenting ${ }^{137} \mathrm{Cs} /{ }^{240} \mathrm{Pu}$ ratios in material derived from Chernobyl indicate that it should be higher than the global fallout average of 0.451 . Thus, whatever the relationship between the refractory and volatile nuclides is in the material that reached the $\mathrm{Ob}$ watershed, the ${ }^{137} \mathrm{Cs} /{ }^{240} \mathrm{Pu}$ ratio should be useful in identifying material from this source.

Due to the conspicuous lack of data documenting material originating from Tomsk-7, the assumption is made that the isotopic composition in materials collected at 
Mayak will be similar to those originating from Tomsk-7. While it is expected that ${ }^{240} \mathrm{Pu} /{ }^{239} \mathrm{Pu}$ ratios will be low and easily distinguishable from global fallout, it is difficult to say with any certainty how much they will resemble materials from Mayak. It is important to note that based on the different programs underway at both facilities and the different types of reactors, the isotopic composition of materials originating from Tomsk7 could be different from those at Mayak. The isotopic ratios measured in sediment cores collected in the Ob River above its confluence with the Irtysh River are the only values available thus far that document contamination originating from Tomsk-7. 
References Chapter 2

Aarkrog, A., Y. S. Tsaturov, et al. (1993). Sources to environmental radioactive sources in the former USSR.

Beasley, T. M., J. M. Kelley, et al. (1998). "Isotopic Pu, U, and Np signatures in soils from Semipalatinsk-21, Kazakh Republic and the Southern Urals, Russia." Journal of Environmental Radioactivity 39(2): 215-230.

Bhandari, N. and D. Lal (1966). "Stratospheric circulation studies based on natural and artificial tracer elements." Tellus XVIII: 391-406.

Bobrovitskaya, N. N., B. G. Skakalsky, et al. (1997). Hydrologic and Hydrochemical Data for the Ob-Irtysh and Yenisey River Systems of Central Russia, 1954-1988. Reston, VA, U. S. Geological Survey: 177.

Bradley, D. J. and D. R. Payson (1997). Behind the nuclear curtain : radioactive waste management in the former Soviet Union. Columbus, Ohio, Battelle Press.

Buesseler, K. O. (1997). "The Isotopic Signature of Fallout Plutonium in the North Pacific." Journal of Environmental Radioactivity 36(1): 69-83.

Buesseler, K. O. and Anonymous (1986). "Plutonium isotopes in the Pacific; understanding the significance of the Marshall Islands testing site for Pu geochemistry

AGU 1986 fall meeting and ASLO winter meeting." AGU 1986 fall meeting and ASLO winter meeting 67(44): 1070.

Buesseler, K. O. and H. D. Livingston (2000). Natural and man-made radionuclides in the Black Sea: 199-217.

Buesseler, K. O., H. D. Livingston, et al. (1985). "(super 239,240) Pu and excess (super 210) $\mathrm{Pb}$ inventories along the shelf and slope of the Northeast U.S.A." Earth and Planetary Science Letters 76(1-2): 10-22.

Buesseler, K. O. and E. R. Sholkovitz (1987). "The geochemistry of fallout plutonium in the North Atlantic; I, A pore water study in shelf, slope and deep-sea sediments." Geochimica et Cosmochimica Acta 51(10): 2605-2622.

Buesseler, K. O. and E. R. Sholkovitz (1987). "The geochemistry of fallout plutonium in the North Atlantic; II, (super 240) Pu/ (super 239) Pu ratios and their significance." Geochimica et Cosmochimica Acta 51(10): 2623-2637. 
Cochran, T. B. and R. S. Norris (1992). Russian/Soviet Nuclear Warhead Production. Washington, DC, Natural Resources Defense Council.

Cochran, T. B. and R. S. Norris (1993). Russian/Soviet Nuclear Warhead Production. Washington, D.C., Natural Resources Defense Council.

DOE (1982). Announced united states nuclear tests; July 1945 through December 1981. Nevada, DOE.

Donnay, A., M. Cherniack, et al. (1995). Russia and the Territories of the Former Soviet Union. Nuclear Wastelands: A Global Guide to Nuclear Weapons Production and its Healt and environmental Effects. A. Makhijani, H. Hu and K. Yih. Cambridge, MA, The MIT Press: 285-392.

Ferber, G. J. (1964). Distribution of radioactivity with heights in nuclear clouds. Proceedings of the second conference on radioactive fallout from nuclear weapons tests, Germantown, MD, NTIS.

HASL (1973). Global atmospheric plutonium-239 and plutonium isotopic ratios for 1959-1970, U. S. Department of Energy: III-2-28.

Joseph, A. B. and P. F. Gustafson (1971). Sources of Radioactivity and their characteristics. Radioactivity in the marine environment. Washington, DC, National Academy of Sciences: 6-41.

Junge, C. E. (1963). Air chemistry and radioactivity. New York, NY, Academic Press.

Kelley, J. M., L. A. Bond, et al. (1998). Inventory and composition of Pu isotopes and Np-237 in soil. International symposium on marine pollution, Monaco, IAEA.

Kirchner, G. and C. C. Noack (1988). "Core history and nuclide inventory of the Chernobyl Core at the time of accident." Nuclear Safety 29(1): 1-5.

Koide, M., K. K. Bertine, et al. (1985). "The (super 240) Pu/ (super 239) Pu ratio; a potential geochronometer." Earth and Planetary Science Letters 72(1): 1-8.

Koide, M. and E. D. Goldberg (1981). "(super 241) Pu/ (super 239+240) Pu ratios in polar glaciers." Earth and Planetary Science Letters 54(2): 239-247.

Koide, M., E. D. Goldberg, et al. (1977). "Transuranic depositional history in South Greenland firn layers." Nature (London) 269(5624): 137-139.

Koide, M., J. J. Griffin, et al. (1975). "Records of plutonium fallout in marine and terrestrial samples." Journal of Geophysical Research 80(30): 4153-4162. 
Koide, M., R. Michel, et al. (1979). "Depositional history of artificial radionuclides in the Ross Ice Shelf, Antarctica." Earth and Planetary Science Letters 44(2): 205-223.

Koide, M., R. L. Michel, et al. (1982). "Characterization of radioactive fallout from preand post-moratorium tests to polar ice caps." Nature (London) 296(5857): 544547.

Krey, P. W., E. P. Hardy, et al. (1976). Mass isotopic composition of global fall-out plutonium in soil

Transuranium nuclides in the environment. Transuranium nuclides in the environment. San Franc., Calif., United States: 671-678.

Krey, P. W., C. S. Klusek, et al. (1986). Radiochemical characterization of Chernobyl fallout in Europe. New York, Environmental Measurements Laboratory: 155-213.

Krey, P. W. and B. Krajewski (1970). Tropospheric scavenging of Sr-90 and H-3. Precipitation Scavenging. Richland, WA, U. S. Department of Energy.

Krishnaswami, S. and D. Lal (1978). Radionuclide Limnochronology. Lakes: Chemistry, Geology, and Physics., Springer-Verlag.

Lal, D. and Rama (1966). "Characteristics of global tropospheric mixing based on C-14, H-3, and Sr-90." JGR. Journal of Geophysical Research. C. Oceans and Atmospheres 71: 2865-2874.

Larsen, R. L. (1980). Worldwide deposition of Sr-90 through 1982. New York, Environmental Measurement Laboratory.

Livingston, H. D., K. O. Buesseler, et al. (1988). Characteristics of Chernobyl fallout in the southern Black Sea

Radionuclides; a tool for oceanography. Radionuclides; a tool for oceanography. Cherbourg, France: 204-216.

Makhijani, A. and S. Salesks (1995). The production of nuclear weapons and environmental hazards. Nuclear Wastelands: A Global Guide to Nuclear Weapons Production and its Health and Environmental effects. A. Makhijani, H. Hu and K. Yih. Cambridge, MA, The MIT Press: 23-64.

Muramatsu, Y., W. Ruhm, et al. (2000). "Concentrations of Pu-239 and Pu-240 and their isotopic ratios determined by ICP-MS in soils collected from the Chernobyl $30-$ km zone." Environmental Science \& Technology, ES \& T 34: 2913-2917.

Oughton, D. H., K. Fifield, et al. (2000). "Plutonium from Mayak: measurement of isotope ratios and activities using accelerator mass spectrometry." Environmental Science \& Technology, ES \& T 34: 1938-1945. 
Perkins, R. W. and C. W. Thomas (1980). Worldwide Fallout. Transuranic elements in the environment. W. C. Hanson. Springfield, VA, U. S. Department of Energy: 53-82.

Sayles, F. L., T. C. Kenna, et al. (1998). Release and transport of artificial radionuclides from nuclear weapons related activities in the Ob River, Siberia ove the course of the nuclear age. International symposium on marine pollution, Monaco, IAEA.

Shebell, P. and A. R. Hutter (1996). Environmental radiation measurements at the Former Soviet Union's Semipalitinsk-21 nuclear test site and surrounding villages. Springfield, VA, U.S. Department of Energy.

Stewart, N. G., R. N. Crooks, et al. (1955). The radiological dose to persons in the U.K. due to debris from nuclear test explosions. Report for the M. R. P. Committee on the medical aspects of nuclear radiation, Atomic Energy Research Establishment.

Thomas, C. W. and J. A. Young (1970). The measurement and behavior of airborne radionuclides since 1962., American Chemical Society.

Trapeznikov, A. V., V. N. Pozolotina, et al. (1993). "Radioaktivnoye zagryazneniye reki Techi na Urale; Techa River radioactive contamination in Urals." Ekologiya 1993(5): $72-77$.

UN (1964). Report of the United Nations Scientific Committee on the Effects of Atomic Radiation, United Nations.

Yamamoto, M., M. Hoshi, et al. (1999). "Pu isotopes and (super 137) Cs in the surrounding areas of the former Soviet Union's Semipalatinsk nuclear test site." Journal of Radioanalytical and Nuclear Chemistry 242(1): 63-74.

Yamamoto, M., T. Tsukatani, et al. (1996). "Residual radioactivity in the soil of the semipalitinsk nuclear test site in the former USSR." Health Physics 71(2): 142148.

Yamamoto, M., A. Tsumura, et al. (1996). "Plutonium isotopic composition in soil from the former Semipalitinsk nuclear test site." Radiochimica Acta 72: 209-215. 

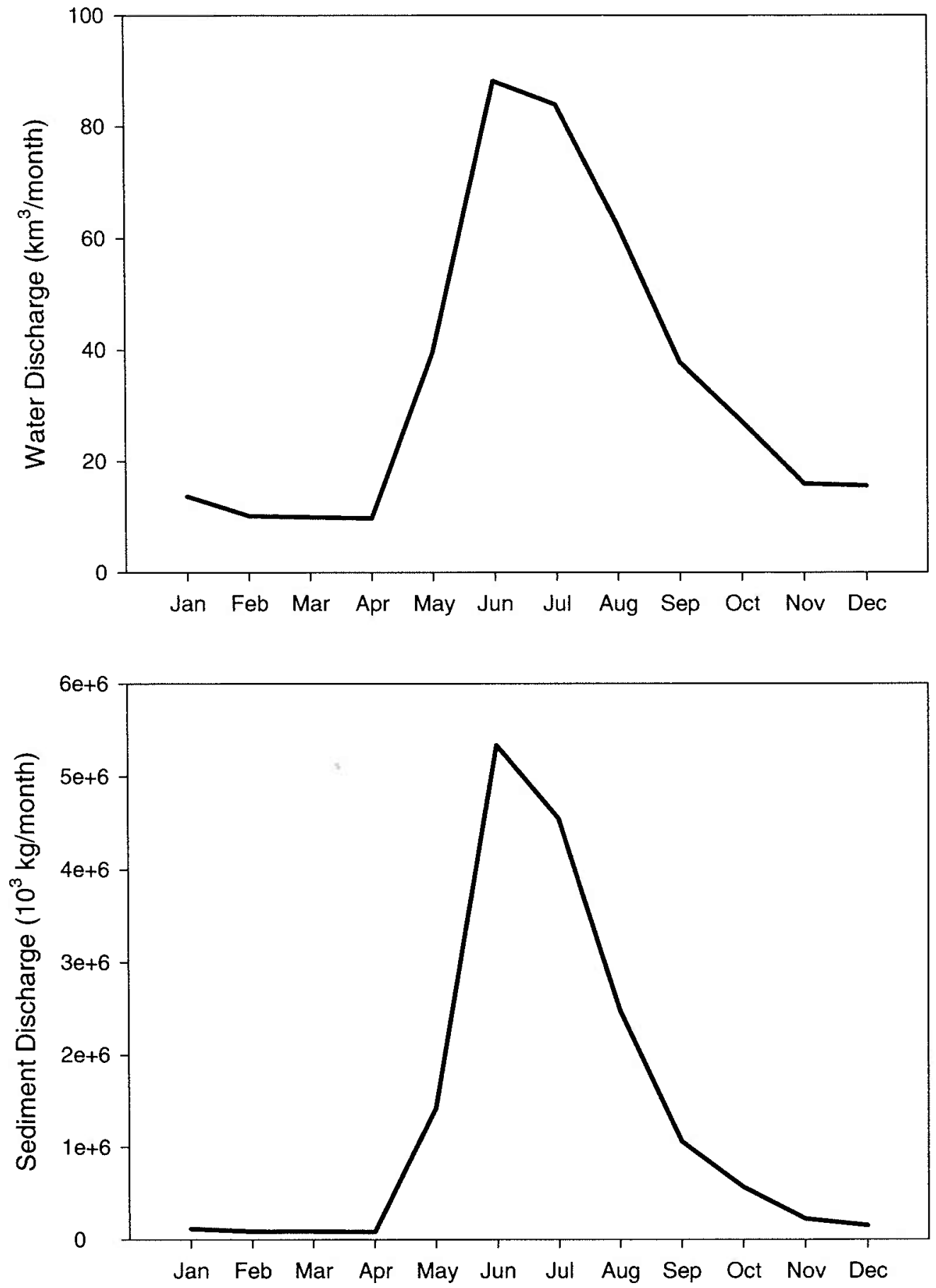

Figure 3:1. Mean monthly water and sediment discharge observed at Salekhard gauging station from 1960 to 1987 (Bobrovitskaya, Skakalsky et al. 1997). 


\section{Chapter 3}

\section{Characteristics of the Ob River system}

\section{Drainage Basin}

The Ob River drainage basin is located in Western Siberia. The Ural Mountains, the Putorana Plateau, and the Sayan Mountains to the west, east, and south, respectively comprise its borders. During the Pleistocene glaciation, the upper (southern) portion was most likely flooded by Lake Mansi, the largest of the ice-dammed lakes, while the lower (northern) portion of the drainage basin was primarily stripped of sediment (Grosswald and Hughes 1995). The scoured lower portions of the basin were the precursor of the present day Ob's massive flood plain. During the Holocene, these areas began trapping large amounts of sediments. At present, these areas, consisting of low-lying forests and swamps, continue to act as excellent sediment traps, limiting delivery of sediment to the Arctic Ocean (Bobrovitskaya, Walling et al. 1996; Meade, Bobrovitskaya et al. 2000).

\section{Hydrologic Regime and Sedimentation}

The annual discharge cycle of the Ob exhibits a low, rather stable flow from November to April and a flood stage during the spring and summer months, which generally peaks during the months of June and July. This is illustrated in Figure 3:1, which shows mean monthly water and sediment discharge data from the Salekhard station $\left(66^{\circ} 32^{\prime} \mathrm{N} \mathrm{x} 66^{\circ} 40^{\prime} \mathrm{E}\right)$ for the years 1960 to 1987 . These data are typical of the cyclic nature of the system and demonstrate that nearly 90 percent of the water and 
sediment delivery occurs during the spring and summer months. It has been shown by Panteleyev (1995) that the "sor" and oxbow lakes, a common feature on the flood plains of the $\mathrm{Ob}$, have the potential to record this annual cycle of sediment deposition, with sediment accumulation rates being related to the flood conditions during any given year. Average sediment accumulation rates between 0.2 and $0.4 \mathrm{~cm} \mathrm{yr}^{-1}$ have been estimated for the lower Ob River, while rates between 1 and $3 \mathrm{~cm} \mathrm{yr}^{-1}$ have been estimated in the mid and upper reaches of the river (Panteleyev 1995; Sayles, Livingston et al. 1997; Kenna and Sayles 2001). Sediments have been characterized as having a structure that is comprised of sheets of sandy loam, loam, sand clays, and peat of varying thickness (Makeyev and Bolshiyanov 1988).

\section{Ice Formation}

Ice covers the region during the winter months, usually from November through May. Values reported by Ivanov et al. (1995; Kenna and Sayles 2001) for ice thickness are between 100 and $150 \mathrm{~cm}$ in the $\mathrm{Ob}$ delta and between 90 and $230 \mathrm{~cm}$ further north in the freshwater portion of the Ob estuary. With regard to lakes located on the flood plain, ice may be an important factor in the preservation of sediment records, as average lake depth is between 2 and $3 \mathrm{~m}$ (Makeyev and Bolshiyanov 1988; Panteleyev 1995). In situations where ice thickness exceeds water depth, ice will incorporate bottom sediments. During the spring break-up, both ice and sediment layers may be carried away. This is potentially important with respect to the preservation of sedimentary 
records in flood plain lakes (i.e. incomplete radionuclide inventories) and as a mechanism of sediment transport.

\section{Marine/Freshwater Boundary}

The extent of saltwater intrusion into the Ob estuary is dependent on the water discharge in any given year. Freshwater fills most of the $\mathrm{Ob}$ and $\mathrm{Taz}$ estuaries during the summer months and may extend into the Kara Sea. The deepest penetration of saltwater occurs during the winter and early spring, however even after a series of low water years, seawater fails to penetrate south of Cape Kamenny (see Figure 3:2)((Ivanov, Medkova et al. 1995).

\section{Water and suspended sediment discharge}

The elements of interest originating from different sources within the $\mathrm{Ob}$ watershed are transported in association with river particulate material. This makes the relative inputs of suspended sediments from each tributary important when assessing levels of contamination originating from each of the suspected sources.

Water and suspended sediment data allow the assessment of sediment transport/storage between gauging stations located on the $\mathrm{Ob}$ and its main tributaries, the Irtysh and Tobol Rivers (Figure 3:2) (Bobrovitskaya, Walling et al. 1996; Bobrovitskaya, Skakalsky et al. 1997; Meade, Bobrovitskaya et al. 2000). Below is a summary of the available water and suspended sediment discharge data. This information has been discussed in greater detail by previous researchers (Bobrovitskaya, Zubkova et al. 1996; 
Bobrovitskaya, Skakalsky et al. 1997). Discharge data consist of mean monthly water and suspended sediment discharge records. At most of the gauging stations data were collected between 1960 and 1987 or 1988, with the largest exception being KhantyMansiysk (Irtysh River, just above its confluence with the Ob River), where data were collected from 1977 to 1988 only. At all stations, mean monthly water discharge data were available for the entire period of data collection. In most cases, mean monthly suspended sediment records are not complete (i.e. mean monthly sediment discharge data are missing for the entire year or for selected months, usually November to March).

In order to compare records from different stations through the entire period (1960-1987), mean suspended sediment discharge data were estimated where actual data are missing. For each station, the relationship between the water and suspended sediment discharge was examined on a monthly basis where both water and suspended sediment data were available, (e.g. all complete records for January at Tobolsk(Irtysh River just below its confluence with the Tobol River)). The relationship between water discharge and suspended sediment discharge commonly used is the power function $Q_{p}=a Q^{b}$ (Syvitski, Pratson et al. 1999).

Where $Q=$ flow rate in cubic meters per second

$Q_{p}=$ sediment flux in kilograms per second

$a=$ tunable parameter

$b=$ tunable parameter.

The relationship between water and suspended sediment discharge data available for the $\mathrm{Ob}$ River and its major tributaries is scattered. A comparison of fits between the power function model and linear regression revealed no difference, with respect to goodness of 


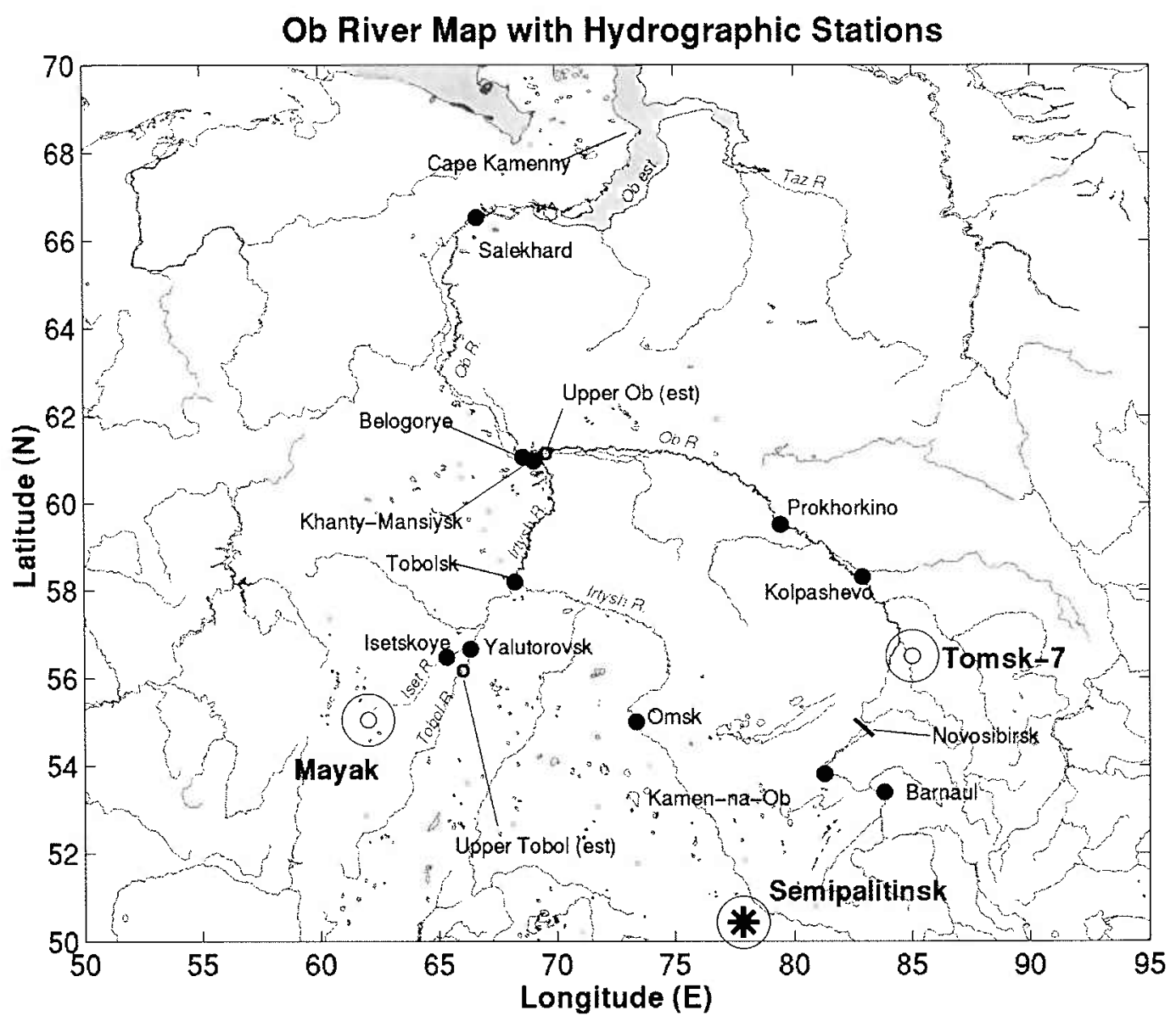

Figure 3:2. Map of Ob River region with hydrographic stations and potential sources of weapons related contamination. Filled circles within circles are nuclear weapons related facilities, stars within circles are weapons test sites. Plain filled circles mark hydrographic stations, and open circles are locations where water and sediment discharge has been estimated (Bobrovitskaya, Zubkova et al. 1996; Bobrovitskaya, Skakalsky et al. 1997). 
fit. As a result, the linear model was used to estimate suspended sediment discharge values where actual data were unavailable.

Completing the record from 1960-1977 for Khanty-Mansiysk was more complicated, as there is no discharge data for this time period. Therefore, the relationship between available monthly water discharge data at Tobolsk and Khanty-Mansiysk was examined, which proved to be clearly linear. Based on this relationship, mean monthly water discharge was estimated at Khanty-Mansiysk for the time period in question. Suspended sediment discharge records were then estimated as described above.

Data from hydrographic stations were grouped according to location: stations located on the Irtysh River and its tributaries, the Ob River above its confluence with the Irtysh, and the lower reaches of the Ob River from Belogorye. For each station, mean annual discharge estimates $( \pm 1 \sigma)$ were calculated. In cases where data were available for two branches of a 3-way confluence (e.g. Ob/Irtysh and Iset/Tobol), annual discharge estimates were computed by the difference between the two known values. Results from these calculations are presented in Table 3:1 and the figures below. 
Table 3:1 Mean annual water and suspended sediment discharge at various locations along the $\mathrm{Ob}$ River and its tributaries (Bobrovitskaya, Skakalsky et al. 1997)

\begin{tabular}{|c|c|c|c|c|c|c|}
\hline \multirow[t]{2}{*}{ Station } & & \multirow[t]{2}{*}{ River } & \multicolumn{2}{|c|}{ Suspended sediment } & \multicolumn{2}{|c|}{ Water } \\
\hline & & & $t y^{-1}$ & $\pm 1 \sigma$ & $\mathrm{km}^{3} \mathrm{yr}^{-1}$ & $\pm 1 \sigma$ \\
\hline Isetskoye & 1960 to 1988 & Iset & $6.40 \mathrm{E}+04$ & $8.49 E+03$ & 2.12 & 0.19 \\
\hline Upper Tobol* & - & Tobol & $3.91 \mathrm{E}+04$ & $6.44 E+03$ & 1.29 & 0.17 \\
\hline Yalutorovsk & 1960 to 1988 & Tobol & $1.03 E+05$ & $5.72 E+03$ & 3.41 & 0.33 \\
\hline Omsk & 1960 to 1988 & Irtysh & $2.82 E+06$ & $1.86 \mathrm{E}+05$ & 26.12 & 0.83 \\
\hline Tobolsk & 1960 to 1988 & Irtysh & $7.99 E+06$ & $5.06 \mathrm{E}+05$ & 65.96 & 3.14 \\
\hline Khanty-Mansiysk ${ }^{\star *}$ & 1974 to 1988 & Irtysh & $1.70 E+07$ & $1.23 E+06$ & 85.82 & 3.51 \\
\hline Barnaul & 1960 to 1987 & $\mathrm{Ob}$ & $7.31 E+06$ & $5.05 E+05$ & 47.32 & 1.65 \\
\hline Kamen-na-Ob & 1963 to 1987 & $\mathrm{Ob}$ & $1.09 \mathrm{E}+07$ & $1.28 \mathrm{E}+06$ & 49.82 & 1.68 \\
\hline Kolpashevo & 1960 to 1987 & $\mathrm{Ob}$ & $1.28 \mathrm{E}+07$ & $6.40 E+05$ & 117.77 & 3.76 \\
\hline Prokhorkino & 1960 to 1987 & $\mathrm{Ob}$ & $1.13 E+07$ & $8.74 \mathrm{E}+05$ & 161.63 & 5.16 \\
\hline Upper Ob* & - & $\mathrm{Ob}$ & $1.12 \mathrm{E}+07$ & $1.17 \mathrm{E}+06$ & 238.18 & 6.59 \\
\hline Belogorye & 1960 to 1987 & $\mathrm{Ob}$ & $2.83 E+07$ & $1.53 \mathrm{E}+06$ & 324.42 & 9.16 \\
\hline Salekhard & 1960 to 1987 & $\mathrm{Ob}$ & $1.49 \mathrm{E}+07$ & $1.11 E+06$ & 413.73 & 12.80 \\
\hline
\end{tabular}

* This value is estimated.

** This value is a combination of collected data from 1976 to 1988 and estimated values from 1960 to 1975.

\section{Irtysh River}

A summary of hydrographic data collected at stations along the Irtysh River is shown in Figure 3:3. Both water and suspended sediment discharge increase at downstream stations. The increase in suspended sediment is attributed to intensive bank erosion processes in this reach of the river (Rossomakhin 1963; Hendelman 1994;

Bobrovitskaya, Zubkova et al. 1996).

No suspended sediment data was available for the Iset River As an upper limit, one could assume that the entire sediment load observed at Yalutorovsk (Tobol River above its confluence with the Irtysh River) originates from the Iset River. Since both rivers 
make a contribution to the suspended sediment load at Yalutorovsk, suspended sediment values for the Iset River were estimated as follows. Using the coefficients from linear regressions of suspended sediment on water discharge, the relative fractions of annual water discharge observed at Isetskoye and calculated by difference for the Tobol River above its confluence with the Iset River were multiplied by the mean annual suspended sediment discharge observed at Yalutorovsk. Results suggest that suspended sediment contributions from the Iset River and the Tobol River above its confluence with the Iset River are comparable and quite small overall, when compared to the observed sediment discharge at Tobolsk (Table 3:1).

The combined suspended sediment loads of both the Tobol and Irtysh Rivers are represented by the mean annual suspended sediment discharge at the Tobolsk gauging station. There is a large difference between sediment discharge at Yalutorovsk and Omsk (i.e. the mean annual suspended sediment at Yalutorovsk and Omsk are $\sim 1.5$ and $\sim 37$ percent of the suspended sediment load observed at Tobolsk, respectively). This difference combined with a significantly longer distance between station and confluence (i.e. more bank erosion) and input from the Isim River (located below Omsk) suggests that the suspended sediment load originating from Irtysh River is significantly greater and dominates the suspended sediment load at Tobolsk. From Tobolsk to Khanty-Mansiysk, the suspended sediment load doubles, further illustrating the effects of bank erosion. 

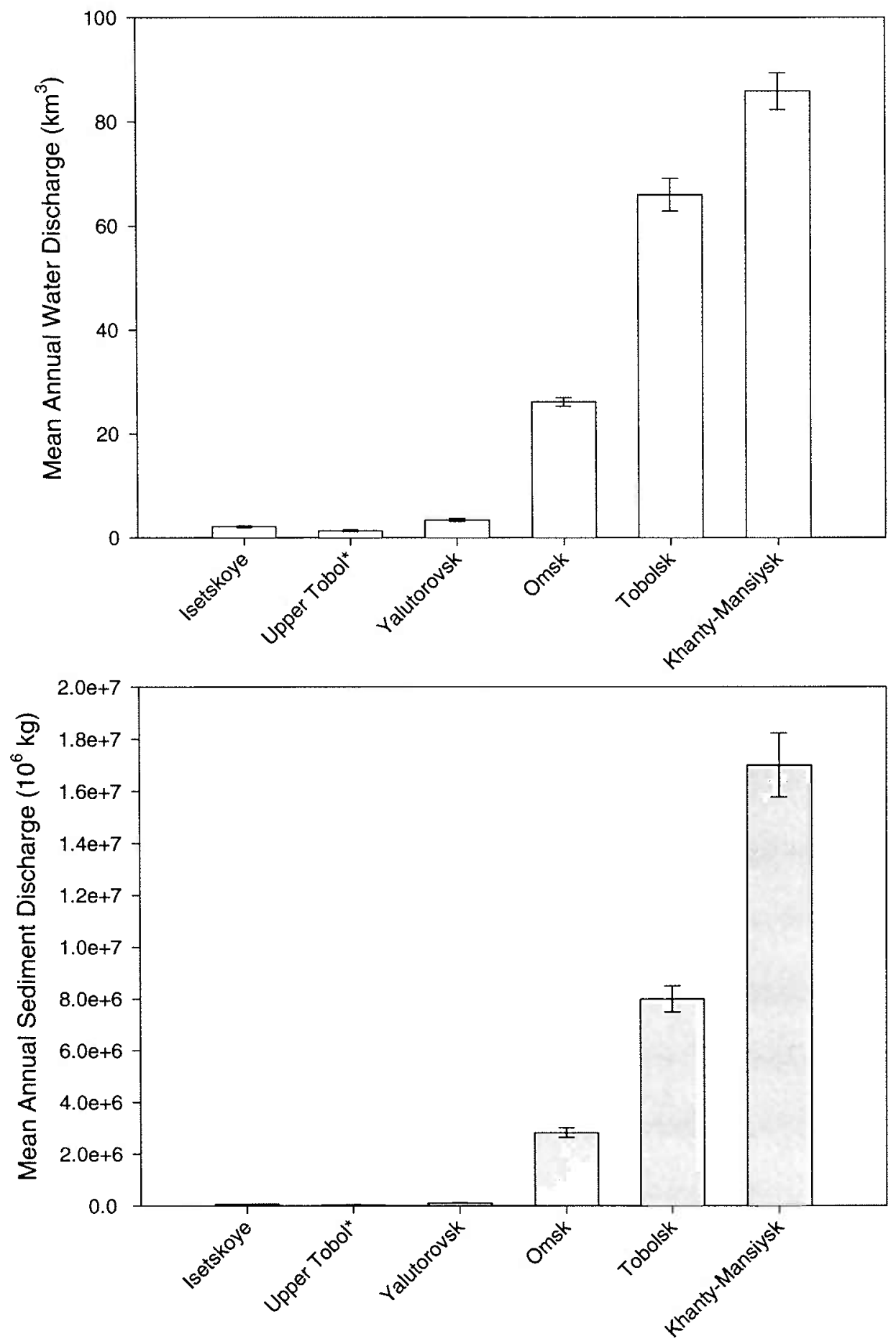

Figure 3:3. Mean annual water and sediment discharge for locations along the Iset, Tobol and Irtysh River above its confluence with the Ob River. * Indicates estimated values (see text for details). 


\section{The upper Ob River}

Hydrographic data collected from stations along the Ob River above its confluence with the Irtysh River are shown in Figure 3:4. Mean annual water discharge increases at down stream stations. The similarity between water discharge at Barnaul and Kamen-na-Ob is most likely a result of their close proximity to each other. The relationship between water discharge and suspended sediment is more complicated than that observed in the Irtysh River. A dam completed in 1957 at Novosibirsk is the most likely explanation (see Figure 3:2). It has been estimated that the resulting reservoir has the capacity to retain as much as 90 percent of the incoming sediment load (Brune, 1953, Avakyan, 1988). Between the period 1961 and 1964 an estimated 70 percent of the sediment load was retained (Bobrovitskaya et al., 1996). This is demonstrated by the small change in suspended sediment load relative to water discharge between Kamen-na$\mathrm{Ob}$ and Kolpashevo. The decrease in suspended sediment discharge between Kolpashevo and Prokhorkino has been attributed to prolonged adjustment to the dam at Novosibirsk and storage on the flood plains between the two stations (Bobrovitskaya, Zubkova et al. 1996; Meade, Bobrovitskaya et al. 2000). Estimates at the Ob River above its confluence with the Irtysh River indicate that water discharge continues to increase while suspended sediment remains the same or slightly decreases, further supporting the idea that sediment is being stored along this reach of the river. 

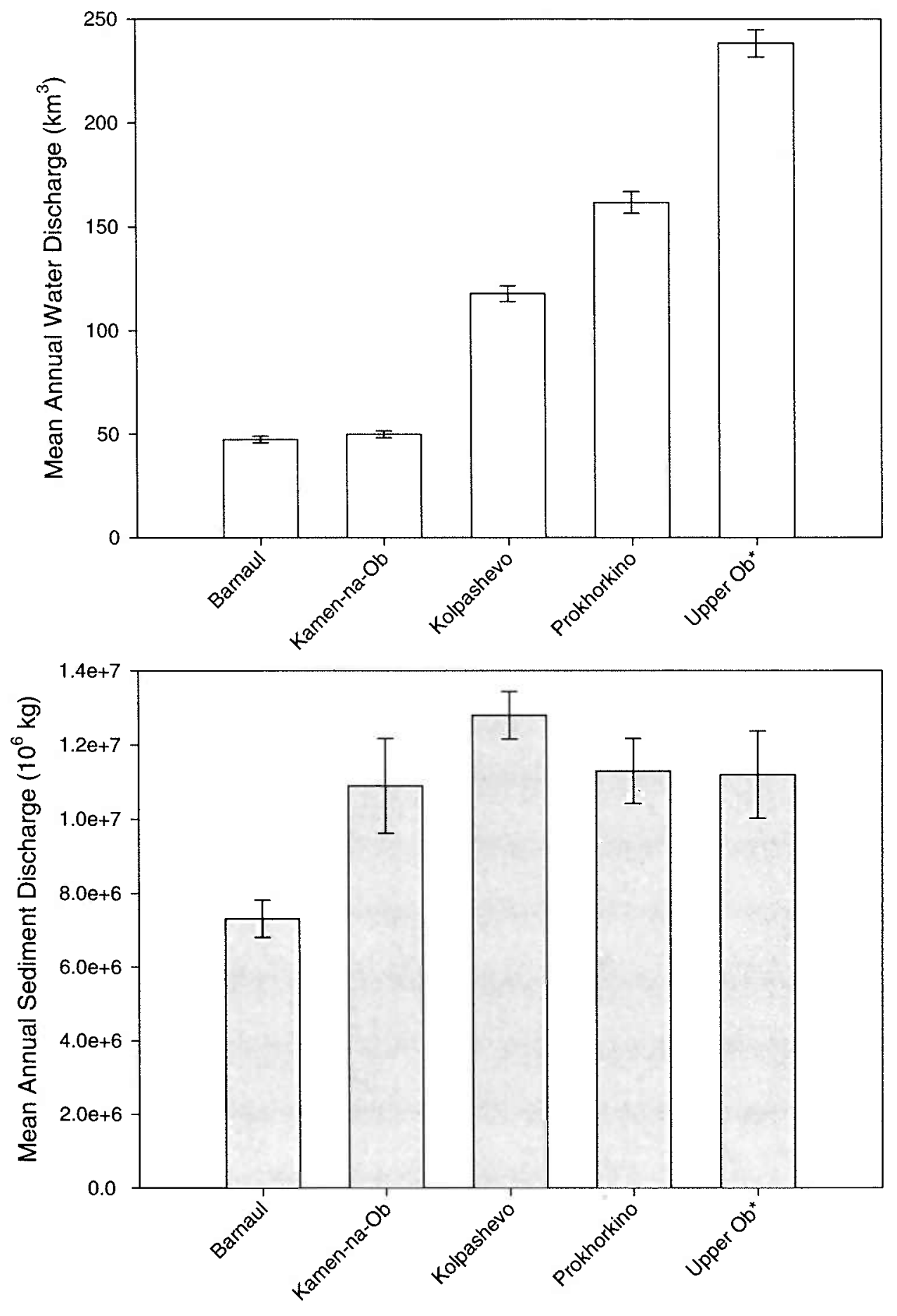

Figure 3:4. Mean annual water and sediment discharge for locations along the Ob River above its confluence with the Irtysh River. * Indicates estimated values (see text for details). 


\section{Ob/Irtysh confluence and $O b$ delta}

Hydrographic data collected at Belogorye and Salekhard along with data and estimates from Khanty-Mansiysk and the Upper $\mathrm{Ob}$ are shown in Figure 3:5. These data suggest that the Ob River above its confluence with the Irtysh River contributes significantly more water than the Irtysh River but substantially less sediment to the lower reaches of the $\mathrm{Ob}$. Between Belogorye and Salekhard, water discharge increases while sediment discharge decreases by $\sim 50$ percent. This loss of material between stations indicates sediment storage on the Ob's massive floodplain (Bobrovitskaya, Zubkova et al. 1996; Meade, Bobrovitskaya et al. 2000).

With regard to the $\mathrm{Ob} /$ Irtysh confluence, data based on mean annual values suggest that the Irtysh River dominated the suspended sediment load at Belogorye between 1960 and 1987 ( $\sim 60$ percent Irtysh, $\sim 40$ percent upper Ob). Given the probable effects of dam construction on the suspended sediment load contribution from the upper $\mathrm{Ob}$, an average for the period between 1960 and 1987 may not accurately reflect the relative contributions from each river prior to 1957 or in each year during the period 1960 to 1987 . Due to the fact that the levels of contamination reaching Belogorye and subsequently the $\mathrm{Ob}$ delta will be directly affected by each river's contribution through time, a closer look at the annual water and sediment discharge records for KhantyMansiysk and the Upper Ob is warranted. The annual water and sediment discharge records are shown in Figure 3:6. Water discharge for both locations indicates that the Upper Ob contributes significantly more water than the Irtysh River for each year of the entire record. However, suspended sediment discharge is quite variable, while the Irtysh 

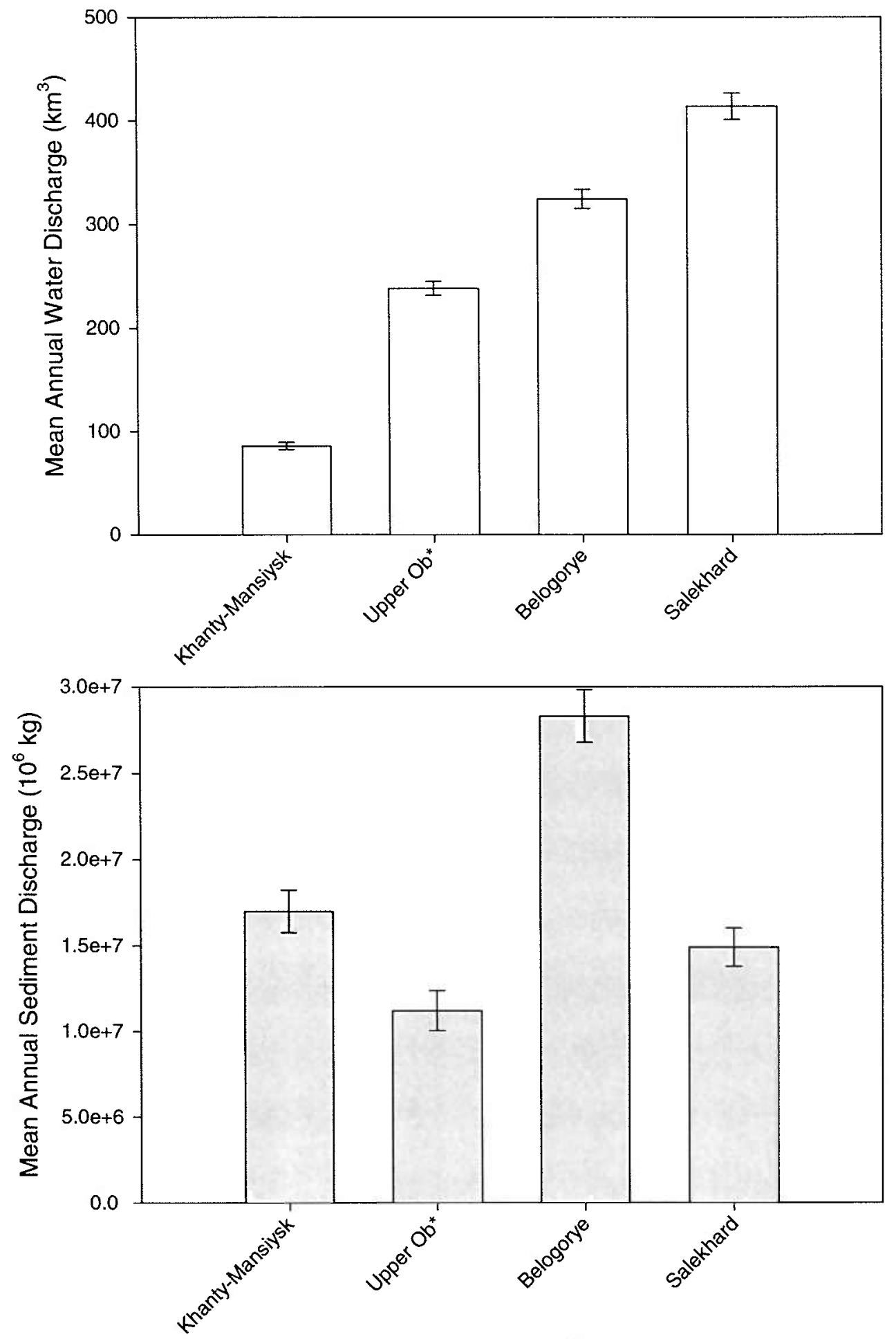

Figure 3:5. Mean annual water and sediment discharge for locations along the Ob River below its confluence with the Irtysh River. ${ }^{*}$ Indicates estimated values (see text for details). 
River has contributed more sediment overall and does so in most years, both rivers have dominated the suspended sediment load at different times throughout the period. Interestingly, the estimated values clearly indicate that the suspended load at Belogorye was dominated by contributions from the Irtysh River from the early 1960s through the early 1970s, which is consistent with the impact of damming the Ob River at Novosibirsk. Between 1975 and 1988 the suspended sediment load at Belogorye was dominated by both rivers in different years. Six years were clearly dominated by the Irtysh River and four years were clearly dominated by the upper $\mathrm{Ob}$, while the contribution from each river was nearly equal for three of the years.

A very simple mass balance calculation can be used to set an upper limit on the suspended sediment load contributions originating from the Techa River, the Irtysh River above Omsk, and the Tom River that pass Salekhard each year through the period 1960 to 1987. The mean suspended sediment discharge of the Techa River has been estimated at $\sim 3 \times 10^{4} \mathrm{t} /$ year $^{-1}$, while those for the Tom River range between 3.5 and $6.6 \times 10^{6} \mathrm{t} /$ year $^{-1}$ (Trapeznikov, Pozolotina et al. 1993; Bobrovitskaya 1994). Since no suspended sediment discharge estimates are available closer to Semipalitinsk, the annual totals observed at Omsk are used. Using suspended sediment data from downstream stations, discharges from these tributaries can be adjusted accordingly. Dilution is indicated where suspended sediment increases between up and downstream stations, suggesting input of sediments by bank erosion (e.g. Yalutorovsk /Tobolsk / Khanty-Mansiesk and Omsk/Tobolsk/ Khanty-Mansiesk). Loss is indicated where suspended, sediment decreases between up and downstream stations, suggesting storage of sediments (e.g. 

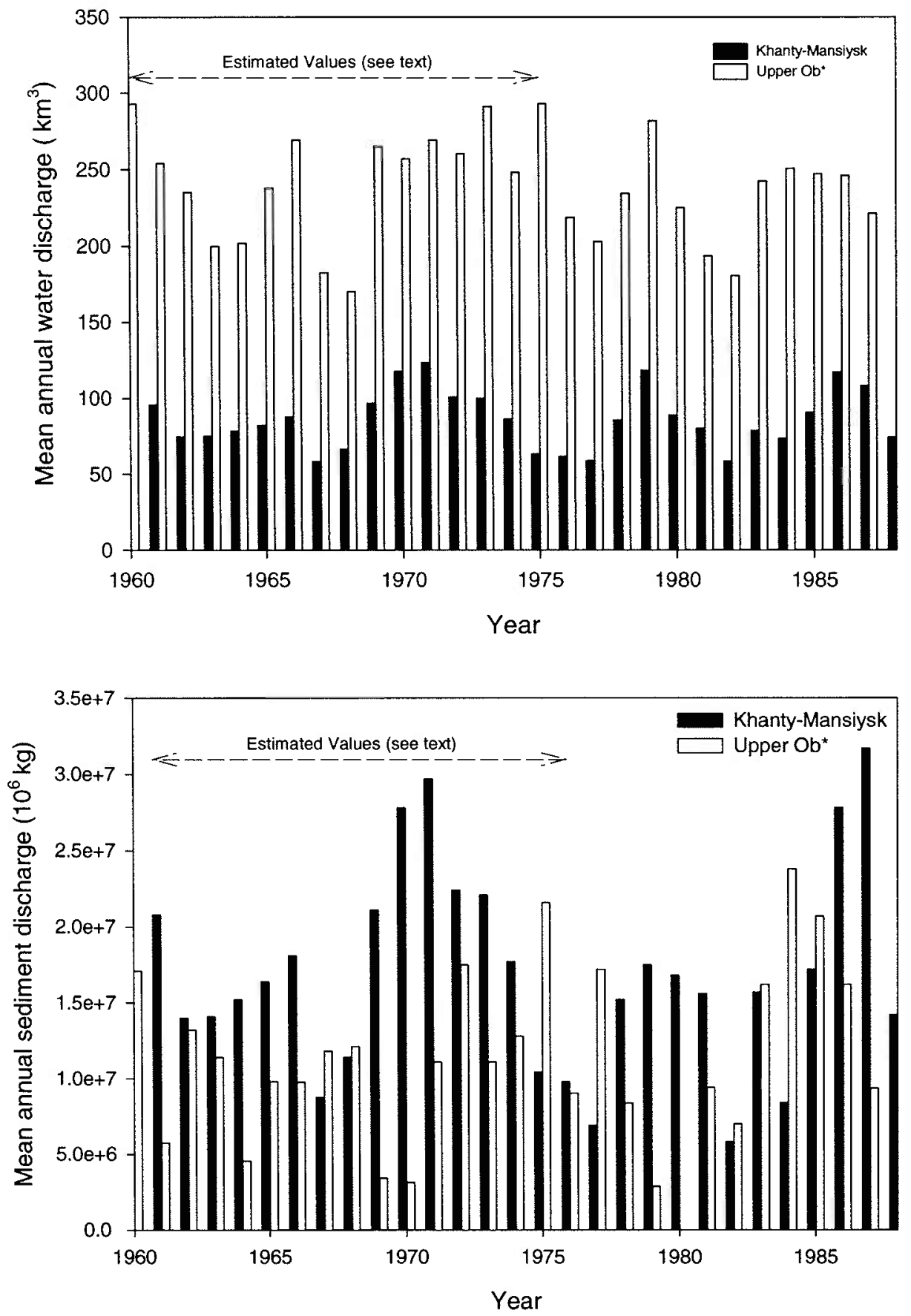

Figure 3:6. Annual water and sediment discharge estimated for Khanty-Mansiysk and the $\mathrm{Ob}$ River above its confluence with the Irtysh. *Dashed arrow indicates where records are estimated, see text for details. 
Belogorye/Salekhard and Kolpashevo/Prokorkino). These estimates are summarized in Figure 3:7. What is readily apparent from these data is that sediments originating from the Techa River constitute a substantially smaller fraction of the total load passing Salekhard than sediments from either the Tom or Irtysh Rivers. The average sediment contribution from the Techa River is estimated to be $\sim 0.07$ percent of the sediment load at Salekhard, while the average annual contributions from Irtysh and Tom Rivers are nearly equal at $\sim 6$ percent. It is also clear from Figure 3.7 that neither the Tom nor the Irtysh River consistently dominates with respect to sediment contributions.

It is important to note that the contributions estimated above by mass balance represent an upper limit of the actual contributions. This due to the fact that they do not take into consideration the effects of inter-annual variability (in the case of the Techa and Tom Rivers) and sediment exchange during transit. They do serve, however, as a measure of relative sediment contributions with regard to the known contaminant sources in the $\mathrm{Ob}$ watershed. Based on the interpretation of the hydrologic data presented above, suspended sediment contributions from tributaries draining the regions containing Semipalitinsk and Tomsk-7 will be similar, while suspended sediment contributions from the tributary draining the region containing Mayak will be more than an order of magnitude less. Depending on the contamination level of suspended sediments in each river, contaminant contributions could be quite different from suspended load contributions. As an example, in order for contaminant contributions to be comparable at Salekhard, the level of contamination in sediments exiting the Techa River would have to be 2-3 orders of magnitude higher than contaminant levels in sediments exiting the Tom 
River or passing Omsk. Plutonium concentrations $\left({ }^{239,240} \mathrm{Pu}\right)$ reported by Oughton et al. (2000) in the Techa River below the dam at Asanov range from $2700 \mathrm{~Bq} \mathrm{gm}{ }^{-1}$, observed $7 \mathrm{~km}$ below the dam, to between 2 and $17 \mathrm{~Bq} \mathrm{gm}^{-1}$ at Zatechinkoye (230 km from the dam at Asanov and just above the Techa/Iset confluence). Data reported at each sampling site by these authors consist of measurements made on surface sediments ( $0-2$ $\mathrm{cm}$ ) and one additional measurement at some depth below the surface, making it difficult to obtain an accurate estimate of the concentration range over the last fifty years. Using the ${ }^{240} \mathrm{Pu} /{ }^{239} \mathrm{Pu}$ ratio provided, the ${ }^{239,240} \mathrm{Pu}$ concentration $\left(\sim 17 \mathrm{~Bq} \mathrm{gm}^{-1}\right)$ of the deeper sample $(26-28 \mathrm{~cm})$ collected at Zatechinkoye converts to ${ }^{239} \mathrm{Pu}$ concentration of $\sim 3 \mathrm{e} 9$ atoms $\mathrm{gm}^{-1}$. This concentration multiplied by the estimated fractional contribution of Techa River sediment present at Salekhard ( $\sim 0.01)$ yields as an upper limit, ${ }^{239} \mathrm{Pu}$ concentration of $\sim 3 \mathrm{e} 7$ atoms $\mathrm{gm}^{-1}$, which is well within the ICP-MS detection limits. Based on this calculation and depending on the accuracy of the estimated contributions, contamination originating from Mayak could be present at detectable levels. 


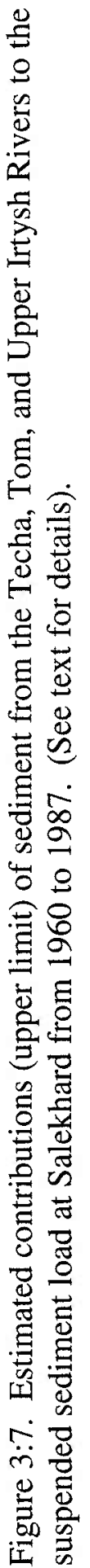




\section{References Chapter 3}

Bobrovitskaya, N. N. (1994). Assessment of trends to sediment discharge variations in the rivers of the Former Soviet Union (FSU). Proceedings from the International Symposium, East-West, North-South Encounter on the State-of-the-Art in River Engineering and Design Philosophies, St. Petersburg, Russia, State Hydrologic Institute.

Bobrovitskaya, N. N., B. G. Skakalsky, et al. (1997). Hydrologic and Hydrochemical Data for the Ob-Irtysh and Yenisey River Systems of Central Russia, 1954-1988. Reston, VA, U. S. Geological Survey: 177.

Bobrovitskaya, N. N., D. E. e. Walling, et al. (1996). "Long-term variations in mean erosion and sediment yield from the rivers of the former Soviet Union

Proceedings of an International symposium on Erosion and sediment yield; global and regional perspectives." International symposium on Erosion and sediment yield; global and regional perspectives 236: 407-413.

Bobrovitskaya, N. N., C. Zubkova, et al. (1996). "Discharges and yields of suspended sediment in the $\mathrm{Ob}^{\prime}$ and Yenisey rivers of Siberia

Proceedings of an International symposium on Erosion and sediment yield; global and regional perspectives." International symposium on Erosion and sediment yield; global and regional perspectives 236: 115-123.

Grosswald, M. G. and T. J. Hughes (1995). "Paleoglaciology's grand unsolved problem." Journal of Glaciology 41(138): 313-332.

Hendelman, M. M. (1994). The laws of meandering of the Irtysh River. Proceedings from the International Symposium, East-West, North-South Encounter on the State-ofthe-Art in River Engineering and Design Philosophies, St. Petersburg, Russia, State Hydrologic Institute.

Ivanov, V. V., V. M. Medkova, et al. (1995). Characteristic features of sedimentation processes in the lower reaches and mouth of the Ob River, The State Research Centre of the Russian Federation: the Arctic and Antarctic Research Institute: 26.

Kenna, T. C. and F. L. Sayles (2001). "The Distribution and History of Nuclear Weapons Related Contamination in Sediments from the Ob River Siberia, as determined by Isotopic Ratios of Plutonium and Neptunium." Journal of Environmental $\underline{\text { Radioactivity(In press). }}$

Makeyev, V. M. and D. Y. Bolshiyanov (1988). "Characteristic morphological features of the Ob mouth valley zone, contemporary delta formation history."

Hydrometeoizdat L: 125-137. 
Meade, R. H., N. N. Bobrovitskaya, et al. (2000). "Suspended-sediment and fresh-water discharges in the $\mathrm{Ob}$ and Yenisey rivers, 1960-1988." International journal of Earth Sciences 89: 461-469.

Oughton, D. H., K. Fifield, et al. (2000). "Plutonium from Mayak: measurement of isotope ratios and activities using accelerator mass spectrometry." Environmental Science \& Technology, ES \& T 34: 1938-1945.

Panteleyev, G. P. (1995). The history of plutonium and cesium-137 contamination of the Ob River delta sediments, Massachusetts Institute of Technology, Cambridge, MA, United States.

Rossomakhin, M. V. (1963). "Investigations of the shape of the valley of the Irtysh River in relation to the sediment and water stage regimes." Soviet Hydrology: Selected Papers 2(4): 336-355.

Sayles, F. L., H. D. Livingston, et al. (1997). "The history and source of particulate (super 137) Cs and (super 239,240) Pu deposition in sediments of the Ob River delta, Siberia

Environmental radioactivity in the Arctic." Second symposium and international conference on Environmental radioactivity in the Arctic 202(1-3): 25-41.

Syvitski, J. P., L. Pratson, et al. (1999). Stratigraphic predictions of continental margins for the U. S. Navy. Tulsa, OK, Society for Sedimentary Geology: 219-236.

Trapeznikov, A. V., V. N. Pozolotina, et al. (1993). "Radioaktivnoye zagryazneniye reki Techi na Urale; Techa River radioactive contamination in Urals." Ekologiva 1993(5): 72-77. 


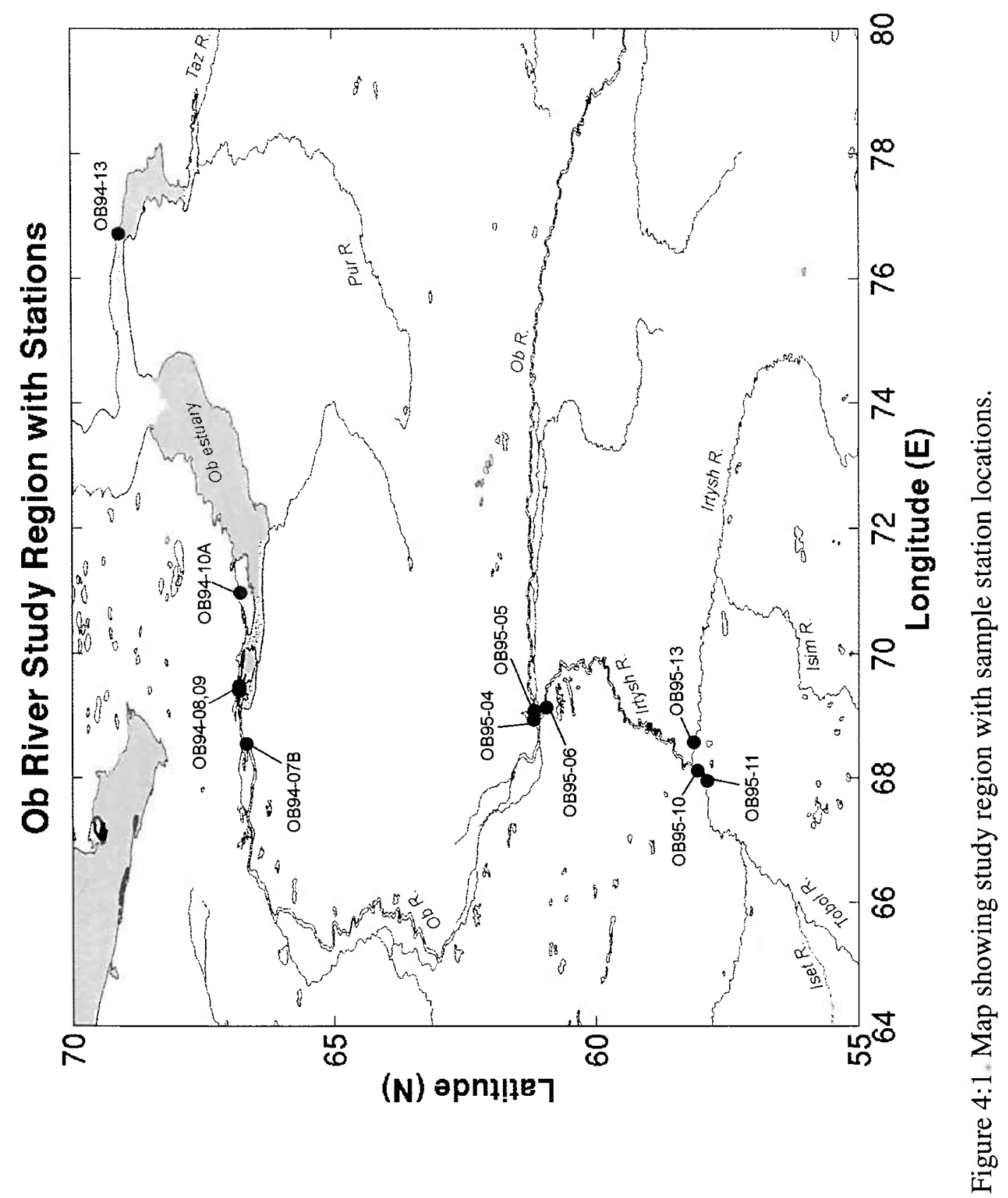




\section{Chapter 4}

\section{Sampling, Analytical Methods, and Data}

\section{Sample Collection}

One of the overriding factors central to the research objectives of this study is the collection of undisturbed sedimentary records from the Ob River region. As noted above, the annual water discharge in the $\mathrm{Ob}$ River is characterized as low flow during the winter, flooding during the spring and summer with a peak in June, and a gradual decrease during the fall (Bobrovitskaya, Zubkova et al. 1996). The suspended sediment transport cycle is quite similar to the water discharge cycle, but with the transport more concentrated in the summer months. The high-energy and heavy bank erosion associated with peak flow plus dredging operations for navigation purposes create an unstable depositional environment, which makes the main river unsuitable for the collection of undisturbed sediments. Panteleyev (1995) showed that a more suitable depositional environment occurs in small lakes located on the flood plain of the main river channel. While these lakes do not receive sedimentary material from the river throughout the year, they do accumulate substantial amounts of sediment during the period of maximum sediment transport. Approximately 90 percent of sediment transport occurs during the months of peak discharge, May through July (Bobrovitskaya, Zubkova et al. 1996). Thus while some material is "missing", the sediment deposits in the lakes should sample a large fraction of the suspended material transported annually. 
During the summer months of 1994 and 1995, more than 30 sediment cores were collected from sites in the Ob River region (Figure 4:1). The focus of sampling during the 1994 season was the Ob Delta as well as the Ob and Taz Estuaries. Studies in the 1995 field season were focused on sampling the Ob River and its major tributaries, the Irtysh and Tobol Rivers. Sampling included the collection of replicate cores at each location, one of which was sectioned at $1-\mathrm{cm}$ intervals in the field for later analysis. The logistics of sampling flood plain lakes required the construction of a specially designed vessel that would permit access to sites through shallow channels and collection of sediment cores; the methods applied are covered in detail elsewhere (Panteleyev 1995; Sayles, Livingston et al. 1997).

In order to identify the sources of contamination to the region, sediment cores were collected from tributaries that drained areas containing known or suspected sources of contamination as well as a "control" from the Taz estuary, a region that was thought to be contaminated only by fallout. An additional criterion used to select sample sites was water depth. As discussed previously, Ivanov et al. (1995) estimates the ice thickness in the freshwater part of the Ob Delta between 90 and $230 \mathrm{~cm}$. In order to avoid sediments disturbed by ice, sediment cores were collected where water depths exceeded the upper limit of ice thickness estimates. The exception to this is OB94-07, which has a water depth within the estimated range of ice thickness although the contaminant record obtained from this core provides strong evidence that post-deposition mixing is minimal or absent (see discussion next chapter). The locations of the selected sample sites, core descriptions, and the potential source(s) of contamination are listed in Table 4:1. 


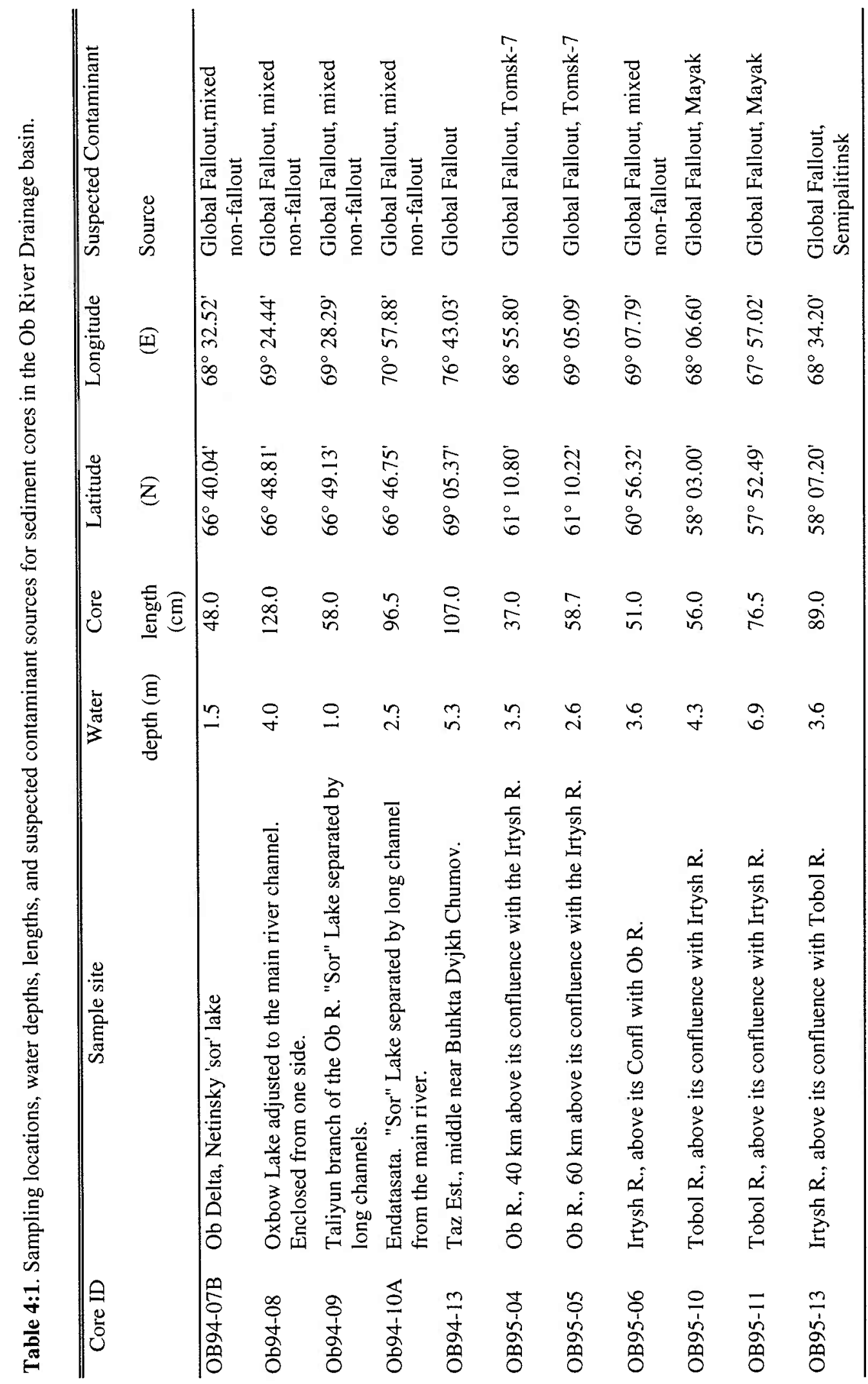


Sample Analyses

Following the approach of Panteleyev (1995) and Sayles, Livingston et al. (1997), the sample analysis scheme entailed screening of cores based on ${ }^{137} \mathrm{Cs}$ activity in un-dried core sections by gamma spectrometry in order to assess core quality and sample processing priority. On cores selected for further analyses, water content was determined by the difference in weight before and after drying at $65^{\circ} \mathrm{C}$ for 2 days. Drying temperature was limited by the melting point of the sample jars. An additional water loss of $\sim 2$ percent was determined at $105^{\circ} \mathrm{C}$; however, no additional correction was made. Wet bulk density was calculated using a grain density of $2.5 \mathrm{~g} / \mathrm{cm}^{3}$. After drying, each core section was ground, homogenized, and sealed for at least two weeks in order to establish radioactive decay equilibrium between ${ }^{226} \mathrm{Ra}$ and its daughters, ${ }^{214} \mathrm{~Pb}$ and ${ }^{214} \mathrm{Bi}$. The concentrations of ${ }^{137} \mathrm{Cs},{ }^{210} \mathrm{~Pb},{ }^{214} \mathrm{~Pb}$, and ${ }^{214} \mathrm{Bi}$ were then determined by gamma spectrometry using calibrated high-resolution, low energy Ge detectors. Detector efficiency calibration, sample geometry and self-absorption corrections are covered in detail elsewhere (Sayles, Livingston et al., 1997).

After non-destructive gamma spectrometry was completed, 2 to10 gram subsamples from core sections were prepared for $\mathrm{Pu}$ and $\mathrm{Np}$ isotopic analysis, using a total digestion procedure, which is summarized in Figure 4:2a and $\mathrm{b}$ and described below. The sub-samples were weighed and combusted at $550^{\circ} \mathrm{C}$ for 24 hours to decompose any organic matter that was present. Next, they underwent the following series of acid digestions: an $\mathrm{HF} /$ aqua regia mixture, concentrated $\mathrm{HCl}$ and $30 \% \mathrm{H}_{2} \mathrm{O}_{2}$, and concentrated $\mathrm{HNO}_{3}$. Solutions were brought to dryness between each of the three digestions. In order 
to remove some of the solublized matrix material prior to ion exchange, nuclides were co-precipitated with $\mathrm{LaOH}$. This involved dissolving dried residues in $3 \mathrm{~N}^{\mathrm{HNO}} 3$ and adding $\mathrm{NH}_{2}-\mathrm{OH} \mathrm{HCl}$, which was necessary to ensure $\mathrm{Pu}$ and $\mathrm{Np}$ reduction to (III) and (IV), respectively. Following the addition of $\mathrm{La}\left(\mathrm{NO}_{3}\right)_{3}$ as a carrier, nuclides were coprecipitated with $\mathrm{LaOH}$ and other hydroxides formed by the addition of concentrated $\mathrm{NH}_{4} \mathrm{OH}$. After cooling, the resulting precipitates were centrifuged and the supernate removed. The precipitates were rinsed and re-centrifuged three additional times with deionized water. The final precipitates were dissolved in concentrated $\mathrm{HNO}_{3}$ and taken to dryness. Ion exchange methods are based on those developed by Maxwell (1997). Load solutions for ion exchange columns were prepared by dissolving precipitate residues in $0.5 \mathrm{~N} \mathrm{AlNO}_{3}: 3 \mathrm{~N} \mathrm{HNO}_{3}$. In order for $\mathrm{Pu}$ and $\mathrm{Np}$ to remain together during ion exchange, both elements must be in a (IV) valence state. This was achieved by first reducing the nuclides with $0.1 \mathrm{~N} \mathrm{FeSO}_{4}$, yielding $\mathrm{Pu}(\mathrm{III})$ and $\mathrm{Np}(\mathrm{IV}) . \mathrm{NaNO}_{2}$ of $0.2 \mathrm{~N}$ was then used to oxidize $\mathrm{Pu}(\mathrm{III})$ to $\mathrm{Pu}(\mathrm{IV})$. At $70^{\circ} \mathrm{C}, \mathrm{NaNO}_{2}$ oxidizes $\mathrm{Np}(\mathrm{IV})$ to $\mathrm{Np}(\mathrm{V})$; at room temperature, however, the effect on $\mathrm{Np}(\mathrm{IV}$ ) is minimal (Maxwell 1997). Load solutions were centrifuged to remove any particulate material that would interfere with flow through ion exchange resin columns. $\mathrm{Pu}$ and $\mathrm{Np}$ were isolated from the load solutions and purified on $\mathrm{TEVA}^{\circledR}$ ion exchange resin columns as an actinide-nitrate complex. In order to obtain adequate separation from uranium, three separate column passes were required. Elutions containing $\mathrm{Pu}$ and $\mathrm{Np}$ were brought to dryness after the final column pass. In preparation for measurement, the purified samples were dissolved in a $10 \%$ $\mathrm{HNO}_{3}: 0.02 \% \mathrm{HF}$ mixture, sonicated and filtered through a 0.2 -micron filter. 


\section{Isotope Dilution and Yield Monitors}

The concentrations and ratios of $\mathrm{Pu}$ and $\mathrm{Np}$ isotopes were determined by the isotope dilution technique. A ${ }^{242} \mathrm{Pu}$ standard, traceable to Lawrence Livermore National Laboratories was added to monitor Pu yields, and a ${ }^{236} \mathrm{~Np}$ standard, obtained from Los Alamos National Laboratories, was used to monitor Np yields (nominal additions of $3 \times$ $10^{9}$ and $5 \times 10^{8}$ atoms, respectively). Homogenization between samples and spikes was achieved by adding weighed spikes before the initial digestion step (i.e. HF/Aqua regia).

Just prior to analysis, an internal standard of ${ }^{243} \mathrm{Am}$ (nominally $1 \times 10^{9}$ atoms) was added to analyte solutions in order to monitor mass spectrometer drift and instabilities. Chemical recoveries for $\mathrm{Pu}$ and $\mathrm{Np}$ were typically 90 and 60 percent, respectively.

\section{Instrumentation and Mass Spectrometer Analysis Method}

The choice of MS-ICPMS over thermal ionization mass spectrometry (TIMS), which can be characterized as having lower detection limits and higher precision, was based primarily on cost effectiveness and instrument availability. Issues concerning detection limits were circumvented by increasing sample size and optimizing chemical recoveries. Concentrations and atom ratios of the isotopes of interest were quantified on an ELEMENT (Finnigan-MAT, Bremen, Germany). The ELEMENT is a magnetic sector inductively coupled plasma mass spectrometer (MS-ICPMS) equipped with a single electron multiplier. All data acquisitions were carried out in low-resolution mode $(\mathrm{m} / \Delta \mathrm{m}=300)$, and sample introduction to the mass spectrometer used a CETAC Microconcentric desolvating nebulizer (MCN 6000), and an ASX-100 auto-sampler. Prior to 
sample analyses, the ELEMENT was tuned using a $0.1 \mathrm{ppb}$ solution of ${ }^{238} \mathrm{U}$ in 5 percent $\mathrm{HNO}_{3}$. Table 4:2 lists an example of typical operating parameters. It is important to note that these parameters were optimized each time the ELEMENT was started. Sensitivities ranged between 5 and $10 \times 10^{6} \mathrm{cps} / \mathrm{ppb}^{238} \mathrm{U}$.

Table 4:2 Example of instrumental operating conditions

Parameter/units

Value

\section{ELEMENT}

Resolution Low (300)

Focus offset $\%$

$\mathrm{Ua} / \mathrm{Ub} / \%$ $-0.348$

Cool gas/l min-1

Aux gas/l min-1

Sample gas// min-1 1.328

Additional 1

Rf plasma power $\mathrm{W}$

Extraction/N

Focus N

$-856.4$

X-Deflection $N$

6.85

Y-Deflection/V

$-6.34$

Shape/N

90.45

Rotation quadrupole $1 / \mathrm{N}$

$-8.38$

Rotation quadrupole $2 / \mathrm{V}$

Focus quadrupole $1 / \mathrm{N}$

Focus quadrupole $2 \mathrm{~N}$

$-0.92$

MATSUDA-Plate/ $\mathrm{V}$

10.5

SEM-Deflection

SEM-Deflection

Guard electrode

MCN-6000

Spray Chamber Heater/W

Desolvator Heater/W

Sweep Gas/I min-1

Nitrogen/l min-1 


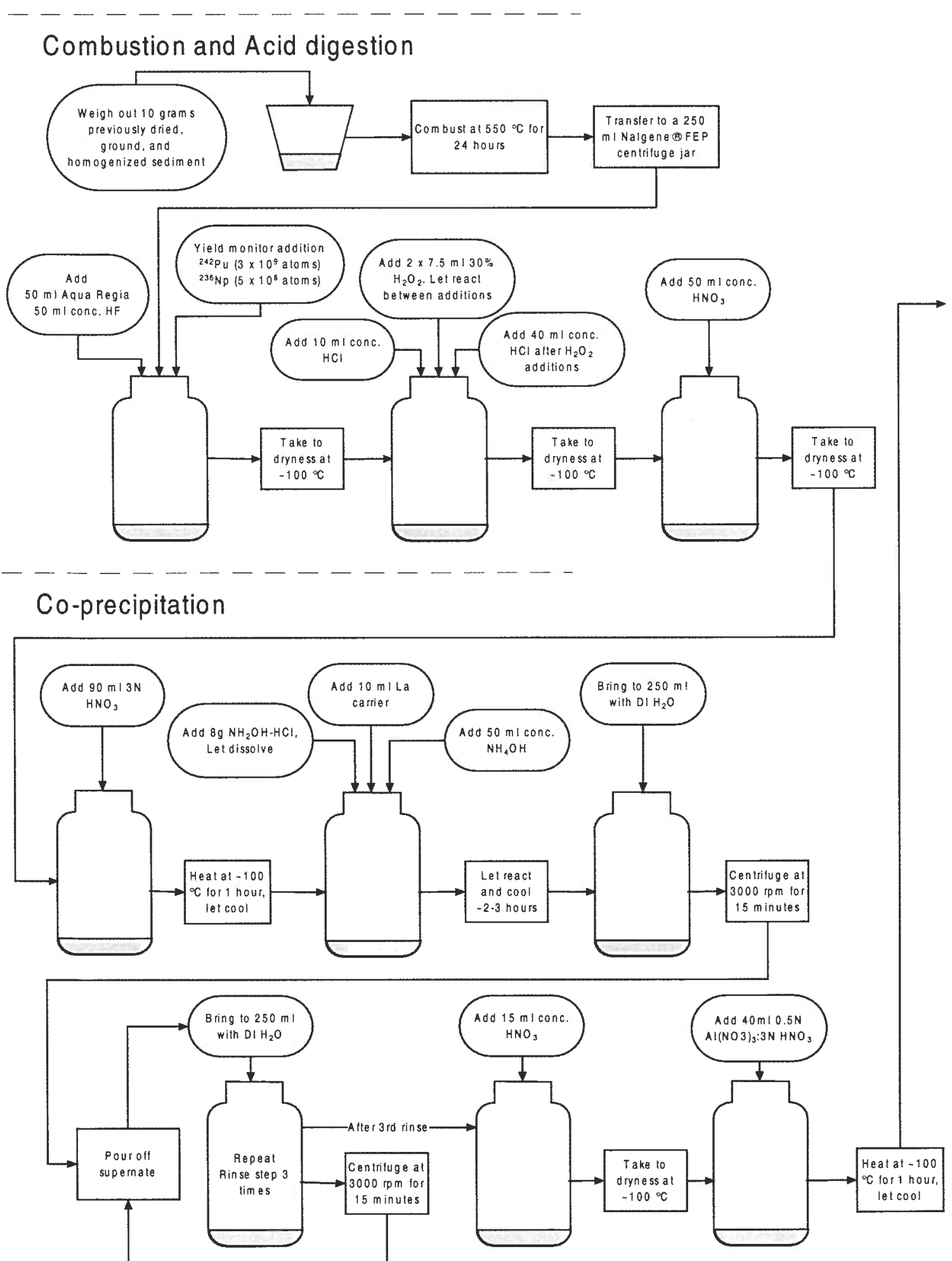

Figure 4:2a Schematic outlining the combustion, acid digestion, and co-precipitation techniques developed at WHOI for Pu and Np ICP-MS isotopic analyses. 

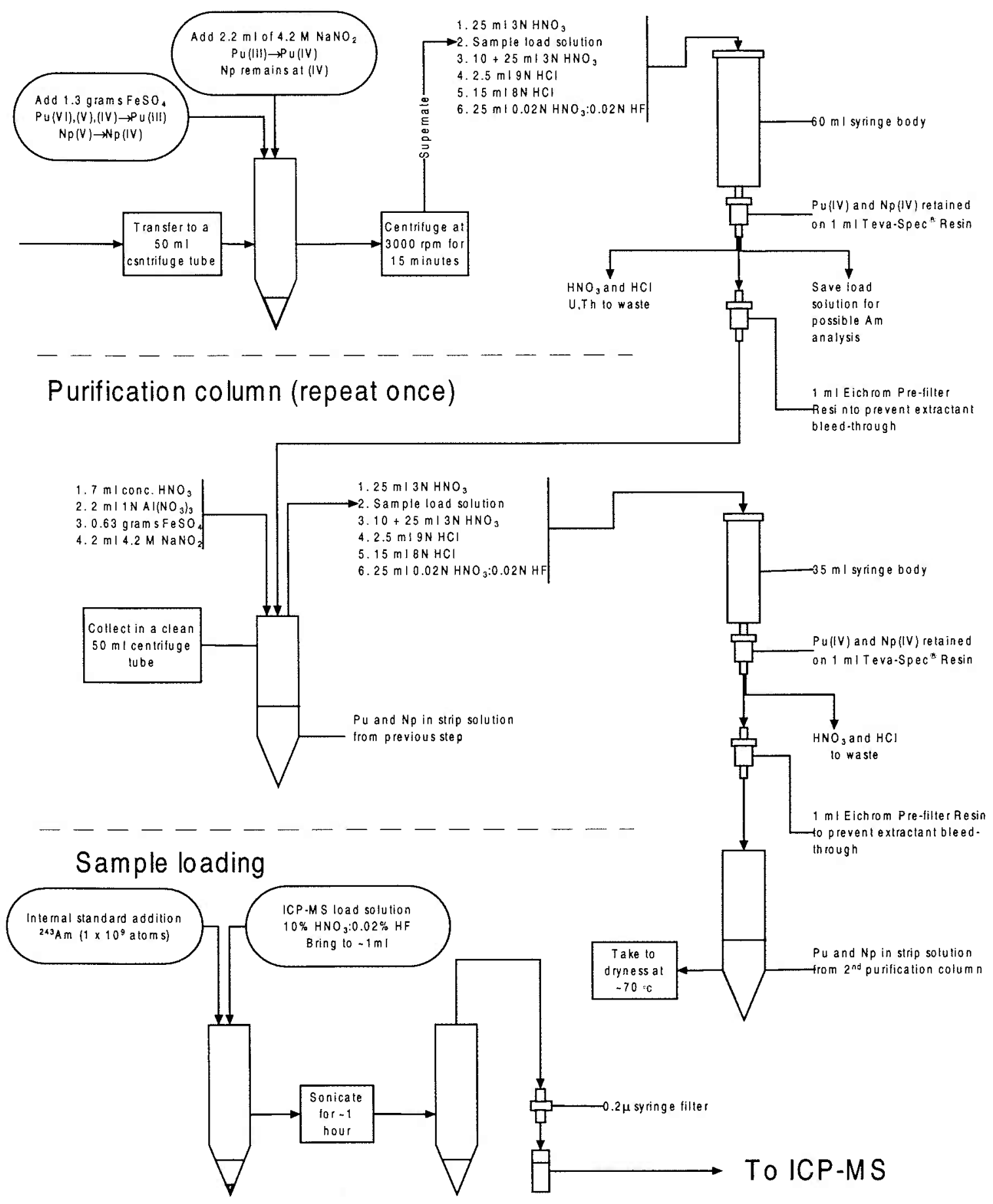

Figure 4.2b. Schematic outlining the ion exchange clean-up and purification and sample loading techniques developed at WHOI for Pu and Np ICP-MS isotopic analyses. 
The peak-tops of the masses of ${ }^{236} \mathrm{~Np},{ }^{237} \mathrm{~Np},{ }^{238} \mathrm{U},{ }^{239} \mathrm{Pu},{ }^{240} \mathrm{Pu},{ }^{241} \mathrm{Pu},{ }^{242} \mathrm{Pu}$, and ${ }^{243} \mathrm{Am}$ were electrostatically scanned at $5 \%$ of the peak-width. Details concerning the measurement method are listed in Table $4: 3$. The atom ratios ${ }^{240} \mathrm{Pu} /{ }^{239} \mathrm{Pu}$, and ${ }^{241} \mathrm{Pu} /{ }^{239} \mathrm{Pu}$ were determined directly from the measurement while concentrations of ${ }^{237} \mathrm{~Np},{ }^{239} \mathrm{Pu}$, ${ }^{240} \mathrm{Pu},{ }^{241} \mathrm{Pu}$ and $\mathrm{Np} / \mathrm{Pu}$ isotope ratios were calculated as a function of the ${ }^{237} \mathrm{~Np} /{ }^{236} \mathrm{~Np}$, ${ }^{239} \mathrm{Pu} /{ }^{242} \mathrm{Pu}$, and ${ }^{240} \mathrm{Pu} /{ }^{242} \mathrm{Pu}$, and ${ }^{241} \mathrm{Pu} /{ }^{242} \mathrm{Pu}$ atom ratios. Due to typically low concentrations in sediments, measurement precision was limited, primarily, by the total number of ions detected. Precision was also limited by the ability to accurately measure isotopic ratios with a single-collector system. For example, the precision to which ${ }^{240} \mathrm{Pu}$ concentration could be determined depended on a combination of the total counts detected at mass 240 as well as the ability to accurately measure the ${ }^{240} \mathrm{Pu} /{ }^{242} \mathrm{Pu}$ isotope ratio. Longer dwell times on the individual peak-tops increased precision by increasing the total number of ions detected at each mass, while rapid scanning between peak-tops increased precision by reducing variations in isotope ratios due to mass spectrometer drift and nebulizer and plasma instabilities.

Measurements were optimized to obtain the best overall precision with respect to these two sources of error. The values for segment duration (i.e. the amount of time each isotope is measured per spectra) are longer than those used by other researchers in cases where ion intensities were not a limiting factor (0.5 s) (Rodushkin and Ruth 1997; Rodushkin, Ruth et al. 1998). For each sample, 40 spectra of the above-mentioned masses were collected. The system was rinsed for 12 minutes in a $10 \% \mathrm{HNO}_{3}: 0.02 \% \mathrm{HF}$ 
mixture between samples. After rinsing and prior to the next sample measurement, this dilute acid solution was measured and used as an acid blank.

Table 4:3. Data acquisition parameters for $\mathrm{Pu} / \mathrm{Np}$ analysis

\begin{tabular}{lrcc} 
Parameter & Value & \\
\hline & & & \\
Runs/Passes (Meas.) & $40^{*} 1$ & & \\
Runs/Passes (Eval) & $40^{\star} 1$ & & \\
Magnet Mass & 236.047 & & \\
Mass Window/\% & 5 & & \\
Samples per Peak & 250 & & \\
Search Window/\% & 60 & & \\
Integration Window/\% & 5 & & \\
Scan Type & Escan & & \\
Detection Mode & Counting & & \\
Integration Type & Average & & \\
& & & \\
Isotope & Settling & Sample & Segment \\
& Time (s) & Time(s) & Duration(s) \\
\hline${ }^{238} \mathrm{U}$ & 0.001 & 0.05 & 0.65 \\
${ }^{236} \mathrm{~Np}$ & 0.003 & 0.1 & 1.3 \\
${ }^{237} \mathrm{~Np}$ & 0.001 & 0.1 & 1.3 \\
${ }^{239} \mathrm{Pu}$ & 0.001 & 0.1 & 1.3 \\
${ }^{240} \mathrm{Pu}$ & 0.001 & 0.1 & 1.3 \\
${ }^{241} \mathrm{Pu}$ & 0.001 & 0.2 & 2.6 \\
${ }^{242} \mathrm{Pu}$ & 0.001 & 0.1 & 1.3 \\
${ }^{243} \mathrm{Am}$ & 0.001 & 0.1 & 1.3 \\
\hline
\end{tabular}

Due to mass spectrometer instabilities and non-random errors introduced by ${ }^{238} \mathrm{U}$ tailing and the addition of sample spikes and internal standards with known amounts of contaminants, corrections to the raw data were required before final concentrations and isotopic ratios were calculated. As a result of nebulizer noise, torch flicker and other system instabilities, the raw data for each of the isotopes and acid blanks were first processed in Matlab, version 5 to remove outliers (single spectra) that were \pm 3 standard deviations from the computed mean. This procedure was repeated 2 additional times, and 
typically resulted in the rejection of between zero and two data points. Following this, each mass of interest was blank-corrected on the basis of the acid, which was run just prior to each sample. Intensities at masses 237 and 239 were corrected for ${ }^{238} \mathrm{U}$ tailing (typically corrections were 5-10 cps). The size of this correction was dependent on the measured intensities at these masses, and it was usually within $2 \sigma$ for both masses. Additionally, mass 237 was corrected for known amounts of ${ }^{237} \mathrm{~Np}$ present in the ${ }^{236} \mathrm{~Np}$ spike, and mass 239 was corrected for known amounts of ${ }^{239} \mathrm{Pu}$ present in the ${ }^{243} \mathrm{Am}$ internal standard (also within $2 \sigma$ ). Occasionally, un-spiked reagent blanks were run along with sediment samples. Specific corrections based on these blanks were not made; rather, they were used in a qualitative fashion to indicate evidence of cross contamination and/or beaker-memory effects. Initially, ${ }^{241} \mathrm{Pu}$ was not measured. However, as the method developed, it became clear that it would be possible. In the case of ${ }^{241} \mathrm{Pu}$, count rates are quite low (usually $\leq 10 \mathrm{cps}$ ), which makes the background and blank corrections much more important than for the other isotopes. In order to make the necessary corrections, sediment samples selected from cores that recovered sediments deposited prior to the nuclear age were sub-sampled and spiked as normal samples. During data processing, samples were blank corrected for both acid blank and sediment blank. Blank corrections were usually on the order of 1 to $3 \mathrm{cps}$ and were insignificant for all but ${ }^{241} \mathrm{Pu}$. To rule out the possibility that ${ }^{241} \mathrm{Am}$ was causing an interference, blank sediments were spiked with ${ }^{243} \mathrm{Am}$ prior to digestion and run as normal samples. In these samples, count rates measured for ${ }^{243} \mathrm{Am}$ were no different from background levels, demonstrating efficient removal of americium in the method. 
Isotope Ratio and Concentration Calculations and Uncertainty Estimates

After processing the raw data, isotopic ratios and concentrations (also a function of an isotope ratio, i.e. isotope dilution) were calculated. Isotope ratios can be computed from the processed data by two different methods. By averaging the intensity of each isotope collected in all spectra, one can compute the ratio of the mean intensities. Alternatively, one can compute a mean ratio by averaging the ratios obtained from each spectrum. Table 4:4 shows an example calculation of the ${ }^{240} \mathrm{Pu} /{ }^{239} \mathrm{Pu}$ atom ratio by both methods along with a comparison of uncertainty estimates based on Poisson counting statistics vs. the application of the Central Limits Theorem (i.e. standard error). Strictly speaking, the ratio of the means equals the mean of the ratios only under certain conditions. However, the differences between the resulting isotope ratios in this study are small and within overall uncertainty estimates of the two approaches (note: additional significant figures are shown in order to illustrate the small difference between resulting ratio values). As expected, uncertainty estimates based on the standard error are larger that those based on Poisson counting statistics. Since standard error estimates are generated from repeated sampling of the parent population (in this case 40) and also include instrumental uncertainties, they are better estimates of the true uncertainty. Isotope ratios and concentrations have uncertainties of 1 to 5 percent, with the exception of ${ }^{241} \mathrm{Pu}$, which is usually around 10 to 15 percent $( \pm 1$ standard error) (Bevington and Robinson 1992). 
Table 4:4. Example of ${ }^{240} \mathrm{Pu} /{ }^{239} \mathrm{Pu}$ calculation and comparison of uncertainty estimates for OB94-10A $(15-16 \mathrm{~cm})$

\begin{tabular}{lrrrr} 
Isotope & $\begin{array}{c}\text { Mean } \\
\text { Intensity (cps) }\end{array}$ & $\begin{array}{c}\text { Total } \\
\text { Counts }\end{array}$ & $\begin{array}{c}\text { Error (cps) } \\
\text { P.C.S }\end{array}$ & $\begin{array}{r}\text { Standard } \\
\text { Error (cps) }\end{array}$ \\
\hline & 3076.278 & 159966 & 7.69 & 12.64 \\
${ }^{239} \mathrm{Pu}$ & 497.3846 & 25864 & 3.09 & 4.72 \\
\hline${ }^{240} \mathrm{Pu}$ & & & & \\
& ${ }^{240} \mathrm{Pu} /{ }^{239} \mathrm{Pu}$ & & & \\
& & & 0.001084 & 0.001672 \\
Ratio of the mean intensities & 0.161684 & & & 0.001589 \\
\hline
\end{tabular}

\section{Laboratory Intercomparison Analyses}

Ten sediment samples from the Ob Delta core (OB94-07b) were processed and analyzed at both WHOI and the Environmental Measurements Laboratory and Pacific Northwest National Laboratories (in collaboration with Tom Beasley and Jim Kelley), hereafter referred to collectively as EML. Additionally, three standard sediments available from the National Institute of Standards and Technology (SRM-4350B) and the International Atomic Energy Agency (IAEA-135 and IAEA-384) were each analyzed on two separate occasions. Samples processed at WHOI employ the method outlined above. Samples processed at EML employ a different digestion and ion exchange method on $1 \mathrm{~g}$ sub-samples and are measured by thermal ionization mass spectrometry (TIMS) (Beasley, Kelley et al. 1998). The EML method is similar to the method developed at WHOI in that it includes total sediment digestion. Results provided by EML are compared to those from WHOI in Figure 4:3 


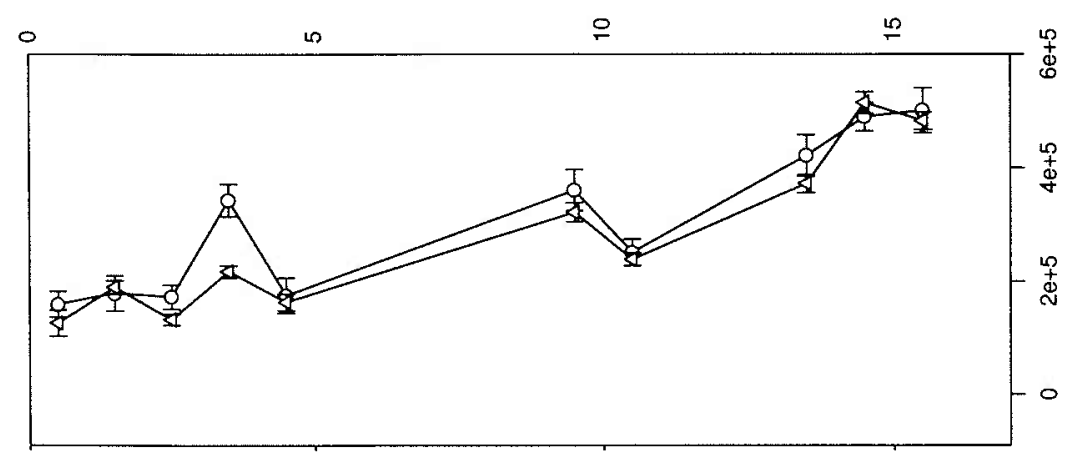

$\sum$

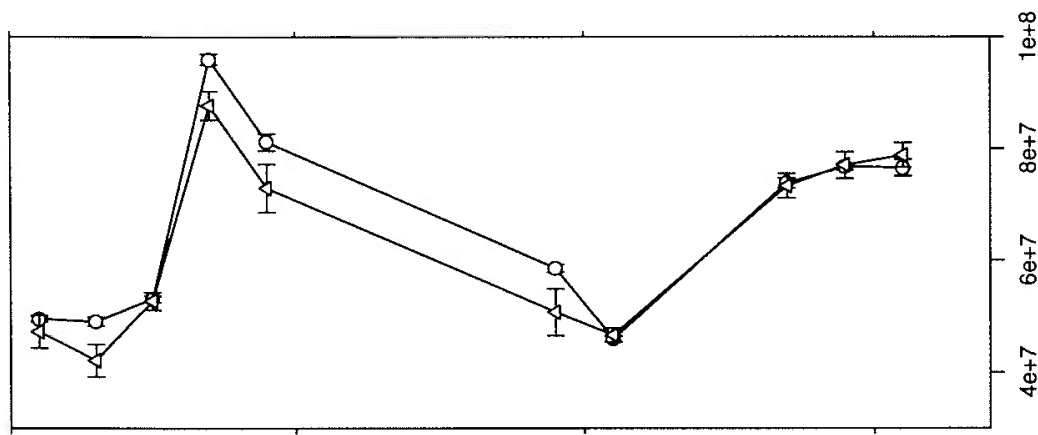

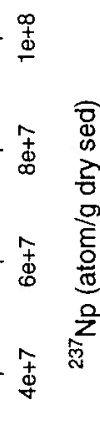
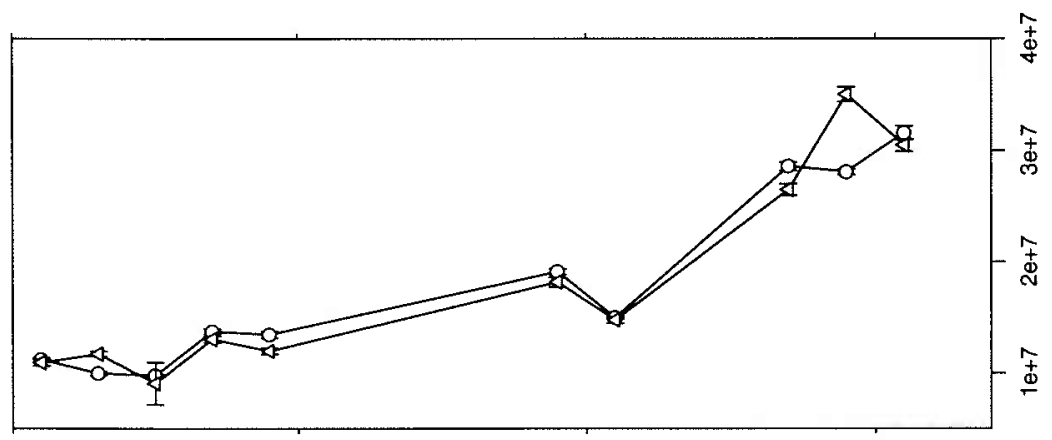

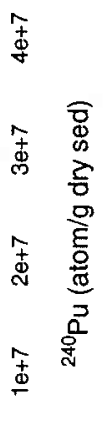

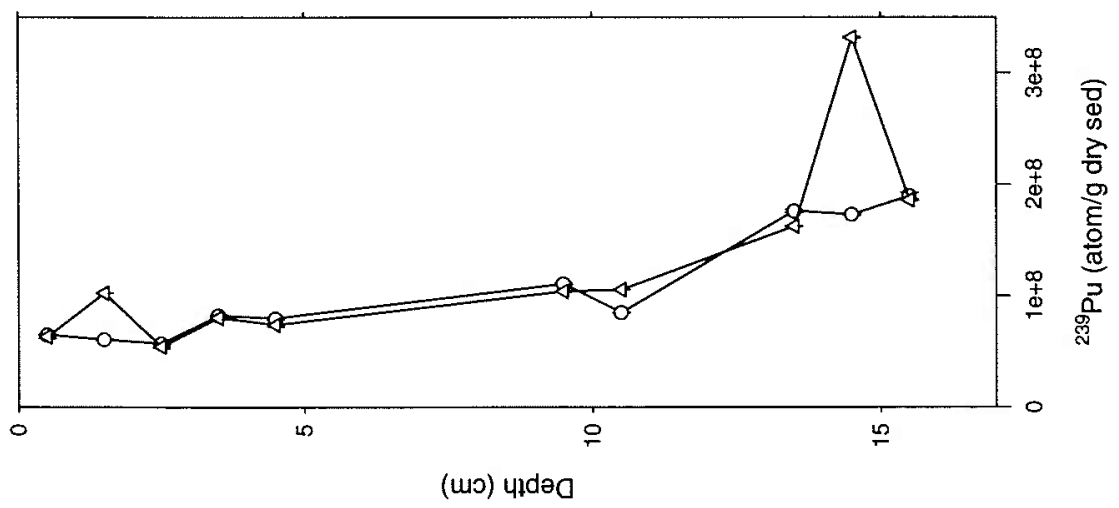

$\sum_{1}$

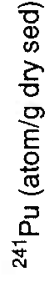

H

弯

0

के

记

$\sum_{0}^{2}$

它

휴

$\circ 8$

3

صี

항

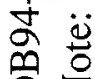

O Z

ث்

\&

央

承

ธิ

己

है

仓?

总

어

弟

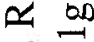

$\ddot{\forall} \dot{s}$

(1)

灵

江 
For most samples, isotopic measurements made at WHOI and EML are not significantly different. There are, however, a few instances where concentration values are different for one or more isotopes between replicates (primarily ${ }^{239} \mathrm{Pu}$ ). In cases where discrepancies were large, EML samples showed excess plutonium. It was initially thought that these differences were induced by differences in sample size (i.e. $10 \mathrm{~g}$ vs. $1 \mathrm{~g}$ for WHOI and EML, respectively), however data from replicate analyses (10g aliquots) performed at WHOI revealed a similar pattern. The origins of these discrepancies appear to be real (i.e. not analytical artifacts) and are discussed in more detail below.

Results of replicate analyses performed on reference materials are listed in Table 4:5a and $\mathrm{b}$. Internal reproducibility is clearly demonstrated in Table 4:5a by the good agreement of concentration values between replicate analyses (note: only a single ${ }^{241} \mathrm{Pu}$ measurement was made on IAEA-135).

Table 4:5a. Replicate radionuclide analyses by WHOI ICP-MS for standard reference sediments ${ }^{\mathrm{A}}$.

\begin{tabular}{|c|c|c|c|c|}
\hline $\begin{array}{l}\text { Standard } \\
\text { Material } \\
\end{array}$ & $\begin{array}{l}{ }^{239} \mathrm{Pu} \\
\text { atoms/g dry sed. }\end{array}$ & $\begin{array}{c}{ }^{240} \mathrm{Pu} \\
\text { atoms/g dry sed }\end{array}$ & $\begin{array}{c}{ }^{237} \mathrm{~Np} \\
\text { atoms/g dry sed. }\end{array}$ & $\begin{array}{c}{ }^{241} \mathrm{Pu}^{\mathrm{B}} \\
\text { atoms/g dry sed. }\end{array}$ \\
\hline IAEA-135 & $1.38 e+11 \pm 1.29 e+9$ & $2.86 e+10 \pm 3.44 e+8$ & $7.73 e+10 \pm 1.26 e+9$ & \\
\hline IAEA-135 & $1.31 e+11 \pm 2.82 e+9$ & $2.62 e+10 \pm 7.62 e+8$ & $7.44 e+10 \pm 2.11 e+9$ & $2.04 e+9 \pm 1.13 e+8$ \\
\hline IAEA-384 & $1.15 e+11 \pm 6.41 e+8$ & $5.74 e+9 \pm 3.82 e+7$ & $9.09 e+8 \pm 2.02 e+7$ & $4.54 e+7 \pm 2.15 e+6$ \\
\hline IAEA-384 & $1.13 e+11 \pm 8.36 e+8$ & $5.68 e+9 \pm 4.70 e+7$ & $9.02 e+8 \pm 2.07 e+7$ & $4.53 e+7 \pm 2.46 e+6$ \\
\hline SRM-4350B & $4.13 e+8 \pm 3.11 e+6$ & $4.46 e+7 \pm 5.36 e+5$ & $1.69 e+7 \pm 6.25 e+5$ & $1.10 e+6 \pm 9.08 e+4$ \\
\hline SRM-4350B & $3.98 e+8 \pm 6.27 e+6$ & $4.57 e+7 \pm 1.07 e+6$ & $1.79 e+7 \pm 7.94 e+5$ & $9.18 e+5 \pm 2.40 e+5$ \\
\hline
\end{tabular}


The activities $\left(\mathrm{Bq} \mathrm{kg}^{-1}\right)$ are given in Table $4: 5 \mathrm{~b}$ for each isotope as well as ${ }^{239,240} \mathrm{Pu}$ activity to allow comparison to the recommended or informational value published (where data are available) for each of the standard sediments (Hoppes 1981; Ballestra, Gastaud et al. 1993; Povinec and Pham 2000). In most cases (13 out of 15), the activities were within the 95 percent confidence intervals reported for standard sediments, indicating good external reproducibility as well. The ${ }^{239,240} \mathrm{Pu}$ activities for IAEA-384 replicates are uniformly high and outside of the 95 percent confidence interval. Due high contaminant levels very small aliquots $(\sim 0.250 \mathrm{~g})$ were required. In the case of IAEA384 , the inhomogeneity $\sim 10 \%$ in $>1 \mathrm{~g}$ samples, but has not been evaluated for smaller samples (P. Povinec, personal communication). It is interesting that the sum of the individual ${ }^{239} \mathrm{Pu}$ and ${ }^{240} \mathrm{Pu}$ activities recommended by IAEA is also outside the 95 percent confidence interval given for the ${ }^{239} \mathrm{Pu},{ }^{240} \mathrm{Pu}$ activity. This may suggest a systematic difference between ${ }^{239} \mathrm{Pu},{ }^{240} \mathrm{Pu}$ determined by alpha and mass spectrometry.

In an effort to better understand the effects of sample size and to further evaluate the quality of data provided by the WHOI method, replicate analyses were performed on $10 \mathrm{~g}$ aliquots from 26 sediment samples (24 from OB94-10A and 2 from OB95-04). These data are shown in Figures 4:5 and 4:6. Replicate analyses results are quite similar to those from the WHOI/EML intercomparison in that the majority of isotopic measurements made on replicate samples are within the uncertainty (usually $\pm 1 \sigma$ ) of the measurements. Also similar to the WHOI/EML intercomparison are a few measurements revealing concentrations between replicates that are quite different. 


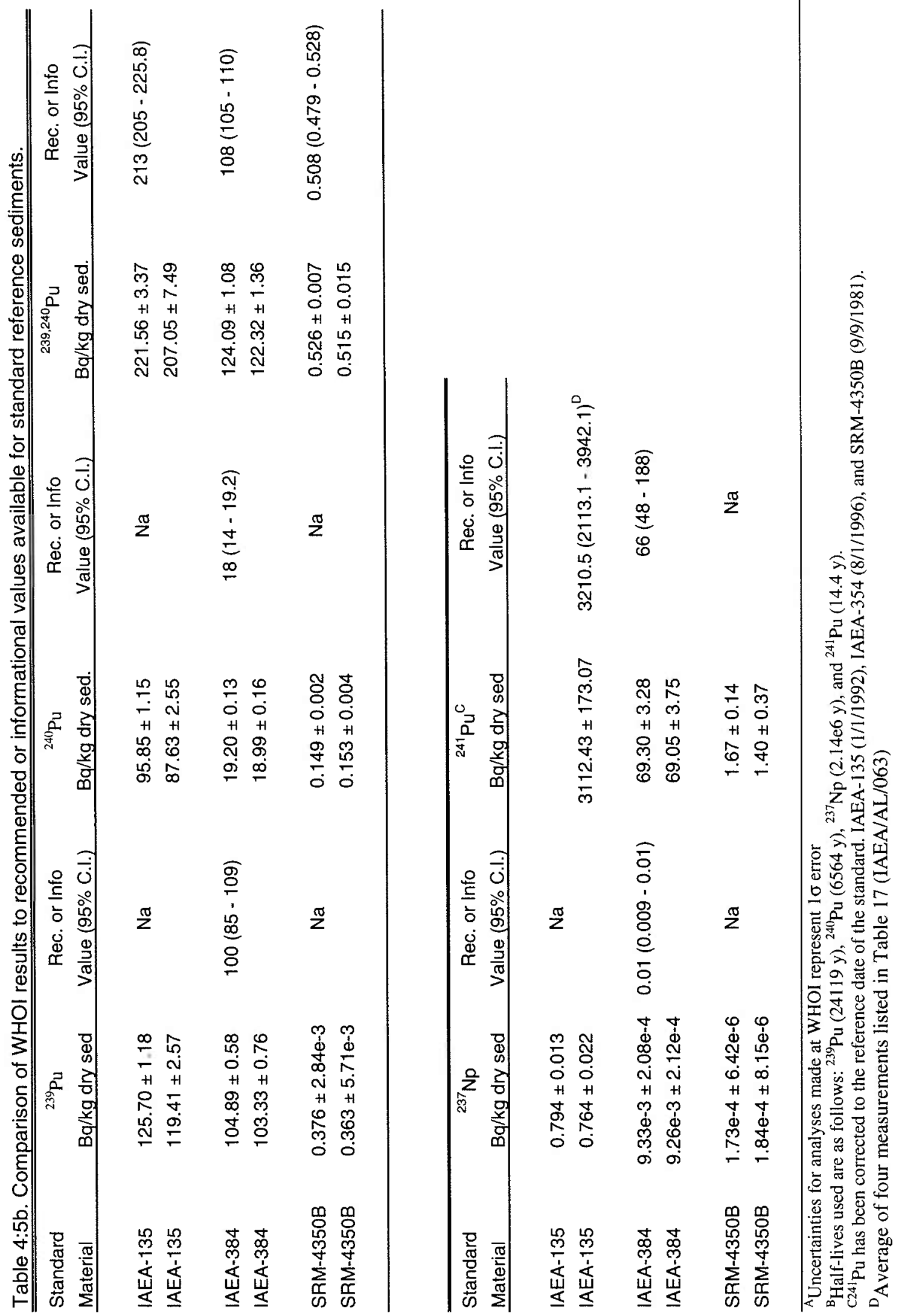



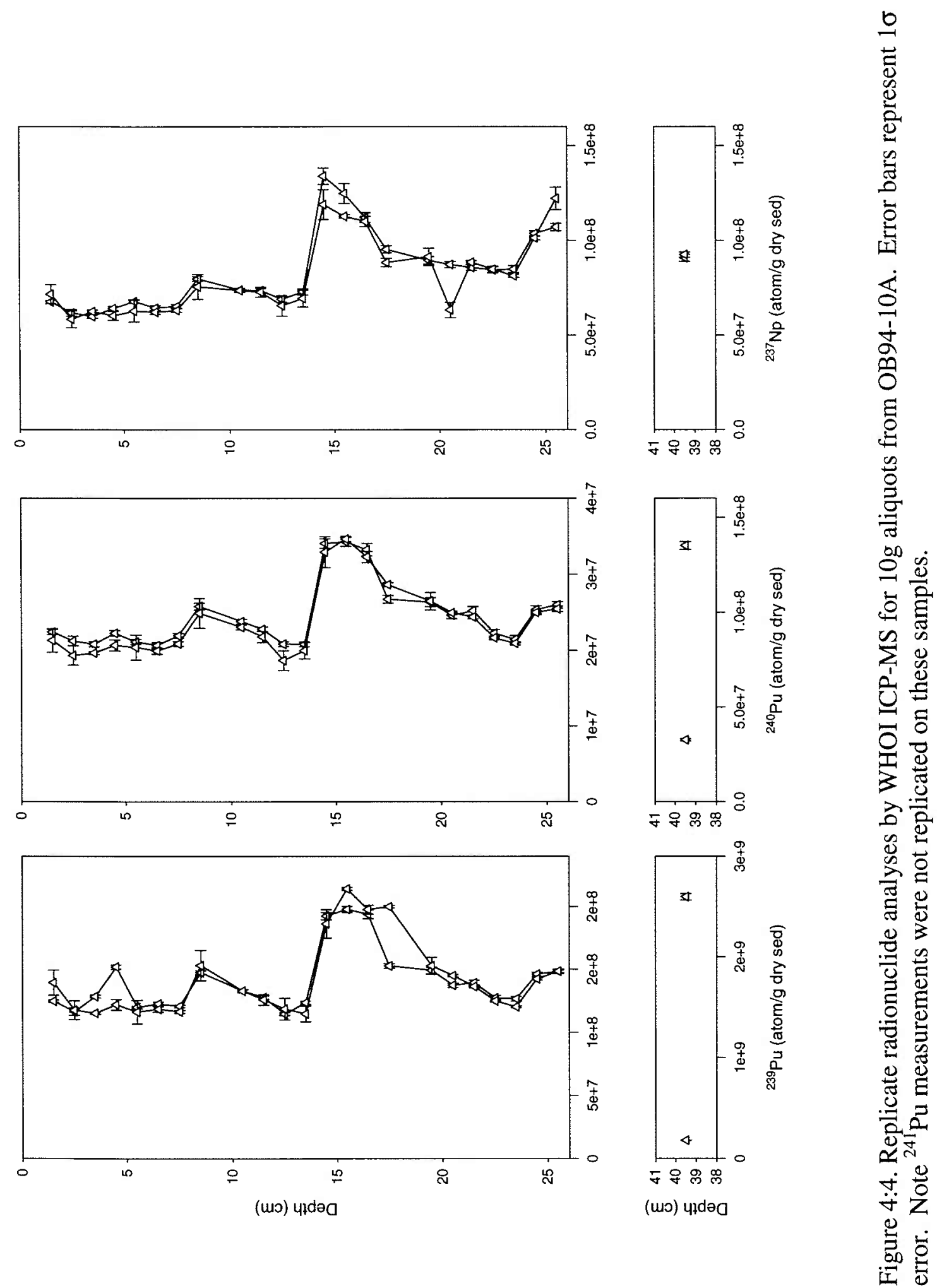

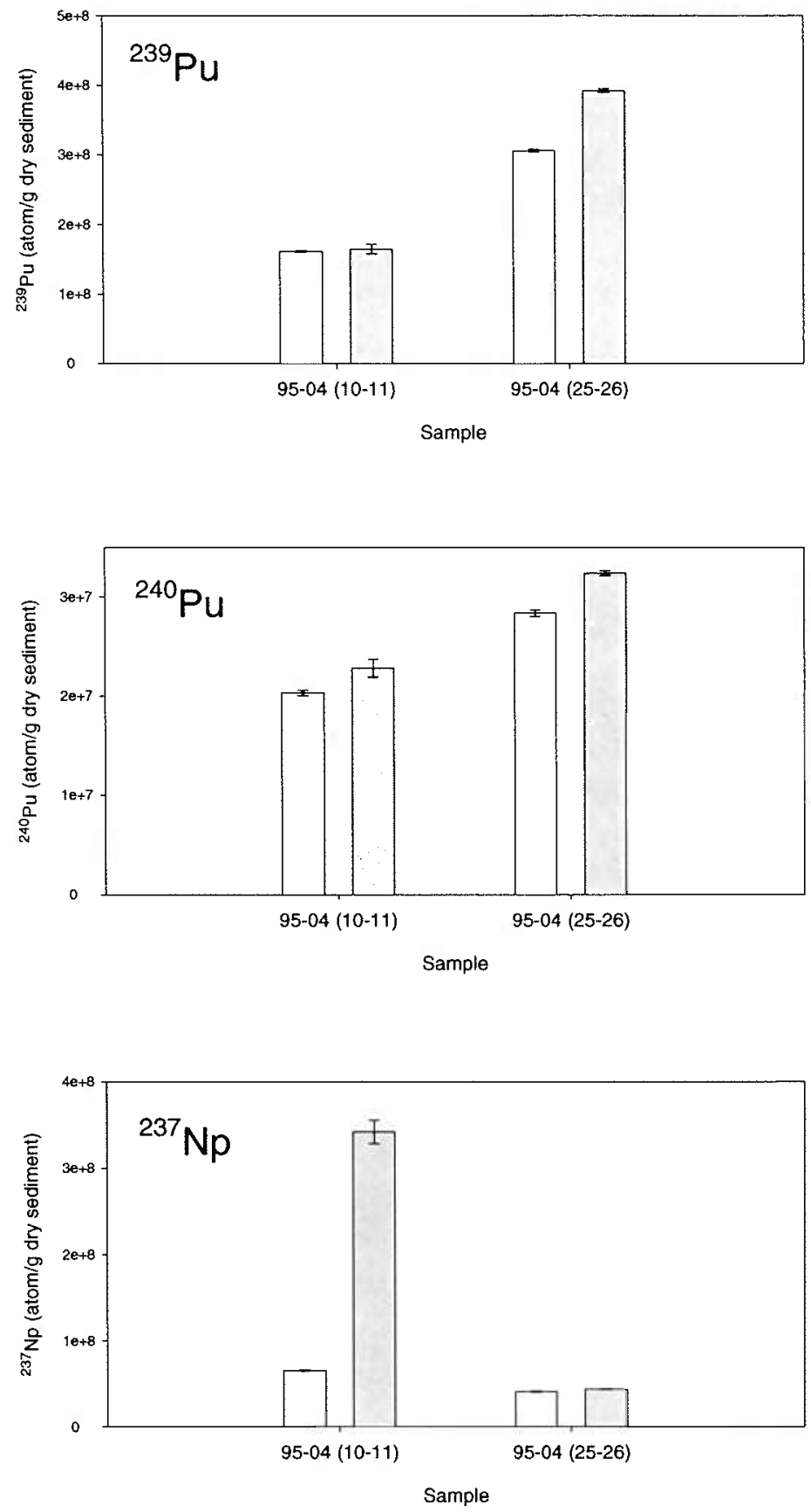

Figure 4:5. Replicate radionuclide analyses by WHOI ICP-MS for 10g aliquots from OB95-04. Error bars represent $1 \sigma$ error. Note ${ }^{241} \mathrm{Pu}$ measurements were not replicated on these samples. 
Of the 37 samples analyzed in duplicate, 18 samples demonstrated a $\geq 3 \sigma$ difference for one or more of the isotopes measured. The ${ }^{239} \mathrm{Pu}$ concentrations were different between replicates by $\geq 3 \sigma$ in 16 samples, 9 of these 16 samples also had ${ }^{240} \mathrm{Pu}$ concentrations that were different by $\geq 3 \sigma$. In these cases, both ${ }^{239} \mathrm{Pu}$ and ${ }^{240} \mathrm{Pu}$ were elevated in the same sample aliquot. The ${ }^{237} \mathrm{~Np}$ concentrations were different between replicates by $\geq 3 \sigma$ in 6 samples, although their relationship to samples containing excess plutonium was not consistent (i.e. the aliquot containing excess plutonium did not always contain the excess ${ }^{237} \mathrm{~Np}$ and a few replicates indicated excess ${ }^{237} \mathrm{~Np}$ with no change in plutonium levels).

While no clear relationship could be discerned for samples with excess ${ }^{237} \mathrm{~Np}$, samples that were different by $\geq 3 \sigma$ for both ${ }^{239} \mathrm{Pu}$ and ${ }^{240} \mathrm{Pu}$ concentrations have common characteristics. The plutonium isotopic concentrations measured between replicate samples can be placed in one of three categories. 1) The concentrations of both ${ }^{240} \mathrm{Pu}$ and ${ }^{239} \mathrm{Pu}$ were the same at the $3 \sigma$ level. 2) The concentrations of both ${ }^{240} \mathrm{Pu}$ and ${ }^{239} \mathrm{Pu}$ were different by $\geq 3 \sigma$ one aliquot. 3) The ${ }^{239}$ Pu concentrations were different by $\geq 3 \sigma$, but the ${ }^{240} \mathrm{Pu}$ concentrations were not. The third category is most likely part of the second given the significantly lower ${ }^{240} \mathrm{Pu}$ concentrations relative to ${ }^{239} \mathrm{Pu}$ observed in non-fallout contamination combined and the rigorous criteria used to define a different concentration between replicates (i.e. $3 \sigma$ ). 
In an effort to explain the plutonium concentration differences between replicates where both ${ }^{240} \mathrm{Pu}$ and ${ }^{239} \mathrm{Pu}$ were significantly different in one or the aliquots, the ratio of the excess ${ }^{240} \mathrm{Pu}$ to the excess ${ }^{239} \mathrm{Pu}$ was calculated as follows:

$$
{ }^{240} \mathrm{Pu}_{\mathrm{ex}}{ }^{239} \mathrm{Pu}_{\mathrm{ex}}=\left({ }^{240} \mathrm{Pu}_{1^{-}}{ }^{240} \mathrm{Pu}_{2}\right) /\left({ }^{239} \mathrm{Pu}_{1_{-}}{ }^{240} \mathrm{Pu}_{2}\right)
$$

Where $\mathrm{Pu}_{1}$ is the sample aliquot containing the higher concentration of both ${ }^{239} \mathrm{Pu}$ and ${ }^{240} \mathrm{Pu}$, and $\mathrm{Pu}_{2}$ is the sample aliquot containing the lower concentrations. The ratios of the excess ${ }^{240} \mathrm{Pu}$ to the excess ${ }^{239} \mathrm{Pu}$ for the nine samples where the concentrations of both isotopes were $3 \sigma$ different are shown in Figure 4:7. These data demonstrate that the isotopic ratio of the excess (higher) plutonium of the first 5 samples (left to right) is strikingly similar and consistent with input from material originating from Semipalitinsk (Beasley, Kelley et al. 1998). The excess ${ }^{240} \mathrm{Pu} /{ }^{239} \mathrm{Pu}$ of the next two samples suggest a mixture of global fallout and low ratio material from either Semipalitinsk or fuel reprocessing facilities. The remaining samples have similar excess ${ }^{240} \mathrm{Pu} /{ }^{239} \mathrm{Pu}$ ratios that fall well above the average global fallout ratio, suggesting a mixture between global fallout and high ratio material. High ratio material is observed in both pre-moratorium global fallout and in materials derived from Chernobyl. The proximity of both samples to the surface (i.e. recently deposited) and the presence of elevated (above global fallout) ${ }^{137} \mathrm{Cs} / 240 \mathrm{Pu}$ ratios indicate that Chernobyl is the source These issues will be dealt with more fully in the following chapters. 
The data presented for intercomparison and replicate analyses demonstrate that the actinide separation and purification process developed at WHOI is robust and provides high quality isotopic data. Further, the clearly similar nature of the plutonium variations in replicate measurements made at both WHOI and EML suggests that samples are not always homogeneous with respect to nuclear contaminants and may indicate the presence of "hot particles". Regarding the ${ }^{237} \mathrm{~Np}$ variations, there is no reason to suggest that these differences are due to analytical artifacts as the majority of replicate analyses were in good agreement. Rather, the different concentrations suggest that neptunium varies independently from plutonium, which is supported by the variable ${ }^{237} \mathrm{~Np}$ in samples collected at Semipalitinsk (Table 2:3). 


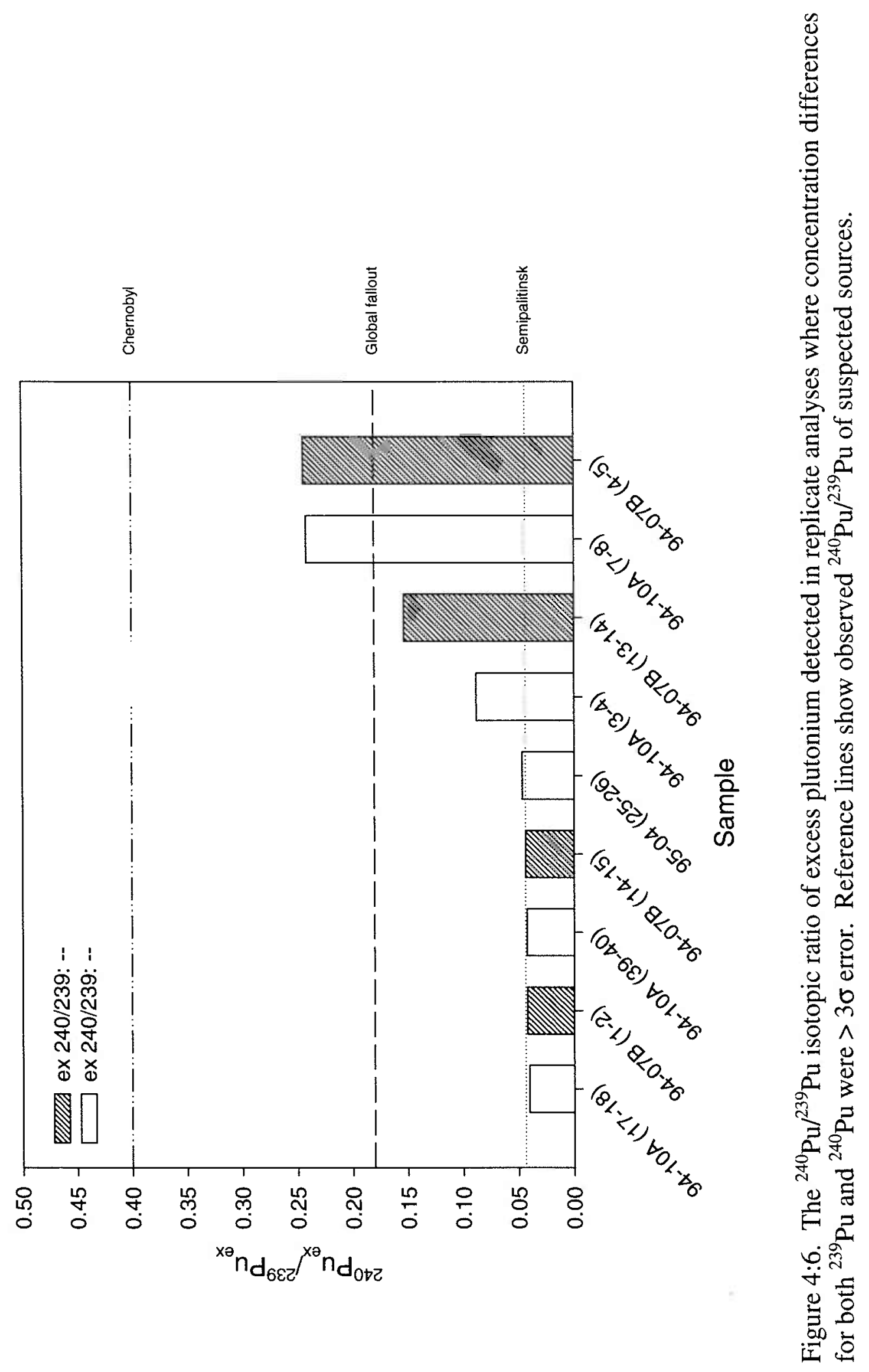




\section{References Chapter 4}

Ballestra, S., J. Gastaud, et al. (1993). Report on the Intercomparison Run IAEA-135: Radionuclides in Irish Sea Sediment. Monaco, International Atomic Energy Agency.

Beasley, T. M., J. M. Kelley, et al. (1998). "Isotopic Pu, U, and Np signatures in soils from Semipalatinsk-21, Kazakh Republic and the Southern Urals, Russia." Journal of Environmental Radioactivity 39(2): 215-230.

Bevington, P. R. and D. K. Robinson (1992). Data reduction and error analysis for the physical sciences. New York, McGraw-Hill.

Bobrovitskaya, N. N., C. Zubkova, et al. (1996). "Discharges and yields of suspended sediment in the $\mathrm{Ob}^{\prime}$ and Yenisey rivers of Siberia. Proceedings of an International symposium on Erosion and sediment yield; global and regional perspectives." International symposium on Erosion and sediment yield; global and regional perspectives 236: 115-123.

Hoppes, D. D. (1981). National Bureau of Standards Certificate Standard Reference Material 4350B. Washington, D. C., National Institute of Standards and Technology: 8 .

Ivanov, V. V., V. M. Medkova, et al. (1995). Characteristic features of sedimentation processes in the lower reaches and mouth of the Ob River, The State Research Centre of the Russian Federation: the Arctic and Antarctic Research Institute: 26.

Maxwell, S. R. (1997). "Rapid Actinide-Separation Methods." Radioactivity and Radiochemistry 8: 36-44.

Panteleyev, G. P. (1995). The history of plutonium and cesium-137 contamination of the Ob River delta sediments, Massachusetts Institute of Technology, Cambridge, MA, United States.

Povinec, P. P. and M. K. Pham (2000). IAEA-384 Radionuclides in Fangataufa Lagoon Sediment. Monaco, International Atomic Energy Agency: 81.

Rodushkin, I. and T. Ruth (1997). "Determination of Trace Metals in Estuarine and Seawater Reference Materials by High Resolution Inductively Coupled Plasma Mass Spectrometry." Journal of Analytical Atomic Spectrometry 12: 1181-1185.

Rodushkin, I., T. Ruth, et al. (1998). "Non-spectral interferences caused by a saline water matrix in quadrupole and high resolution inductively coupled plasma mass spectrometry." Journal of Analytical Atomic Spectrometry 13: 159-166. 
Sayles, F. L., H. D. Livingston, et al. (1997). "The history and source of particulate (super 137) Cs and (super 239,240) Pu deposition in sediments of the Ob River delta, Siberia". Environmental radioactivity in the Arctic." Second symposium and international conference on Environmental radioactivity in the Arctic 202(13): $25-41$. 


\section{Chapter 5}

\section{$\underline{\text { Radionuclide distributions, sedimentation rates and core chronologies }}$}

\section{Radionuclide distributions}

The radionuclide profiles measured in sediment cores exhibit many similar features such as the first appearance of each artificial radionuclide at some depth. This is followed by a rise in the concentrations to a maximum that is generally closer to the depth of first appearance than it is to the surface. Above their respective maxima, the concentration of each radionuclide generally decreases. Nearly all radionuclide profiles however, exhibit additional concentration maxima above the main one. In several cases, these maxima do not co-vary between the different radionuclide profiles obtained for a particular (i.e. each) core, or for that matter, between profiles of the same radionuclide measured in cores from different locations. The concentrations and length scales do differ from core to core as a result of variations in the characteristics of the sediment, sedimentation rate, and variations in the proportion of uncontaminated sediment. In general, the profile variations measured in sediments collected for this study are consistent with the pattern of global fallout deposition record (see Figure 2:3). The bimodal atmospheric/fallout deposition maximum (i.e. 1958 and 1963) however, is not resolved in all cores. Variable inputs from different local sources, which are superimposed on the global fallout pattern are also clear.

Using concentration data alone to identify input from non-fallout sources is difficult at best. This is due to the effects of variable dilution by uncontaminated 
sediments, lithologic factors such as mineral type and grain-size, and the inability to differentiate the input of global fallout material from other sources on the basis of concentration. The radionuclide concentration profiles are essential however, in that they allow the extent of sediment mixing to be evaluated at each of the sampling sites. Mixing of sediments due to disturbances caused by ice and other natural processes as well as anthropogenic activities is possible; in fact, sediments collected from several locations were ruled out for further analyses because mixing was evident. The preservation of the global fallout signal in the cores selected for this study suggests that they are largely undisturbed. The concentrations of ${ }^{137} \mathrm{Cs},{ }^{239} \mathrm{Pu},{ }^{240} \mathrm{Pu},{ }^{241} \mathrm{Pu}$, and ${ }^{237} \mathrm{~Np}$ measured in each of the core sections analyzed are tabulated in Appendix I. The ${ }^{241} \mathrm{Pu}$ profiles are incomplete or entirely lacking for sediment cores collected from suspected non-fallout source tributaries. Therefore, ${ }^{241} \mathrm{Pu}$ measurements are excluded from the following discussion. The ${ }^{137} \mathrm{Cs},{ }^{239} \mathrm{Pu},{ }^{240} \mathrm{Pu}$, and ${ }^{237} \mathrm{~Np}$ profiles are summarized below.

${ }^{137} \mathrm{Cs}$

The ${ }^{137} \mathrm{Cs}$ profiles in cores from the Ob delta and Taz estuary exhibit many of the common features discussed above (Figure 5:1a). Of special note are the different depths of initial appearance, which is the deepest in OB94-10A $(\sim 60 \mathrm{~cm})$, the concentration scales (i.e. main maximum concentrations between 1.5 and $4.5 \mathrm{dpm} \mathrm{g}^{-1}$ ), and the number of small maxima located above the main maximum in each core. The profiles OB9407B, 10A, and 13 all show at least two maxima, while those of OB94-08 and 09 show 
only one, indicating non-deposition of contaminants, mixing, or perhaps a loss of surface sediments.

The ${ }^{137} \mathrm{Cs}$ profiles in sediment cores from the upper reaches of the $\mathrm{Ob}$, Irtysh and Tobol Rivers in many respects are quite different with respect to each other as well as those in the delta. The ${ }^{137} \mathrm{Cs}$ profiles in $\mathrm{OB} 95-04,06$, and 11 do not attain a zero concentration at depth, which indicates that these cores probably did not recover sediments deposited prior to the nuclear age. OB95-04, furthermore, exhibits multiple maxima both large and small. The profile obtained from OB95-05 is similar is similar to OB95-04 in that it also exhibits multiple peaks, differences between these two cores, however, are evident. With the exception of the top two samples, the general concentration decrease observed in many cores including OB95-04 (collected $20 \mathrm{~km}$ downstream on the same branch of the river) does not occur. This suggests that OB95-05 may be missing the top portion of the sedimentary record. The ${ }^{137} \mathrm{Cs}$ profiles from OB9510 and 11 (both collected in the Tobol River) and OB95-13 (collected in the Irtysh River) show two maxima of similar concentration separated by $\sim 20 \mathrm{~cm}$. As in the delta, the concentration of the main maximum is variable and ranges between 1 and $8 \mathrm{dpm} \mathrm{g}^{-1}$ at upstream sample sites. 

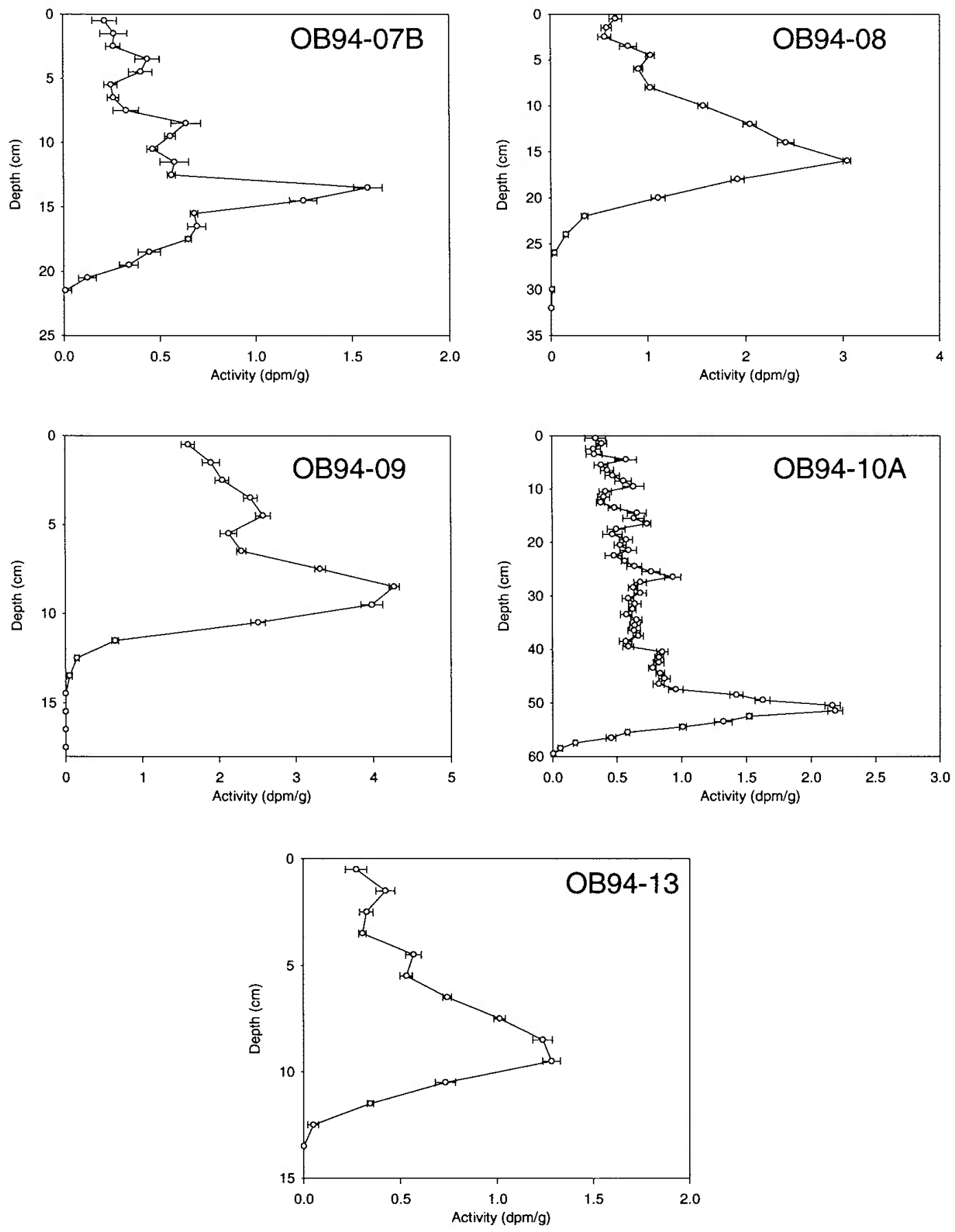

Figure 5:1a. Depth distributions of ${ }^{137} \mathrm{Cs}$ in sediment cores from the Ob delta and Taz estuary. ${ }^{137} \mathrm{Cs}$ has been decay corrected to $1 / 1 / 1995$. Error bars represent $1 \sigma$ error. See Figure 4:1 for core locations. 

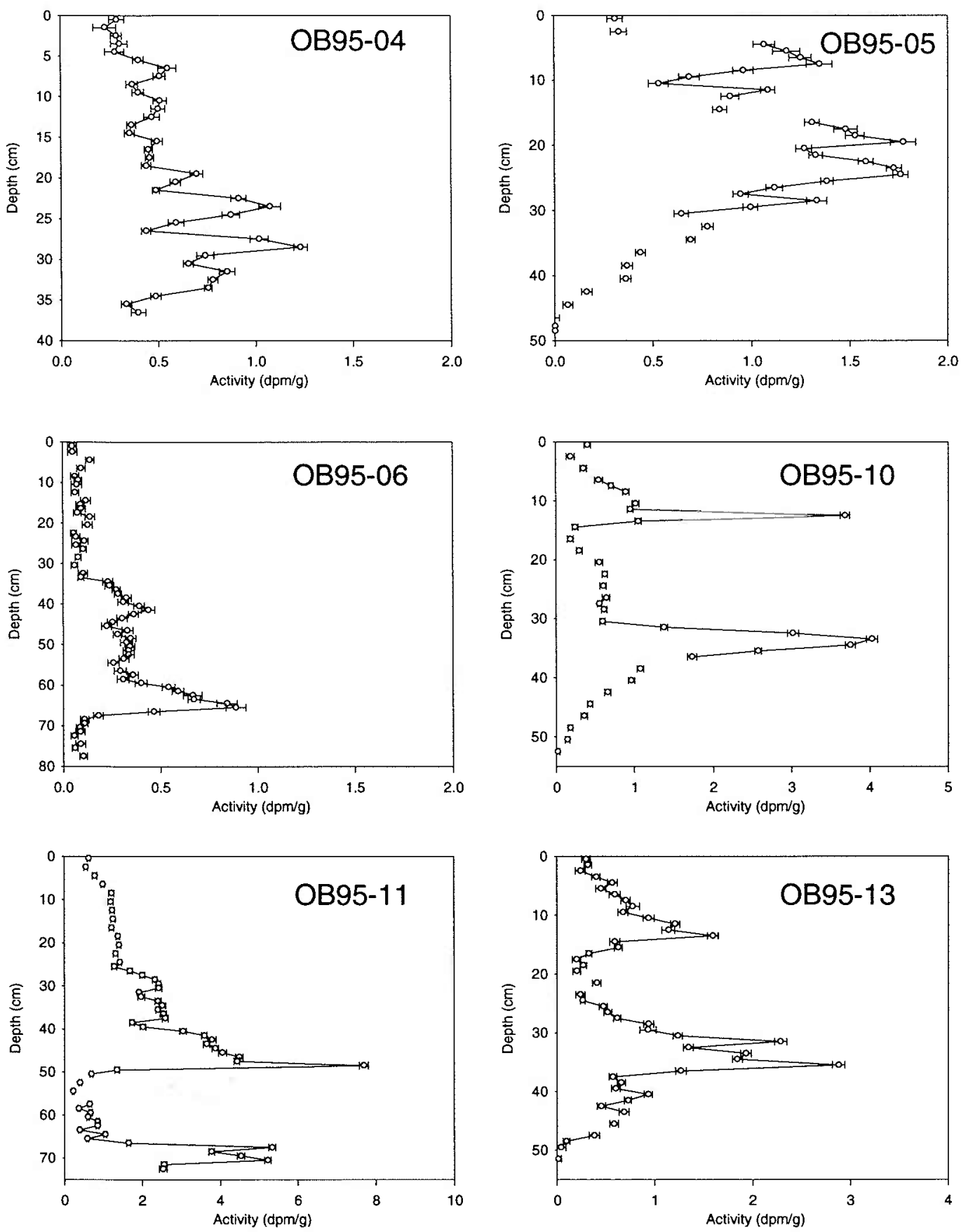

Figure 5:1b. Depth distributions of ${ }^{137} \mathrm{Cs}$ in sediment cores from the upper reaches of the Ob, Irtysh, and Tobol Rivers. ${ }^{137} \mathrm{Cs}$ has been decay corrected to 1/1/1995. Error bars represent $1 \sigma$ error. Broken line indicates where one or more core sections were not analyzed. See Figure 4:1 for core locations. 
${ }^{239} \mathrm{Pu}$

The ${ }^{239} \mathrm{Pu}$ distribution profiles obtained from cores that were collected in the $\mathrm{Ob}$ delta and one from the Taz estuary exhibit patterns that are, to a large extent, similar to their ${ }^{137} \mathrm{Cs}$ profiles and are shown in Figure 5:2a. Subtle differences in the peak shapes are apparent in OB94-10A, and 13, and a few large concentrations, usually limited to one sample are also evident (OB94-10A, 07B, and 09). As replicate analyses have shown (discussed previously and shown here as squares), plutonium is not always homogeneously distributed within the sediments. Thus while some of the differences are no doubt real (i.e. different ${ }^{137} \mathrm{Cs} /{ }^{239} \mathrm{Pu}$ ratios in non-fallout contaminants), differences between the size of the samples analyzed by gamma (the entire core section) vs. ICP-MS analysis $(10 \mathrm{~g})$ combined with apparent sample heterogeneity may also contribute to the observed profile differences.

The depth distributions of ${ }^{239} \mathrm{Pu}$ in cores from the upper reaches of the Ob, Irtysh and Tobol Rivers are shown in Figure 5:2b. In all cases, the ${ }^{239} \mathrm{Pu}$ distribution profiles exhibit differences from the corresponding ${ }^{137} \mathrm{Cs}$ profiles. The shape of the main maximum in OB95-04 is quite different, and the ${ }^{239} \mathrm{Pu}$ concentrations observed in the profile of OB95-06 are typically an order of magnitude or more lower than ${ }^{239} \mathrm{Pu}$ concentrations observed in the other cores. Moreover, the ${ }^{239} \mathrm{Pu}$ profile shape in OB9506 does not resemble the global fallout pattern, suggesting additional problems besides a non-zero concentration at depth. The profiles obtained from OB95-10 and OB95-13, in addition to differences in the shape of the maxima observed at $\sim 35 \mathrm{~cm}$, exhibit no upper ${ }^{239} \mathrm{Pu}$ maxima that corresponds to those observed in their respective ${ }^{137} \mathrm{Cs}$ profiles. The 

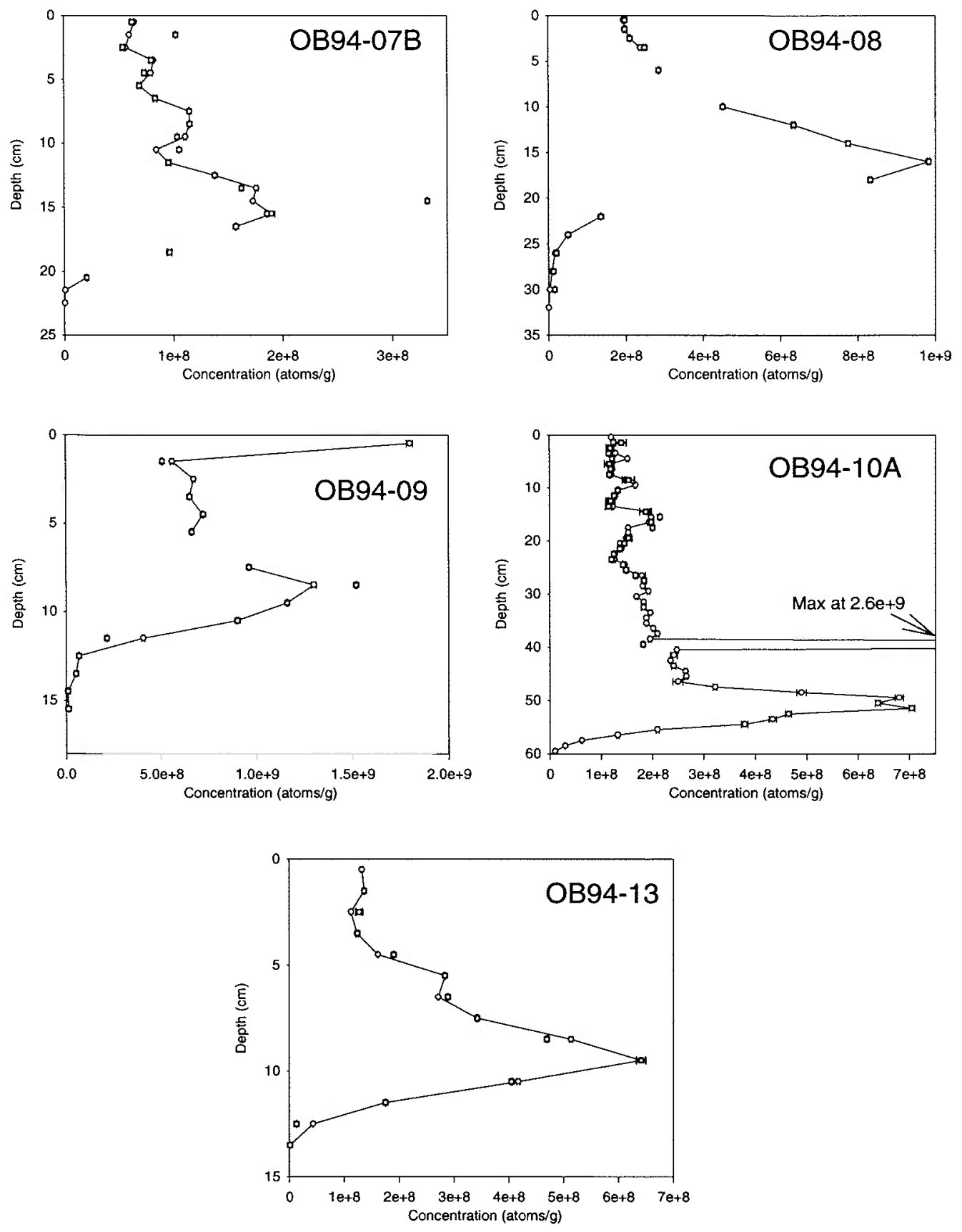

Figure 5:2a. Depth distributions of ${ }^{239} \mathrm{Pu}$ in sediment cores from the Ob delta and Taz estuary. Error bars represent $1 \sigma$ error. Squares represent replicate analyses. Broken line indicates where one or more core sections were not analyzed. See Figure 4:1 for core locations. 

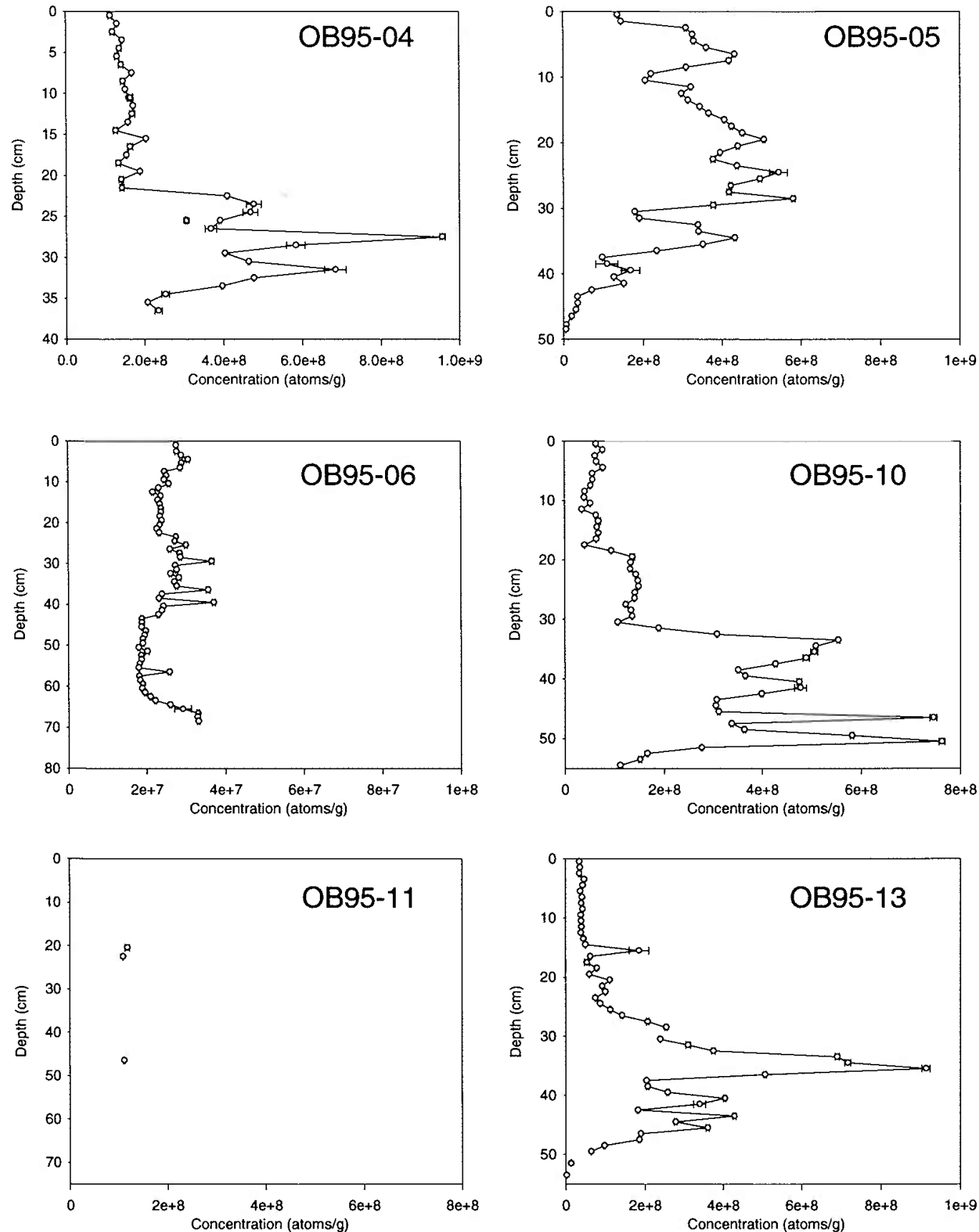

Figure 5:2b. Depth distributions of ${ }^{239} \mathrm{Pu}$ in sediment cores from the upper reaches of the $\mathrm{Ob}$, Irtysh, and Tobol Rivers. Error bars represent $1 \sigma$ error. Squares represent replicate analyses. Broken line indicates where one or more core sections were not analyzed. See Figure 4:1 for core locations. 
${ }^{239} \mathrm{Pu}$ profile in OB95-10 is further complicated by peaks near the bottom of the profile and a non-zero concentration at depth. The presence of high ${ }^{239} \mathrm{Pu}$ concentrations at this depth in the sedimentary record is consistent with reports of early waste disposal practices at Mayak.

${ }^{240} \mathrm{Pu}$

The depth distributions of ${ }^{240} \mathrm{Pu}$ obtained from sediment cores collected in the $\mathrm{Ob}$ delta and Taz estuary and those obtained from upstream locations are shown in Figure 5:3a and $\mathrm{b}$, respectively. The ${ }^{240} \mathrm{Pu}$ distribution profiles, in general, are quite similar to the corresponding ${ }^{239} \mathrm{Pu}$ profiles with regard to profile shape, although concentrations are much lower. One clear difference between the ${ }^{240} \mathrm{Pu}$ and ${ }^{239} \mathrm{Pu}$ profiles is that a few of the concentration differences observed for replicate samples are smaller, indicating that ${ }^{239} \mathrm{Pu}$ is enriched relative to ${ }^{240} \mathrm{Pu}$ in some samples. This suggests the presence of contamination in that is non-fallout in origin. 

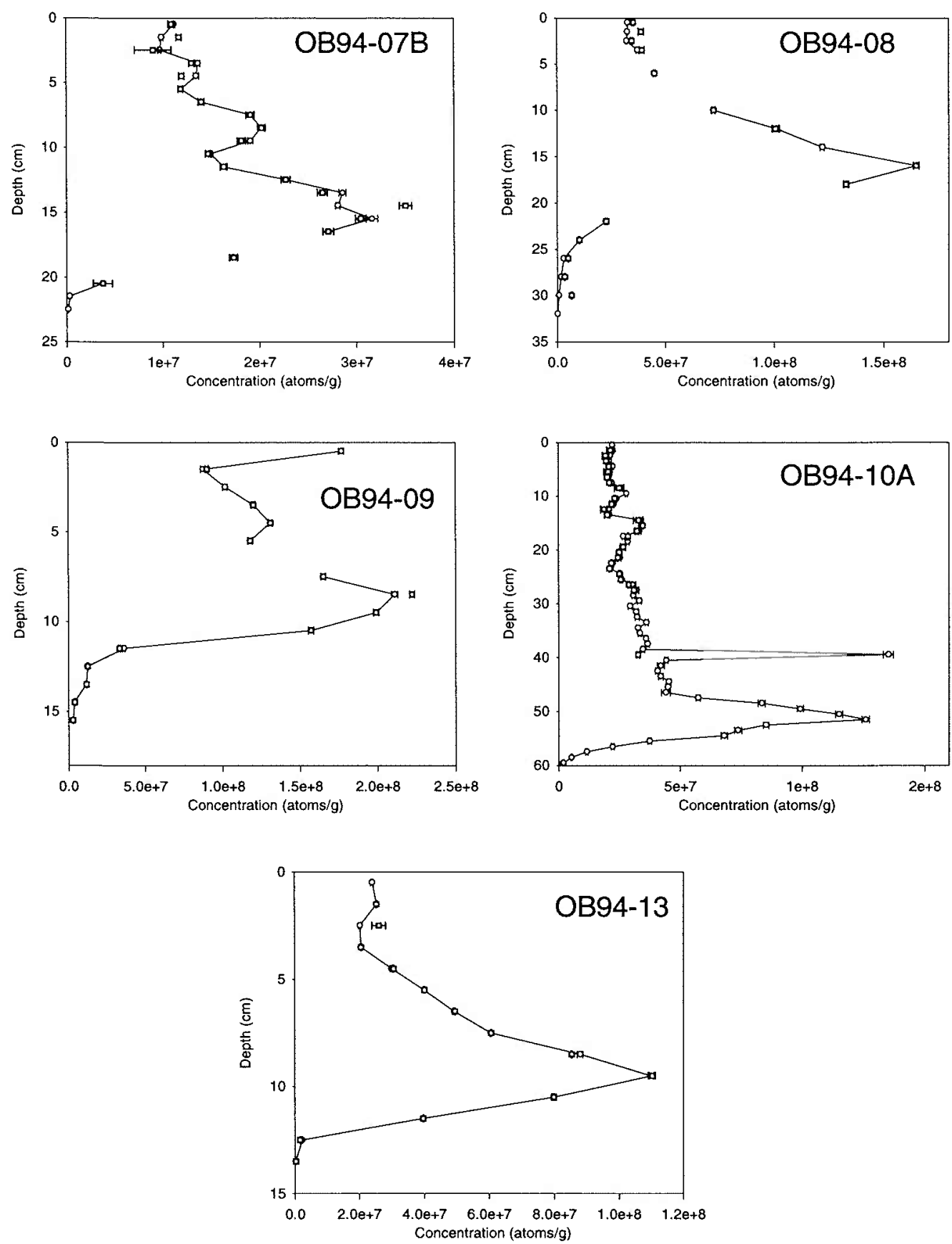

Figure 5:3a. Depth distributions of ${ }^{240} \mathrm{Pu}$ in sediment cores from the $\mathrm{Ob}$ delta and Taz estuary. Error bars represent $1 \sigma$ error. Squares represent replicate analyses. Broken line indicates where one or more core sections were not analyzed. See Figure 4:1 for core locations. 

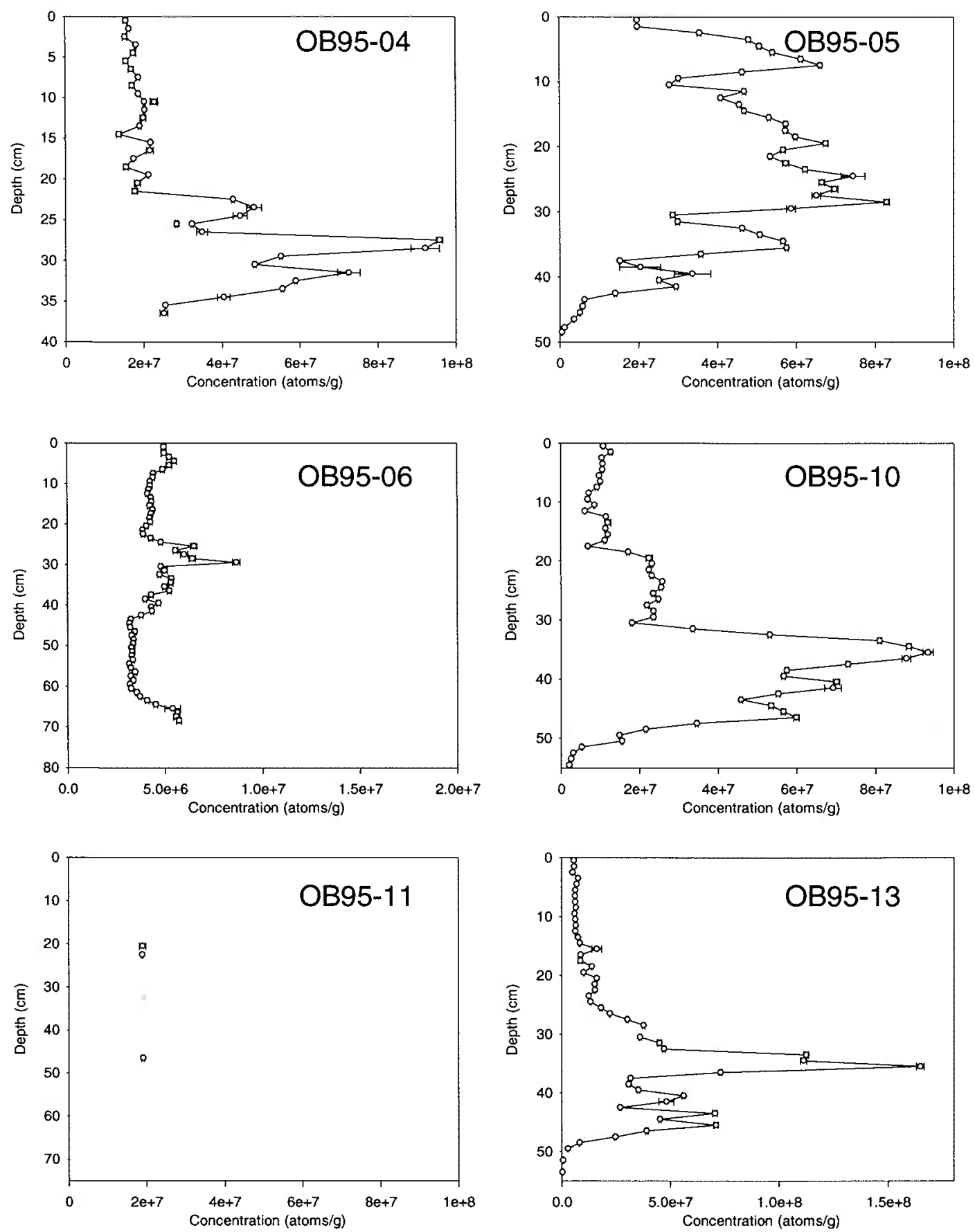

Figure 5:3b. Depth distributions of ${ }^{240} \mathrm{Pu}$ in sediment cores from the upper reaches of the Ob, Irtysh, and Tobol Rivers. Error bars represent $1 \sigma$ error. Squares represent replicate analyses. Broken line indicates where one or more core sections were not analyzed. See Figure 4:1 for core locations. 
${ }^{237} \mathrm{~Np}$

The depth distributions of ${ }^{237} \mathrm{~Np}$ in sediment cores obtained from the Ob delta and one from the Taz estuary are shown in Figure 5:4a. While the distribution profile in OB94-13 is similar to its other radionuclide profiles, the ${ }^{237} \mathrm{~Np}$ profiles measured in OB94-07B and 10A, have several features that are not reflected in the other radionuclide profiles for these cores. The largest ${ }^{237} \mathrm{~Np}$ maximum in OB94-07B occurs closer to the surface than the main maximum of the other radionuclide profiles. OB94-10A also exhibits additional ${ }^{237} \mathrm{~Np}$ maxima towards the surface (in this case they are smaller than the main fallout maximum). In both of these cores, ${ }^{237} \mathrm{~Np}$ varies independently from the other radionuclides, (e.g. the ${ }^{237} \mathrm{~Np}$ maxima $\sim 4$ and $\sim 25 \mathrm{~cm}$ in OB94-07B and 10A, respectively, have no corresponding ${ }^{137} \mathrm{Cs},{ }^{239} \mathrm{Pu}$, or ${ }^{240} \mathrm{Pu}$ concentration maxima at these depths). This indicates a relative enrichment of ${ }^{237} \mathrm{~Np}$ in these samples, which makes input from a non-fallout source likely.

In a similar fashion, the ${ }^{237} \mathrm{~Np}$ depth distributions measured in sediment cores from the upper reaches of the Ob, Irtysh, and Tobol Rivers also show some differences from the corresponding ${ }^{137} \mathrm{Cs},{ }^{239} \mathrm{Pu}$, and ${ }^{240} \mathrm{Pu}$ profiles (Figure 5:4b). Most notably, the ${ }^{237} \mathrm{~Np}$ profile in OB94-04 shows many large maxima with the main maximum being closest to the surface. Furthermore, the ${ }^{237} \mathrm{~Np}$ profile observed in $\mathrm{OB} 95-04$ is quite similar to one observed in OB94-07B. This profile similarity and the fact that the ${ }^{237} \mathrm{~Np}$ concentration in OB95-04 is nearly twice that observed in OB94-07B (maximum peak concentration), strongly suggests the source of this feature is located in the Ob above its confluence with the Irtysh River (i.e. Tomsk-7). 

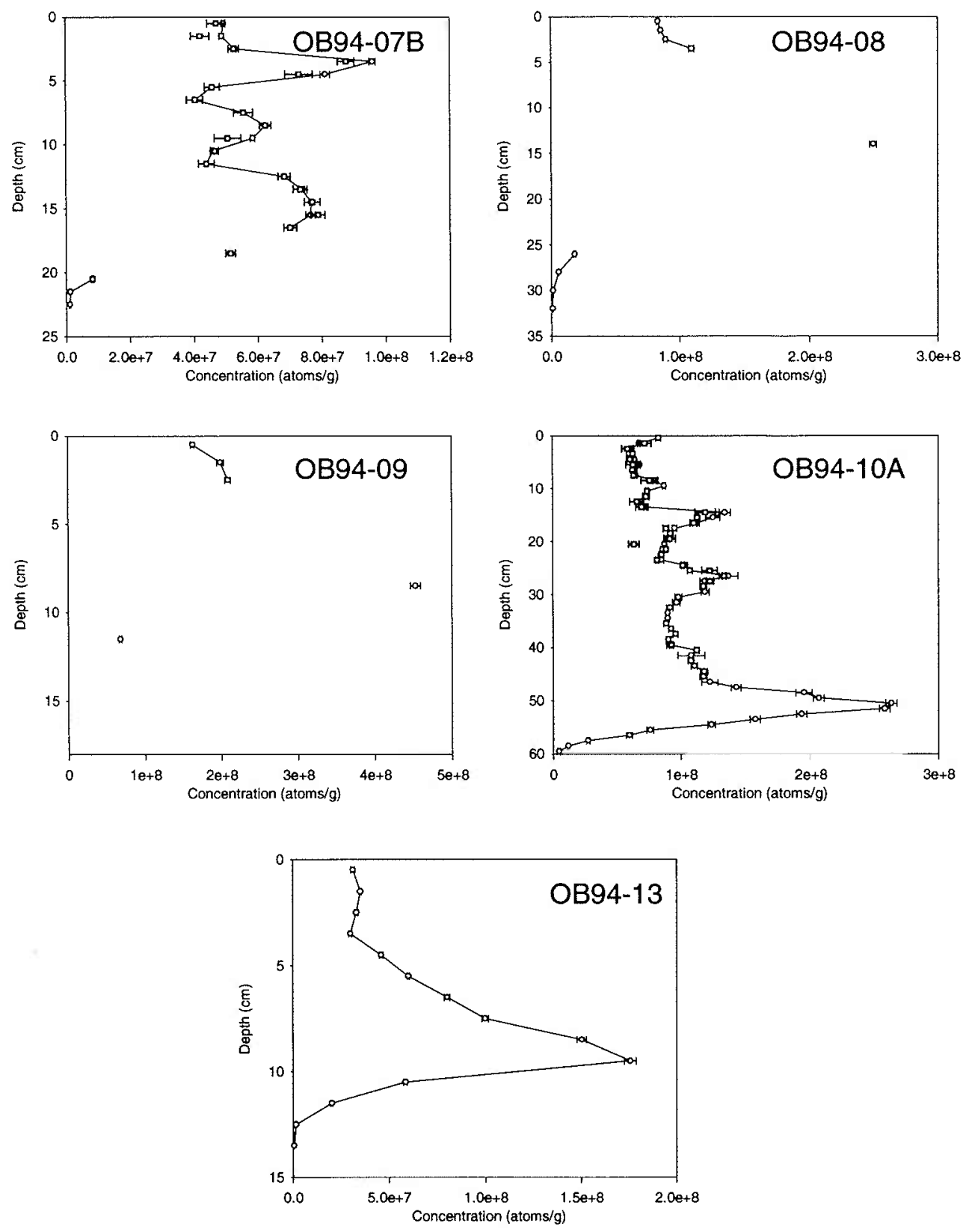

Figure 5:4a. Depth distributions of ${ }^{237} \mathrm{~Np}$ in sediment cores from the Ob delta and Taz estuary. Error bars represent $1 \sigma$ error. Squares represent replicate analyses. Broken line indicates where one or more core sections were not analyzed. See Figure 4:1 for core locations. 

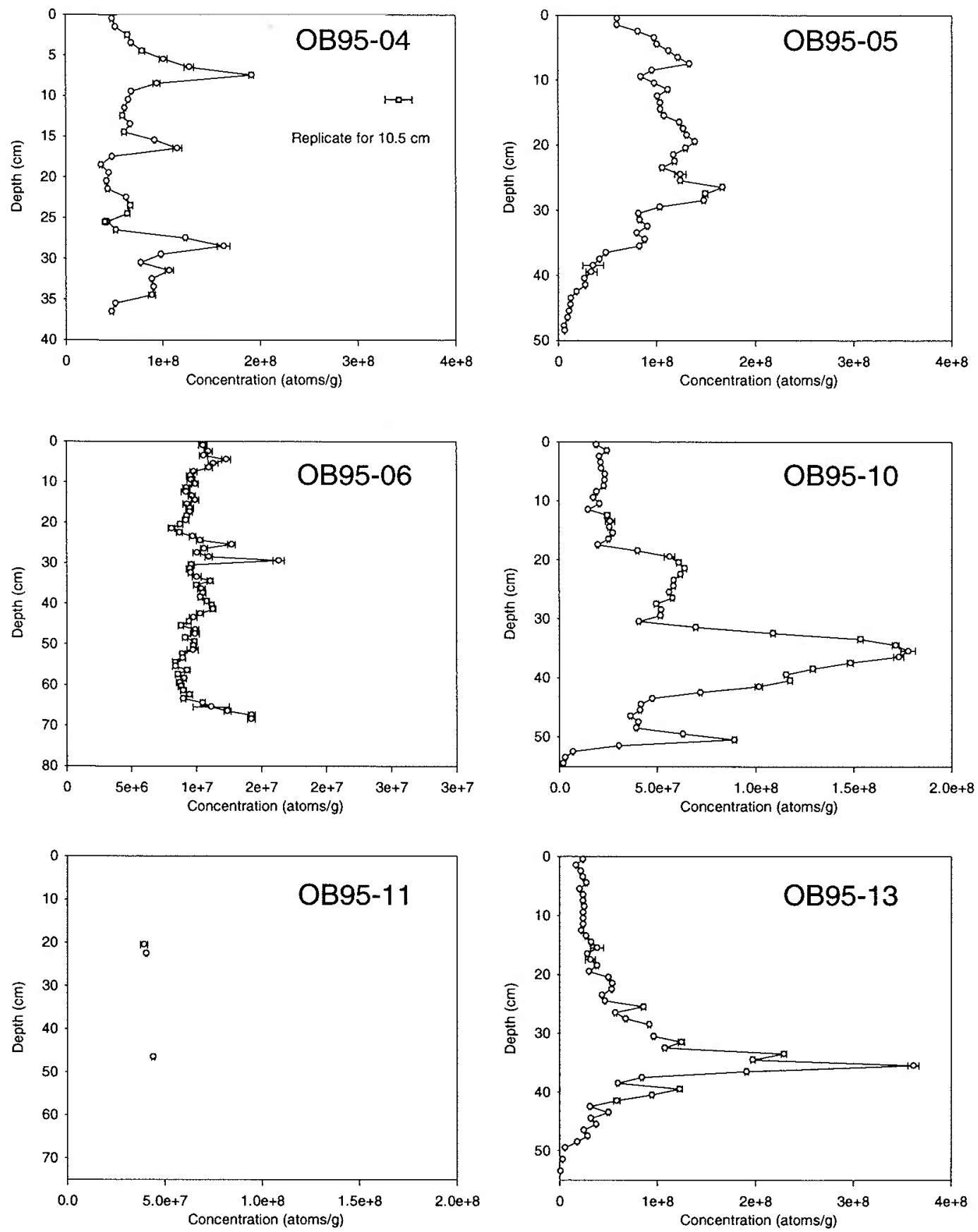

Figure 5:4b. Depth distributions of ${ }^{237} \mathrm{~Np}$ in sediment cores from the upper reaches of the $\mathrm{Ob}$, Irtysh, and Tobol Rivers. Error bars represent $1 \sigma$ error. Squares represent replicate analyses. Broken line indicates where one or more core sections were not analyzed. See Figure 4:1 for core locations. 


\section{Sedimentation rates and core chronologies}

The ability to relate contaminant records to global or local events as well as to relate events between cores from different locations depends upon the ability to establish accurate chronologies. The certainty to which the depth vs. age relationship could be established varied between cores. Based on the discussion of the hydrologic regime in the Ob River system (see Chapter 3), deposition of sediments is very likely episodic, and any sedimentation rate thus only approximates the ideal steady state system. The age models discussed below are based on a presumed internal consistency between ${ }^{210} \mathrm{~Pb}_{\mathrm{xs}}$ and other radionuclides as well as the assumption of no significant fractionation of plutonium and cesium. Based on the good internal agreement between two different deposition age models, chronologies could be established with a high degree of certainty in most cores. In a few cores however, establishing chronologies was more complicated. This was a result of apparently missing surface layers, failure to penetrate the sediments

deep enough to recover material deposited prior to the nuclear age, and disturbed ${ }^{210} \mathrm{~Pb}_{\mathrm{xs}}$ profiles that were unsuitable for dating.

Core chronologies were established by using the ${ }^{210} \mathrm{~Pb}_{\mathrm{xs}}$ activity method and by using the known or expected appearance of radionuclide profile features that can be associated with the timing of global fallout (i.e. initial appearance and maximum deposition) and the Chernobyl accident. In this study, the second method is referred to as the radionuclide horizon method. Both methods have been successfully applied to obtain sediment deposition chronologies in a variety of marine and aquatic environments where sediments rapidly accumulate (Goldberg 1963; Krishnaswami, Lal et al. 1971; Koide, 
Soutar et al. 1972; Edgington and Robbins 1975; Miller and Heit 1986). Based on the good agreement between deposition ages estimated by both methods in the majority of sediment cores analyzed for this study, the radionuclide horizon method alone was used where variability in ${ }^{210} \mathrm{~Pb}_{\mathrm{xs}}$ activities precludes use for the reliable estimation of deposition age.

Dating by the ${ }^{210} P b_{x s}$ method

The use of the decay of ${ }^{210} \mathrm{~Pb}_{\mathrm{xs}}$ was the first choice as a means of establishing core chronologies. Deposition ages established by the ${ }^{210} \mathrm{~Pb}_{\mathrm{xs}}$ method offer an independent means of verifying those obtained using the radionuclide horizon method. Good correlation between deposition ages estimated by both methods not only allows the use of global fallout timing where ${ }^{210} \mathrm{~Pb}_{\mathrm{xs}}$ profiles are unsuitable for dating, but it also indicates the level to which the transport timing of non-fallout contamination can be determined. This approach generally yielded internally consistent results for the Ob Delta cores (Panteleyev 1995). Assuming decay equilibrium, the unsupported ${ }^{210} \mathrm{~Pb}$ activity $\left({ }^{210} \mathrm{~Pb}_{\mathrm{xs}}\right)$ was determined by the difference between ${ }^{210} \mathrm{~Pb}$ and ${ }^{214} \mathrm{~Pb}$ activities. As Panteleyev (1995) observed, ${ }^{214} \mathrm{~Pb}$ measurements had slightly smaller uncertainties than ${ }^{214} \mathrm{Bi}$ measurements and age estimates by ${ }^{214} \mathrm{~Pb}$ were generally more consistent with the timing suggested by global fallout. ${ }^{214} \mathrm{Bi}$ data are listed in Appendix I, however, ${ }^{214} \mathrm{~Pb}$ was used to determine ${ }^{210} \mathrm{~Pb}_{\mathrm{xs}}$ deposition ages. 
In order to obtain deposition ages from ${ }^{210} \mathrm{~Pb}_{\mathrm{xs}}$, it was assumed that input of ${ }^{210} \mathrm{~Pb}_{\mathrm{xs}}$ and the sedimentation rate were both constant. Average sedimentation rates and deposition ages were calculated using the following equations:

$$
A_{z}=A_{0} e^{-(\lambda) z}
$$

Where $A_{z}$ equals the activity of ${ }^{210} \mathrm{~Pb}_{\mathrm{xs}}$ per unit dry weight of sample at depth $\mathrm{z}, A_{0}$ equals the activity of ${ }^{210} \mathrm{~Pb}_{\mathrm{xs}}$ per unit dry weight at the surface $(\mathrm{z}=0), \lambda$ equals the decay constant of ${ }^{210} \mathrm{~Pb}(\ln (2) / 22.26 \mathrm{yr}$.), and $s$ equals the average sedimentation rate. From equation 5.1 it also follows that the age $(t)$ of the sample (i.e. elapsed time since deposition) can be calculated from the following equation:

$$
t=1 / \lambda \ln \left(A_{0} / A_{z}\right)
$$

If the initial activity of ${ }^{210} \mathrm{~Pb}_{\mathrm{xs}}$ has remained constant through the time interval of interest, and the core top is intact (i.e. it represents the date of collection), then $t$ may be used to calculate a deposition age $\left(A g e_{d}\right)$ using:

$$
\text { Age }_{d}=\text { Collection date }-t
$$

The extent to which the assumptions of constant initial activity and constant sedimentation rate are both valid limit the accuracy of the sample age and sedimentation rate estimates. Evaluation of core top integrity is important as it can result in a systematic error with respect to the calculated deposition age. If the integrity of the core top is suspect or the age estimates of the profile features used for dating by the radionuclide horizon method are systematically too young, it is reasonable to calculate deposition ages based on a date other than collection, if it is known with more certainty. Based on hydrographic data (Chapter 3), it is clear that sedimentation rates in the $\mathrm{Ob}$ 
River are not constant on a monthly basis. The delivery of materials at regular intervals during the annual flood however, reasonably approximates a constant sedimentation rate for the time period of interest (i.e. the last 50 years.) with respect to the 22.26 year halflife of ${ }^{210} \mathrm{~Pb}$.

The ${ }^{210} \mathrm{~Pb}$ xs profiles, model fits, correlation coefficients, and average sedimentation rates $( \pm 1 \sigma$ of the exponential coefficient) for Ob delta cores and the Taz estuary are shown in Figure 5:5a. Although some departures from the assumptions made are evident in all cores such as changes in slope, subsurface increases, and scatter, the model fits were acceptable with a few exceptions. Excluding OB94-10A, which appears to have a change in sedimentation rate at $\sim 30 \mathrm{~cm}$, resulting model fits for all cores from the $\mathrm{Ob}$ delta and Taz estuary yielded $\mathrm{r}^{2}$ values between 0.71 and 0.90 . Average sedimentation rates in the delta ranged between $\sim 0.2$ to $0.8 \mathrm{~cm} \mathrm{yr}^{-1}$, although the upper portion of OB94-10A appears to be substantially higher at $\sim 4 \mathrm{~cm} \mathrm{yr}^{-1}$, demonstrating the variability of the depositional environment at this location.

${ }^{T}{ }^{210} \mathrm{~Pb}_{\mathrm{xs}}$ profiles for cores collected from the upper reaches of the $\mathrm{Ob}$, Irtysh, and Tobol Rivers are generally more scattered than in those of the delta cores (Figure $5: 5 b)$. Four of the six cores yielded reasonable model fits $\left(\mathrm{r}^{2}\right.$ between 0.52 and 0.91$)$. The model fit for OB95-06 yielded an $\mathrm{r}^{2}$ value of 0.16 and the ${ }^{210} \mathrm{~Pb}_{\mathrm{xs}}$ profile in OB95-11 exhibited no exponential trend. Sedimentation rates estimated for the upper Ob River and its major tributaries are quite variable, ranging from $\sim 0.5$ to $1.5 \mathrm{~cm} \mathrm{yr}^{-1}$ for most cores. The estimated sedimentation rate in OB95-06 is substantially higher $\left(\sim 6.0 \mathrm{~cm} \mathrm{yr}^{-1}\right)$, and the near-vertical trend observed in OB95-11 suggests that it too may be very high. 

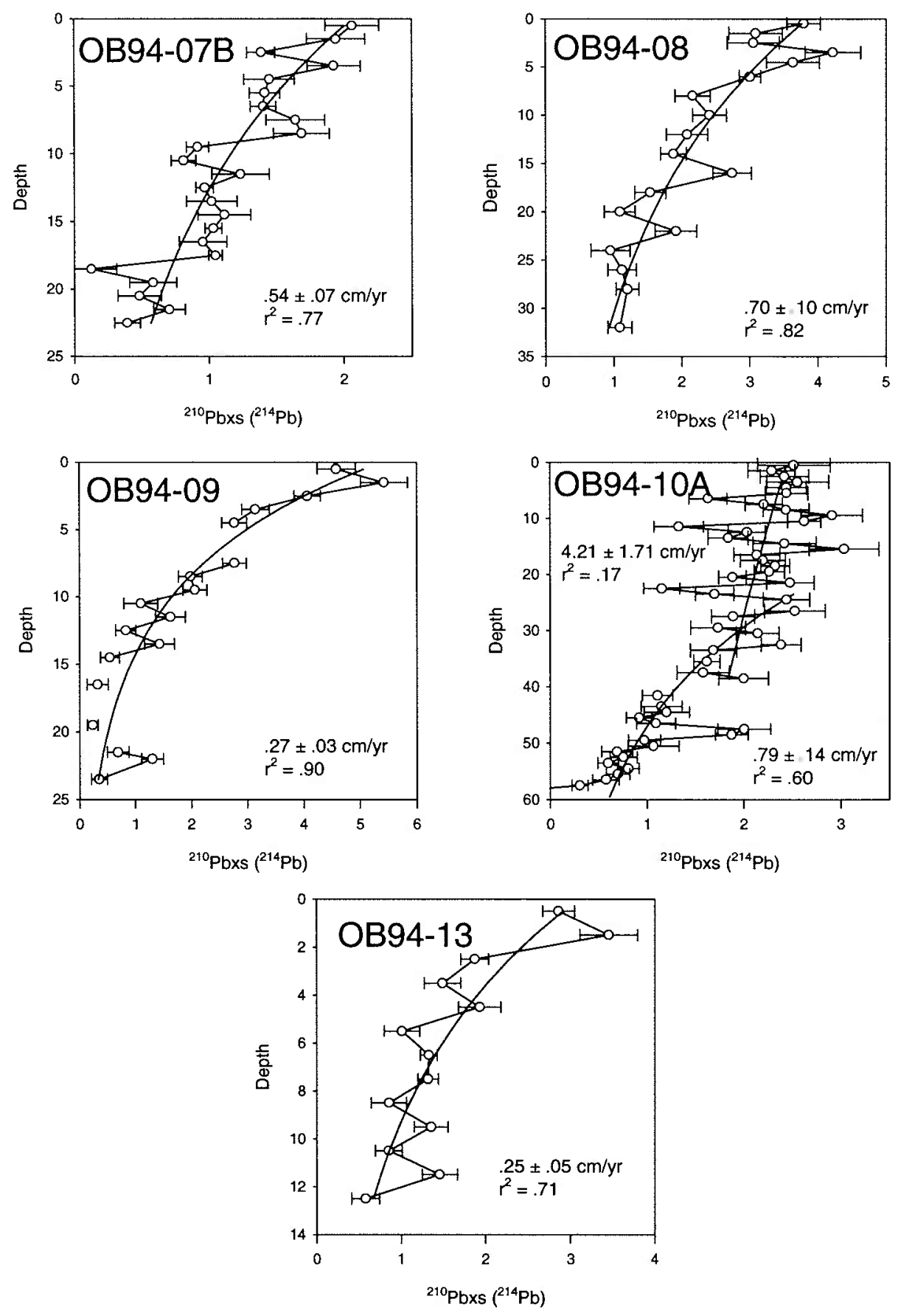

Figure 5:5a. ${ }^{210} \mathrm{~Pb}_{\mathrm{xs}}$ with exponential fits for sediment cores from the Ob delta and Taz estuary. Error bars represent $1 \sigma$ error of the measurement. Note ${ }^{210} \mathrm{~Pb}_{\mathrm{xs}}$ has been decay corrected to 1/1/1995. See Figure 4:1 for core locations. 

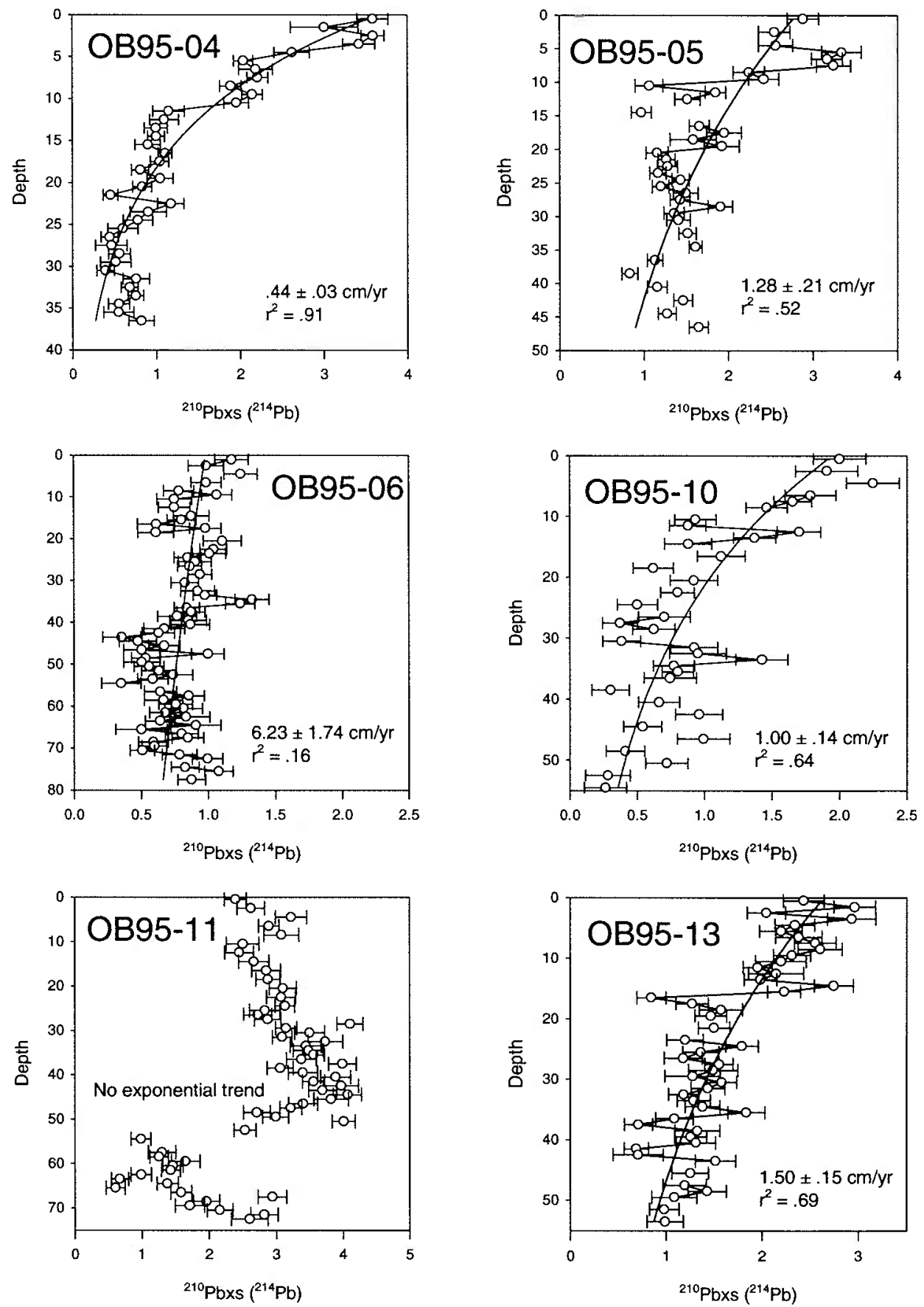

Figure 5:5b. ${ }^{210} \mathrm{~Pb}_{\mathrm{xs}}$ with exponential fits for the upper reaches of the Ob, Irtysh and Tobol Rivers. Error bars represent $1 \sigma$ error of the measurement. Note: ${ }^{210} \mathrm{~Pb}_{\mathrm{xs}}$ has been decay corrected to $1 / 1 / 1995$. See Figure 4:1 for core locations. 
Sedimentation rate estimates from both ${ }^{210} \mathrm{~Pb}_{\mathrm{xs}}$ and the radionuclide horizon method (below) will be compared at the end of the chapter.

\section{Deposition ages by the radionuclide horizon method}

The radionuclide horizon method typically uses the initial appearance and maximum concentration in a ${ }^{137} \mathrm{Cs}$ profile to represent the onset and maximum of global fallout derived from atmospheric weapons tests (Jaakkola, Tolonen et al. 1983; Miller and Heit 1986). Sedimentation rates are calculated between the assigned time horizons and used to estimate the depth to age relationship. Using this approach in the Ob Delta and Taz Estuary, Sayles et al. (1997) observed that independent ${ }^{210} \mathrm{~Pb}_{\mathrm{xs}}$ age estimates were consistent with known and expected features of ${ }^{137} \mathrm{Cs}$ profiles. Deposition age estimates for cores OB94-07 and OB94-13 and several other cores from the Ob Delta have been previously published (Sayles, Livingston et al. 1997). In these cores, the authors demonstrated a synchronicity between ${ }^{210} \mathrm{~Pb}_{\mathrm{xs}}$ age estimates, and the main features of ${ }^{137} \mathrm{Cs}$ and ${ }^{239,240} \mathrm{Pu}$ profiles, which reflect global fallout deposition. The first appearance and the maximum concentrations of ${ }^{137} \mathrm{Cs}$ and ${ }^{239,240} \mathrm{Pu}$ have mean ${ }^{210} \mathrm{~Pb}_{\mathrm{xs}}$ ages of $1953 \pm 5 \mathrm{y}$ and $1966 \pm 4$, respectively. Within the uncertainty of the ${ }^{210} \mathrm{~Pb}_{\mathrm{xs}}$ age estimates, these data do not differ significantly from the timing of global fallout deposition. With the availability of additional isotopic information, it became evident that the ${ }^{137} \mathrm{Cs}$ maximum did not always represent the maximum in global fallout deposition (discussed below). Additionally, several cores had multiple ${ }^{137} \mathrm{Cs}$ peaks, likely due to the influence of local sources, making the selection of the global fallout peak by 
this method rather arbitrary (e.g. OB95-04 and 05). Due to these complications, a more robust method of radionuclide horizon selection was developed, which allowed the verification of proposed event horizons. In general, this method had little or no effect on conclusions made by previous researchers, (Panteleyev 1995; Sayles, Livingston et al. 1997). To ensure consistency in this study however, all cores were treated in the same manner, including those from the $\mathrm{Ob}$ delta and Taz estuary reported earlier in the publications noted.

Chronologies established by the radionuclide horizon method are based on four profile features. 1) The deepest core section with detectable levels of ${ }^{240} \mathrm{Pu}$ was given an age of 1950 (see below). 2) The core section containing the largest fraction of global fallout plutonium was selected as the year of maximum global fallout (1963.5) (procedure discussed below). 3) Chernobyl material (if present) was used to fix deposition of this horizon to the time of the accident (1986.5). 4) In most cores, the surface sediments were assumed intact, and the core collection date was used to date the surface (1994.5 or 1995.5).

\section{Initial appearance of weapons related contamination}

The timing of the initial appearance of nuclear weapons related contamination is usually associated with the onset of global fallout. The onset of global fallout deposition is attributed to the Ivy Mike test, a 10.4 Mt surface explosion conducted on October 31, 1952 at Enwetak atoll, which deposited substantial amounts of material in the troposphere and stratosphere (Machta, List et al. 1956). A review of activities at 
Semipalitinsk and ${ }^{210} \mathrm{~Pb}_{\mathrm{xs}}$ age estimates of the initial appearance of ${ }^{239,240} \mathrm{Pu}$ in the GISP ice core suggests that nuclear weapons related contamination was likely present in the $\mathrm{Ob}$ region prior to 1952 (Koide, Goldberg et al. 1977; DOE 1982). The first atmospheric weapon test at Semipalitinsk occurred in August 1949 and others followed in September and October of 1951 (DOE, 1982). Based on this information, 1950 was selected to date the first appearance of ${ }^{240} \mathrm{Pu}$ and ${ }^{137} \mathrm{Cs}$, with an estimated uncertainty of 1 to 2 years. Table 5:1 gives the depth of first appearance for both ${ }^{137} \mathrm{Cs}$ and ${ }^{240} \mathrm{Pu}$. In many cases, where data are available, ${ }^{240} \mathrm{Pu}$ appears deeper than ${ }^{137} \mathrm{Cs}$. This is most likely due to the higher precision and lower detection limits of the ICP-MS method. Furthermore, ${ }^{137} \mathrm{Cs}$ has a half-life of 30.17 years, which means that any ${ }^{137} \mathrm{Cs}$, initially deposited $\sim 1950$ would have decreased by nearly 75 percent by the time it was measured in this study. With one exception, the core section containing the first appearance of ${ }^{240} \mathrm{Pu}$ was used to indicate the onset of fallout from weapons tests and given the date of 1950 . The deepest core section recovered by OB95-10 (Tobol River) was interesting in that it contained elevated levels of plutonium with a ${ }^{240} \mathrm{Pu} /{ }^{239} \mathrm{Pu}$ isotopic composition ( 0.016) that indicated it was clearly not associated with the onset of fallout. However, based on the reported activities at Mayak, weapons-grade plutonium would not be present in the river prior to June 1948 , which is within the uncertainty of the date attached to the initial appearance of nuclear contaminants in the other cores.

Down core distribution profiles obtained from OB95-04, 06, and 11, presented earlier in this chapter, indicate that the deepest samples recovered by these cores contain ${ }^{240} \mathrm{Pu}$ and other radionuclide concentrations that are well above ICP-MS detection limits. 
Based on this, it was concluded that these cores did not recover sediments deposited prior to the nuclear age, and the depth of the initial appearance of ${ }^{240} \mathrm{Pu}$ could not be determined.

In the remaining cores, the deposition ages of the core sections containing the initial appearance were fixed at 1950 and compared to their corresponding deposition ages estimated by the ${ }^{210} \mathrm{~Pb}_{\mathrm{xs}}$ method. Table 5:1 lists the depths of the depths first appearance (DFA) of both ${ }^{137} \mathrm{Cs}$ and ${ }^{240} \mathrm{Pu}$. The ${ }^{210} \mathrm{~Pb}_{\mathrm{xs}}$ age estimates correspond to the first appearance of ${ }^{240} \mathrm{Pu}$. With a few exceptions, ${ }^{210} \mathrm{~Pb}_{\mathrm{xs}}$ deposition ages are in good agreement with the assigned date of 1950 .

Table 5:1. Selection of 1950 horizon for Ob River Sediment cores

\begin{tabular}{|c|c|c|c|c|c|c|}
\hline Core ID & $\begin{array}{l}\text { 37 Cs DFA } \\
(\mathrm{cm})\end{array}$ & - & $\begin{array}{c}{ }^{4{ }^{40} \mathrm{Pu} \text { DFA }} \\
\text { (cm) }\end{array}$ & - & $\begin{array}{l}{ }^{210} \mathrm{~Pb}_{x \mathrm{~s}} \mathrm{Age} \\
\text { of }{ }^{240} \mathrm{Pu} \text { DFA }\end{array}$ & Comments \\
\hline OB94-07B & 21.5 & MZB & 23.5 & DSAL & $1949.4 \pm 6.0$ & - \\
\hline OB94-08 & 30.0 & MZB & 32.0 & DSAL & $1948.9 \pm 6.3$ & - \\
\hline OB94-09 & 13.5 & DSAL & 15.5 & DSAL & $1937.0 \pm 7.1$ & - \\
\hline OB94-10A & 59.5 & DSAL & 59.5 & DSAL & $1950.7 \pm 2.6$ & - \\
\hline OB94-13 & 12.5 & MZB & 13.5 & DSAL & $1941.5 \pm 10.7$ & - \\
\hline OB95-04 & $36.5^{*}$ & No DFA & $36.5^{\star}$ & - & $1912.3 \pm 5.4$ & Record truncated \\
\hline OB95-05 & 46.5 & MZB & 48.5 & DSAL & $1956.5 \pm 6.2$ & \\
\hline OB95-06 & $77.5^{\star}$ & No DFA & $77.5^{\star}$ & - & $1982.1 \pm 3.5$ & Record truncated \\
\hline OB95-10 & 53.5 & MZB & $54.5^{\star \star}$ & DSAH & $1941.1 \pm 7.5$ & \\
\hline OB95-11 & $72.5^{\star}$ & No DFA & $72.5^{\star}$ & - & - & Record truncated \\
\hline OB95-13 & 52.5 & MZB & 53.5 & DSAL & $1959.9 \pm 3.6$ & \\
\hline
\end{tabular}

DFA - depth of first appearance

MZB - samples analyzed below this depth contained no ${ }^{137} \mathrm{Cs}$

DSAL - deepest core section analyzed, but concentrations were quite low

DSAH - deepest section analyzed, but concentrations were elevated

* For truncated records, ${ }^{210} \mathrm{~Pb}_{x s}$ ages, if available, and depths are given for the deepest section analyzed.

** This sample shows clear evidence of non-fallout contamination, but can still be dated at $~ 1950$ (see text) Note: uncertainties for ${ }^{210} \mathrm{~Pb}_{\mathrm{xs}}$ ages are \pm 1 se based on the exponential coefficient from model fits.

Bold depth values indicate selected depth of first appearance (DFA). 


\section{Global fallout maximum}

In many of the sediment cores, the clearest features observed in ${ }^{137} \mathrm{Cs}$ and ${ }^{240} \mathrm{Pu}$ profiles are their concentration maxima. The decision to use ${ }^{240} \mathrm{Pu}$ was made based on the fact that it exhibits far smaller non-fallout contributions due to its very low abundance in non-fallout contaminant releases. This makes ${ }^{240} \mathrm{Pu}$ much less sensitive to local contamination and much more strongly dominated by global fallout. In general, when using the timing of global fallout to establish chronologies, the concentration maximum is attributed to the maximum deposition of global fallout in mid-1963. The relationship between the large numbers of atomic weapons tests conducted between 1961 and 1963 and the subsequent maximum in deposition of global fallout in mid-1963 has been clearly demonstrated by worldwide monitoring programs (Larsen 1980).

In order to resolve the global fallout peak from other peaks due to non-fallout contamination, the global fallout plutonium fraction was estimated based on a twocomponent end member mixing-model. First, it is assumed that the majority of plutonium observed in the $\mathrm{Ob}$ watershed can be characterized as mixture of global fallout and materials from weapons production and testing facilities. Second, the plutonium isotopic compositions of these sources are well characterized by their published isotopic values (i.e. ${ }^{240} \mathrm{Pu} /{ }^{239} \mathrm{Pu}$ of global fallout $\cong 0.18$ and the ${ }^{240} \mathrm{Pu} /{ }^{239} \mathrm{Pu}$ of non-fallout contamination is substantially lower, between .016 and .04). A wealth of published information indicates that both these assumptions are quite reasonable (see chapter 2). The actual values of the fractions are dependent upon the true end member values. For the intended purpose of identifying the maximum due to global fallout however, a non- 
fallout ${ }^{240} \mathrm{Pu} /{ }^{239} \mathrm{Pu}$ ratio that is significantly lower than global fallout is all that is required. For this exercise, the isotopic ratio used to represent global fallout is 0.18 and non-fallout plutonium is represented by a ${ }^{240} \mathrm{Pu} /{ }^{239} \mathrm{Pu}$ ratio of 0.03 . Based on these values, estimates of the relative contaminant contributions from each end-member are made by using the following equations:

$$
\mathrm{R}_{\mathrm{M}}=\mathrm{GF}_{\mathrm{F}}\left(\mathrm{R}_{\mathrm{GF}}\right)+\left(1-\mathrm{GF}_{\mathrm{F}}\right)\left(\mathrm{R}_{\mathrm{NF}}\right)
$$

Thus,

$$
\mathrm{GF}_{\mathrm{F}}=\left(\mathrm{R}_{\mathrm{M}}-\mathrm{R}_{\mathrm{NF}}\right) /\left(\mathrm{R}_{\mathrm{GF}}-\mathrm{R}_{\mathrm{NF}}\right)
$$

Where,

$\mathrm{GF}_{\mathrm{F}}=$ the global fallout fraction

$R_{M}=$ the measured ${ }^{240} \mathrm{Pu} /{ }^{239} \mathrm{Pu}$ isotopic ratio

$\mathrm{R}_{\mathrm{NF}}=$ the ${ }^{240} \mathrm{Pu} /{ }^{239} \mathrm{Pu}$ ratio of non-fallout plutonium, in this case $(0.03)$

$\mathrm{R}_{\mathrm{GF}}=$ the ${ }^{240} \mathrm{Pu} /{ }^{239} \mathrm{Pu}$ ratio of global fallout $(0.18)$

Multiplying the calculated $\mathrm{GF}_{\mathrm{F}}$ of each sample by the measured ${ }^{240} \mathrm{Pu}$ concentration, allows the down-core profiles of the plutonium attributable to global fallout to be estimated. Following this procedure, the down-core profiles of global fallout ${ }^{240} \mathrm{Pu}$ concentrations were examined, and the core section with the maximum value was selected as the peak of global fallout deposition (GFM) and assigned a date of 1963.5. The results of these calculations for OB94-07B are shown in Figure 5:6. The top two panels show the measured ${ }^{240} \mathrm{Pu}$, and both the estimated global fallout and non-fallout concentrations. The bottom panels show the measured ${ }^{137} \mathrm{Cs}$ concentration and the measured ${ }^{137} \mathrm{Cs} /{ }^{240} \mathrm{Pu}$ atom ratio. From the estimates, it is clear that an increase in the levels of non-fallout ${ }^{240} \mathrm{Pu}$ and ${ }^{137} \mathrm{Cs}$ occurred above the GFM. Along with an increase in non-fallout ${ }^{240} \mathrm{Pu}$, non-fallout ${ }^{137} \mathrm{Cs}$ is also present between 13 and $15 \mathrm{~cm}$ (i.e. the 
presence of non-fallout ${ }^{240} \mathrm{Pu}$ alone would drive the resulting ${ }^{137} \mathrm{Cs} /{ }^{240} \mathrm{Pu}$ ratio below global fallout, not above it). The sample containing the ${ }^{137} \mathrm{Cs}$ concentration maximum, exhibits ${ }^{137} \mathrm{Cs} /{ }^{240} \mathrm{Pu}$ ratios that also fall well above the $\pm 2 \sigma$ range calculated for average global fallout, while the sample selected as the global fallout maximum falls within the \pm $2 \sigma$ range. The ${ }^{137} \mathrm{Cs} /{ }^{240} \mathrm{Pu}$ ratios further support the selection of $15.5 \mathrm{~cm}$ as the global fallout maximum.

The selection of the GFM for all cores where it was recovered by the method outlined above is summarized in Table 5:2. Based on the ${ }^{137} \mathrm{Cs} /{ }^{240} \mathrm{Pu}$ ratios (see next section), it was determined that OB95-06 and 11 did not recover the GFM. In the remaining cores, the core sections containing the GFM were assigned the date of 1963.5 and compared to their corresponding deposition ages estimated by the ${ }^{210} \mathrm{~Pb}_{\mathrm{xs}}$ method where possible. In the case of OB95-05 and OB95-13, alternate age estimates were calculated using the first appearance, dated at 1950, and the average sedimentation rate calculated by ${ }^{210} \mathrm{~Pb}_{\mathrm{xs}}$. Both the alternate deposition age and the age based on the collection date are shown for these two cores. As with the DFA, there are a few exception, however, the majority of ${ }^{210} \mathrm{~Pb}_{\mathrm{xs}}$ deposition age estimates are in good agreement with the assigned date of 1963.5 . 

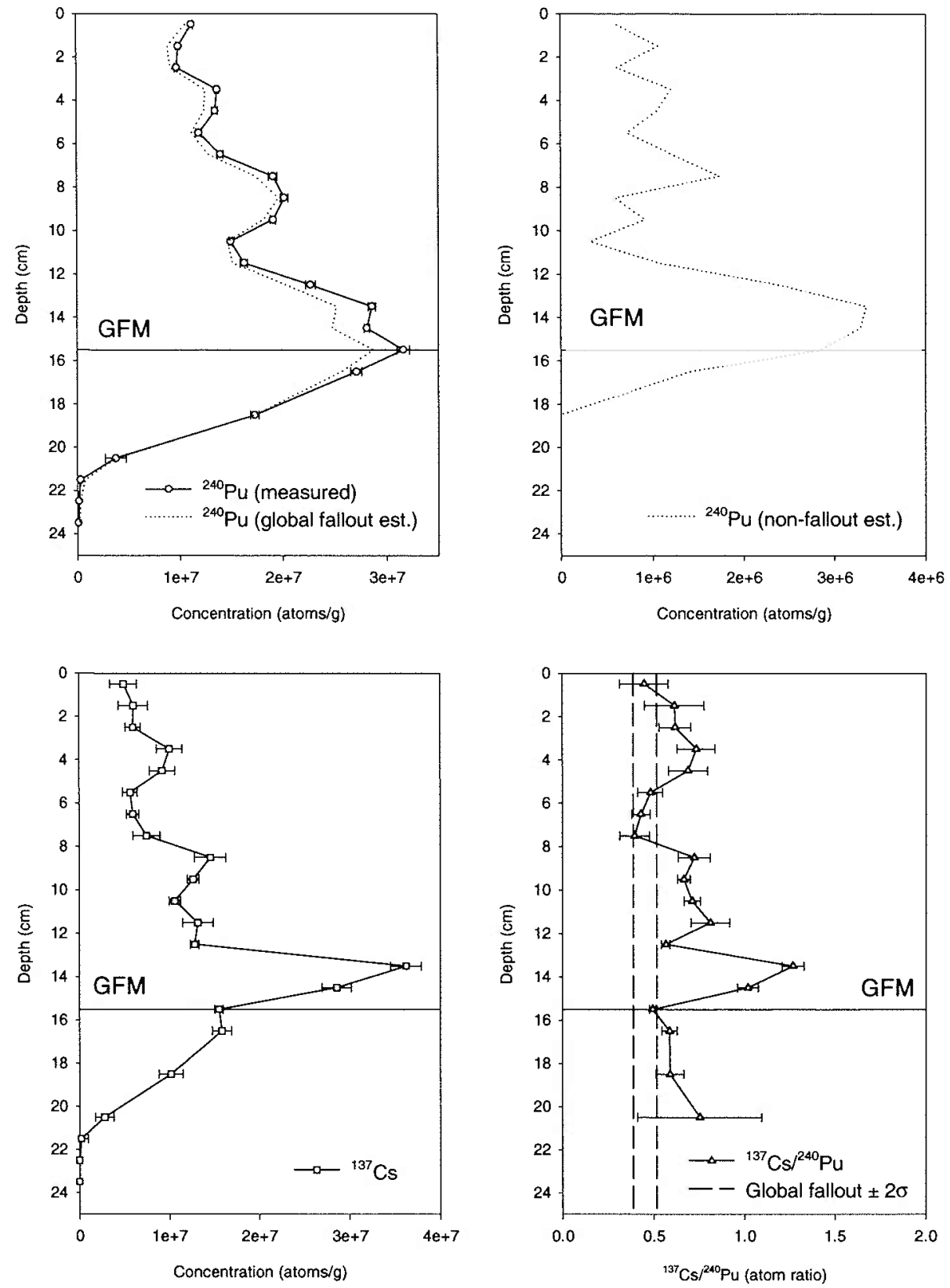

Figure 5:6. Estimated fractions of global fallout and non-fallout ${ }^{240} \mathrm{Pu}$ in OB94-07B. Also shown are the down core ${ }^{240} \mathrm{Pu}$ and ${ }^{137} \mathrm{Cs}$ distributions as well as the ${ }^{137} \mathrm{Cs} /{ }^{240} \mathrm{Pu}$ atom ratio. Error bars represent $1 \sigma$ error of the measurement. Note: ${ }^{137} \mathrm{Cs}$ has been decay corrected to $1 / 1 / 1995$. The solid horizontal line indicates the global fallout maximum and the dashed lines indicate the $\pm 2 \sigma$ range calculated for average global fallout. See table 2:3 for details and Figure 4:1 for core locations. 
Table 5:2 Selection of 1963.5 horizon for Ob River Sediment cores

\begin{tabular}{lccc}
\hline \multicolumn{1}{c}{ Core ID } & $\begin{array}{c}\text { Depth of GFM } \\
(\mathrm{cm})\end{array}$ & $\begin{array}{c}{ }^{210} \mathrm{~Pb} \text { xs Age } \\
-\end{array}$ & Comments \\
\hline OB94-07B & 15.5 & $1966.0 \pm 3.8$ & - \\
OB94-08 & 16.0 & $1971.7 \pm 3.1$ & - \\
OB94-09 & 9.5 & $1959.3 \pm 4.4$ & - \\
OB94-10A & 51.5 & $1960.7 \pm 2.2$ & - \\
OB94-13 & 9.5 & $1957.2 \pm 7.5$ & - \\
OB95-04 & 28.5 & $1930.5 \pm 4.2$ & - \\
OB95-05 & 26.5 & $1972.2 \pm 3.7$ & - \\
OB95-05 & 26.5 & $1967.2 \pm 4.5$ & Alternate date* \\
OB95-06 & - & - & GFM not recovered \\
OB95-10 & 35.5 & $1960.0 \pm 4.9$ & - \\
OB95-11 & - & - & GFM not recovered \\
OB95-13 & 35.5 & $1971.9 \pm 2.4$ & - \\
- & 35.5 & $1962.0 \pm 2.7$ & Alternate date \\
\hline
\end{tabular}

Note: uncertainties for ${ }^{210} \mathrm{~Pb}_{\mathrm{xs}}$ ages are \pm 1 se based on the exponential coefficient from model fits.

* Alternate date - due to a large ${ }^{210} \mathrm{~Pb}_{\mathrm{xs}}$ disturbance between surface and/or GFM and missing core top resulted in both the FA and GFM being systematically too young. An alternate date was obtained by selecting 1950 for the FA and calculating the GFM age using the ${ }^{210} \mathrm{~Pb}_{\mathrm{xs}}$ average sedimentation rate.

\section{Chernobyl}

The ${ }^{137} \mathrm{Cs}$ enrichment due to material originating from the Chernobyl accident in April 1986, if identifiable, may also be used to obtain a date of deposition. With regard to contamination from the Chernobyl accident, a maximum in the ${ }^{137} \mathrm{Cs}$ profile located above the main fallout peak is observed in nearly all cores, in some cases, multiple maxima are present. These maxima are weak or ambiguous in cores from the upper $\mathrm{Ob}$ River, the delta, and the Taz estuary but especially pronounced in cores from the Tobol and Irtysh Rivers (OB95-10 and OB95-13, respectively) (see Figure 5:1a and b).

Due to a number of possible non-fallout sources of ${ }^{137} \mathrm{Cs}$ local to the Ob region, the question of whether or not ${ }^{137} \mathrm{Cs}$ enrichments derived from the Chernobyl accident are also present must first be addressed before deposition age information can be obtained. That the very large maxima in OB95-10 and OB95-13 correspond to a Chernobyl signal 
is supported by several observations. The first is the presence of measurable amounts of ${ }^{134} \mathrm{Cs}$ associated with the maximum in OB95-10 (Sayles, Kenna et al. 1998). The relatively short half-life of ${ }^{134} \mathrm{Cs}\left(\mathrm{t}_{1 / 2}=2.06 \mathrm{y}\right)$ eliminates atmospheric testing as its origin. Second, the fact that clear maxima are observed in sediments from different tributaries (i.e. the Tobol and the Irtysh rivers) indicates an atmospheric origin rather than input via a local source such as weapons facilities. Third, there are no reported events to offer a reasonable alternative to a Chernobyl origin such as activities or accidents in the Ob region during the 1970s or 1980s that would have resulted in the atmospheric delivery of ${ }^{137} \mathrm{Cs}$ (and ${ }^{134} \mathrm{Cs}$ in $\mathrm{OB} 95-10$ ) to the locations where it is observed.

In sediments from the Tobol and Irtysh Rivers (OB95-10, 13, and 06), Chernobyl material can be identified by its characteristically high ${ }^{137} \mathrm{Cs} /{ }^{240} \mathrm{Pu}$ atom ratio relative to global fallout. Figure 5:7a shows the ${ }^{137} \mathrm{Cs} /{ }^{240} \mathrm{Pu}$ atom ratio profiles from their respective global fallout maxima to the surface for cores from the upper reaches of the Ob, the Irtysh, and the Tobol Rivers. The profiles from both OB95-10 and 13 contain extremely elevated ${ }^{137} \mathrm{Cs} /{ }^{240} \mathrm{Pu}$ ratios associated with the ${ }^{137} \mathrm{Cs}$ maxima located closest to the surface. The event that caused the large ${ }^{210} \mathrm{~Pb}_{\mathrm{xs}}$ disturbance in OB95-13 does not appear to have disturbed the ${ }^{137} \mathrm{Cs} /{ }^{240} \mathrm{Pu}$ profile. The ${ }^{137} \mathrm{Cs} /{ }^{240} \mathrm{Pu}$ ratios in OB95-06 and OB95-11 (limited as they are) also support a Chernobyl origin for their observed ${ }^{137} \mathrm{Cs}$ maxima $\left({ }^{137} \mathrm{Cs}\right.$ profile shown in OB95-11 as a reference). This is consistent with the ${ }^{210} \mathrm{~Pb}_{\mathrm{xs}}$ profiles in both cores (i.e. near vertical trends) and the high sedimentation rates, relative to other cores, calculated for OB95-06. Additionally, the estimated ${ }^{210} \mathrm{~Pb}_{\mathrm{xs}}$ deposition age for the deepest sample recovered by OB95-06 is $~ 1982$, which rules out global fallout but 

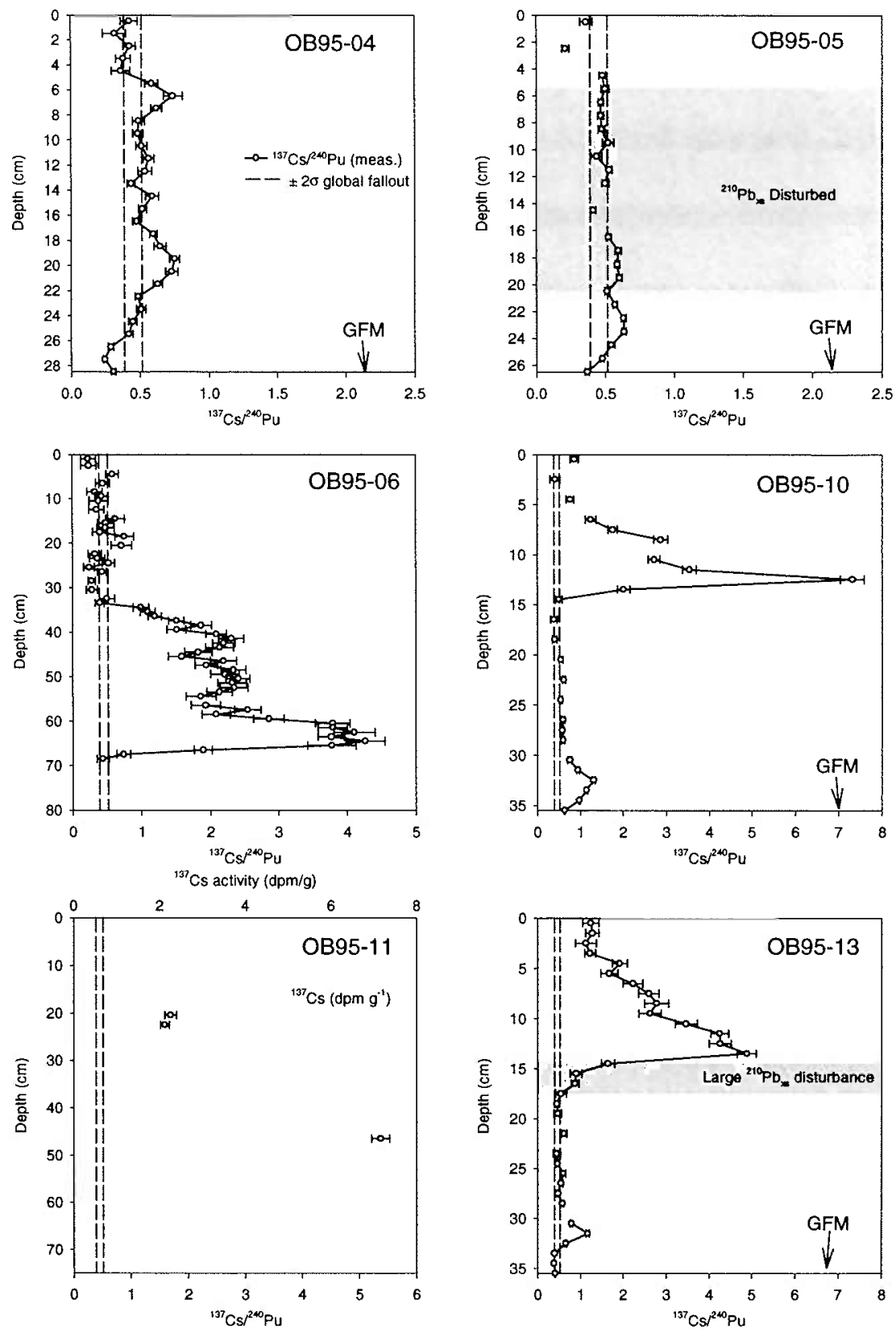

Figure 5:7a. ${ }^{137} \mathrm{Cs} /{ }^{240} \mathrm{Pu}$ profiles from sediment cores collected in the upper reaches of the $\mathrm{Ob}$, Irtysh, and Tobol Rivers from global fallout maximum (GFM) to surface. See OB95-04 for legend. ${ }^{137} \mathrm{Cs}$ activity profile shown for OB95-11 as a reference. Gray regions indicate areas where ${ }^{210} \mathrm{~Pb}_{\mathrm{xs}}$ is disturbed. ${ }^{137} \mathrm{Cs}$ has been decay corrected to $1 / 1 / 1995$. Error bars represent $1 \sigma$ error. Broken line indicates where one or more core sections were not analyzed. See Figure 4:1 for core locations. 
is consistent with the timing of the Chernobyl accident (see Table 5:1).

With regards to refractory element depletions such as plutonium and neptunium in Chernobyl material, the possible presence of ${ }^{240} \mathrm{Pu}$ in OB95-10 and OB95-13 from either Mayak or Semipalitinsk, respectively, introduces some uncertainty. First order estimates of the refractory element depletions in Chernobyl material are possible however, if one assumes that the measured isotopic compositions in the sample from OB95-10 containing the maximum ${ }^{137} \mathrm{Cs} /{ }^{240} \mathrm{Pu}$ ratio resulted from a mixture of global fallout and Chernobyl material only. Using equations similar to 5.4.1, the plutonium and cesium isotopic composition can be described as follows:

$$
\begin{aligned}
& { }^{240} \mathrm{Pu} /{ }^{239} \mathrm{Pu}_{\mathrm{M}}=\mathrm{GF}_{\mathrm{F}}\left({ }^{240} \mathrm{Pu} /{ }^{239} \mathrm{Pu}_{\mathrm{GF}}\right)+\left(1-\mathrm{GF}_{\mathrm{F}}\right)\left({ }^{240} \mathrm{Pu} /{ }^{239} \mathrm{Pu}_{\mathrm{CH}}\right) \\
& { }^{137} \mathrm{Cs} /{ }^{240} \mathrm{Pu}_{\mathrm{M}}=\mathrm{GF}_{\mathrm{F}}\left({ }^{137} \mathrm{Cs} /{ }^{240} \mathrm{Pu}_{\mathrm{GF}}\right)+\left(1-\mathrm{GF}_{\mathrm{F}}\right)\left({ }^{137} \mathrm{Cs} /{ }^{240} \mathrm{Pu}_{\mathrm{CH}}\right)
\end{aligned}
$$

Where :

$\mathrm{GF}_{\mathrm{F}}=$ the global fallout fraction

${ }^{240} \mathrm{Pu} /{ }^{239} \mathrm{Pu}_{\mathrm{M}}=$ measured ${ }^{240} \mathrm{Pu} /{ }^{239} \mathrm{Pu}$ ratio in OB95-10 $(12$ to $13 \mathrm{~cm})=(0.183)$

${ }^{240} \mathrm{Pu} /{ }^{239} \mathrm{Pu}_{\mathrm{GF}}={ }^{240} \mathrm{Pu} /{ }^{239} \mathrm{Pu}$ in global fallout (both 0.166 and 0.18 were used)

${ }^{240} \mathrm{Pu} /{ }^{239} \mathrm{Pu}_{\mathrm{CH}}={ }^{240} \mathrm{Pu} /{ }^{239} \mathrm{Pu}$ in Chernobyl material $(0.4)$

${ }^{137} \mathrm{Cs} /{ }^{240} \mathrm{Pu}_{\mathrm{M}}=$ measured ${ }^{137} \mathrm{Cs} /{ }^{240} \mathrm{Pu}$ ratio in OB95-10 $(12$ to $13 \mathrm{~cm})=(7.31)$

${ }^{137} \mathrm{Cs} /{ }^{240} \mathrm{Pu}_{\mathrm{GF}}={ }^{137} \mathrm{Cs} / 240 \mathrm{Pu}$ in global fallout $(0.451)$

${ }^{137} \mathrm{Cs} /{ }^{240} \mathrm{Pu}_{\mathrm{CH}}={ }^{137} \mathrm{Cs} /{ }^{240} \mathrm{Pu}$ ratio in Chernobyl material reaching the $\mathrm{Ob}$ region (?)

Based on a two-end-member system, the fractions of global fallout and Chernobyl derived material must be the same in equations 5.5.1 and 5.5.2. Since there is little 
evidence or likelihood that plutonium isotopic fractionation occurred in material from Chernobyl, The ratio of 0.4 measured in soils collected near the site of the accident is assumed for ${ }^{240} \mathrm{Pu} /{ }^{239} \mathrm{Pu}_{\mathrm{CH}}$ (Muramatsu, Ruhm et al. 2000). Due to the possible presence of plutonium derived from Mayak (i.e. ${ }^{240} \mathrm{Pu} /{ }^{239} \mathrm{Pu}_{\mathrm{M}}<0.18$ for many of the samples with elevated ${ }^{137} \mathrm{Cs} /{ }^{240} \mathrm{Pu}$ ratios), the $\mathrm{GF}_{\mathrm{F}}$ in equation 5.5.1 was solved for by using both 0.166 $(-2 \sigma$ global fallout $)$ and 0.18 to represent ${ }^{240} \mathrm{Pu} /{ }^{239} \mathrm{Pu}_{\mathrm{GF}}$. This resulted in global fallout fractions between 92 and 98 percent and Chernobyl fractions between 8 and 2 percent, respectively. Using these fractions to solve equation 5.5 .2 for ${ }^{137} \mathrm{Cs} /{ }^{240} \mathrm{Pu}_{\mathrm{CH}}$, results in ratio values between 94 and 456 . These calculations strongly suggest refractory element depletions in material that was deposited in the Ob region as a result of the Chernobyl accident. This is consistent with the refractory element depletions observed in Chernobyl contamination deposited at locations in northern Europe and the Black Sea (Krey, Klusek et al. 1986; Livingston, Buesseler et al. 1988; Buesseler and Livingston 2000).

If Chernobyl material in the $\mathrm{Ob}$ is depleted in refractory elements as the calculations suggest, contamination from Chernobyl in some sense can be treated as only ${ }^{137} \mathrm{Cs}$. The observed ${ }^{137} \mathrm{Cs} /{ }^{240} \mathrm{Pu}$ ratio therefore, will be a function of the amount of Chernobyl material present (i.e. ${ }^{137} \mathrm{Cs}$ ) and the amount of ${ }^{240} \mathrm{Pu}$ present from other sources. While a high ${ }^{137} \mathrm{Cs} /{ }^{240} \mathrm{Pu}$ ratio is a good indicator of Chernobyl material, a ${ }^{137} \mathrm{Cs}$ maximum that does not correspond to a high ${ }^{137} \mathrm{Cs} /{ }^{240} \mathrm{Pu}$ ratio does necessarily rule out a Chernobyl origin. It is possible that the presence of additional ${ }^{240} \mathrm{Pu}$ from local sources results in a lower ${ }^{137} \mathrm{Cs} /{ }^{240} \mathrm{Pu}$ ratio. 
While there is good evidence to support its presence in cores from the Irtysh and Tobol Rivers, Chernobyl material is not as obvious elsewhere in the region. Based on down core concentration profiles, OB95-05 is likely missing part of its surface, which would explain the lack of Chernobyl material in this core. In the case of OB95-04, two ${ }^{137} \mathrm{Cs} /{ }^{240} \mathrm{Pu}$ ratio maxima, of similar magnitude, are observed at $\sim 7 \mathrm{~cm}$ and $\sim 20 \mathrm{~cm}$. The lack of clear ${ }^{137} \mathrm{Cs} /{ }^{240} \mathrm{Pu}$ evidence to support the identification of Chernobyl materials in OB95-04 is likely due in part to the presence of relatively larger fractions of non-fallout ${ }^{240} \mathrm{Pu}$. Furthermore, the lack of acceptable ${ }^{210} \mathrm{~Pb}_{\mathrm{xs}}$ age estimates in this core makes selecting between the two possible ${ }^{137} \mathrm{Cs} /{ }^{240} \mathrm{Pu}$ maxima rather arbitrary.

Where the identification of Chernobyl derived material is uncertain due to weak isotopic signatures or multiple maxima, its presence can be confirmed by a comparison of the deposition ages of likely ${ }^{137} \mathrm{Cs}$ features located above the GFM such as weak ${ }^{137} \mathrm{Cs} /{ }^{240} \mathrm{Pu}$ or ${ }^{137} \mathrm{Cs}$ maxima. At this point in the core dating process, there are several ways to estimate deposition age. In addition to deposition ages suggested by the ${ }^{210} \mathrm{~Pb}_{\mathrm{xs}}$ method, deposition age estimates can be obtained by calculating sedimentation rates between the surface and both the depths of the FA and the GFM. These rates are listed in Table 5:3. In OB95-04, it was only possible to estimate a deposition age based on the sedimentation rate between the surface and the GFM. By this method the deposition age of the ${ }^{137} \mathrm{Cs} /{ }^{240} \mathrm{Pu}$ maximum at $\sim 7 \mathrm{~cm}$ is 1988.2 versus 1972.5 at $\sim 20 \mathrm{~cm}$, which supports a Chernobyl origin for the $7 \mathrm{~cm}$ maximum and allows the rejection of the deeper ${ }^{137} \mathrm{Cs} /{ }^{240} \mathrm{Pu}$ maximum. 
The ${ }^{137} \mathrm{Cs} /{ }^{240} \mathrm{Pu}$ atom ratio profiles from cores collected in the Ob delta and one in the Taz estuary are shown in Figure 5:7b. In cases where ${ }^{137} \mathrm{Cs} /{ }^{240} \mathrm{Pu}$ data is limited or inconclusive, ${ }^{137} \mathrm{Cs}$ profiles are also shown. Chernobyl material is clearly present in OB94-07B, which contains a clear ${ }^{137} \mathrm{Cs} /{ }^{240} \mathrm{Pu}$ maximum at $\sim 4 \mathrm{~cm}$ and deposition age estimates based on FA and GFM $\sim 1988$. In OB94-08, ${ }^{137} \mathrm{Cs} /{ }^{240} \mathrm{Pu}$ data is limited, however, the ${ }^{137} \mathrm{Cs}$ maximum $\sim 5 \mathrm{~cm}$ has deposition age estimates between $\sim 1986$ and 1988, which support its association with Chernobyl. Based on its down core concentration profiles, OB94-09 is likely missing its surface record. OB94-10A contains two ${ }^{137} \mathrm{Cs} /{ }^{240} \mathrm{Pu}$ maxima. As a result of the change in sedimentation rate observed at $\sim 30$ $\mathrm{cm}$, deposition ages based on the sedimentation rates between the surface and the DFA and the GFM are less certain than in other cores. Although the ${ }^{210} \mathrm{~Pb}_{\mathrm{xs}}$ is scattered, the estimated sedimentation rate is $4.1 \pm 1.7 \mathrm{~cm} \mathrm{yr}^{-1}$. Using the uncertainty as an upper and lower limit for the sedimentation rate, an event that occurred 8 years before collection (1994.5 - 1986.5) would be between 47 and $19 \mathrm{~cm}$. This allows the association of the ${ }^{137} \mathrm{Cs} /{ }^{240} \mathrm{Pu}$ at $\sim 30 \mathrm{~cm}$ with Chernobyl and the rejection of the shallow single point maximum $\sim 4 \mathrm{~cm}$ as being more recent than the Chernobyl accident. There is no indication of elevated ${ }^{137} \mathrm{Cs} /{ }^{240} \mathrm{Pu}$ ratios in OB94-13, however, the ${ }^{137} \mathrm{Cs}$ maximum at $\sim 2$ $\mathrm{cm}$ has deposition age estimates $\sim 1989$, which indicate that it is likely derived from Chernobyl. The measured ${ }^{240} \mathrm{Pu} /{ }^{239} \mathrm{Pu}$ ratio for this sample indicates that it is contaminated by global fallout only. This rules out the possibility that non-fallout ${ }^{240} \mathrm{Pu}$ is driving the ${ }^{137} \mathrm{Cs} /{ }^{240} \mathrm{Pu}$ ratio low. There is some evidence to suggest that the location in 

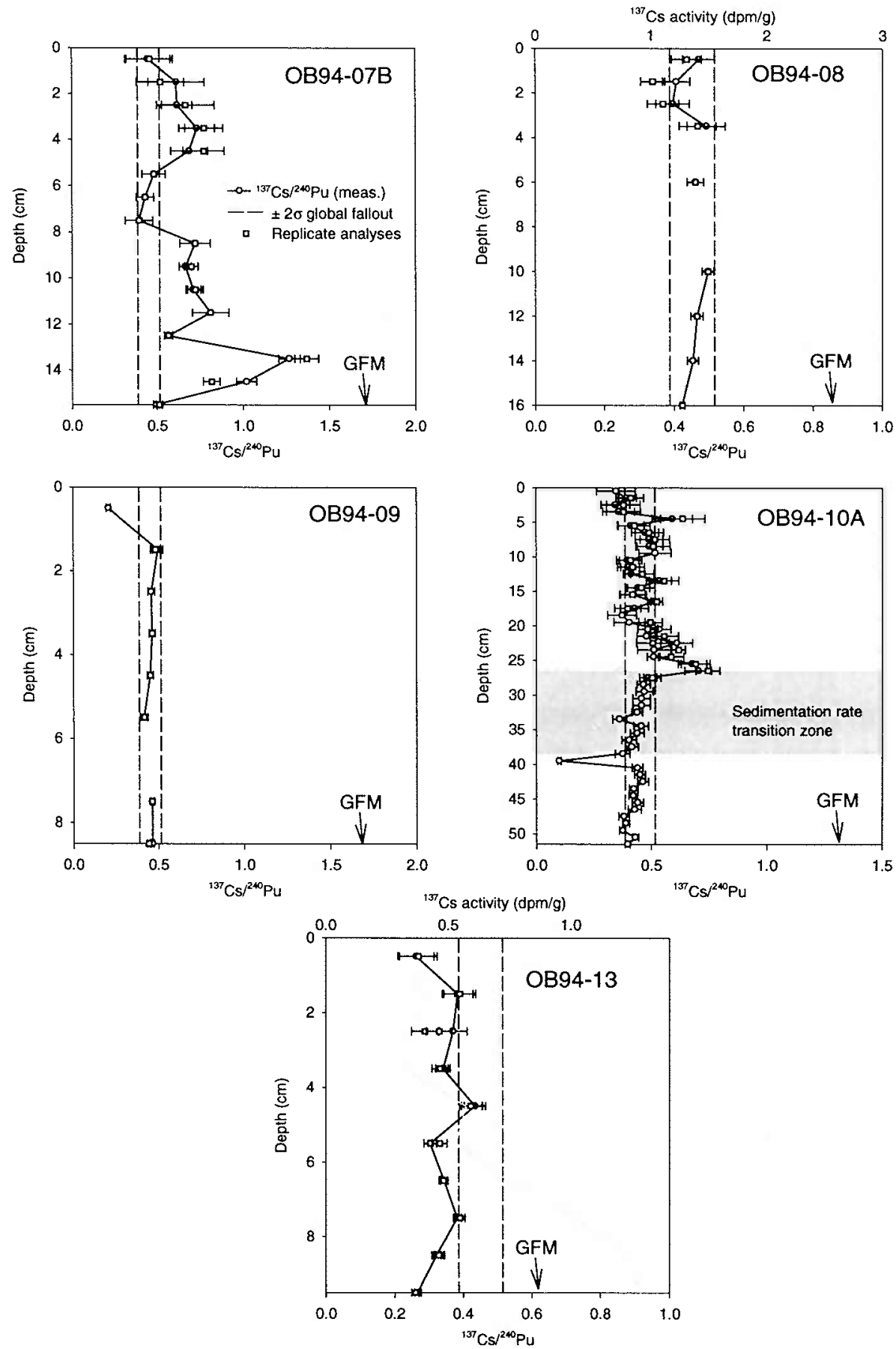

Figure 5:7b. ${ }^{137} \mathrm{Cs} /{ }^{240} \mathrm{Pu}$ profiles from sediment cores collected in the Ob delta and Taz estuary from global fallout maximum (GFM) to surface. See OB94-07B for legend. ${ }^{137} \mathrm{Cs}$ activity profiles shown for OB94-08 and 13 as a reference. Gray region indicates the zone of sedimentation rate transition in $\mathrm{OB} 94-10 \mathrm{~A} .{ }^{137} \mathrm{Cs}$ has been decay corrected to $1 / 1 / 1995$. Error bars represent $1 \sigma$ error. Broken line indicates where one or more core sections were not analyzed. See Figure 4:1 for core locations 
the Taz estuary where this core was collected may be affected by periodic incursions of seawater, which would explain the low ${ }^{137} \mathrm{Cs} /{ }^{240} \mathrm{Pu}$ ratios observed in this core. This is discussed more thoroughly in the next chapter.

In cores where the input of Chernobyl material occurs as a single point maximum it was assigned the deposition date of 1986.5. In cores where input occurs over several core sections, the deepest core section, rather than the section containing the peak maximum was assigned the deposition date of 1986.5. In this regard, the Chernobyl maximum selected in OB94-10A is quite close to the sedimentation rate transition zone. Thus, the estimated ${ }^{210} \mathrm{~Pb}_{\mathrm{xs}}$ deposition age is somewhat dependent upon the depth selected to begin using the higher rate. Based on the intersection of the two model fits, $30.5 \mathrm{~cm}$ was chosen as the transition depth (see Figure 5:5a).

The selection of the 1986.5 horizon in sediment cores is summarized in Table 5:3. An examination of the deposition ages estimated for the features associated with Chernobyl reveals a concurrence of deposition ages estimated by ${ }^{210} \mathrm{~Pb}_{\mathrm{xs}}$ and those based on the depths of the GFM and FA. Only in one case (OB95-04) do the estimates differ by more than a few years. 


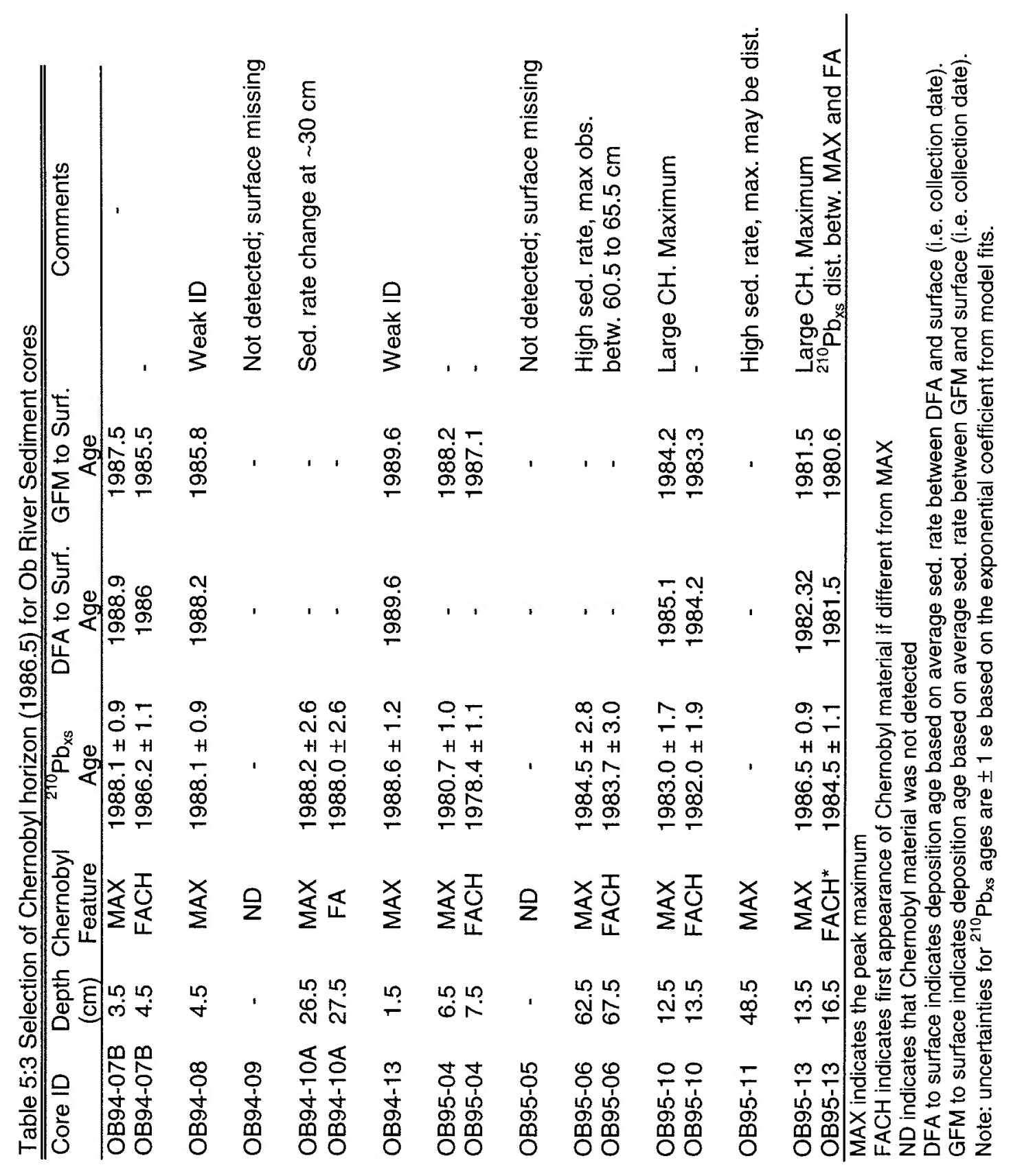




\section{Sedimentation rates}

Table 5:4 summarizes the sedimentation rates and the dates of radionuclide

profile features that were obtained using the ${ }^{210} \mathrm{~Pb}_{\mathrm{xs}}$ method where it was possible, and the radionuclide horizon method. For the majority of cores dated by both methods, the averages of the sedimentation rates calculated between radionuclide features agree with those obtained by the ${ }^{210} \mathrm{~Pb}_{\mathrm{xs}}$ method, which is an average rate for the entire core. This demonstrates that the assumption of a constant sedimentation rate is a good approximation of actual sedimentation in most cores.

Excluding the upper portion of OB94-10A, sedimentation rates in the Ob delta are $\sim 0.6 \mathrm{~cm} \mathrm{yr}^{-1}$, while those in the Taz estuary are $\sim 0.25 \mathrm{~cm} \mathrm{yr}^{-1}$. Sedimentation rates in the $\mathrm{Ob}$ above its confluence with the Irtysh range between 0.8 and $1.5 \mathrm{~cm} \mathrm{yr}^{-1}$, while those in Irtysh and Tobol Rivers are much more variable, ranging between 0.8 and $7.6 \mathrm{~cm} \mathrm{yr}^{-1}$.

To some degree variability is observed between selected time intervals in many of the cores, which suggests that the radionuclide horizon method provides more accurate deposition ages than the ${ }^{210} \mathrm{~Pb}_{\mathrm{xs}}$ method in these instances. Sedimentation rates observed in complete cores from the Irtysh and Tobol Rivers are similar for the same time intervals and indicate a period of relatively lower sedimentation rate between 1963.5 and 1986.5. The incomplete records of OB95-11 and OB95-06 (see Figure 4:1 for core locations) indicate that sedimentation rates were significantly higher at these locations from 1986.5 to 1995.5 . This suggests a larger variability in sedimentation rates between coring sites in the Irtysh and Tobol Rivers and the other locations. 
The preservation of sharp profile variations reflecting local sources that are superimposed on the global fallout deposition pattern indicate that the sediment cores used in this study are not subject to significant amounts of mixing. Radionuclide profile features that are missing in some cores but present in others from the same general location (i.e. the delta and/or the upper reaches of the Ob River) suggest some uncertainty as to their degree of disturbance and whether or not the core top is intact. The differences between OB95-04 and OB95-05 are distinct (i.e. the general lack of low concentration values in all profiles near the surface). In the delta cores however, the differences are less clear. Sedimentation processes can vary considerably in the Ob region. It is entirely possible that channels leading to the selected coring sites have opened and/or closed during the past fifty years, and these sites may not have received regular input of contaminated sediments. If this is the case, sediment cores lacking specific radionuclide profile features may still yield reasonable ${ }^{210} \mathrm{~Pb}_{\mathrm{xs}}$ deposition ages

Processes such as non-deposition of any sediments and/or erosion during a particular year are difficult to detect. However, the sharply varying nature observed in the majority of profiles as well as the similarities between cores, suggests that the effects of these processes are limited. In general, the distribution profiles indicate good quality (and in some cases high resolution) records that document the history of nuclear weapons related contamination at several points along the Ob River and its major tributaries as well as the delta. It is also clear that concentration profiles can only be used to provide qualitative indicators of the presence of non-fallout contaminants. 


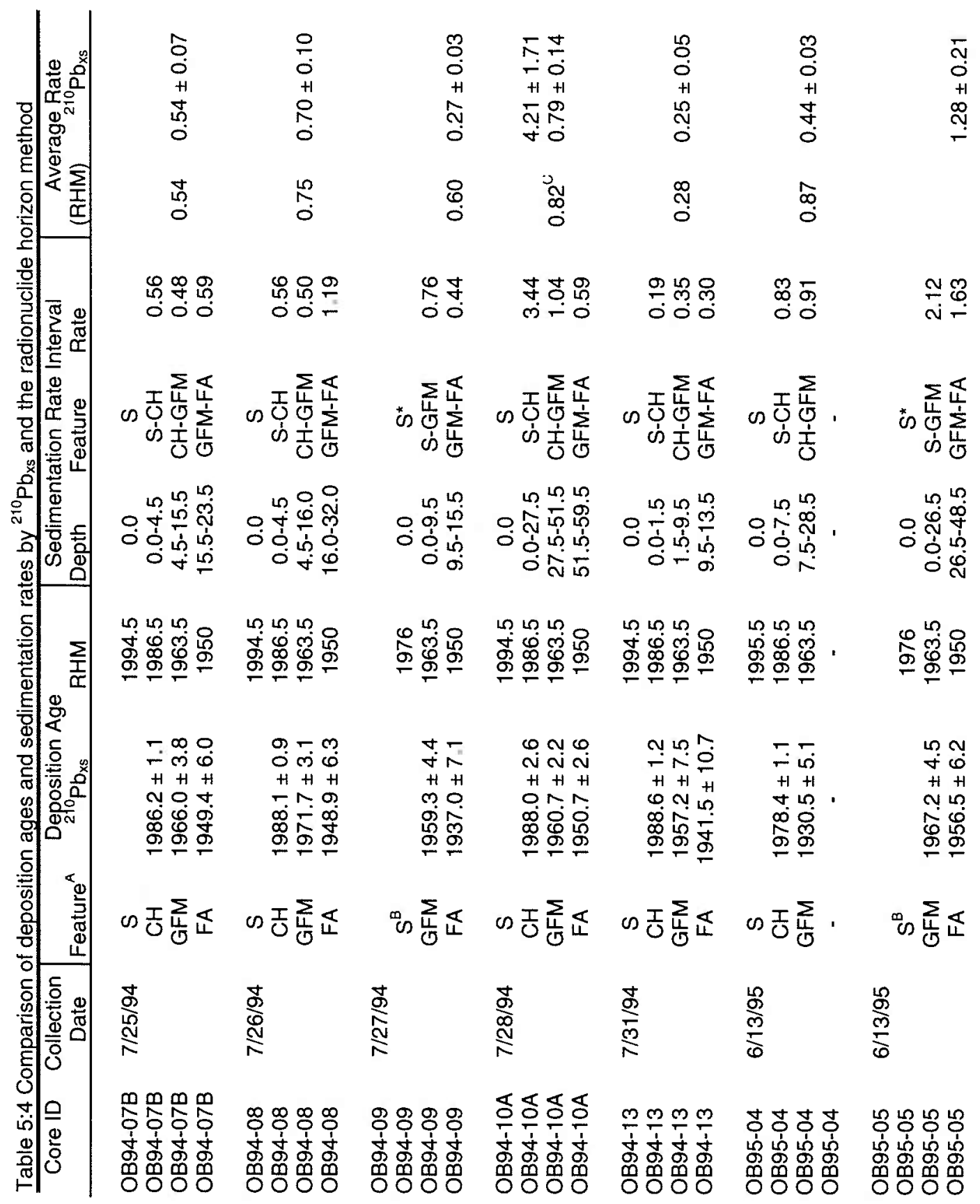




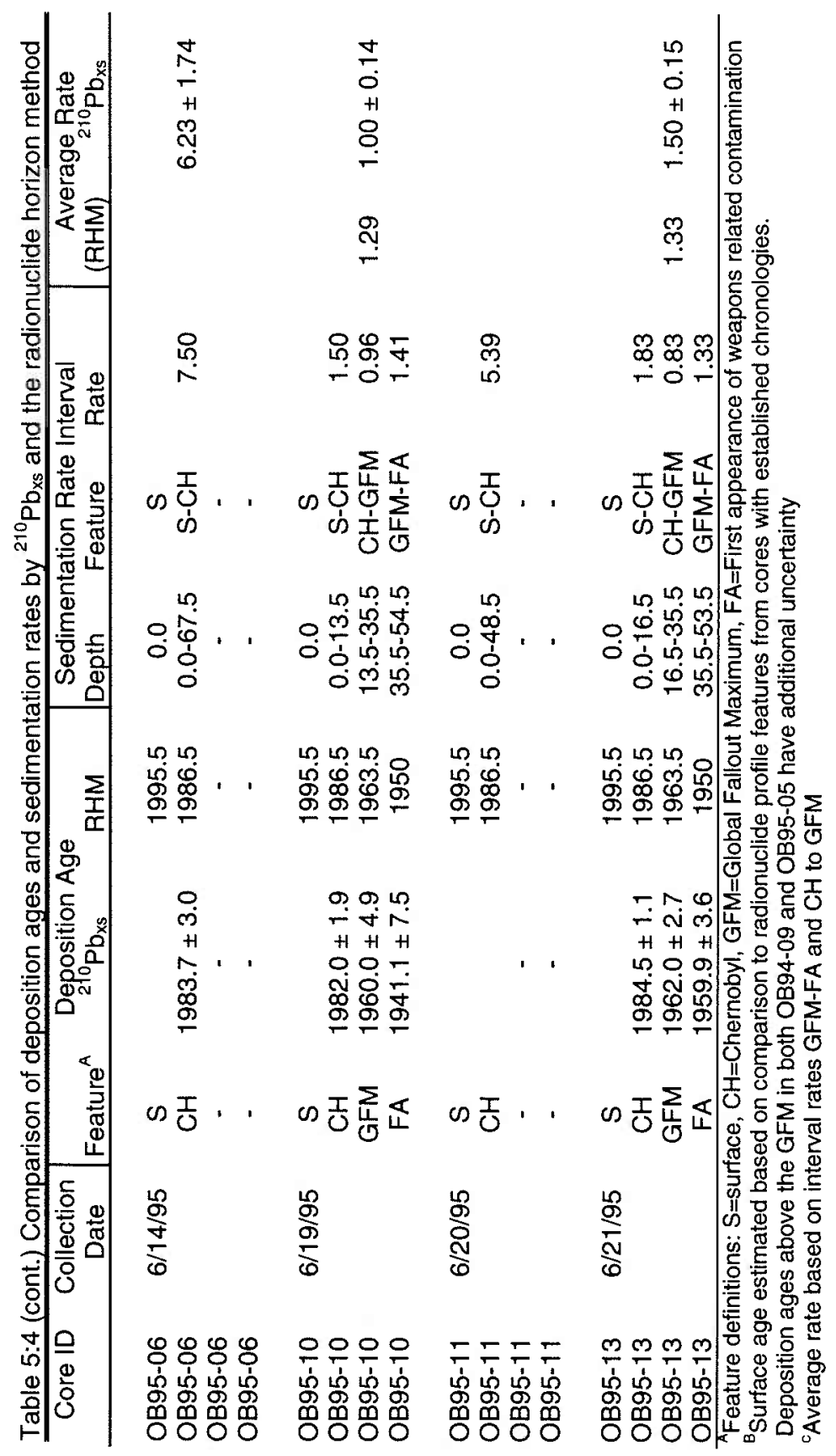


Time scales

Time scales based on sedimentation rates will be attached to down core contaminant records and discussed in the next chapter. Regarding time scale uncertainty, there are two important factors. First, the relationship between the sampling interval and sedimentation rate, to a large extent, controls the maximum time resolution that can be expected. As an example, the sedimentation rate estimated for OB94-13, which was sectioned at $1 \mathrm{~cm}$ intervals is $\sim 0.25 \mathrm{~cm} \mathrm{yr}^{-1}$, results in best possible resolution being $\sim 4$ years. Attaching the deposition age to the mid-depth of a core section in this example, results in a minimum uncertainty of \pm 2 years for events contained in different core sections. Due to the nature of annual flooding (i.e. 90 percent of sediments delivered in the spring and summer months), the time resolution that can be expected, even in cores with extremely high sedimentation rates is $\sim 1$ year, which imposes a minimum uncertainty of \pm 0.5 years. Second, it is important to note that constant sedimentation rates are assumed between radionuclide horizons. In cores demonstrating variability between intervals, the average rate calculated between horizons may not reflect the actual variability. Age uncertainties due to this factor are likely to be related to sample depth relative to the depth of the nearest dated horizon. The actual deposition age uncertainty will likely be a result of some combination of both of the factors discussed above and is likely to vary both within and between cores. A reasonable estimation of deposition age uncertainty is in the range of 1 to 4 years. 
References Chapter 5

Buesseler, K. O. and H. D. Livingston (2000). Natural and man-made radionuclides in the Black Sea: 199-217.

DOE (1982). Announced united states nuclear tests; July 1945 through December 1981. Nevada, DOE.

Edgington, D. N. and J. A. Robbins (1975). The behaviour of plutonium and other longlived radionuclides in Lake Michigan; II, Patterns of deposition in the sediments. Impacts of nuclear releases into the aquatic environment, Otaniemi, Finland.

Goldberg, E. (1963). Geochronology with Pb-210. Radioactive dating, IAEA: 121-131.

Jaakkola, T., K. Tolonen, et al. (1983). "The use of fallout (super 137) Cs and (super $239,240)$ Pu for dating of lake sediments. Paleolimnology; proceedings of the Third international symposium on paleolimnology." Third international symposium on paleolimnology 103: 15-19.

Koide, M., E. D. Goldberg, et al. (1977). "Transuranic depositional history in South Greenland firn layers." Nature (London) 269(5624): 137-139.

Koide, M., A. Soutar, et al. (1972). "Marine geochronology with (super 210) Pb." Contributions - University of California, San Diego, Scripps Institution of Oceanography 42, Part 2(14): 997-1001.

Krey, P. W., C. S. Klusek, et al. (1986). Radiochemical characterization of Chernobyl fallout in Europe. New York, Environmental Measurements Laboratory: 155-213.

Krishnaswami, S., D. Lal, et al. (1971). "Geochronology of lake sediments." Earth and Planetary Science Letters 11: 407-414.

Larsen, R. L. (1980). Worldwide deposition of Sr-90 through 1982. New York, Environmental Measurement Laboratory.

Livingston, H. D., K. O. Buesseler, et al. (1988). Characteristics of Chernobyl fallout in the southern Black Sea. Radionuclides; a tool for oceanography. Radionuclides; a tool for oceanography. Cherbourg, France: 204-216.

Machta, L., R. J. List, et al. (1956). "World-wide travel of atomic debris." $\underline{\text { Science } 124:}$ 474-477.

Miller, K. M. and M. Heit (1986). "A time resolution methodology for assessing the quaility of lake sediment cores that are dated by (super $137 £ C s . "$ Limnology and Oceanography 31(6): 1292-1300. 
Muramatsu, Y., W. Ruhm, et al. (2000). "Concentrations of Pu-239 and Pu-240 and their isotopic ratios determined by ICP-MS in soils collected from the Chernobyl 30km zone." Environmental Science \& Technology, ES \& T 34: 2913-2917.

Panteleyev, G. P. (1995). The history of plutonium and cesium-137 contamination of the Ob River delta sediments, Massachusetts Institute of Technology, Cambridge, MA, United States.

Sayles, F. L., T. C. Kenna, et al. (1998). Release and transport of artificial radionuclides from nuclear weapons related activities in the Ob River, Siberia ove the course of the nuclear age. International symposium on marine pollution, Monaco, LAEA.

Sayles, F. L., H. D. Livingston, et al. (1997). "The history and source of particulate (super 137) Cs and (super 239,240) Pu deposition in sediments of the Ob River delta, Siberia. Environmental radioactivity in the Arctic." Second symposium and international conference on Environmental radioactivity in the Arctic 202(1-3): $25-41$. 


\section{Chapter 6}

\section{Contaminant records}

In this chapter, isotopic ratios measured in core sections are combined with corresponding deposition age estimates, which results in the historical record of weapons related contamination at each of the sites sampled in the Ob River region. In order to relate isotopic information between cores, time scales established by the radionuclide horizon method are used. The contaminant records in sediments from the Ob River region contain both large and small deviations from the average isotopic composition of global fallout. While the small deviations are no doubt real, efforts have been focused on the large unambiguous variations observed in the suspected source tributaries that can be linked to contamination in the Ob Delta.

\section{Characterization of nuclear weapons related contamination}

To discern sources of observed weapons related materials, contaminant records in sediments are compared to published isotopic information for the various sources of contamination (for additional information, see Table 2:3). Depending on the location of the core, published values for the most likely source(s) are used to represent isotopic end members. For global fallout, the $\pm 2 \sigma$ range for average isotopic values is used (Kelley, Bond et al. 1998). For sediments thought to contain contamination originating from weapons production facilities (i.e. Mayak or Tomsk-7), isotopic ratios measured in core sections are compared to those reported for contaminated soils collected at Mayak 
(Beasley, Kelley et al. 1998; Oughton, Fifield et al. 2000). For sediments thought to contain contamination originating from Semipalitinsk, isotopic values are measured in core sections are compared to those reported for soils collected at both the main above ground test site and the Balapan test site (Shebell and Hutter 1996; Yamamoto, Tsukatani et al. 1996; Yamamoto, Tsumura et al. 1996; Beasley, Kelley et al. 1998; Yamamoto, Hoshi et al. 1999; Oughton, Fifield et al. 2000). In cases where contamination from both weapons production facilities and Semipalitinsk is possible (i.e. the Ob delta), all endmembers are shown. The contaminant records for sediment cores from the $\mathrm{Ob}$ region are presented below. For each record, horizontal lines indicating the selected radionuclide horizons are shown along with their corresponding depths (secondary y-axis ${ }^{137} \mathrm{Cs} /{ }^{240} \mathrm{Pu}$ record).

\section{Tobol River (OB95-10)}

Weapons related materials originating from Mayak are delivered to the Tobol River via the Techa and Iset Rivers. OB95-10 was collected from the Tobol River above its confluence with the Irtysh River. Environmental contamination is well documented at the Mayak facility and discussed in Chapter 2 (Bradley, 1997).

A comparison of the isotopic ratio profiles obtained from the Tobol River with global fallout values and ratios reported for contaminated soils collected near the Mayak facility is shown in Figure 6:1. The isotopic records indicate input of material that is quite different from global fallout between $\sim 1948$ and the early 1970 s. The ${ }^{240} \mathrm{Pu} /{ }^{239} \mathrm{Pu}$ ratios between 1948 and 1953 plot very closely to published values for sediments from 


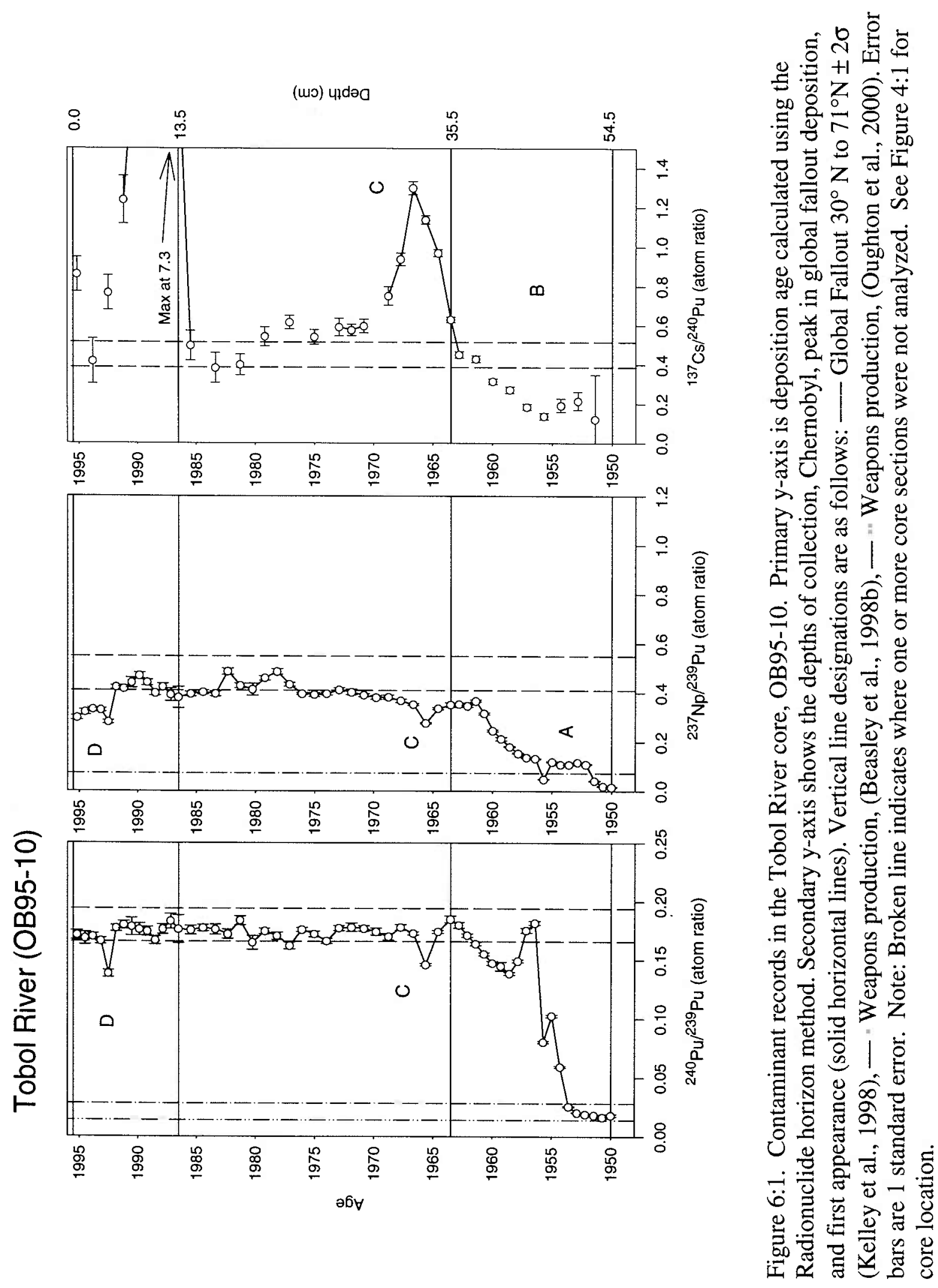


the Asanov swamp and are consistent with reports of waste disposal practices at Mayak between 1948 to 1951(Bradley and Payson 1997; Oughton, Fifield et al. 2000). It is interesting to note that the ${ }^{237} \mathrm{~Np} /{ }^{239} \mathrm{Pu}$ value published for soils contaminated by the 1957 tank explosion at Kyshtym (i.e. the - line) plots between isotopic ratios observed in sediments deposited between $\sim 1948$ and $\sim 1957$ (see A, middle panel). This suggests that the tank involved in the explosion may have contained a mixture of wastes dating from the beginning of operations at Mayak. Also noteworthy is the observation that while both the ${ }^{240} \mathrm{Pu} /{ }^{239} \mathrm{Pu}$ and ${ }^{237} \mathrm{~Np} /{ }^{239} \mathrm{Pu}$ signatures are clearly indicative of non-fallout contamination early in the record, the contaminated horizons do not contain similar ${ }^{137} \mathrm{Cs}$ enrichments (see B, right panel and Figure 5:1b), which is surprising as ${ }^{137} \mathrm{Cs}$ is known to have been a major component of waste releases at this time. This may suggest a differential mobility of $\mathrm{Cs}$ from that of $\mathrm{Pu}$ or $\mathrm{Np}$, which could be a result of differing chemical forms in various waste streams originating from Mayak during its early years of operation.

Although no published ${ }^{137} \mathrm{Cs} /{ }^{240} \mathrm{Pu}$ values are available for Mayak, the isotopic ratio varies considerably throughout the entire record, falling below global fallout between $\sim 1948$ and $\sim 1963$ and within or above global fallout thereafter with large maxima at $\sim 1967$ and 1986. The maximum observed in 1986 is associated with Chernobyl, and the majority of samples plot off scale ( $n=6$, maximum at 7.3; see Figure 5:7a for full scale plot). The timing of the peak $\sim 1967$ is consistent with the Lake Karachai wind transfer event, however, ${ }^{137} \mathrm{Cs} /{ }^{240} \mathrm{Pu}$ ratios elevated above global fallout appear as early as 1964 , which suggests that the event leading to the maximum may have 
occurred prior to 1967 . Both the ${ }^{240} \mathrm{Pu} /{ }^{239} \mathrm{Pu}$ and ${ }^{237} \mathrm{~Np} /{ }^{239} \mathrm{Pu}$ profiles show a decrease towards the weapons end members $\sim 1965$, which is $\sim$ two years earlier than the ${ }^{137} \mathrm{Cs} /{ }^{240} \mathrm{Pu}$ maximum, suggesting perhaps that two different events may have lead to these features (see note $\mathrm{C}$, all three panels).

After the mid-1960s, the ${ }^{240} \mathrm{Pu} /{ }^{239} \mathrm{Pu}$ record indicates that input of material is not significantly different than global fallout, except for a brief (single sample) period of low ratios in the early 1990s. The ${ }^{237} \mathrm{~Np} /{ }^{239} \mathrm{Pu}$ record continues to show evidence of nonfallout contamination until the early to mid 1970 s. The ${ }^{237} \mathrm{~Np} /{ }^{239} \mathrm{Pu}$ profile also shows a period of ratios that are below global fallout beginning in the early 1990s.

Unlike the ${ }^{240} \mathrm{Pu} /{ }^{239} \mathrm{Pu}$ record, the ${ }^{237} \mathrm{~Np} /{ }^{239} \mathrm{Pu}$ record indicates that non-fallout material is supplied to this location until the date of core collection (mid-1995) (see note $\mathrm{D}$, left and middle panel).

The contaminant records from the Tobol River have several implications with regards to contamination originating from the Mayak facility. 1) Contamination resulting from the early waste disposal practices at Mayak has been transported at least as far as the Tobol/Irtysh confluence. 2) Up until 1995, at least, dam construction efforts (completed in 1964) have been largely successful in containing wastes produced at Mayak; this is evidenced by the dominance of global fallout after the mid-1960s. Nonfallout contamination was delivered to this location in the early 1990s, indicating the potential for future contamination near the $\mathrm{Ob} / \mathrm{Irtysh}$ confluence resulting from activities at Mayak. There is some isotopic evidence supporting the presence of material from the 1967 Lake Karachai wind-event. 
Irtysh River (OB95-13)

A comparison of the isotopic ratio profiles obtained from OB95-13 to published information characterizing global fallout and values reported for soils collected at the Semipalitinsk test site is shown in Figure 6:2. OB95-13 was collected from the Irtysh River above its confluence with the Tobol River. Any weapons materials originating from drainage of the Semipalitinsk test site or nearby regions contaminated by close-in fallout may be transported to this location via the upper reaches of the Irtysh River. The ${ }^{240} \mathrm{Pu} /{ }^{239} \mathrm{Pu}$ isotopic ratio record obtained from the upper Irtysh River is quite variable indicating input of material with an isotopic composition that is different from global fallout at various times between 1950 and 1995 . The $\operatorname{low}^{240} \mathrm{Pu} /{ }^{239} \mathrm{Pu}$ ratios in the early 1950 s that plot close to the reported value of soils from Semipalitinsk are consistent with contamination from early above ground weapons tests (see A, left panel). With the exception of 2 points $\sim 1955$, the majority of ${ }^{240} \mathrm{Pu} /{ }^{239} \mathrm{Pu}$ ratios are consistent with a mixture of global fallout and 10 to $20 \%$ materials observed at Semipalitinsk. Much larger fractions are required to accommodate the isotopic ratios in sediments deposited in the early 1950 s and $1987, \sim 100$ and $66 \%$, respectively. It is surprising that a sharp increase in the fraction of non-fallout contamination is observed 20 years after the ban on aboveground testing (see B, left panel). The suspended sediment discharge estimates for the Irtysh above its confluence with the Ob River reach a maximum during 1986 to 1987 , which supports the remobilization of previously contaminated sediments (see Figure 3:6). Additionally, other information suggests that there was an increase in underground 


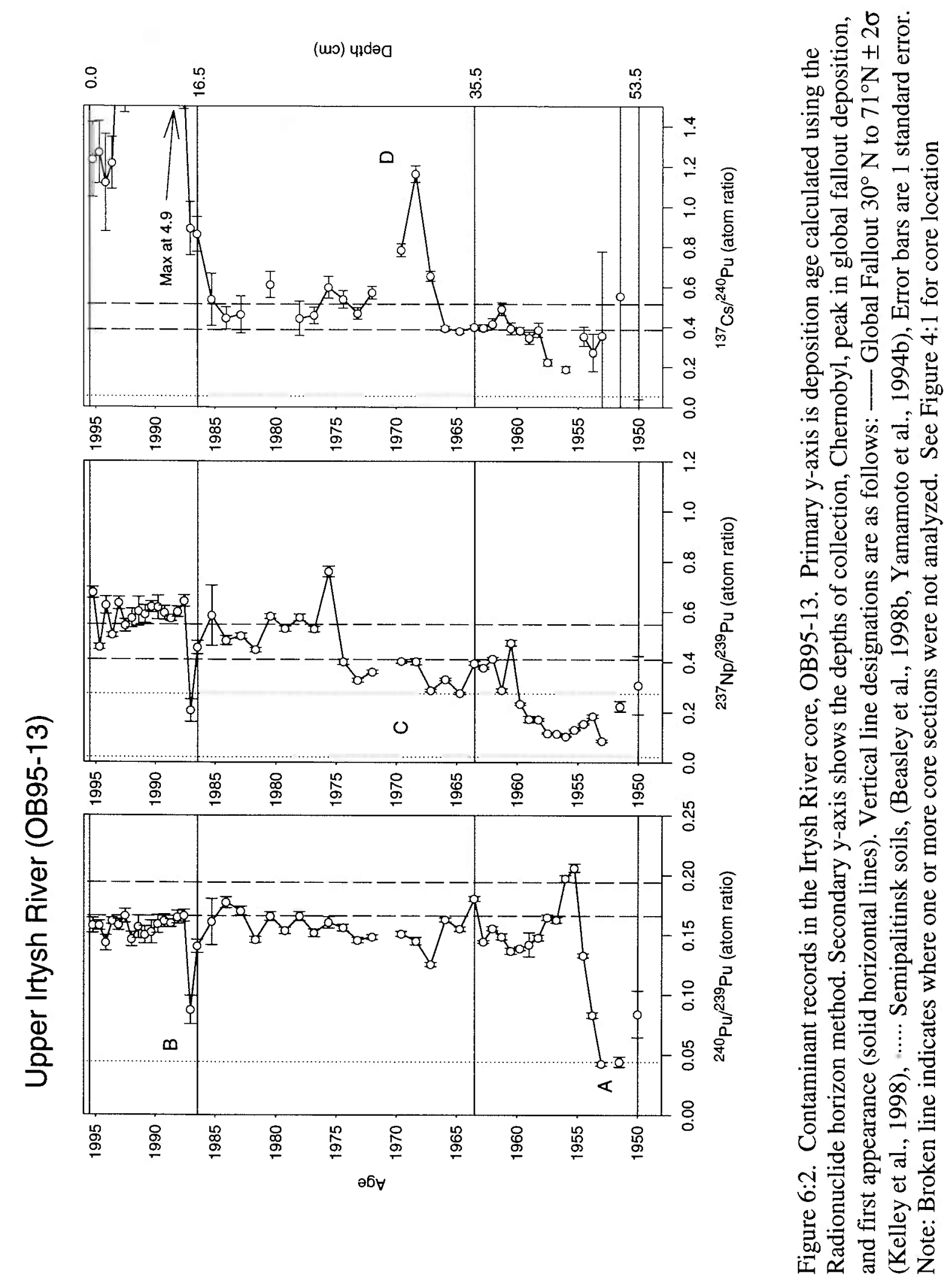


testing between 1983 and 1985, making contaminant releases from these activities are another potential source(Bradley and Payson 1997).

The ${ }^{237} \mathrm{~Np} /{ }^{239} \mathrm{Pu}$ record obtained from OB95-13 is also quite variable and exhibits substantial departures from global fallout. In general, a trend is observed from values that are lower than global fallout in the early portion of the record (1953 to 1960). The low (below global fallout) ${ }^{237} \mathrm{~Np} /{ }^{239} \mathrm{Pu}$ ratios observed in sediments deposited between 1965 and 1974 are consistent with material observed at Balapan (site of the Chagan Lake cratering explosion), suggesting that some of this material may be present in sediments from the upper Irtysh River (see C, middle panel). Values that are higher than global fallout are observed in sediments deposited after $\sim 1975$. Lower than global fallout ${ }^{237} \mathrm{~Np} /{ }^{239} \mathrm{Pu}$ ratios are consistent with input from Semipalitinsk; however, isotopic ratios that are higher than the reported average global fallout value are not consistent with the reported isotopic composition in any of the soils collected at Semipalitinsk. Kelley et al. (1998) attributes variability in the relative abundances of $\mathrm{Np}$ and $\mathrm{Pu}$ in global fallout to differences in the types of weapons tested. It is reasonable to expect similar devicerelated variability as a result of different types of weapons tested at Semipalitinsk between 1949 and 1991. To a certain extent, this variability is demonstrated by the different ${ }^{237} \mathrm{~Np} /{ }^{239} \mathrm{Pu}$ values observed at the first experimental test site and Balapan. The trend from low values early to high values later in the record also suggests that contamination observed after the mid-1970s did not originate from early above ground tests. This further supports the idea that some of the contamination observed in the 
vicinity of the Irtysh/Tobol confluence is derived from underground tests conducted at Semipalitinsk.

The ${ }^{137} \mathrm{Cs} /{ }^{240} \mathrm{Pu}$ ratios in $\mathrm{OB} 95-13$ are also quite variable, falling quite close to global fallout prior to 1955, below global fallout between $\sim 1955$ and $\sim 1957$, and at or significantly above global fallout thereafter. The large maximum $\sim 1967$, is similar to that observed in OB95-10 with respect to both ratio and timing (see D, right panel). It is different however in that it is more sharply defined. Thus, it may be due to a different event such as the Chagan Lake explosion in early 1965, which reportedly distributed large amounts of debris to the surrounding area. Resolving the timing of two events occurring so close in time that may have distributed non-fallout contamination in the vicinity of both sampling sites is not possible (i.e. Chagan Lake in 1965 and Lake Karachai in 1967).

Other similarities between the records from the Tobol and upper Irtysh rivers occur $\sim 1955$ and can be characterized by ${ }^{240} \mathrm{Pu} /{ }^{239} \mathrm{Pu}$ ratios at or above global fallout, but both ${ }^{237} \mathrm{~Np} /{ }^{239} \mathrm{Pu}$ and ${ }^{137} \mathrm{Cs} /{ }^{240} \mathrm{Pu}$ well below global fallout. It seems very unlikely that the similarity of these two records with such strong signals is a coincidence. At this point, the origin of this similarity can not be determined. It is noteworthy that later in the record, the $\mathrm{Np}$ and $\mathrm{Pu}$ isotopic ratios of the two rivers clearly diverge.

The contaminant records obtained from the upper Irtysh River indicate that materials originating from weapons tests at Semipalitinsk have been a continued, if intermittent, source of non-fallout contamination in the vicinity of the Irtysh/Tobol confluence. The data suggest that, in addition to above ground tests, later underground 
tests may also have been a source of contamination. Similarities observed between contaminant records from the Tobol and Irtysh Rivers suggest the possibility of some common sources of contamination in the early portions of both records, but with the disappearance of these very strong signals, the records appear to reflect largely different non-fallout components.

\section{Lower Irtysh River (OB95-06)}

The contaminant records obtained from OB95-06 is shown in Figure 6:3. Although the time period is limited, this record is important in that it allows the assessment of the relative contributions of contaminants originating from the Tobol and upper Irtysh Rivers (i.e. Mayak, and Semipalitinsk, respectively). Compared to cores from these rivers, the contaminant records contained in OB95-06 are more similar to the records obtained from the Tobol rather than the upper Irtysh River. The ${ }^{137} \mathrm{Cs} /{ }^{240} \mathrm{Pu}$ ratios in OB95-06 associated with Chernobyl are similar to records from both rivers in that the majority of samples plot off scale $(n=33$, maximum at 4.3$)$. There are however, some differences between the record obtained in OB95-06 and those from upstream locations. The elevated ${ }^{240} \mathrm{Pu} /{ }^{239} \mathrm{Pu}$ ratios present in OB95-06 1992 are not seen in either the Tobol or upper Irtysh River (see A, left panel). While elevated ${ }^{240} \mathrm{Pu} /{ }^{239} \mathrm{Pu}$ ratios suggest that the source may be Chernobyl, the identification is uncertain due to the arrival of this material $\sim 5$ years after ${ }^{137} \mathrm{Cs}$ from Chernobyl. The difference in timing and lack of elevated ${ }^{240} \mathrm{Pu} /{ }^{239} \mathrm{Pu}$ ratios associated with Chernobyl contaminated horizons at upstream 

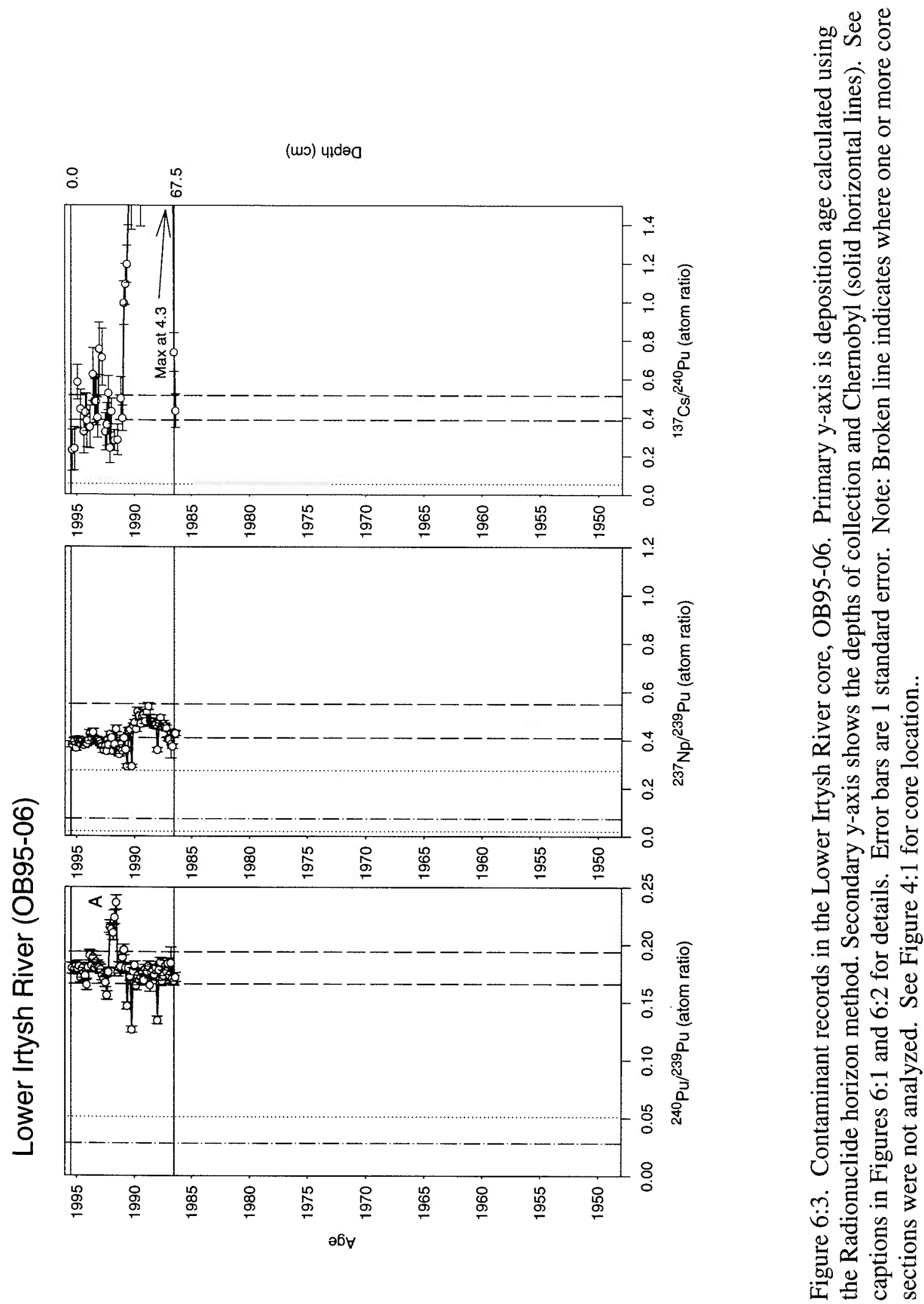
locations suggest that contamination from an additional, and as yet unidentified, source has been delivered to the vicinity of the Irtysh/Ob confluence.

\section{Upper Ob River (OB95-04 and 05)}

A comparison of the isotopic ratio records obtained from OB95-04 and OB95-05 to published information characterizing weapons related contamination is shown in Figure 6:4a and $\mathrm{b}$. Both cores were collected from the Ob River above its confluence with the Irtysh River. The isotopic records from both cores are substantially different from global fallout for most of the time between 1950 and 1995, clearly indicating the presence of weapons materials originating from Tomsk-7 that are transported to this location via the upper reaches of the Ob River.

The ${ }^{240} \mathrm{Pu} /{ }^{239} \mathrm{Pu}$ record indicates a significant fraction of non-fallout $\mathrm{Pu}$ throughout the entire record of both cores. Estimates using available end member values indicate that between 35 to 40 - percent of the plutonium is non-fallout in origin. The transition from high to low ${ }^{240} \mathrm{Pu} /{ }^{239} \mathrm{Pu}$ ratios $\sim 1955$ is consistent with the beginning of reactor operations at Tomsk 7. Although the dating in OB95-05 is somewhat uncertain

above 1963.5 , the ${ }^{240} \mathrm{Pu} /{ }^{239} \mathrm{Pu}$ ratios, on average, in this core are higher than those observed in OB95-04, likely indicating either a larger fraction of sediments contaminated as a result of global fallout or relatively less contamination from Tomsk-7.

${ }^{237} \mathrm{~Np} /{ }^{239} \mathrm{Pu}$ ratios are also significantly different from global fallout over much of the records in both cores. Low values consistent with weapons production dominate from $\sim 1955$ to $\sim 1975$, and values that are significantly higher than global fallout between 1975 


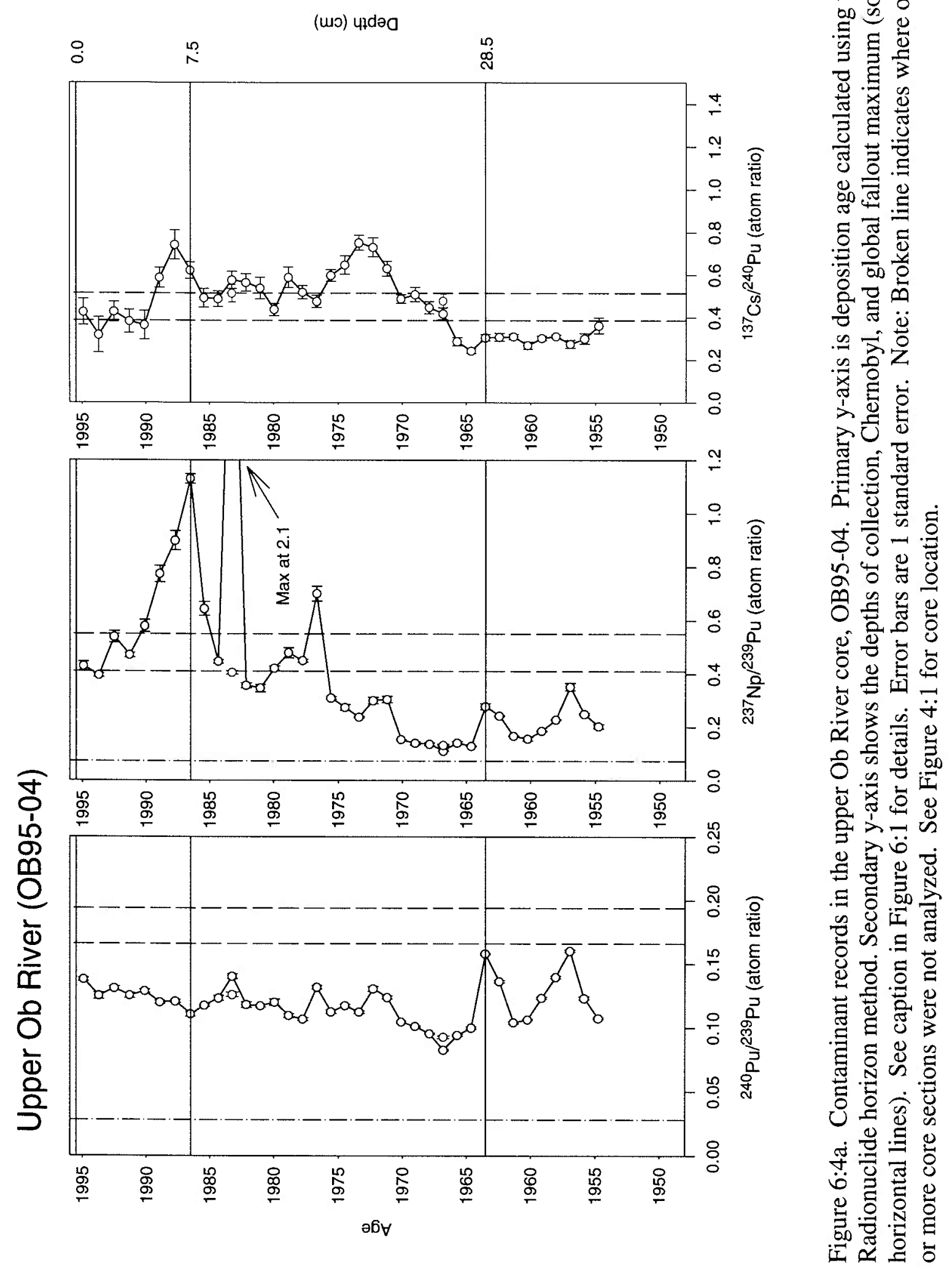




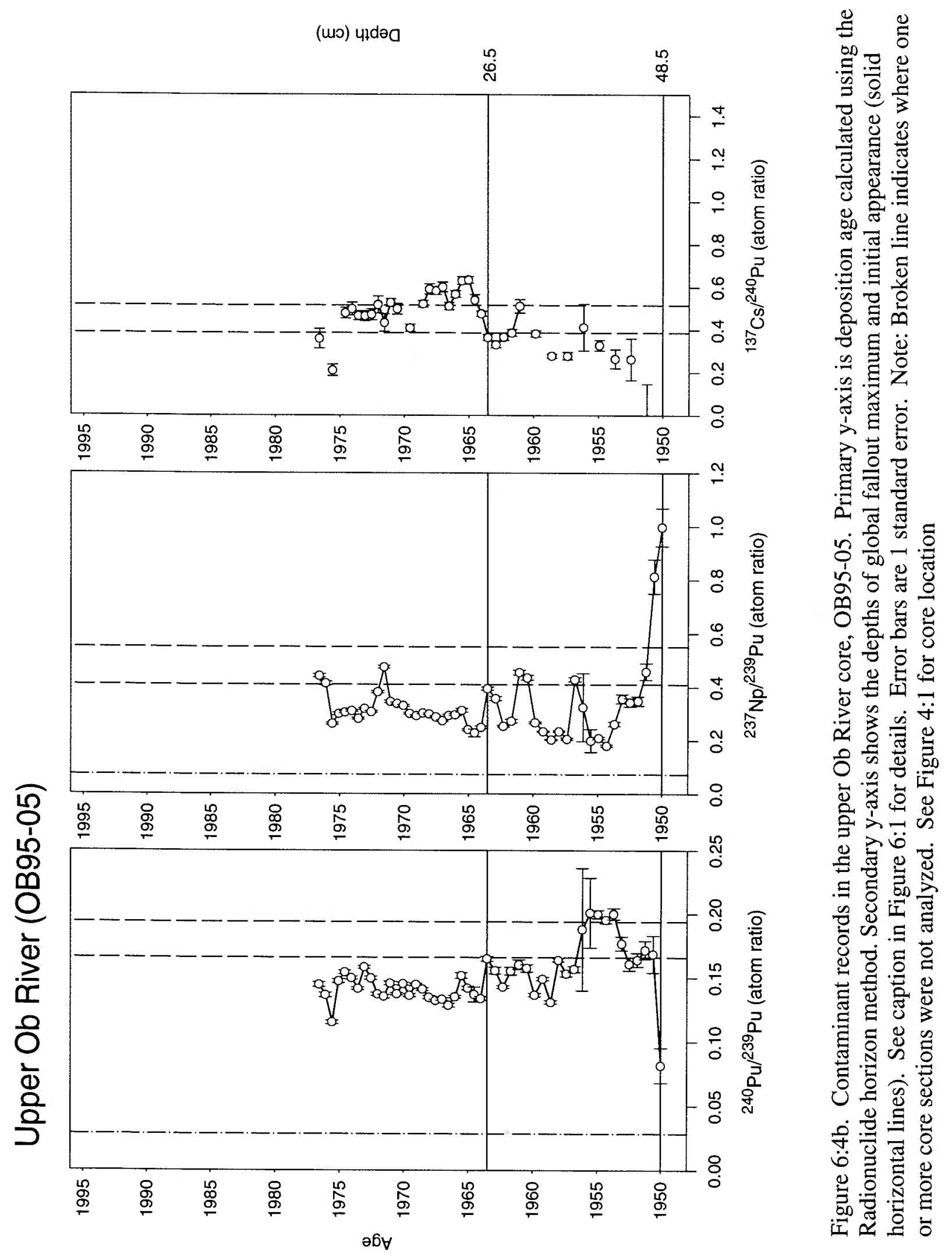


and the early 1990s with large maxima 1982 and 1986 in OB95-04. The elevated ${ }^{237} \mathrm{~Np} /{ }^{239} \mathrm{Pu}$ ratios $\sim 1950(\mathrm{OB} 95-05)$ are not consistent with any known weapons related activities in the upper $\mathrm{Ob}$ River. This may be an indication of ${ }^{237} \mathrm{~Np}$ variability in early global fallout or perhaps contamination from close-in fallout as a result of early tests at Semipalitinsk. The lack of elevated ratios in the Irtysh River (OB95-13) during this period suggests the former rather than the latter as the more likely explanation.

The timing of elevated ${ }^{237} \mathrm{~Np} /{ }^{239} \mathrm{Pu}$ ratios $\sim 1976$ in $\mathrm{OB} 95-04$ is consistent with the arrival of irradiated fuels from Mayak, which may have resulted in a change in the isotopic composition of the waste-stream originating from Tomsk-7. The ${ }^{237} \mathrm{~Np} /{ }^{239} \mathrm{Pu}$ maximum that is closest to the surface has an arrival time that is quite similar to that of Chernobyl and seems to suggest that it too may be related to the accident. This is not the case however, based on the lack of ${ }^{237} \mathrm{~Np}$ increases in contaminant records from other locations with more substantial amounts of Chernobyl material (e.g. Tobol and upper and lower Irtysh). That these features are two separate events in time is further supported by the observation that ${ }^{237} \mathrm{~Np} /{ }^{239} \mathrm{Pu}$ ratios begin to rise and reach a maximum $1-2$ years before the arrival of Chernobyl material. Additionally, replicate analyses indicates that elevated levels of ${ }^{237} \mathrm{~Np}$ (a factor of 2 higher) were present as early as $\sim 1983$.

The ${ }^{137} \mathrm{Cs} /{ }^{240} \mathrm{Pu}$ records in both cores are also quite variable. Values generally are below global fallout prior to 1970 and at or above global fallout thereafter. The profile in OB95-04 shows two maxima. The first maximum $\sim 1973$ has not been associated with any known contamination event. Noteworthy is the fact this feature does not appear in 
OB95-05. The second maximum 1988 in OB95-04, which has been discussed in Chapter 5, is most likely a result of Chernobyl.

The observation of non-fallout ratios in these cores throughout the sedimentary record indicates that material originating in the upper $\mathrm{Ob}$, presumably from Tomsk-7, continues to be a source of contamination in the vicinity of the Ob-Irtysh confluence. The different isotopic compositions observed between OB95-04 and OB95-05 indicates that the levels of contamination derived from Tomsk-7 vary between sample locations.

\section{Ob delta cores}

As previously mentioned, non-fallout materials have been identified in the $\mathrm{Ob}$ delta (Sayles, Kenna et al. 1998). The potential source(s) of contamination can be evaluated by comparing the contaminant records obtained from the Tobol, Irtysh, and upper $\mathrm{Ob}$ Rivers to the records obtained from sediment cores collected in the Ob delta. For comparison, each of the three different isotope ratio profiles obtained from delta cores will be shown together. The ${ }^{240} \mathrm{Pu} /{ }^{239} \mathrm{Pu}$ contaminant records obtained from OB9407B, 10A, 09, and 08 are shown in Figure 6:5a and $\mathrm{b}$.

In general, the ${ }^{240} \mathrm{Pu} /{ }^{239} \mathrm{Pu}$ ratios indicate a dominance of global fallout in all four cores, with distinct (i.e. single sample) departures towards non-fallout values that are consistent with input from either weapons facilities or Semipalitinsk (i.e. the ${ }^{240} \mathrm{Pu} /{ }^{239} \mathrm{Pu}$ departures from global fallout $\sim 1965, \sim 1975$, and $\sim 1993$ ). Similar departures towards non-fallout end-members or consistently low ratios are observed in each of the three suspected source tributaries $\sim 1965$, suggesting that any or all of the local sources may be 

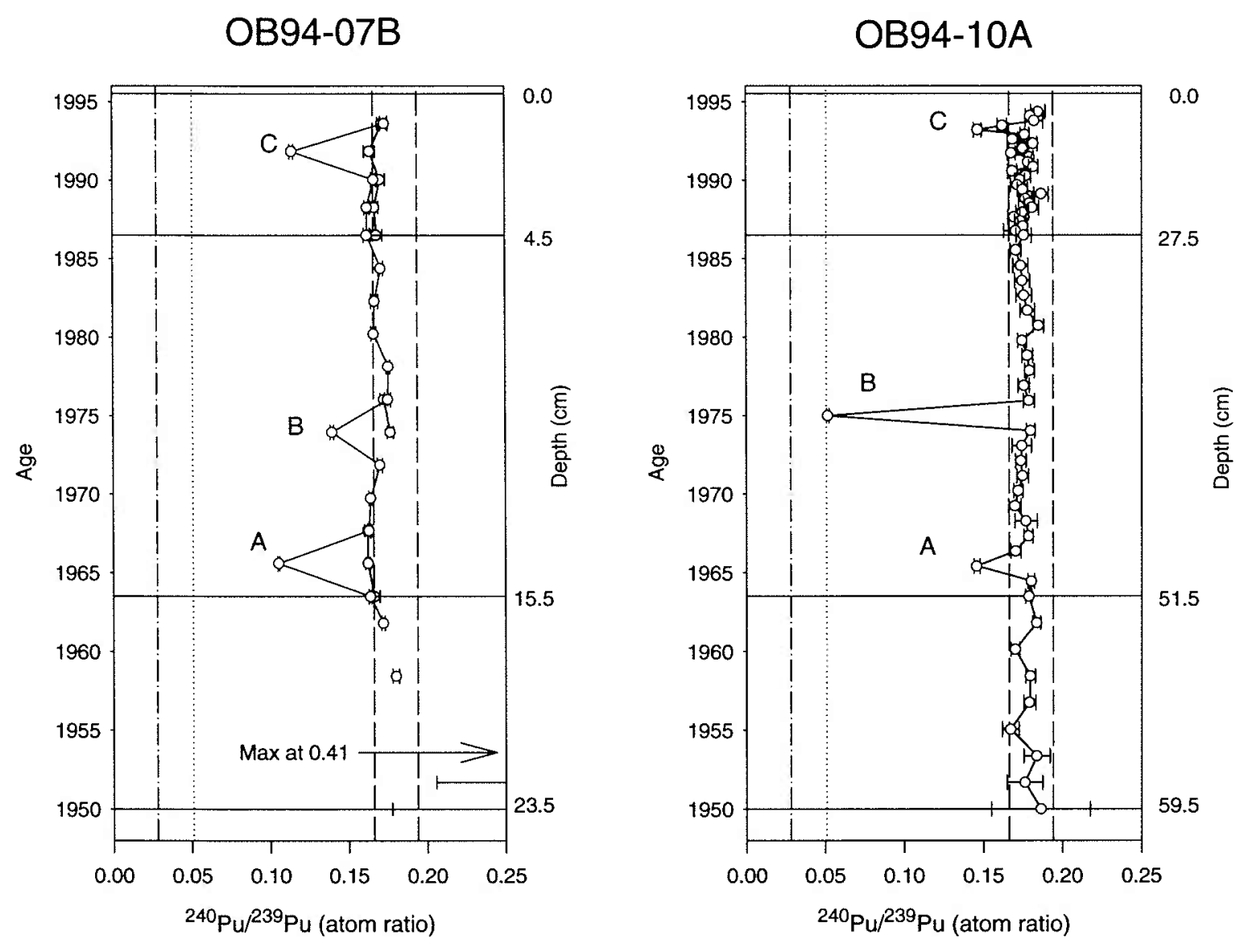

Figure 6:5a. ${ }^{240} \mathrm{Pu} /{ }^{239} \mathrm{Pu}$ records in Ob delta cores, OB94-07B and OB94-10A (left to right). Primary $y$-axis is deposition age calculated using the Radionuclide horizon method. Secondary y-axis shows the depths of collection, Chernobyl, the global fallout maximum and initial appearance (solid horizontal lines). See captions in Figure 6:1 and 6:2 for details. Error bars are 1 standard error. Note: Broken line indicates where one or more core sections were not analyzed. See Figure 4:1 for core location 
OB94-09

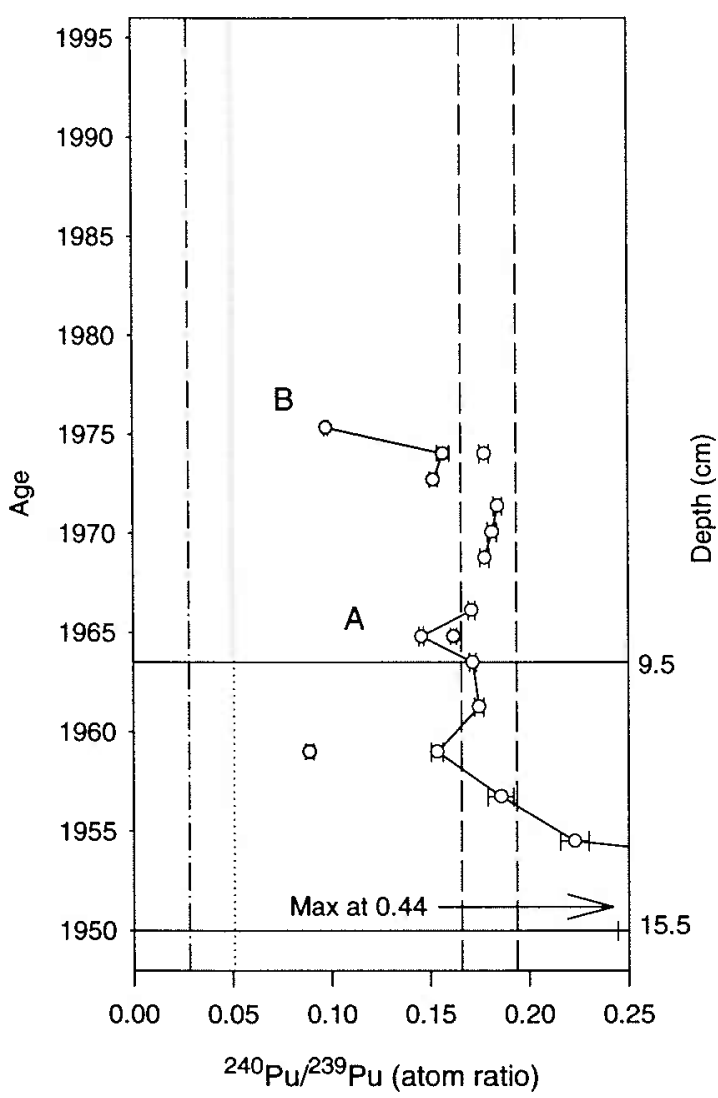

OB94-08

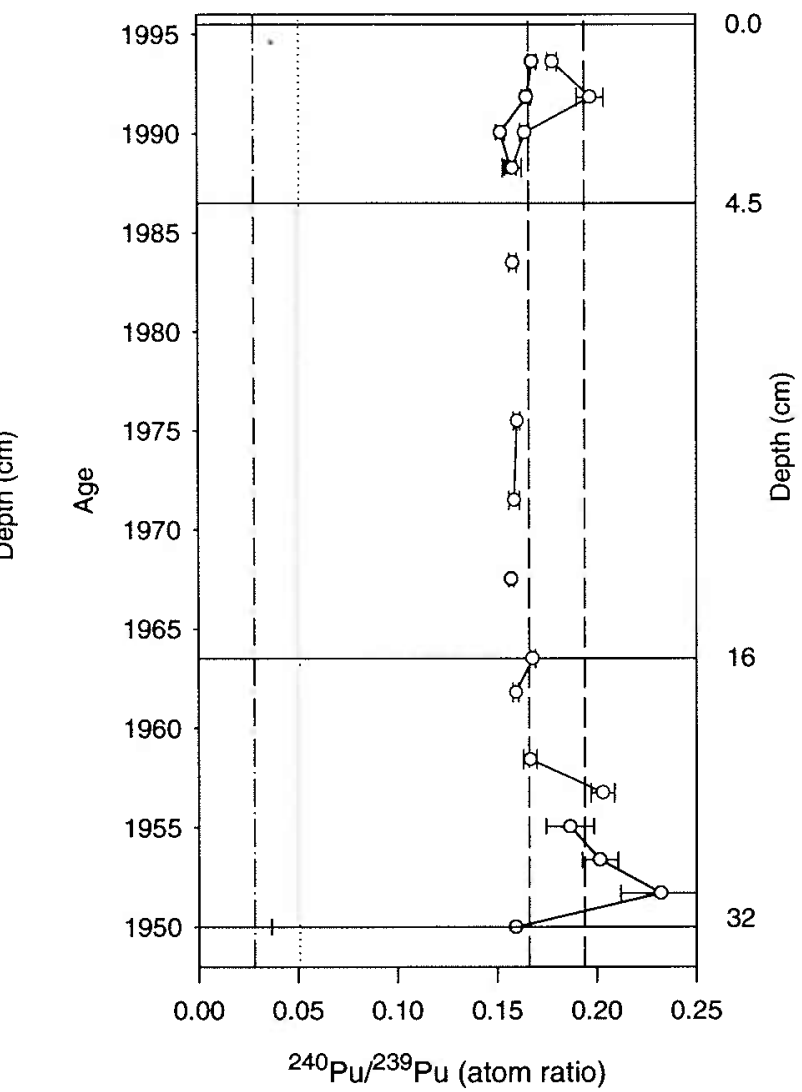

Figure 6:5b. ${ }^{240} \mathrm{Pu} /{ }^{239} \mathrm{Pu}$ records in Ob delta cores, OB94-09 and OB94-08 (left to right). Primary $\mathrm{y}$-axis is deposition age calculated using the Radionuclide horizon method. Secondary y-axis shows the depths of collection, Chernobyl, the global fallout maximum and initial appearance (solid horizontal lines). See captions in Figure 6:1 and 6:2 for details. Error bars are 1 standard error. Note: Broken line indicates where one or more core sections were not analyzed. See Figure 4:1 for core locations. 
responsible (see $\mathrm{A}, 07 \mathrm{~B}, 10 \mathrm{~A}, 09$ ). It is interesting that a large departure corresponding to very low ratios in the $\mathrm{Ob}$ delta $~ 1975$ (three out of four cores) is not observed in any of the suspected source tributaries (see B, 07B, 10A, 09). Although replicate analyses have shown that plutonium is not always homogeneously distributed within the sediments, the consistency with respect to the timing of the departures suggests that the low ${ }^{240} \mathrm{Pu} /{ }^{239} \mathrm{Pu}$ are event-related (hydrologic) rather than coincidental. Two cores also show low ratios in the mid-1990s, indicating the continued presence of non-fallout contamination in the delta (see C, O7B and 10A). The remaining samples generally fall at or just below the $2 \sigma$ value of global fallout, indicating a small but chronic input of non-fallout Pu. It is also noteworthy that three out of the four cores exhibit elevated ${ }^{240} \mathrm{Pu} /{ }^{239} \mathrm{Pu}$ values in the early to mid-1950s. The appearance of high ratios around this time is consistent with premoratorium ${ }^{240} \mathrm{Pu} /{ }^{239} \mathrm{Pu}$ values and data available for stratospheric material collected in 1952 and 1954 , which exhibited ${ }^{240} \mathrm{Pu} /{ }^{239} \mathrm{Pu}$ ratios of .27 and .36 , respectively (Diamond, Fields et al. 1961; Krey, Hardy et al. 1976).

The ${ }^{237} \mathrm{~Np} /{ }^{239} \mathrm{Pu}$ records from OB94-07B, 10A, 09, and 08 are shown in figure 6:6a and $\mathrm{b}$. The most prominent feature is the records in OB94-07B and 10A from 1984 to 1994 . There is clear input of ${ }^{237} \mathrm{~Np}$-enriched material to both core locations, which reaches a maximum in both cores $\sim 1987$. Of the three suspected source tributaries, the ${ }^{237} \mathrm{~Np} /{ }^{239} \mathrm{Pu}$ record obtained in sediments from the upper Ob River (i.e. OB95-04) is the only one that exhibits similar isotopic variations. This strongly suggests Tomsk-7 as the source of the elevated levels of ${ }^{237} \mathrm{~Np}$ in the delta after $\sim 1986$. The records prior to 1955 for OB94-07B, 09, and 08 show ratios that are significantly higher than global fallout. 

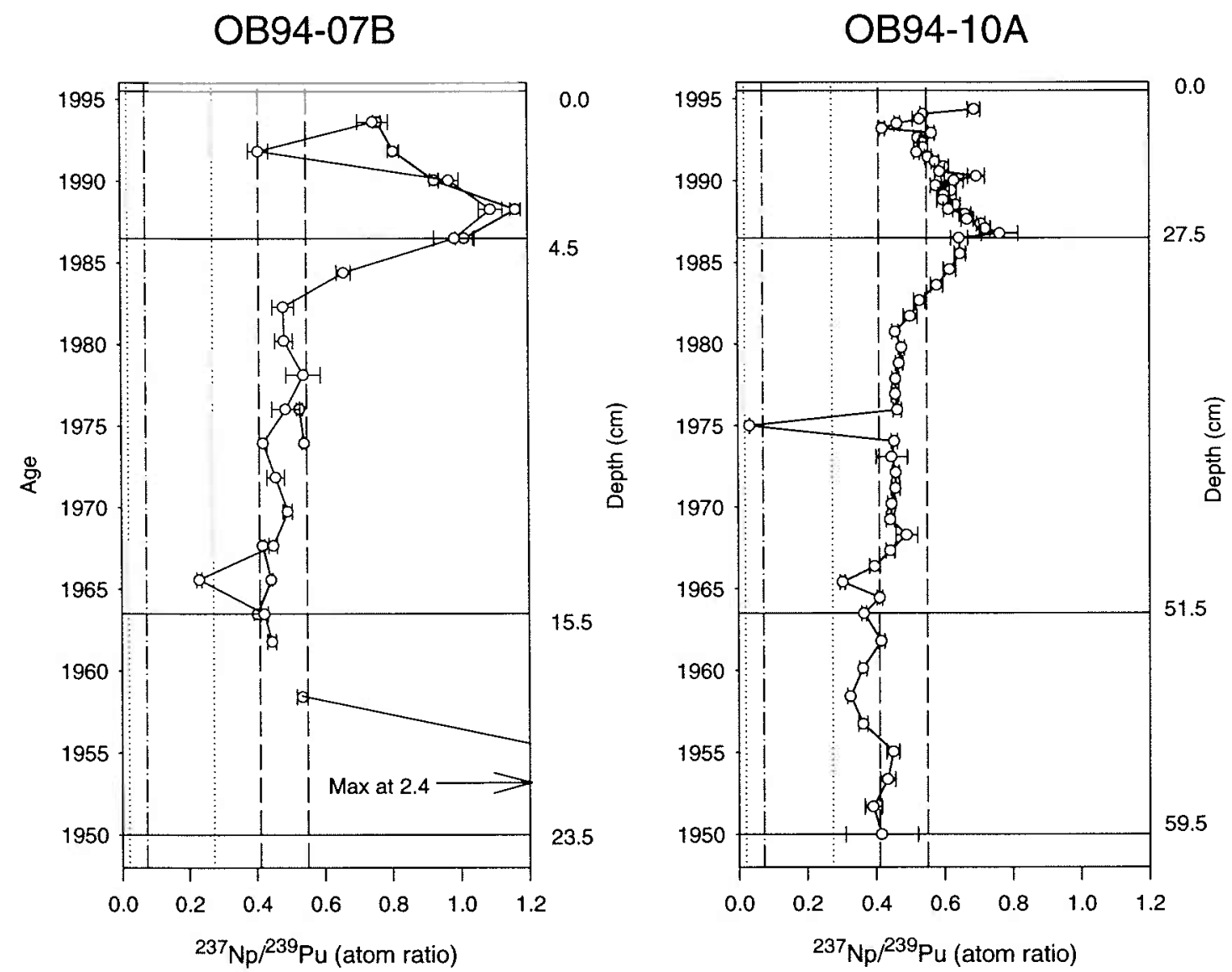

Figure 6:6a. ${ }^{237} \mathrm{~Np} /{ }^{239} \mathrm{Pu}$ records in Ob delta cores, OB94-07B and OB94-10A (left to right). Primary y-axis is deposition age calculated using the Radionuclide horizon method. Secondary $y$-axis shows the depths of collection, Chernobyl, the global fallout maximum and initial appearance (solid horizontal lines). See captions in Figure 6:1 and 6:2 for details. Error bars are 1 standard error. Note: Broken line indicates where one or more core sections were not analyzed. See Figure 4:1 for core location 

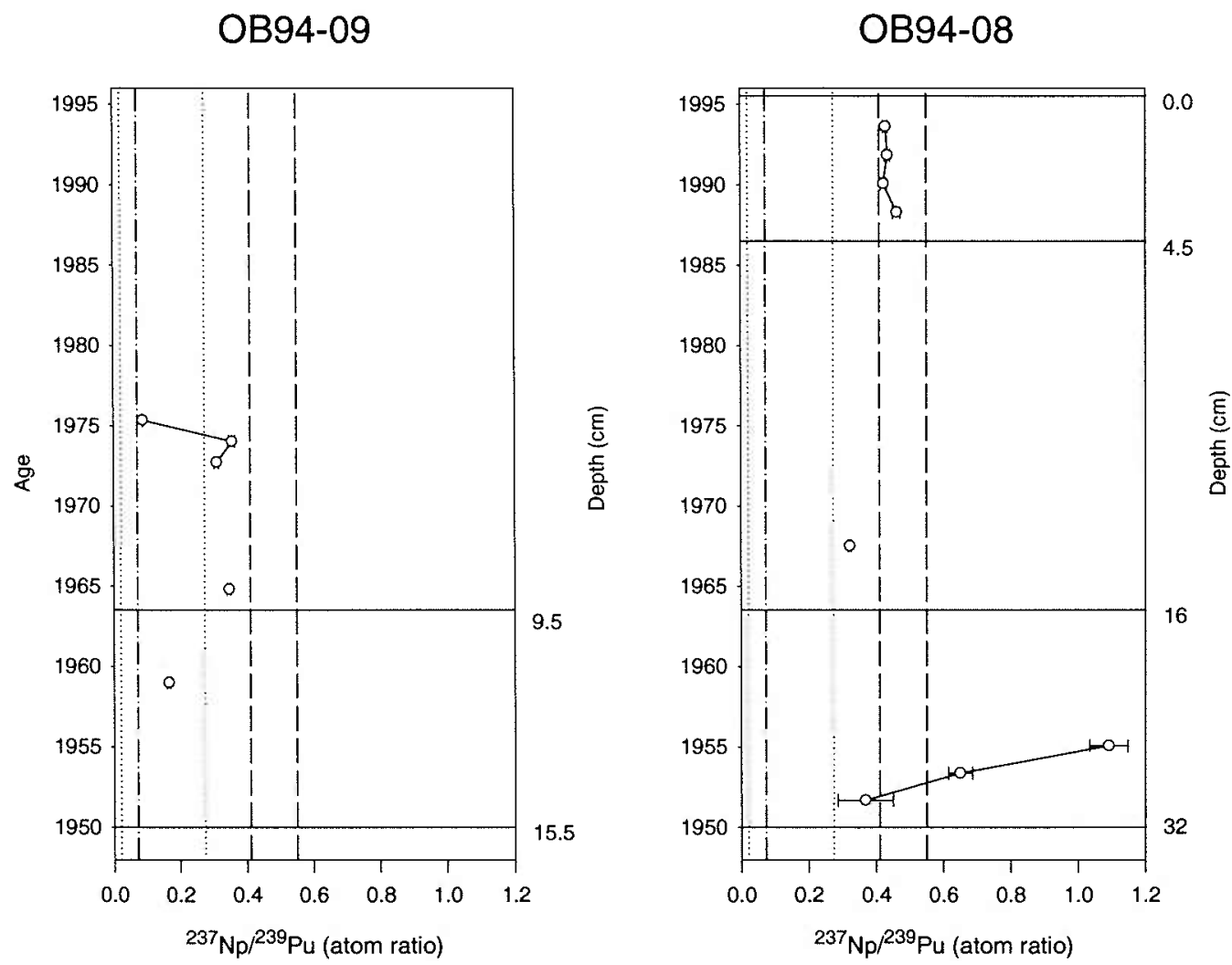

Figure 6:6b. ${ }^{237} \mathrm{~Np} /{ }^{239} \mathrm{Pu}$ records in Ob delta cores, OB94-09 and OB94-08 (left to right). Primary $\mathrm{y}$-axis is deposition age calculated using the Radionuclide horizon method. Secondary $y$-axis shows the depths of collection, Chernobyl, the global fallout maximum and initial appearance (solid horizontal lines). See captions in Figure 6:1 and 6:2 for details. Error bars are 1 standard error. Note: Broken line indicates where one or more core sections were not analyzed. See Figure 4:1 for core location 
The highest value observed in any of the suspected source tributaries for this time period is $\sim 1$, which is in the upper $\mathrm{Ob}$ prior to the beginning of weapons related activities. Although no ${ }^{237} \mathrm{~Np} /{ }^{239} \mathrm{Pu}$ data are available for the stratospheric samples mentioned above, they do coincide with the elevated ${ }^{240} \mathrm{Pu} /{ }^{239} \mathrm{Pu}$ values, suggesting that ${ }^{237} \mathrm{~Np}$ in this material may have been elevated as well. Elevated values do not appear in the record obtained for OB94-10A, demonstrating perhaps variable deposition of this material or the dominance of lower ratio material that is present in both the Irtysh and Tobol Rivers during this period. From $\sim 1960$ to $\sim 1980$, the ${ }^{237} \mathrm{~Np} /{ }^{239} \mathrm{Pu}$ records indicate mostly fallout values with a few departures towards non-fallout end members. The departures in OB9409 and OB94-10A ( 1975) are quite large, indicating significant amounts of non-fallout contamination in these samples. Low ${ }^{237} \mathrm{~Np} /{ }^{239} \mathrm{Pu}$ ratios in these samples are likely a result of increased ${ }^{239} \mathrm{Pu}$ concentrations rather than decreased ${ }^{237} \mathrm{~Np}$, which is supported by very low ${ }^{240} \mathrm{Pu} /{ }^{239} \mathrm{Pu}$ ratios in the same samples $(\sim 0.05$ and 0.09 in OB94-10A and 09 , respectively. It is interesting that the 1975 horizon in OB94-07B also exhibits a ${ }^{240} \mathrm{Pu} /{ }^{239} \mathrm{Pu}$ ratio below global fallout $(\sim 0.14)$ but a ${ }^{237} \mathrm{~Np} /{ }^{239} \mathrm{Pu}$ ratio that falls within the range of global fallout.

The ${ }^{137} \mathrm{Cs} /{ }^{240} \mathrm{Pu}$ records from OB94-07, 10A, 09, and 08 are shown in figure 6:7a and $\mathrm{b}$. The ${ }^{137} \mathrm{Cs} /{ }^{240} \mathrm{Pu}$ record obtained from OB94-07B is quite different from the other delta cores, exhibiting values above global fallout over most of the record. The maximum $\sim 1967$ is quite similar to those observed in both the Tobol and upper Irtysh Rivers, suggesting contaminant transport from one of these upstream sources. The extended period of high ${ }^{137} \mathrm{Cs} /{ }^{240} \mathrm{Pu}$ ratios in OB94-07B between $\sim 1973$ and $\sim 1978$ are 

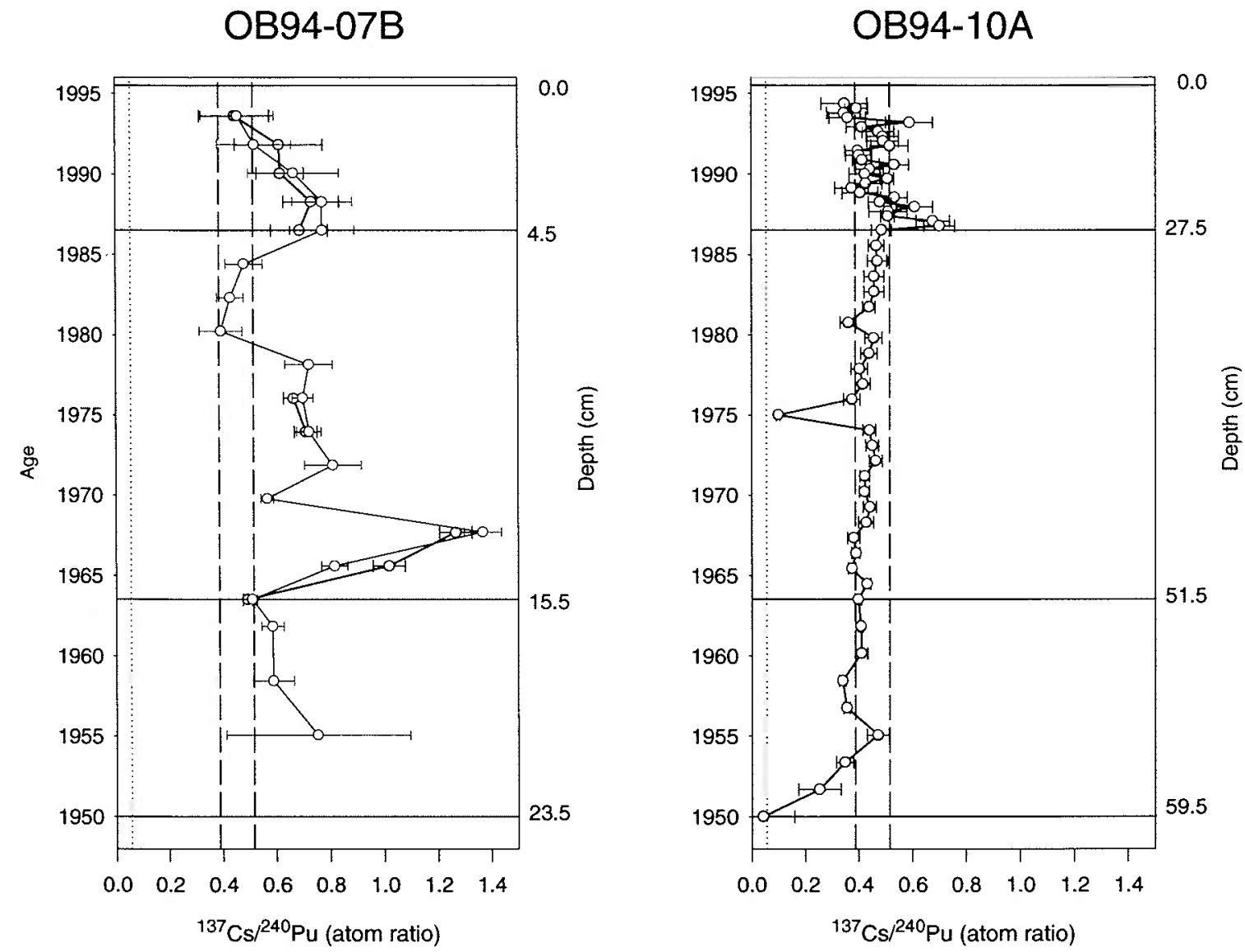

Figure 6:7a. ${ }^{137} \mathrm{Cs} / 240 \mathrm{Pu}$ records in Ob delta cores, OB94-07B and OB94-10A (left to right). Primary $\mathrm{y}$-axis is deposition age calculated using the Radionuclide horizon method. Secondary y-axis shows the depths of collection, Chernobyl, the global fallout maximum and initial appearance (solid horizontal lines). See captions in Figure 6:1 and 6:2 for details. Error bars are 1 standard error Note: Broken line indicates where one or more core sections were not analyzed. See Figure 4:1 for core location 
OB94-09

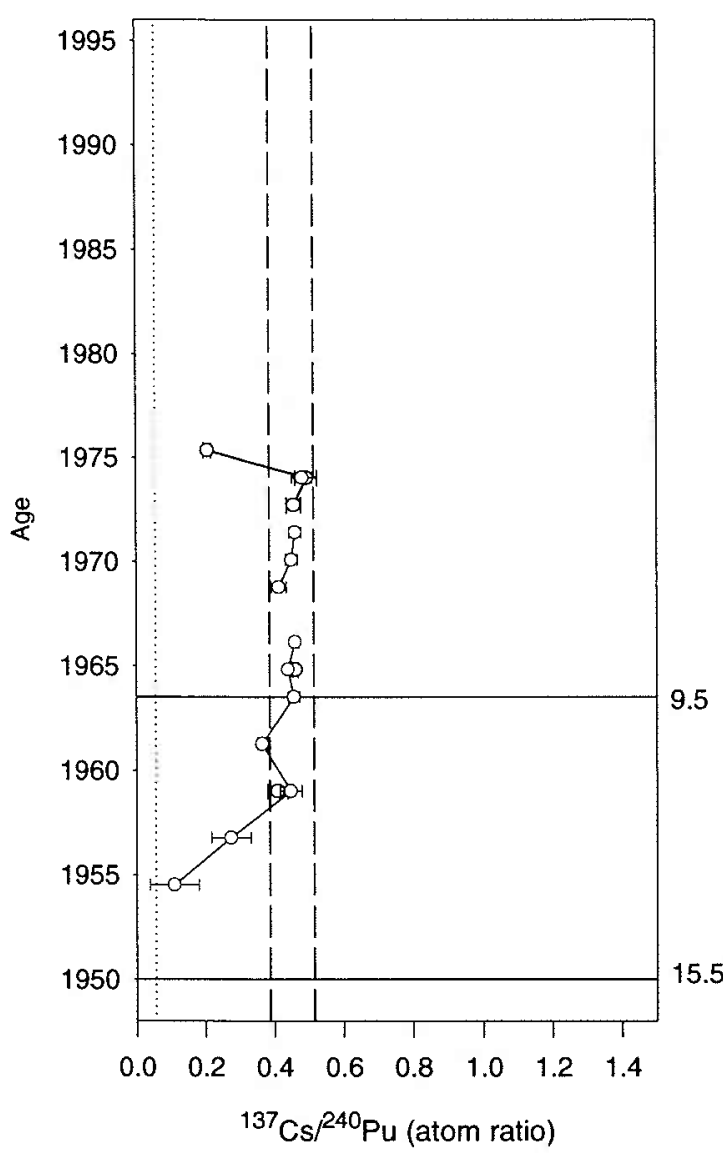

OB94-08

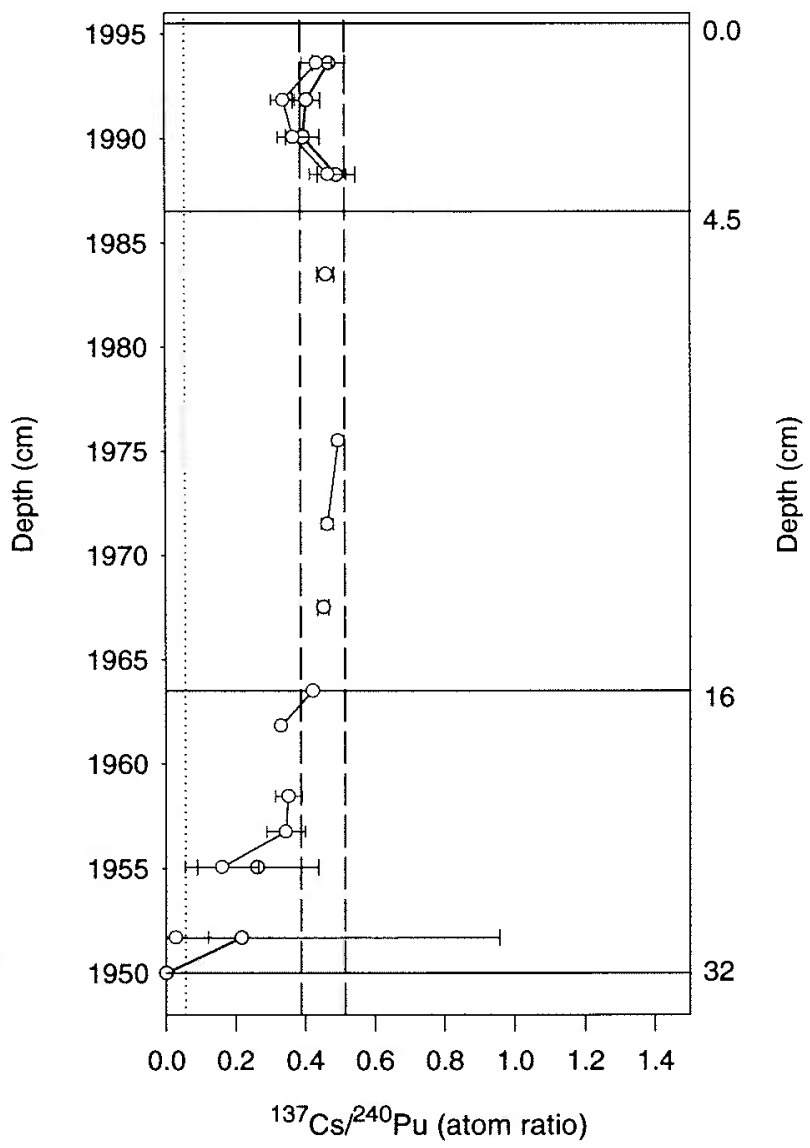

Figure 6:7b. ${ }^{137} \mathrm{Cs} /{ }^{240} \mathrm{Pu}$ records in Ob delta cores, OB94-09 and OB94-08 (left to right). Primary $y$-axis is deposition age calculated using the Radionuclide horizon method. Secondary $y$-axis shows the depths of collection, Chernobyl, the global fallout maximum and initial appearance (solid horizontal lines). See captions in Figure 6:1 and 6:2 for details. Error bars are 1 standard error. Note: Broken line indicates where one or more core sections were not analyzed. See Figure 4:1 for core location 
consistent with the ${ }^{137} \mathrm{Cs} /{ }^{240} \mathrm{Pu}$ record obtained from the upper Ob River (OB95-04), and likely indicates contamination derived from Tomsk-7 is present during this time period. The records are quite similar in OB94-10A, 09, and 08, exhibiting values below global fallout prior to $\sim 1960$, and values that are within or slightly above the global fallout range (OB94-10A; Chernobyl) from $\sim 1960$ to $\sim 1995$. The low ${ }^{137} \mathrm{Cs} /{ }^{240} \mathrm{Pu}$ ratios $\sim 1975$ in both OB94-09 and 10A are similar to the other corresponding records at this time; all three isotopic records from each core are consistent with materials collected at Semipalitinsk.

\section{Taz Estuary (OB94-13)}

The contaminant records obtained from OB94-13 are shown in Figure 6:8.

OB94-13 was collected from the Taz estuary. There are no documented sources of weapons related materials that are located within this region. A core was collected at this location in order to characterize global fallout to the watershed.

With the exception of the low value $\sim 1975$, the ${ }^{240} \mathrm{Pu} /{ }^{239} \mathrm{Pu}$ record in OB94-13 indicates that after the mid-1960s, all values are within the range of global fallout. Prior to 1960 , values that are both well above and below global fallout are observed. These features are similar to those observed in cores from the $\mathrm{Ob}$ delta and the early part of the record contained in OB95-05 ( 1950 to $\sim 1955$, prior to the commencement of activities at Tomsk-7). To a large extent, the elevated ratios in the early portions of the ${ }^{240} \mathrm{Pu} /{ }^{239} \mathrm{Pu}$ records in these cores are consistent with the reported isotopic composition of global fallout during this time period. The low values are not. These could indicate a contaminant source local to the Taz estuary, but they more likely indicate input from 


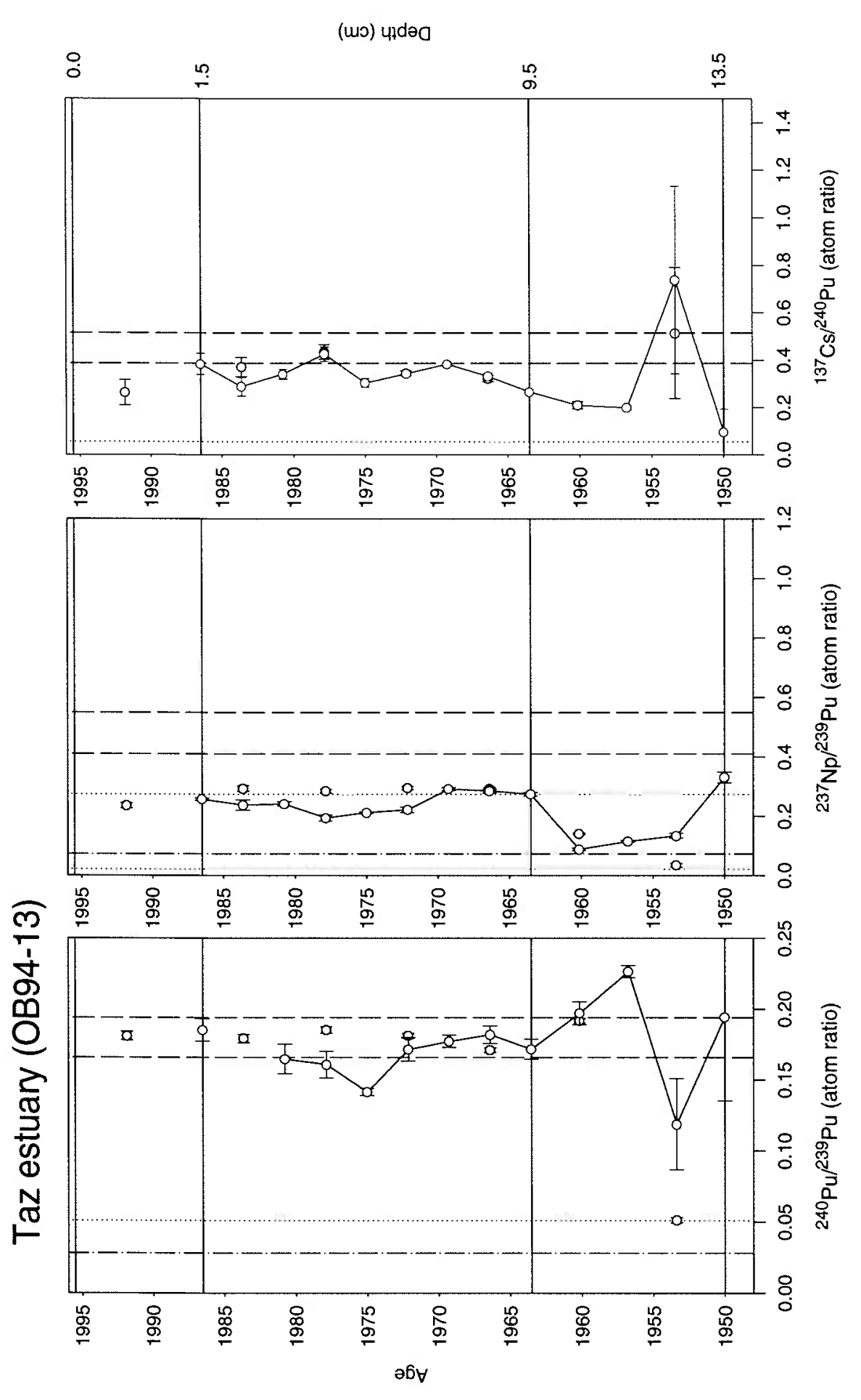

岕

恕灾

蛋

总 票:

융

욤 氜

용

夌

응트

ชे 홍

$\approx$ U

尝实

근

를

을 $\frac{0}{0}$

लं

고웜

흐

产守

ए

8 उे

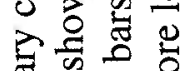

芑.

密式

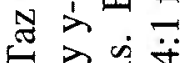

\& 寻

흏

.

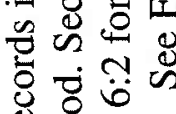

过总

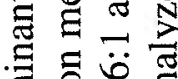

高

릉 홍ㅎㅀ

记浣

$\infty$.

$\dot{0}$

ํㅗㄹ

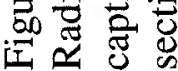


early weapons tests at Semipalitinsk. Additionally, not all atmospheric tests conducted at Novaya Zemlya were high-yield. Close-in fallout as a result of the low-yield tests at Novaya Zemlya cannot be entirely ruled out In contrast, all of the ${ }^{237} \mathrm{~Np} /{ }^{239} \mathrm{Pu}$ ratios and the majority of ${ }^{137} \mathrm{Cs} /{ }^{240} \mathrm{Pu}$ ratios measured in sediments from the Taz estuary are below global fallout. It is difficult to reconcile these records with the ${ }^{240} \mathrm{Pu} /{ }^{239} \mathrm{Pu}$ record as being a result of input from multiple sources. First, there are no reports of additional sources of contamination on either the Taz or the Pur Rivers. While this does not necessarily rule out the influence of a previously unreported source of non-fallout contamination, the observed isotopic profiles suggest that input from such a source is complex. The global fallout pattern is quite clear in the down-core radionuclide concentration profiles of OB94-13 (see Figures 5:1a through 5:4a). If the low ${ }^{237} \mathrm{~Np} /{ }^{239} \mathrm{Pu}$ and ${ }^{137} \mathrm{Cs} /{ }^{240} \mathrm{Pu}$ isotopic ratios are due to the influence of such a source in addition to global fallout, its isotopic composition would need to be similar to global fallout, with respect to ${ }^{240} \mathrm{Pu} /{ }^{239} \mathrm{Pu}$ ratio but much lower with respect to ${ }^{137} \mathrm{Cs}$ and ${ }^{237} \mathrm{~Np}$. Furthermore, its input would have to have been similar with respect to both timing and concentration to that of global fallout deposition, which changed dramatically between the period 1950 to 1995 . The existence of such a source with these characteristics seems unrealistic.

A much more likely explanation of the observed isotope ratios measured in OB94-13 are the effects of periodic intrusion of seawater into the Taz estuary. The location of the seawater penetration boundary has been estimated to reach as far south as Cape Kamenny (Ivanov, Medkova et al. 1995). The true extent of seawater intrusion is 
difficult to accurately assess as salinity profiles are unavailable for the $\mathrm{Ob}$ and $\mathrm{Taz}$ estuaries. One would expect seawater penetration to be most likely during the winter months with very low fresh water flow. Estimated concentration factors $\left(K_{d} s\right)$ in coastal sediments are $1 \times 10^{5}, 5 \times 10^{3}$, and $3 \times 10^{3}$ for plutonium, neptunium, and cesium, respectively (IAEA 1985). The differences in $\mathrm{K}_{\mathrm{d}}$ values support the preferential loss of both neptunium and cesium relative to plutonium as a result of sediment seawater interactions. While geochemical fractionation of $\mathrm{Pu}, \mathrm{Np}$, and $\mathrm{Cs}$ may occur in the Taz and $\mathrm{Ob}$ estuaries, sediments collected in the delta and upper reaches of the $\mathrm{Ob}$ and its major tributaries are freshwater environments and therefore will not be subject to the effects of seawater. Geochemical fractionation of $\mathrm{Pu}, \mathrm{Np}$, and $\mathrm{Cs}$ in these freshwater environments is discussed more thoroughly in Chapter 7.

\section{Contaminant record summary}

The different isotopic records observed in cores from the Ob delta suggest several important points. 1) Global fallout is the dominant source of weapons related contamination in the $\mathrm{Ob}$ delta. 2) Contamination derived from local sources has been transported the full length of the tributaries that drain each at various times throughout the period from 1950 to 1995 . 3) There is clear evidence linking non-fallout contamination in $\mathrm{Ob}$ delta sediments to sources located on the upper reaches of the $\mathrm{Ob}$ River as well as the Tobol and/or the upper Irtysh River (i.e. Tomsk-7, Mayak, and/or Semipalitinsk, respectively). 4) The contaminant records contained in delta sediments from different locations suggest that the distribution of non-fallout contamination derived 
from upstream sources is not homogeneously distributed throughout the Ob delta. This is indicated by the lack of elevated ${ }^{137} \mathrm{Cs} /{ }^{240} \mathrm{Pu}$ ratios in OB94-10A $\sim 1967$, which are observed in OB94-07B, as well as the lack of a clear Chernobyl signal in all delta cores.

\section{Atom ratio mixing plots}

An additional tool that is useful in the identification of mixing trends and different end-members are comparisons of the different atom ratios relative to each other (i.e. atom ratio mixing plots). Previous researchers have used ${ }^{240} \mathrm{Pu} /{ }^{239} \mathrm{Pu}$ vs. ${ }^{237} \mathrm{~Np} /{ }^{239} \mathrm{Pu}$ and ${ }^{241} \mathrm{Pu}{ }^{239} \mathrm{Pu}$ to demonstrate mixing trends (Beasley, Kelley et al. 1998; Kelley, Bond et al. 1998). While all of the samples contain some contamination derived from global fallout, in an effort to clarify these trends, samples that were not significantly different from global fallout were removed from the data set. Table 6:1 lists each ratio, the total number of measurements made, and the percentage of samples that fall outside the $\pm 2 \sigma$ range of global fallout (see Table 2:3 for details). The data in Table 6:1 indicate that $\sim 1 / 2$ of the samples measured contain significant fractions of non-fallout contamination, regardless of the isotopic ratio used. This by itself is an indicator of the strong influence exhibited by non-fallout contaminant sources in the $\mathrm{Ob}$ region. 
Table 6:1. Percentage of samples containing non-fallout contamination as indicated by the different ratios used

\begin{tabular}{ccc}
\hline $\begin{array}{c}\text { Isotope } \\
\text { Ratio }\end{array}$ & $\begin{array}{c}\text { Total number of } \\
\text { Measurements }\end{array}$ & $\begin{array}{c}\% \\
\text { Non-fallout }\end{array}$ \\
\hline${ }^{240} \mathrm{Pu} /{ }^{239} \mathrm{Pu}$ & 459 & $42 \%$ \\
${ }^{237} \mathrm{~Np} /{ }^{239} \mathrm{Pu}$ & 418 & $61 \%$ \\
${ }^{237} \mathrm{~Np} /{ }^{240} \mathrm{Pu}$ & 418 & $53 \%$ \\
${ }^{241} \mathrm{Pu} /{ }^{239} \mathrm{Pu}$ & 196 & $44 \%$ \\
${ }^{137} \mathrm{Cs} /{ }^{240} \mathrm{Pu}$ & 402 & $50 \%$ \\
\hline
\end{tabular}

* includes replicate analyses

Tobol and Irtysh Rivers 1986 to 1995

A comparison of the isotopic composition in samples from OB95-10, 11, and 13 to OB95-06 allows the relative influence of each of the suspected source tributaries (i.e. the Tobol, and upper Irtysh Rivers) to sediments in the lower Irtysh River. Samples that fall outside of the $\pm 2 \sigma$ range of global fallout with respect to either ${ }^{240} \mathrm{Pu} /{ }^{239} \mathrm{Pu}$ or ${ }^{237} \mathrm{~Np} /{ }^{239} \mathrm{Pu}$ are shown in Figure 6:9, along with the available data for global fallout, Mayak, and Semipalitinsk. The large gray rectangle represents the $\pm 2 \sigma$ range of global fallout for both ${ }^{240} \mathrm{Pu} /{ }^{239} \mathrm{Pu}$ and ${ }^{237} \mathrm{~Np} /{ }^{239} \mathrm{Pu}$ ratios. Lines drawn from the upper left and lower right-hand corners of the global fallout rectangle to end-member values indicate the range of isotopic compositions that are explainable by two-component mixing within the uncertainties of the measurements.

In the case of Mayak, a rectangle that encompasses the range of very low values observed in the early record obtained from the Tobol River are used to represent the 
weapons production end-member. The values published for soils contaminated by the Kyshtym tank explosion, which is also shown as a reference, do not reflect the observed variability in Tobol River sediments. The isotopic variability in soils collected at Semipalitinsk results in a rather large area that is explainable by a mixture between global fallout and contamination derived from that location.

The data shown in Figure 6:9 demonstrates clear differences between non-fallout contamination originating from the Tobol and upper Irtysh Rivers between 1986 and 1995. Material from the Tobol River is depleted in both ${ }^{237} \mathrm{~Np}$ and ${ }^{240} \mathrm{Pu}$, relative to global fallout, while material from the upper Irtysh River is enriched in ${ }^{237} \mathrm{~Np}$, relative to global fallout. The majority of samples collected in the lower Irtysh River have an isotopic composition that is similar to those observed in the Tobol River. This indicates that contamination originating from the Tobol exerts a stronger influence in the lower Irtysh River from the period $\sim 1986$ to $\sim 1995$. It is interesting that elevated ${ }^{240} \mathrm{Pu} /{ }^{239} \mathrm{Pu}$ ratios are present in the lower Irtysh but do not appear in the Tobol or the upper Irtysh Rivers. The few samples from the lower Irtysh River that plot between the single sample from the upper Irtysh River with low ${ }^{240} \mathrm{Pu} /{ }^{239} \mathrm{Pu}$ and ${ }^{237} \mathrm{~Np} /{ }^{239} \mathrm{Pu}$ ratios may indicate some influence of contamination derived from Semipalitinsk, however, these samples also plot between global fallout and Mayak end-members and thus, the true source can not be resolved. The five data points with high ${ }^{240} \mathrm{Pu} /{ }^{239} \mathrm{Pu}$ ratios observed in OB95-06 can not be attributed to a known source. While ${ }^{240} \mathrm{Pu} /{ }^{239} \mathrm{Pu}$ ratios that are elevated above the global fallout value are observed in test debris from weapons tests in the early 1950s, 


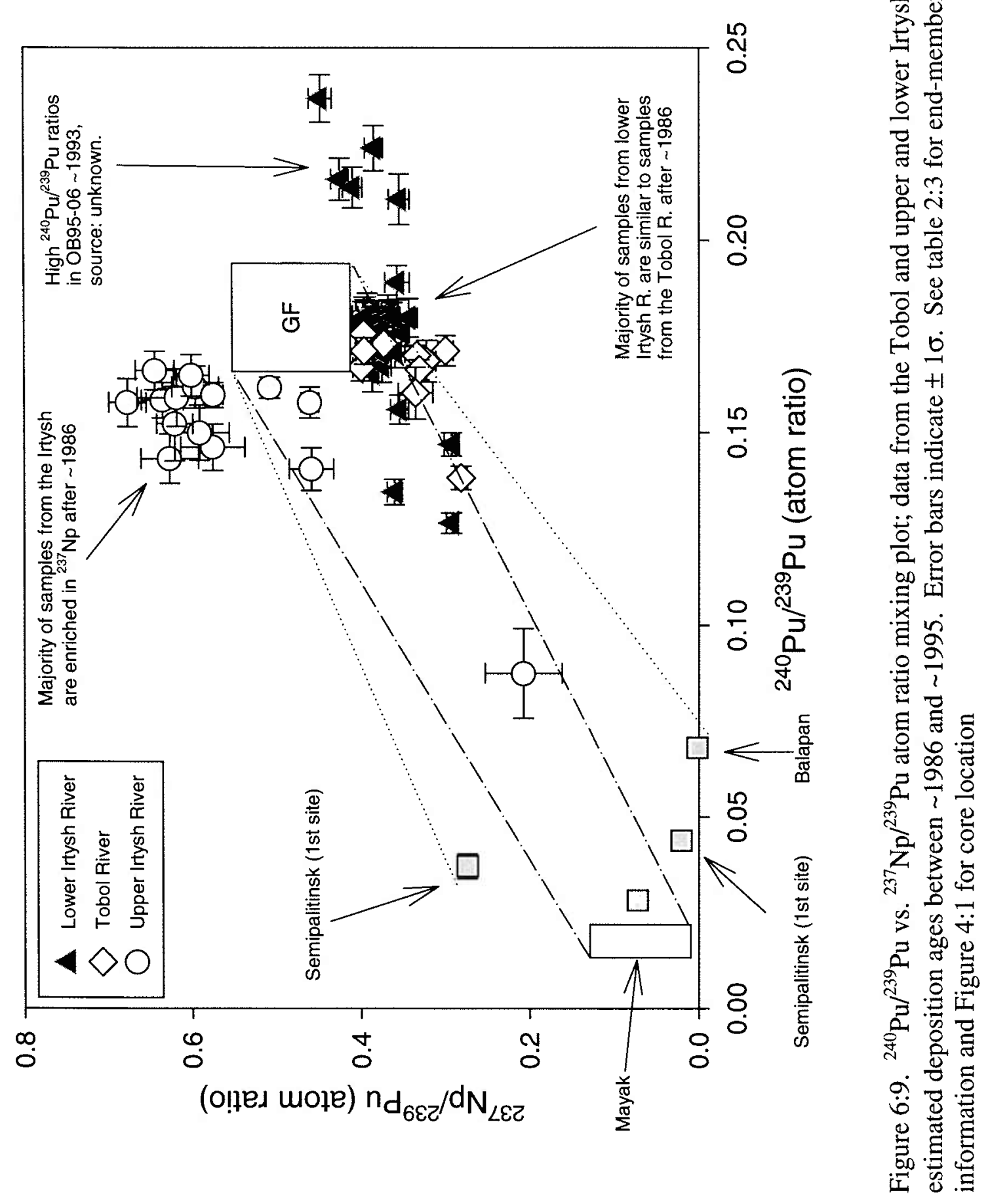


these samples also contain elevated ${ }^{241} \mathrm{Pu} /{ }^{239} \mathrm{Pu}$ ratios (not shown, see Appendix I), which rules this out as a possible source.

In a similar fashion, ${ }^{137} \mathrm{Cs} /{ }^{240} \mathrm{Pu}$ ratios are compared to ${ }^{239} \mathrm{Pu} /{ }^{240} \mathrm{Pu}$ ratios (note: reciprocal ratio) from the Tobol and upper and lower Irtysh River in Figure 6:10. Although samples from both the Tobol and upper Irtysh exhibit ${ }^{137} \mathrm{Cs}$ enrichments relative to global fallout, they can be differentiated by their ${ }^{239} \mathrm{Pu} /{ }^{240} \mathrm{Pu}$ ratios. All of the samples from the upper Irtysh that contain elevated ${ }^{137} \mathrm{Cs}$ also contain elevated ${ }^{239} \mathrm{Pu}$ relative to global fallout, while samples from the Tobol exhibiting similar ${ }^{137} \mathrm{Cs}$ enrichments do not. The majority of samples in the lower Irtysh River contain isotopic compositions that are consistent with a mixture between global fallout and materials observed in the Tobol River during this period. The data presented in figures $6: 9$ and $6: 10$ both indicate that the influence of contamination originating from the upper Irtysh River and likely derived from Semipalitinsk is relatively small compared to contamination originating from the Tobol River (Mayak) during the period 1986 to 1995. 


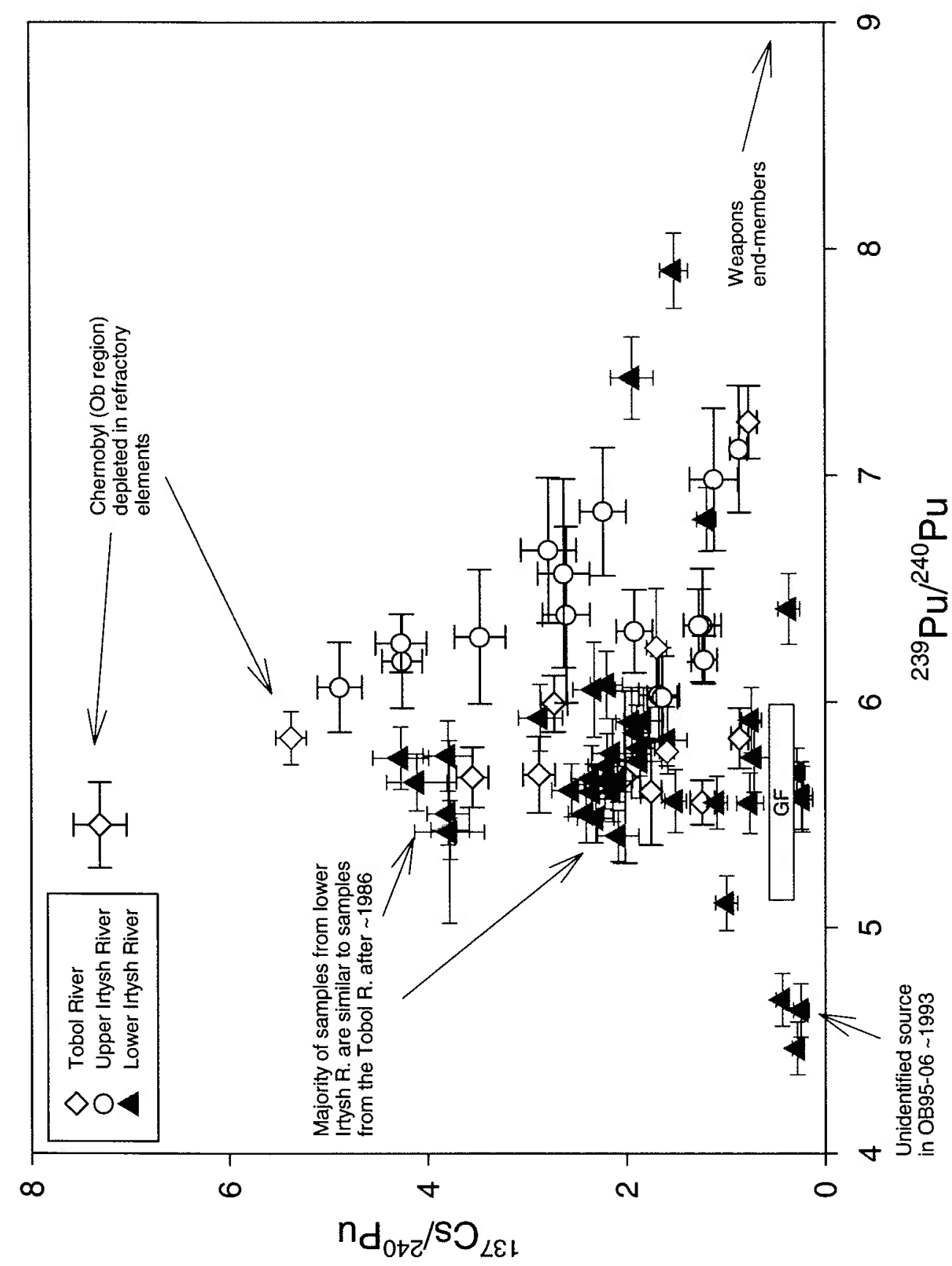

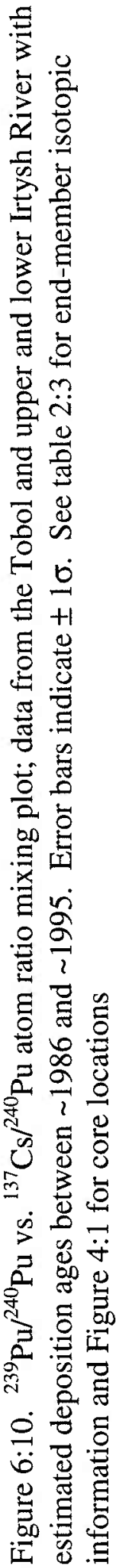


Lower Irtysh River, Upper Ob River and Ob delta from 1986 to 1995

A comparison of the isotopic composition in samples with estimated deposition ages after $\sim 1986$ from the upper Ob River (OB95-04), lower Irtysh River, and samples from the $\mathrm{Ob}$ delta allows assessment of the relative influence of each river on the contamination of delta sediments. All of the samples that fall outside of the $\pm 2 \sigma$ range of global fallout with respect to either ${ }^{240} \mathrm{Pu} /{ }^{239} \mathrm{Pu}$ or ${ }^{237} \mathrm{~Np} /{ }^{239} \mathrm{Pu}$ are shown in Figure $6: 11$. As in the previous figures, the $\pm 2 \sigma$ range of global fallout is represented by a gray rectangle. Due to the scale used, an arrow is used to indicate the mixing trend between global fallout and weapons end-members. As observed in Figure 6:9, samples from the lower Irtysh contain ${ }^{237} \mathrm{~Np} /{ }^{239} \mathrm{Pu}$ ratios that are at or below global fallout levels, and ${ }^{240} \mathrm{Pu} /{ }^{239} \mathrm{Pu}$ ratios are consistent with a mixture between global fallout and weapons endmembers.

Samples from the upper $\mathrm{Ob}$ indicate that materials originating from this river were very different from material in the Irtysh River between 1986 and 1995 . While some low ${ }^{240} \mathrm{Pu} /{ }^{239} \mathrm{Pu}$ ratios are present indicating the presence of materials consistent with known weapons end-members, several samples also exhibit ${ }^{237} \mathrm{~Np} /{ }^{239} \mathrm{Pu}$ ratios that are quite elevated compared to any published information. The pattern of isotopic ratios observed in the upper Ob River suggests that contamination originating from Tomsk-7 has varied with respect to its plutonium and neptunium concentrations. Contamination with elevated ${ }^{237} \mathrm{~Np} /{ }^{239} \mathrm{Pu}$ ratios is not observed in either the Tobol River or the upper Irtysh River and indicates that some of the contamination originating from Tomsk-7 is very 

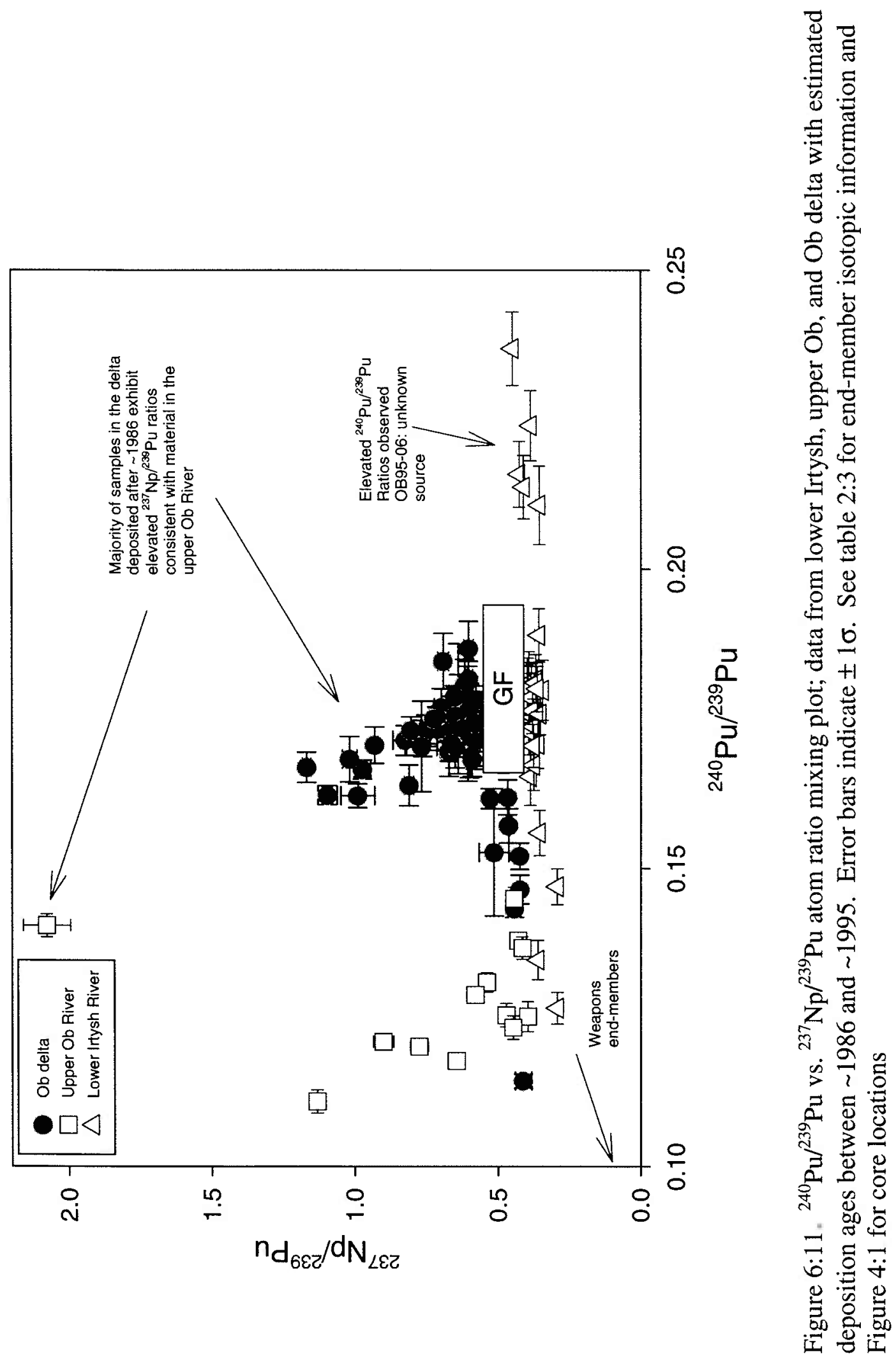
different from Mayak contamination. These differences likely reflect differences in the nuclear programs underway at each facility.

The isotopic composition of samples from the Ob delta deposited after the mid1980s clearly demonstrates that the main source of non-fallout contamination originates from the Ob River above its confluence with the Irtysh River (i.e. Tomsk-7). Non-fallout contamination originating from the Irtysh River cannot be entirely ruled out however, due to the fact that the high value in the upper Ob, global fallout, and the majority of isotopic values measured in Irtysh River sediments fall on the same mixing line, making its presence impossible to resolve (Figure 6:11).

In a similar fashion, Figure 6:12 shows a comparison of ${ }^{137} \mathrm{Cs} /{ }^{240} \mathrm{Pu}$ ratios to ${ }^{239} \mathrm{Pu} /{ }^{240} \mathrm{Pu}$ ratios (note: reciprocal ratio) in samples from the upper $\mathrm{Ob}$, lower Irtysh, and the Ob delta with estimated deposition ages between 1986 and 1995. The majority of samples from the lower Irtysh River exhibit elevated ${ }^{137} \mathrm{Cs} /{ }^{240} \mathrm{Pu}$ ratios, but ${ }^{239} \mathrm{Pu} /{ }^{240} \mathrm{Pu}$ ratios that for the most part are consistent with global fallout. In contrast, samples from the upper Ob River exhibit elevated ${ }^{239} \mathrm{Pu} /{ }^{240} \mathrm{Pu}$ ratios and ${ }^{137} \mathrm{Cs} /{ }^{240} \mathrm{Pu}$ ratios that are the same or slightly elevated above, global fallout values. Sediments deposited in the $\mathrm{Ob}$ delta after 1986 generally fall on a line between the samples from the upper Ob River and global fallout. There is a group of samples that do exhibit slightly elevated ${ }^{137} \mathrm{Cs} /{ }^{240} \mathrm{Pu}$. This could be a result of either a small amount of material from the lower Irtysh River or the direct deposition of material from Chernobyl in the delta. The lack of elevated. ${ }^{137} \mathrm{Cs} /{ }^{240} \mathrm{Pu}$ ratios in delta sediments similar to those in the lower Irtysh River 


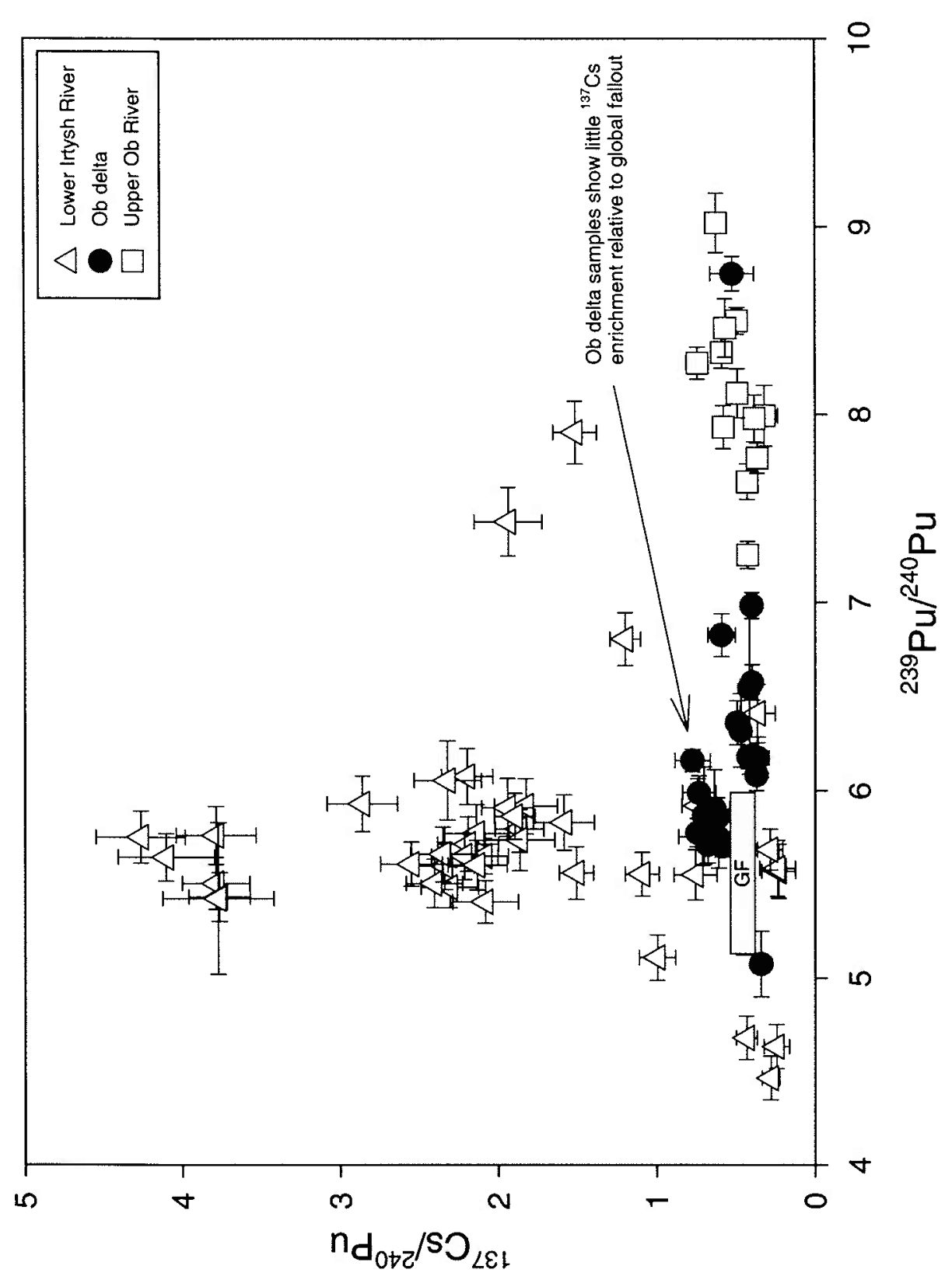

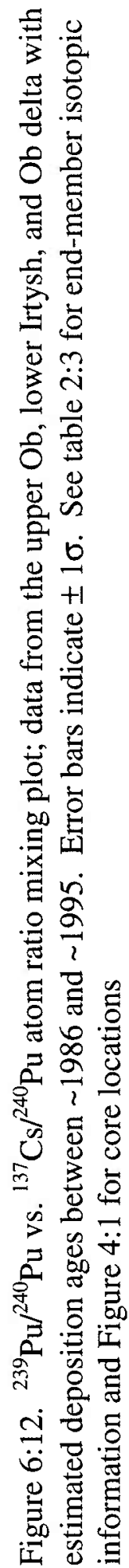


and no delta samples exhibiting intermediate isotopic compositions between those in the lower Irtysh and upper $\mathrm{Ob}$ River suggest the latter possibility. In both Figures 6:11 and 6:12, the majority of delta samples fall on a mixing-line between global fallout and materials in the upper Ob River. This strongly suggests that Tomsk-7 is the main source of non-fallout contamination to delta sediments between $\sim 1986$ and $\sim 1995$.

Tobol River, Irtysh River, Upper Ob River and Ob delta prior to the mid-1980s

The main point of the following discussion is to resolve the source of the material with elevated ${ }^{137} \mathrm{Cs} /{ }^{240} \mathrm{Pu}$ ratios that appears in sediments from the Tobol River, Irtysh River, and Ob delta (OB94-07B) during the mid to late 1960s. Figure 6:13 shows a comparison of the ${ }^{237} \mathrm{~Np} /{ }^{239} \mathrm{Pu}$ to ${ }^{240} \mathrm{Pu} /{ }^{239} \mathrm{Pu}$ ratios in samples containing non fallout contamination from the upper Irtysh, Tobol and upper Ob Rivers as well as the Ob delta with deposition ages before $\sim 1985$. These data show clear evidence of mixing between global fallout and weapons end-members, demonstrating the presence of contamination from these sources in the $\mathrm{Ob}$ delta. Unfortunately, samples from each of the suspected source tributaries as well as the delta samples all exhibit the same trend, making source resolution by these data impossible.

The ${ }^{137} \mathrm{Cs} /{ }^{240} \mathrm{Pu}$ ratios and ${ }^{239} \mathrm{Pu} /{ }^{240} \mathrm{Pu}$ ratios for the same samples are shown in Figure 6:14. Similar to figure $6: 13$, the majority of samples in this figure are consistent with mixing between weapons end-members (note: end-member values not shown at this scale) and global fallout. There is however, a clear trend in delta samples towards 


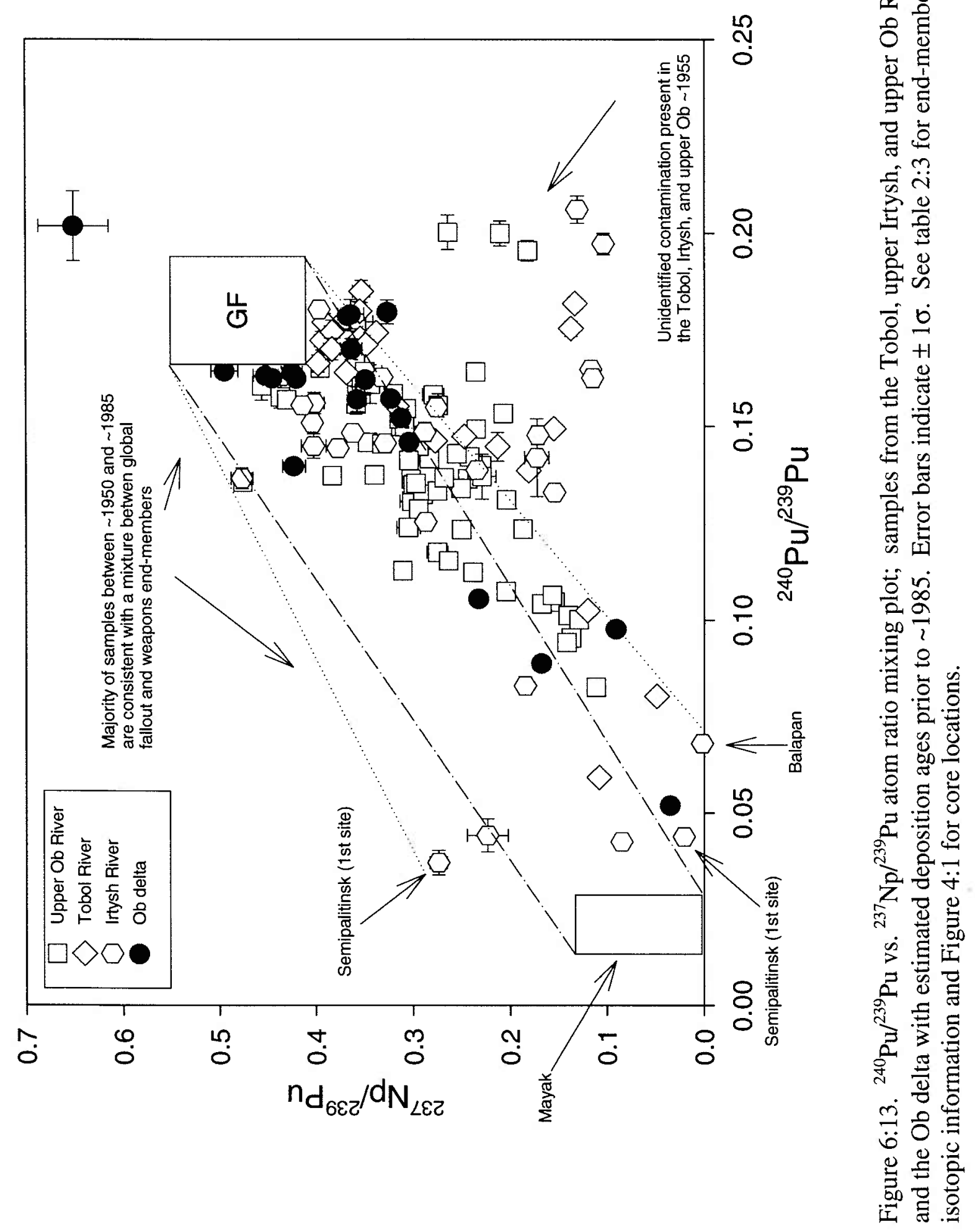



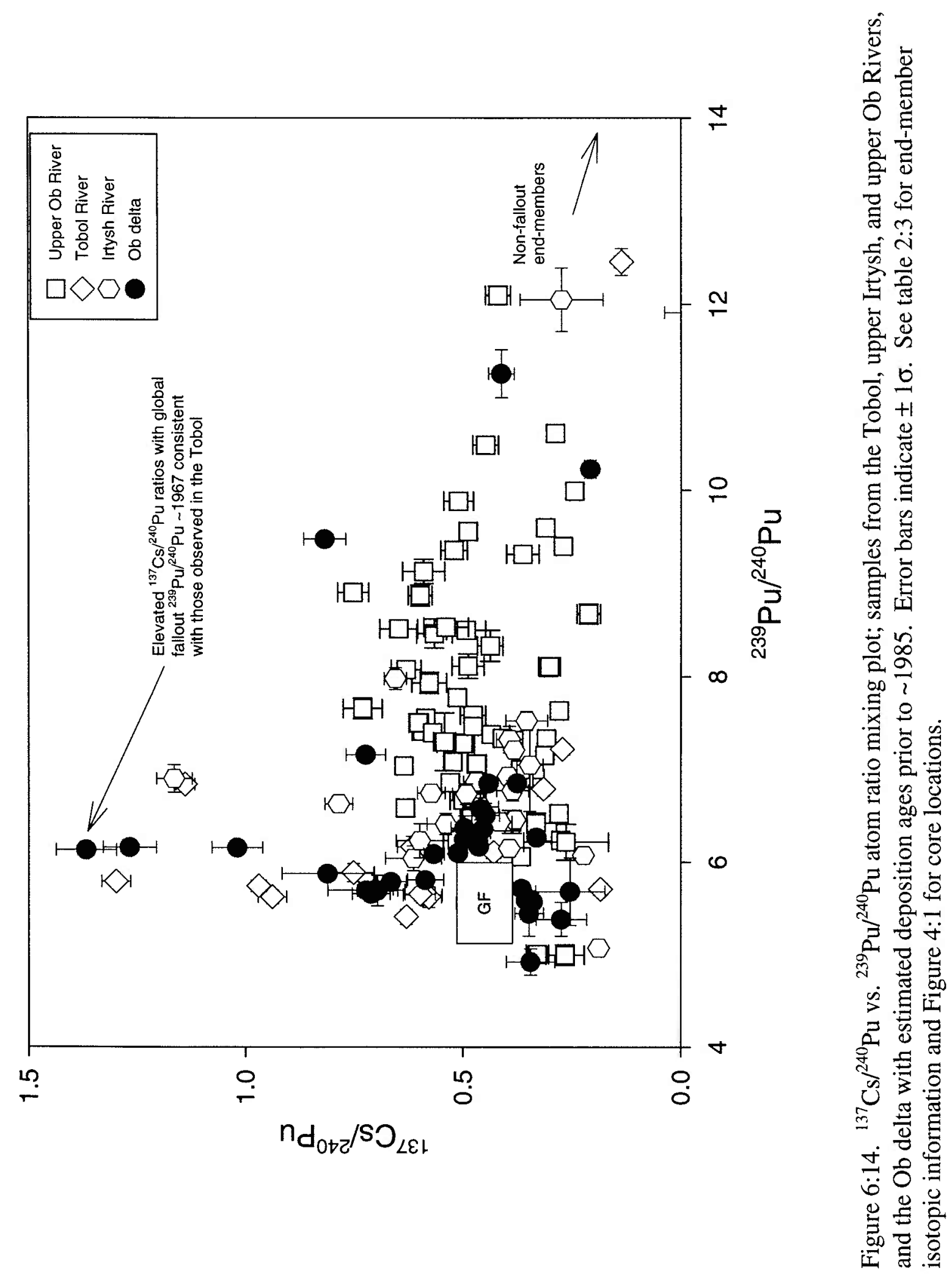
elevated ${ }^{137} \mathrm{Cs} / 240 \mathrm{Pu}$ values, which are observed in the Tobol and upper Irtysh river samples deposited during the mid to late 1960 s. It is noteworthy that elevated ${ }^{137} \mathrm{Cs} /{ }^{240} \mathrm{Pu}$ ratios do not appear in any of the samples from the region deposited prior to this time. Samples from the upper Irtysh River that exhibit elevated ${ }^{137} \mathrm{Cs} /{ }^{240} \mathrm{Pu}$ ratios also exhibit elevated ${ }^{239} \mathrm{Pu} /{ }^{240} \mathrm{Pu}$ ratios relative to global fallout. Conversely, samples with elevated ${ }^{137} \mathrm{Cs} /{ }^{240} \mathrm{Pu}$ ratios collected in the Tobol River are quite similar to the global fallout value. Delta samples with elevated ${ }^{137} \mathrm{Cs} /{ }^{240} \mathrm{Pu}$ ratios plot between the elevated values in samples collected from both rivers. Based on the distinctive ${ }^{239} \mathrm{Pu} /{ }^{240} \mathrm{Pu}$ ratios observed in samples from the Irtysh River, there is a larger influence of material originating from the Tobol River during the mid-1960s. Furthermore, the lack of similarities between delta samples and samples from the upper $\mathrm{Ob}$ river indicate that material originating from the Tobol River was the main source of non-fallout contamination to delta sediments during this period.

\section{Summary Chapter six}

The isotopic information presented above consistently suggests that in addition to debris from atmospheric weapons tests, materials derived from local sources have also played a role in nuclear weapons related contamination of the $\mathrm{Ob}$ region. In several instances, substantially different isotopic compositions are observed in sediments collected from tributaries draining each of the suspected non-fallout sources. In cases where materials with unique isotopic compositions and deposition ages are observed in a 
particular source tributary and the Ob delta, it has been possible to link contamination in the Ob delta to Mayak, Tomsk-7, or Semipalitinsk.

With regard to contaminated sediment transport (discussed more fully in Chapter 8), the similar timing of the appearance of non-fallout materials in a particular source tributary and its subsequent deposition in the delta suggests that transport is quite rapid. Additionally, contamination from the Tobol River (i.e. Mayak) has played a larger role than expected, given the suspended sediment contribution of this river. The mean annual suspended discharges at Yalutorovsk (Tobol R.) and Omsk (Irtysh R.) are 1.5 and 37 percent, respectively, of the suspended sediment load observed at Tobolsk. If suspended load estimates are correct, it implies that contaminant inventories are much greater in the Tobol River. While contaminant inventories do indicate higher levels in the Tobol River ( $<$ factor of two, see Appendix II and discussion therein), differences much greater than those observed are required to reconcile with the suspended load contributions. This is problematic and suggests that suspended sediment discharge estimates may not be useful indicators of contaminated sediment contributions from each suspected source tributary. 


\section{References Chapter 6}

Beasley, T. M., J. M. Kelley, et al. (1998). "Isotopic Pu, U, and Np signatures in soils from Semipalatinsk-21, Kazakh Republic and the Southern Urals, Russia." Journal of Environmental Radioactivity 39(2): 215-230.

Bradley, D. J. and D. R. Payson (1997). Behind the nuclear curtain : radioactive waste management in the former Soviet Union. Columbus, Ohio, Battelle Press.

Diamond, H., P. R. Fields, et al. (1961), "Heavy isotope abundances in "Mike" thermonuclear device." Health Physics 119: 2000-2004.

IAEA (1985). Sediment Kds and concentration factors for radionuclides in the marine environment. Vienna, International Atomic Energy Agency: 73.

Ivanov, V. V., V. M. Medkova, et al. (1995). Characteristic features of sedimentation processes in the lower reaches and mouth of the Ob River, The State Research Centre of the Russian Federation: the Arctic and Antarctic Research Institute: 26.

Kelley, J. M., L. A. Bond, et al. (1998). Inventory and composition of Pu isotopes and $\mathrm{Np}-237$ in soil. International symposium on marine pollution, Monaco, IAEA.

Krey, P. W., E. P. Hardy, et al. (1976). Mass isotopic composition of global fall-out plutonium in soil". Transuranium nuclides in the environment. Transuranium nuclides in the environment. San Franc., Calif., United States: 671-678.

Oughton, D. H., K. Fifield, et al. (2000). "Plutonium from Mayak: measurement of isotope ratios and activities using accelerator mass spectrometry." Environmental Science \& Technology, ES \& T 34: 1938-1945.

Sayles, F. L., T. C. Kenna, et al. (1998). Release and transport of artificial radionuclides from nuclear weapons related activities in the Ob River, Siberia ove the course of the nuclear age. International symposium on marine pollution, Monaco, IAEA.

Shebell, P. and A. R. Hutter (1996). Environmental radiation measurements at the Former Soviet Union's Semipalitinsk-21 nuclear test site and surrounding villages. Springfield, VA, U.S. Department of Energy.

Yamamoto, M., M. Hoshi, et al. (1999). "Pu isotopes and (super 137) Cs in the surrounding areas of the former Soviet Union's Semipalatinsk nuclear test site." Journal of Radioanalytical and Nuclear Chemistry 242(1): 63-74. 
Yamamoto, M., T. Tsukatani, et al. (1996). "Residual radioactivity in the soil of the semipalitinsk nuclear test site in the former USSR." Health Physics 71(2): 142148.

Yamamoto, M., A. Tsumura, et al. (1996). "Plutonium isotopic composition in soil from the former Semipalitinsk nuclear test site." Radiochimica Acta 72: 209-215. 


\section{$\underline{\text { Chapter } 7}$}

\section{The distributions of ${ }^{239} \mathrm{Pu},{ }^{240} \mathrm{Pu}$, and ${ }^{237} \mathrm{~Np}$ among chemically defined components of sediments from the Ob River}

Data presented in this study thus far, have clearly documented nuclear weapons related contamination derived from both global and local sources in sediments collected at various locations in the $\mathrm{Ob}$ region (see Figure 4:1 for sampling locations). Clear also is the fact that fluvial transport is an important mechanism in the dispersal of contaminated sediments.

As noted in the introduction, the focus of this study is the history of weapons related contamination as it is recorded by particle reactive elements in sediments from the Ob region. It is the particle reactive nature or the tendency of plutonium, neptunium, and cesium to form strong associations with river particulate material that allows non-fallout contamination measured in delta sediments to be linked to upstream sources. While it is not possible for environmental processes to alter the isotopic composition of plutonium, possible differences in the geochemistries of neptunium, cesium, and plutonium make elemental fractionation (i.e. selective removal from particles) an important issue. This is especially true when source information is derived from $\mathrm{Np} / \mathrm{Pu}$ and $\mathrm{Cs} / \mathrm{Pu}$ ratios.

By using isotopic ratios of different elements, their corresponding $K_{d} s$, or distribution coefficients, are assumed to be sufficiently and similarly large (i.e. grams per unit weight solid $\gg>$ grams per unit weight solution). This allows the equation of contaminant transport with contaminated sediment transport. Preservation of the global 
fallout pattern, the largely co-varying nature of radionuclide distribution profiles both within and between sediment cores from different locations, and the presence of ${ }^{237} \mathrm{~Np} /{ }^{239} \mathrm{Pu}$ and ${ }^{137} \mathrm{Cs} /{ }^{240} \mathrm{Pu}$ ratios with global fallout values strongly support these assumptions. However, the question of preferential neptunium loss was raised in Chapter 6. Due to different sample size requirements and different measurement techniques used in the determination of cesium, the discussion below is limited to plutonium and neptunium only.

Several factors can affect the partitioning behavior of these elements. Plutonium and neptunium can exist in multiple oxidation states ranging from trivalent to hexavalent, which allows their complexation by a variety of different chemical species (Fuger 1992). The physico-chemical form of materials released to the environment because of weapons related activities are variable, which may also affect partitioning. Activities at weapons production facilities include isotopic separation by organic liquid as well as the machining of metallic plutonium for the production of individual weapon components. Debris produced as a result of surface or atmospheric weapons tests can be made refractory by fusing with soils. In the case of high yield weapons test (i.e. global fallout), debris can be further modified during the $\sim 11$ month residence time in the stratosphere. Over time, once contamination has been introduced into the environment, other factors can affect partitioning such as weathering reactions and microbial activity. Sequential extraction techniques performed on sediments and soils have been used by many researchers to obtain elemental partitioning, mobility, and transport information (Edgington, Alberts et al. 1976; Wahlgren, Alberts et al. 1976; Alberts, Muller et al. 
1977; Alberts, Muller et al. 1977; Muller and Sprugel 1977; Muller, Sprugel et al. 1977; Muller and Tisue 1977; Muller 1978; Tessier, Campbell et al. 1979; Kersten, Foerstner et al. 1986; Alberts, Wahlgren et al. 1989; Ruttenberg 1992; Oughton, Salbu et al. 1993; Salbu, Oughton et al. 1994; JNREG and group 1997; Beasley, Kelley et al. 1998). The main goals of this sequential extraction study are to: 1) Test the assumptions made concerning the reversibility of adsorption of plutonium and neptunium, and thereby gain a better understanding of the partitioning behavior of these elements onto sediments. 2) Determine if contaminants originating from the various sources are partitioned differently between solid phase reservoirs.

In support of these objectives, a sub-set of sediments containing bulk isotopic compositions that indicated the presence of non-fallout contamination were sub-sampled and sequentially leached with a series of different reagents. Samples included sediments from the upper $\mathrm{Ob}$ and Irtysh Rivers as well as the $\mathrm{Ob}$ delta. The distributions of ${ }^{239} \mathrm{Pu}$, ${ }^{240} \mathrm{Pu}$, and ${ }^{237} \mathrm{~Np}$ among these chemically defined sedimentary fractions are reported.

Plutonium results are compared to previous studies that examined its sediment partitioning behaviour using selective extraction techniques. The implications for the mobility of nuclear weapons related contaminants originating from different sources are also discussed.

Overview of selective leach fractions and experimental design

Due to the large number of minerals (both crystaline and amorphous) that are present in river sedimentary material, it is impossible to precisely define the actual 
dissolution specificity of each reagent used in these types of experiments. Previous researchers (noted above) have used operational definitions to describe the fraction of sedimentary material solublized by each reagent. The treatments range from gentle to total dissolution, and each is designed to approximate different environmental processes that may occur or selectively extract trace metals contained in different solid phase reservoirs thought to be present in the sediments. The partitioning behavior or mobility of an element is inferred by the relative concentrations liberated by each treatment.

There is some variation between published studies with respect to the number and order of different treatments, fraction definitions (i.e. target minerals), and the reagents/treatments used to selectively leach each fraction. The majority of studies generally follow a modified version of the experimental design of Tessier et al. (1979). The techniques used in the present study were also initially based on the design of Tessier et al. (1979). However, based on data from other studies, particularly those conducted by Ruttenberg (1992), Alberts et al. (1976), Alberts and Whalgren (1989), Muller (1978), and JNREG (1992) certain modifications were made. The last study referenced examined the partitioning behavior of plutonium in sediments collected near Mayak and is of particular interest. The fractions selected and treatments used in this study are summarized in Table 7:1 and discussed below. Note that the term 'trace metals' in the descriptions below is synonymous with plutonium and neptunium. 
Table 7:1. Fractions and reagents used for sequential extraction.

\begin{tabular}{|c|c|c|}
\hline Fraction & Extraction Reagent ${ }^{\star}$ & Target Phase, (Potential Complexes) \\
\hline F1 Exchangeable & $1 \mathrm{M} \mathrm{NH}_{4}$-acetate, $\mathrm{pH} 7(\mathrm{NaOH})$ & Exchangeable ions, (acetate) \\
\hline F2 Reducible & $\begin{array}{l}0.3 \mathrm{M} \mathrm{Na}_{3} \text {-citrate: } 1 \mathrm{M} \mathrm{NaHCO}_{3}, 1.3 \mathrm{~g} \\
\mathrm{Na} \text {-dithionite (CDB), } \mathrm{pH} 7.6\end{array}$ & $\begin{array}{l}\text { Easily reducible or reactive } \mathrm{Fe}^{3+} \text { or } \\
\mathrm{MnO}_{\mathrm{x}} \text {-bound, (citrate, carbonate, and } \\
\text { sulfite) }\end{array}$ \\
\hline F3 Carbonate & $1 \mathrm{M} \mathrm{Na}$-acetate, $\mathrm{pH} 5$ (acetic acid) & Carbonates, (acetate) \\
\hline F4 Organic & $30 \% \mathrm{H}_{2} \mathrm{O}_{2}, \mathrm{pH} 2\left(\mathrm{HNO}_{3}\right), 85^{\circ} \mathrm{C}$ & Oxidizable, organic matter, sulfides \\
\hline F5 Acid Leachable & $8 \mathrm{~N} \mathrm{HNO}_{3}, 85^{\circ} \mathrm{C}$ & Lithogenic-bound \\
\hline F6 Refractory & Aqua regia:HF, $100^{\circ} \mathrm{C}$ & Refractory, silicates \\
\hline
\end{tabular}

Fraction 1 (F1) - Exchangeable. Typically, this fraction is first in the series. It is designed to liberate trace metals that are loosely sorbed onto the surfaces of sedimentary materials such as hydrated iron oxides and humic substances, or present at exchangeable sites in clay minerals (Tessier et al., 1979). Dilute solutions of $\mathrm{MgCl}_{2}$ and Na-Acetate, usually at room temperature and neutral or near-neutral $\mathrm{pH}$ have been used as extractants. Once present in solution, $\mathrm{Mg}^{2+}$ and/or $\mathrm{NH}_{4}{ }^{+}$compete with trace metals and displace them from the ion exchange sites they occupy.

Fraction 2 (F2) - Reducible. The reducible fraction is designed to liberate trace metals that are scavenged by oxides of iron or manganese that would be released under anoxic conditions. Tessier et al., (1979) leached the reducible fraction later in the sequence using heated solutions $\left(80-97^{\circ} \mathrm{C}\right)$ of $\mathrm{NH}_{2}-\mathrm{OH}-\mathrm{HCl}$ at low $\mathrm{pH}$, or sodium dithionite-citrate. Other studies specifically investigating the partitioning behavior of plutonium in aquatic sediments, observed that the majority of total plutonium in sediments from Lake Michigan and Buzzard's Bay was found in the citrate-dithionite extract (Alberts et al., 1976, Alberts and Whalgren, 1989, Edgington et al., 1976). Due to 
the possible effects of elevated temperatures and low $\mathrm{pH}$ on $\mathrm{Pu}$ and $\mathrm{Np}$ adsorption, it is unclear what percent of the plutonium observed in the 'reducible' fraction is actually the result of the reduction of iron and manganese. The results, however, are very interesting in that they indicate that most of the plutonium is less refractory than previously thought. Ruttenberg (1992) used a buffered solution of sodium-citrate-dithionite to extract ferric iron-bound phosphorous at room temperature in order to mitigate the effects sulfide formation and minimize the dissolution of carbonates. This method offered the ability to examine the effects of the citrate-dithionite extractant on $\mathrm{Pu}$ and $\mathrm{Np}$ partitioning without the effects of high temperature and low $\mathrm{pH}$, and it was selected for use in the present study.

Fraction 3 (F3) - Carbonate. The carbonate fraction is designed to liberate any trace metals that are associated with carbonate minerals. The extraction techniques used by previous researchers were conducted at room temperature using dilute solutions of sodium or ammonium acetate adjusted to a pH of $\sim 5$ with acetic acid. While it is not expected that carbonate minerals will represent a significant portion of Ob River sediments, carbonates are efficient scavengers of trace metals, and they may be important.

Fraction 4 (F4) - Organic. The organic fraction is designed to liberate trace metals bound to organic matter. Solutions used to extract the organic fraction include heated solutions of concentrated $\mathrm{H}_{2} \mathrm{O}_{2}$ at low $\mathrm{pH}$, and dilute solutions of $\mathrm{NaOH}$. (Cochran, Moran et al. 2000) observed a significant increase in the $\mathrm{Kd}$ of americium 
before and after UV-destruction of DOC in Ob River water. This suggests that the organic fraction could play an important role in the partitioning of nuclear contaminants.

Fraction 5 (F5) - Acid leachable. The acid leachable fraction is designed to liberate trace metals bound to lithogenic materials that are present in sediments. This fraction is referred to in many studies as the residual fraction. Although Tessier et al. (1979) used a mixture of hot $\mathrm{HF}$ and $\mathrm{HClO}_{4}$, the majority of other studies employ a hot $\mathrm{HNO}_{3}$ leach to extract this fraction. The possible presence of a refractory contaminant phase, formed by the fusion of weapon components and soil silicates during surface tests a Semipalitinsk, prompted the development of total digestion techniques for bulk sediment isotopic analyses (see chapter 4). In the sequential extraction method used here, attempts are made to verify the existence of this material by conducting an $8 \mathrm{~N} \mathrm{HNO}_{3}$ acid leach at $85^{\circ} \mathrm{C}$, as a separate extraction, prior to total dissolution by $\mathrm{HF}$.

Fraction 6 (F6) - Refractory. As discussed above, this fraction is designed to liberate any trace metals that are associated with silicates or other acid leach resistant mineral phases. The use of a mixture of HF-aqua regia results in the total digestion of residual materials.

The treatments outlined in Table 7:1 were employed sequentially on $10 \mathrm{~g}$ sediment sub-samples (dry weight of the sample prior to the first extraction). A $10 \mathrm{~g}$ sub-sample of pre-nuclear age sediment, collected in the Ob River delta, was included for the assessment of blank contaminant levels and ICP-MS measurement artifacts (e.g., mass interference). A flow diagram of the selective extraction procedure is shown in Figure $7: 1$. 
Extractions were conducted in $250 \mathrm{ml}$, HDPE centrifuge bottles. Following each extraction, sediments were centrifuged for 15 minutes at $\sim 3000 \mathrm{rpm}$. The resulting supernatants were then filtered through either a $.45 \mu \mathrm{m}$ polysulfone or GF/F filter. After filtration, filters and filter-chambers were rinsed with the next reagent in the sequence and combined with the residual solids from the centrifugation step. For fractions F1 through F5, each extraction step was repeated twice. Fractions F2 through F4 also included an additional $\mathrm{NH}_{4}$-acetate extraction step as a wash in order to de-sorb any $\mathrm{Pu}$ or $\mathrm{Np}$ adsorbed during the extraction step. All $22^{\circ} \mathrm{C}$ (room temperature) extractions and $\mathrm{NH}_{4}$-acetate washes were conducted on a Gyrotory ${ }^{\circledR}$ shaker (model G2) at $\sim 300 \mathrm{rpm}$. Heated extractions (F4, F5, and F6) were carried out either on a hot plate or in a temperature controlled water bath and agitated intermittently. For each treatment, supernatants were combined with $\mathrm{NH}_{4}$-acetate washes. The solutions corresponding to each treatment and the final remaining sample residue (F6) were transferred to individual $250 \mathrm{ml}$ teflon centrifuge bottles; leached fractions were then taken to dryness. Following this step, yield monitors were added and $\mathrm{Pu}$ and $\mathrm{Np}$ analysis was carried out on each fraction (see chapter 4 for analytical details). 
Eigure 7:1 Sequential Extraction Procedure

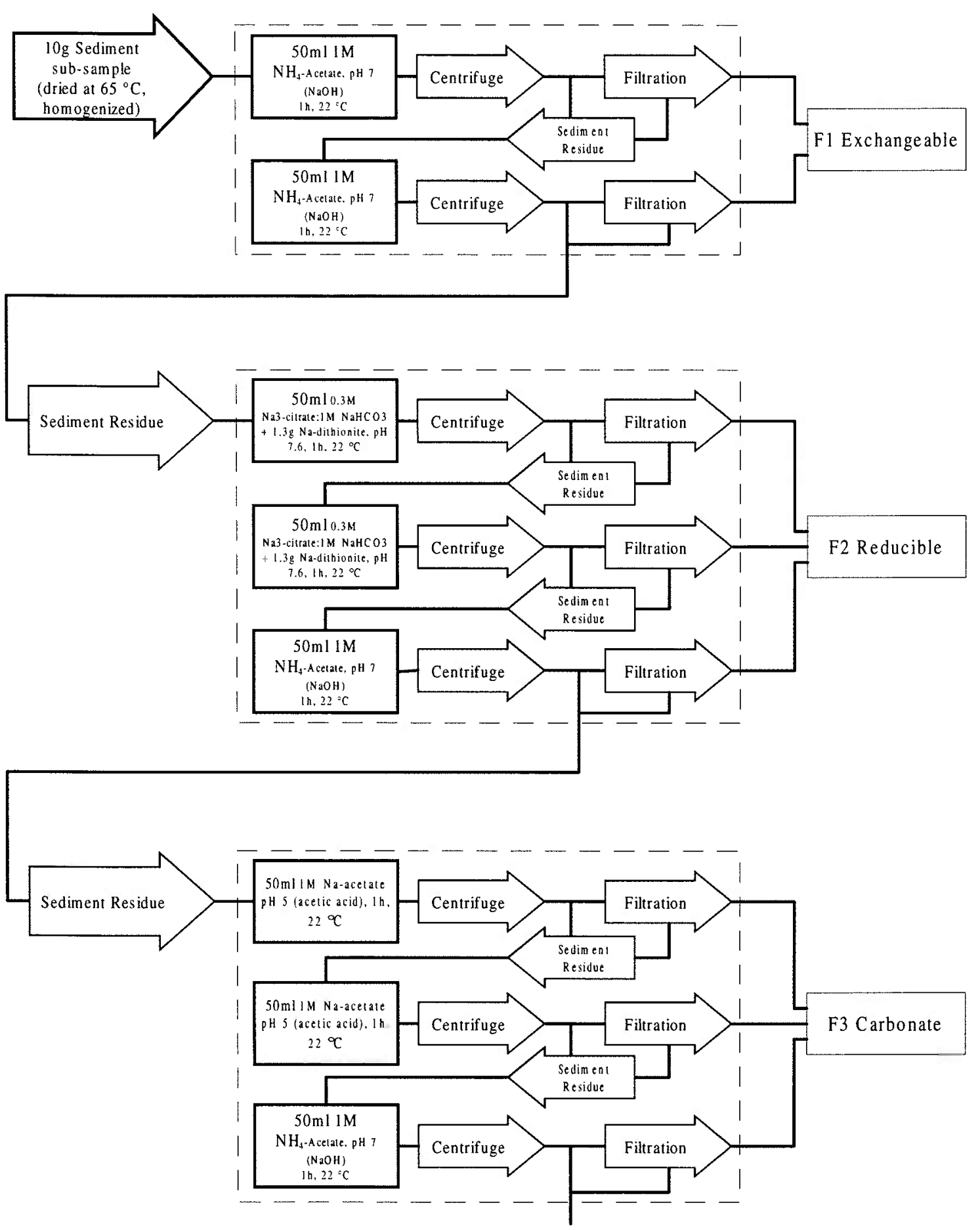

To F4-Organic Extraction 


\section{Eigure 7:L Sequential Extraction Procedure (cont.)}

From F3-Carbonate Extraction

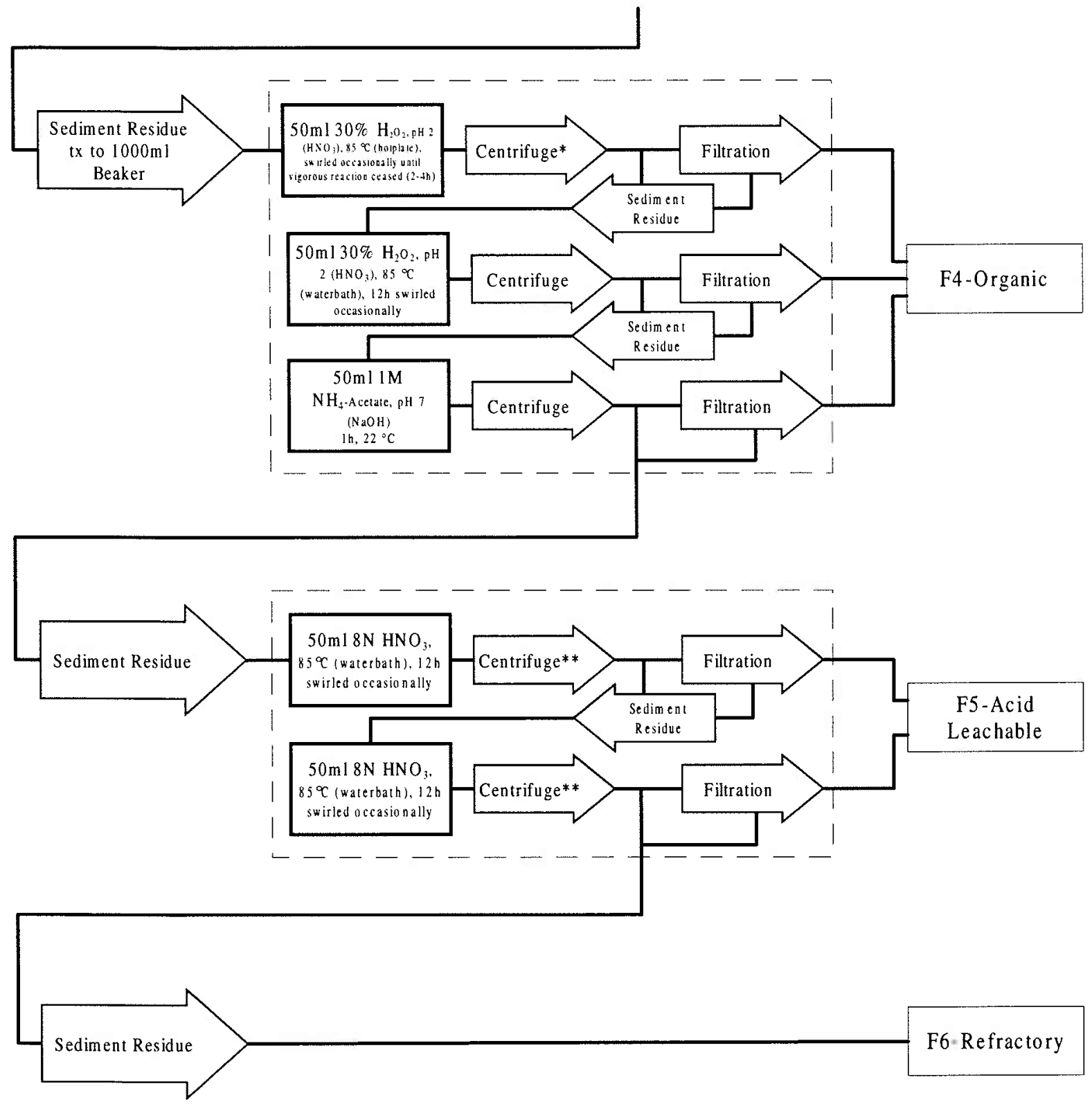

* Sample was cooled, tx back to 250ml HDPE jar; a small amount of $1 \mathrm{M} \mathrm{NH4-acetatesolution} \mathrm{was} \mathrm{used} \mathrm{for} \mathrm{rinsing}$

** Sample was cooled prior to centrifugation 


\section{Results and discussion}

The sequential extraction technique outlined above was carried out on a sub-set of five samples with bulk sediment isotopic compositions that were significantly different from published global fallout values. Table 7:2 lists sample information, bulk-sediment isotopic composition, and the suspected contaminant source(s) for each of the selected samples. OB94-7B $(3-4 \mathrm{~cm})$ and OB94-10A $(39-40 \mathrm{~cm})$ were both collected in the delta, yet they have dramatically different isotopic compositions. The isotopic composition measured in OB94-7B $(3-4 \mathrm{~cm})$ suggests that it is contaminated with material originating from the upper Ob River. The isotopic composition measured in OB94-10A $(39-40 \mathrm{~cm})$ suggests that it contains a large percentage of material that is consistent with the isotopic composition of soils collected from Semipalitinsk. OB95-04 $(7-8 \mathrm{~cm})$ and OB95-04 (16$17 \mathrm{~cm}$ ) were selected in order to characterize the partitioning behavior of contamination originating from Tomsk. The down-core ${ }^{237} \mathrm{~Np} /{ }^{239} \mathrm{Pu}$ profile revealed maxima at both horizons (chapter 6). Additionally, deposition age estimates indicate that the non-fallout contamination observed in both OB95-04 (7-8 cm) and OB94-07B $(3-4 \mathrm{~cm})$ likely originate from the same source (i.e.Tomsk-7). OB95-13 $(16-17 \mathrm{~cm})$ was chosen in order to characterize the partitioning behavior of contamination originating from Semipalitinsk. OB95-13 (15-16) exhibited a ${ }^{240} \mathrm{Pu} /{ }^{239} \mathrm{Pu}$ ratio of 0.08 , but there was not enough bulk sediment remaining on which to perform sequential extraction. OB95-13 (16-17) is the sample immediately below; it also exhibits a low ${ }^{240} \mathrm{Pu} /{ }^{239} \mathrm{Pu}$ ratio and is likely related to the same source of contamination. 
Table 7:2. Bulk Sediment Samples Selected for Sequential Extraction

\begin{tabular}{cclcccc}
\hline $\begin{array}{c}\text { Sample } \\
\text { ID }\end{array}$ & $\begin{array}{c}\text { Depth } \\
\text { interval }\end{array}$ & Location & $\begin{array}{r}\text { Deposition } \\
\text { Year }\end{array}$ & $\begin{array}{c}{ }^{240} \mathrm{Au} /{ }^{239} \mathrm{Pu} \\
\text { Atom ratio }\end{array}$ & \multicolumn{1}{c}{ Atom ratio } & $\begin{array}{r}\text { Suspected } \\
\text { Source }(\mathrm{s})^{*}\end{array}$ \\
\hline $94-07 \mathrm{~B}$ & $3-4$ & Ob delta & 1988 & $0.167 \pm 0.003$ & $1.166 \pm 0.015$ & $\mathrm{GF,T}$ \\
$94-10 \mathrm{~A}$ & $39-40$ & Ob delta & 1975 & $0.052 \pm 0.001$ & $0.035 \pm 0.001$ & GF,S \\
$95-04$ & $7-8$ & Ob River & 1988 & $0.111 \pm 0.002$ & $1.131 \pm 0.018$ & GF,T \\
$95-04$ & $16-17$ & Ob River & 1975 & $0.132 \pm 0.001$ & $0.7 \pm 0.028$ & GF,T \\
$95-13$ & $16-17$ & Irtysh River & 1982 & $0.141 \pm 0.006$ & $0.458 \pm 0.026$ & GF,S \\
\hline
\end{tabular}

${ }^{*} \mathrm{GF}=$ global stratospheric fallout, $\mathrm{T}=$ Tomsk-7, $\mathrm{S}=$ Semipalitinsk.

Distributions of ${ }^{239} \mathrm{Pu},{ }^{240} \mathrm{Pu}$, and ${ }^{237} \mathrm{~Np}$ among Fractions

The distributions of ${ }^{239} \mathrm{Pu},{ }^{240} \mathrm{Pu}$, and ${ }^{237} \mathrm{~Np}$ measured in each sample are

summarized in Table 7:3. In general, the sediments from different locations behaved in a comparable manner. The majority of the total extracted plutonium and neptunium distributed similarly between the reducible, carbonate, acid leachable and refractory (F6) fractions, with reducible fraction containing by far the highest percentage of both elements. The exchangeable and organic fractions together contain approximately 20 percent of the total extracted neptunium and little or no plutonium. This suggests that a minor portion of the total neptunium may be affected by environmental conditions that have little or no effect on plutonium. The acid leachable and refractory fractions to gether contain $\sim 10$ to 20 percent of the plutonium and $\sim 7$ percent of the neptunium. The results from each extraction are discussed below.

Exchangeable Fraction (F1)

$$
{ }^{239} \mathrm{Pu} \text { and }{ }^{240} \mathrm{Pu} \text { extracted by the } \mathrm{NH}_{4} \text {-acetate treatment ranged from } 0 \text { to } 1
$$
percent, with most values below detection, indicating that little if any Pu is held in an ion 
exchangeable form (Table 7:3). In contrast, the proportion of ${ }^{237} \mathrm{~Np}$ in $\mathrm{F} 1$ ranged from 10 to 15 percent, which indicates the presence of easily exchangeable ${ }^{237} \mathrm{~Np}$. This suggests that some of the neptunium may be more easily removed from particles than plutonium. Table 7:4 summarizes the results of earlier studies, in which selective extraction techniques were used to assess Pu mobility in a variety of environmental samples. These include sediments and/or soils from Lake Michigan, Buzzards Bay, southern Ohio, and the region surrounding Mayak (Alberts et al., 1974, Edgington et al., 1976, Muller, 1978, JNREG, 1997). Results from studies that used either $\mathrm{NH}_{4}$-acetate or $\mathrm{MgCl}_{2}$ to extract exchangeable plutonium (methods A and C, Table 7:4) indicate the presence of a small amount of plutonium in the exchangeable fraction. It is noteworthy that JNREG (1997), using a technique similar to the one in the present study, observed measurable amounts of plutonium in the exchangeable fractions of materials collected near Mayak. Given the extremely elevated plutonium concentrations measured by Oughton et al. (2000) especially in the reservoir $10\left(\sim 4 \times 10^{5} \mathrm{~Bq} \mathrm{~kg}^{-1}\right)$, the small percentages observed by JNREG (1997) could represent significant amounts of exchangeable plutonium.

\section{Reducible Fraction (F2)}

The results clearly indicate that the majority of $\mathrm{Pu}$ and $\mathrm{Np}$ contained in Ob River sediments is associated with the $\mathrm{CDB}$ extractable phase. The relative proportions of contaminants extracted by the CDB treatment ranged from 73 to 97 percent for ${ }^{239} \mathrm{Pu}$ and ${ }^{240} \mathrm{Pu}$ and from 66 to 76 percent for ${ }^{237} \mathrm{~Np}$ (Table 7:3). Furthermore, the high percentages of the total plutonium extracted by CDB observed in the present study are in good 


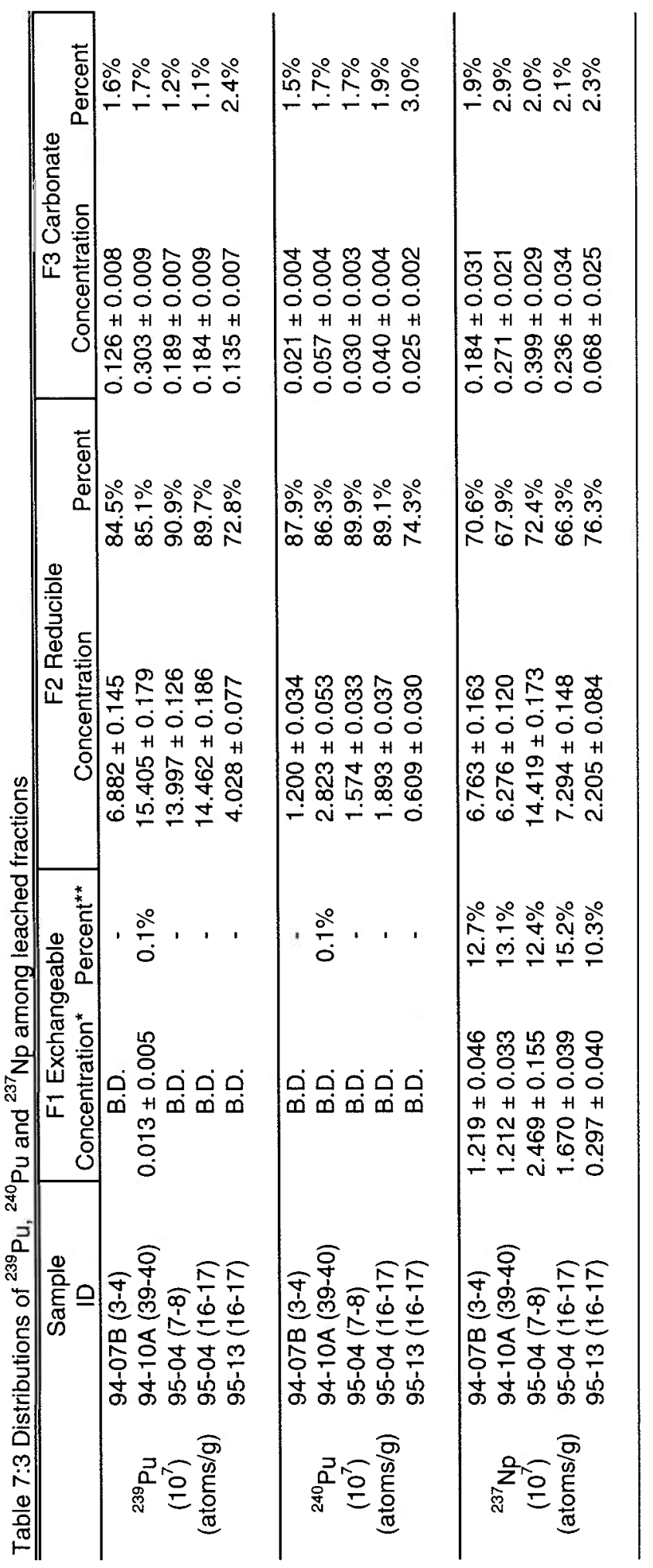




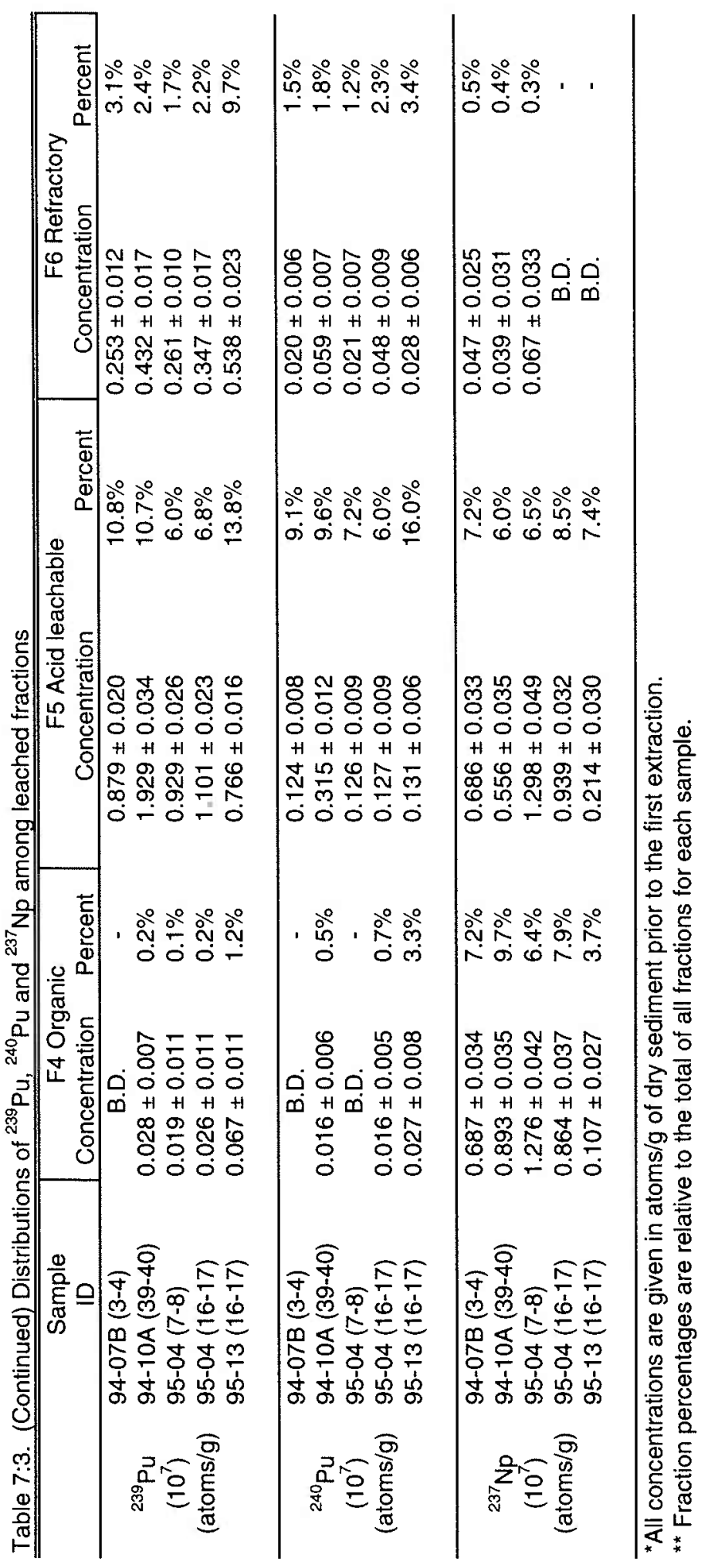


agreement with previous research that used variations of the $\mathrm{CDB}$ treatment (method $\mathrm{D}$, see Table 7:4 for references). This indicates that the effects of temperature and lower $\mathrm{pH}$ are minimal. Ruttenberg (1992) demonstrated that the CDB technique efficiently solubilizes Fe(III) minerals, thus it is reasonable to assume the reduction of a large percentage of minerals containing $\mathrm{Fe}^{3+}$ and other redox sensitive elements (i.e. $\mathrm{MnO}_{\mathrm{X}}$ ) during the extraction of $\mathrm{Ob}$ sediments. Using $\mathrm{NH}_{2} \mathrm{OH}-\mathrm{HCl}$ as the reducing extractant, JNREG (1997) also observed that a substantial percentage of plutonium (30 to 50 percent) was solublized in some samples. This makes it difficult to argue against an association of some type between $\mathrm{Pu}$ and $\mathrm{Np}$ and redox sensitive elements, whether they are in the form of hydrous oxides or true minerals. The effect of complexation alone or in combination with reduction is another matter.

The CDB technique combines a strong reductant with several ligands capable of forming aqueous complexes with Pu and Np. The stability constants for Pu-citrate complexes have been estimated at $1.7 \times 10^{27}$ and $1 \times 10^{11}$ for $\mathrm{Pu}^{4+}$ and $\mathrm{Pu}^{3+}$, respectively (Vinogradov and Gryzin, 1952). There is also solid evidence to suggest that the reduction of $\mathrm{Pu}$ and $\mathrm{Np}$ causes these elements to become less soluble (i.e. $\mathrm{K}_{\mathrm{d}} \mathrm{Pu}(\mathrm{III}$, IV) $>K_{d} P u(V, V I)$ (Edgington 1981). The presence of complexing agents in the F2 treatment at high concentrations is important and likely to prevent $\mathrm{Pu}$ and $\mathrm{Np}$ liberated by reduction of host phases from re-adsorbing on available mineral surfaces. Edgington et al. (1976) and Kung et al. (1998) attempted to resolve the individual contributions of reduction and complexation by comparing the extractable proportions of plutonium between CDB (treatment $\mathrm{D}$ and $\mathrm{L}$ ), citrate-only (treatment $\mathrm{E}$ ), and dithionite-only 


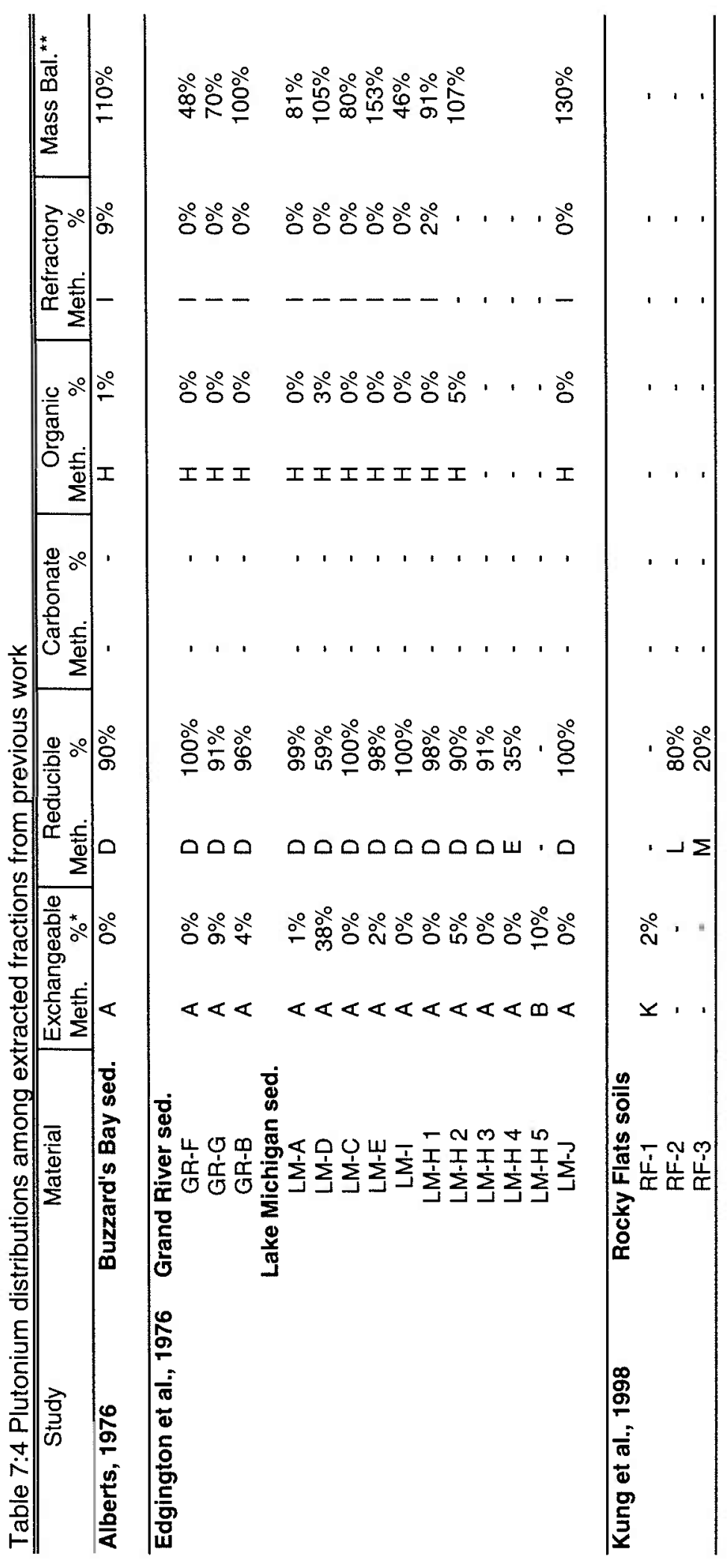




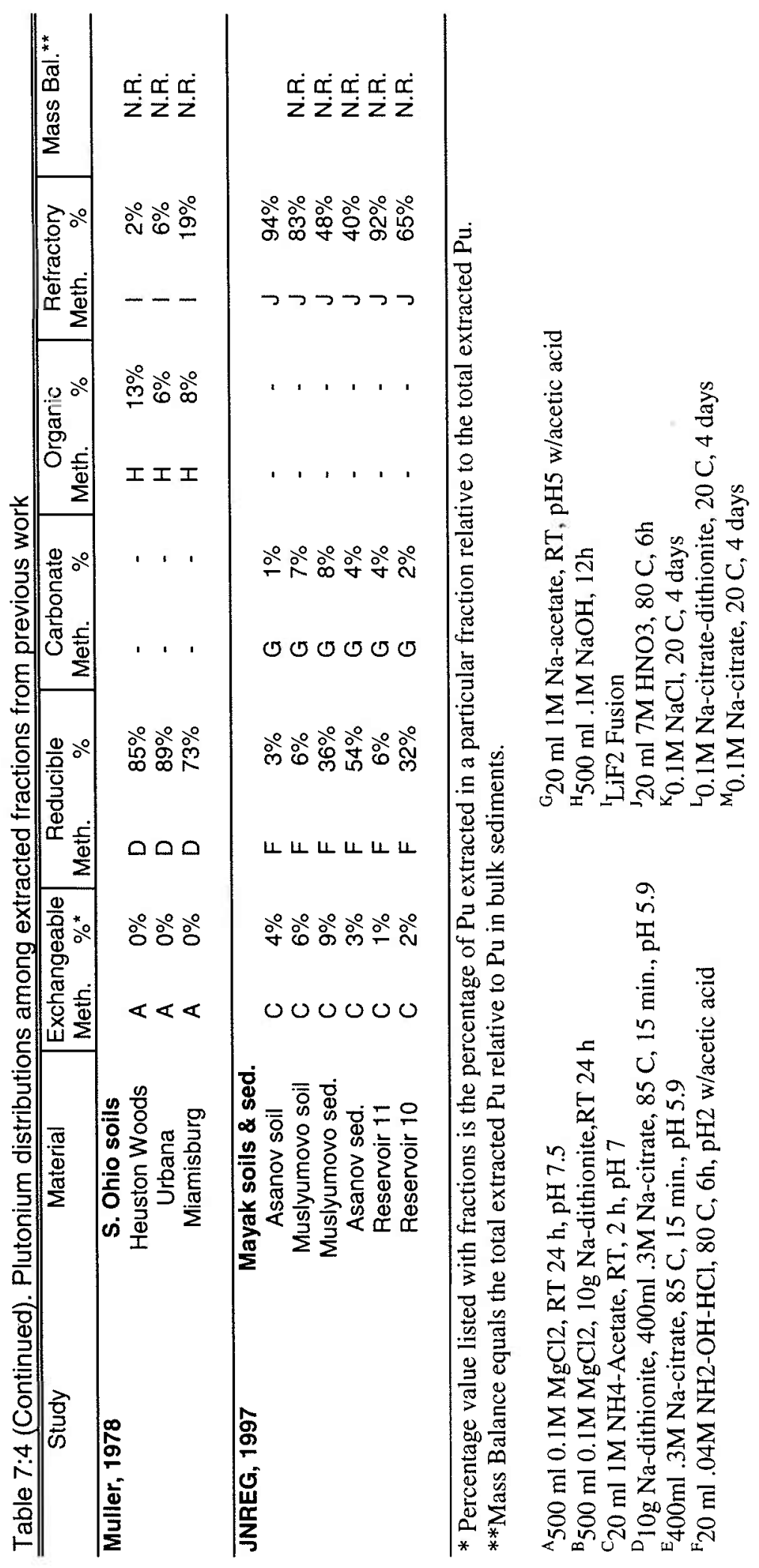


(treatment M). Compared to the total Pu measured in bulk samples (LM-H1 through $\mathrm{LM}-\mathrm{H} 3$, and $\mathrm{RF}-2$ and 3), the $\mathrm{MgCl}_{2} /$ dithionite treatment (B) extracted 10 percent and the citrate-only treatments ( $\mathrm{E}$ and $\mathrm{M})$ extracted between 20 and 35 percent. These results are quite different from the results of the $\mathrm{MgCl}_{2}$ (no Pu extracted) and citrate-dithionite treatments, which extracted between 80 and 90 percent. There also appears to be an effect of adding both citrate and dithionite together as the total amount of Pu released by the combined reagents is twice that obtained from separate additions (Edgington, Wahlgren et al. 1976).

From the results presented here and by other researchers, several important conclusions can be drawn concerning the $\mathrm{CDB}$ extractable fraction. Global fallout (presumably the only source of contamination to Lake Michigan) appears to be present in multiple forms that are collectively extracted by the citrate-dithionite treatment. While separate extractions by dithionite and citrate were not performed in the present study, large fractions of total $\mathrm{Pu}$ and $\mathrm{Np}$ were extracted with $\mathrm{CDB}$ from sediments containing both fallout and non-fallout contamination from different sources. This indicates that a large percentage nuclear weapons related contamination, regardless of the source, exhibits a similar behavior with respect to $\mathrm{CDB}$ extraction. The environmental implications of CDB extractable plutonium and neptunium will be discussed at the end of the chapter. 
Carbonate Fraction (F3)

Only a small amount of plutonium and neptunium is associated with carbonates or other Na-acetate soluble mineral phases. The relative proportions of contaminants extracted by the Na-acetate treatment ranged from 1 to 3 percent for ${ }^{239} \mathrm{Pu},{ }^{240} \mathrm{Pu}$, and ${ }^{237} \mathrm{~Np}$. These results are not surprising as carbonates are not expected to be a significant component of $\mathrm{Ob}$ River sediments. Although a different reagent was used to extract the carbonate mineral phases prior to the reducible fraction $\left(\mathrm{NH}_{4}\right.$-acetate, $\left.\mathrm{pH} 5\right)$, JNREG (1997) results are only slightly higher than those from the present study. That different extraction techniques and a different extraction order yield similar results supports the idea that that contaminants associated with carbonate phases are not significant in $\mathrm{Ob}$ River sediments.

\section{Organic Fraction (F4)}

These data indicate that the $\mathrm{H}_{2} \mathrm{O}_{2}$ extractable phase contains only a small percentage of both elements, but it plays a more important role in $\mathrm{Np}$ partitioning. The relative proportions of ${ }^{239} \mathrm{Pu}$ and ${ }^{240} \mathrm{Pu}$ extracted by the $\mathrm{H}_{2} \mathrm{O}_{2}$ treatment were $<3$ percent and the proportions of $\mathrm{Np}$ were $<10$ percent (Table 7:3), which suggests that some $\mathrm{Np}$ partitions more easily into the organic phase. Additionally, the proportions of ${ }^{239} \mathrm{Pu}$ and ${ }^{240} \mathrm{Pu}$ extracted by the $\mathrm{H}_{2} \mathrm{O}_{2}$ treatment were $<1$ percent in all sediment samples except for those from the Irtysh River where values ranged from 1 to 3 percent. In contrast, the proportions of ${ }^{237} \mathrm{~Np}$ ranged from 6 to 10 percent in all sediment samples except for those from the Irtysh River where the value was $<4$ percent. The relative proportions of $\mathrm{Pu}$ and 
Np observed in Irtysh River sediments compared to sediments from other locations may indicate that some of the contamination derived from Semipalitinsk may partition differently into the organic phase.

Table 7:5. Weight percent organic material for selected samples

\begin{tabular}{lrc}
\hline \hline Core ID & $\begin{array}{c}\text { Depth } \\
\text { Interval }\end{array}$ & $\begin{array}{c}\% \text { Org } \\
\text { (dry wt.) }\end{array}$ \\
\hline & & \\
OB94-07B & $(1-2)$ & $3.79 \%$ \\
& $(2-3)$ & $3.55 \%$ \\
& $(3-4)$ & $4.73 \%$ \\
& $(4-5)$ & $4.44 \%$ \\
& $(7-8)$ & $5.32 \%$ \\
& $(8-9)$ & $4.20 \%$ \\
& $(9-10)$ & $4.82 \%$ \\
& $(14-15)$ & $3.08 \%$ \\
OB94-10A & $(16-17)$ & $3.28 \%$ \\
& $(8-9)$ & \\
& $(9-10)$ & $2.95 \%$ \\
& $(10-11)$ & $2.76 \%$ \\
& $(24-25)$ & $3.66 \%$ \\
& $(25-26)$ & $5.15 \%$ \\
& $(26-27)$ & $4.55 \%$ \\
& $(27-28)$ & $4.62 \%$ \\
& $(39-40)$ & $4.90 \%$ \\
& $(40-41)$ & $3.39 \%$ \\
& $(41-42)$ & $3.28 \%$ \\
OB95-13 & $(42-43)$ & $2.90 \%$ \\
& $(9-10)$ & $3.43 \%$ \\
& $(10-11)$ & \\
& $(39-40)$ & $0.02 \%$ \\
& & $0.18 \%$ \\
\end{tabular}

In order to approximate the percentage of organic material (by weight) in $\mathrm{Ob}$ River sediments, 1 gram sub-samples of bulk sediments were dried and weighed before and after treatment with $30 \% \mathrm{H}_{2} \mathrm{O}_{2}$. The results are shown in Table 7:5. Percent organic matter in sediments from the $\mathrm{Ob}$ delta range between 2 to 5 percent while sediments collected from the upper Irtysh River contain $\sim$ an order of magnitude less organic matter 
( 0 to 0.36 percent). Although representative samples from all core locations were not measured in this fashion, the data demonstrate that organic material accounts for only a small portion of the total sediment mass. It is also clear that percent organic matter varies between sediments collected from the delta and at least one of the upstream tributaries. Furthermore, the smaller amount of organic material observed in sediments from the upper Irtysh River offers a reasonable explanation of the smaller fraction of ${ }^{237} \mathrm{~Np}$ observed in the organic fraction of OB95-13 (16-17).

Previous studies have used a $.1 \mathrm{M} \mathrm{NaOH}$ extraction to represent $\mathrm{Pu}$ associated with organic matter. While Muller et al. (1978) observed greater proportions of $\mathrm{Pu}$ in the organic fractions of Ohio soils, results from Buzzzard's Bay and Lake Michigan are all in good agreement with results from the present study.

Acid leachable Fraction (F5)

A minor percentage of both elements are associated with lithogenic phases and accessible by harsh treatments (Table 7:3). The relative proportions of ${ }^{239} \mathrm{Pu},{ }^{240} \mathrm{Pu}$, and ${ }^{237} \mathrm{~Np}$ extracted by the $\mathrm{HNO}_{3}$ treatment ranged from 6 to 15 percent. These results are in good agreement with the majority of the previous studies, but they are significantly different from the results published for sediments collected near Mayak, which indicated that this fraction contained between 40 and 94 percent of the total Pu (JNREG, 1997) (Table 7:4). This difference may indicate a difference in partitioning behavior of material originating from Mayak, but it is most likely due to the use of $\mathrm{NH}_{2}-\mathrm{OH}-\mathrm{HCl}$ as the reducible phase extractant. If one compares the results of Edgington et al. (1976) for 
LM-H-5 (method B, reducible plus exchangeable; see Table 7:4), only 10\% of the plutonium was extracted. Assuming that the treatment of this sample with hot concentrated $\mathrm{HNO}_{3}$ following method $\mathrm{B}$ would result in the extraction of the remaining $90 \%$, the results of JNREG (1997) are explainable. However, the large percentage of plutonium and neptunium (this study) observed in association with the CDB extractable fraction clearly demonstrates that the contaminants are not truly refractory.

Refractory Fraction (F6)

The relative proportions of ${ }^{239} \mathrm{Pu}$ and ${ }^{240} \mathrm{Pu}$ extracted by totally digesting the sediment residues in HF:aqua regia treatment were 1-3 percent for all sediments except for those collected from the Itrysh River, which contained $\sim 10$ percent of the total ${ }^{239} \mathrm{Pu}$. The relative proportions of ${ }^{237} \mathrm{~Np}$ were $<1$ percent for all sediments. A relatively larger fraction of plutonium in sediments from the Irtysh River, which likely contain contamination as a result of weapons tests at Semipalitinsk, supports the existence of plutonium that is in an acid leach resistant form.

Comparison of ${ }^{239} \mathrm{Pu},{ }^{240} \mathrm{Pu}$, and ${ }^{237} \mathrm{~Np}$ measured in bulk sediments and fraction totals A comparison of the ${ }^{239} \mathrm{Pu},{ }^{240} \mathrm{Pu},{ }^{237} \mathrm{~Np}$ concentrations measured in bulk sediments and the fraction totals for each isotope are given in table 7:6. In general, mass balances between summed fractions and bulk sediments are good. For each sample, the total ${ }^{237} \mathrm{~Np}$ concentration (i.e. sum of all fractions) was within $\pm 2 \sigma$ of their corresponding bulk sediment values. This demonstrates that the extraction methods employed are 
robust and that any material lost during the extractions was insignificant. Pu isotopes exhibit some variability between summed fractions and bulk sediments, most notably 9410A (39-40). These discrepancies are similar to those observed between replicate analyses in some samples and are likely further evidence of heterogeneous distribution of plutonium derived from non-fallout sources (see Chapter 4 for details). An examination of the total extracted and bulk sediment ${ }^{237} \mathrm{~Np}$ concentrations indicates that mass balance is good for 94-10A (39-40), which precludes significant mass loss during sequential extraction as the cause of very different plutonium concentrations.

Table 7:6 Concentrations ${ }^{*}$ of ${ }^{239} \mathrm{Pu},{ }^{240} \mathrm{Pu}$ and ${ }^{237} \mathrm{~Np}$ for Fraction Totals and Bulk Sediments

\begin{tabular}{clccc}
\hline \hline & \multicolumn{1}{c}{ Sample } & \multicolumn{1}{c}{$\sum$ Fractions } & Bulk Sediment & $\Sigma$ Fxns/Bulk Sed. \\
\hline & $94-07 \mathrm{~B}(3-4)$ & $8.148 \pm 0.147$ & $8.234 \pm 0.063$ & $0.99 \pm 0.02$ \\
${ }^{239} \mathrm{Pu}$ & $94-10 \mathrm{~A}(39-40)$ & $18.111 \pm 0.184$ & $259.720 \pm 3.283$ & $0.07 \pm 0.00$ \\
$\left(10^{7}\right)$ & $95-04(7-8)$ & $15.369 \pm 0.131$ & $16.929 \pm 0.165$ & $0.91 \pm 0.01$ \\
$($ atoms/g) & $95-04(16-17)$ & $16.126 \pm 0.189$ & $16.457 \pm 0.658$ & $0.98 \pm 0.04$ \\
& $95-13(16-17)$ & $5.532 \pm 0.083$ & $6.190 \pm 0.218$ & $0.89 \pm 0.03$ \\
\hline & & & & $0.99 \pm 0.03$ \\
${ }^{240} \mathrm{Pu}$ & $94-07 \mathrm{~B}(3-4)$ & $1.366 \pm 0.036$ & $1.375 \pm 0.020$ & $0.24 \pm 0.01$ \\
$\left(10^{7}\right)$ & $94-10 \mathrm{~A}(39-40)$ & $3.272 \pm 0.056$ & $13.510 \pm 0.205$ & $0.87 \pm 0.03$ \\
$($ atoms/g) & $95-04(7-8)$ & $1.627 \pm 0.042$ & $1.877 \pm 0.034$ & $0.98 \pm 0.04$ \\
& $95-13(16-17)$ & $2.130 \pm 0.040$ & $2.172 \pm 0.087$ & $0.95 \pm 0.05$ \\
& & $0.828 \pm 0.032$ & $0.870 \pm 0.033$ & $1.00 \pm 0.02$ \\
\hline${ }^{237} \mathrm{~Np}$ & $94-07 \mathrm{~B}(3-4)$ & $9.586 \pm 0.180$ & $9.600 \pm 0.097$ & $1.02 \pm 0.03$ \\
$\left(10^{7}\right)$ & $95-10 \mathrm{~A}(39-40)$ & $9.248 \pm 0.140$ & $9.075 \pm 0.190$ & $1.04 \pm 0.02$ \\
$($ atoms/g) & $95-04(16-17)$ & $11.016 \pm 0.166$ & $19.147 \pm 0.245$ & $0.96 \pm 0.04$ \\
& $95-13(16-17)$ & $2.892 \pm 0.109$ & $2.835 \pm 0.128$ & $1.02 \pm 0.06$ \\
\hline
\end{tabular}

${ }^{*}$ All concentrations are given in atoms/g of dry sediment prior to the first extraction. Uncertainties are given in \pm 1 sigma.

Comparison $\mathrm{Pu}$ and Np isotopic composition of bulk sediments and leached fractions

One of the objectives of the present study was to determine if contaminants originating from different sources are partitioned into distinct solid phase reservoirs. By 
employing the same approach as that used for bulk sediments (chapter 4), the ${ }^{240} \mathrm{Pu} /{ }^{239} \mathrm{Pu}$ and ${ }^{237} \mathrm{~Np} /{ }^{239} \mathrm{Pu}$ isotope ratios measured in each fraction can be compared to published values for global fallout and other known or suspected sources. The ability to achieve reasonable precision when calculating the isotopic composition of individual leached fractions is limited by low quantities of ${ }^{239} \mathrm{Pu},{ }^{240} \mathrm{Pu}$, and ${ }^{237} \mathrm{~Np}$ present in some cases.

For discussion purposes, all fractions are regrouped into two distinct geochemical fractions: Accessible (F1 through F4) and Refractory (F5 and F6). This is a reasonable division given that any $\mathrm{Pu}$ or $\mathrm{Np}$ associated with fractions F1 through F4 could be affected by environmental processes. In contrast, $\mathrm{Pu}$ and $\mathrm{Np}$ requiring strong acid treatments for removal from sediments are reasonably characterized as irreversibly bound and environmentally unavailable, hence refractory.

A comparison of ${ }^{240} \mathrm{Pu} /{ }^{239} \mathrm{Pu}$ isotope ratios $( \pm 2 \sigma)$ calculated for accessible and refractory fractions and the $\pm 2 \sigma^{240} \mathrm{Pu} /{ }^{239} \mathrm{Pu}$ for global fallout is shown Figure 7:2. The ${ }^{240} \mathrm{Pu} /{ }^{239} \mathrm{Pu}$ observed in accessible and refractory fractions ranged between 0.11 and 0.18 . The ${ }^{240} \mathrm{Pu} /{ }^{239} \mathrm{Pu}$ ratios observed in the accessible fractions of $94-07 \mathrm{~B}(3-4)$ and $95-13$ (1617), as well as both accessible and refractory fractions of 94-10A (39-40), and are indistinguishable from global fallout. The ${ }^{240} \mathrm{Pu} /{ }^{239} \mathrm{Pu}$ ratios in the refractory fractions of both 94-07B (3-4) and 95-13 (16-17) are significantly different from both global fallout and their corresponding accessible fractions. These observations clearly demonstrate the presence of an isotopically distinct source of plutonium of a refractory nature. The refractory ${ }^{240} \mathrm{Pu} /{ }^{239} \mathrm{Pu}$ ratios in all samples except $94-10 \mathrm{~A}(39-40)$ are essentially identical and have a mean ratio value of $0.123 \pm 0.001(1 \sigma)$. The presence of similarly low 

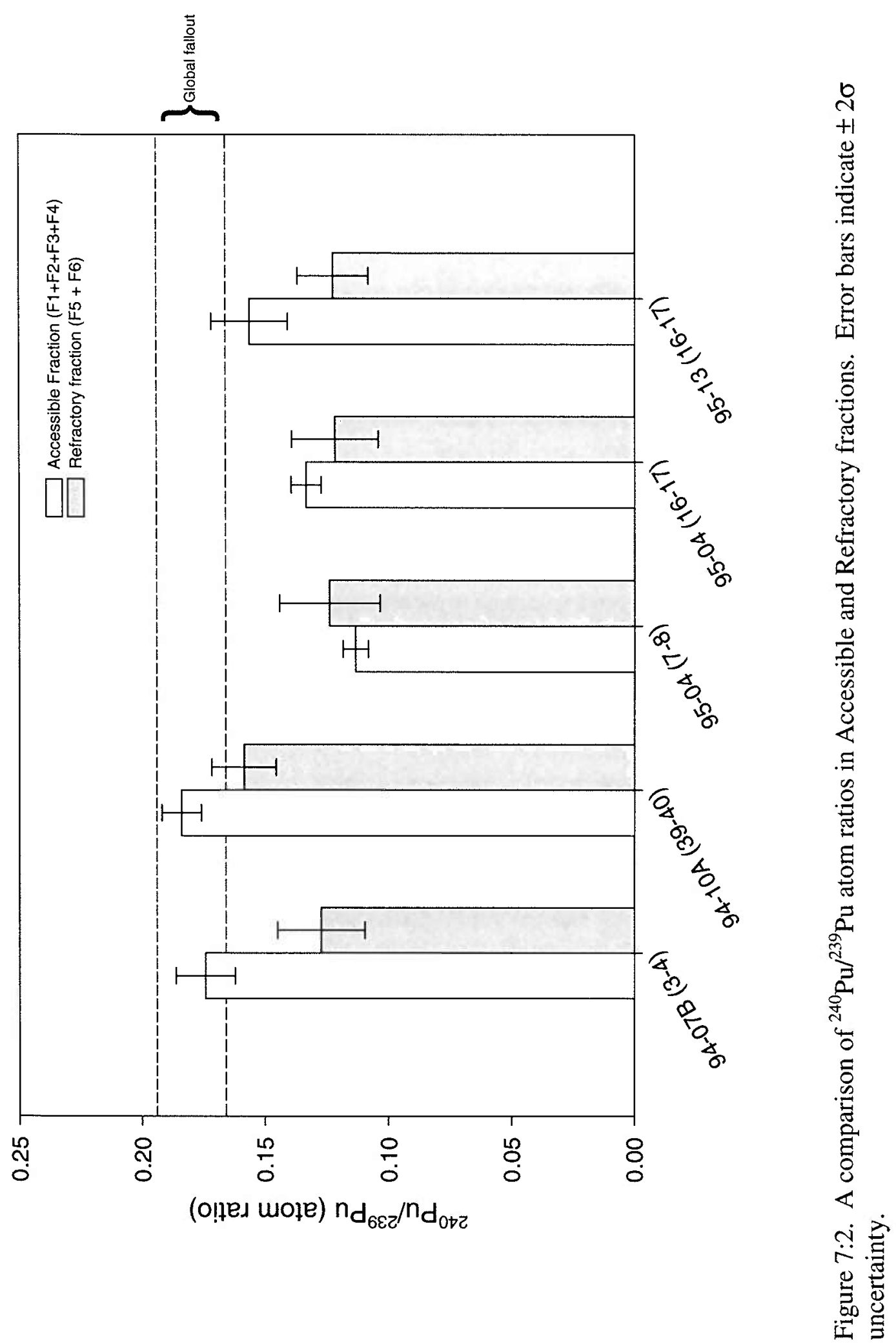
${ }^{240} \mathrm{Pu} /{ }^{239} \mathrm{Pu}$ ratios in refractory fractions of sediments from the $\mathrm{Ob}$ and Irtysh Rivers suggests either a source of refractory plutonium in each river or one that is common to both rivers. Interestingly, both samples from the upper Ob River show no difference between accessible and refractory fractions. This suggests two possible scenarios: 1) A single source of low ratio plutonium that is common to more than one tributary and associates with both accessible and refractory sedimentary phases. 2) Two (or more) sources with similar plutonium isotopic compositions that associate with the accessible and refractory sedimentary phases, respectively.

The ${ }^{237} \mathrm{~Np} /{ }^{239} \mathrm{Pu}$ ratios $( \pm 2 \sigma)$ calculated for the accessible and refractory fractions are shown in Figure 7:3 along with values for global fallout and Semipalitinsk. The most obvious feature is the similarity between the accessible fraction in 94-07B (3-4) and both the accessible and refractory fractions in $95-04(7-8)$. They exhibit ${ }^{237} \mathrm{~Np} /{ }^{239} \mathrm{Pu}$ ratios that are elevated well above global fallout and are only observed in the upper Ob River. This is true for the extracted fractions as well as bulk sediments. With regard to the two different samples from the upper Ob River, both exhibit similar ${ }^{240} \mathrm{Pu} /{ }^{239} \mathrm{Pu}$ ratios but have very different ${ }^{237} \mathrm{~Np} /{ }^{239} \mathrm{Pu}$ ratios. Additionally, a comparison of the isotopic compositions of accessible and refractory fractions extracted from upper Ob River sediments reveals no difference within each sample. This seems to indicate that contamination originating from Tomsk-7 contains variable amounts of ${ }^{237} \mathrm{~Np}$ but is partitioned similarly between accessible and refractory sedimentary phases. Another noteworthy feature is the similarity between the fractions in 94-10A (39-40) and 95-13 (16-17), which suggests a link between contamination in the delta sample and 


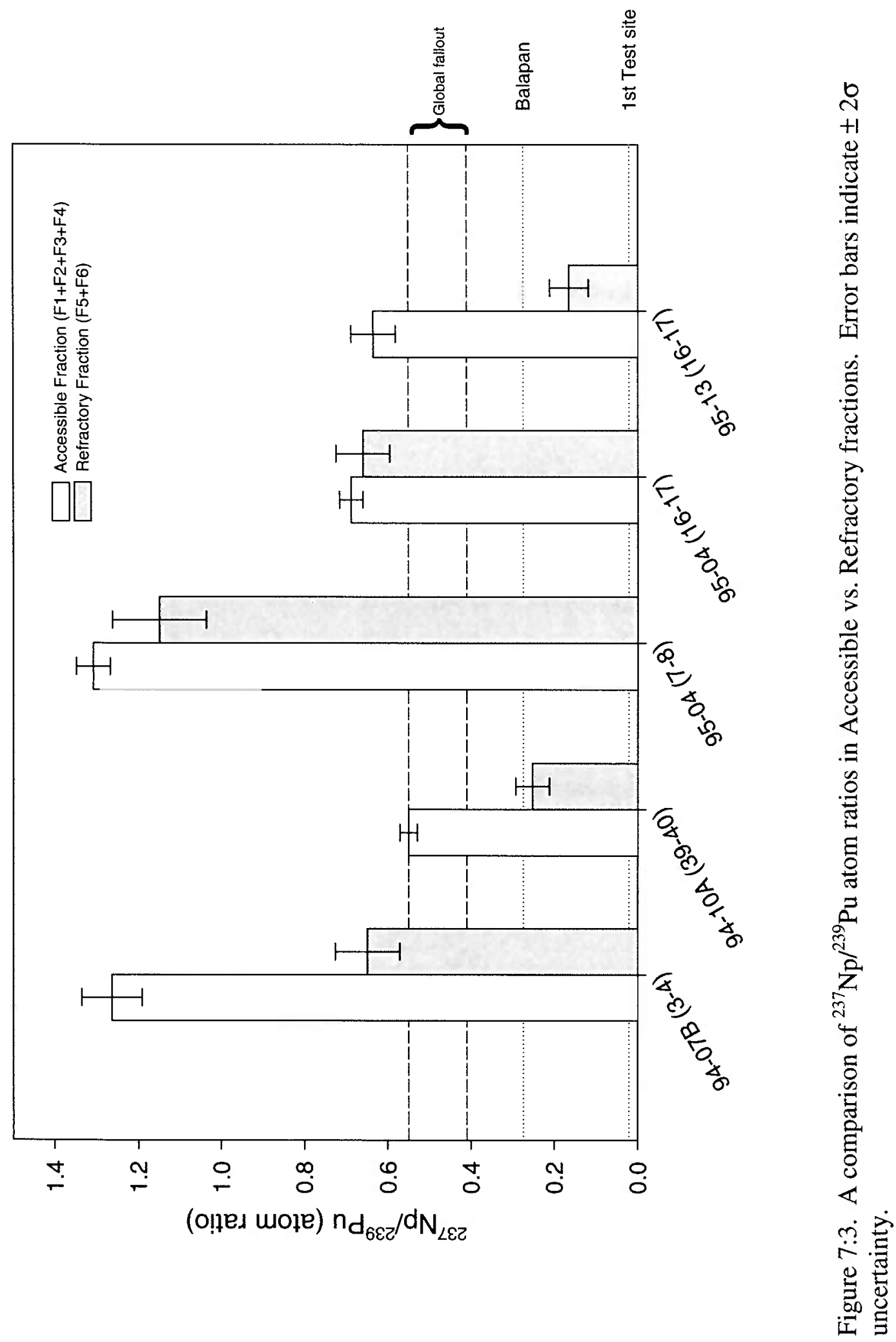


material in the Irtysh River. This is interesting for several reasons, the bulk sediment isotopic composition as well as the ${ }^{240} \mathrm{Pu}_{\mathrm{ex}}{ }^{239} \mathrm{Pu}$ ex ratio (i.e. $\Delta{ }^{240} \mathrm{Pu}$ between replicates/ $\Delta$ ${ }^{239} \mathrm{Pu}$ between replicates) determined from replicate analyses of 94-1ӨA (39-40) (see chapter 4) are consistent with contamination from Semipalitinsk. The ${ }^{240} \mathrm{Pu} /{ }^{239} \mathrm{Pu}$ and ${ }^{237} \mathrm{~Np} /{ }^{239} \mathrm{Pu}$ ratios calculated from the totals extracted are 0.181 and 0.511 , respectively (see Table 7:6), which indicates that bulk sediment isotopic analysis of this sample would have identified global fallout as the only source. Selective extraction evidence that also suggests that the source of non-fallout contamination is Semipalitinsk demonstrates the ability of this technique to identify the presence of non-fallout at low levels. It also further supports the idea that the non-fallout contamination in this sample is not distributed homogeneously.

Samples collected from the upper $\mathrm{Ob}$ and Irtysh Rivers exhibit different nonfallout ${ }^{237} \mathrm{~Np} /{ }^{239} \mathrm{Pu}$ ratios but very similar ${ }^{240} \mathrm{Pu} /{ }^{239} \mathrm{Pu}$ ratios in their refractory fractions. This suggests that the refractory phases in sediments from each river contain contamination originating from different sources.

\section{Fractionation}

A thorough discussion of the implications of the $\mathrm{Np}$ isotopic data presented in this study would not be complete without considering the possible effects of geochemical fractionation. The environmental implications of $\mathrm{CDB}$-extractable plutonium and neptunium are unclear. Kung et al.(1998) measured Eh values between -700 and $500 \mathrm{mv}(\mathrm{pH}=7)$ during the first 4 hours of $\mathrm{CDB}$ extraction. While specific redox data are 
unavailable for the $\mathrm{Ob}$ region, the presence of large areas of low-lying swamps that trap sediments as well as organic material implies that anerobic environments are likely. The values measured by Kung et al. (1998) during CDB extraction however, are well below those estimated in the natural environment (see Figure 7:4 from Garrels and Christ (1965). Furthermore, given the very low Eh values observed by Kung et al. (1998), it is entirely reasonable to assume that $\mathrm{Pu}$ and $\mathrm{Np}$ are reduced along with $\mathrm{Fe}^{3+}$. Given the increase in $K_{d}$ values of tetra and trivalent plutonium, the presence of reducing conditions may not necessarily lead to its increased mobility (Edgington 1981). However, it is important to attempt to establish whether or not significant post-depositional migration has occurred and influenced estimates of the nature and distribution of end members in sediments.

There are many features of these data, which strongly argue against postdepositional migration of $\mathrm{Pu}, \mathrm{Np}$, and $\mathrm{Cs}$ in sediments from the upper reaches of the $\mathrm{Ob}$ River, its major tributaries, and the Ob delta. The global fallout pattern is preserved in nearly all cores and radionuclide distribution profiles largely co-vary both within and between sediment cores from different locations. Although there is some variability between cores with regard to spreading observed in the radionuclide profiles, several provide evidence of the bimodal pattern of global fallout (e.g. OB94-07B, OB95-13). Other cores, collected primarily in the delta, do show evidence of greater spreading (e.g. OB94-08, 09, and 13). However, there is no evidence of dispersion that cannot be accounted for by limited post-depositional mixing. It is important to remember that the resolution of radionuclide profiles is a function of sedimentation rate and sampling 
interval ( $1 \mathrm{~cm}$ for most cores, $2 \mathrm{~cm}$ for OB94-08). In cores where accumulation rates are low, artifacts as a result of sampling will contribute to the observed spreading.

Many samples $(\sim 1 / 2$; see Table 6:2; fallout $=1-$ non-fallout $)$ exhibit global fallout ${ }^{237} \mathrm{~Np} /{ }^{239} \mathrm{Pu}$ and ${ }^{137} \mathrm{Cs} /{ }^{240} \mathrm{Pu}$ ratios. This includes samples from all cores and all depths and demonstrates no post-depositional migration of global fallout contamination. Contamination derived from weapons production facilities and Chernobyl however, must be assessed as well.

Many radionuclide profiles, where non-fallout contamination is confirmed by isotopic ratios, contain steep concentration gradients that persist for decades. The best example of this is the very sharp gradient observed in the distribution profiles of OB9410A (i.e. concentration spike $\sim 1975$ ). This feature could not persist, if post depositional mobility is a significant factor. Concentration differences between replicate analyses of this and several other samples indicate numerous cases where contamination ( $\mathrm{Pu}$ and $\mathrm{Np}$ ) is not even even distributed through just one sample $(1 \mathrm{~cm})$. 


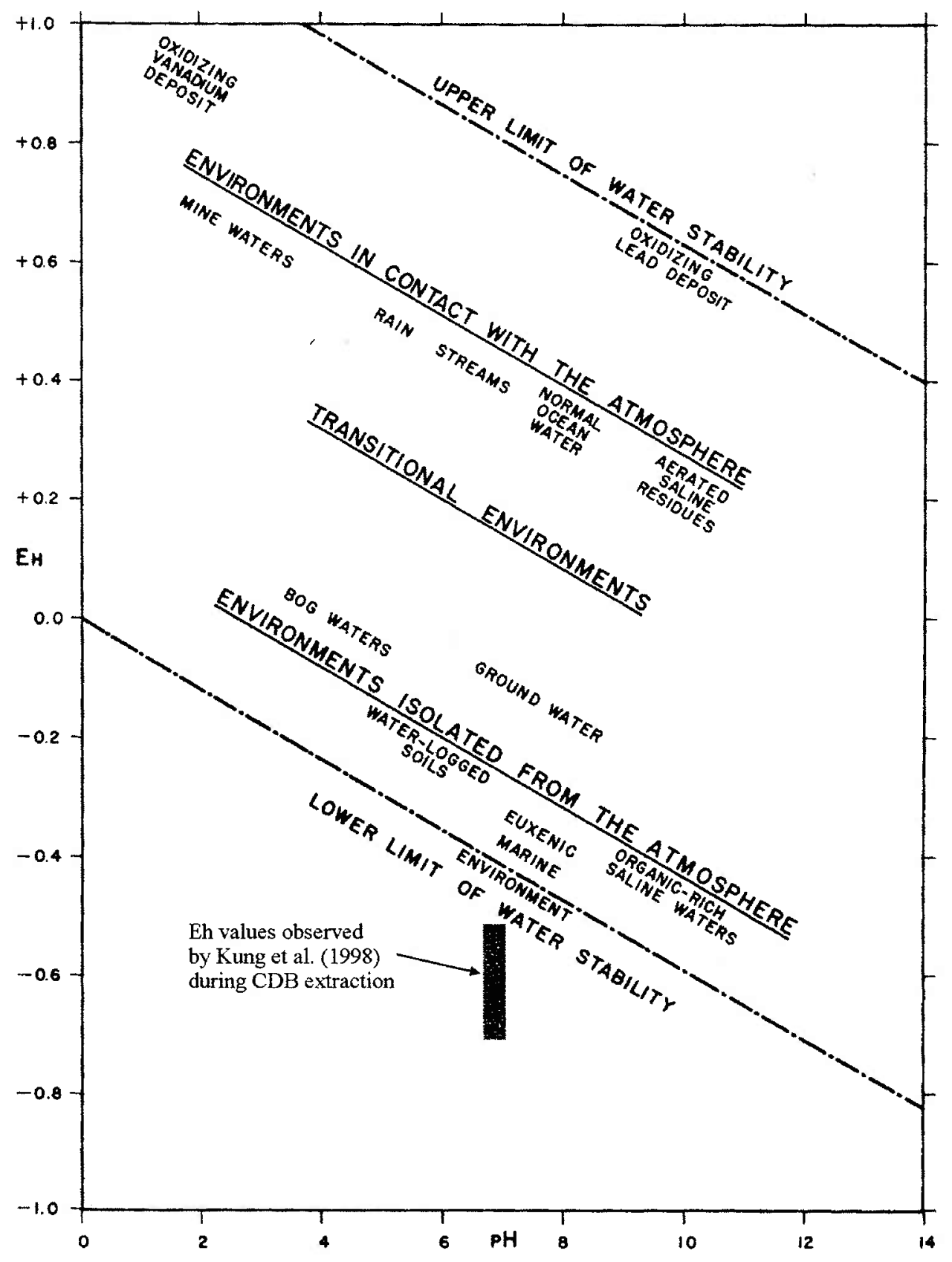

Figure 7:4. Approximate positions of some natural environments as characterized by Eh and $\mathrm{pH}$. Gray rectangle indicates $\mathrm{CDB}$ extraction conditions. Source: Garrels and Christ (1965). 
To further rule out post-depositional migration, one can use the sharp concentration gradients observed in core profiles (weapons and Chernobyl contamination) to estimate the diffusion coefficient that would be necessary to maintain such a gradient according to the following equation:

$$
\frac{C_{\min }}{C_{\max }}=\exp \left[\frac{-\left(\Delta z^{2}\right)}{4 \cdot D_{B} \cdot \Delta t}\right]
$$

Where:

$\mathrm{C}_{\min }$ is the baseline concentration at time of core collection ( 1995)

$\mathrm{C}_{\max }$ is the concentration maximum at time of deposition.

$\Delta \mathrm{z}=$ the distance between the samples;

$\Delta t=$ the time in seconds since deposition of $\mathrm{C}_{\max }$ (i.e. collection date - deposition age of $\mathrm{C}_{\max }$ ).

$D_{B}$ is the diffusion coefficient necessary to maintain the observed gradient.

Resulting diffusion coefficients for several cases where contamination is attributed to weapons sources or Chernobyl are shown in Table 7:7. The diffusion coefficients for $\mathrm{Pu}, \mathrm{Np}$, and $\mathrm{Cs}$ derived from various non-fallout sources are exceedingly small and range between $\sim 1 \mathrm{e}-9$ and $1 \mathrm{e}-10 \mathrm{~cm}^{2} \mathrm{~s}-1$, indicating that diffusion is insignificant. Furthermore, due to the assumption that the measured concentration of Cmax (in 1995) equals the concentration delivered to the sediments at the time of deposition, the estimates shown in Table 7:7 represent upper limits on the rates of radionuclide diffusion. The results from these calculations strongly support the conclusion that $\mathrm{Pu}, \mathrm{Np}$, and $\mathrm{Cs}$ from a variety of sources are tightly bound to particles. 


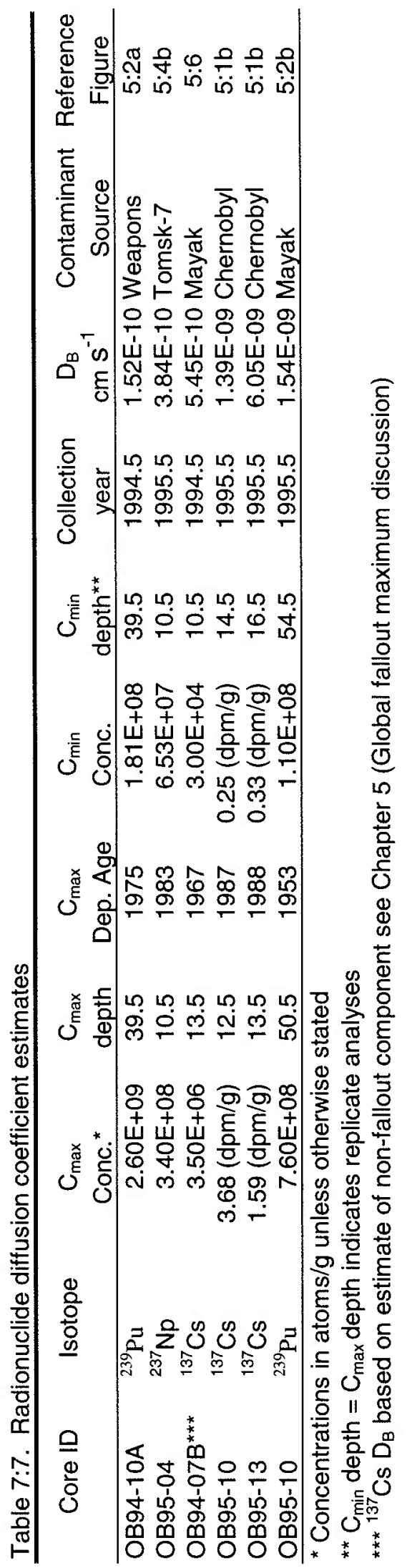


Selective leaching data presented in this study also provide evidence that the majority of plutonium and neptunium form similar associations with sediments from locations in the upper $\mathrm{Ob}$ and Irtysh Rivers as well as the delta. Approximately 80 percent of the total extracted plutonium and neptunium exhibit a distribution of similar proportions within the reducible, carbonate, acid leachable and refractory (F6) fractions. The fact that this is observed in sediments with different deposition ages and sample locations, containing contamination derived from different sources strongly argues against the large-scale selective mobilization of either neptunium or plutonium from river particulate matter. Additionally, the fact that plutonium and neptunium are released from sediments during the $\mathrm{CDB}$ extraction implies that this treatment must be more reducing than the environmental conditions at sampling locations.

Approximately 20 and $\leq 3$ percent of the total extracted neptunium and plutonium, respectively, are observed in the exchangeable and organic fractions (F1 and F4). This suggests that a minor portion of the total neptunium may be affected by environmental conditions that have little or no effect on plutonium. It is important to keep in mind that the ability to separate $\mathrm{Np}$ from $\mathrm{Pu}$ in the laboratory is not proof that it is occurring in situ. It is also important to remember that $\mathrm{Pu}$ and $\mathrm{Np}$ have substantially different applications in the nuclear industry, and the isotopic composition of wastes originating from a facility will be reflective of the different programs underway. The accessible fractions in each sample account for most of the weapons related contamination and exhibit ${ }^{237} \mathrm{~Np} /{ }^{239} \mathrm{Pu}$ ratios that are greater than or equal to global fallout values. This is also true when ${ }^{237} \mathrm{~Np} /{ }^{239} \mathrm{Pu}$ ratios were calculated without the ${ }^{237} \mathrm{~Np}$ 
contributions from the exchangeable and organic fractions, indicating that the loss of the ${ }^{237} \mathrm{~Np}$ contained in these fractions is minimal. It is worth noting also that samples were selected for sequential extraction based on non-fallout bulk sediment isotopic compositions, not based on the suspicion of fractionation of neptunium from plutonium (see below).

Data from the $\mathrm{Ob}$ and Taz estuaries provides some evidence for fractionation of $\mathrm{Np}$ from Pu at these locations. Cooper et al., (2000) have suggested this mechanism to explain characteristically low ${ }^{237} \mathrm{~Np} /{ }^{239} \mathrm{Pu}$ ratios measured in a surface grab from the $\mathrm{Ob}$ estuary. Interestingly, their data are quite similar to results in this study from the Taz estuary (OB94-13), a core that was taken only $124 \mathrm{~km}$ away from the site sampled by Cooper et al. (2000). Both sample locations are near the southern limit of seawater penetration at Cape Kamenny (Ivanov et al., 1995). As discussed in Chapter 6, if fractionation is not occurring, the tight clustering of ${ }^{237} \mathrm{~Np} /{ }^{239} \mathrm{Pu}$ values $\sim 0.3$ for both locations and ${ }^{240} \mathrm{Pu} /{ }^{239} \mathrm{Pu}$ values indistinguishable from global fallout require addition of $\mathrm{a}^{237} \mathrm{~Np}$-depleted source with a global fallout ${ }^{240} \mathrm{Pu} /{ }^{239} \mathrm{Pu}$ ratio. Further, input of the proportion of this material must remain constant over the period of large changes in global fallout deposition rate. This seems highly improbable; leading to the conclusion that a fractionation process occurs in these sediments. Cochran et al. (2000) observed similar depletions in suspended sediments from the Taz and Ob estuaries (sampled at core locations), but failed to observe systematically low ${ }^{237} \mathrm{~Np} /{ }^{239} \mathrm{Pu}$ ratios at upriver sites. Whatever the origin of low ${ }^{237} \mathrm{~Np}$ material in the Taz and Ob Estuaries, there is no evidence to support substantial fractionation in the delta or at upstream locations. 


\section{Conclusions}

The main goals of this sequential extraction study were to test the assumptions made concerning the reversibility of adsorption of plutonium and neptunium, and determine if contaminants originating from the various sources are partitioned differently between solid phase reservoirs.

Selective leaching data indicate the majority of the total extracted plutonium and neptunium exhibits a distribution of similar proportions within many of the extracted fractions, with the largest percentage of both elements being observed in the reducible fraction. The environmental implications of the reducible fraction are unclear. Although an association of plutonium and neptunium with redox sensitive elements is likely, available data indicate little if any selective mobilization of plutonium or neptunium is occurring. Minor amounts of neptunium partition differently in sediments and are associated with the exchangeable and organic phases. The isotopic data discussed in this section suggest that plutonium and neptunium are strongly bound to particulate matter, and that the equation of contaminant transport with contaminated sediment transport is entirely reasonable in the $\mathrm{Ob}$ delta and upstream locations. Finally, there is clear isotopic evidence that suggests some non-fallout contamination has a refractory nature. However, the amount of this material present in the samples analyzed is small compared to the amount of contamination in accessible fractions. 
References chapter 7

Alberts, J. J., R. N. Muller, et al. (1977). "Particle size and chemical phase distribution of plutonium in an estuarine sediment. Radiological and Environmental Research Division annual report; ecology, January through December 1976." 34-36.

Alberts, J. J., R. N. Muller, et al. (1977). Distribution of fallout and stack-derived plutonium in some Midwestern soils. Radiological and Environmental Research Division annual report; ecology, January through December 1976.: 43-46.

Alberts, J. J., M. A. Wahlgren, et al. (1989). "The distributions of Pu-239,240, Am-241, and Cs-137 among chemically-defined components of sediments, settling particulates, and net plankton of Lake Michigan." Journal of Environmental Radioactivity 9:89-103.

Beasley, T. M., J. M. Kelley, et al. (1998). "Isotopic Pu, U, and Np signatures in soils from Semipalatinsk-21, Kazakh Republic and the Southern Urals, Russia." Journal of Environmental Radioactivity 39(2): 215-230.

Cochran, J. K., S. B. Moran, et al. (2000). "Sources and transport of anthropogenic radionuclides in the Ob River system, Siberia." Earth and Planetary Science Letters 179(1): 125-137.

Edgington, D. N. (1981). A review of the persistence of long-lived radionuclides in the marine environment-sediment/water interactions. Impacts of radionuclide releases into the marine environment, Vienna, IAEA.

Edgington, D. N., J. J. Alberts, et al. (1976). Plutonium and americium in Lake Michigan sediments". Transuranium nuclides in the environment. Transuranium nuclides in the environment. San Franc., Calif., United States: 493-516.

Edgington, D. N., M. A. Wahlgren, et al. (1976). The behavior of plutonium in aquatic ecosystems; a summary of studies on the Great Lakes: Environmental toxicity of aquatic radionuclides; models and mechanisms. Rochester international conference on Environmental toxicity, 8th, 1975; Radioisotopes in the aquatic environment; models and mechanisms. Rochester, NY, United States: 45-79.

Fuger, J. (1992). The Actinide aqueous inorganic complexes. Vienna, International Atomic Energy Agency.

Garrels, R. M. and C. L. Christ (1965). Solutions, Minerals, and Equilibria. New York, Harper and Row.

JNREG and J. N.-R. e. group (1997). Sources contributing to radioactive contamination of the Techa River and areas surrounding the "Mayak" Production Association, 
Urals, Russia. Osteras, Norway, Joint Norwegian-Russian expert group for investigation of radioactive contamination in the northern areas.

Kersten, M., U. Foerstner, et al. (1986). "Chemical fractionation of heavy metals in anoxic estuarine and coastal sediments". Estuarine and coastal pollution; detection, research and control." IAWPRC/NERC specialised conference ;Estuarine and coastal pollution; detection, research and control 18(4-5): 121-130.

Kung, K. S., N. Lu, et al. (1998). "Chemical extraction of plutonium and americium from contaminated Rocky Flats soil." Radiochimica Acta 80: 13-21.

Muller, R. N. (1978). "Chemical characterization of local and stratospheric plutonium in Ohio soils." Soil Science 125(3): 131-136.

Muller, R. N. and D. G. Sprugel (1977). "Distribution of local and stratospheric plutonium in Ohio soils." Health Physics 33(5): 405-409.

Muller, R. N., D. G. Sprugel, et al. (1977). "Behavior and transport of industrially derived plutonium in the Great Miami River, Ohio." Health Physics 33(5): 411-416.

Muller, R. N. and G. T. Tisue (1977). "Preparative-scale size fractionation of soils and sediments and an application to studies of plutonium geochemistry." Soil Science 124(4): 191-198.

Oughton, D. H., B. Salbu, et al. (1993). "Under-determination of strontium-90 in soils containing particles of irradiated uranium oxide fuel." Analyst (London) 118(9): 1101-1105.

Ruttenberg, K. C. (1992). "Development of a sequential extraction method for different forms of phosphorus in marine sediments." Limnology and Oceanography 37(7): $1460-1482$.

Salbu, B., D. H. Oughton, et al. (1994). "The mobility of (super 137) Cs and (super 90) Sr in agricultural soils in the Ukraine, Belarus, and Russia, 1991." Health Physics 67(5): 518-528.

Tessier, A., P. G. C. Campbell, et al. (1979). "Sequential extraction procedure for the speciation pf particulate trace metals." Analytical chemistry 51(7): 844-850.

Wahlgren, M. A., J. J. Alberts, et al. (1976). Study of the behaviour of transuranics and possible chemical homologues in Lake Michigan water and biota". Transuranium nuclides in the environment. Transuranium nuclides in the environment. San Franc., Calif., United States: 9-24. 


\section{Chapter 8}

\section{Contaminated sediment transport rates}

\section{and contribution estimates from suspected source tributaries}

The main goal of this chapter is to obtain estimates of the time required for contaminated sediments to pass down the river from the upstream sources identified. These estimates are based on the isotopic composition measured in sediment cores collected at a variety of locations and their corresponding chronologies. Initially, the relationship between distance (i.e. between core locations) and time (i.e. difference in deposition age) of unique isotopic ratio 'signals' is examined, and first order rate estimates are obtained. Using a slightly different approach, isotopic ratios in the delta for a given year are modeled as a function of the isotopic composition of material measured in each source tributary for successively earlier years, plus a global fallout component. Analysis of model fit residuals obtained from different time lags between source tributaries and delta locations allows further assessment of transport rates. Based on the modeled isotope ratios, it is also possible to estimate the contaminated sediment contributions from each source tributary in $\mathrm{Ob}$ delta sediments, which may be compared to the estimated total suspended sediment contributions of each tributary.

\section{Contaminated sediment transport rates}

A straightforward method of arriving at the rate of contaminated sediment transport is to use deposition ages of unique isotopic compositions that can be identified 
in the upper $\mathrm{Ob}$ region and are clearly present in the delta. The distance between the locations of cores that contain a specific contaminant 'signal' relative to the difference in deposition ages allows transport rates to be estimated. From the contaminant records in Chapter 6, there are two cases where these criteria are met. The clearest case is the ${ }^{237} \mathrm{~Np} /{ }^{239} \mathrm{Pu}$ ratios, elevated well above the global fallout value, which are observed in the upper $\mathrm{Ob}$ river and in the $\mathrm{Ob}$ delta (OB94-07B and $\mathrm{OB} 94-10 \mathrm{~A})$ during the mid-to-late 1980s. The second case is the ${ }^{137} \mathrm{Cs} /{ }^{240} \mathrm{Pu}$ ratios, also elevated well above the global fallout value, which are observed in both the Tobol and Irtysh Rivers and in the Ob delta (OB94-07B) during the mid to late 1960s. While there is isotopic evidence suggesting that this material likely originates from the Tobol River (i.e. Mayak) and is a result of the Lake Karachai wind-transfer event, the origin of this material makes little difference with regard to transport rates. The distances to the delta from the core locations on the two tributaries are similar and the ${ }^{137} \mathrm{Cs} /{ }^{240} \mathrm{Pu}$ features have similar deposition age estimates.

Table 8:1 summarizes the contaminated sediment transport rate estimates based on the first appearance and maximum of the isotopic ratio profile features discussed above. In sediment cores where ${ }^{210} \mathrm{~Pb}_{\mathrm{xs}}$ profiles yielded deposition ages estimates that were consistent with those obtained by the radionuclide horizon method (RHM), both ages were used in transport rate calculations. Additionally, transport rates are estimated using the ${ }^{137} \mathrm{Cs} /{ }^{240} \mathrm{Pu}$ features in both the Tobol and Irtysh Rivers as the source of the elevated ${ }^{137} \mathrm{Cs} /{ }^{240} \mathrm{Pu}$ ratios in the delta (OB94-07B; see Figure 4:1 for locations). The main conclusion is that contaminated sediments transit the distance between source tributaries and delta on the order of $\sim 1$ year or less although some variability is observed 
in the estimated transport rates. Most notably, the differences in transport rates estimated for the ${ }^{237} \mathrm{~Np} /{ }^{239} \mathrm{Pu}$ first appearance and maximum in OB94-10A and the negative values estimated by RHM ages for the ${ }^{137} \mathrm{Cs} /{ }^{240} \mathrm{Pu}$ first appearance and maximum in OB95-13 (shown in parentheses). The variability in transport rates falls within deposition age uncertainties for the respective features in each core, and all of these estimates, including negative $\Delta$ age values, support the transport of contaminated sediments from source to delta in $\sim 1$ year (or season).

A comparison of sediment transport rate estimates to water transport rates in the $\mathrm{Ob}$ is useful in determining whether or not sediment transport rates are plausible (i.e. sediment transport rates should be $\leq$ water transport rates). Linear transport rates for water are based on measured water discharge and river cross-sectional area, which is in turn a function of the physical river cross-section and river flood stage (i.e. water depth) at a particular location. While one can expect some variability in water transport rates through time and at different locations, rates determined in 1995 at several locations throughout the year range between .38 and $1.39 \mathrm{~m} \mathrm{~s}^{-1}$ (R.H. Meade, personal communication). These are 1 to 2 orders of magnitude greater than transport rates estimated for contaminated sediments (0.009 to 0.123$)$ and not inconsistent with sediment transport rates. Since transport is likely associated with peak discharge months (May 


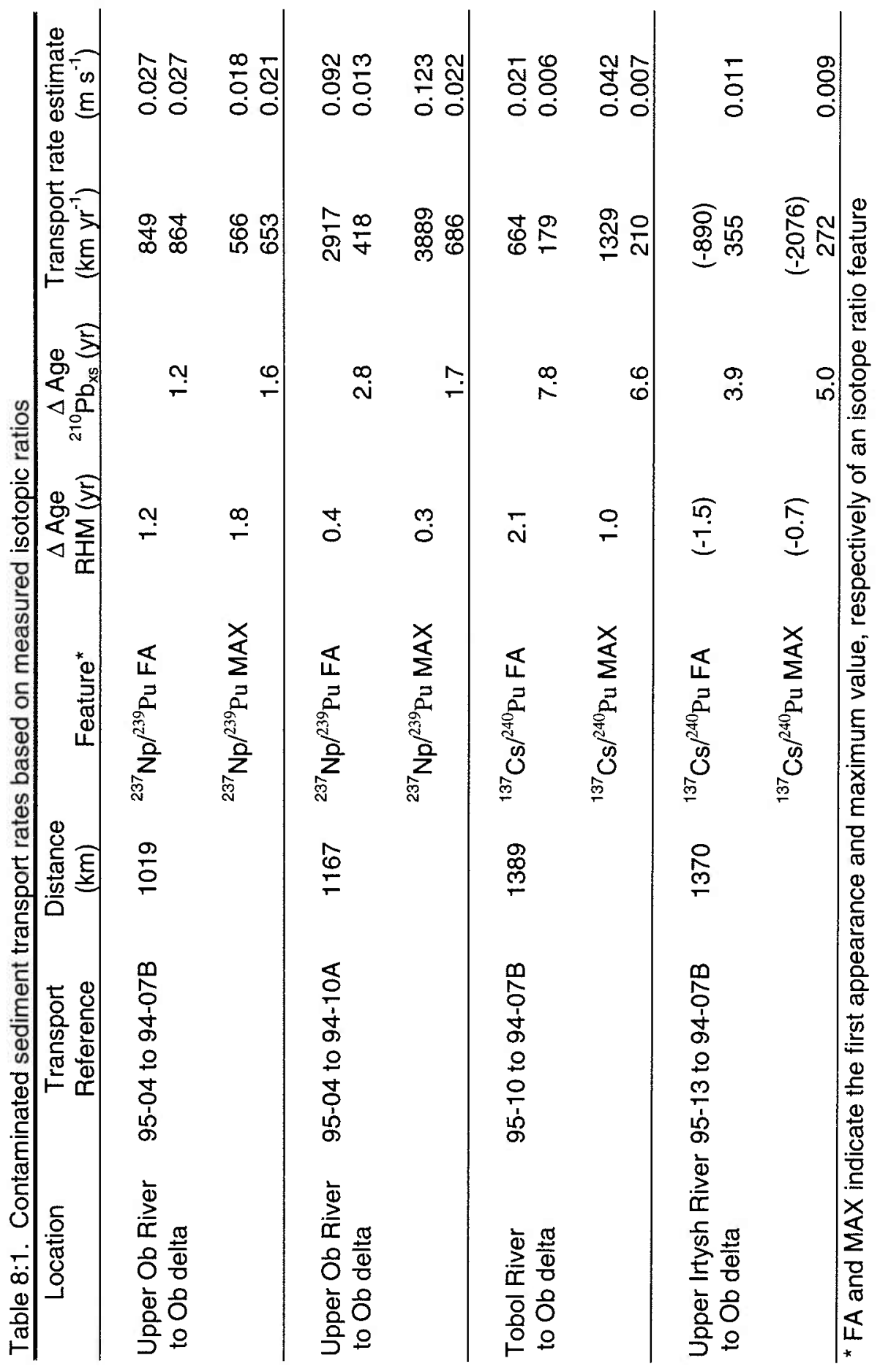


through July), the estimated sediment transport rates represent lower limits (R.H. Meade, personal communication).

In an effort to further constrain contaminated sediment transport rates, a simple model was formulated based on the following assumptions. 1) Plutonium, neptunium, and cesium are irreversibly bound to particles. 2) Radioactive contamination in the $\mathrm{Ob}$ delta (i.e. OB94-07B and 10A) is a mixture of contamination observed in the upper $\mathrm{Ob}$, Tobol, and Irtysh Rivers, plus some fraction of global fallout. 3) The influence of other unknown non-fallout sources is negligible. 4) Sediments added to the suspended load between upstream (source) and downstream locations (i.e. erosion or sediment exchange) are characterized by the isotopic composition of global fallout. It is important to note that contaminated sediments from the source tributaries contain a substantial fraction of global fallout contamination. No attempt is made here to separate global fallout from non-fallout contamination in the source tributaries. The observed isotopic composition for each year in each tributary is treated as an end-member (see below).

For sediment cores OB95-04, OB95-10, OB95-13, OB94-07B, and OB94-10A, the inventories of ${ }^{239} \mathrm{Pu},{ }^{240} \mathrm{Pu},{ }^{237} \mathrm{~Np}$, and ${ }^{137} \mathrm{Cs}$ were calculated for each core section, which were then binned according to deposition year and the annual inventory of each isotope was calculated. In cases where binning resulted no sample for a particular year, inventories were interpolated based on the average of the inventories in the year immediately preceding and following the 'missing' year. Based on the annual isotope inventories, the ${ }^{240} \mathrm{Pu} /{ }^{239} \mathrm{Pu},{ }^{237} \mathrm{~Np} /{ }^{239} \mathrm{Pu}$, and ${ }^{137} \mathrm{Cs} /{ }^{240} \mathrm{Pu}$ ratios were calculated for each 

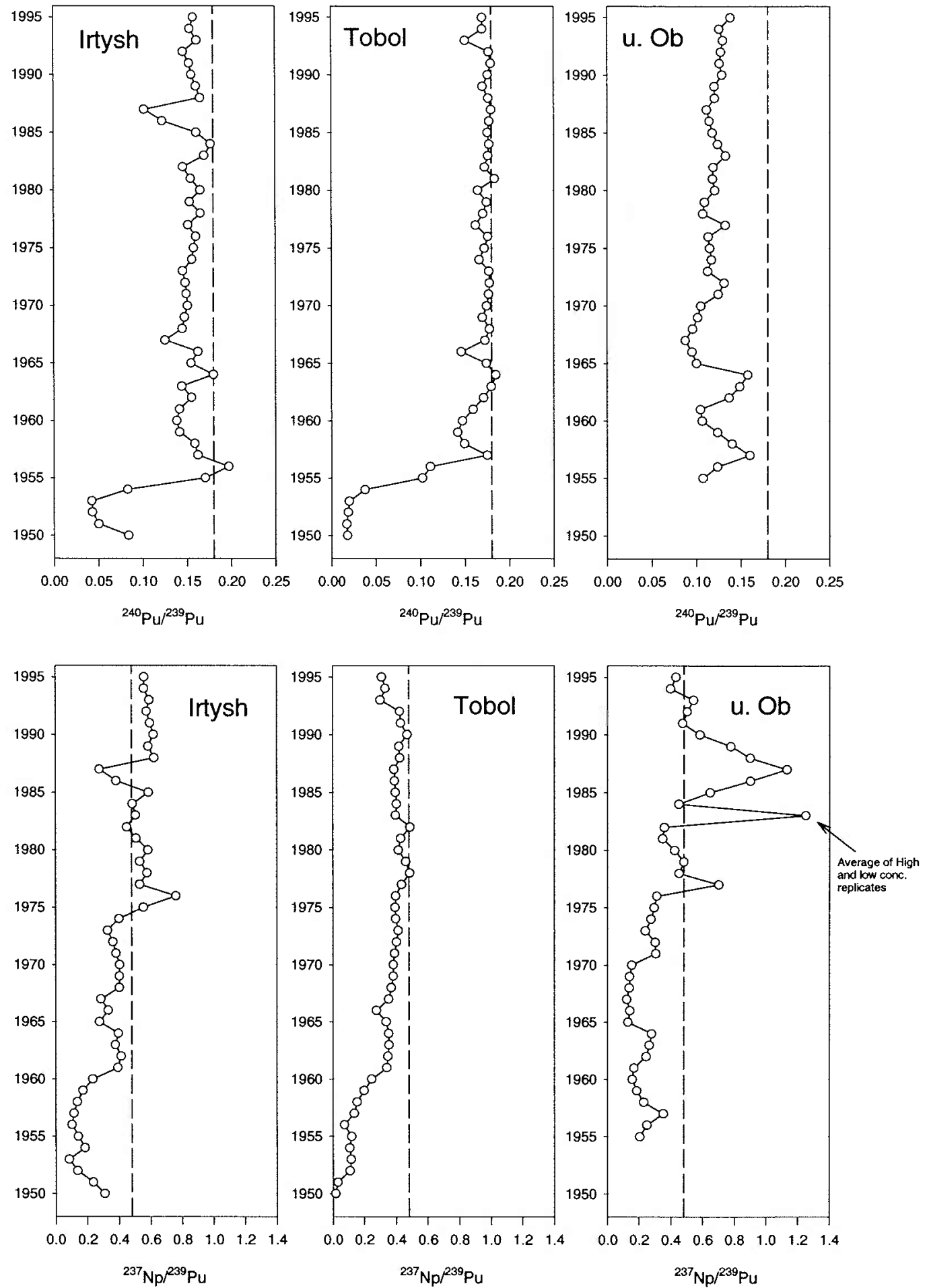

Figure 8:1 Yearly ${ }^{240} \mathrm{Pu} /{ }^{239} \mathrm{Pu}$ and ${ }^{237} \mathrm{~Np} /{ }^{239} \mathrm{Pu}$ isotopic ratios of source tributaries used in model. Dashed line represents average global fallout values (Kelley, Bond et al. 1998). 

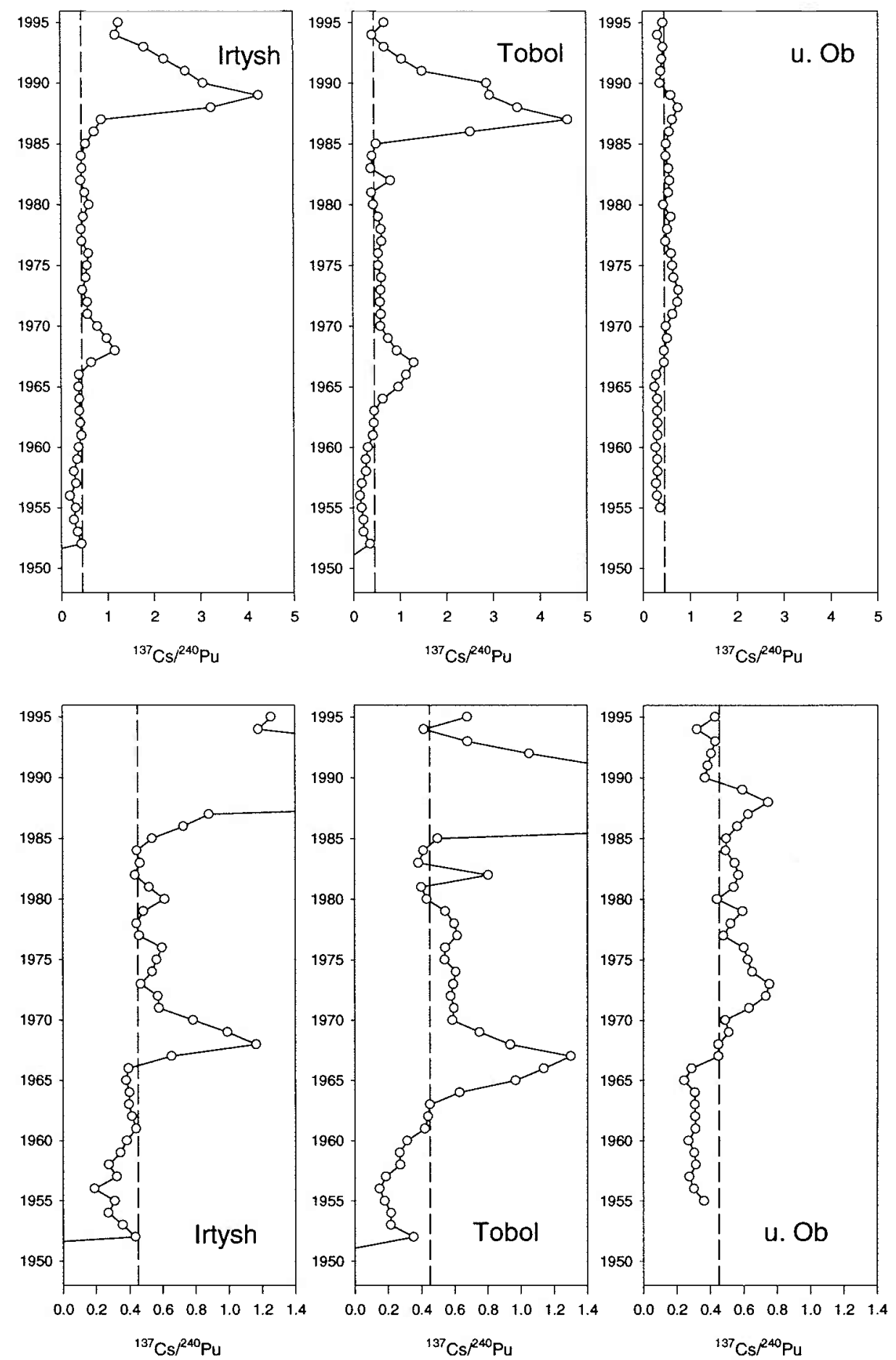

Figure 8:2 Yearly ${ }^{137} \mathrm{Cs} /{ }^{240} \mathrm{Pu}$ isotopic ratios of source tributaries used in model shown at two different scales. Dashed line represents average global fallout value (Kelley, Bond et al. 1998). 
year. Figures $8: 1$ and $8: 2$ show the yearly isotopic compositions for the source tributaries.

According to the assumptions made above, contamination in the delta cores for any given year can be described by the following equations:

$$
\begin{aligned}
& \mathrm{R} 1_{\mathrm{D}}=\mathrm{F} 1 \times \mathrm{R} 1_{\mathrm{Ob}}+\mathrm{F} 2 \times \mathrm{R} 1_{\mathrm{Tob}}+\mathrm{F} 3 \times \mathrm{R} 1_{\mathrm{Irt}}+\mathrm{F} 4 \times \mathrm{R} 1_{\mathrm{GF}} \\
& \mathrm{R} 2_{\mathrm{D}}=\mathrm{F} 1 \times \mathrm{R} 2_{\mathrm{Ob}}+\mathrm{F} 2 \times \mathrm{R} 2_{\mathrm{Tob}}+\mathrm{F} 3 \times \mathrm{R} 2_{\mathrm{Irt}}+\mathrm{F} 4 \times \mathrm{R} 2_{\mathrm{GF}} \\
& \mathrm{R} 3_{\mathrm{D}}=\mathrm{F} 1 \times \mathrm{R} 3_{\mathrm{Ob}}+\mathrm{F} 2 \times \mathrm{R} 3_{\mathrm{Tob}}+\mathrm{F} 3 \times \mathrm{R} 3_{\mathrm{Irt}}+\mathrm{F} 4 \times \mathrm{R} 3_{\mathrm{GF}} \\
& 1=\mathrm{F} 1+\mathrm{F} 2+\mathrm{F} 3+\mathrm{F} 4
\end{aligned}
$$

$\mathrm{R} 1, \mathrm{R} 2$, and $\mathrm{R} 3$ correspond to ${ }^{240} \mathrm{Pu} /{ }^{239} \mathrm{Pu},{ }^{237} \mathrm{~Np} /{ }^{239} \mathrm{Pu}$, and ${ }^{137} \mathrm{Cs} /{ }^{240} \mathrm{Pu}$ ratios, respectively $F 1, F 2, F 3$, and F4 correspond to the fraction of the total contamination in a delta sample that originates from the upper $\mathrm{Ob}$, Tobol, Irtysh, and global fallout, respectively, which must sum to one. This formulation results in four simultaneous equations, which are linear in four coefficients (i.e. the fractions F1 through F4), and thus can be solved uniquely by linear least-squares techniques for each year. This leads to the following matrix equation:

$$
\left[\begin{array}{c}
R_{1 D} \\
R_{2 D} \\
R_{3 D} \\
1
\end{array}\right]=\left[\begin{array}{cccc}
R_{11} & R_{12} & R_{13} & 0.18 \\
R_{21} & R_{22} & R_{23} & 0.48 \\
R_{31} & R_{32} & R_{33} & 0.45 \\
1 & 1 & 1 & 1
\end{array}\right] \times\left[\begin{array}{c}
F_{1} \\
F_{2} \\
F_{3} \\
F_{4}
\end{array}\right]
$$

Due to measurement and deposition age uncertainties, however, there was not always an exact solution. An additional constraint needed to obtain meaningful results is that all coefficients must be $\geq 0$. In order to force the model to consider only positive solutions, the Matlab ${ }^{\circledR}$ function LSQNONNEG (Least squares non-negative) was used. 
Initially, the isotopic ratios of the delta cores and one from the lower Irtysh River (OB95-06) were fit for each year using the ratios observed in the source tributaries for that same year. This would be the case if contaminants arriving at core locations in each of the source tributaries are transported to sediment core locations in the lower Irtysh and Ob delta all in the same year. Following this, the isotopic ratios of the cores were fit for each year using the ratios observed in the source tributaries for successively earlier years, simulating successively slower transport rates. For each core, the RMS of the residual was compared between model runs using different lag times. The lag time resulting in the best fit of the isotopic data (i.e. the lowest RMS of the residual) yields an estimate of contaminated sediment transport rate.

A comparison of the residuals vs. lag year and the corresponding best fits compared to measured isotopic ratios for each core are shown in Figures 8:3 through 8:5. For all three cores, the best fit was obtained with a time lag of 0 to 1 years; model runs with longer lag-times resulted in poorer fits. These results are in good agreement with transport rates estimated by the first method. In OB94-10A (see Figure 8:4), the isotopic data was compiled with (gray line) and without (black line) the low ratio replicate (i.e. the large departure towards non-fallout end-members, which appears $\sim 1975$ and is represented by the single circle. The RMS of the residuals for both cases are shown, and an improvement is observed in the overall model fit with the low ratio replicate excluded. The improvement of the model fit at a 10-year lag with the low ratio replicate included may indicate that some of the contamination is transported at a slower rate. Even the best fit obtained with the low ratio replicate included however, is poor compared to the fit 
RMS of the Residual vs. Time lag for delta core OB94-07B

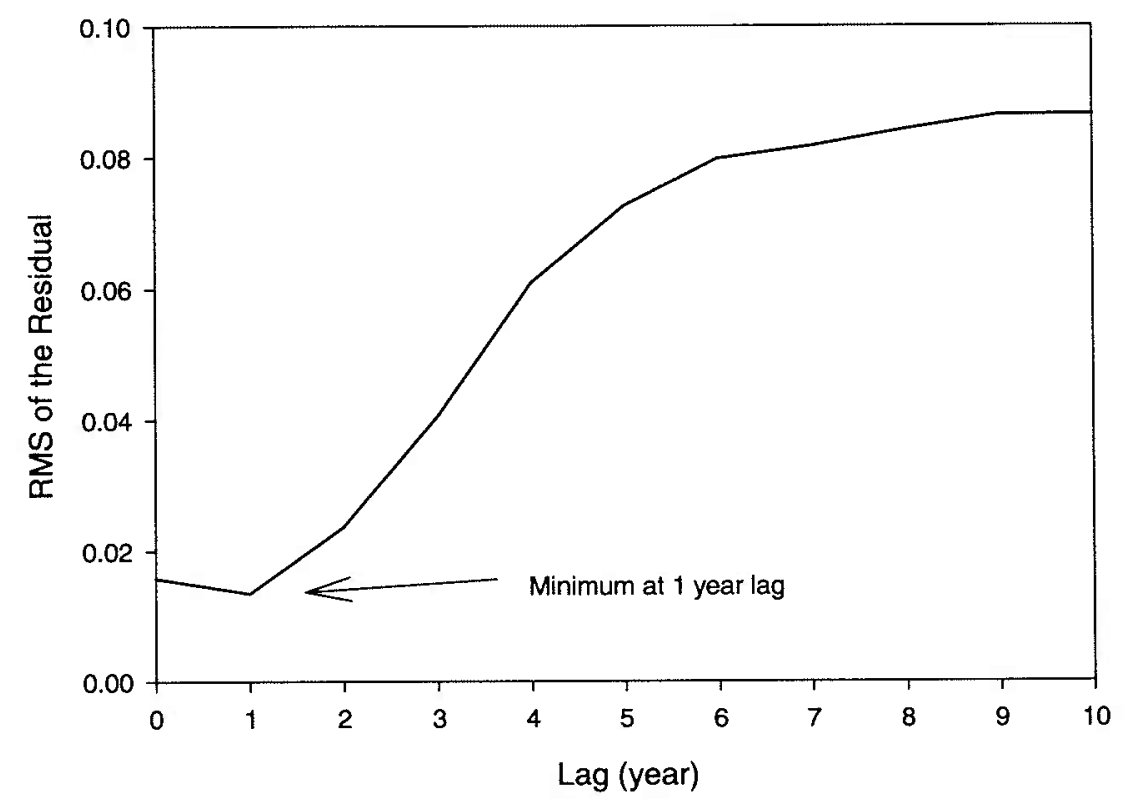

-... rationmod. Data vs. Model Fits delta core OB94-07B; $\mathrm{Lag}=1$ year
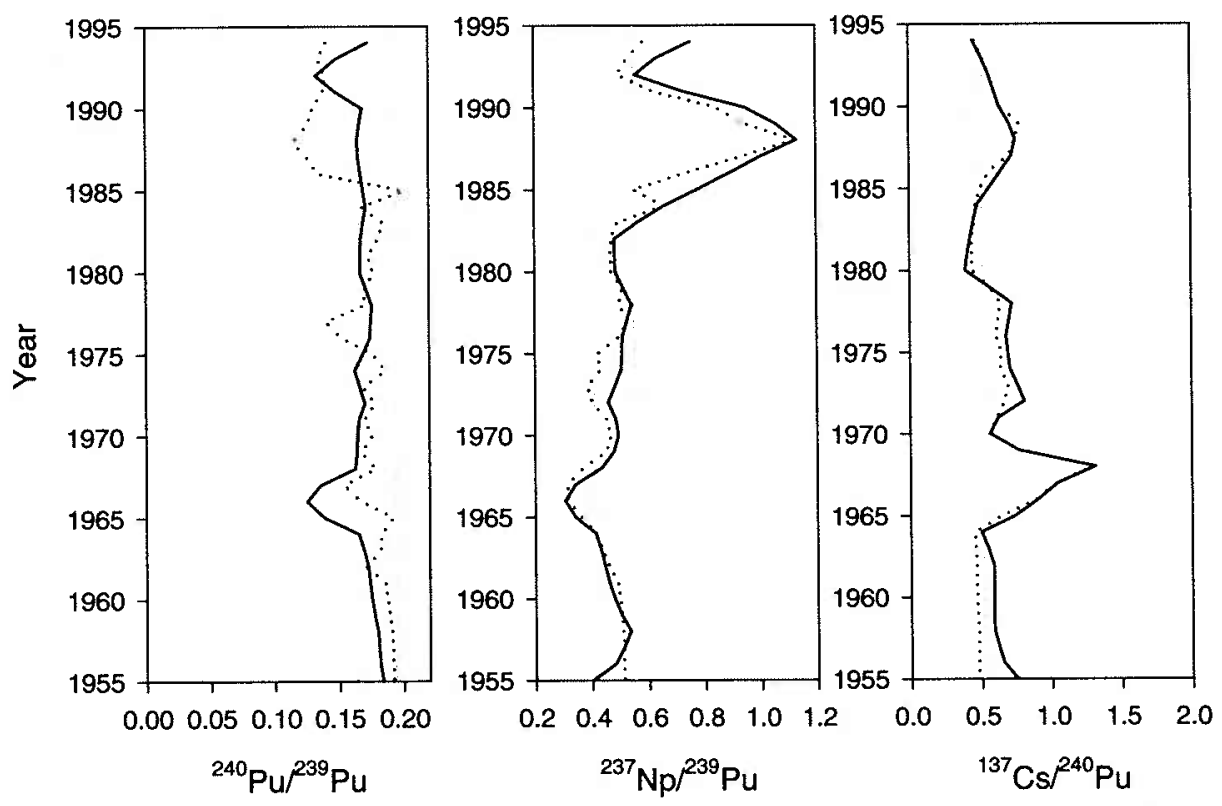

Figure 8:3. Model results for delta core OB94-07B. Top figure shows the RMS of the residual for model runs using 0 to 10 year lag period (see text for details). Bottom figure shows model output where the RMS of the residual reached a minimum. 
RMS of the Residual vs. Time lag for delta core OB94-10A
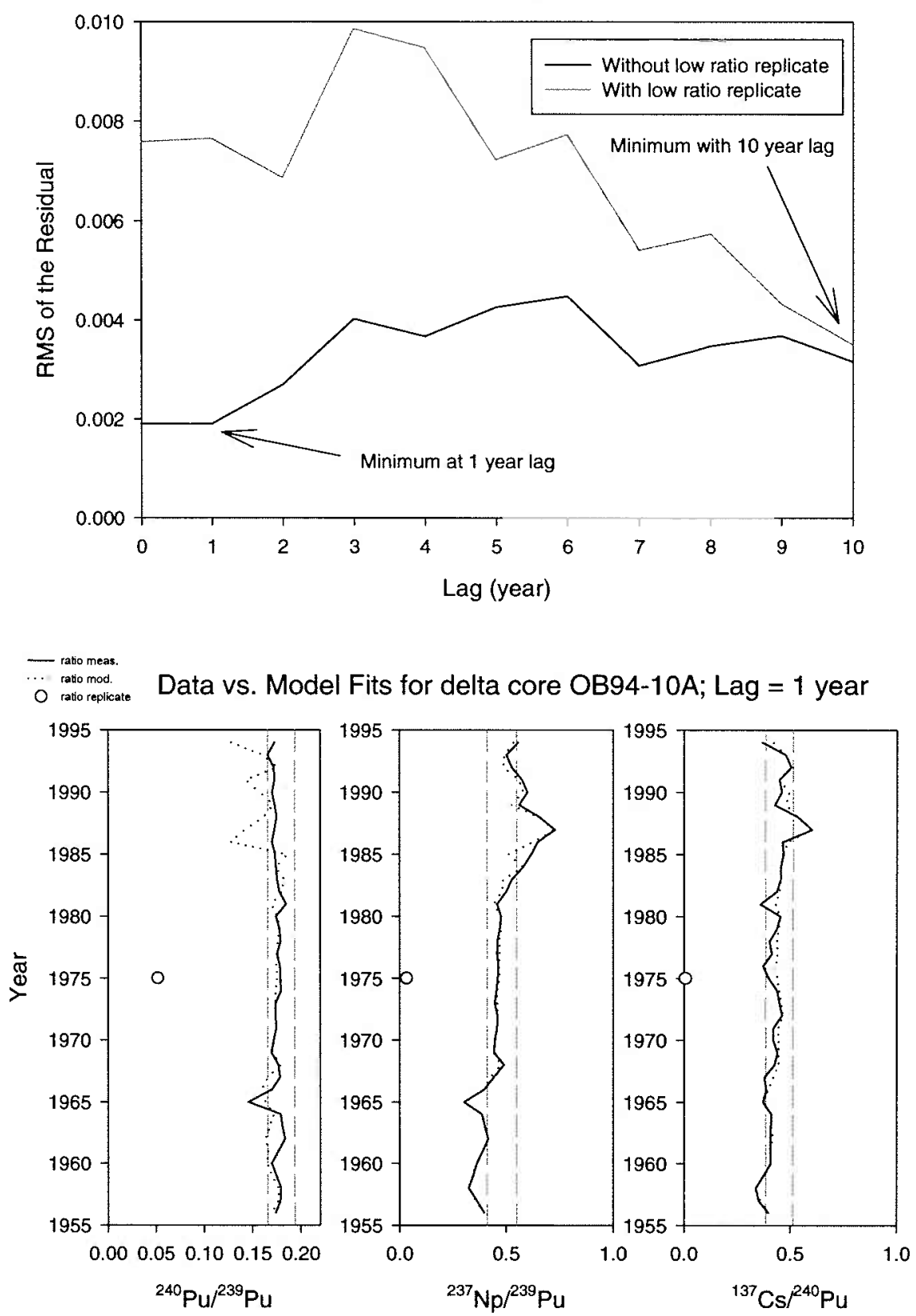

Figure 8:4. Model results for delta core OB94-10A. Top figure shows the RMS of the residual for model runs using 0 to 10 year lag period (see text for details). The gray line indicates the RMS of the residual for model runs with the low ratio replicate included in the data set; the black line indicates the RMS of the residual for model runs without the low ratio replicate. Bottom figure shows model output where the RMS of the residual reached a minimum (low ratio replicate excluded, but shown as a reference). 
RMS of the Residual vs. Time lag for lower Irtysh
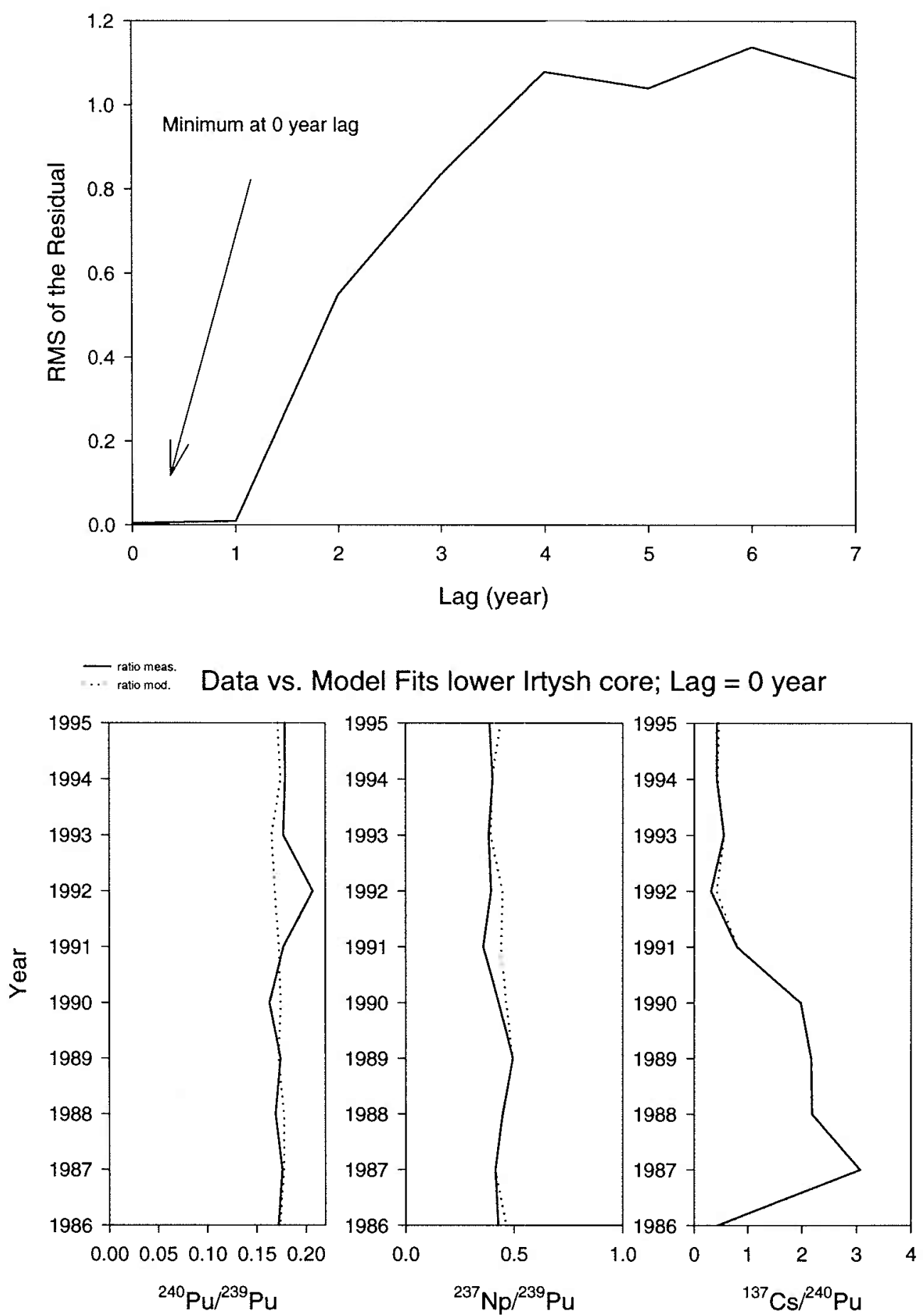

Figure 8:5. Model results for lower Irtysh core OB95-06. Top figure shows the RMS of the residual for model runs using 0 to 7 year lag period (see text for details). Bottom figure shows model output where the RMS of the residual reached a minimum. 
obtained at a 1-year lag with the low ratio replicate excluded. This demonstrates the sensitivity of the model to a single sample. The results are not surprising, given the formulation of the model. None of the sediment cores collected from source tributaries exhibit very low ${ }^{240} \mathrm{Pu} /{ }^{239} \mathrm{Pu},{ }^{237} \mathrm{~Np} /{ }^{239} \mathrm{Pu}$, or ${ }^{137} \mathrm{Cs} /{ }^{240} \mathrm{Pu}$ ratios that correspond to those observed in OB94-10A during the period 1965 to 1975 (i.e. the period of time-lag analysis). While clearly non-fallout ratios confirm the presence of contamination derived from sources other than global fallout, replicate analyses fail to show consistent results (in OB94-10A and 07B) where low ${ }^{240} \mathrm{Pu} /{ }^{239} \mathrm{Pu}$ ratios are observed. This suggests that low ratios observed in only one replicate are not necessarily representative of the bulk of the weapons related contamination for the entire sample.

In the delta cores, the model fits for ${ }^{237} \mathrm{~Np} /{ }^{239} \mathrm{Pu}$ and ${ }^{137} \mathrm{Cs} /{ }^{240} \mathrm{Pu}$ ratios are generally better that the resulting fits for the ${ }^{240} \mathrm{Pu} /{ }^{239} \mathrm{Pu}$ ratio. This is especially true where large contributions from the upper $\mathrm{Ob}$ River are required to fit the data. This is a consequence of consistently low ${ }^{240} \mathrm{Pu} /{ }^{239} \mathrm{Pu}$ ratios observed in the upper Ob River while ${ }^{237} \mathrm{~Np} /{ }^{239} \mathrm{Pu}$ and ${ }^{137} \mathrm{Cs} /{ }^{240} \mathrm{Pu}$ ratios change dramatically (see Figure 6:7a). The fact that high ${ }^{237} \mathrm{~Np} /{ }^{239} \mathrm{Pu}$ ratios measured in delta cores are not accompanied by low ${ }^{240} \mathrm{Pu} /{ }^{239} \mathrm{Pu}$ ratios is problematic, but is likely due to the model formulation (i.e. the only source of elevated ${ }^{237} \mathrm{~Np} /{ }^{239} \mathrm{Pu}$ ratios, upper $\mathrm{Ob}$, also has low ${ }^{240} \mathrm{Pu} /{ }^{239} \mathrm{Pu}$ ratios), rather than independent transport of neptunium and cesium versus plutonium. The isotope ratio mixing plot shown in Figure 6:14 suggests that two different components are present in the waste stream originating from Tomsk-7 (i.e. one characterized by low ${ }^{240} \mathrm{Pu} /{ }^{239} \mathrm{Pu}$ ratios and another characterized by high ${ }^{237} \mathrm{~Np} /{ }^{239} \mathrm{Pu}$ ratios). The ${ }^{237} \mathrm{~Np}$ enriched 
component may be have $\mathrm{a}^{237} \mathrm{~Np} /{ }^{239} \mathrm{Pu}$ ratio that is $\geq 2.11$ and a ${ }^{240} \mathrm{Pu} /{ }^{239} \mathrm{Pu}$ ratio $\sim 0.14$; these ratios were observed in one sample. The isotopic composition of the ${ }^{237} \mathrm{~Np} /{ }^{239} \mathrm{Pu}$ maximum in OB94-07B has a ${ }^{240} \mathrm{Pu} /{ }^{239} \mathrm{Pu}$ and $\mathrm{a}^{237} \mathrm{~Np} /{ }^{239} \mathrm{Pu}$ of 0.166 and 1.16 , respectively. If the ${ }^{237} \mathrm{~Np}$ enriched material originating from Tomsk-7 has a constant isotopic composition, which is similar to the one observed in the single sample from the upper Ob River, the isotopic composition observed in the delta sample is explainable by a mixture of global fallout and contamination from Tomsk-7 in the proportion of $\sim 2: 1$.

The model fits for the isotope ratios in OB95-06 are also generally good, the largest exception being the ${ }^{240} \mathrm{Pu} /{ }^{239} \mathrm{Pu}$ ratios elevated above global fallout, which are not observed in either the Tobol or Irtysh Rivers.

Contaminated tributary sediment vs. global fallout contributions

In addition to providing contaminated sediment transport rate information, the model described above also gives estimates of the global and contaminated tributary sediment contributions (i.e. the fractions F1 through F4). It is important to remember that contaminated sediments originating from suspected source tributaries also contain a component of global fallout (see model assumptions). Figures 8:6 through 8:8 show these results, presented in two different ways. First, the total contaminated tributary sediment fraction is compared to the global fallout fraction, and second, the contaminated tributary sediment contributions from the source tributaries are compared relative to each other. 
Global Fallout vs. Total Contaminanted Tributary Sediment Fraction lag $=1$ year

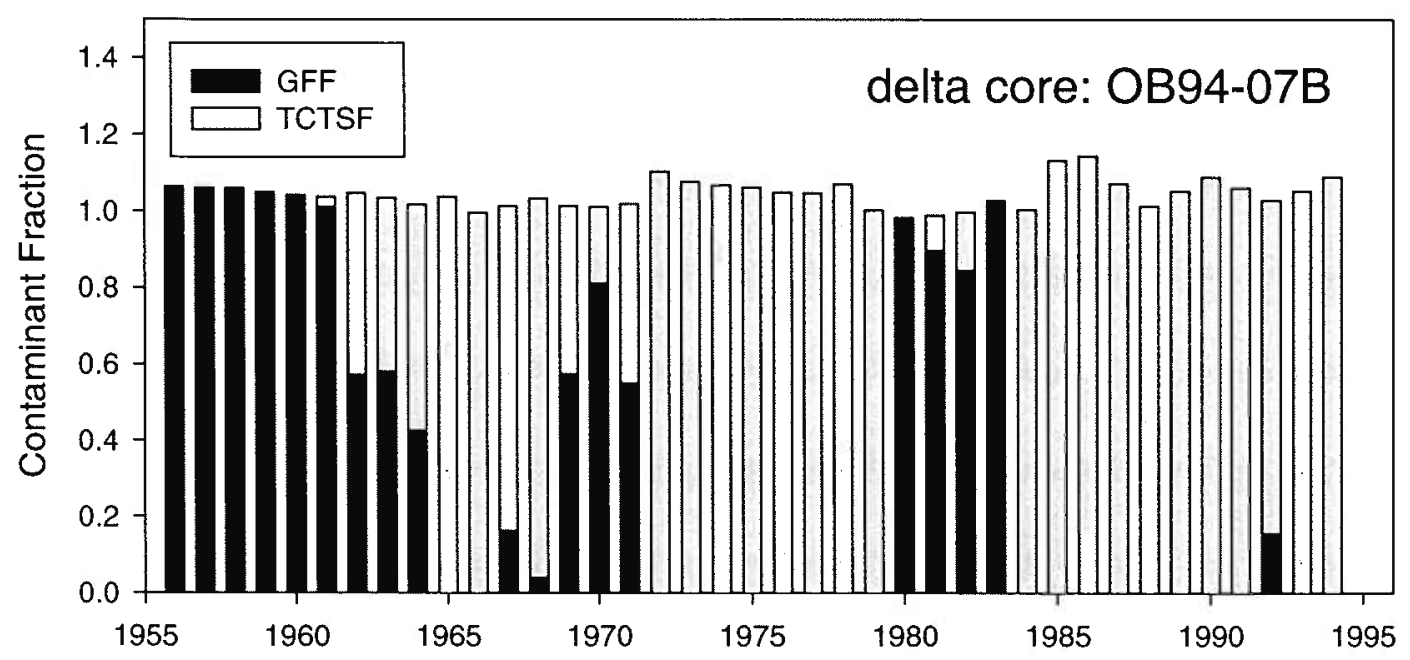

Relative contaminanted sediment contribution from Source Tributaries lag $=1$ year

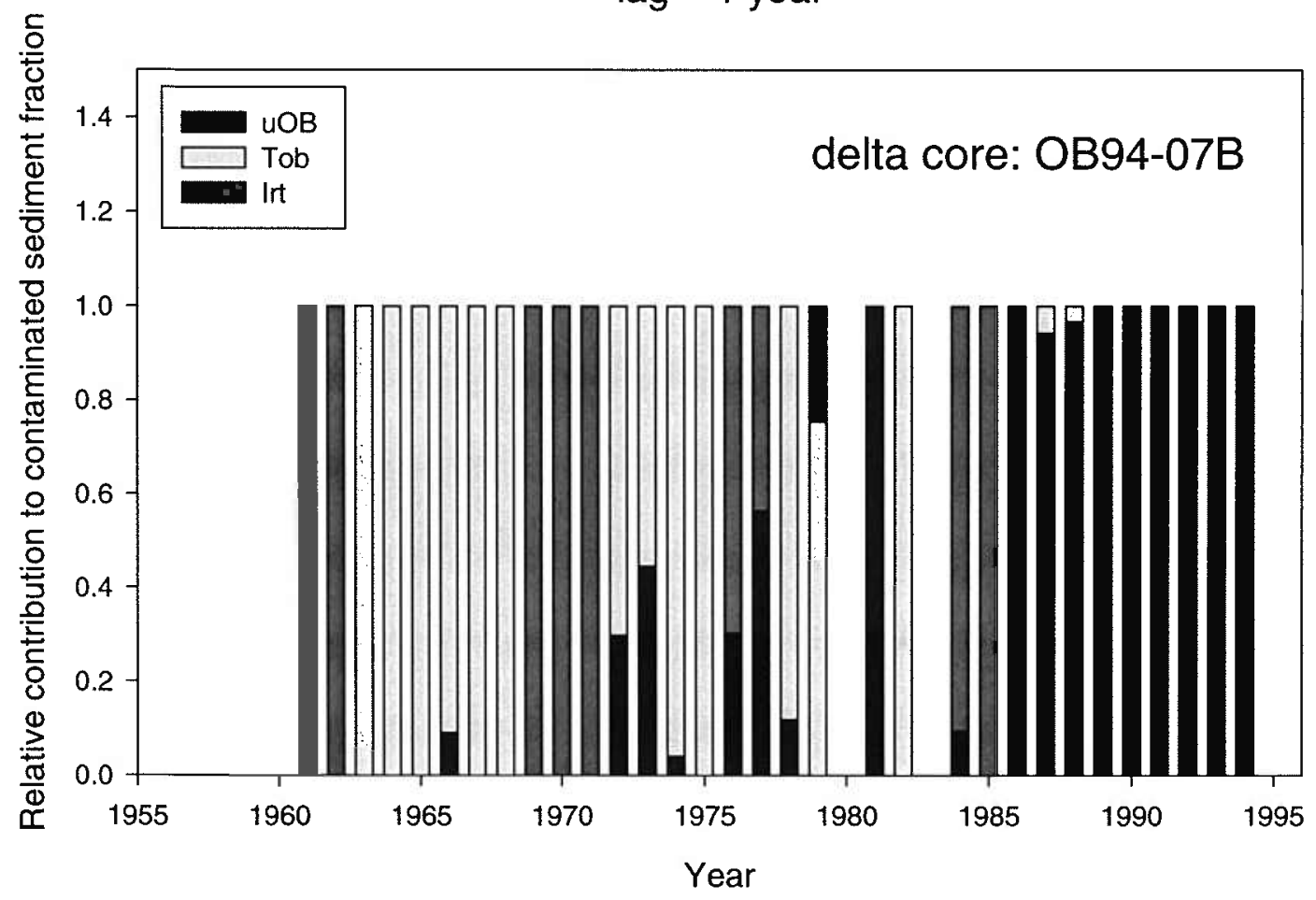

Figure 8:6. Model results for delta core OB94-07B (1-year lag). Total contaminated tributary sediment fraction vs. global fallout fraction (upper figure). Relative contaminated sediment contributions from the source tributaries (lower Figure). 
Global Fallout vs. Total Contaminanted Tributary Sediment Fraction lag $=1$ year

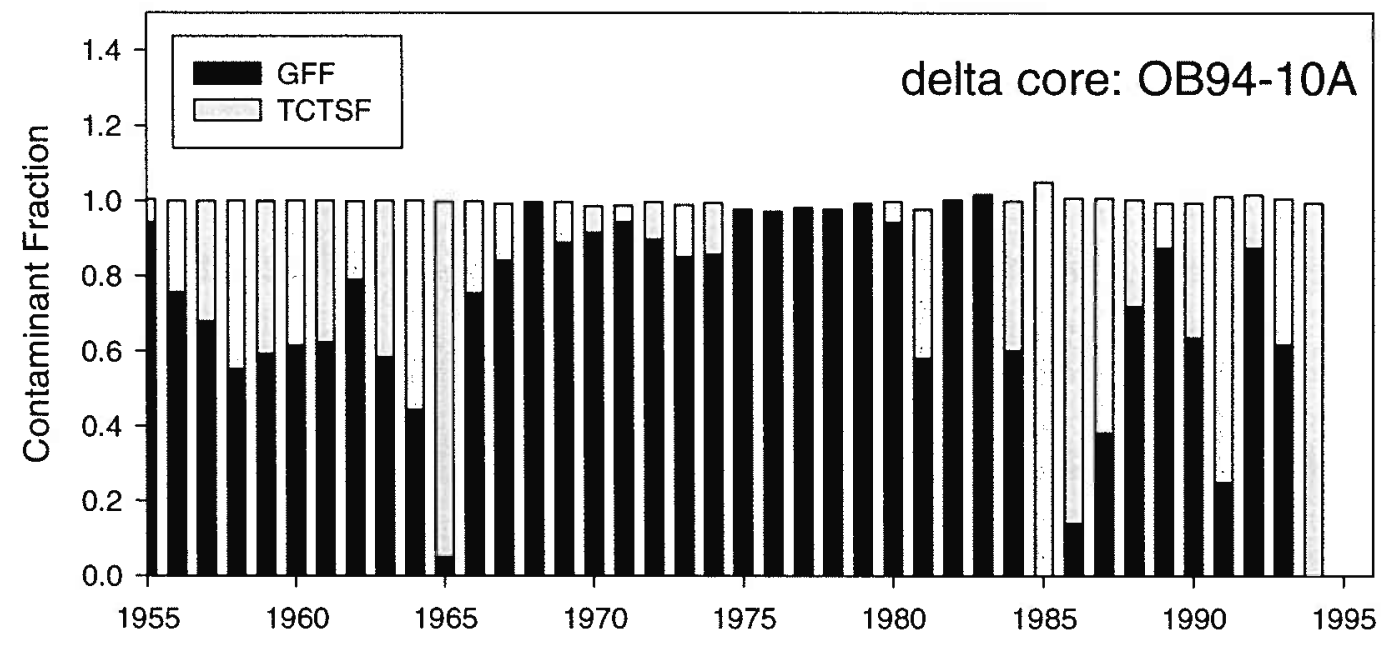

Relative contaminanted sediment contribution from Source Tributaries $\operatorname{lag}=1$ year

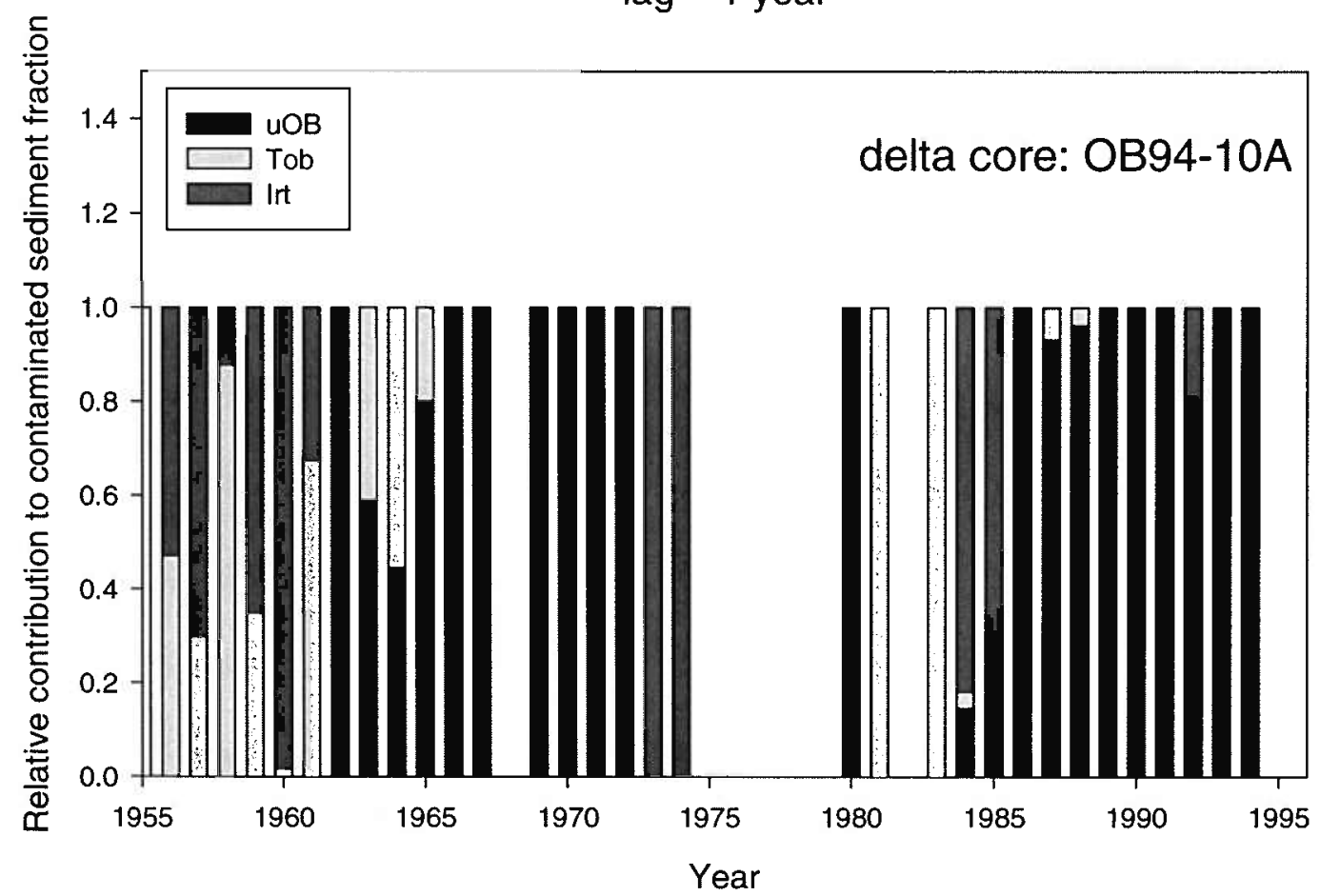

Figure 8:7. Model results for delta core OB94-10A (1-year lag, low ratio replicate excluded). Total contaminated sediment tributary fraction vs. global fallout fraction (upper figure). Relative contaminated sediment contributions from the source tributaries (lower Figure). 
Global Fallout vs. Total Contaminanted Tributary Sediment Fraction lag $=0$ year

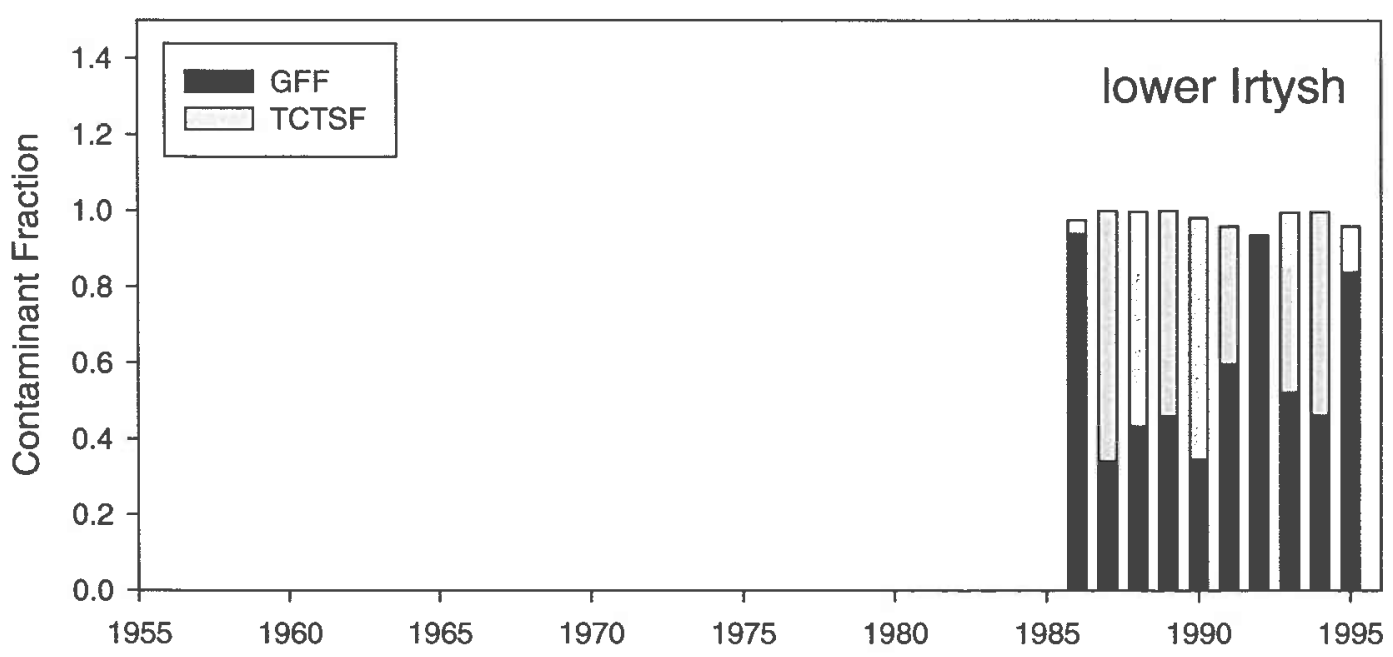

Relative contaminanted sediment contribution from Source Tributaries lag $=0$ year

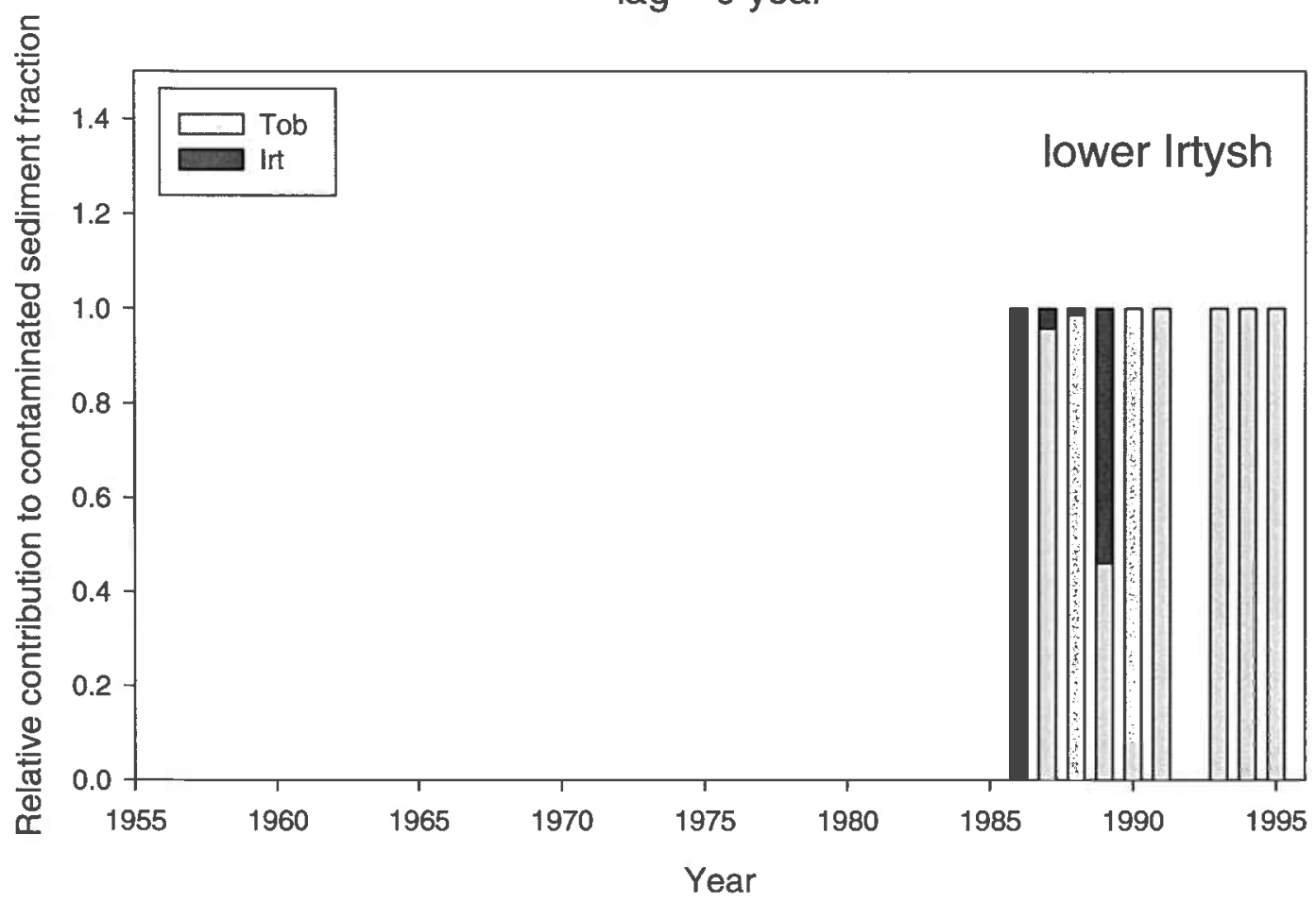

Figure 8:8. Model results for lower Irtysh core OB95-06 (0-year lag). Total contaminated tributary sediment fraction vs. global fallout fraction (upper figure). Relative contaminated sediment contributions from the source tributaries (lower Figure). 
The total contaminated tributary sediment fraction and the global fallout fraction sum to one in nearly all years (allowing for some uncertainty due to measurements and deposition age estimates, etc.), indicating that overall, the fraction balance is quite good (upper figures). In the delta cores and the one from the lower Irtysh River, some annual horizons contain only global fallout or only contaminated tributary sediment, while others contain some contribution from both.

It is important to remember that these data only give information about the contaminated load, not the total sediment load. For example, an annual horizon in the delta where the model solution indicates only global fallout contamination could mean one of two things: 1) Contaminated sediments in the delta had an isotopic composition similar to global fallout and different from the isotopic compositions observed in the tributaries for a particular lag year. 2) The isotopic compositions in the source tributaries and the delta were all indistinguishable from global fallout. The second case would have resulted in a matrix singularity during the model run, which did not occur. This supports the first case as the likely explanation.

In terms of the core locations, there are really two mechanisms, which could result in the contamination of sediments by global fallout (i.e. direct deposition during the period of atmospheric tests and/or wash-in of global fallout contaminated sediments). Prior to $\sim 1965$, it is impossible to resolve which mechanism is the primary means of contamination; it is likely some combination of the two. After 1965 however, global fallout deposition was significantly reduced, and annual horizons that contain only global fallout must be primarily a result of wash-in. A comparison of global fallout and 
contaminated tributary sediment fractions in the two delta cores suggests that the sources of contaminated sediments to each location differed throughout most of the period 1955 to 1995 .

Conversely, annual horizons in delta sediments indicating dominance of the contaminated tributary sediment fraction does not mean that global fallout is not present. Rather, they indicate that the observed isotopic composition in the delta can be explained by some linear combination of contamination observed in the suspected source tributaries, each tributary likely containing some unresolved fraction of global fallout contamination (see model assumptions). During the period 1986 to 1995 , both OB95-06 and OB94-10A contain some combination of global fallout and contaminated river sediments, while OB94-07B contains primarily contaminated river sediments. This is likely related to the relatively higher sedimentation rates estimated during this period for OB95-06 and OB94-10A compared to OB94-07B, which are $~ 6,4$, and $0.5 \mathrm{~cm} \mathrm{yr}^{-1}$, respectively. It suggests that environments experiencing high rates of sediment deposition may receive larger portions of sediments that were previously contaminated by global fallout deposition. This would be the case if bank erosion, sediment slumping, etc. were contributing to the contaminated sediment load in the high deposition rate environments.

A comparison of contaminated sediment contributions from source tributaries relative to each other (lower figures) reveals an interesting feature. In approximately 50 percent of annual horizons where the model indicated contaminated sediment contributions from source tributaries, only a single tributary is indicated. Furthermore, in 
the majority of cases where contributions from more than one river are indicated in the delta, it is the upper Ob River plus either the Tobol or the Irtysh River. There are relatively few years where contaminant contributions from both the Tobol and the Irtysh Rivers are indicated.

One of the features not discussed in Chapter 3 concerning the hydrology of the $\mathrm{Ob}$ and its major tributaries is the progression of annual flooding from south to north. This begins first on the Irtysh River and gradually moves north to include the Ob River as spring thawing continues. In most years, there is a delay of flood wave movement in the upper Ob compared to the Irtysh (Paluszkiewicz, Hibler et al. 1997). This type of regime could have important ramifications with regard to contaminated sediment transport from each tributary to the delta. Under the flood regime described above, the source of sediments reaching the delta at any given time during the spring flood would strongly depend upon which river was flooding. Given the difference in latitude of the areas drained by the Irtysh, Tobol, and $\mathrm{Ob}$, it is conceivable that each river dominates the contaminated sediment load at different times during the spring flood. Given the stochastic nature of the flooding process, it is also possible that the sites where sediment cores were collected did not receive a constant supply of sediments during the spring flood progression.

While available hydrographic data are not of sufficient resolution (geographically or temporally) to clearly resolve the flood progression of each river, a scenario similar to the one outlined above is supported by the isotopic data. As mentioned at the end of Chapter 6, one of the inconsistencies encountered in this study are the isotopic ratios 
measured in the lower Irtysh River and the Ob delta (OB94-07B) that suggest the presence of contamination that can be linked to Mayak. Under a hydrologic regime where each river floods sequentially, it is plausible that the contaminated sediment load is dominated by contributions from each suspected source tributary at different times throughout spring flooding.

Another factor that could play an important role in contaminated sediment transport is the sediment grain-size distribution in the suspected source tributaries. Although this has not been assessed in the current study, it is expected, given the increase in surface area, that the majority of particle reactive contaminants such as $\mathrm{Pu}, \mathrm{Np}$ and $\mathrm{Cs}$ would be associated with the finest particles. Differences in grain-size distribution between sediments originating from the Tobol, Irtysh, and upper Ob rivers could be important to better understanding contaminant transport. This is especially true if sediments originating from the Tobol contain a higher percentage of finer particles relative to the Irtysh and Tobol Rivers.

\section{Summary}

The data and modeling results presented in this chapter are in good agreement and suggest that it takes between 0 and 1 years for contaminated sediments originating from the upper $\mathrm{Ob}$, Irtysh, and Tobol Rivers to be transported to down stream locations. Results also suggest that a hydrographic mechanism, likely related to the spring flood progression, allow each river to dominate the contaminated sediment load that is transported to downstream locations at different times through out the period 1955 to 
1994. These data have important implications with respect to the large inventories of radionuclides in storage reservoirs and tanks at both Mayak and Tomsk-7. Assuming similar transport rates for contaminated sediments in the upper $\mathrm{Ob}$ and the Techa-IsetTobol system, large releases of contaminants at these locations could result in measurable levels in the delta within 1 to 2 years. Although the isotopic ratios are very useful for identifying the source of contamination in sediments collected from the lower Irtysh River and Ob delta, their use is limited in assessing the total flux of contaminated sediments from each source. 
References chapter 8

Kelley, J. M., L. A. Bond, et al. (1998). Inventory and composition of Pu isotopes and $\mathrm{Np}-237$ in soil. International symposium on marine pollution, Monaco, IAEA.

Paluszkiewicz, T., L. F. Hibler, et al. (1997). "An assessment of the flux of (super 90) $\mathrm{Sr}$ contamination through the Ob' River and estuary to the Kara sea

Environmental radioactivity in the Arctic." Second symposium and international conference on Environmental radioactivity in the Arctic 202(1-3): 43-56. 


\section{Chapter 9}

\section{Conclusions}

The objectives of this study were to depict the history of nuclear weapons related contamination in the Ob River system and obtain better understanding of the transport and mobility of these materials in a large arctic river system. In pursuit of these goals, a rapid, low cost plutonium and neptunium analysis method was developed. Down core distributions of the weapons related isotopes ${ }^{239} \mathrm{Pu},{ }^{240} \mathrm{Pu},{ }^{237} \mathrm{~Np}$ and ${ }^{137} \mathrm{Cs}$ in sediment cores collected from flood plain lakes in Ob delta, the Ob, Irtysh, and Tobol Rivers, and one core from the Taz estuary were measured. Similarities between deposition ages suggested by ${ }^{210} \mathrm{~Pb}_{\mathrm{xs}}$ and the timing of the deposition of radionuclides associated with global fallout and contamination from the Chernobyl accident have been used to develop time scales for down-core isotope distributions. The atom ratios ${ }^{240} \mathrm{Pu} /{ }^{239} \mathrm{Pu},{ }^{237} \mathrm{~Np} /{ }^{239} \mathrm{Pu}$ and ${ }^{137} \mathrm{Cs} /{ }^{240} \mathrm{Pu}$ have been used to characterize contamination originating from the various weapons related sources in the Ob River basin as well as to differentiate between local sources and global fallout.

The different isotopic records observed in cores from the Ob delta suggest several important points. 1) Global fallout is the dominant source of weapons related contamination in the $\mathrm{Ob}$ delta. 2) Contamination derived from the nuclear facilities, Mayak, Tomsk-7, and Semipalitinsk has been transported the full length of the Tobol, upper $\mathrm{Ob}$, and upper Irtysh Rivers at various times throughout the period from 1950 to 1995. 3) There is clear evidence linking non-fallout contamination in Ob delta sediments to sources located on the upper reaches of the Ob River as well as the Tobol and/or the 
upper Irtysh River (i.e. Tomsk-7, Mayak, and/or Semipalitinsk, respectively). 4) In some cases delta sediments show evidence of non-fallout contamination at least as recent as 1995 (i.e. core collection), indicating the potential for future contamination of the $\mathrm{Ob}$ delta as a result of activities at nuclear facilities.

Selective leaching experiments indicate the majority of the total plutonium and neptunium exhibits a distribution of similar proportions within many of the extracted fractions, with the largest percentage of both elements being observed in the reducible fraction. While the CDB-extractable fraction does not likely simulate environmental conditions in the $\mathrm{Ob}$ region, they do imply an association of plutonium and neptunium with redox sensitive elements. Available data indicate however, that little if any selective mobilization of plutonium, neptunium, or cesium is occurring and that they are strongly bound to particulate matter. Minor amounts of neptunium partition differently in different sediments and are associated with the exchangeable and organic phases. Finally, there is clear isotopic evidence that suggests some non-fallout contamination has a refractory nature. However, the amount of this material present in the samples analyzed is small compared to the amount of contamination in accessible fractions.

Transport rate estimates suggest that it takes $\leq 1$ year for contaminated sediments originating from the upper $\mathrm{Ob}$, Irtysh, and Tobol Rivers to reach the delta. Results also suggest that a hydrographic mechanism, likely related to the spring flood progression, results in different rivers dominating the contaminated sediment load that is transported to downstream locations at different times through out the period 1955 to 1994 . These data have important implications with respect to the large inventories of radionuclides in storage reservoirs and tanks at both Mayak and Tomsk-7. Assuming similar transport 
rates for contaminated sediments in the upper $\mathrm{Ob}$ and the Techa-Iset-Tobol system, large releases of contaminants at either Tomsk-7 or Mayak could result in measurable levels in the delta within 1 to 2 years (Note: increase in transport time is a result of including additional transport of sediments between fuel reprocessing facilities and the main tributaries studied).

Evaluation of radionuclide inventories contained in sediment cores collected from various locations throughout the $\mathrm{Ob}$ region indicate that contaminant levels are comparable to those measured in soils collected from mid-latitudes, which were contaminated as a result of atmospheric weapons testing.

\section{Future work}

Additional research of radioactive contamination in the $\mathrm{Ob}$ region can be divided into two categories: studies of fluvial sediments and processes and those involving estuarine processes and input to the Arctic Ocean. Of particular interest is the grain size distribution in the suspected source tributaries (i.e. the Tobol, Irtysh, and Ob Rivers) and the $\mathrm{Ob}$ delta as well as the distribution of contaminants among different grain size fractions. Since the majority of $\mathrm{Pu}$ and $\mathrm{Np}$ are associated with the reducible fraction, this relationship should be further explored using a variety of treatments that are less rigorous than the $\mathrm{CDB}$ extraction. If possible, selective leaching experiments should also be conducted on larger sediment samples in order to improve the precision to which Pu and $\mathrm{Np}$ (and Cs) concentrations and isotope ratios can be determined for individual fractions. Additional selective leaching experiments could also be performed on samples collected at both Semipalitinsk and Mayak, which exist in the EML archives. 
In the estuary, the effects of seawater intrusion on the mobility of $\mathrm{Pu}, \mathrm{Np}$, and $\mathrm{Cs}$ should also be more fully explored. These effects could be important with respect to evaluating FSU fuel reprocessing facilities as potential sources of contamination to the Arctic Ocean. Furthermore, if FSU fuel reprocessing facilities turn out to be a source of contamination to the Arctic Ocean, it might also be possible to development contaminants as tracers with which study water and ice transport. 


\section{$\underline{\text { Appendix I }}$}

\section{Sample Data Tables}

Note: Data tables are organized by core, in increasing order (i.e. year/core number). Data for each core are listed in three separate tables. Table 1 contains physical parameters, ${ }^{210} \mathrm{~Pb},{ }^{214} \mathrm{~Pb},{ }^{214} \mathrm{Bi}$, and ${ }^{137} \mathrm{Cs}$ activity measurements, and deposition age model information. Table 2 contains ${ }^{239} \mathrm{Pu},{ }^{240} \mathrm{Pu},{ }^{237} \mathrm{~Np}$ concentration data (atoms/g dry sediment) as well as ${ }^{239,240} \mathrm{Pu}$ activity (dpm/g dry sediment) for each sample (with replicates). Table 3 contains ${ }^{240} \mathrm{Pu} /{ }^{239} \mathrm{Pu}$, ${ }^{237} \mathrm{~Np} /{ }^{239} \mathrm{Pu},{ }^{237} \mathrm{~Np} /{ }^{240} \mathrm{Pu},{ }^{241} \mathrm{Pu} /{ }^{239} \mathrm{Pu},{ }^{137} \mathrm{Cs} /{ }^{240} \mathrm{Pu}$ atom ratios as well as ${ }^{239,240} \mathrm{Pu} /{ }^{137} \mathrm{Cs}$ activity ratio (with replicates). Radionuclide half-lives used to convert between atom concentrations and activities are as follows: ${ }^{239} \mathrm{Pu}(24119$ y), ${ }^{240} \mathrm{Pu}(6564 \mathrm{y}),{ }^{241} \mathrm{Pu}(14.4 \mathrm{y}),{ }^{237} \mathrm{~Np}\left(2.14 \times 10^{6} \mathrm{y}\right)$, and ${ }^{137} \mathrm{Cs}(30.1 \mathrm{y})$. 


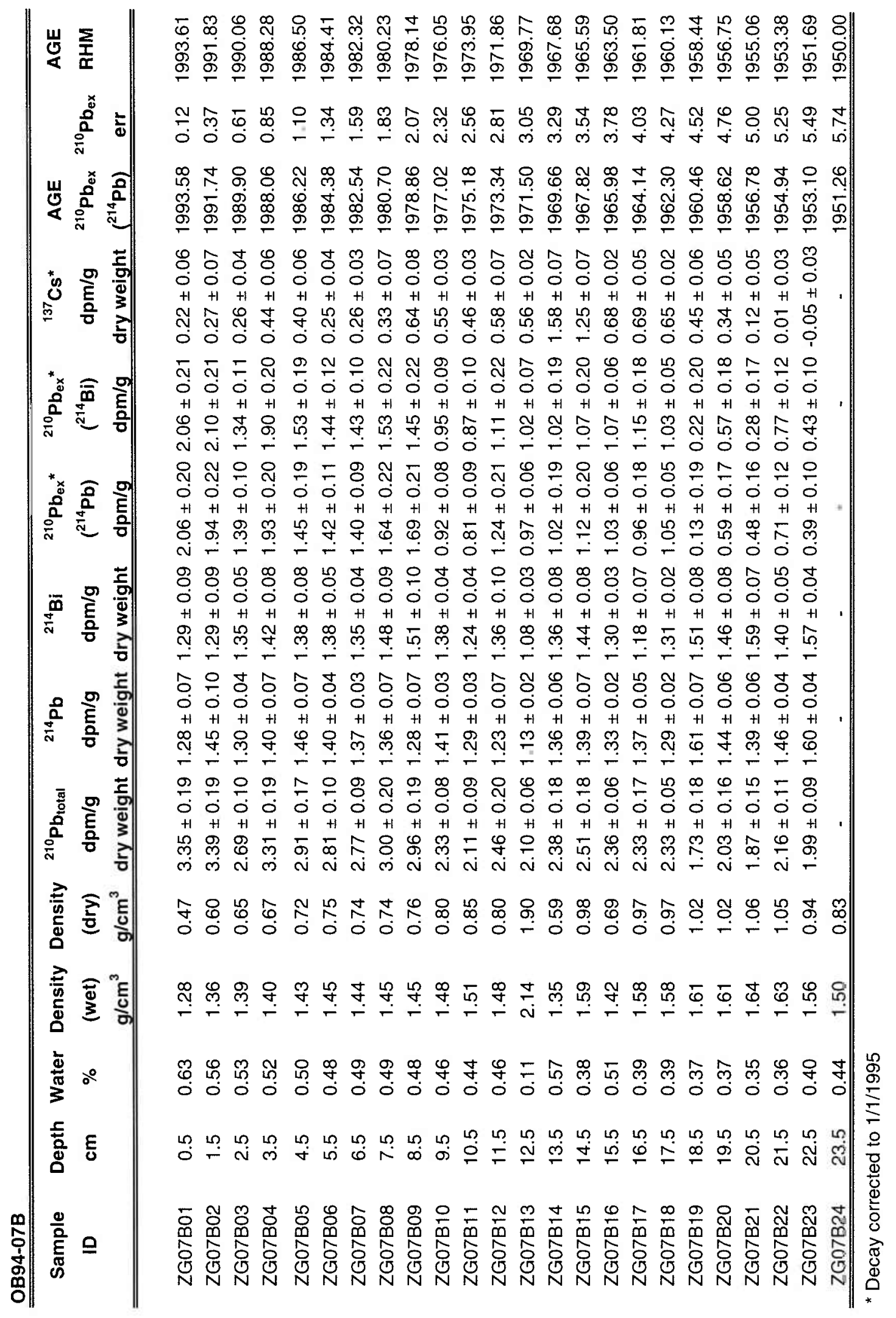




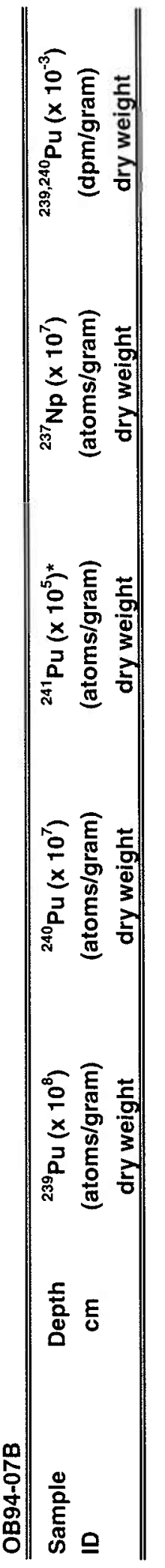

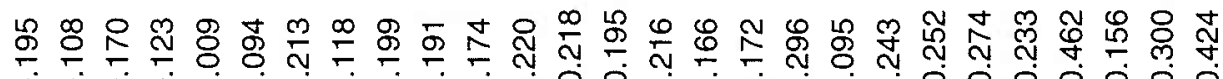

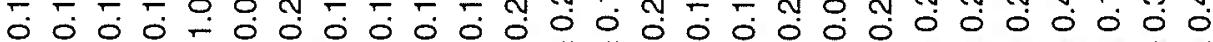

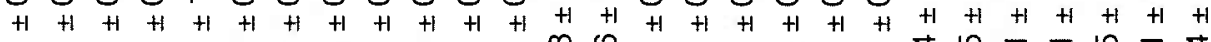
뉴유유응 ம்

荧劳

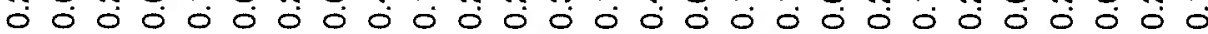
$+1+1+1+1+1+1+i+1+1+1+1+1+1+1+1+1+1+1+1+1+1+1+1+1+1+1+1$

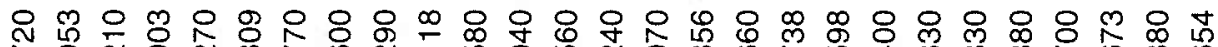

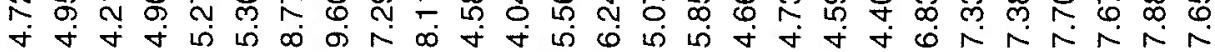

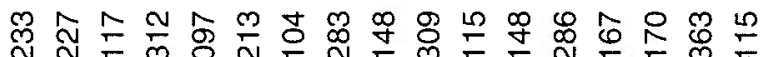
○ o H H H H H H H H H H H H H H H H H

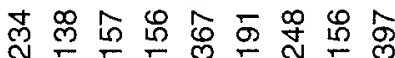

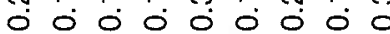

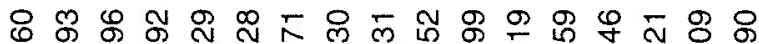
幽

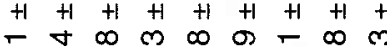

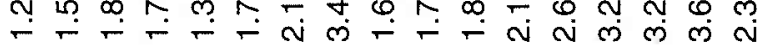

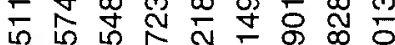

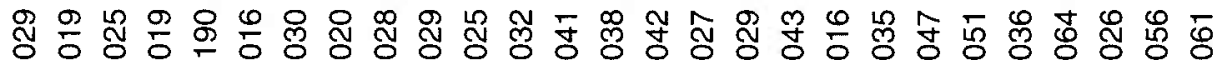

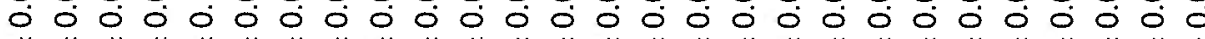

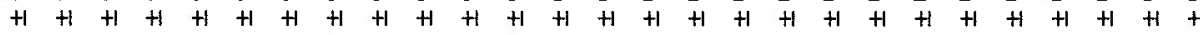

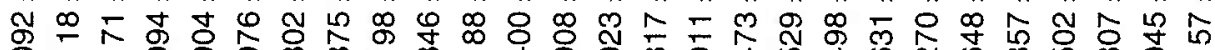
듬

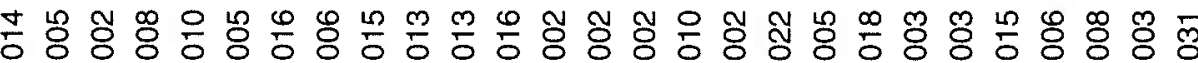

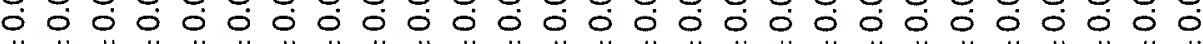
.

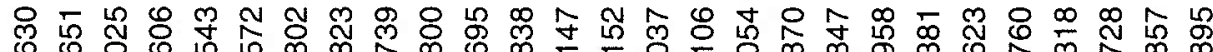

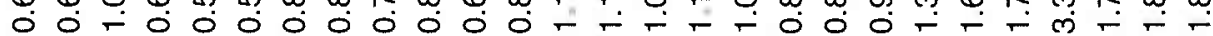

ח ח

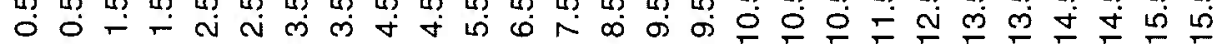

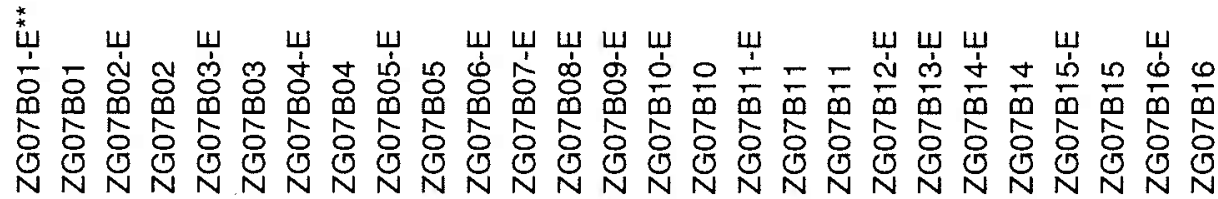




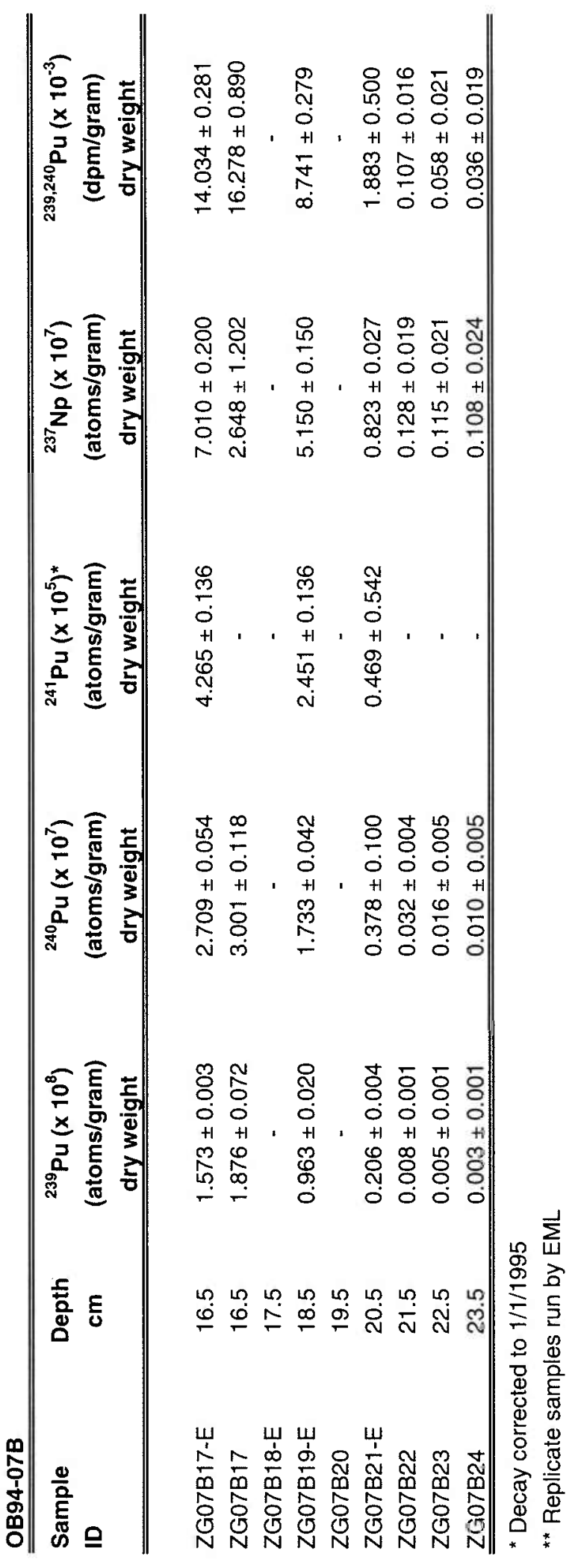




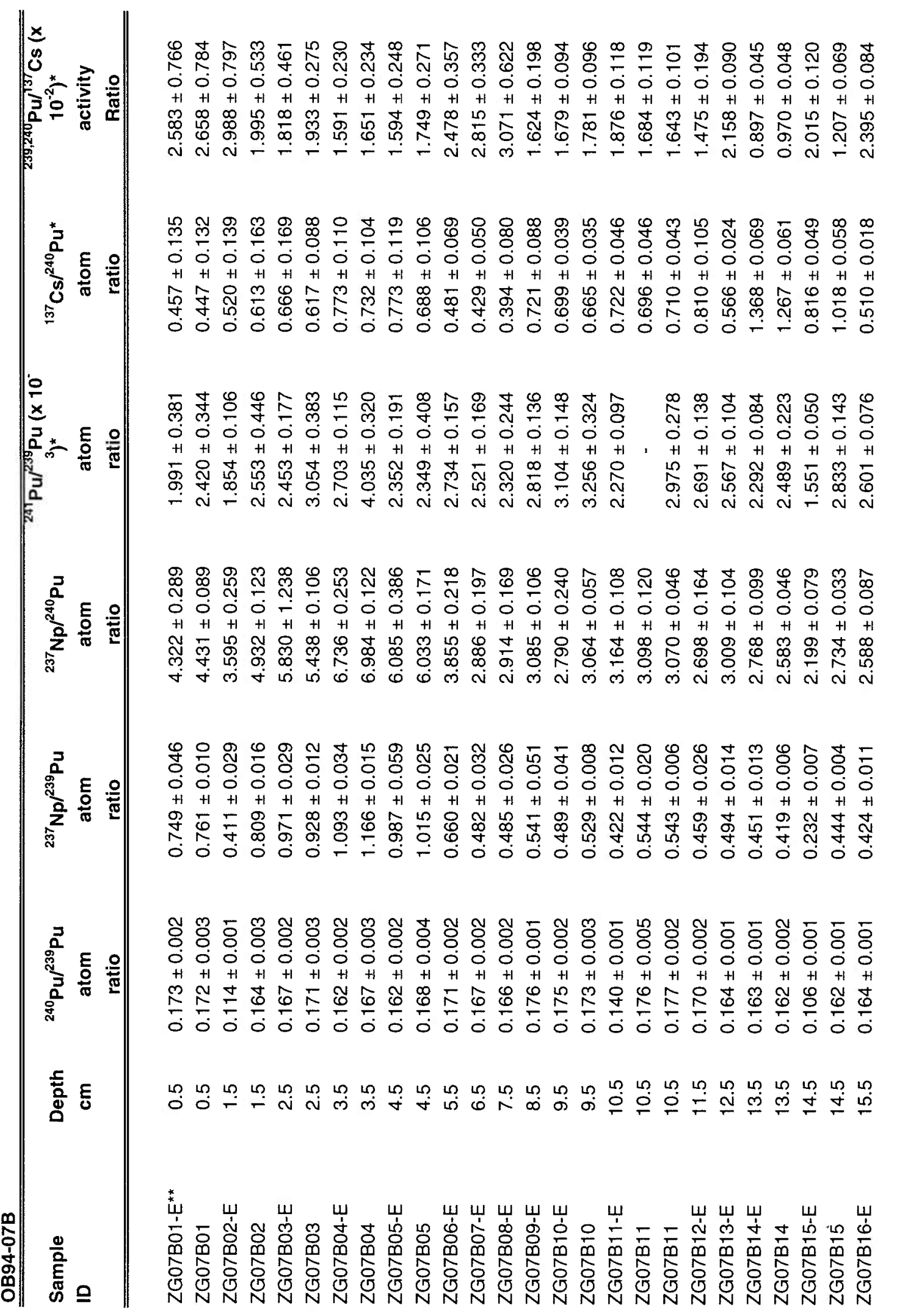




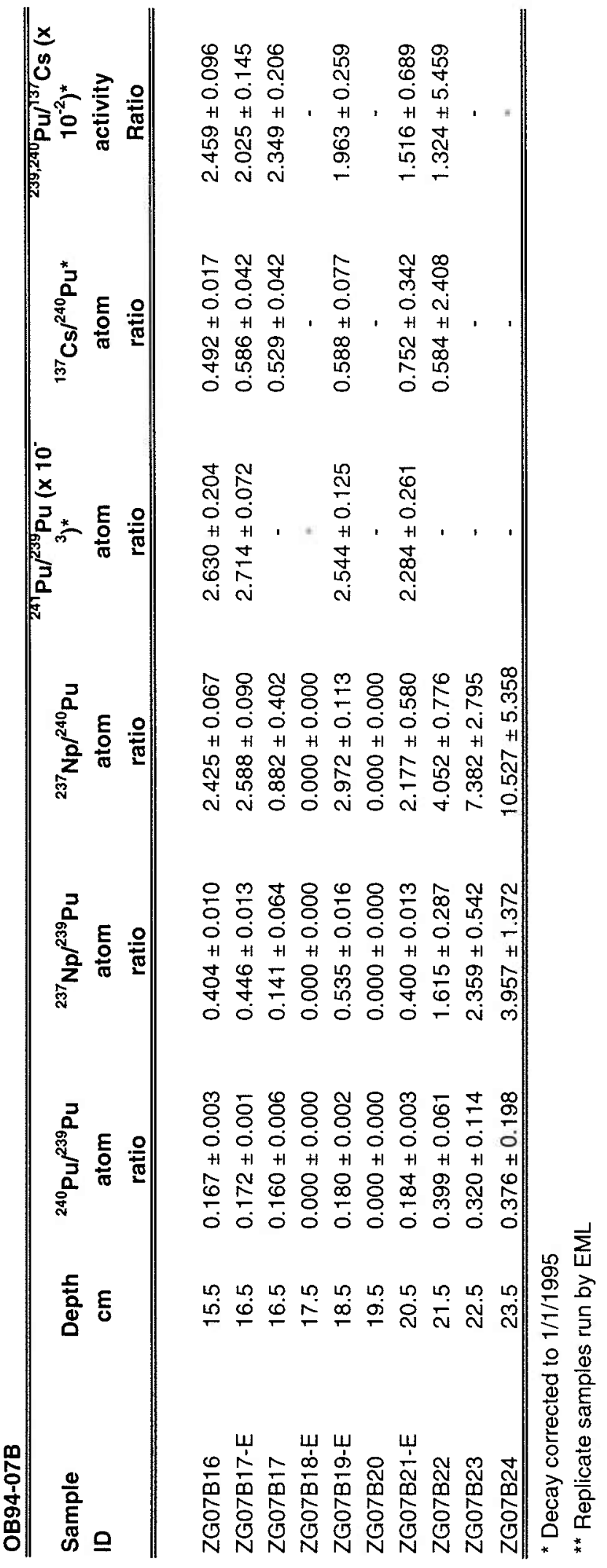




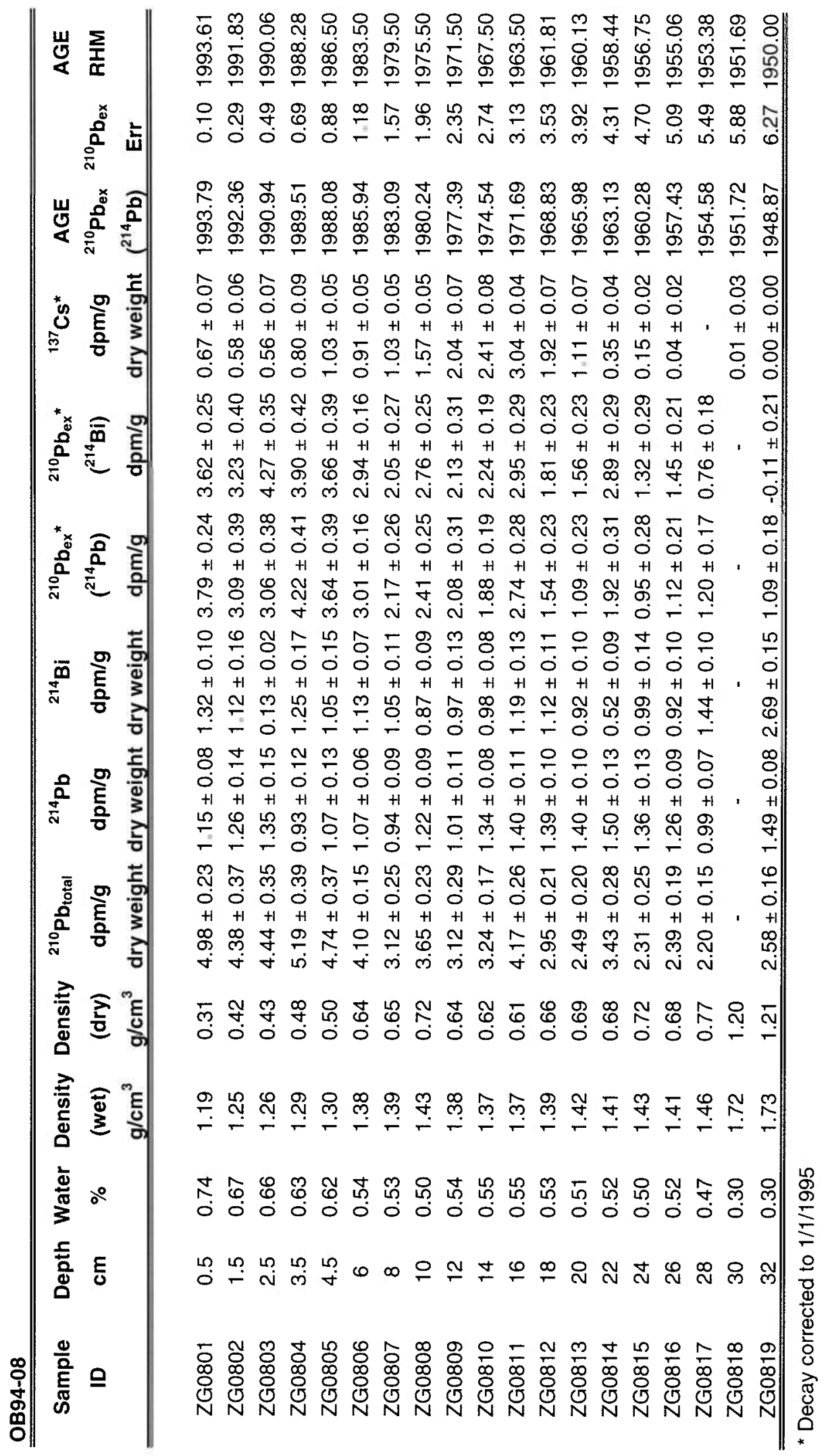




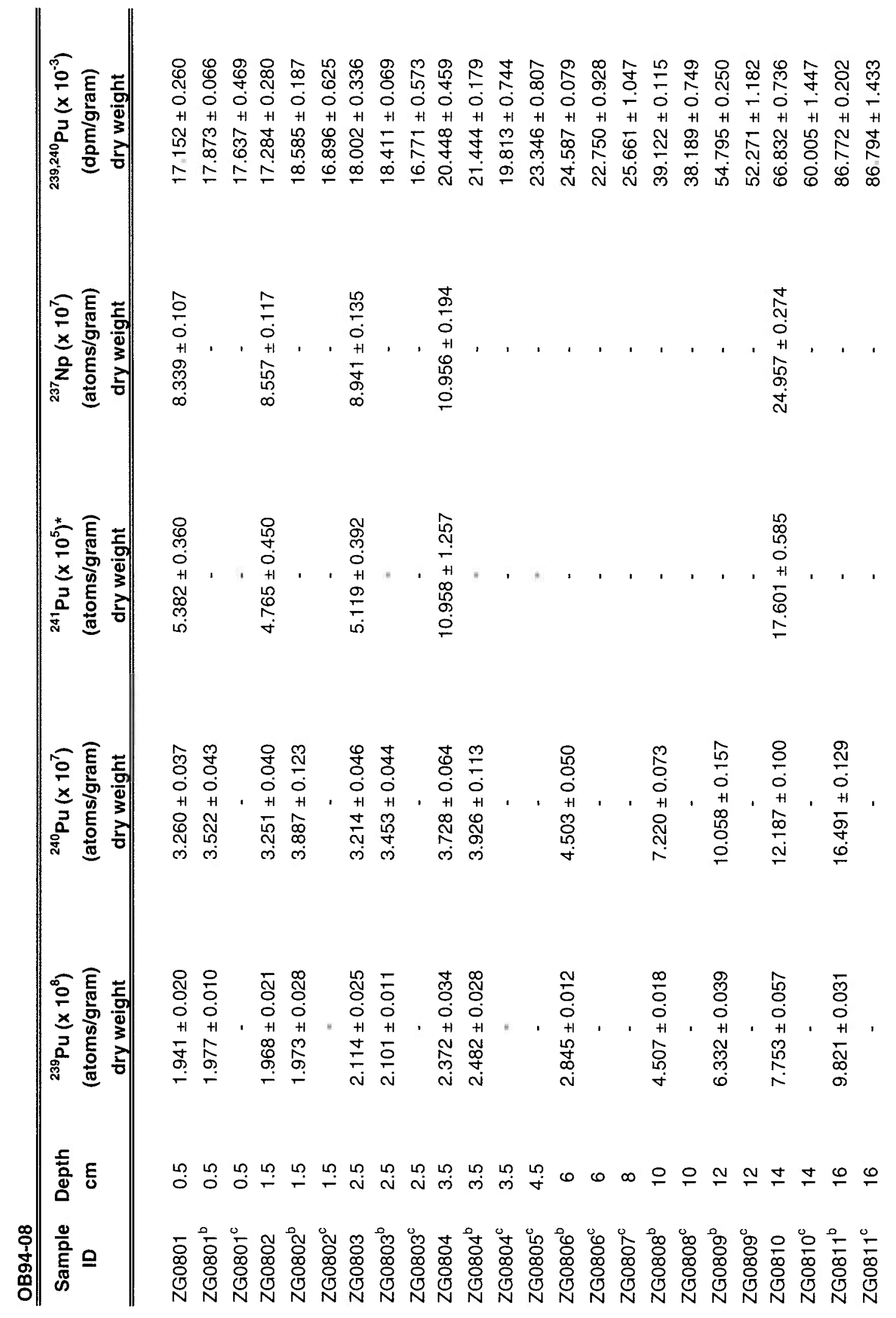




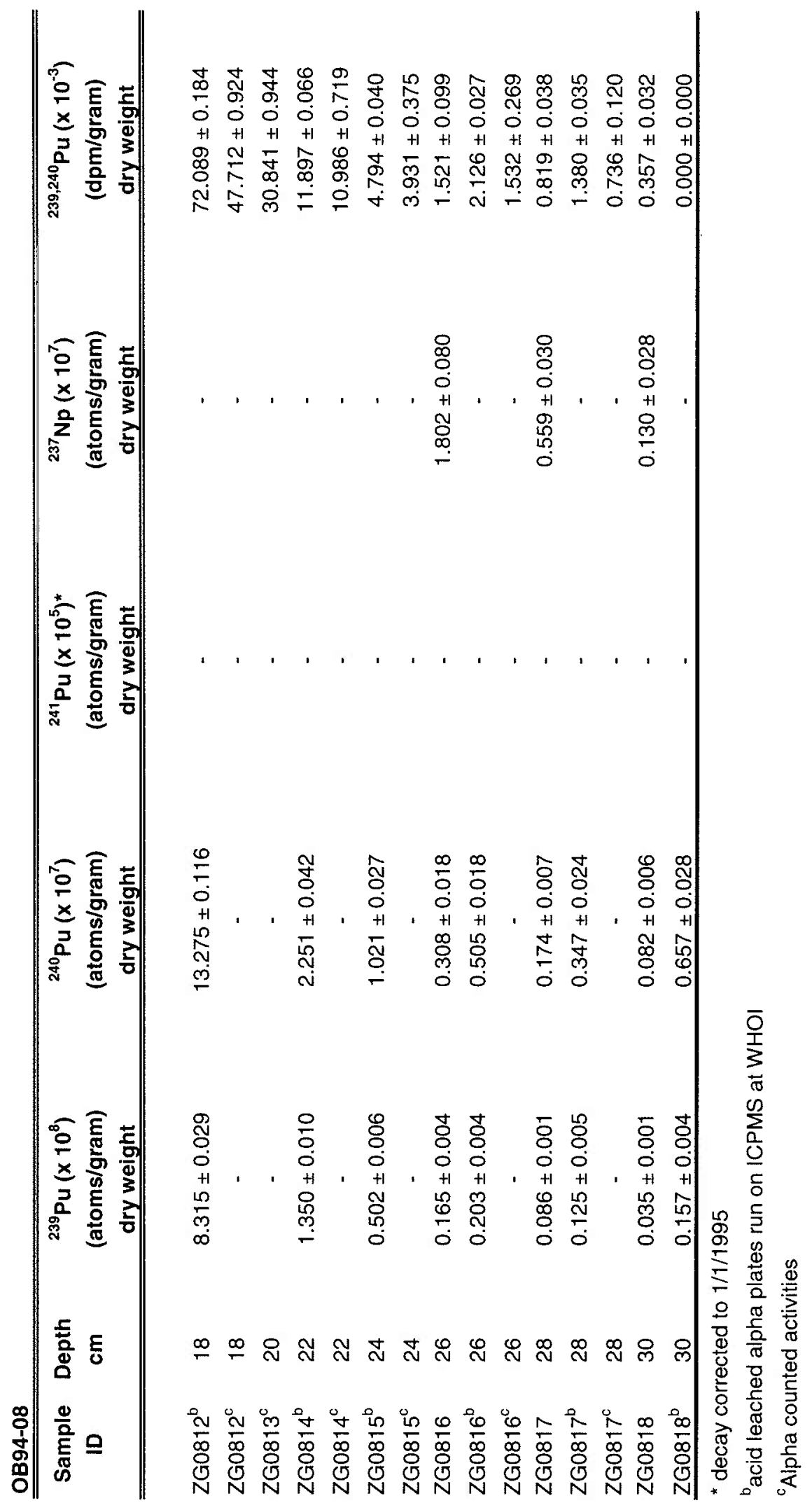




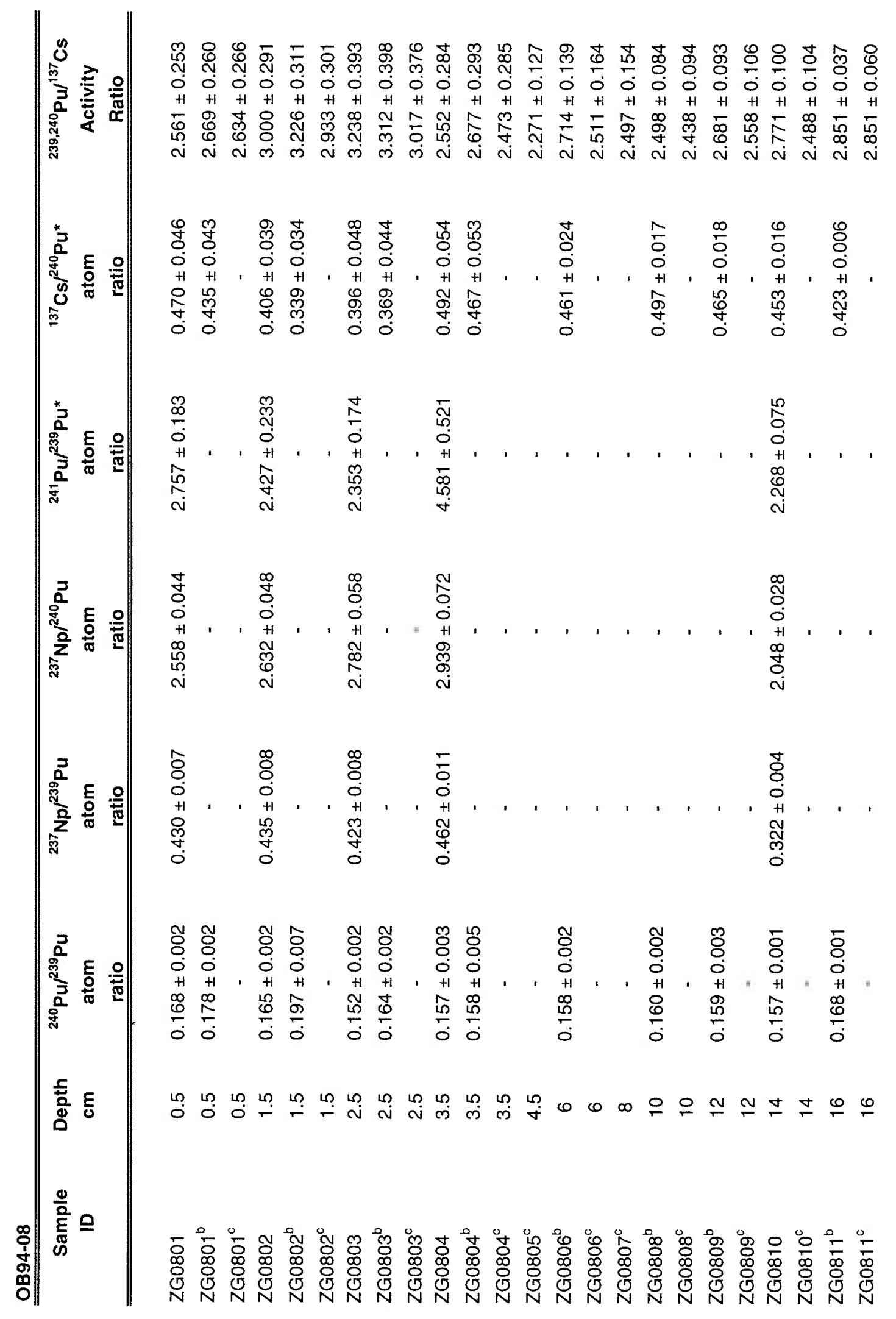




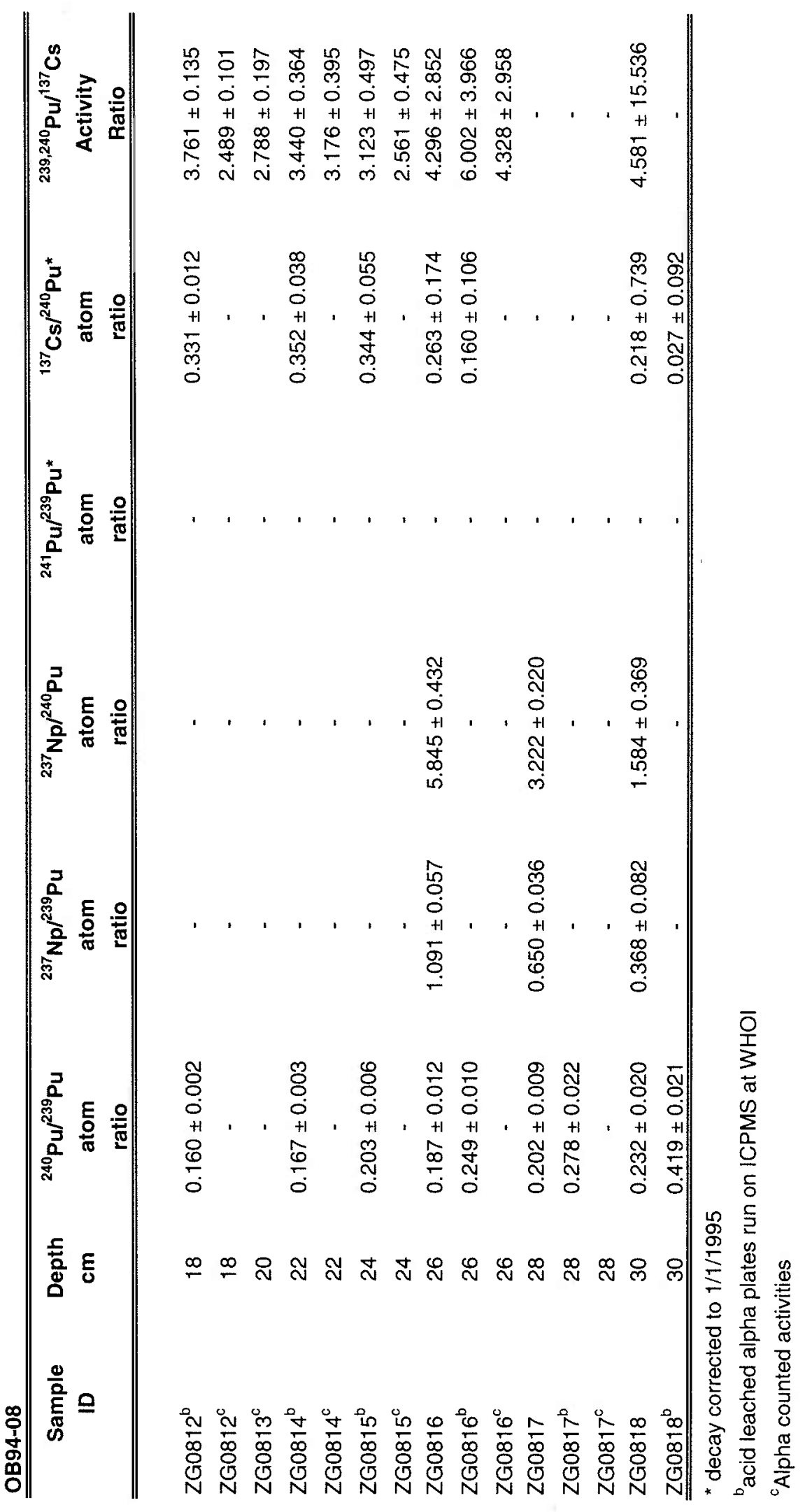




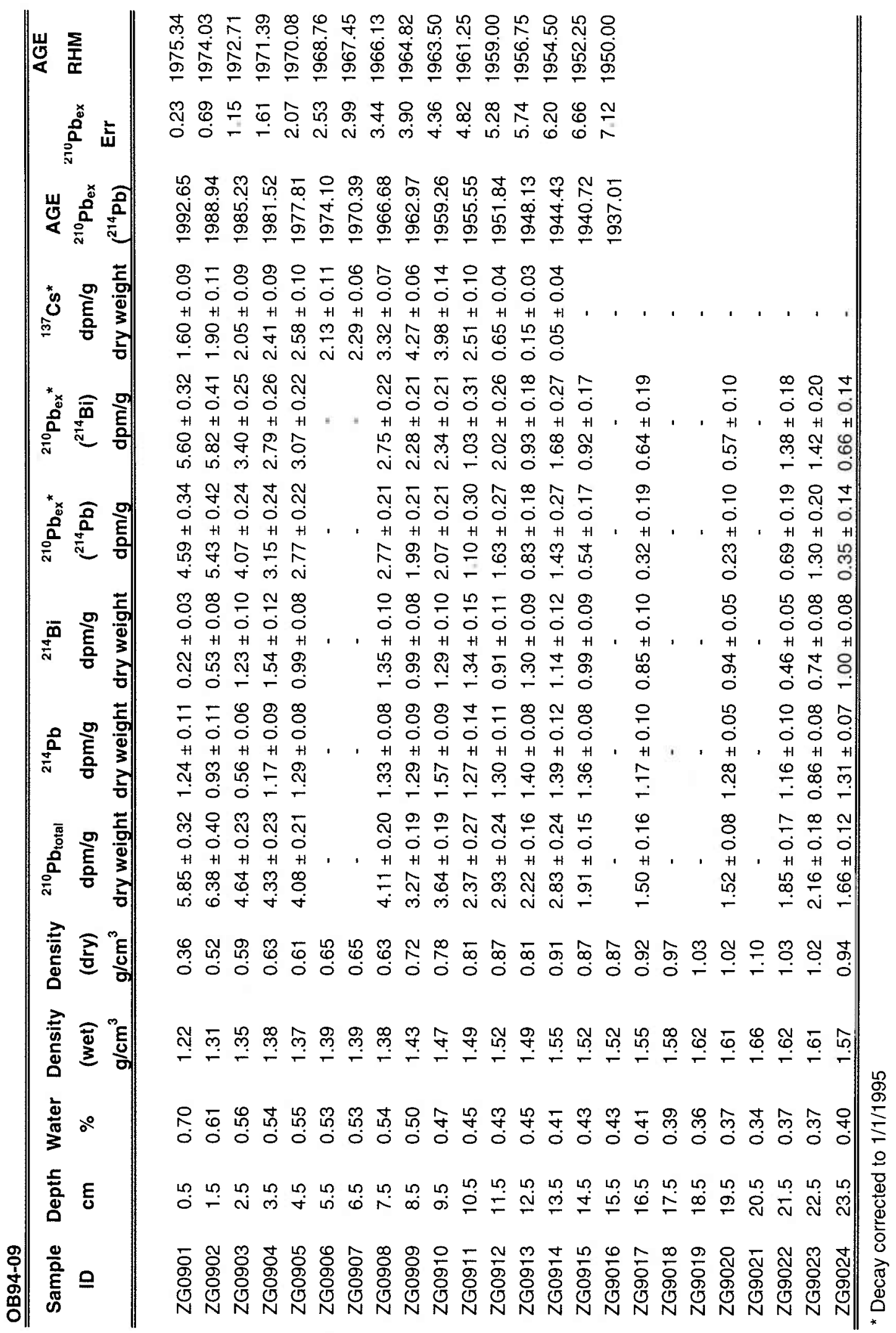




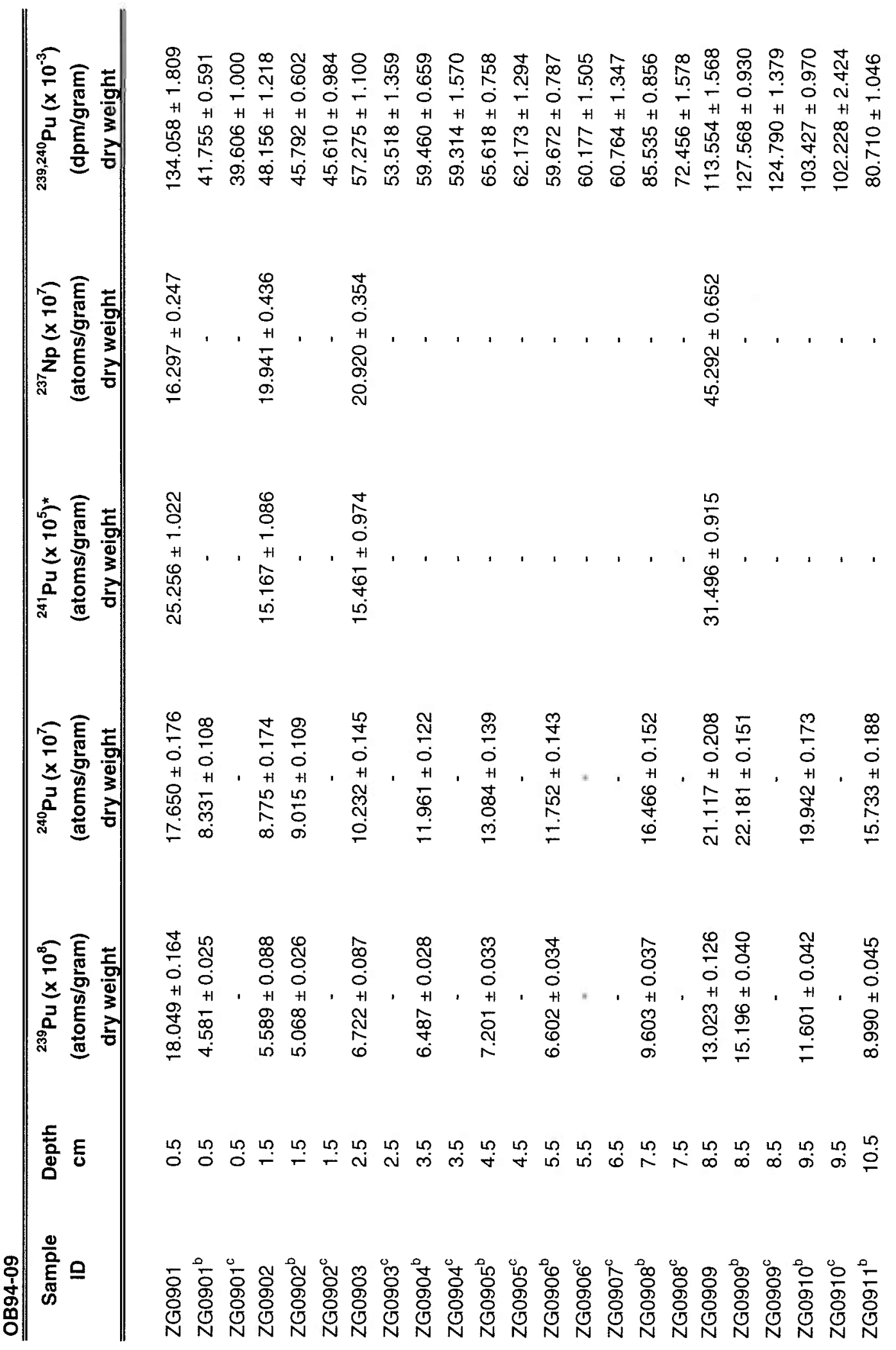




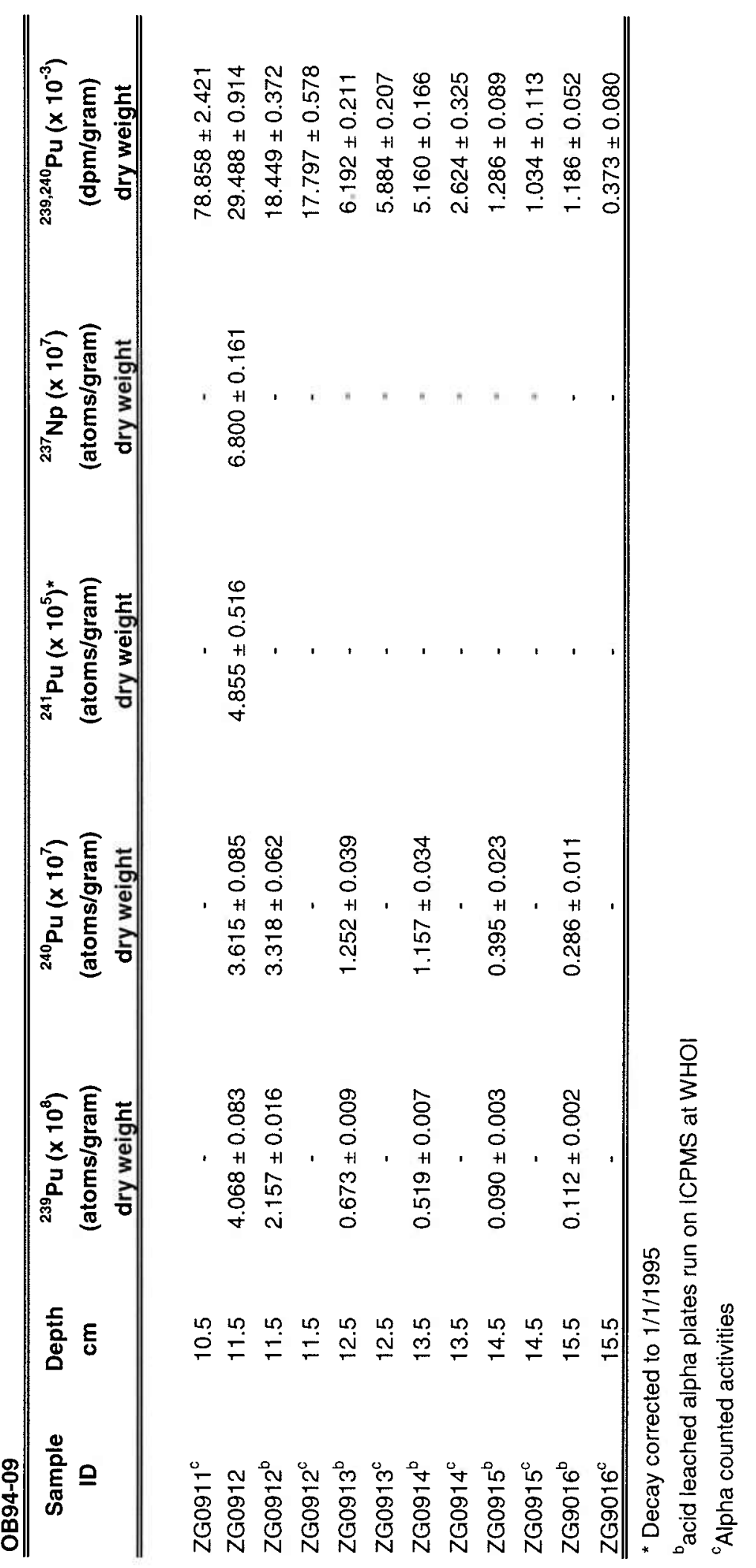




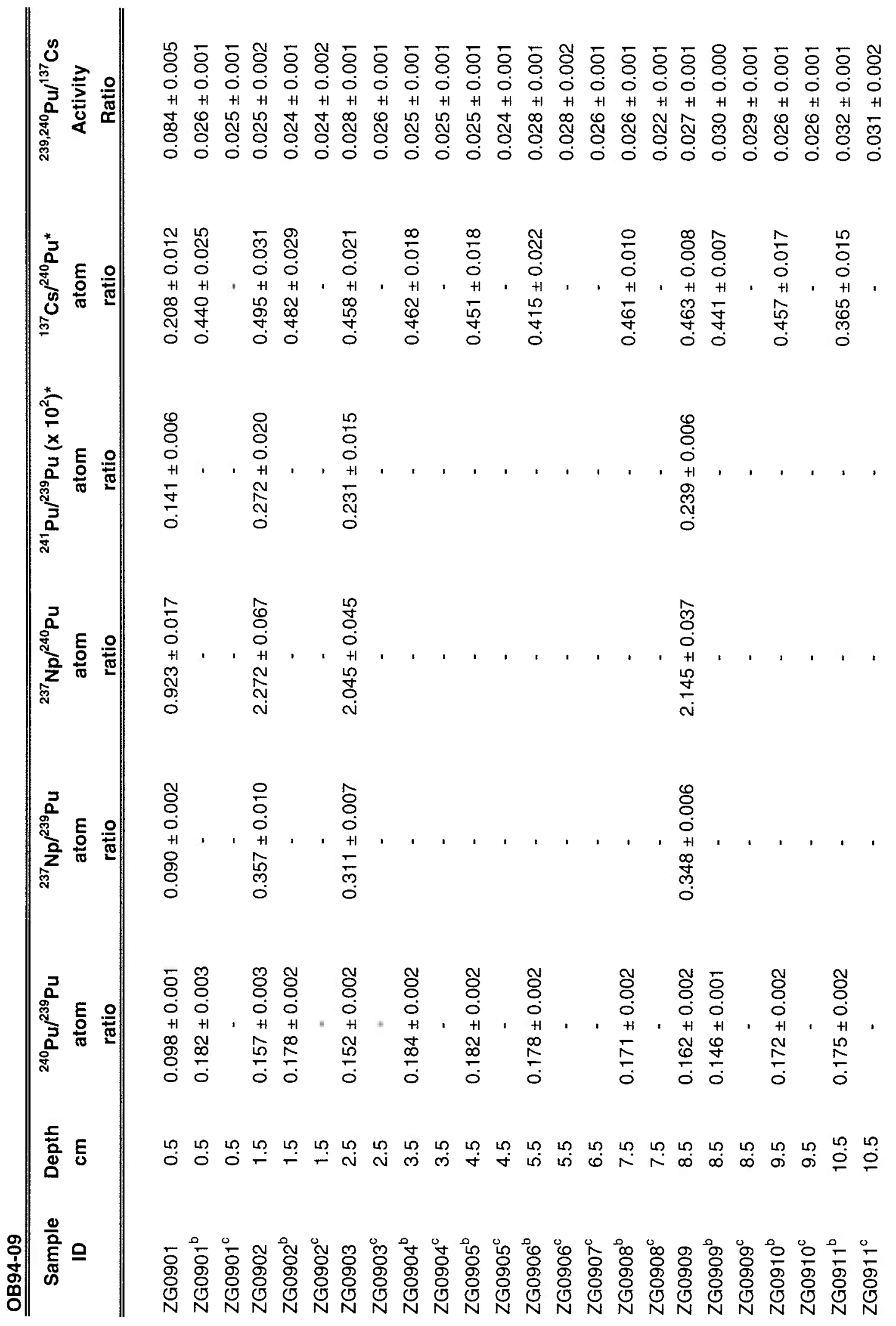




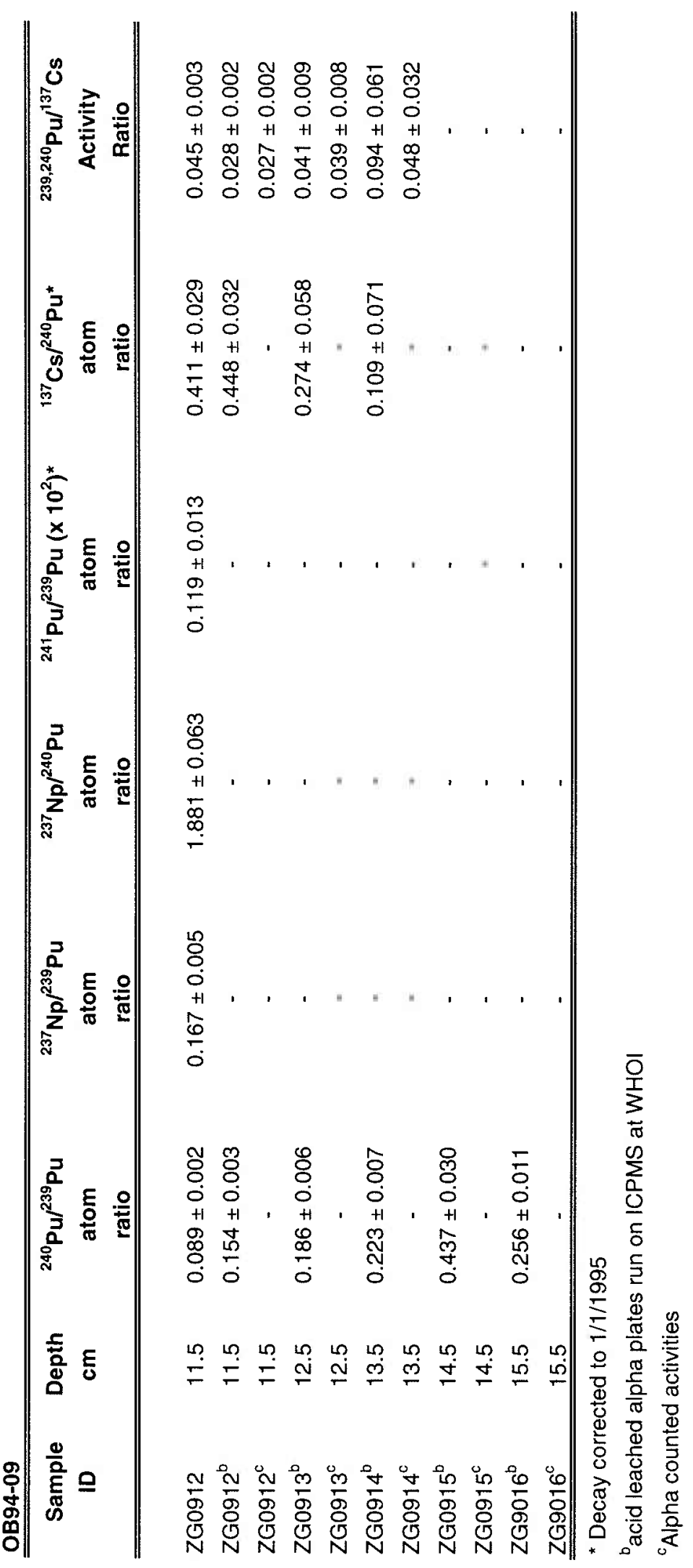




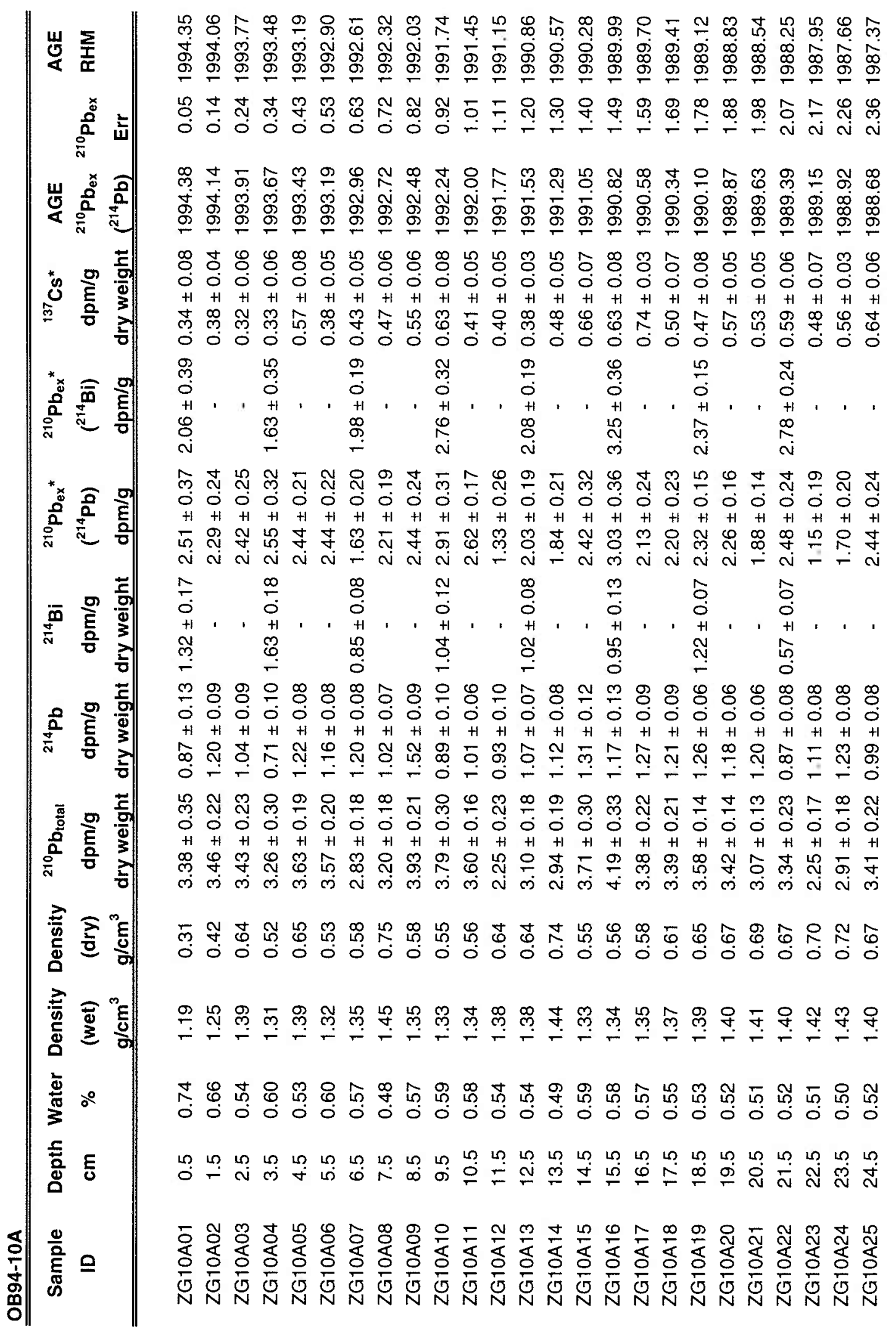




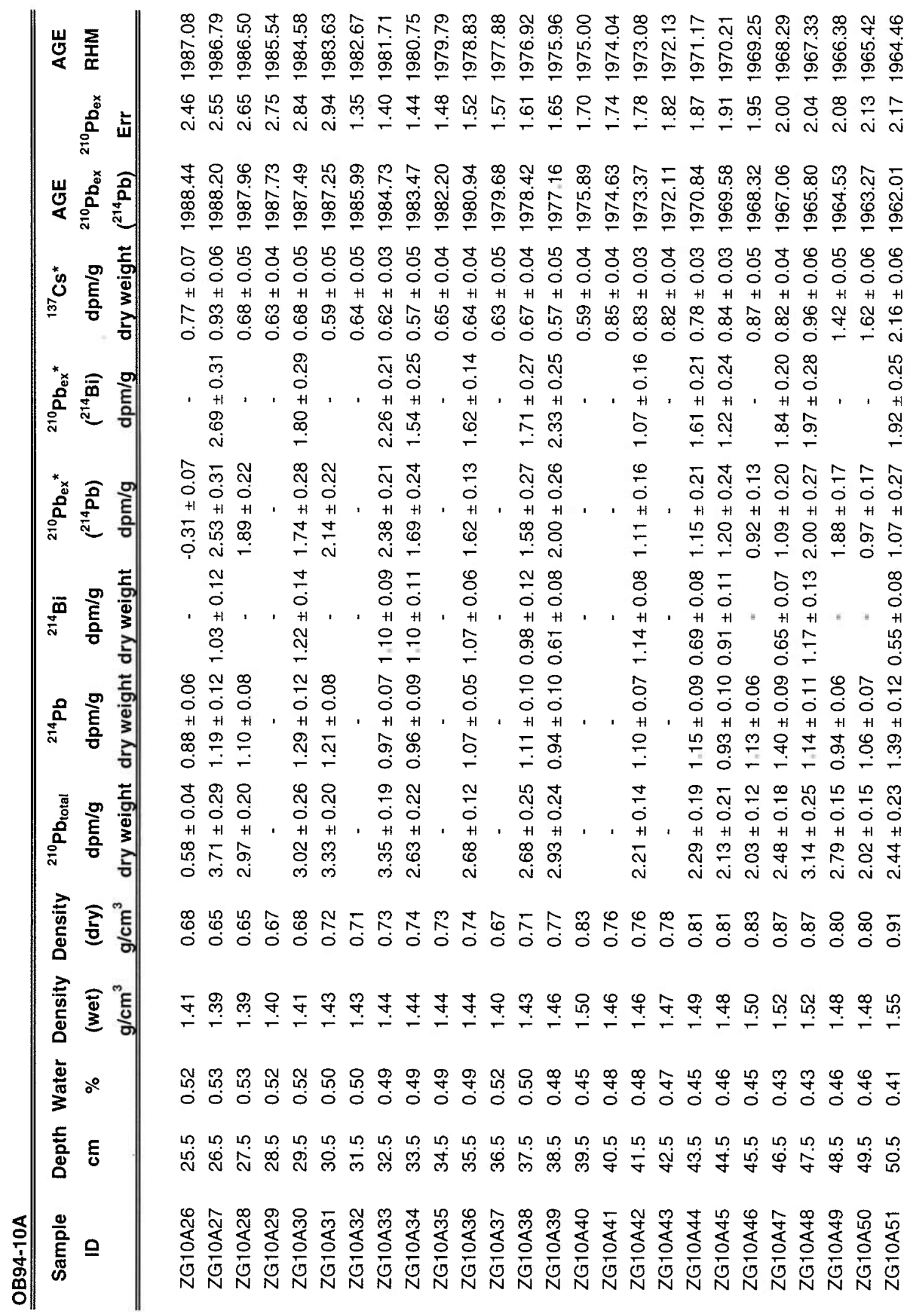




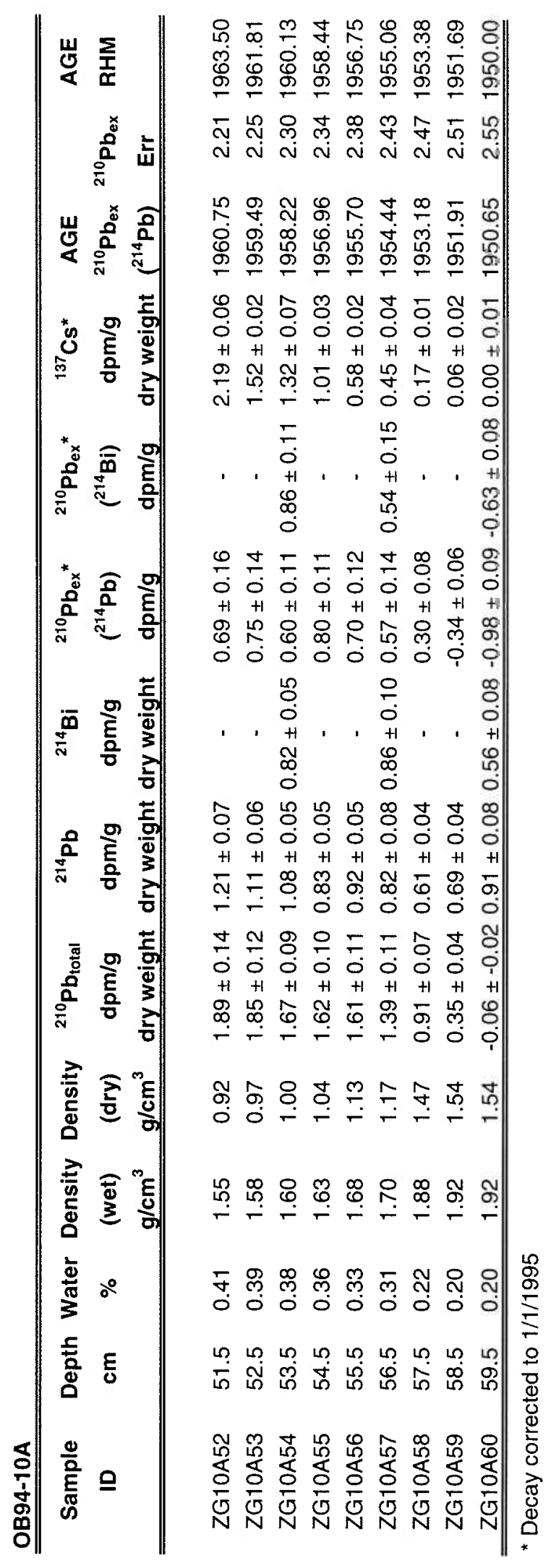




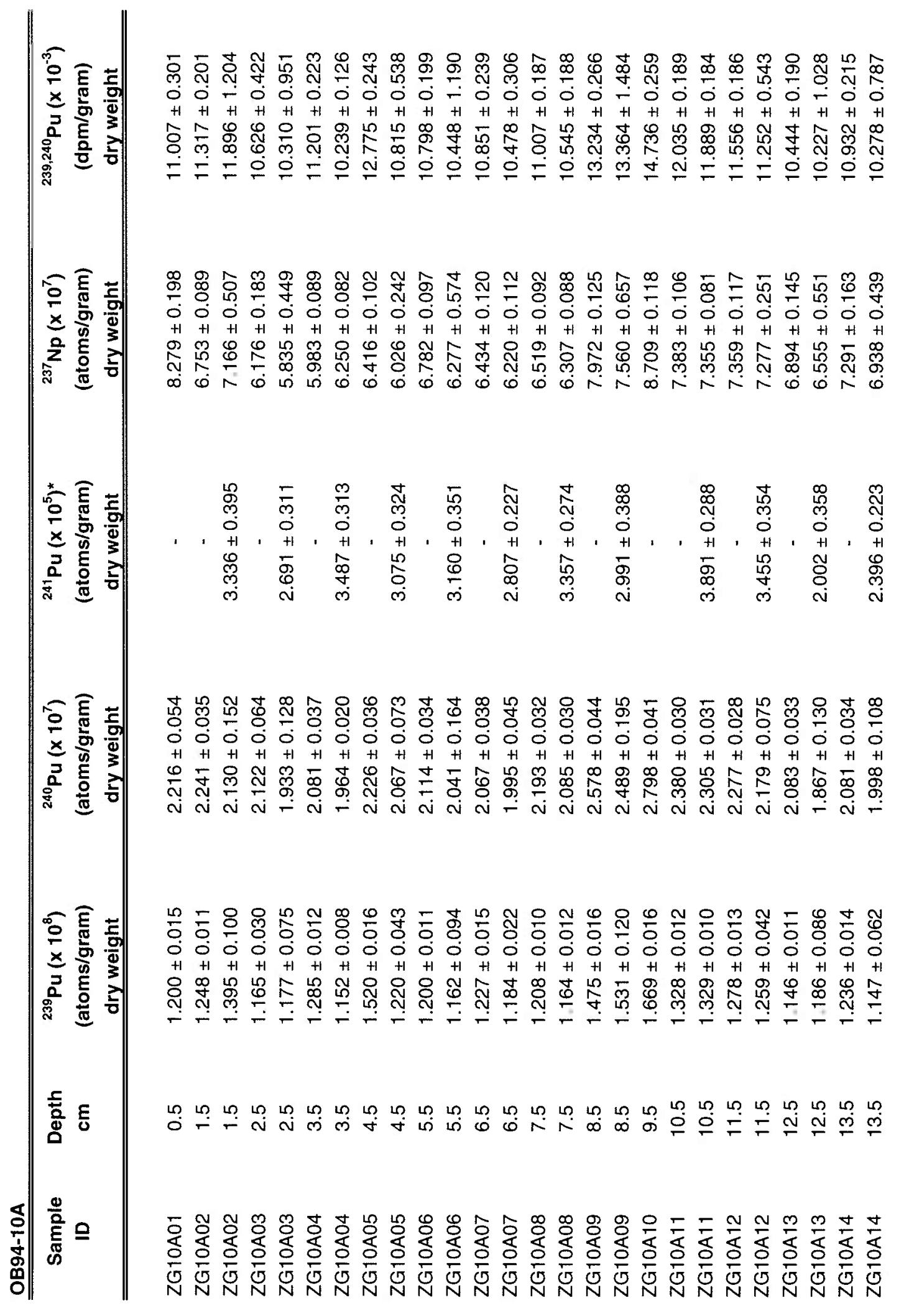




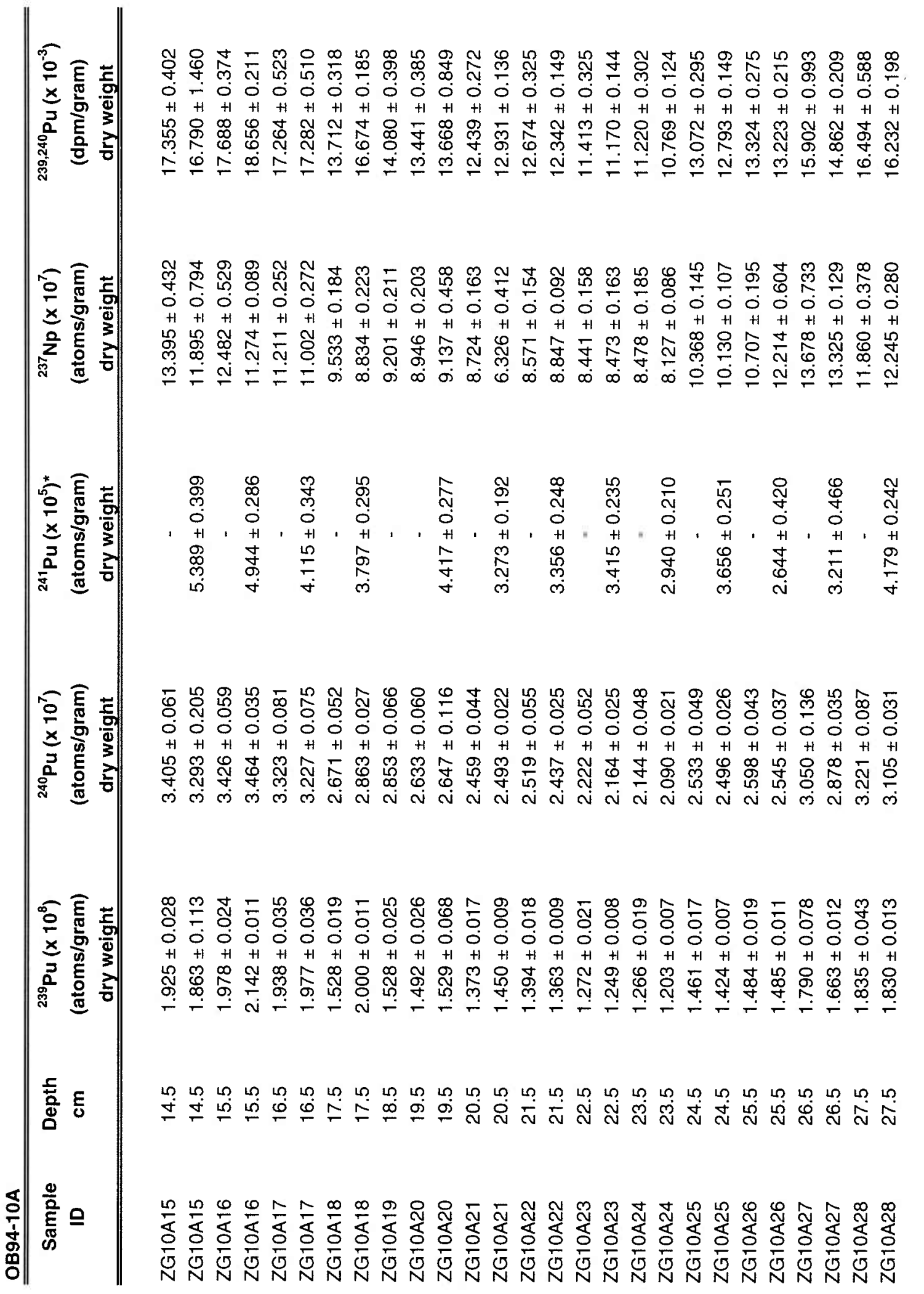




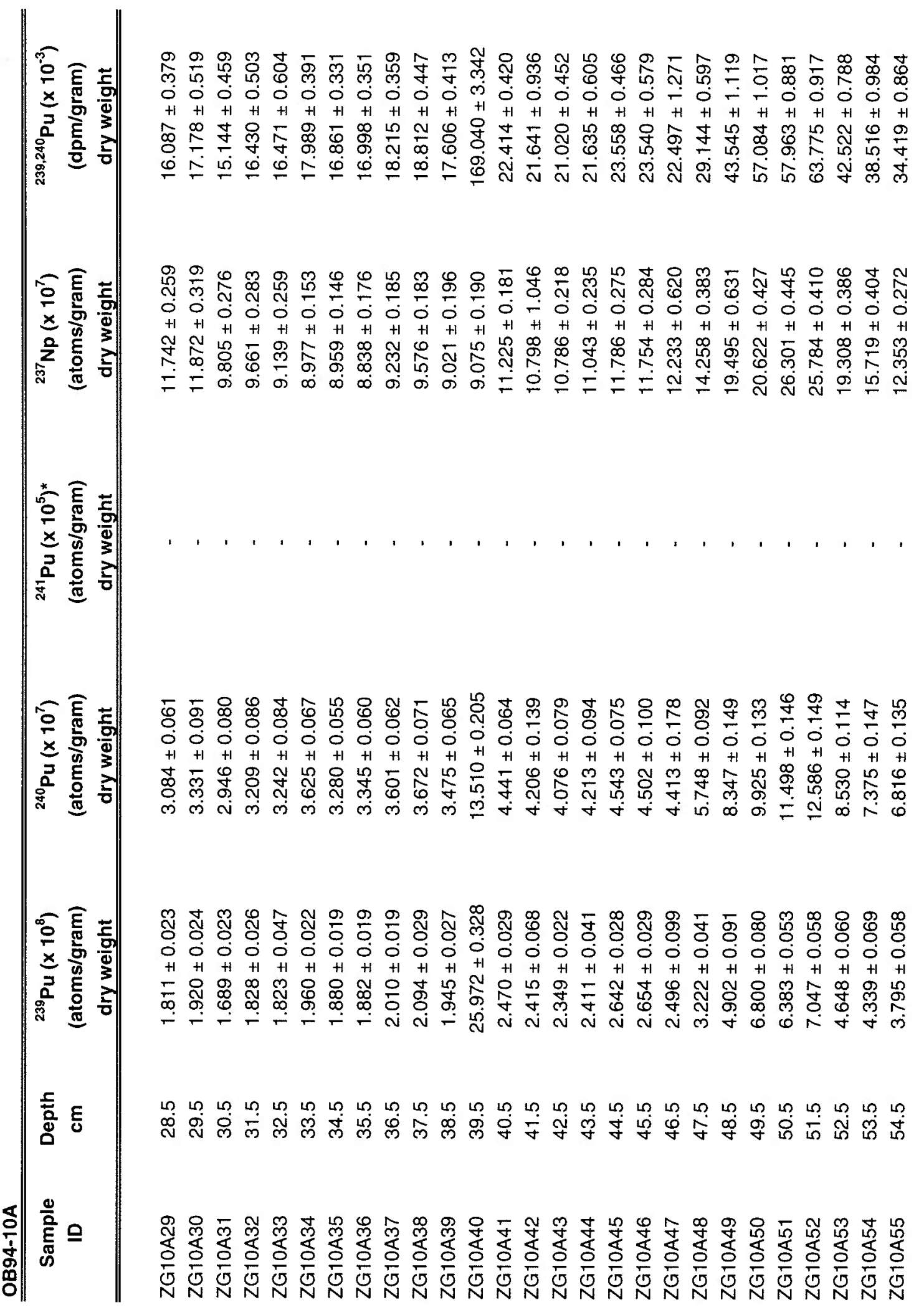




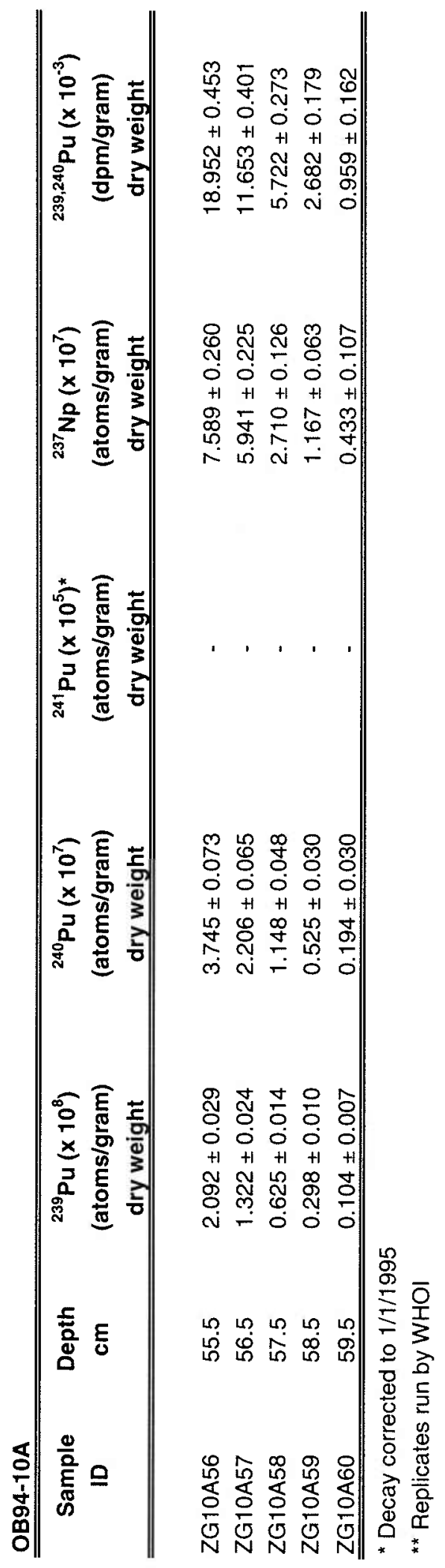




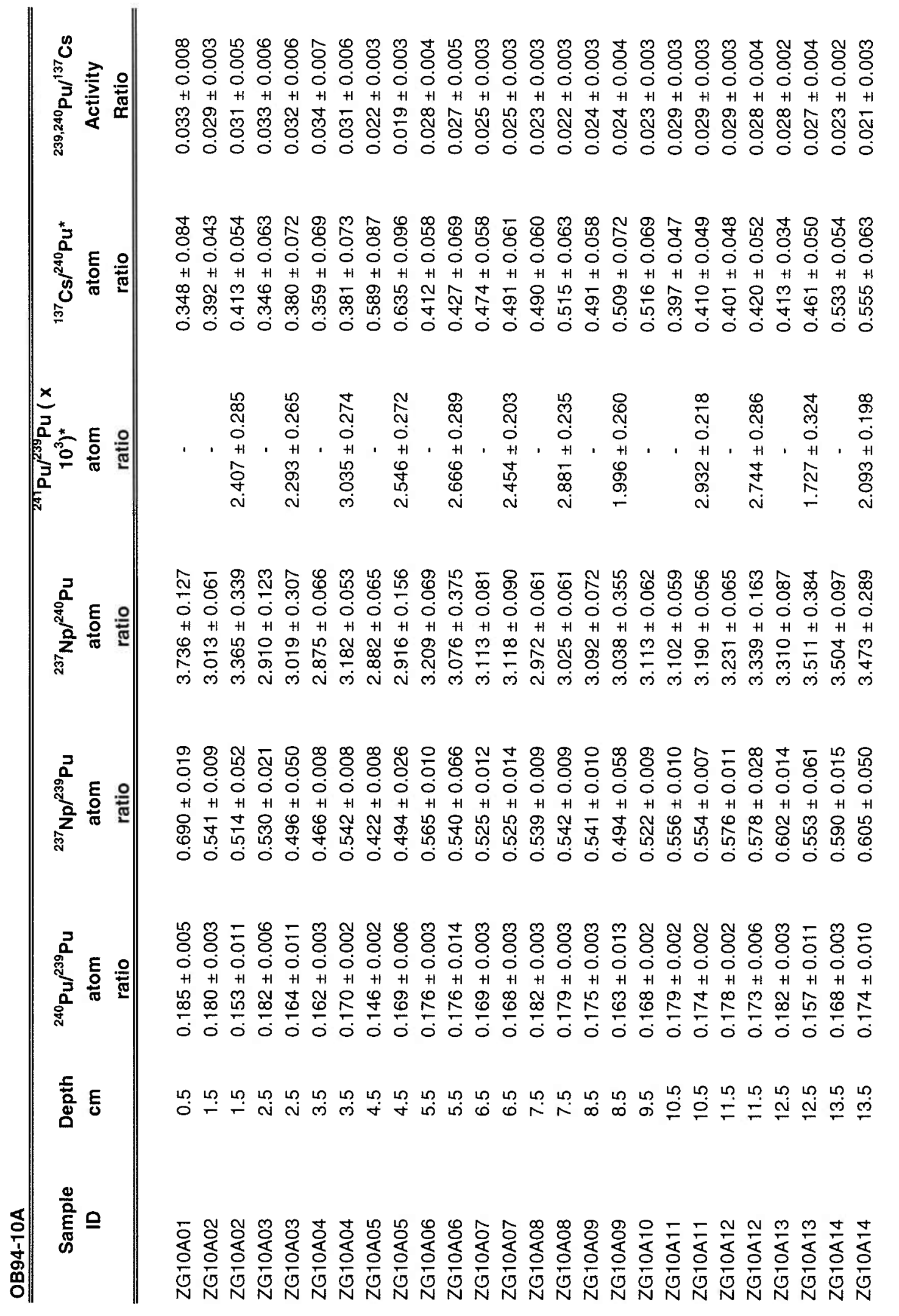




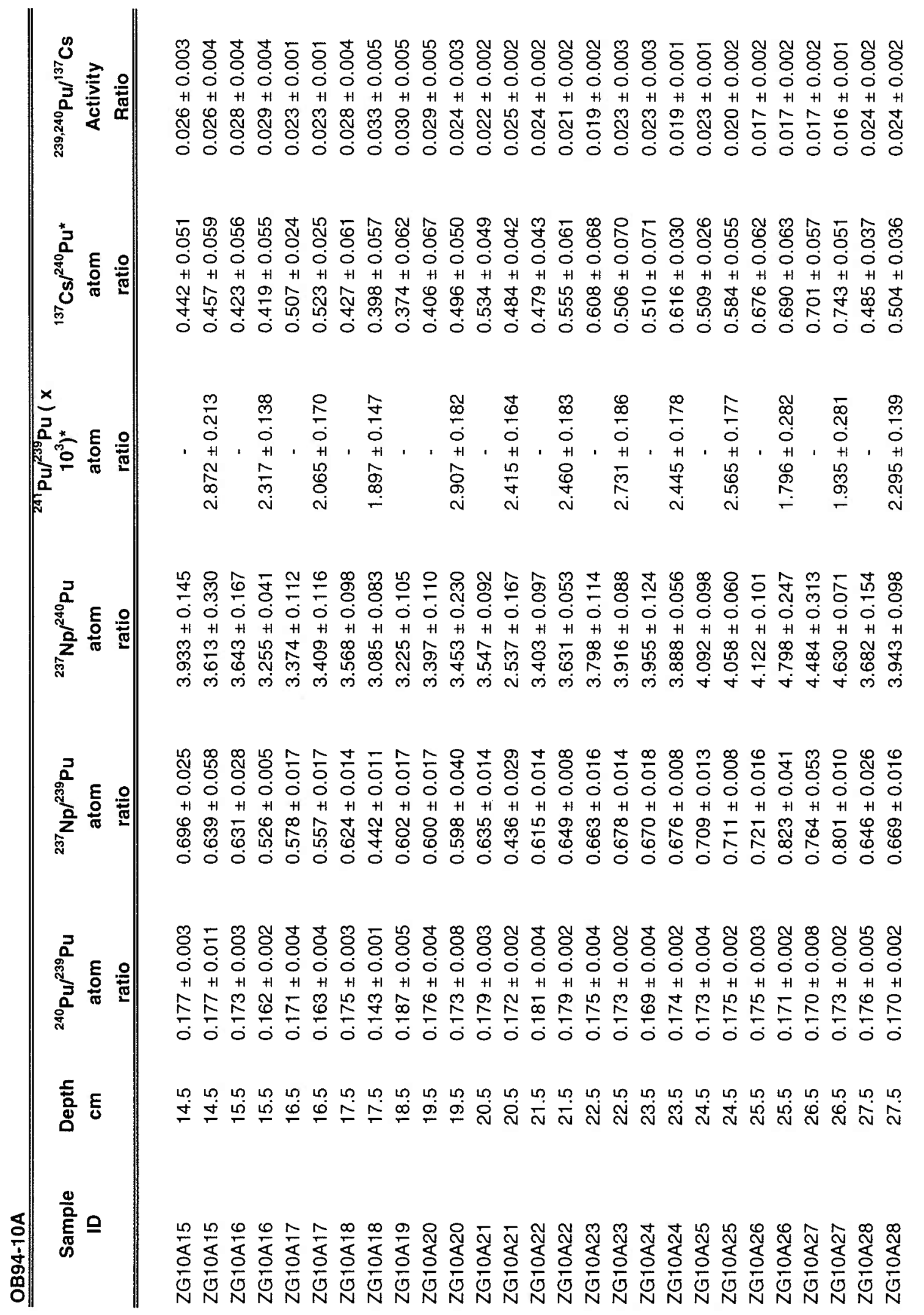




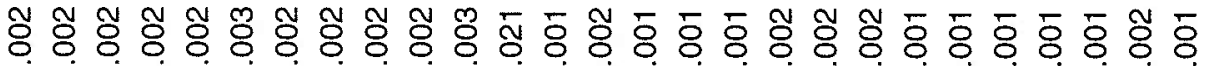

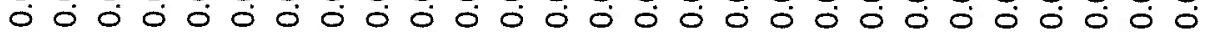

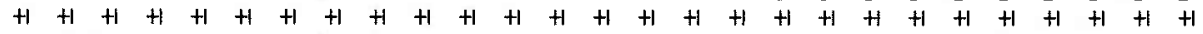
芩

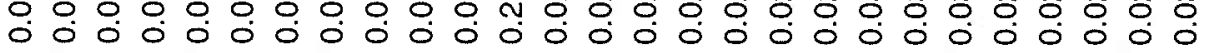

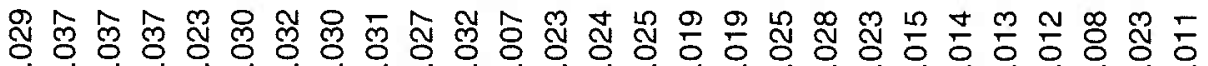

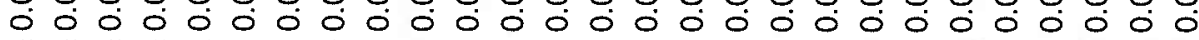
$+1+1+1+1+1+1+1+1+1+1+1+1+1+1+1+1+1+1+1+1+1+1+1+1+1+1+1$

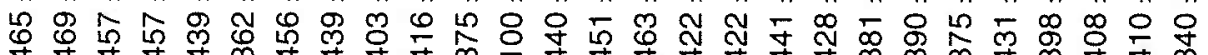

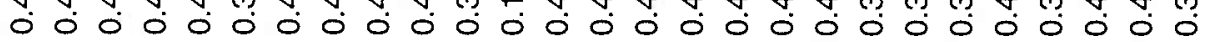

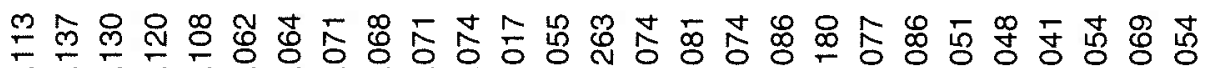
б.

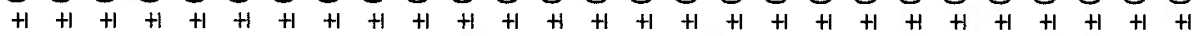

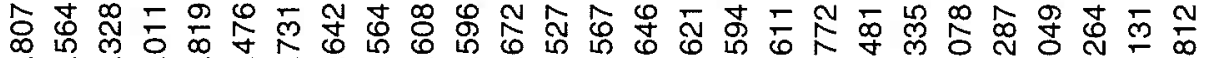
m

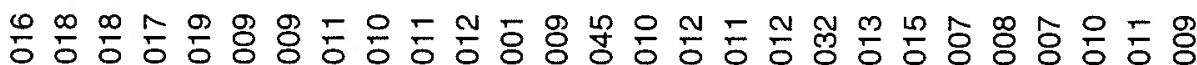

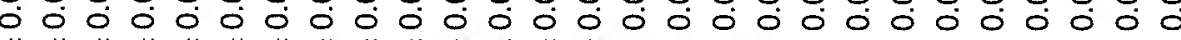
$+1+1+1+1+1+H+1+1+1+1+1+1+1+1+1+1+1+1+1+1+1+1$

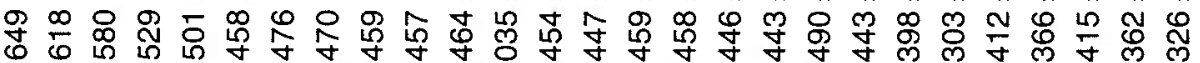

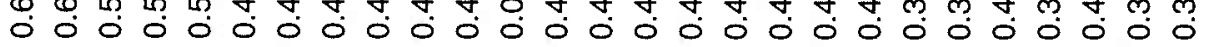

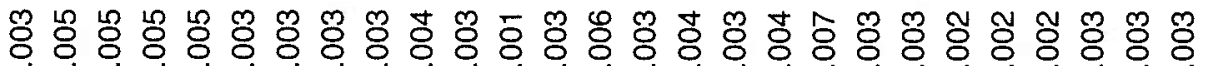

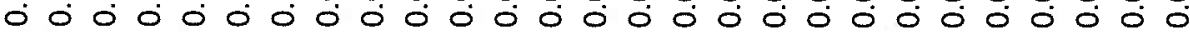
$+1+1+1+1+1+1+H+1+1+1+H+1+1+1+1+1+1+1+1+1+1+1+1+1$

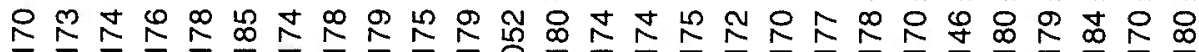
ঢ.

ח

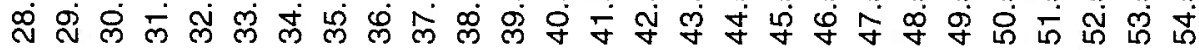

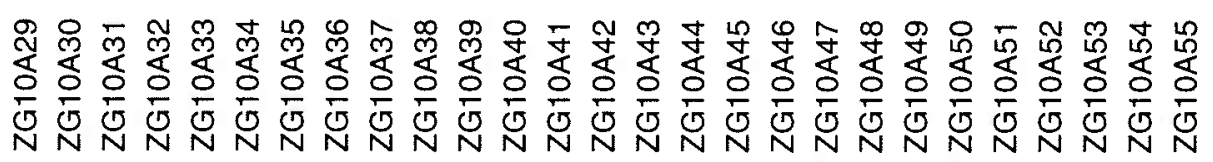




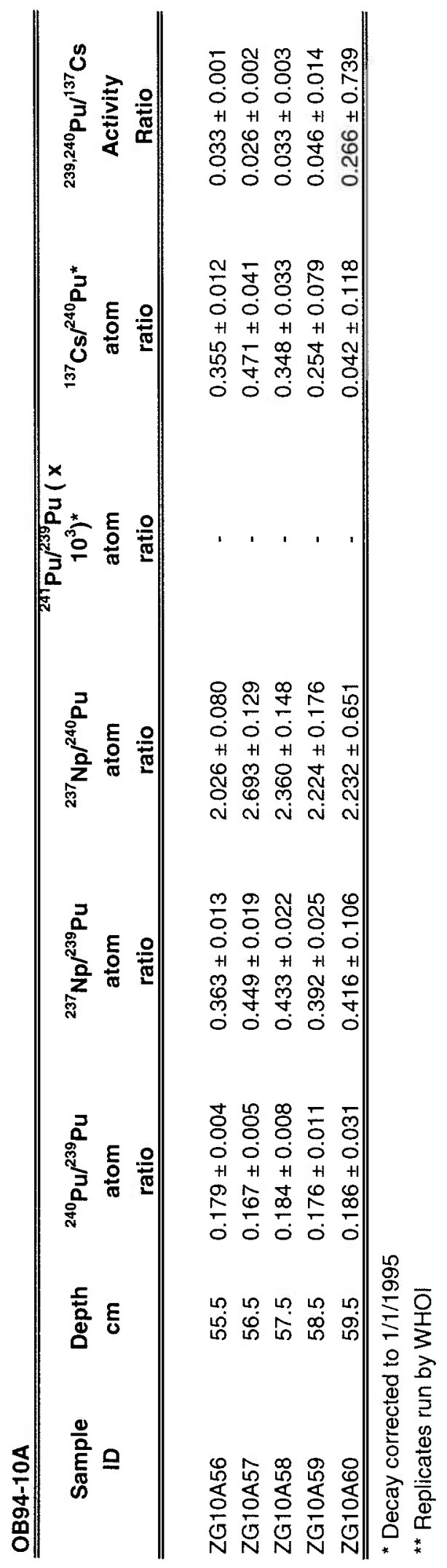




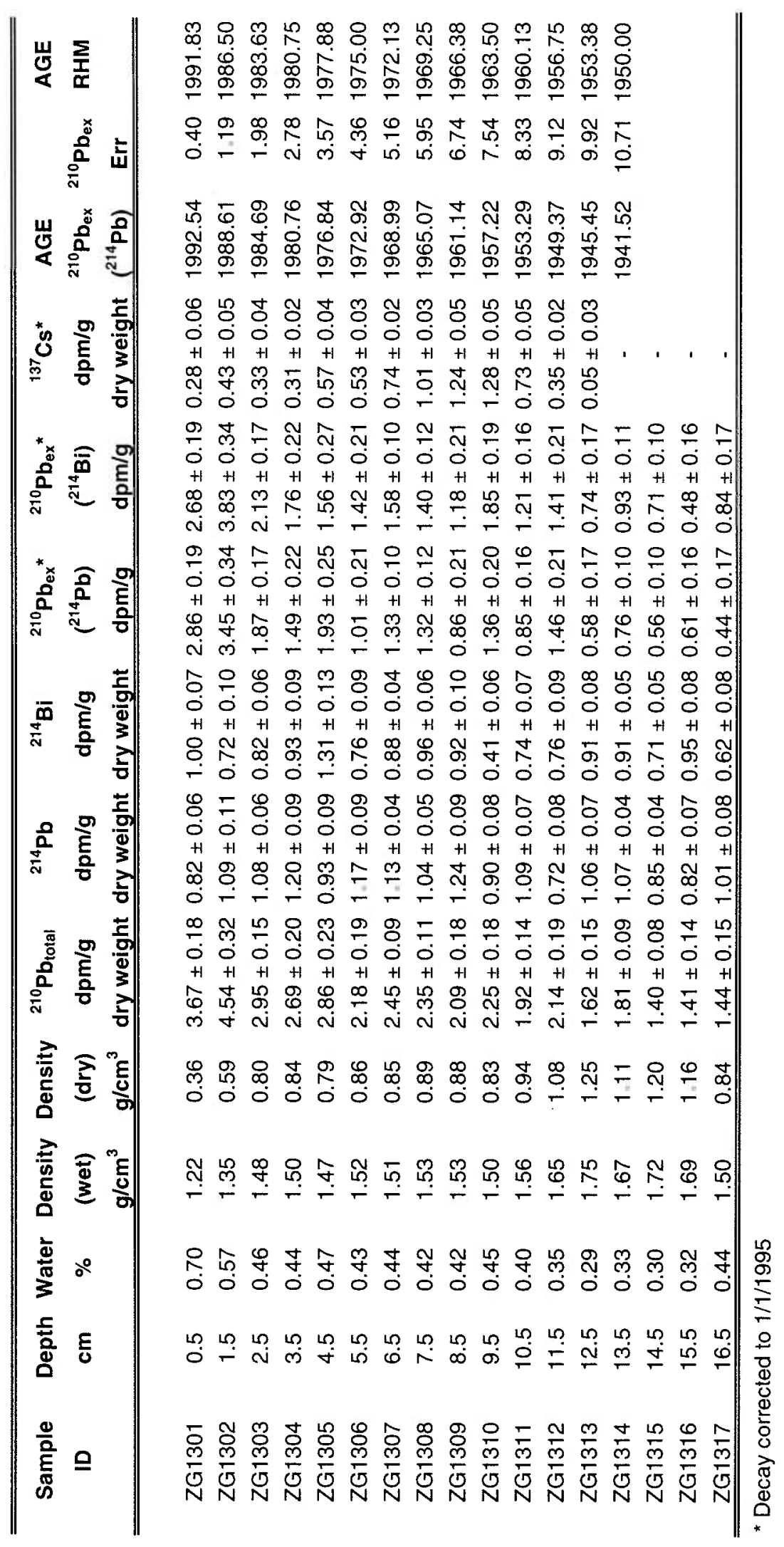




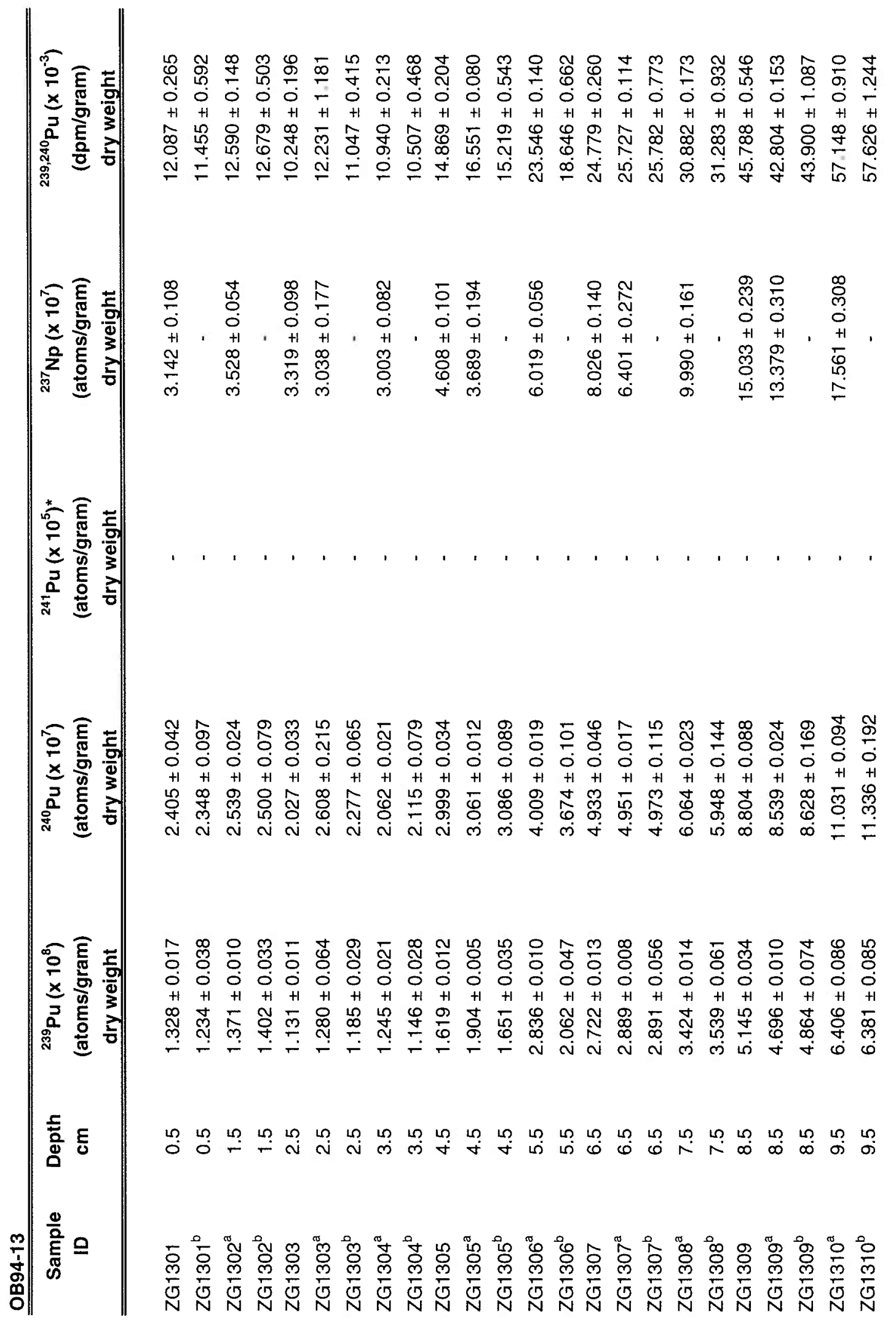




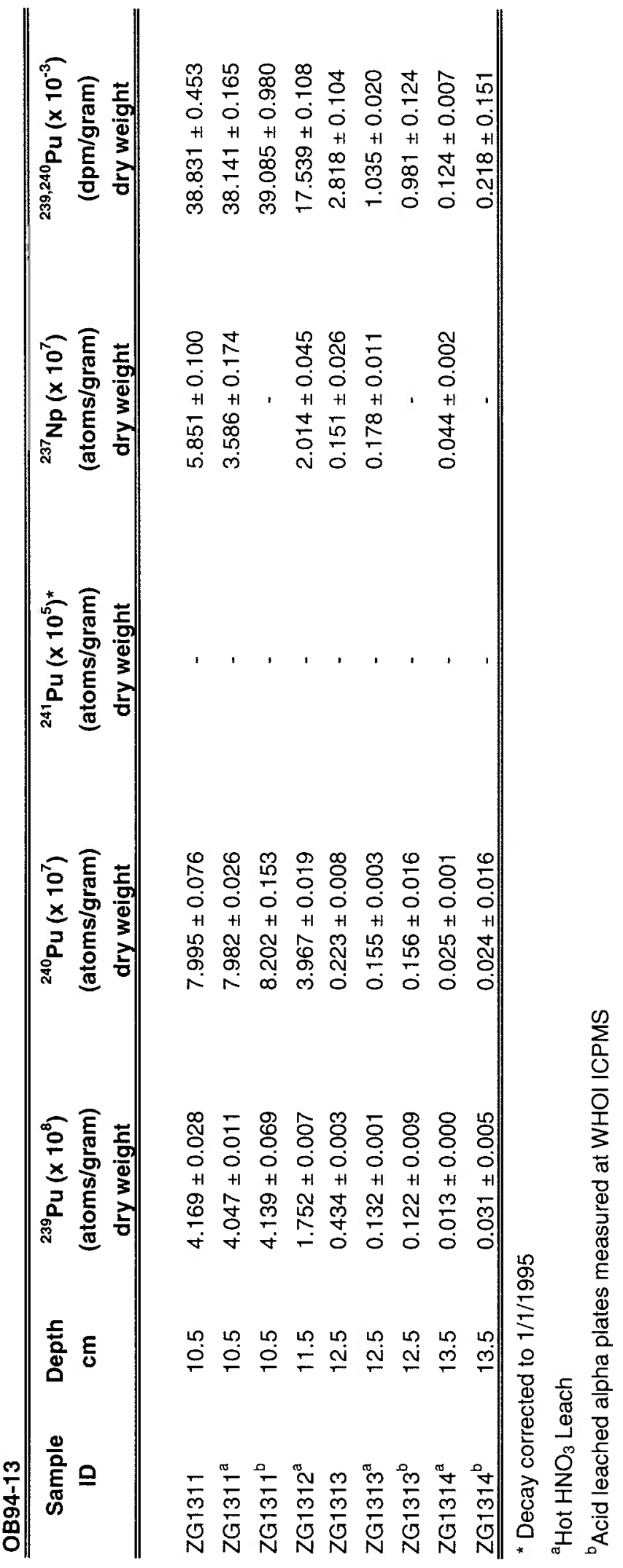




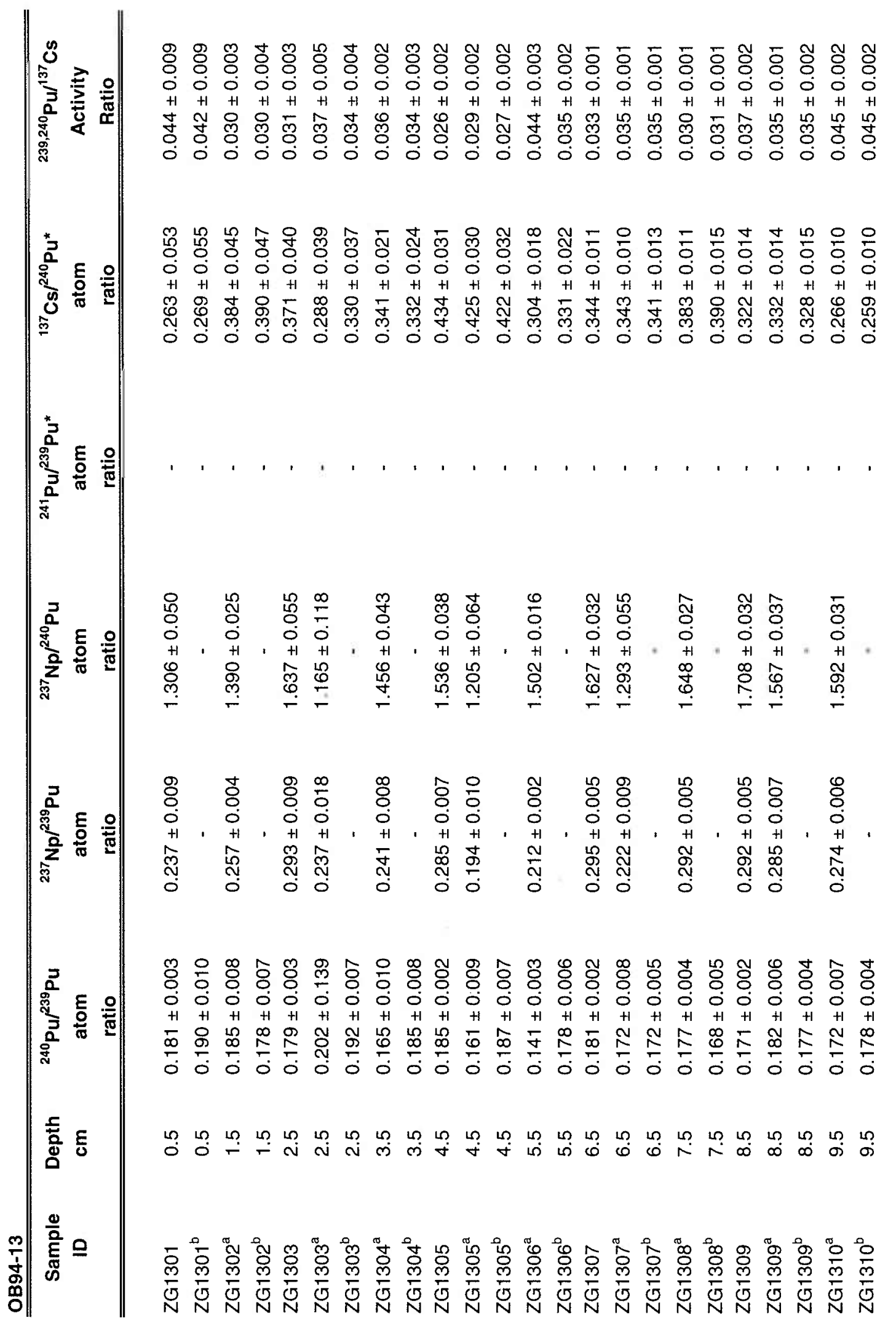




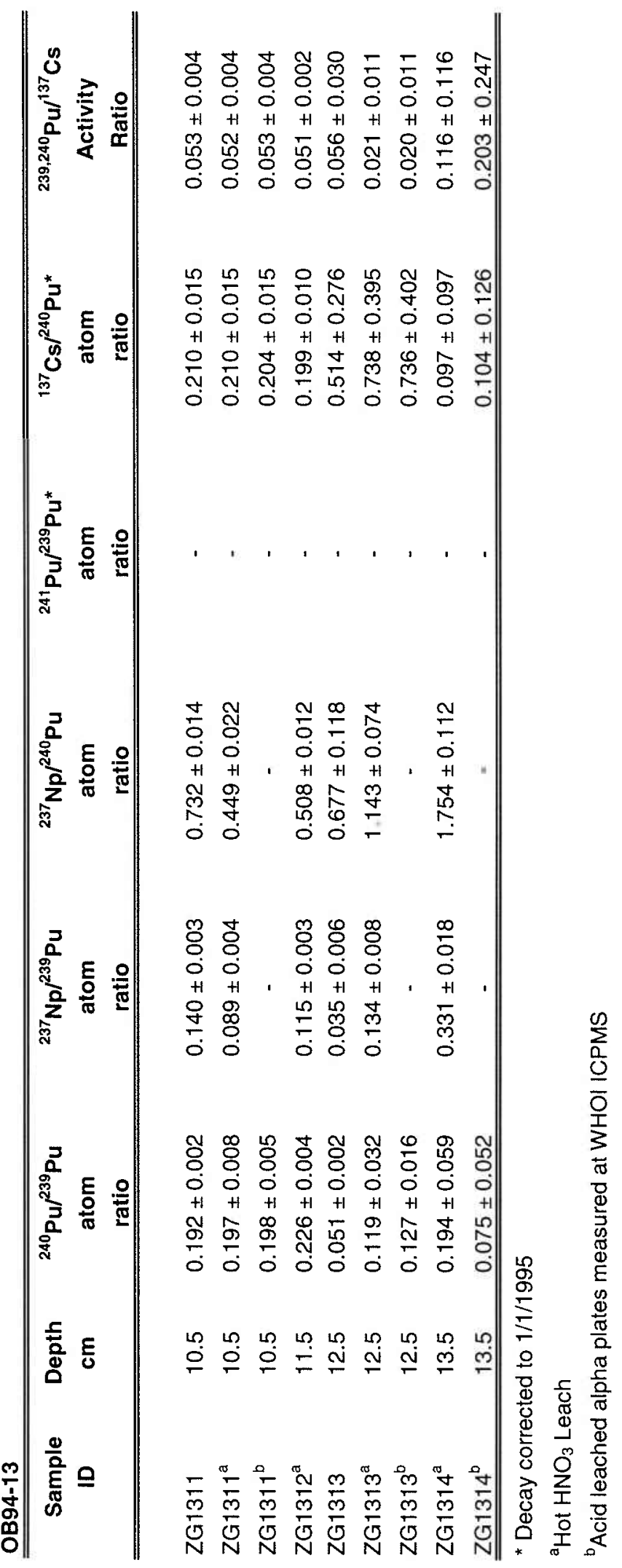




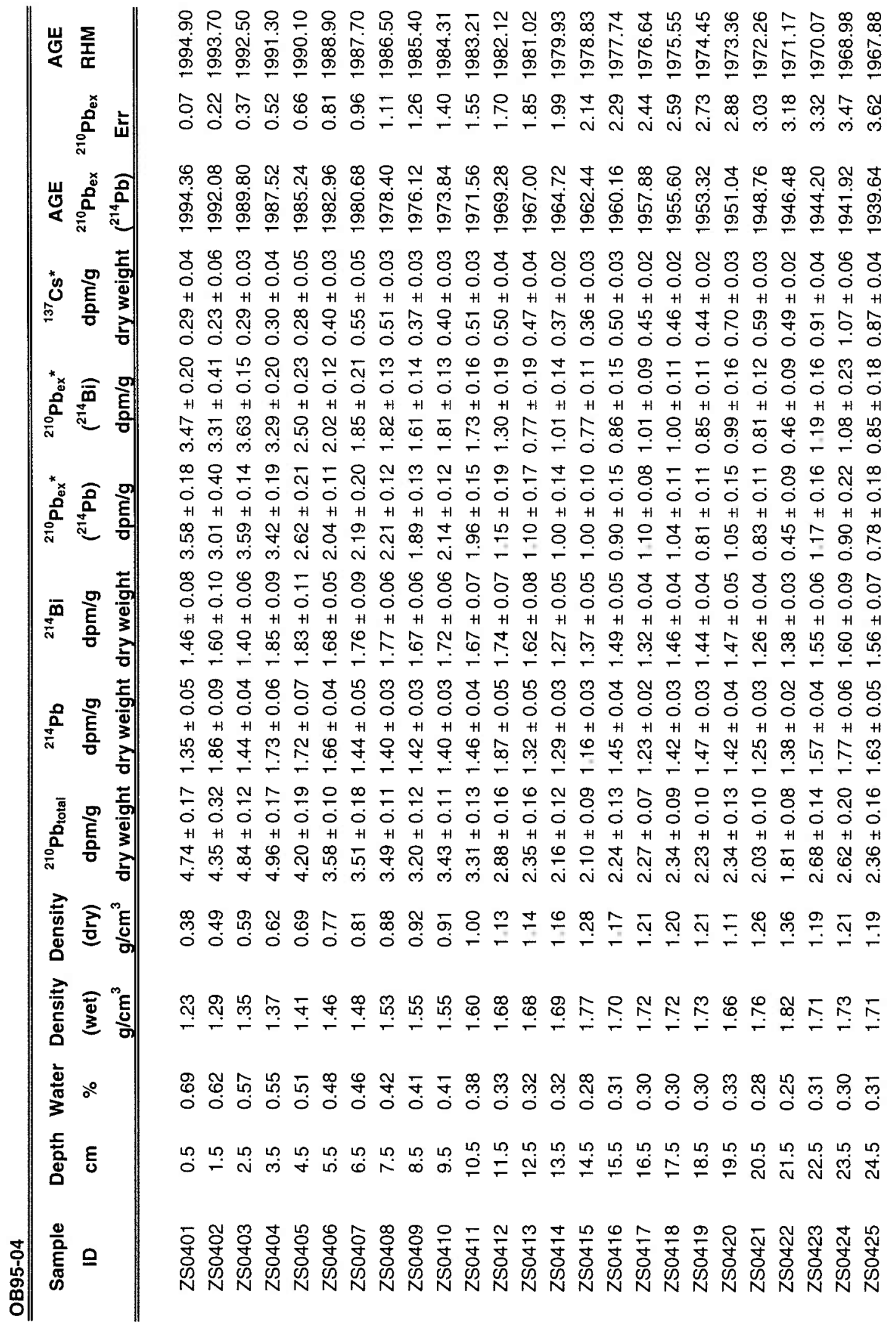




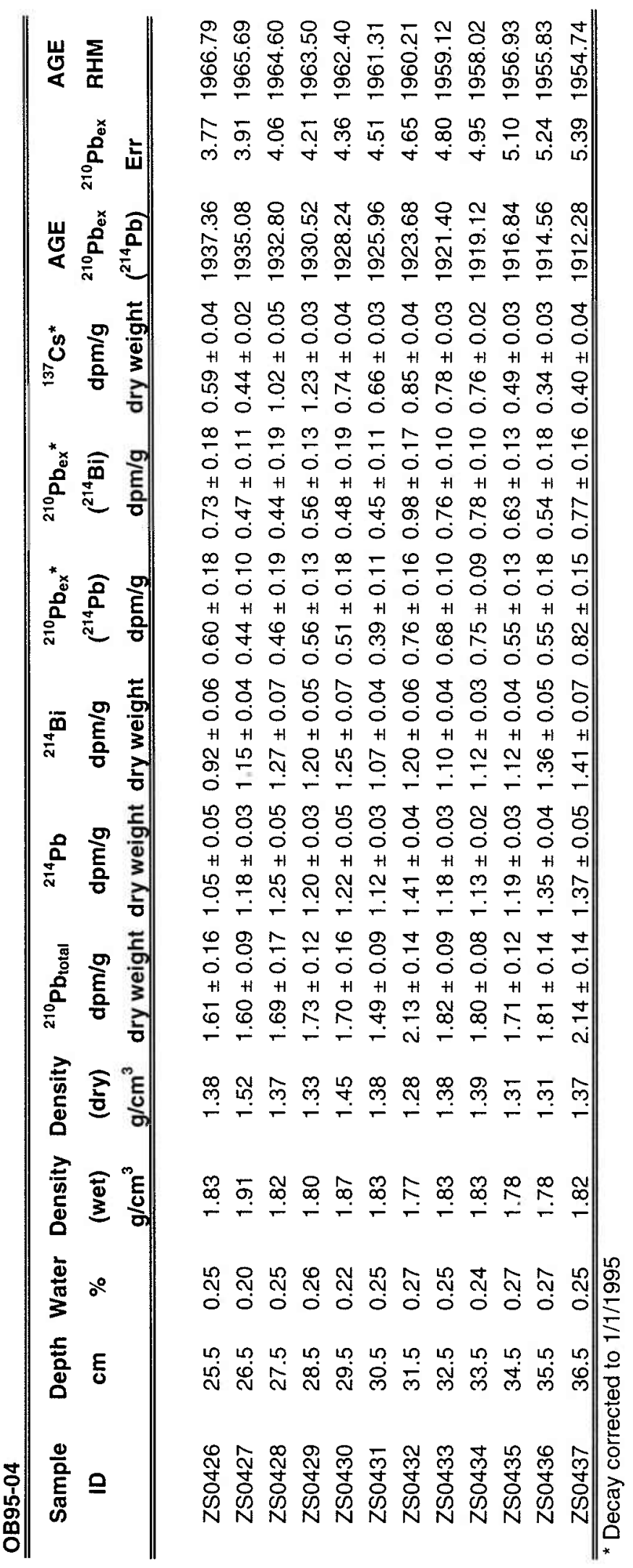




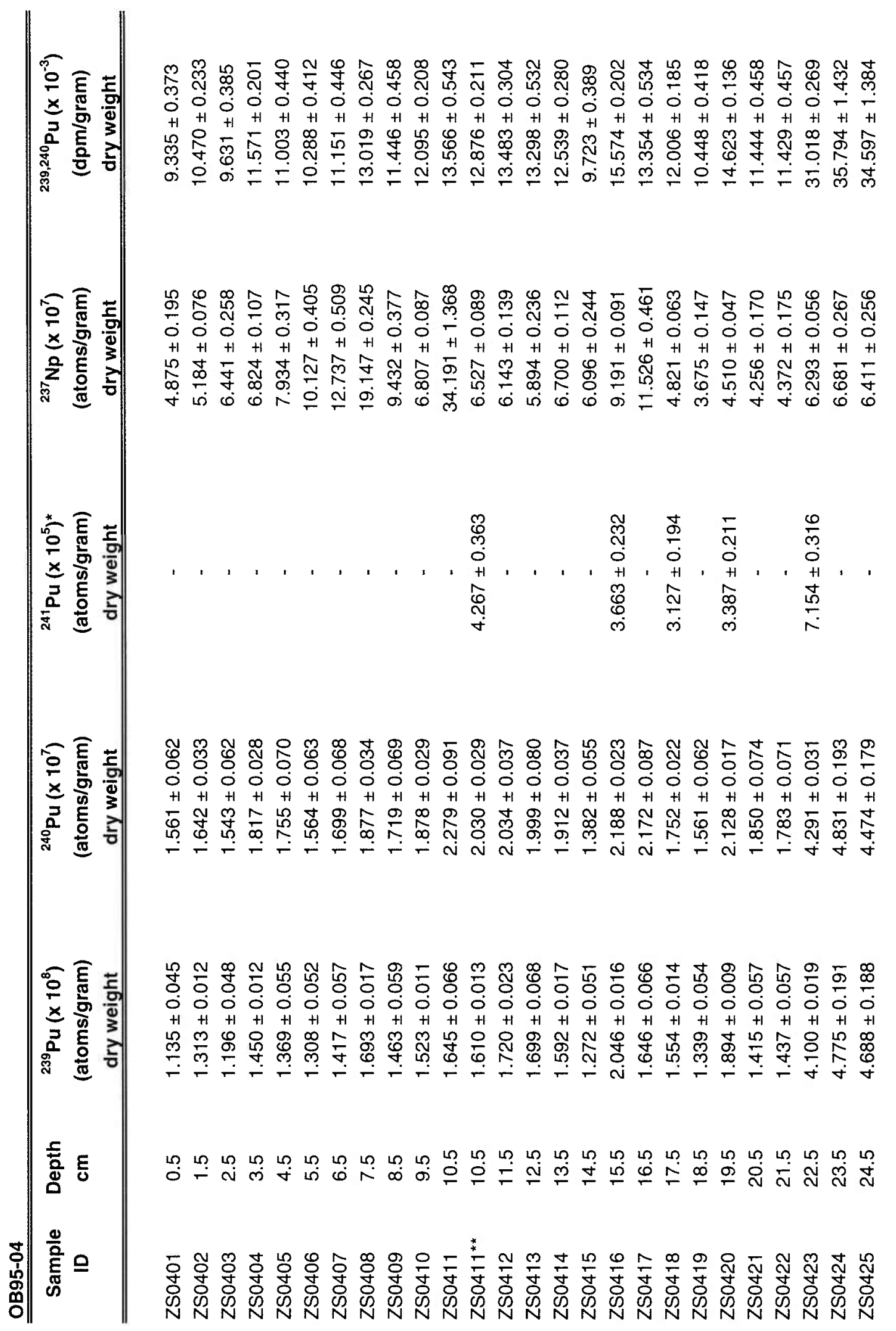




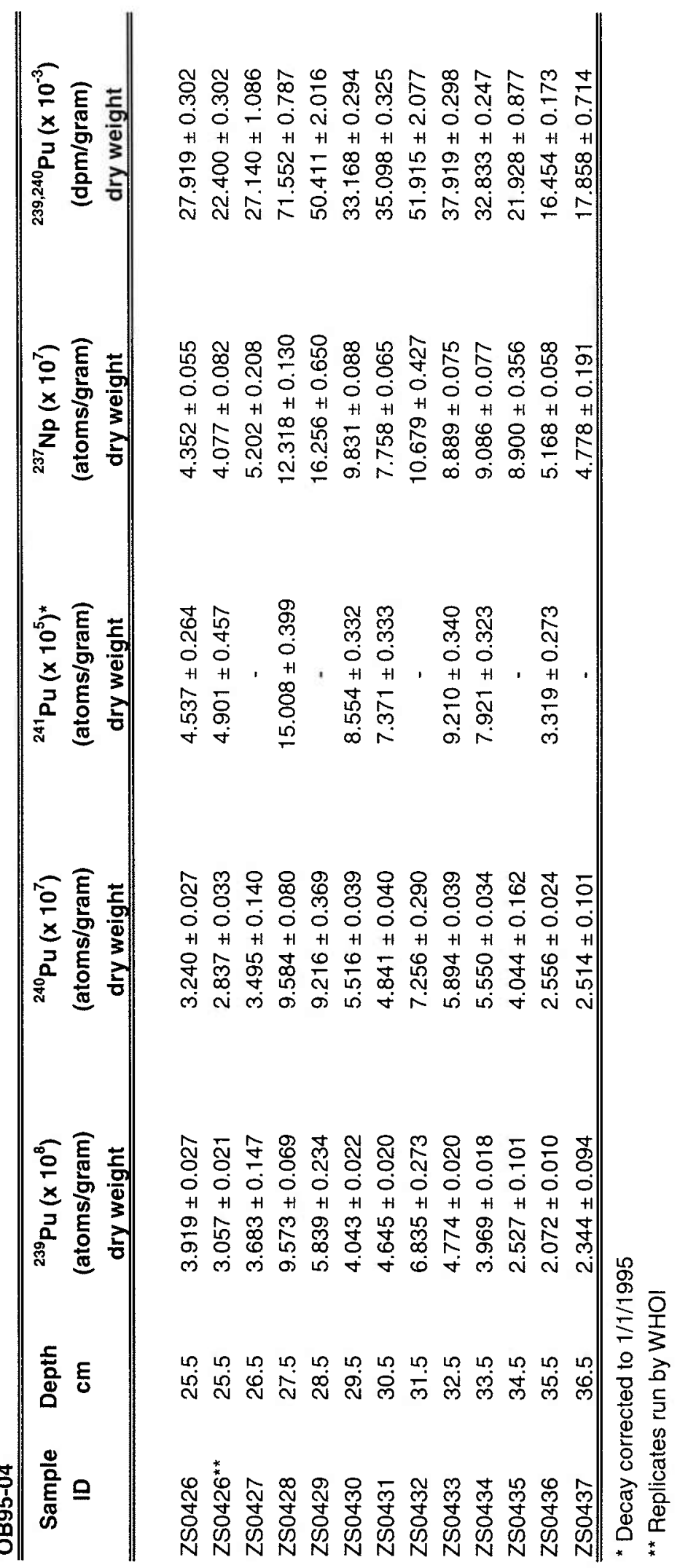




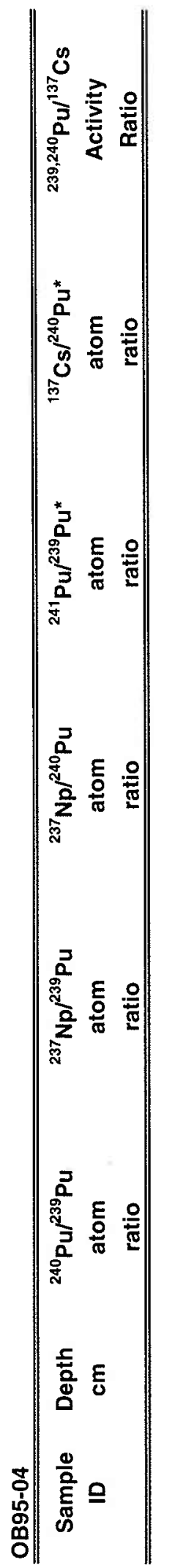

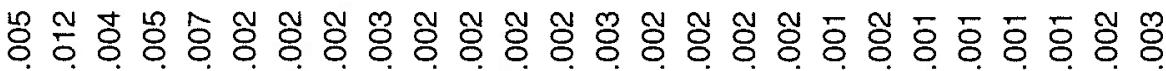

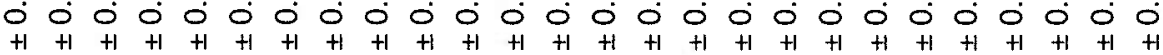

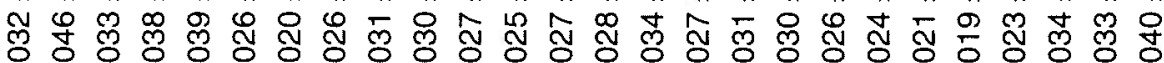

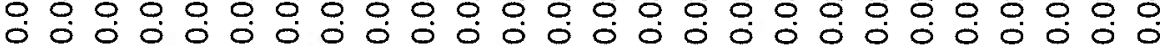

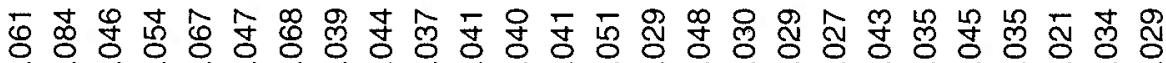

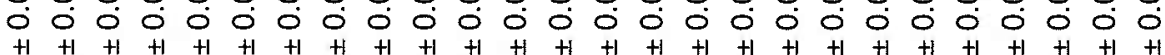

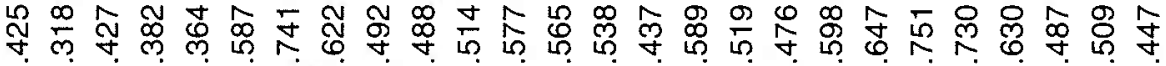
०००00000000000000000000000

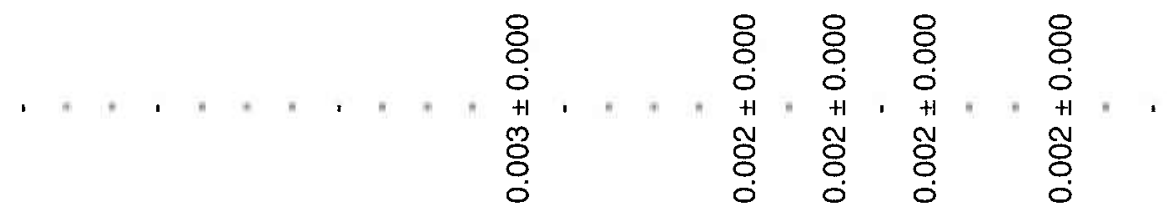

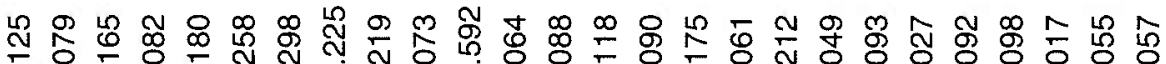

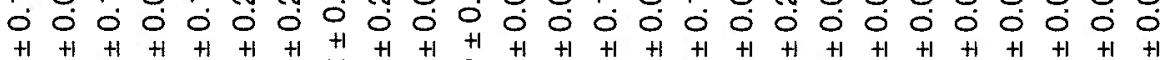

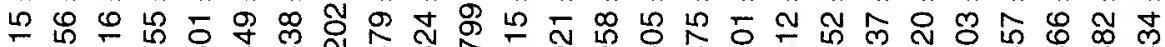

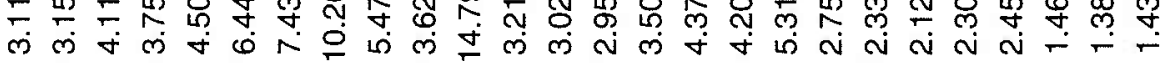

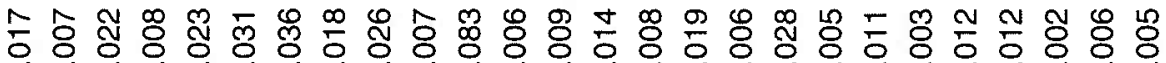

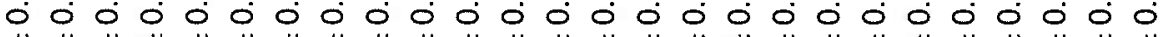

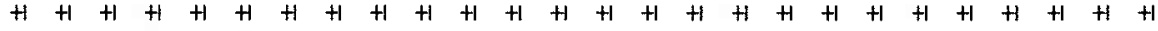

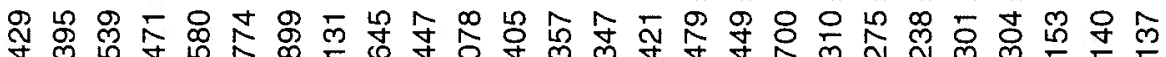

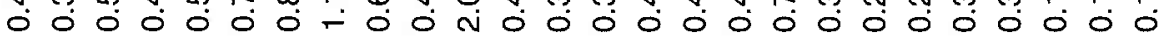

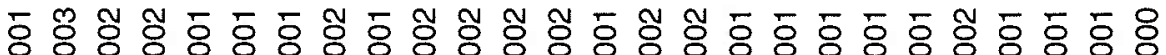

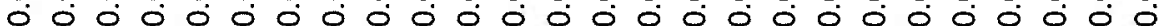

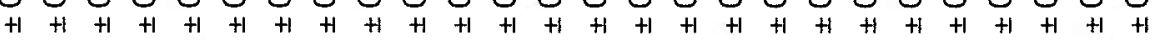

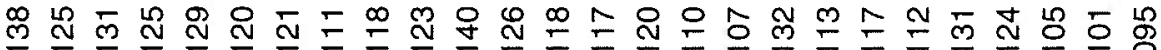

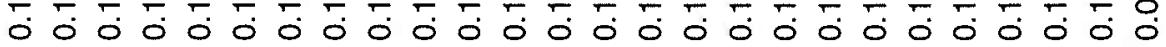

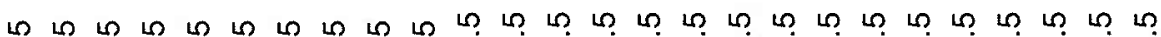

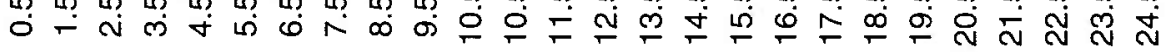

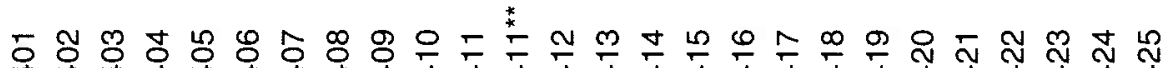

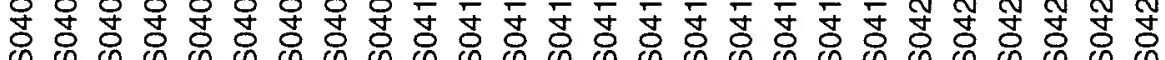
N 


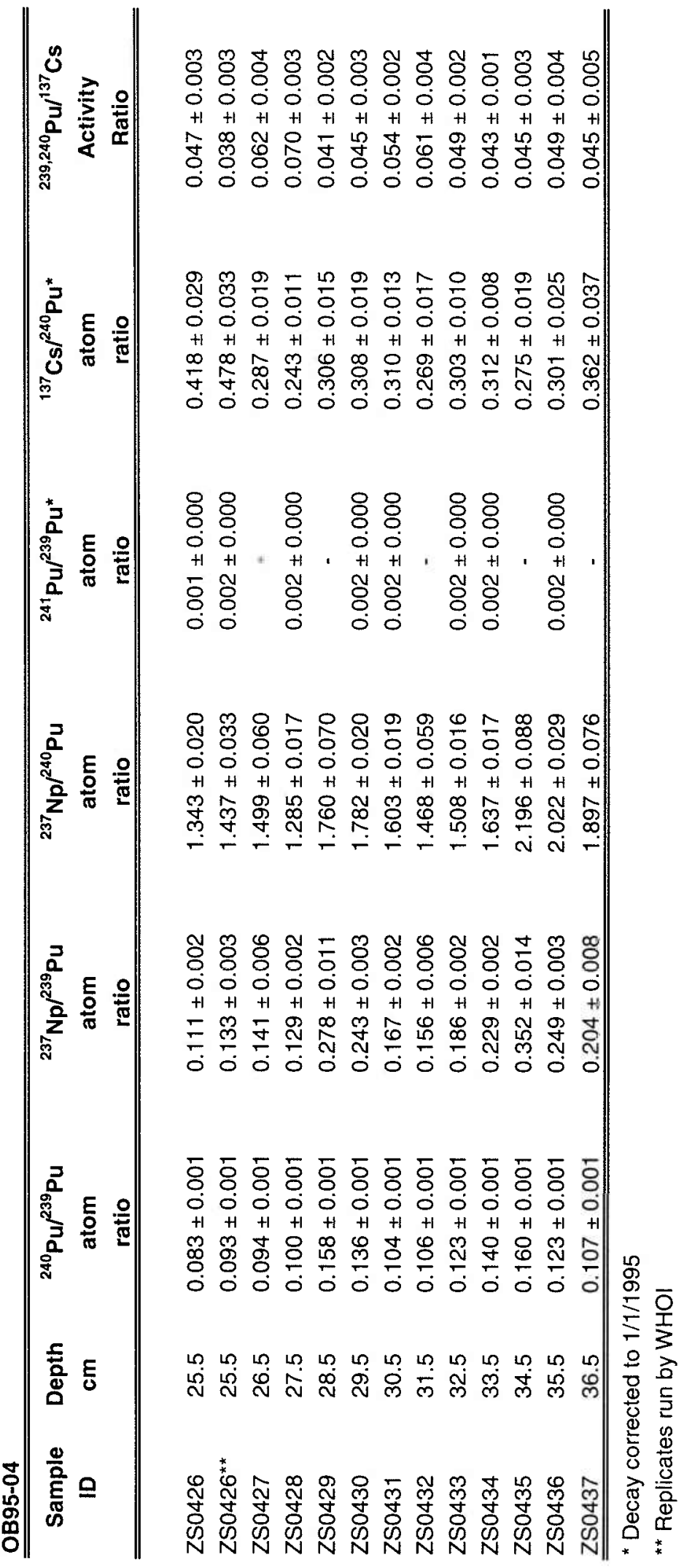




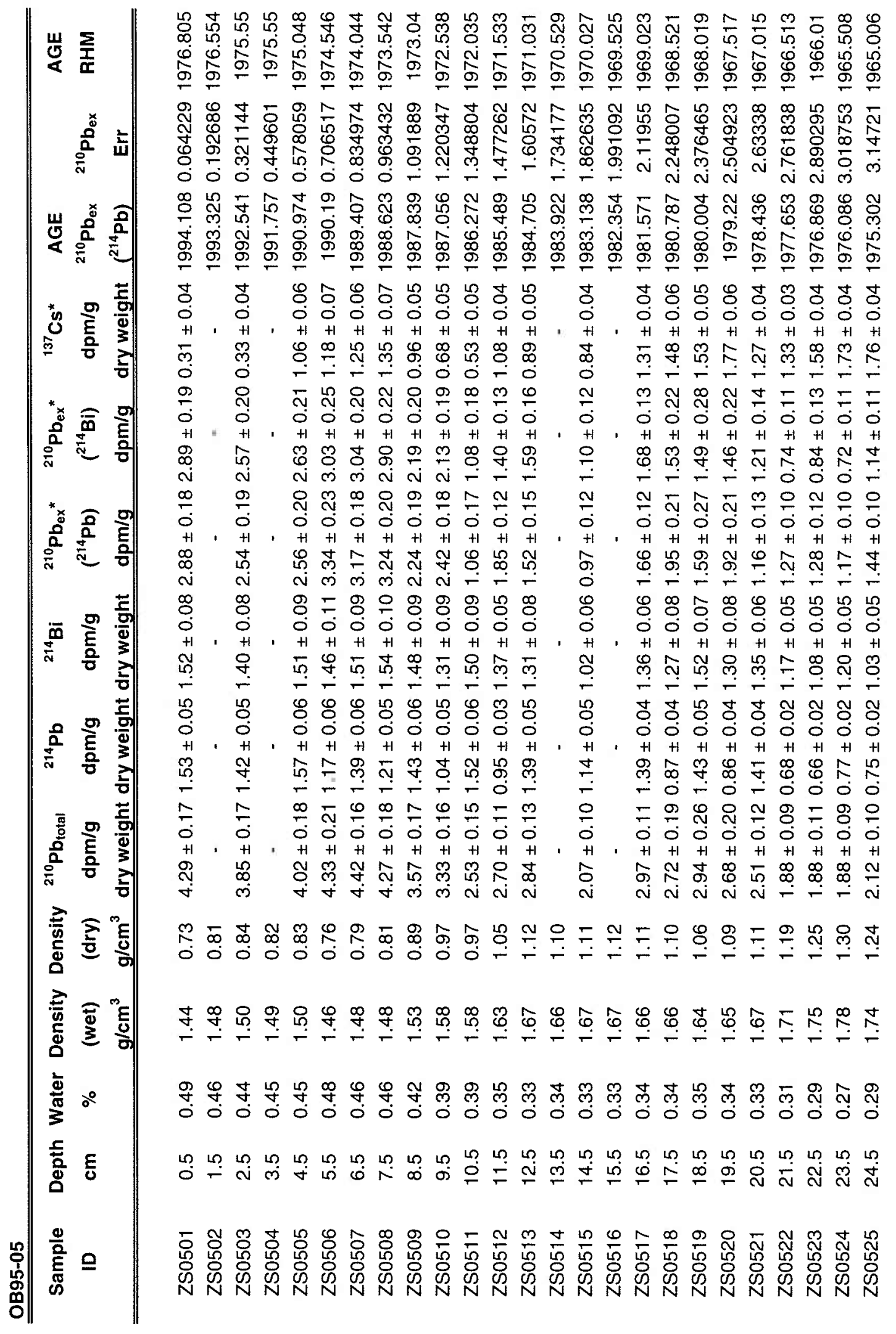




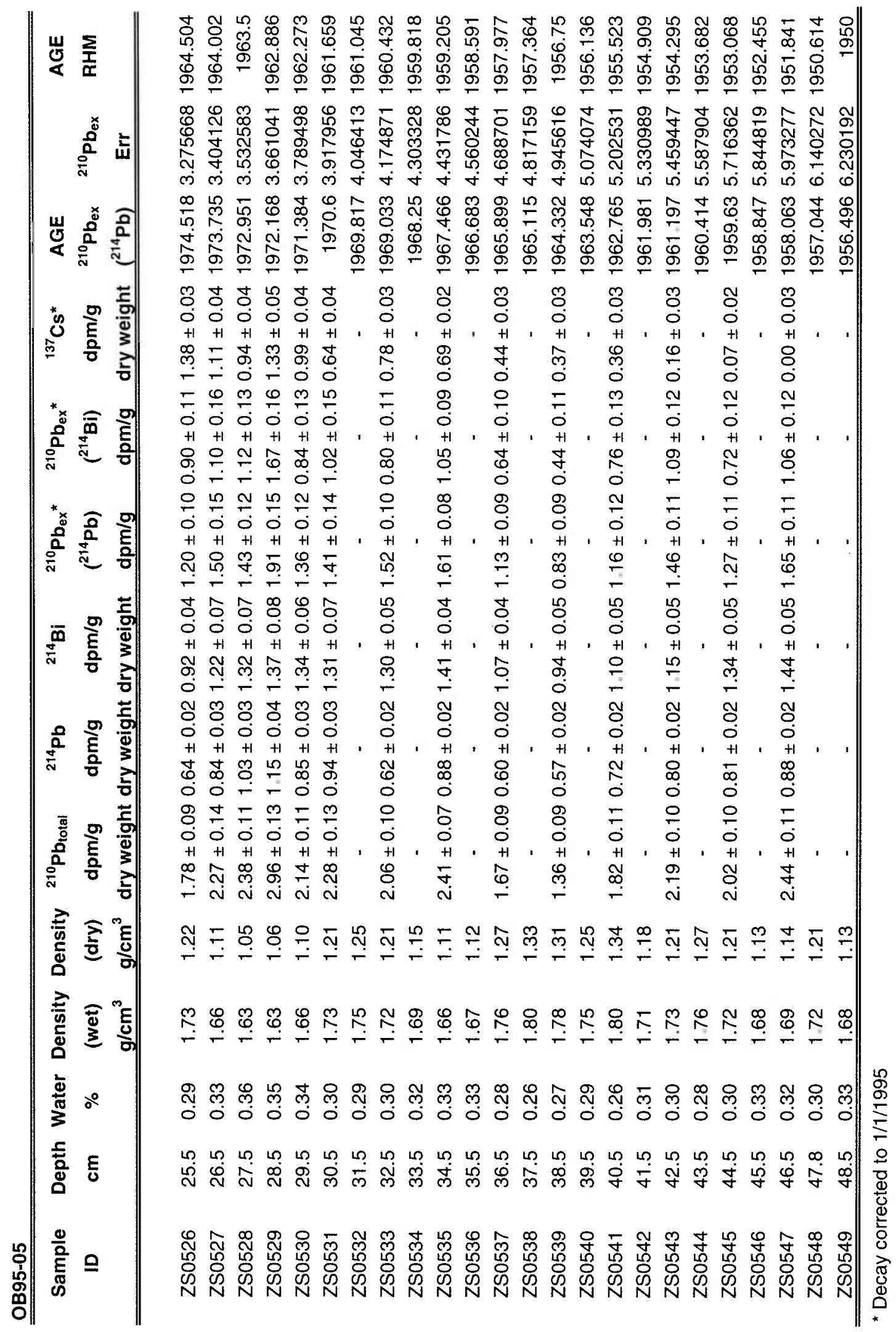




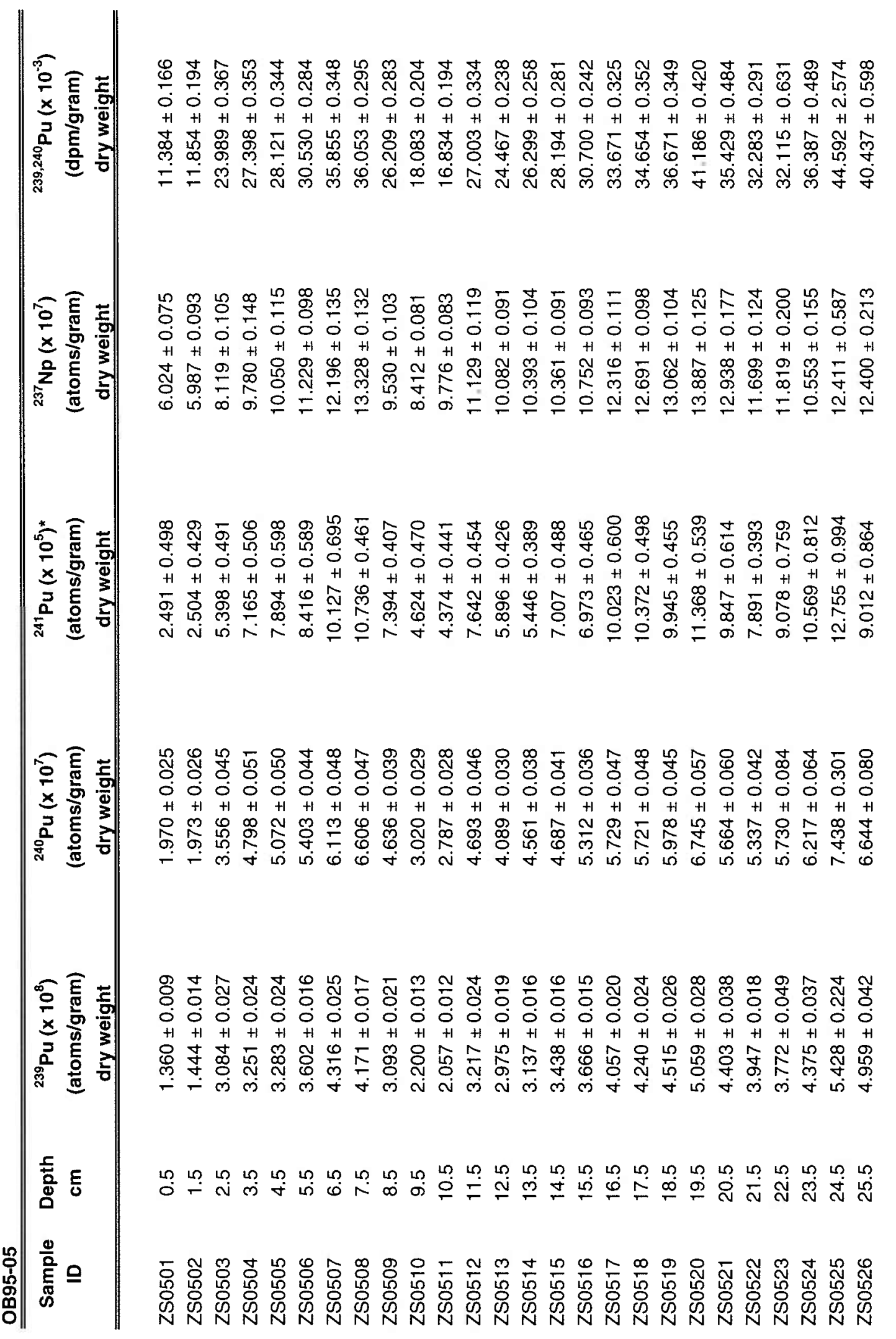




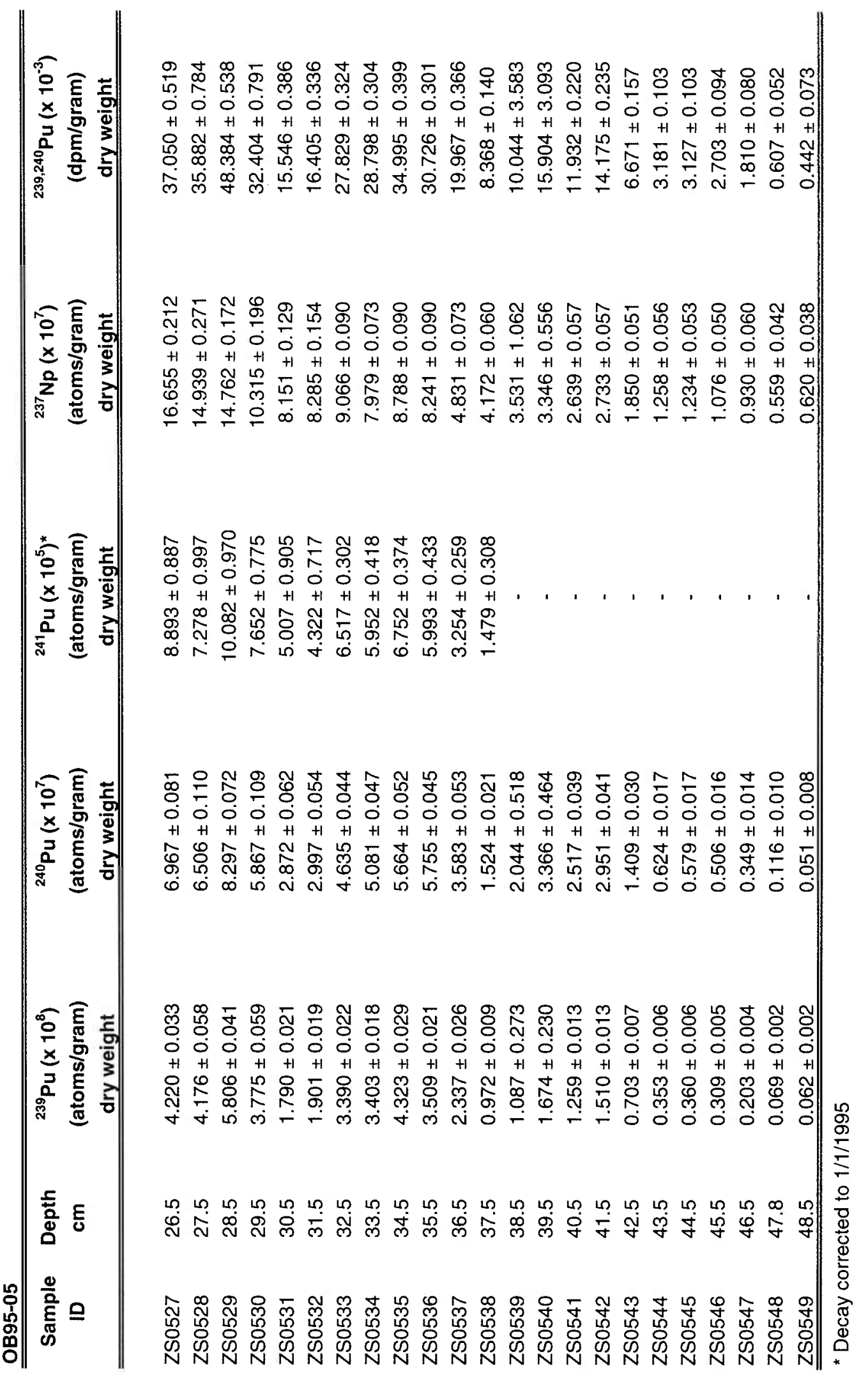




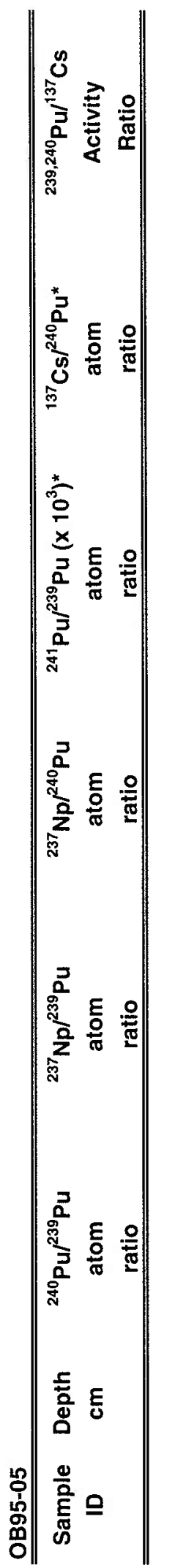

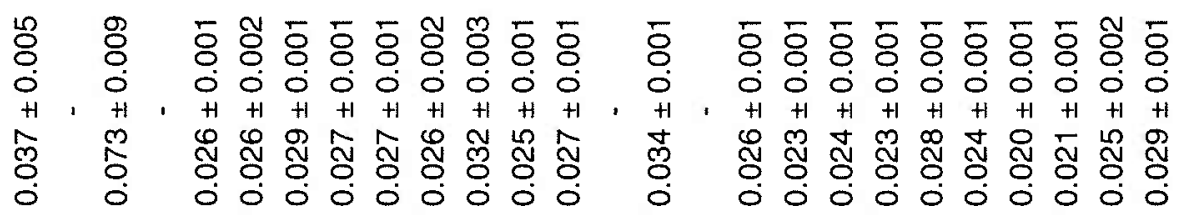

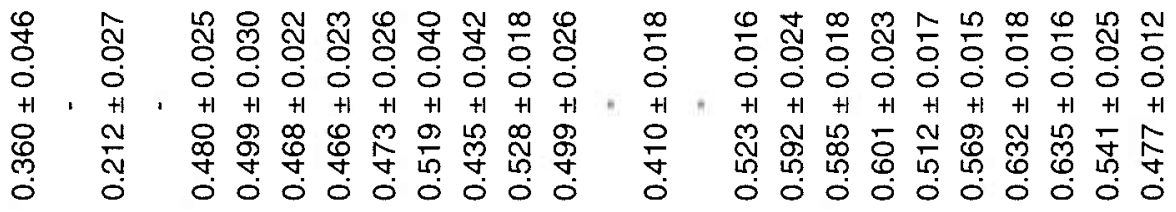

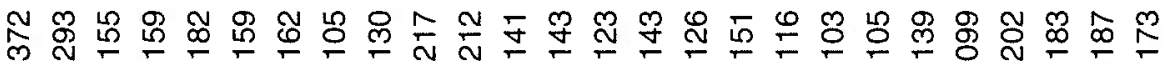

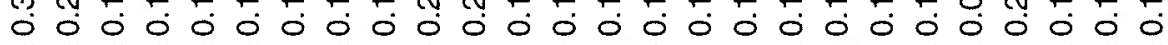

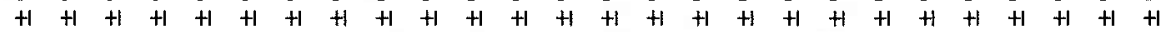

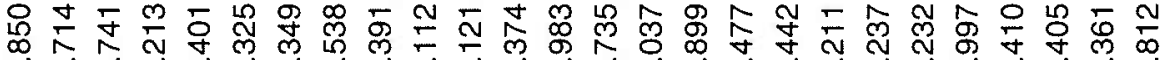

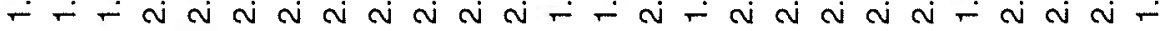

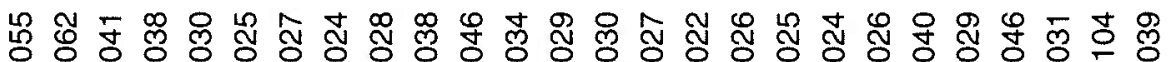
०.

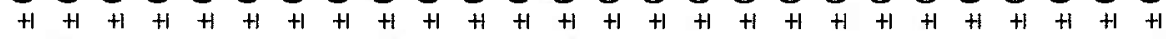

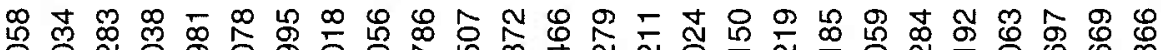
闭们 N

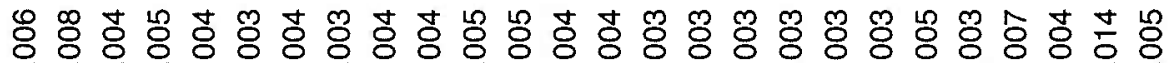
00000000000000000000000000

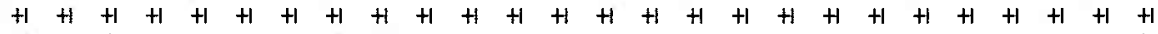

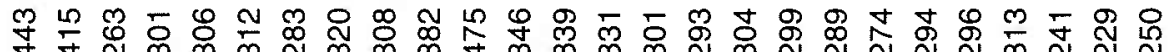

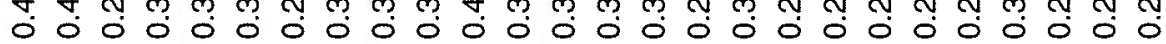

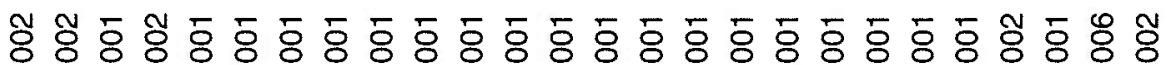

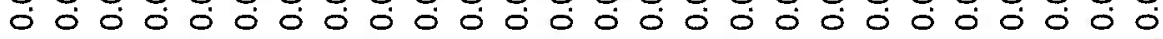

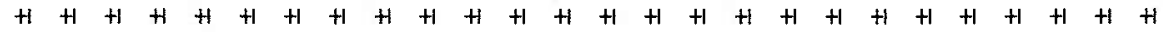

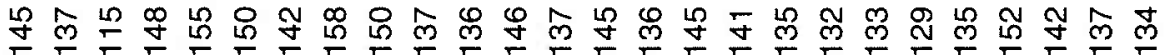

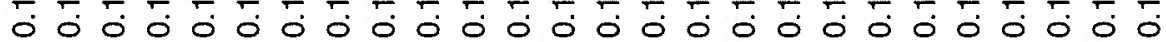

L

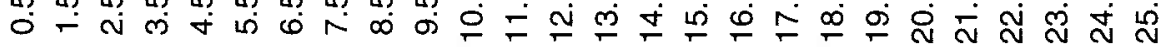

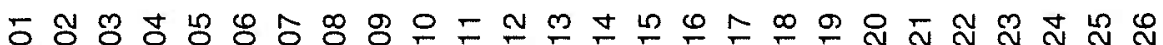

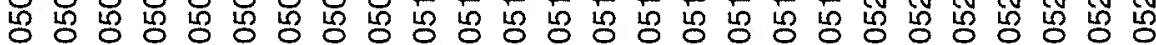
N 


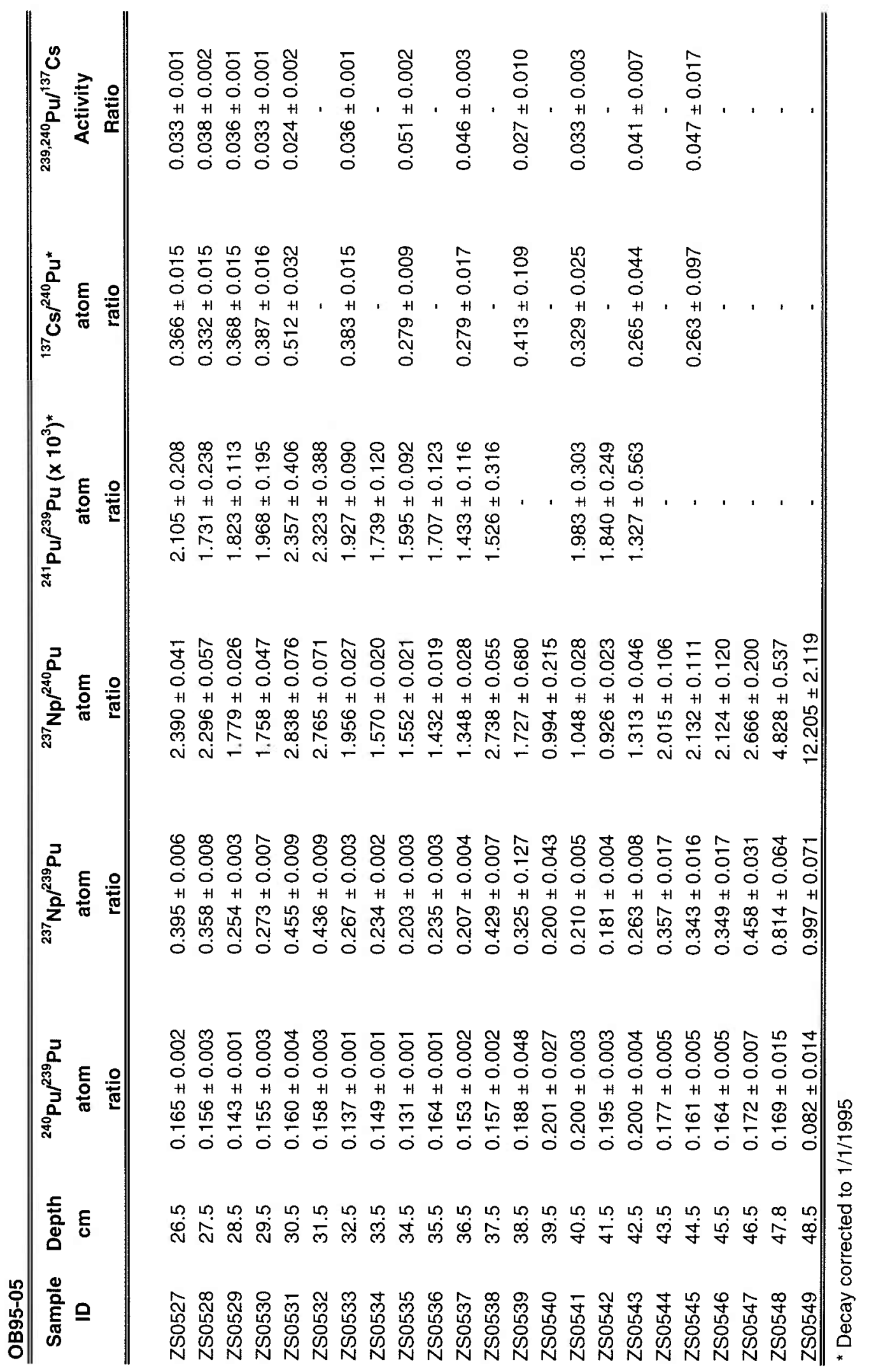




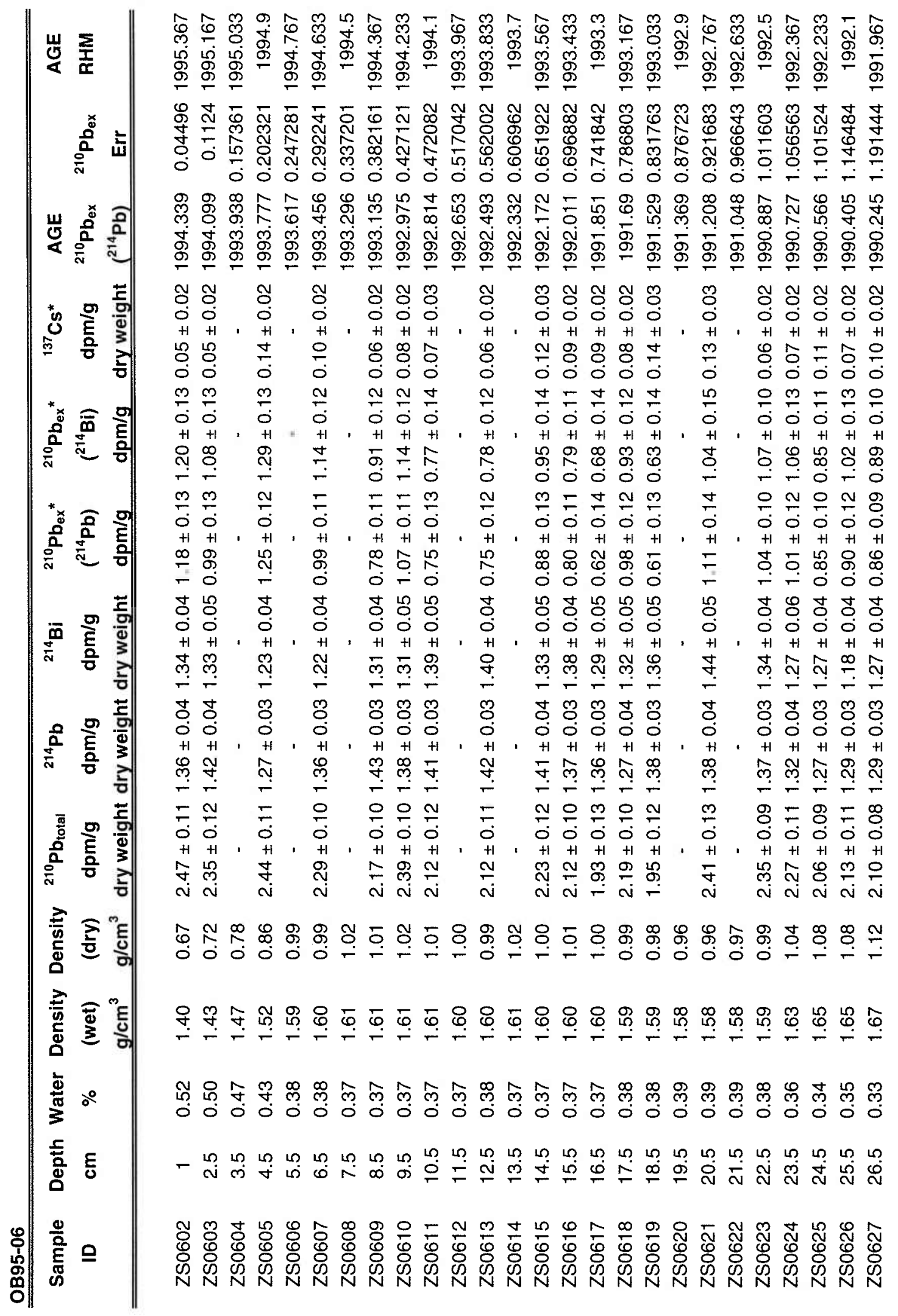




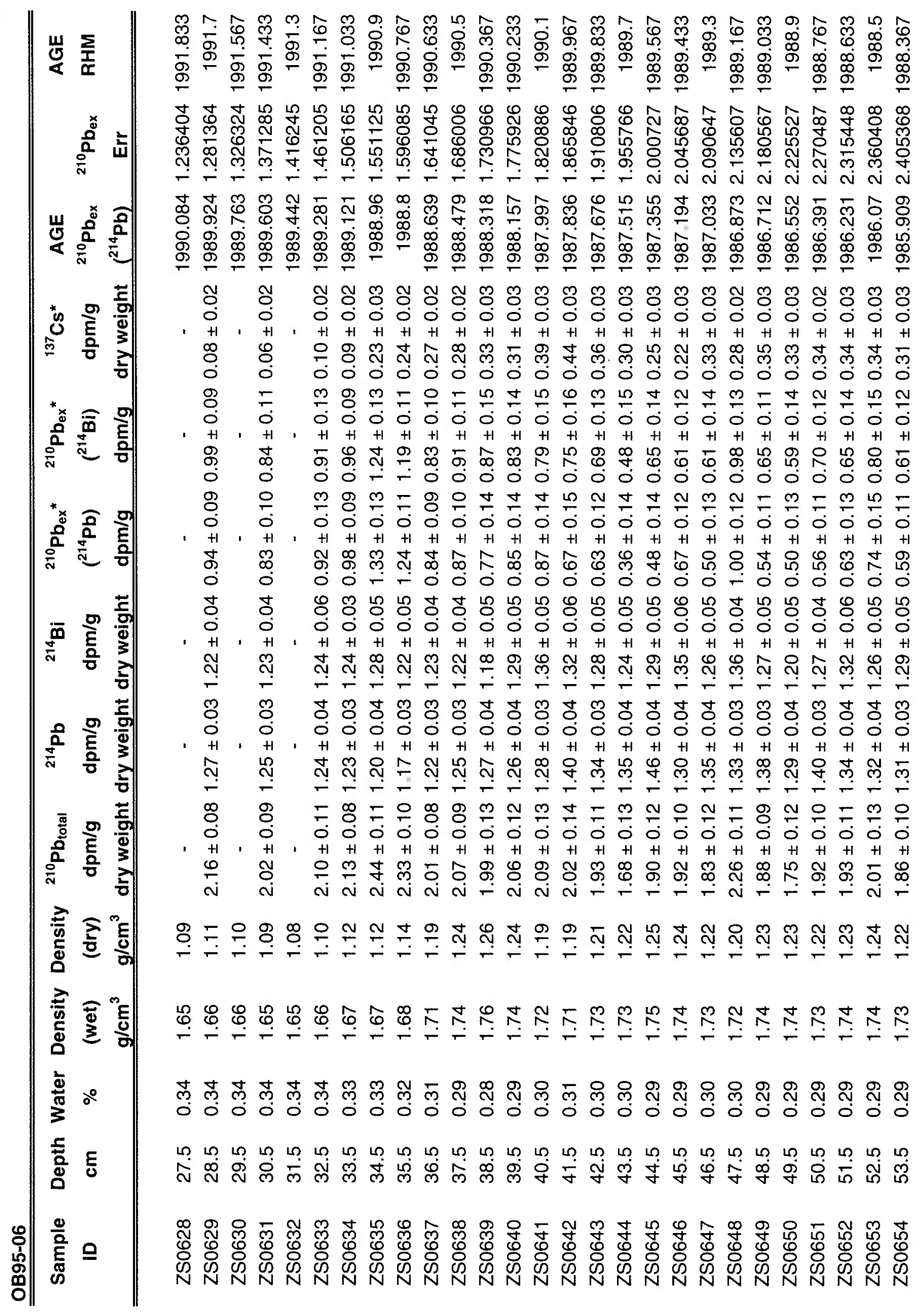




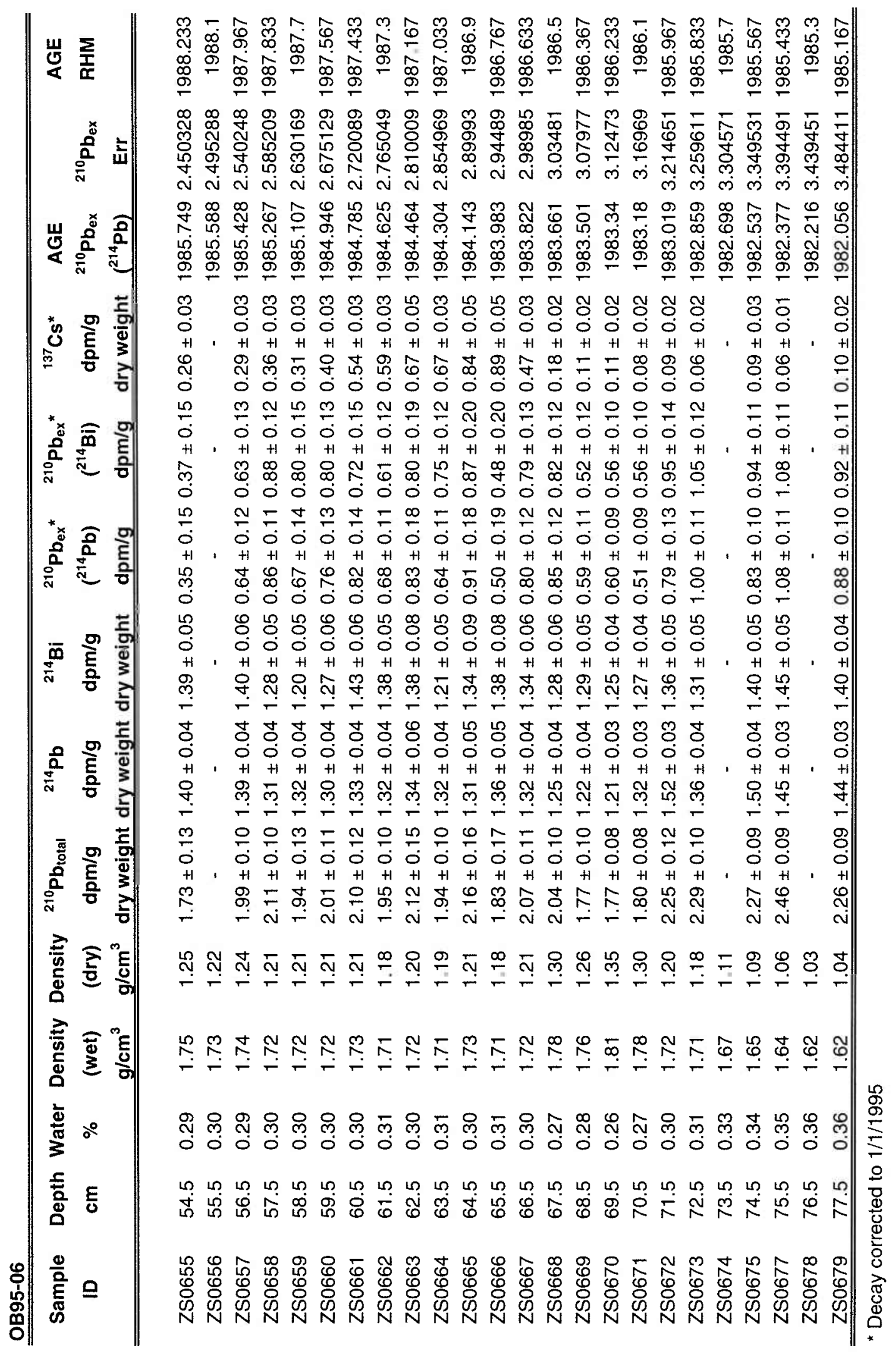




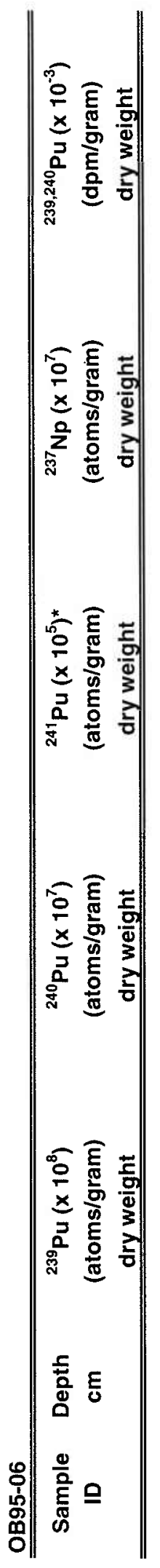

\& 츙 \&

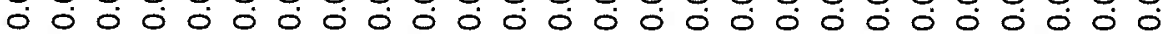

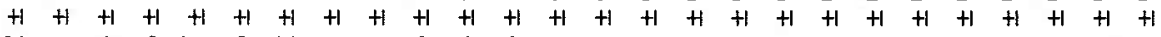

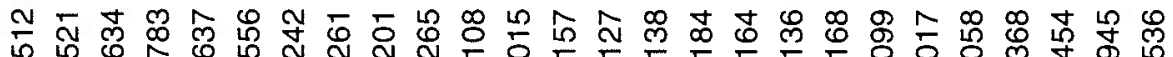

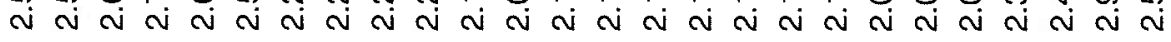

ల్లె $\bar{\delta} \tilde{\delta}$

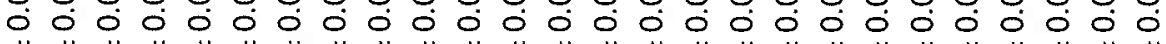

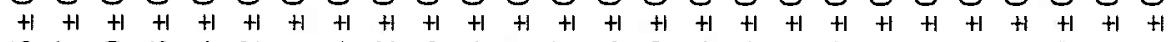

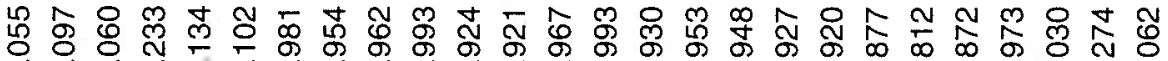
$\stackrel{-}{-}-\mp$ -

ชิ้ ○ं

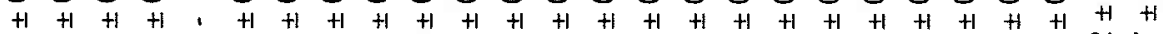

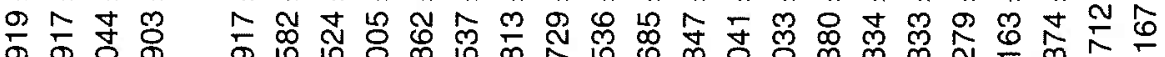

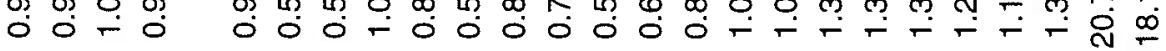

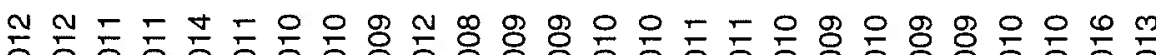

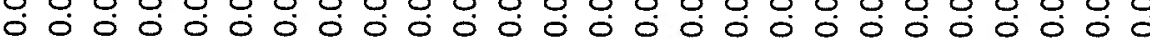

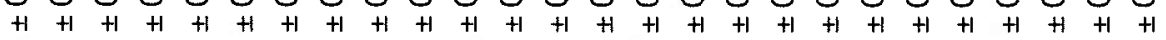

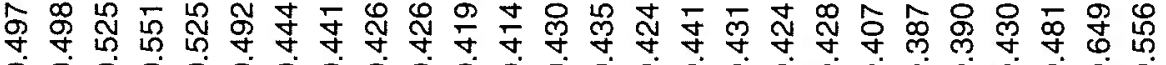

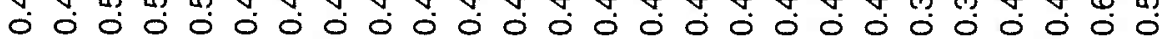

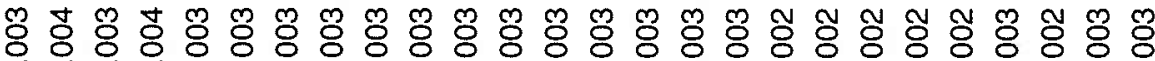

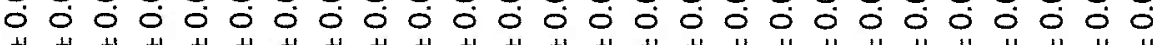

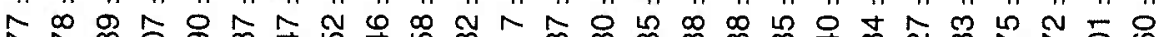

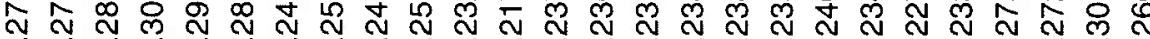

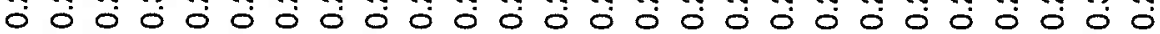

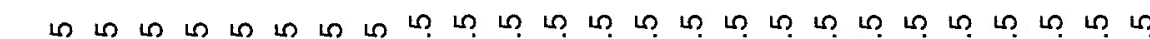
- ल

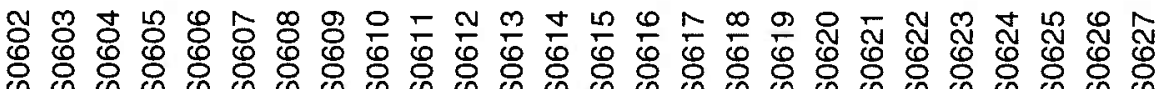
N 


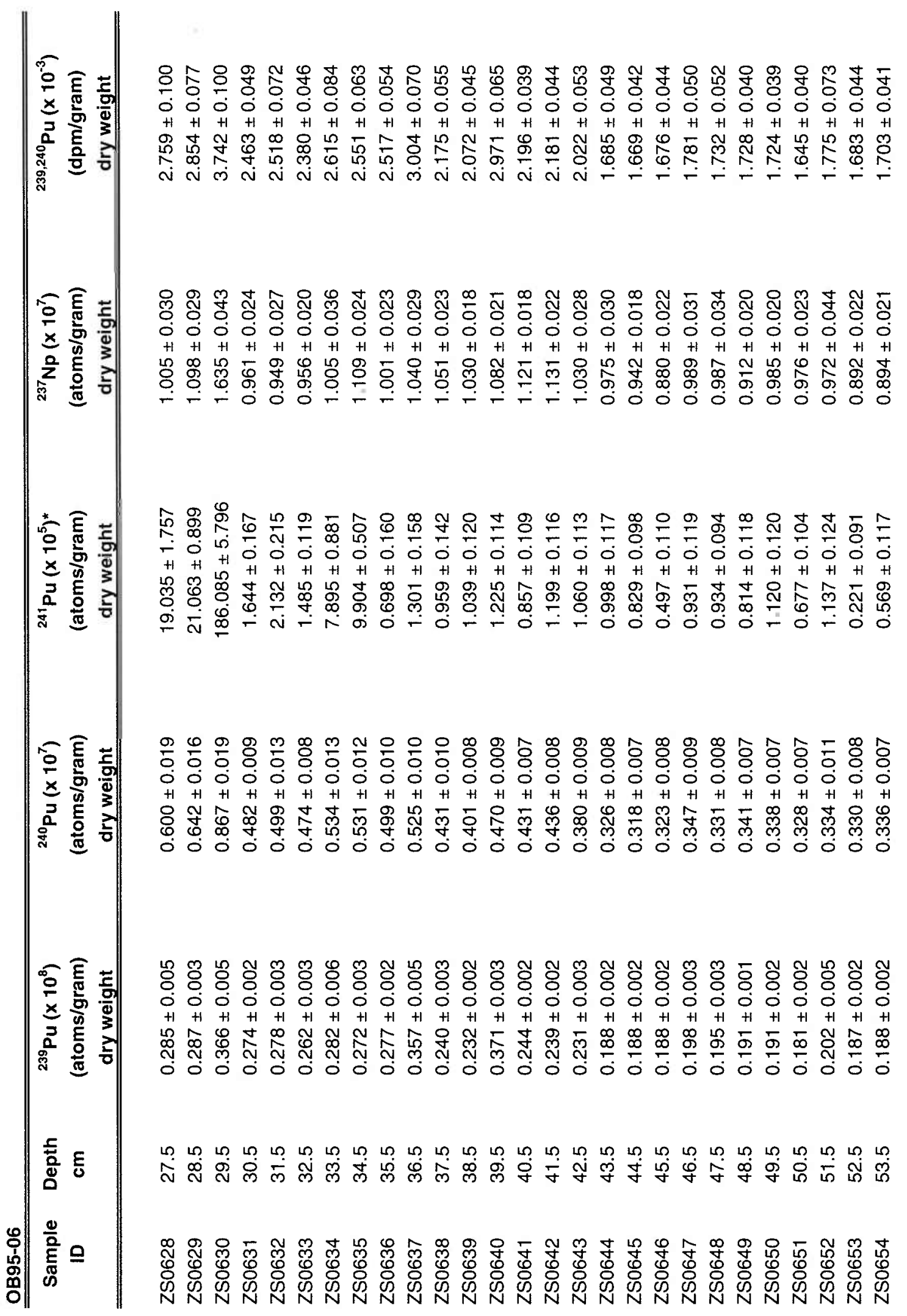




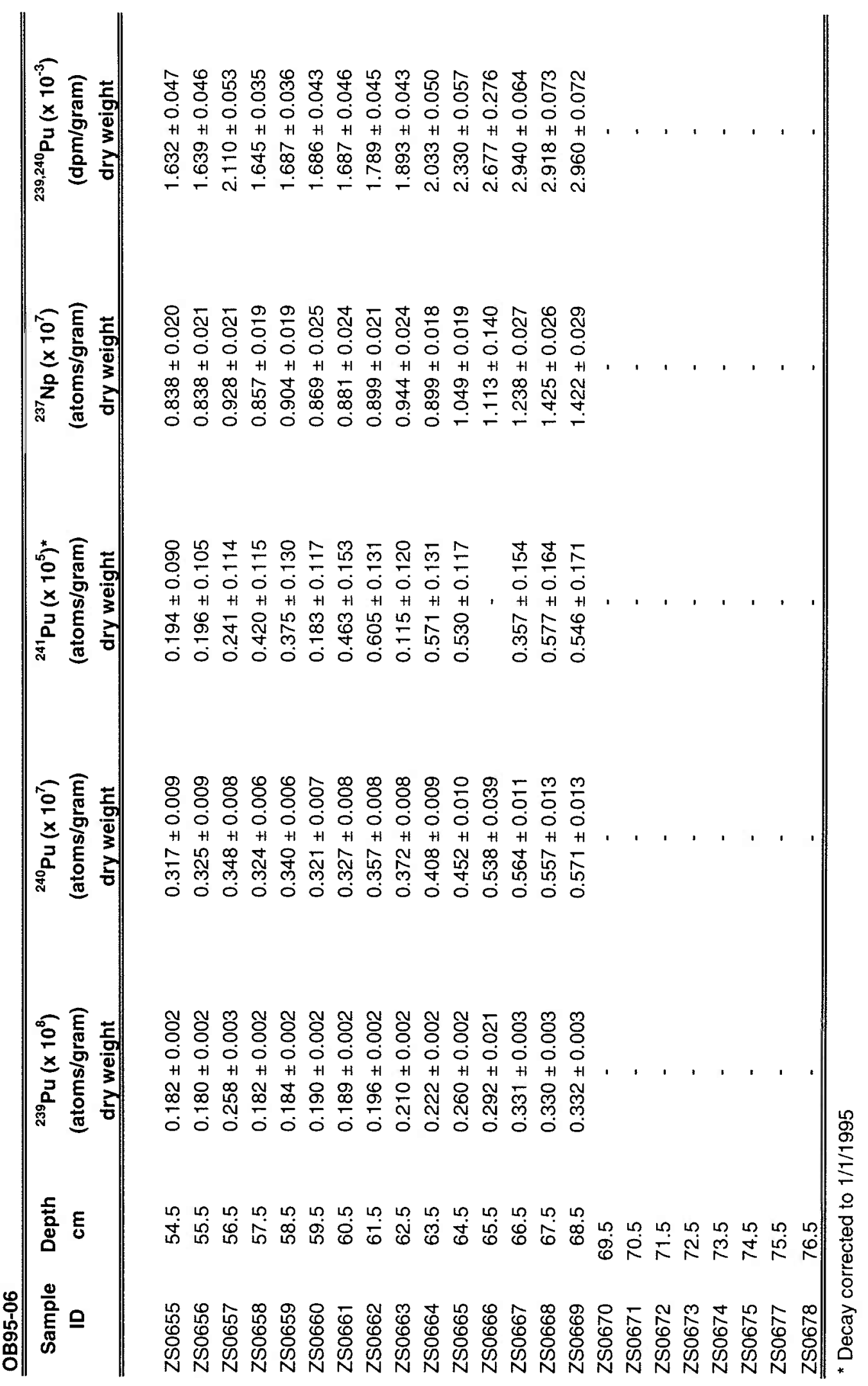




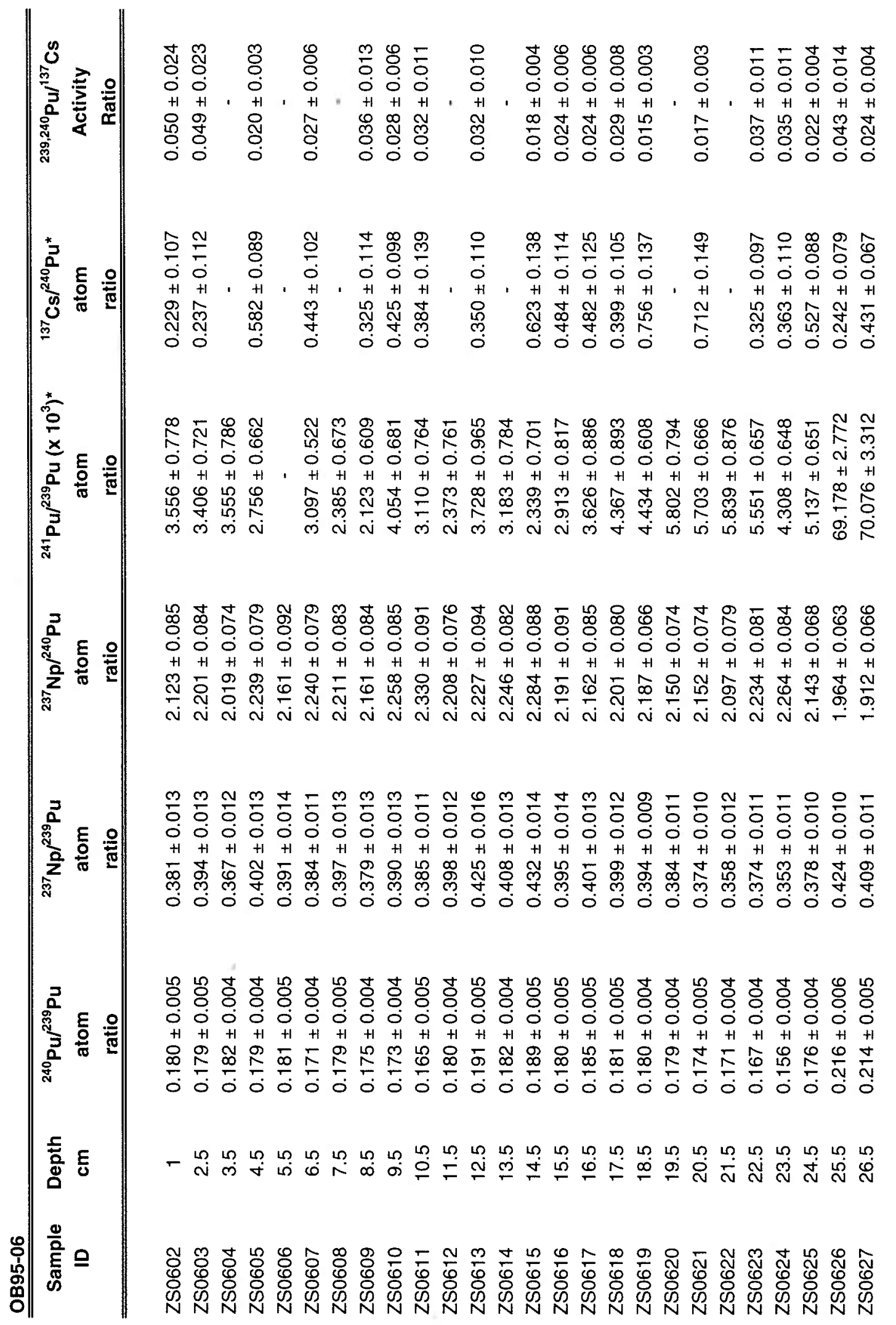




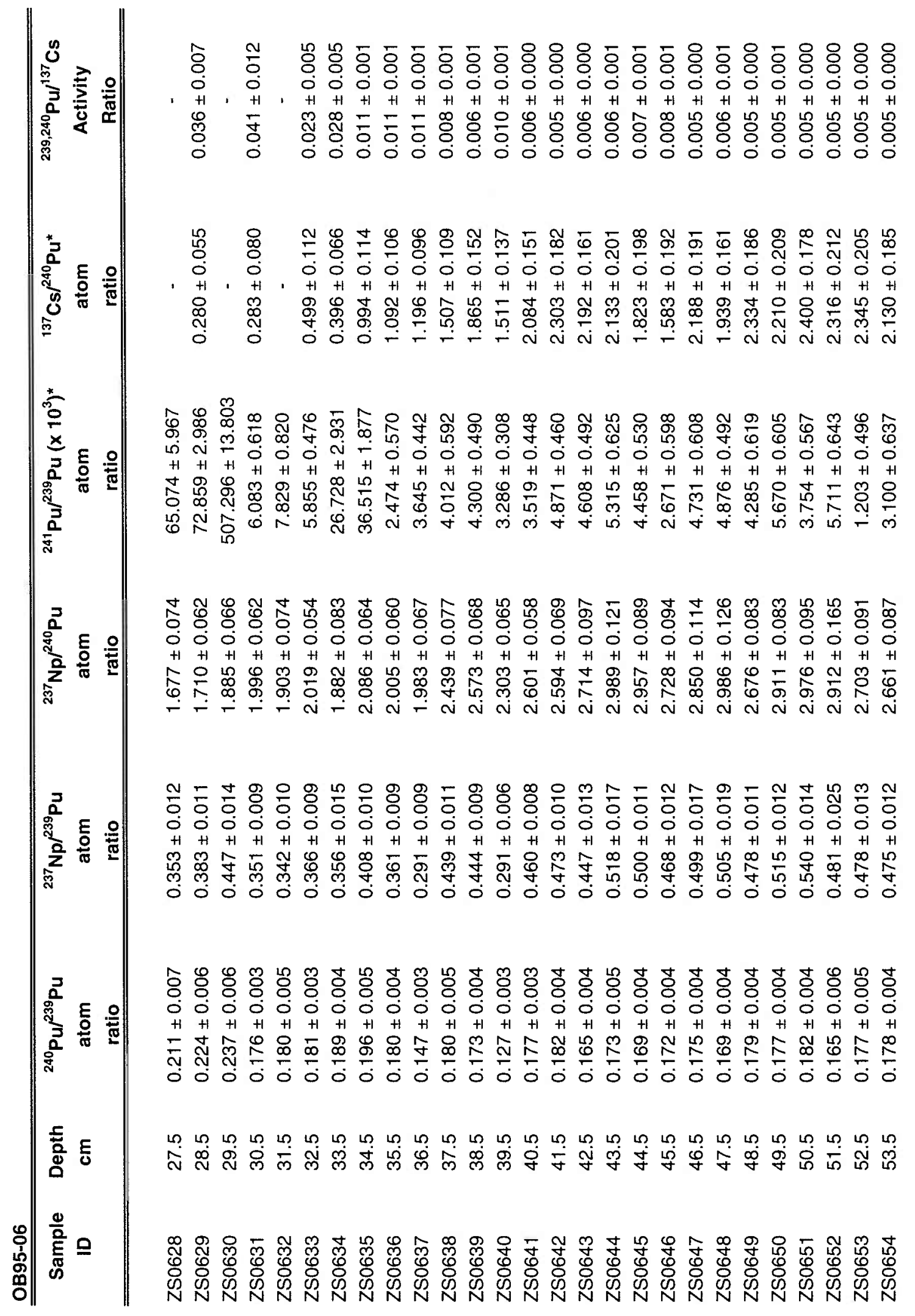




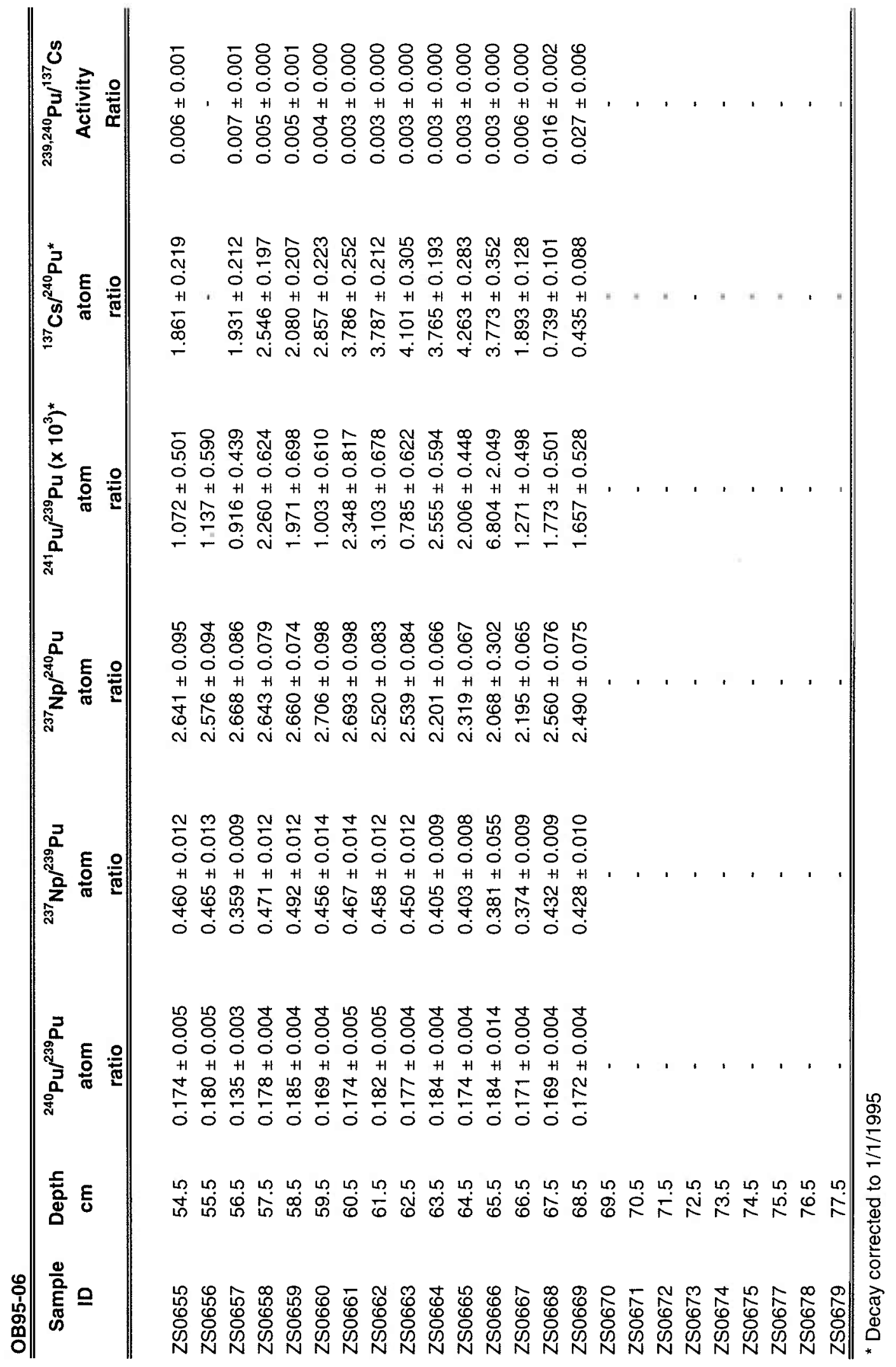




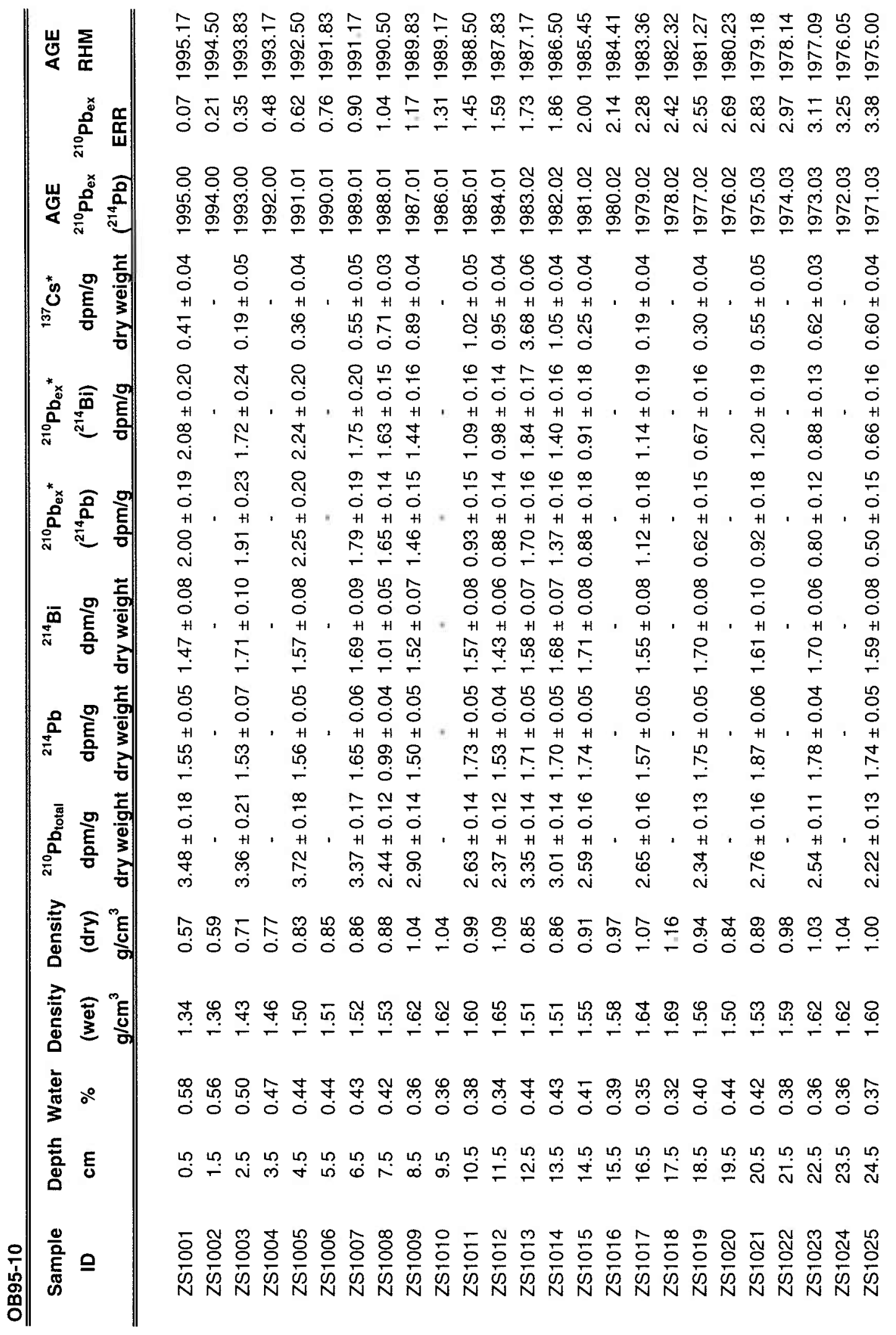




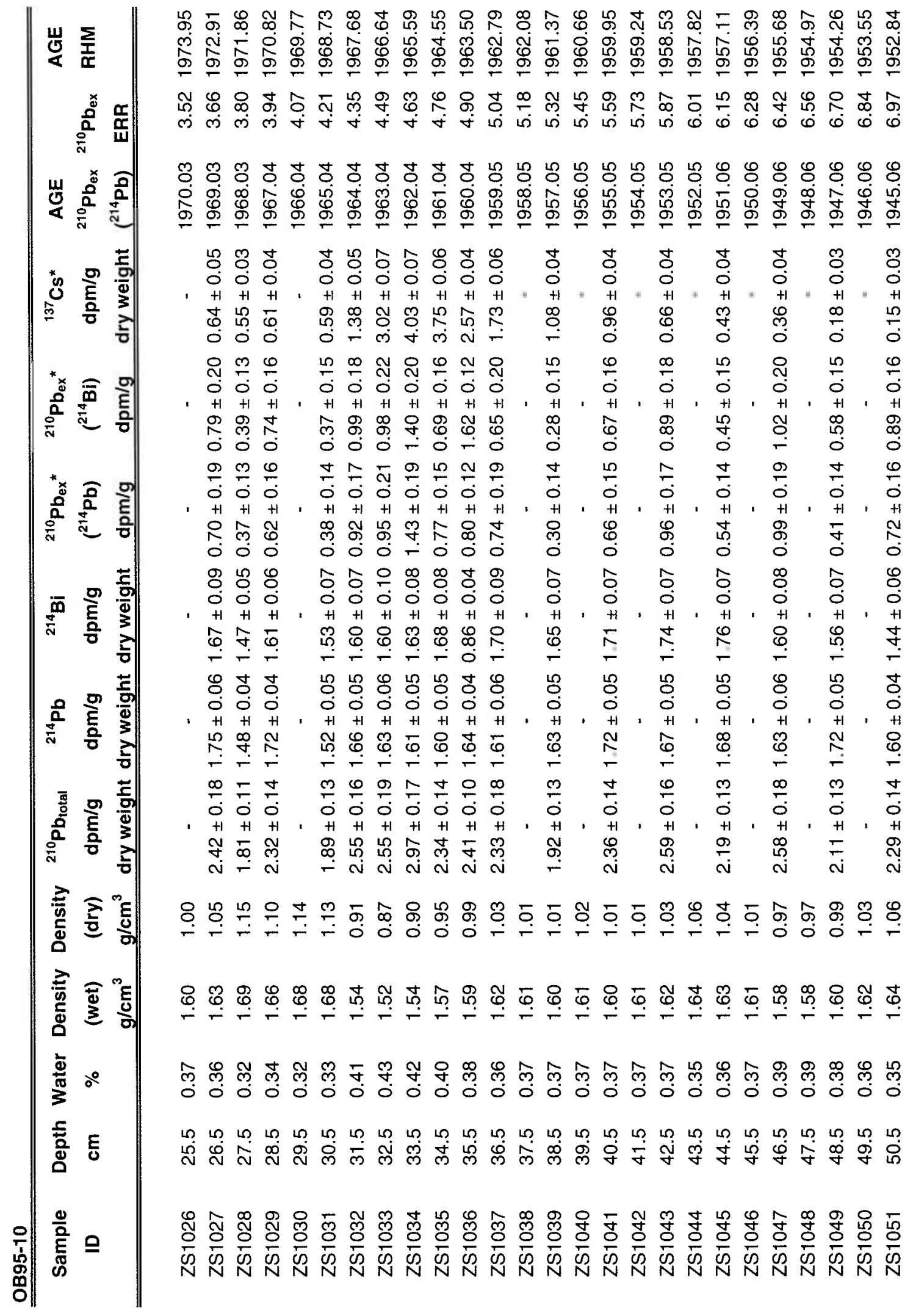




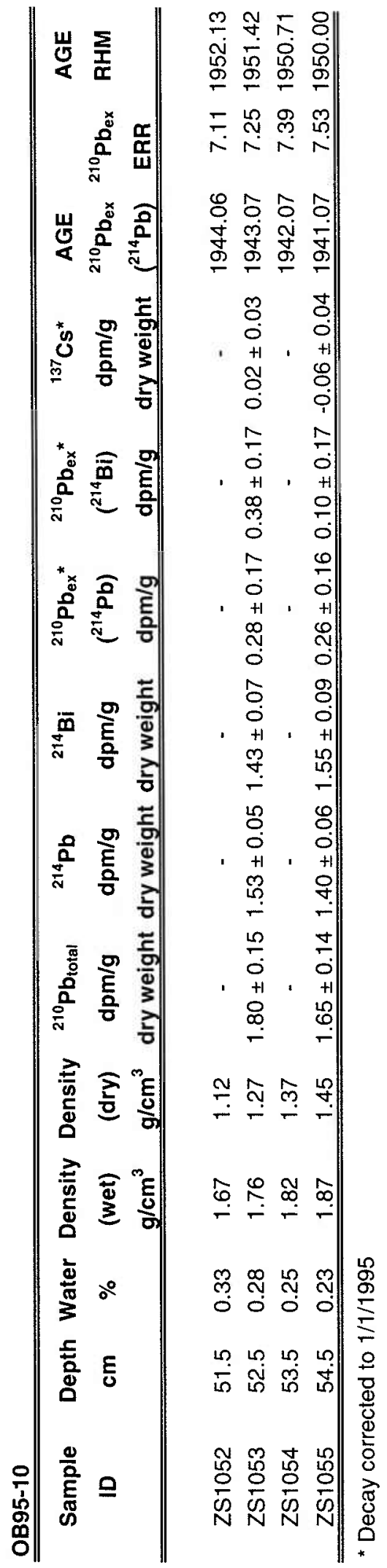




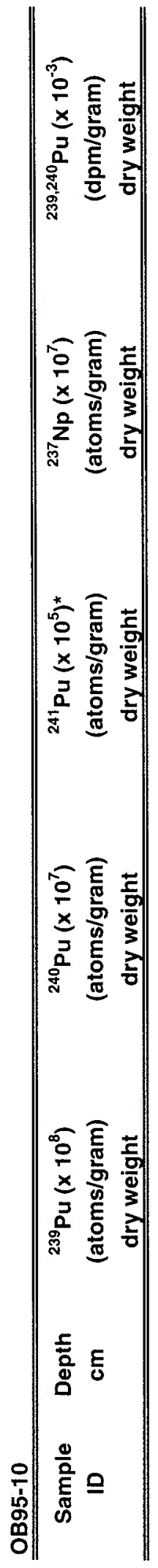

苜 於

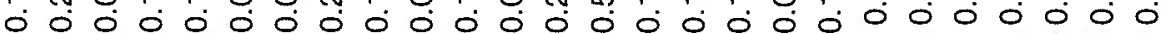

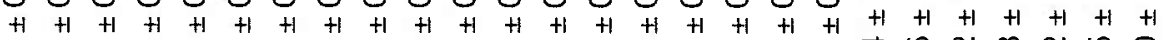
乐舟员员 மं $\hat{0}$ in

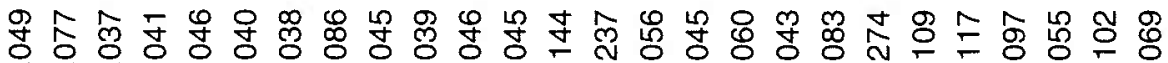

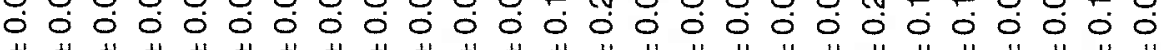

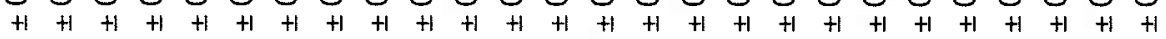

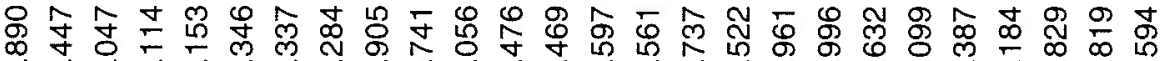

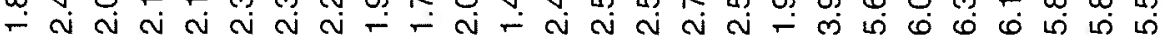

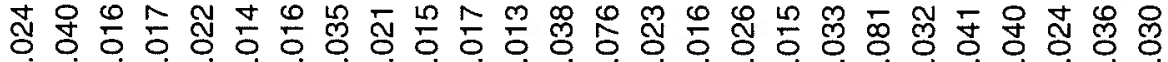

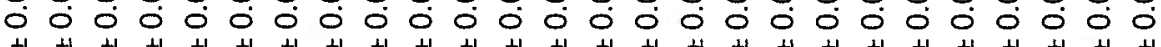

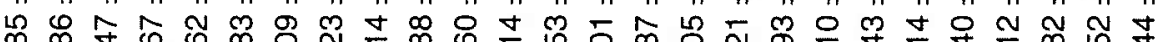

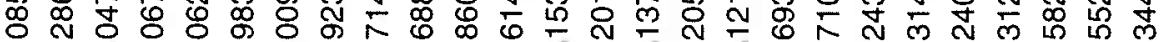

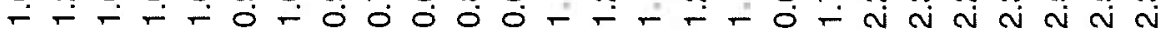

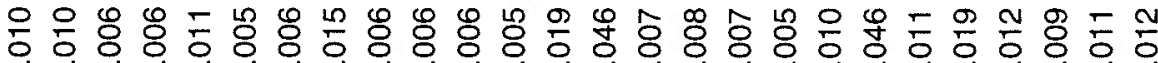

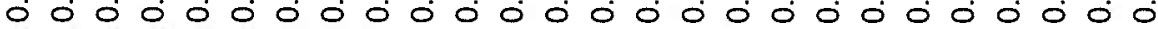
$+1+1+1+H+H+1+1+1+H+1+1+1+1+1+1+1+1+1+1+1+H+1+1+1+1$

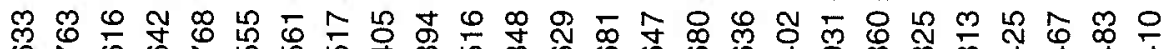

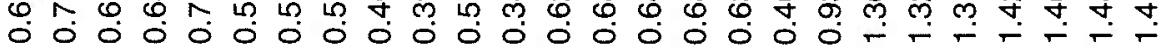

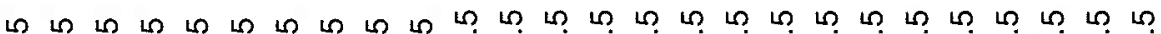

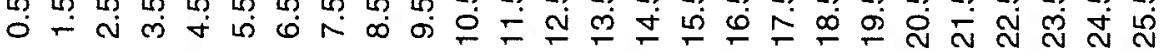

ธ NN 


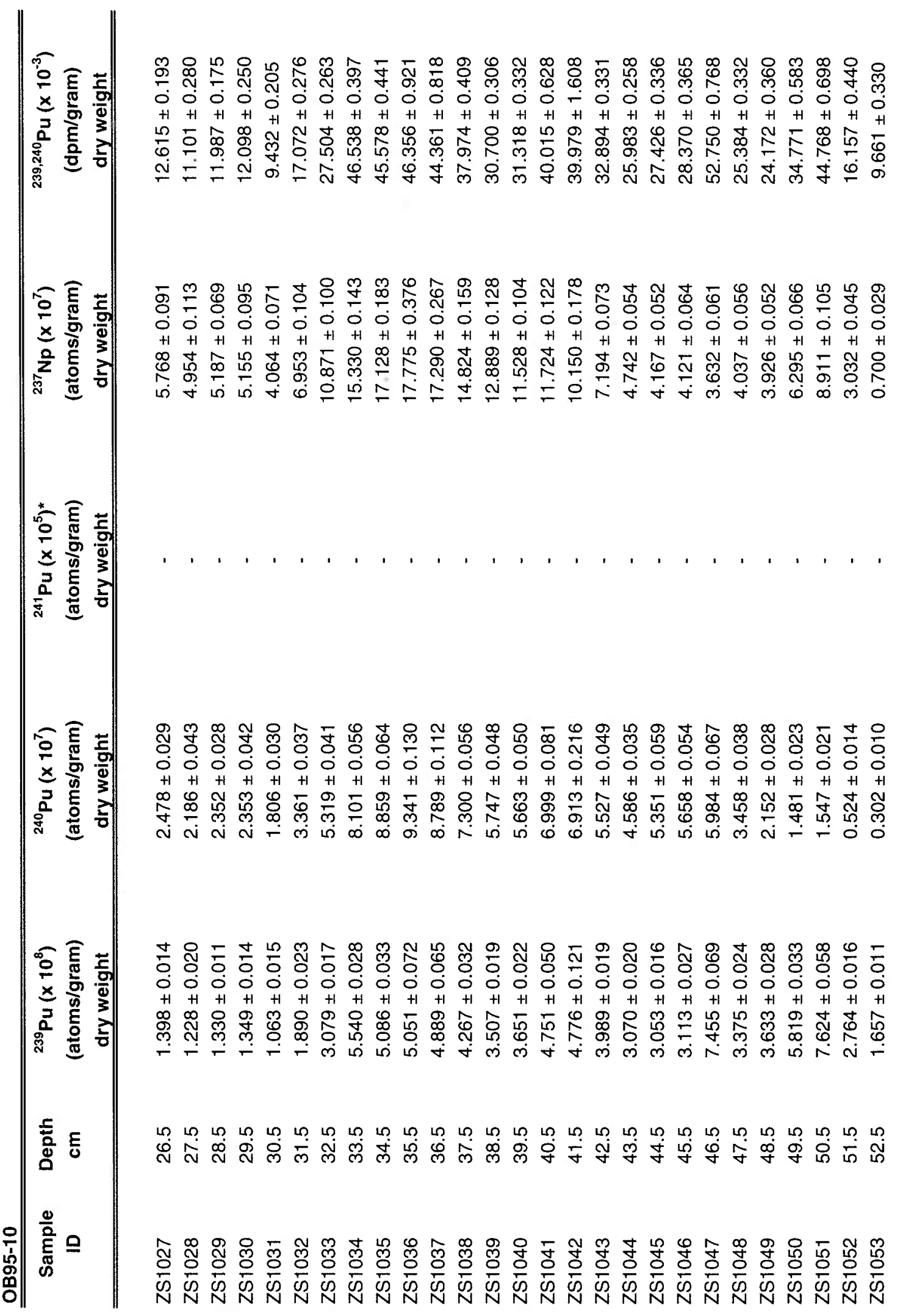




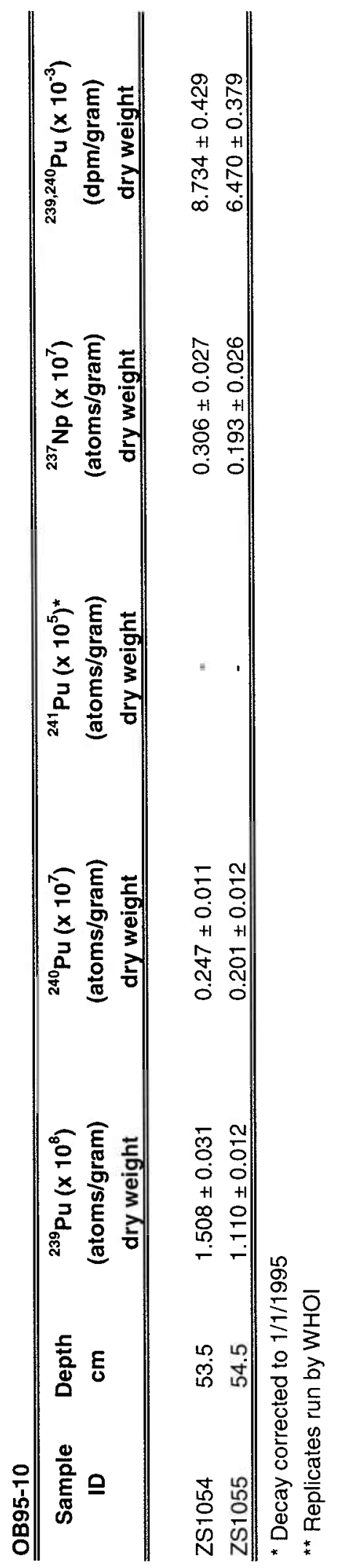




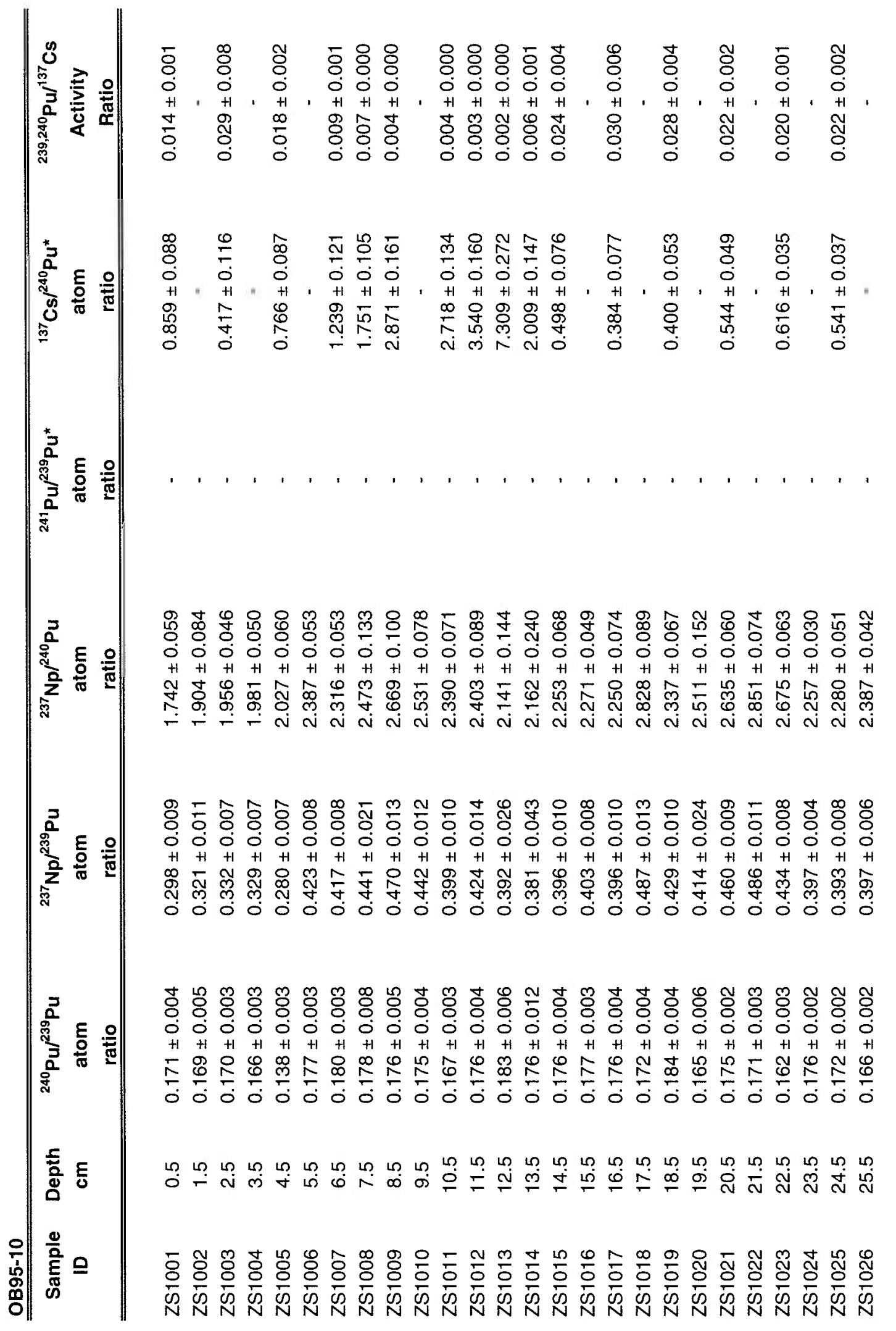




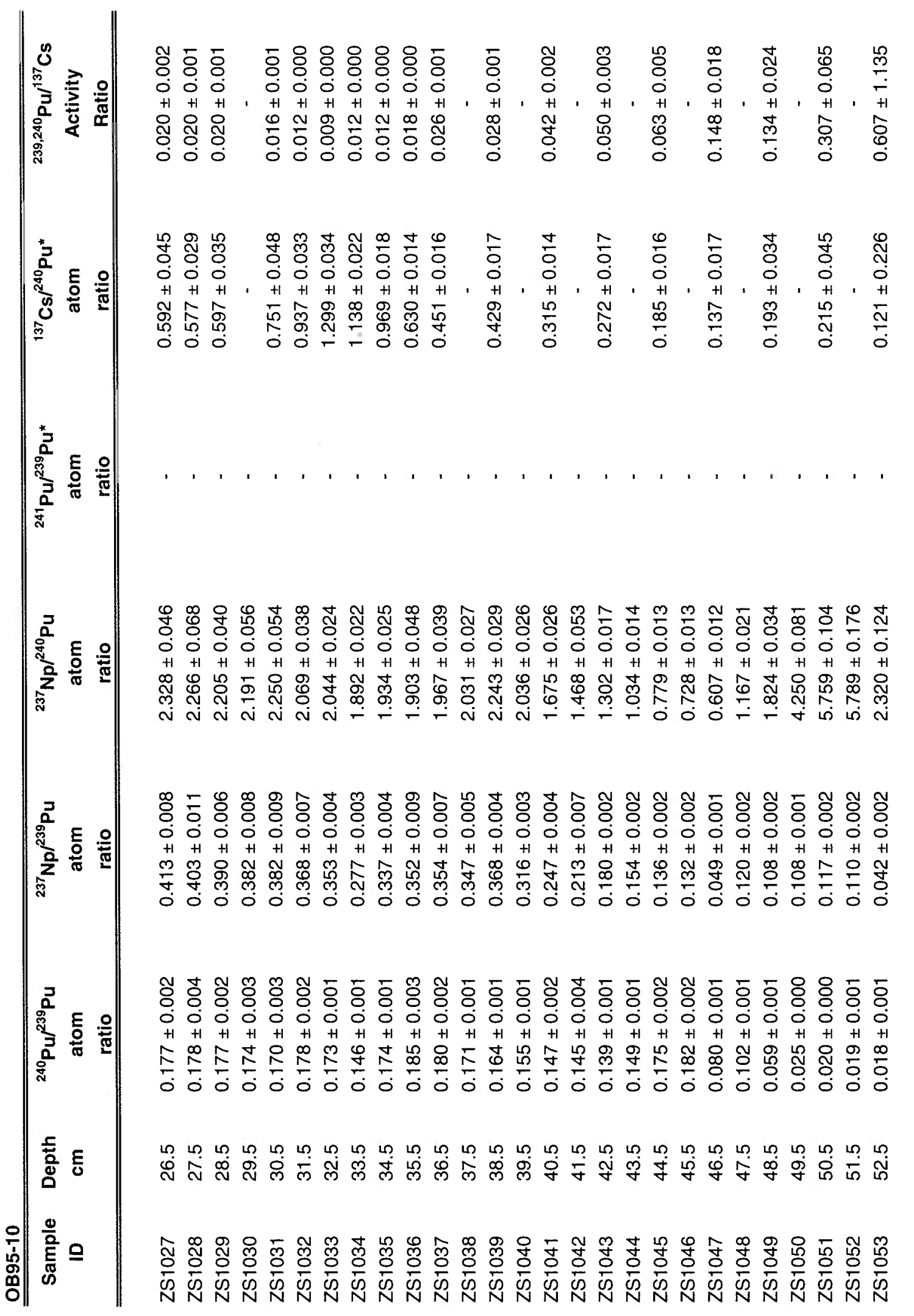




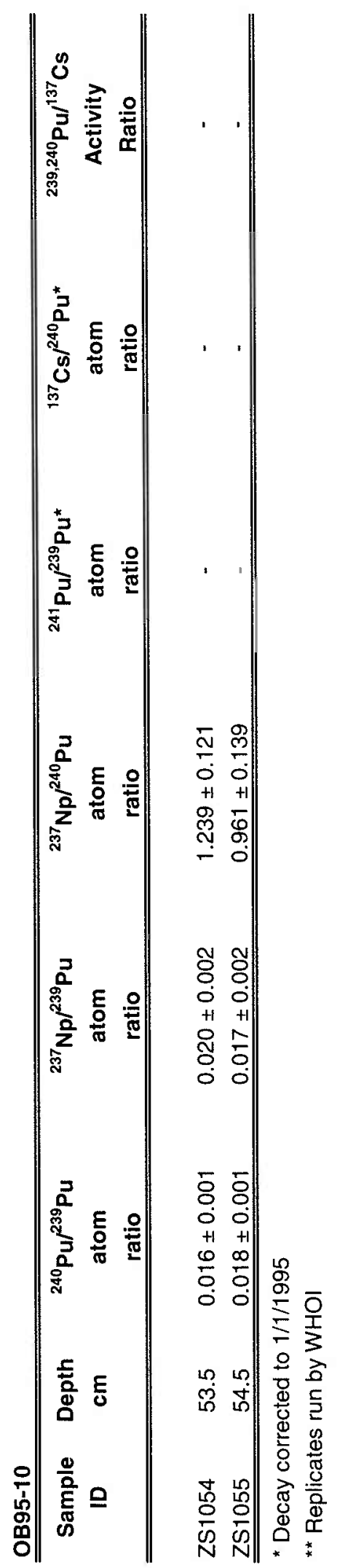


341 


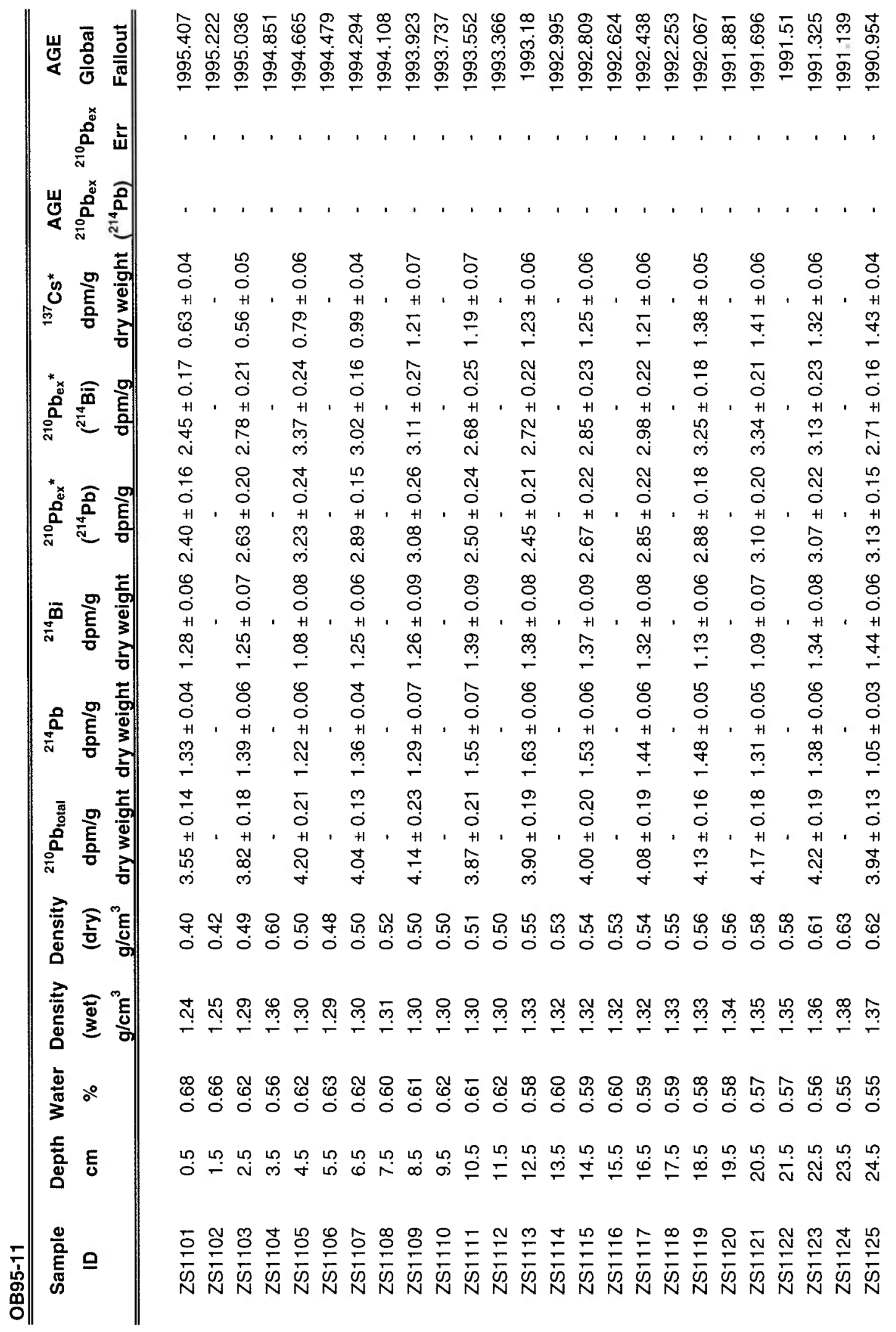




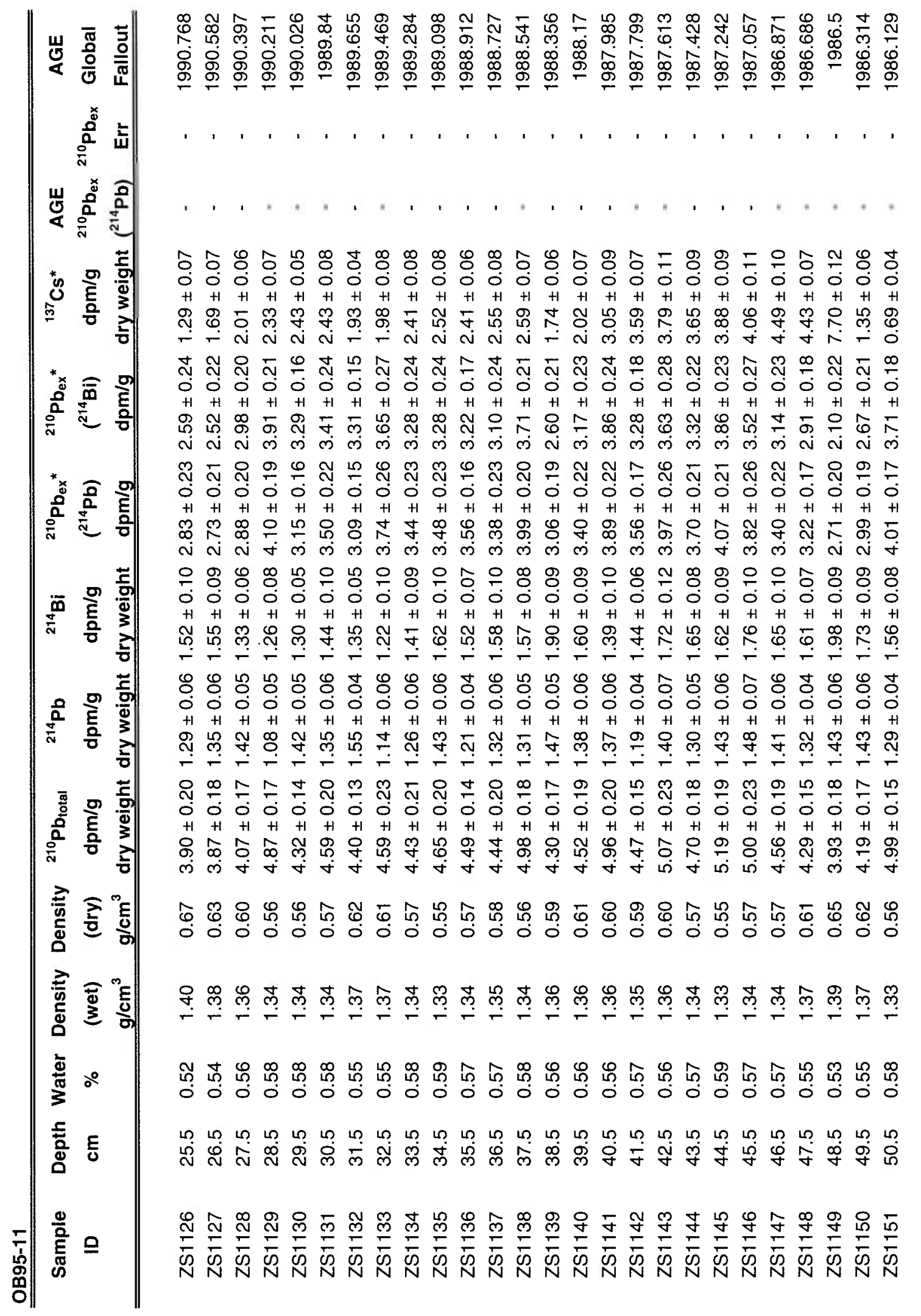




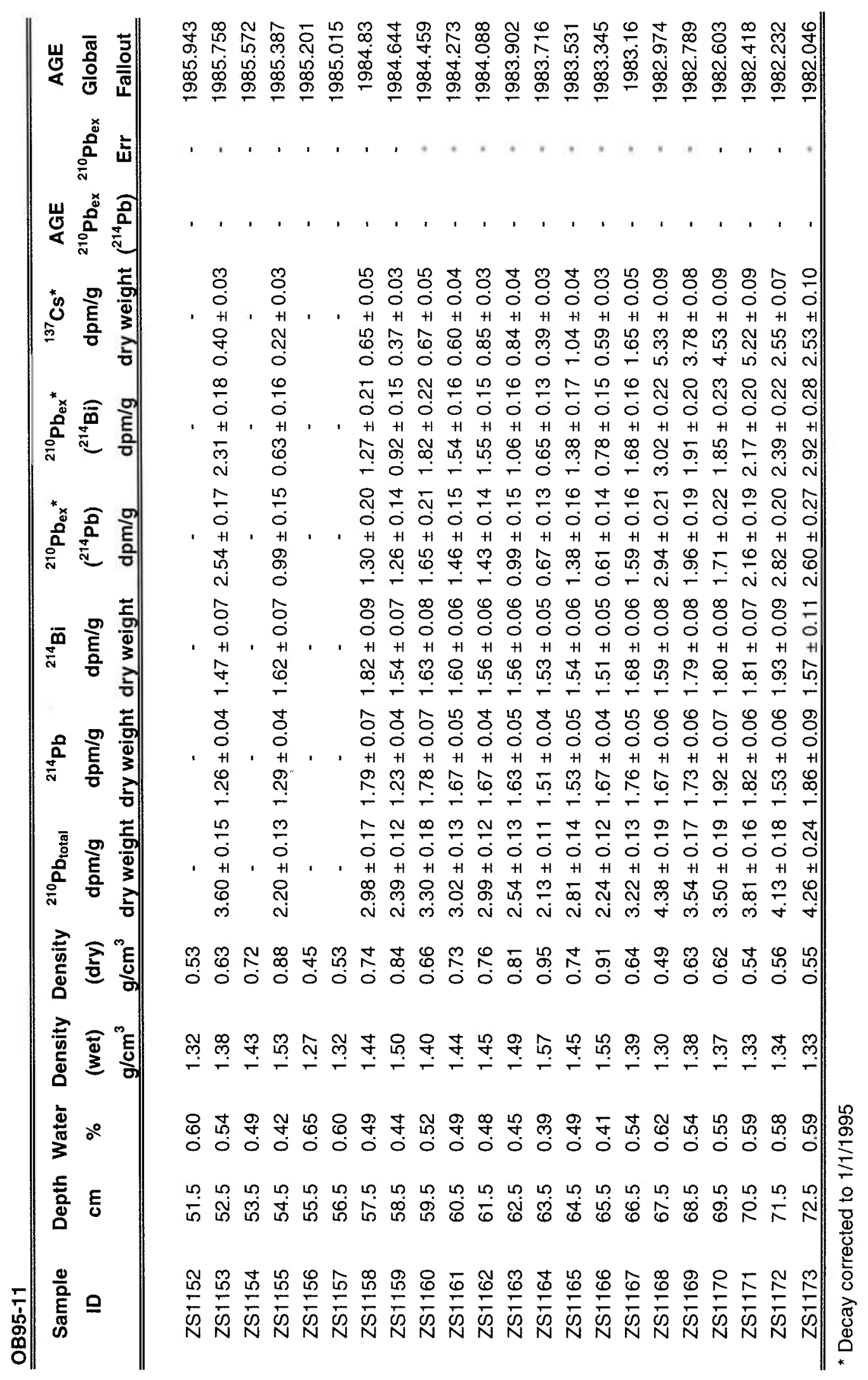




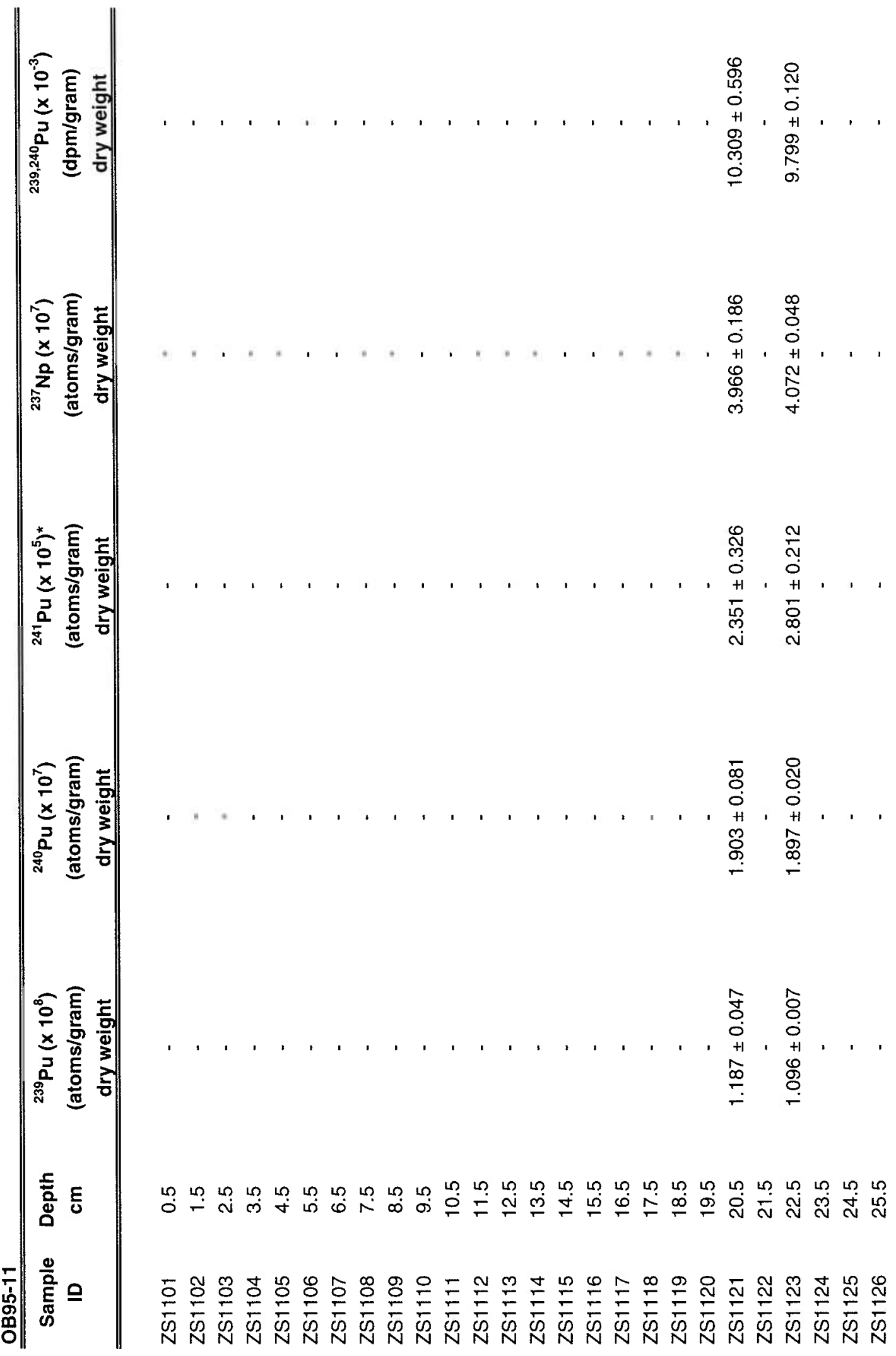




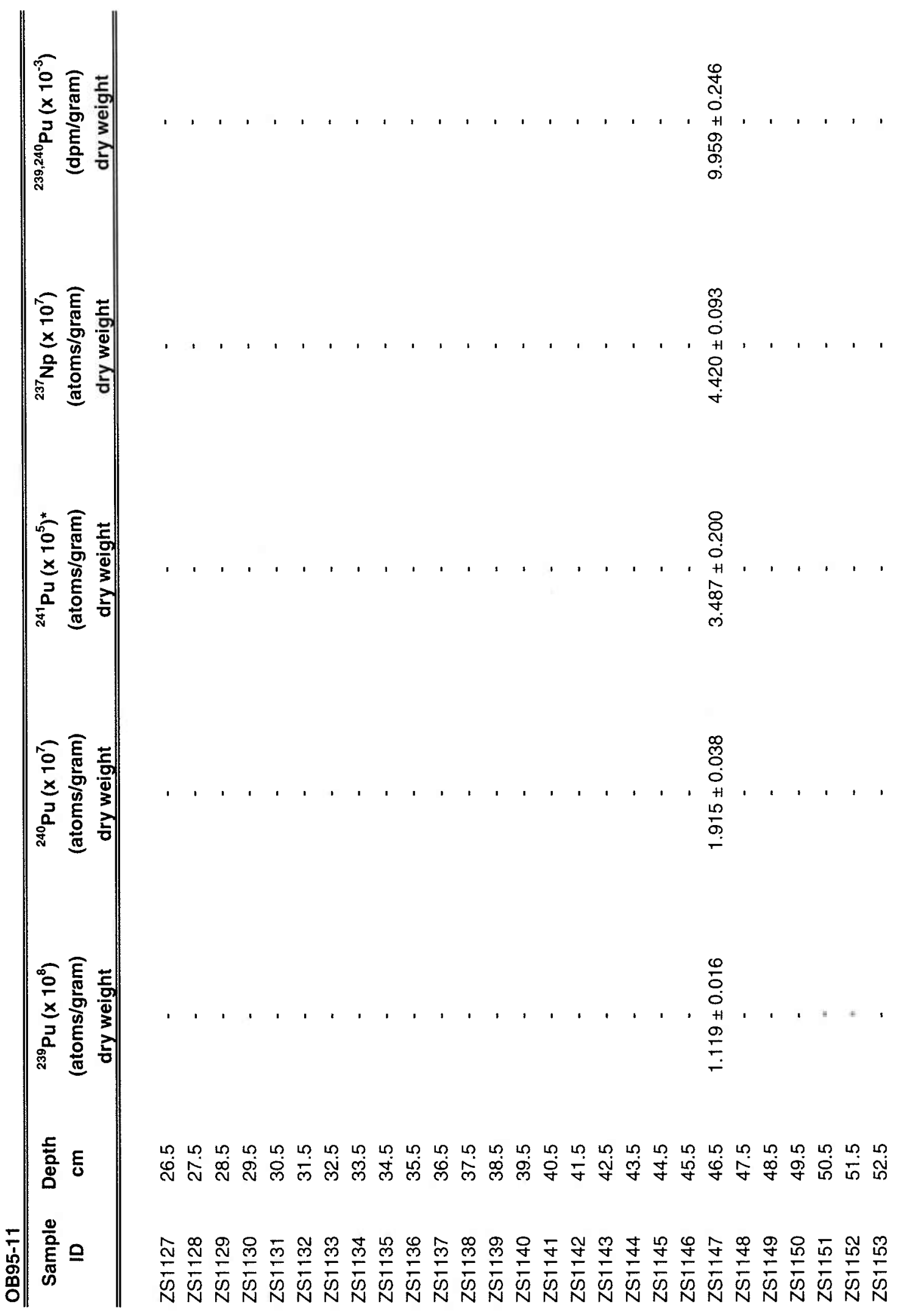




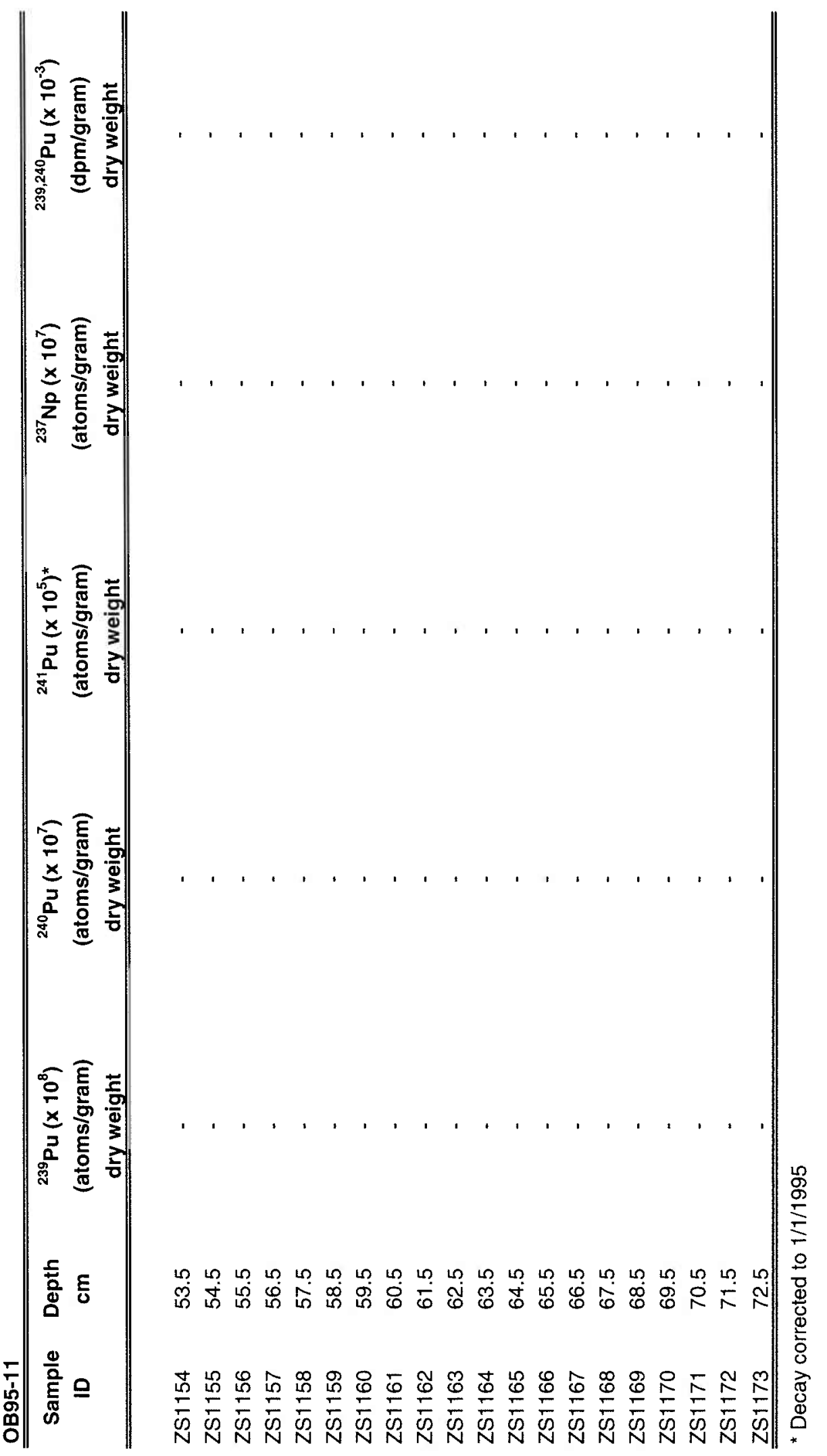




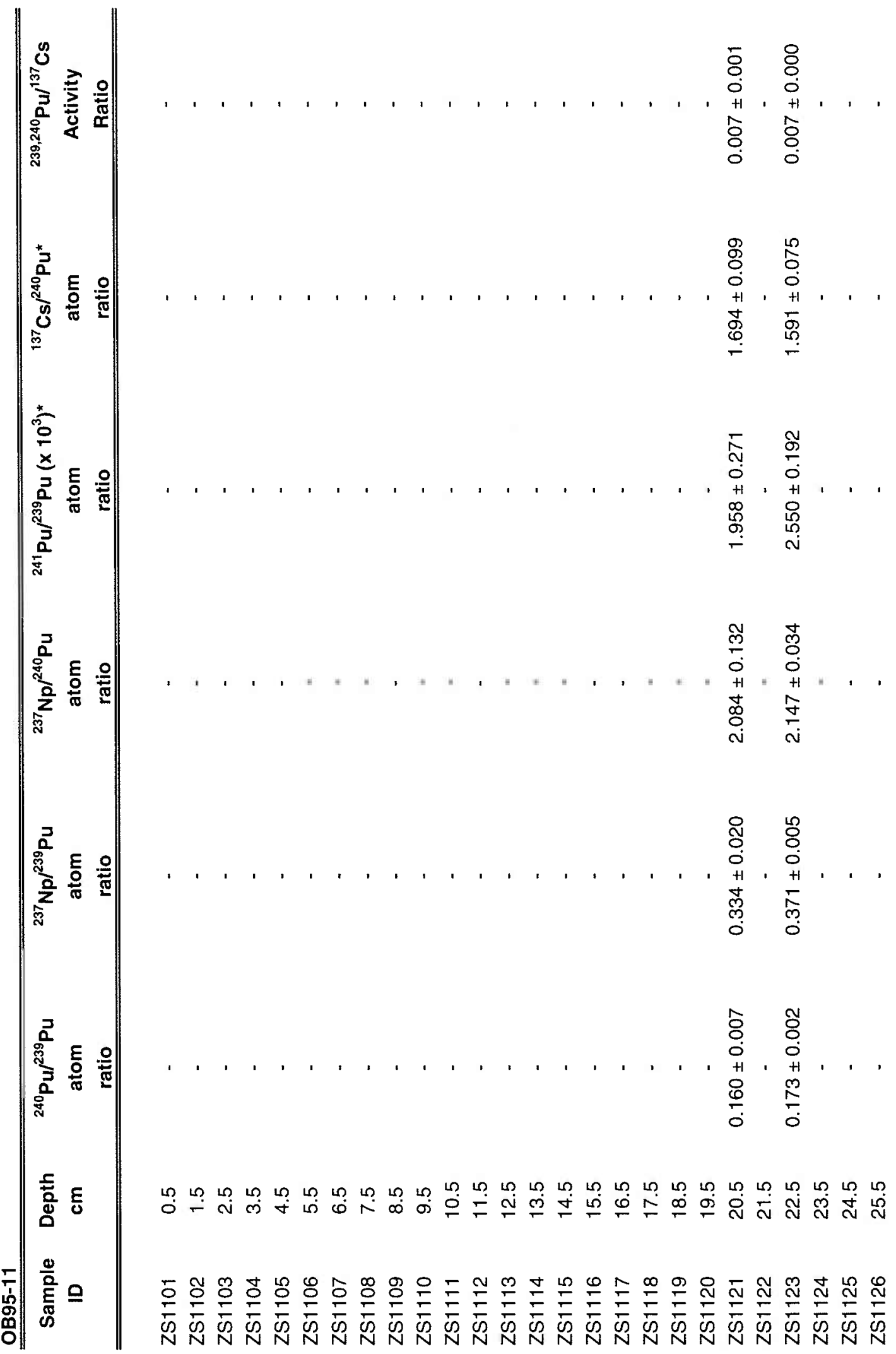




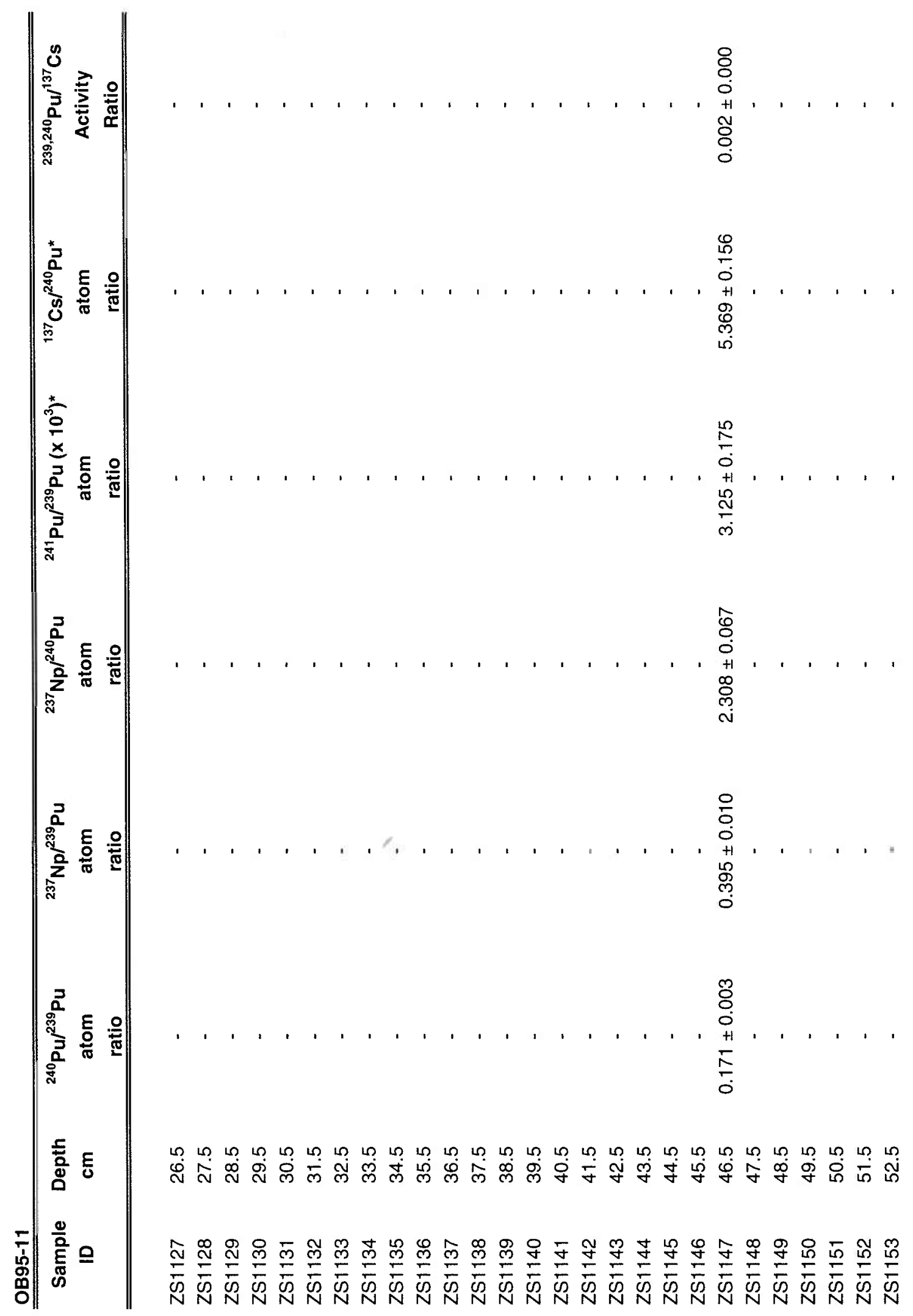




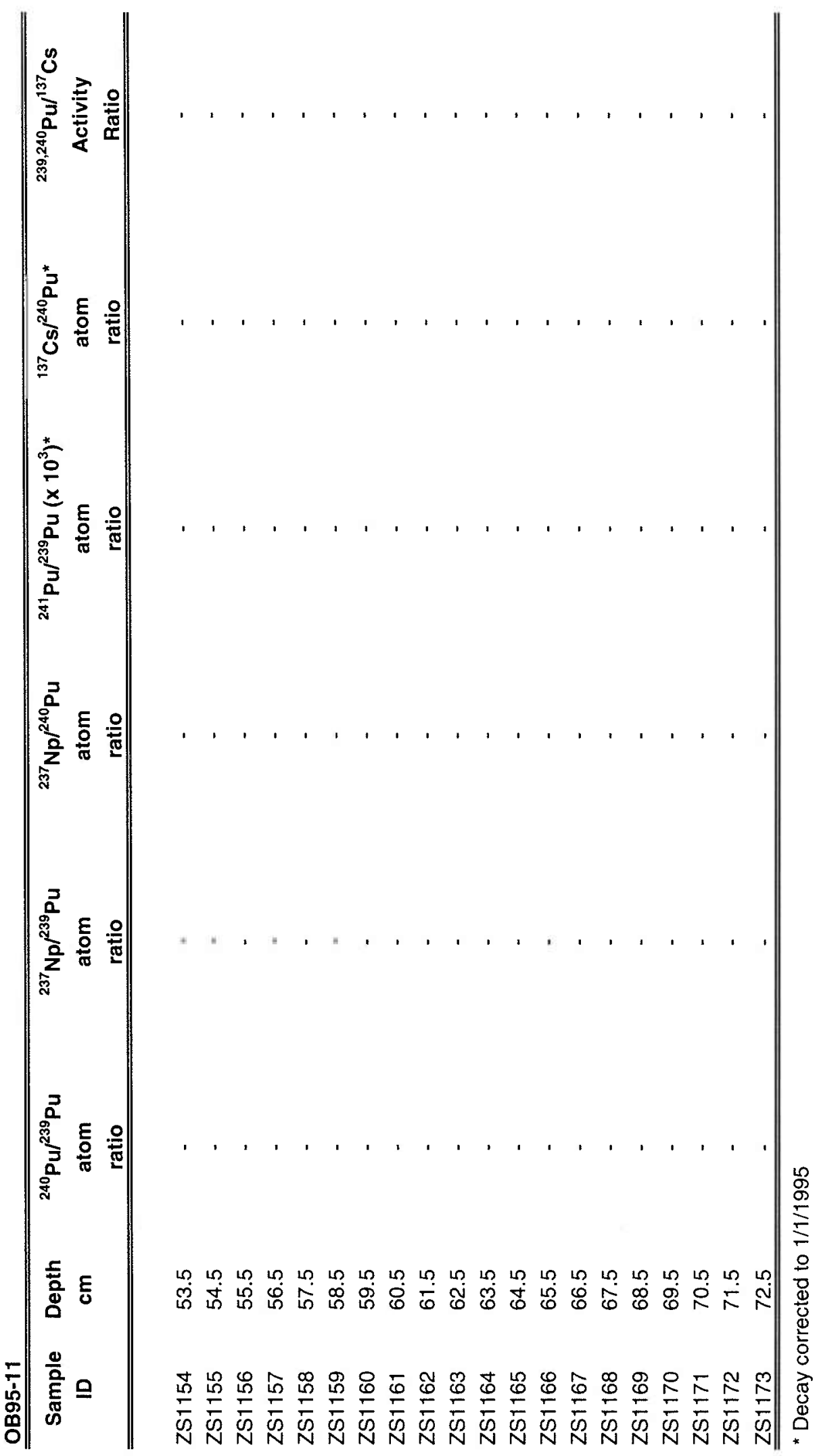




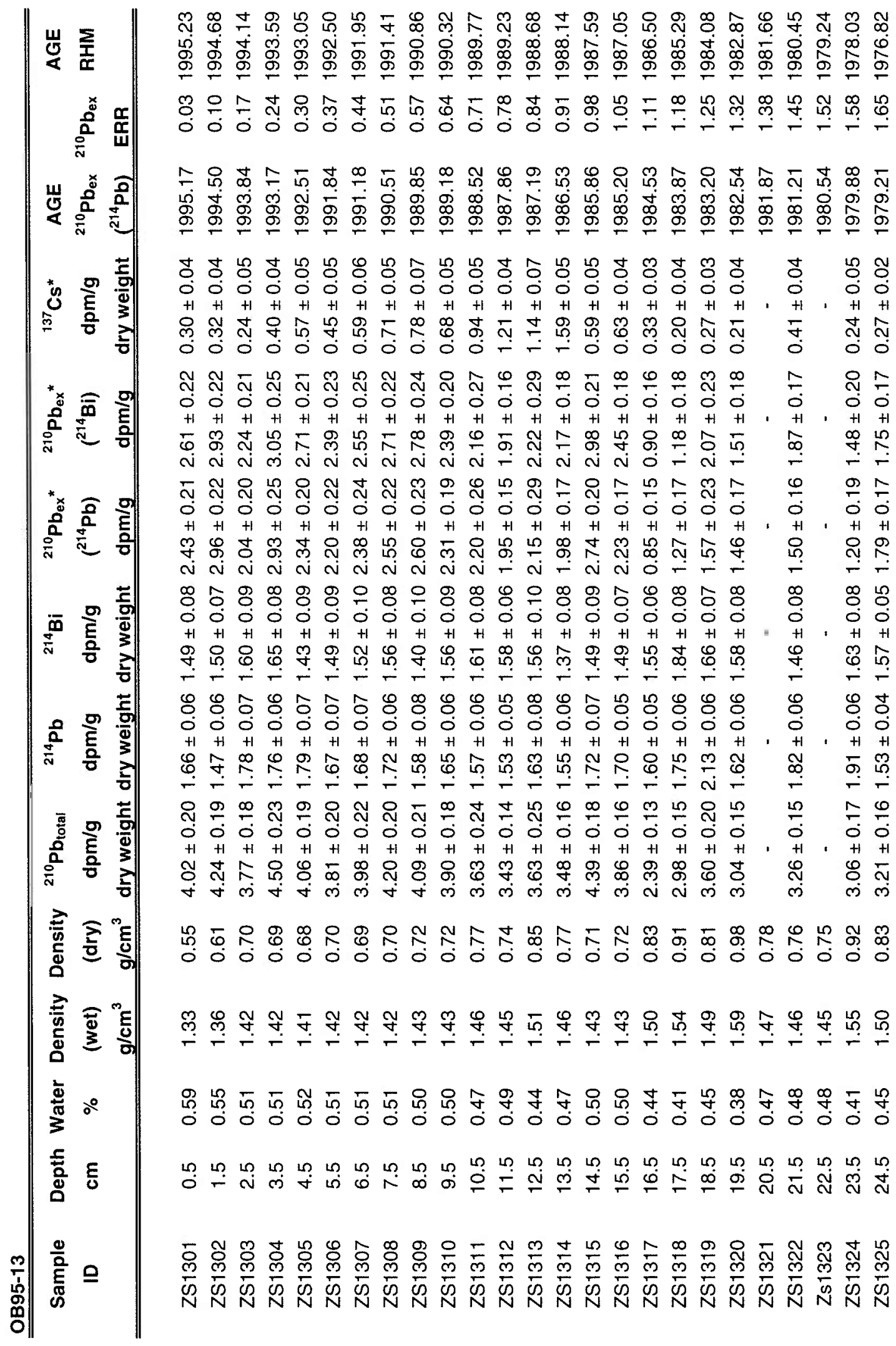




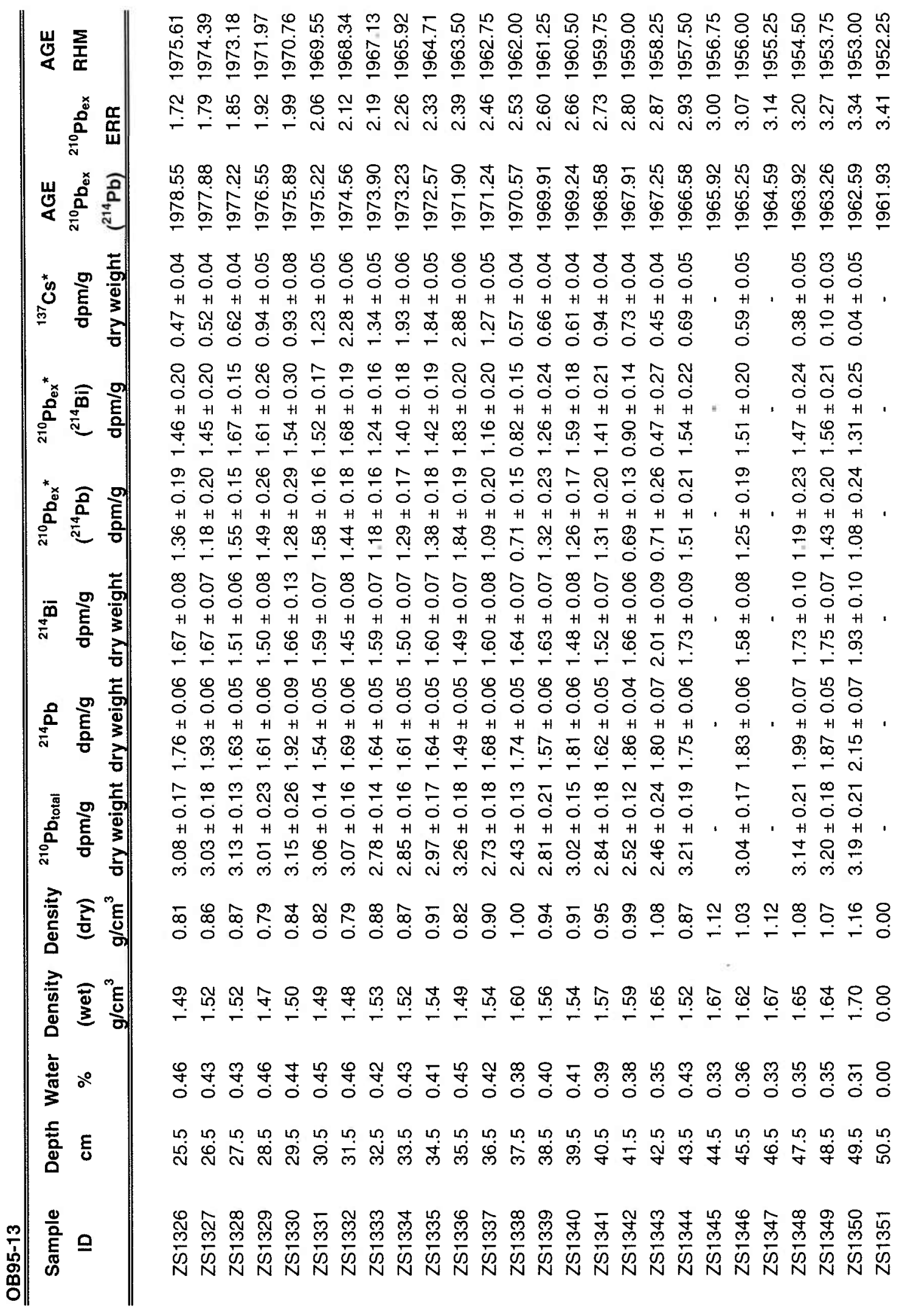




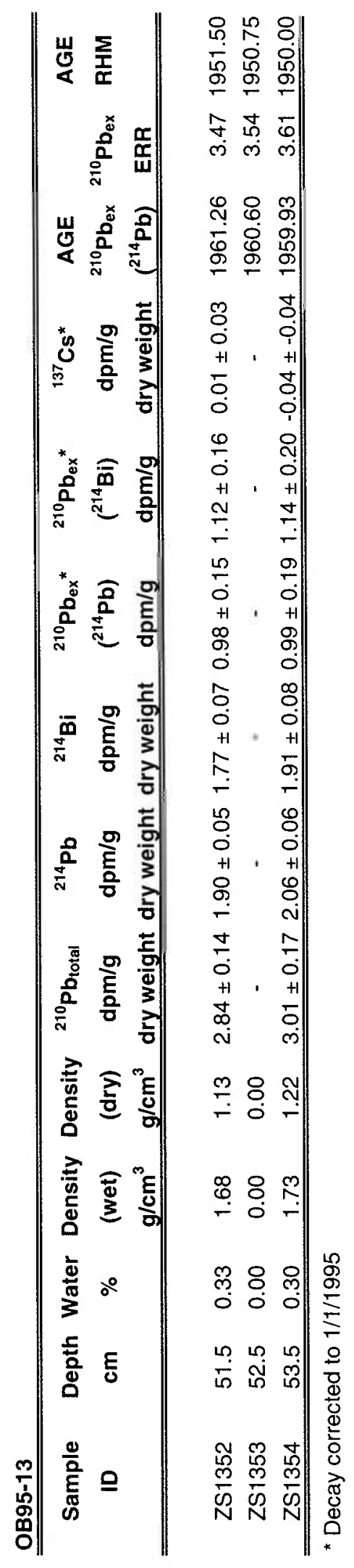




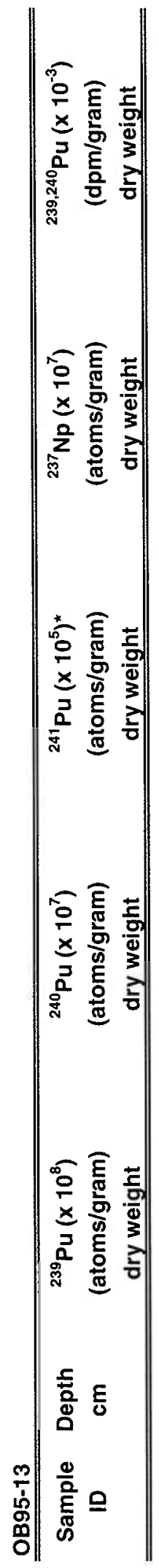

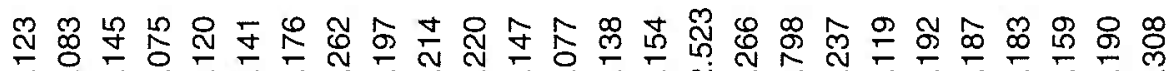

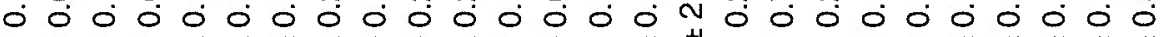

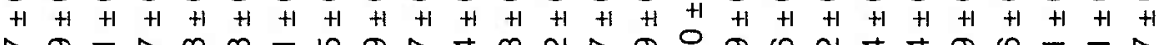

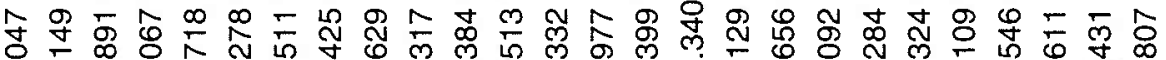

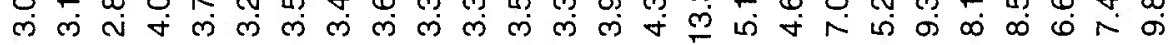

下

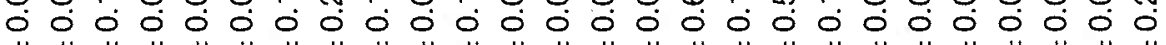

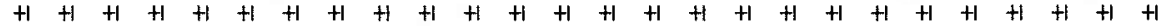
战

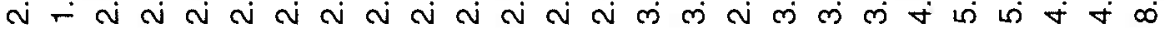

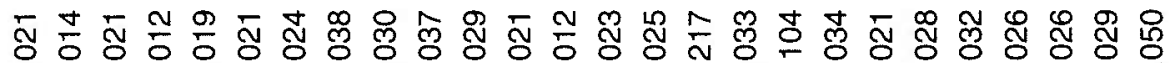

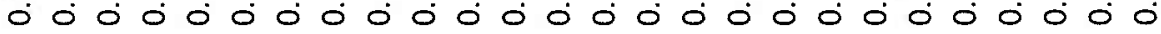
$\begin{array}{llllllllllllllllllllllll}+1 & +1 & +1 & +1 & +1 & +1 & +1 & +1 & +1 & +1 & +1 & +1 & +1 & +1 & +1 & +1 & +1 & +1 & +1 & +1 & \text { H } & +1 & +1 & +1\end{array}+1$ in 0 क

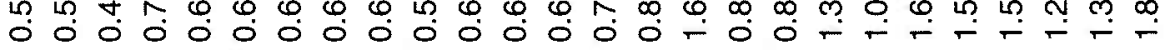

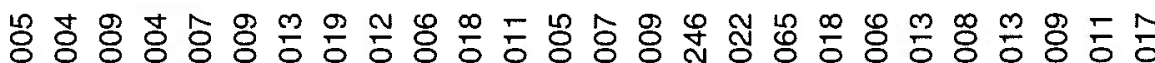

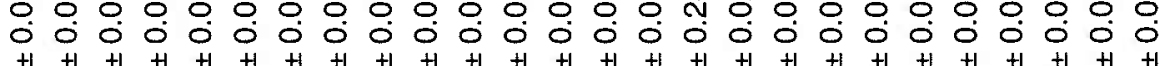

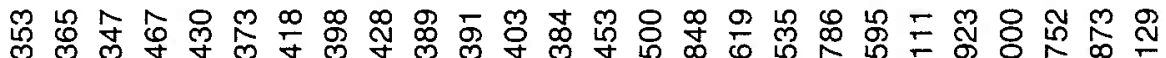
留留

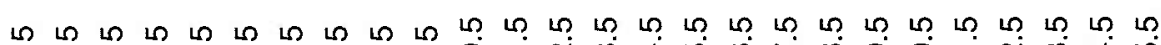

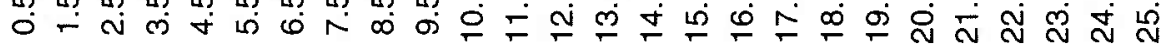

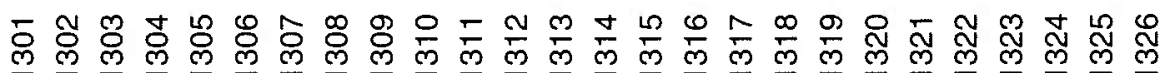

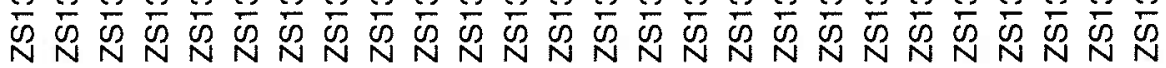




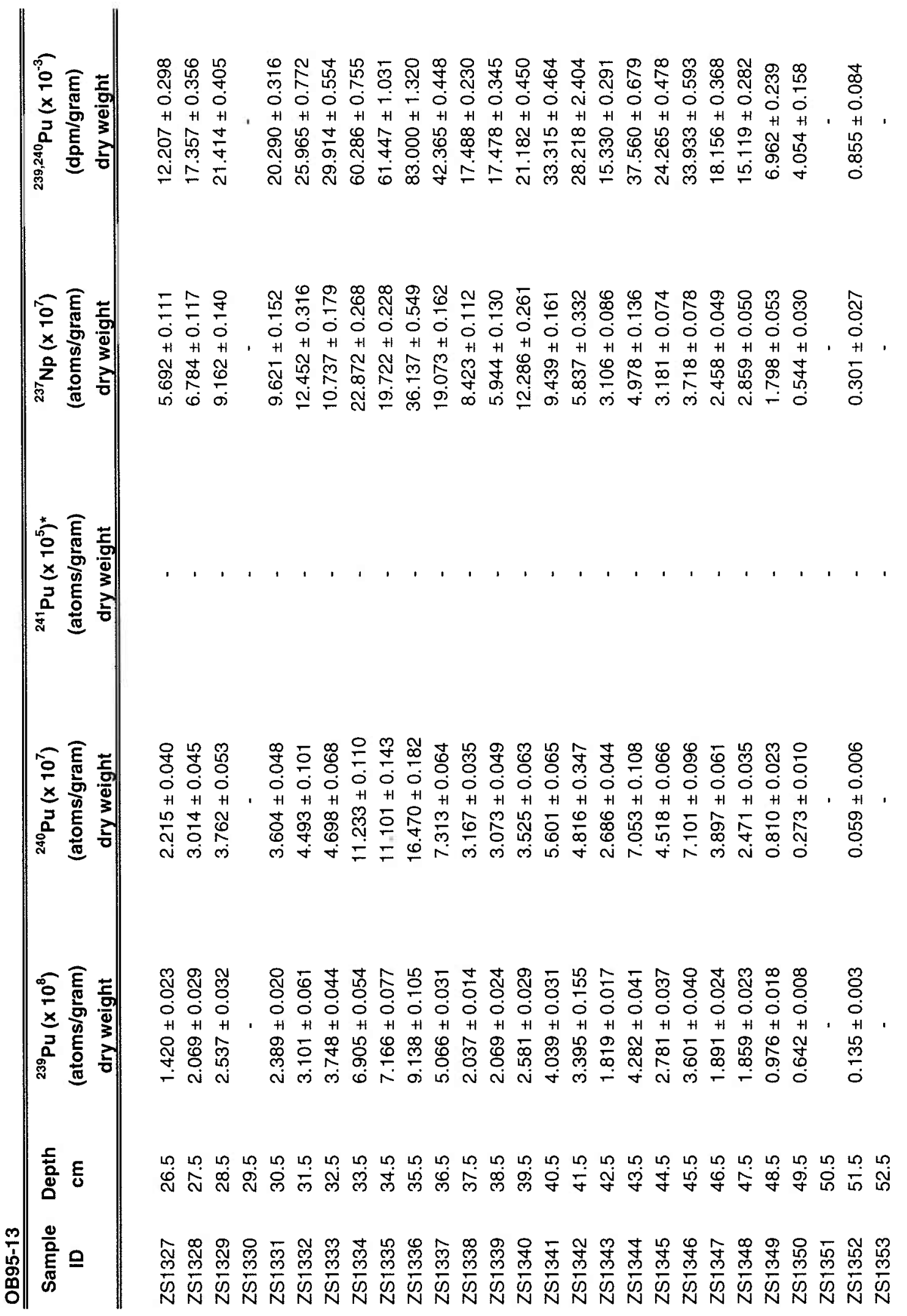




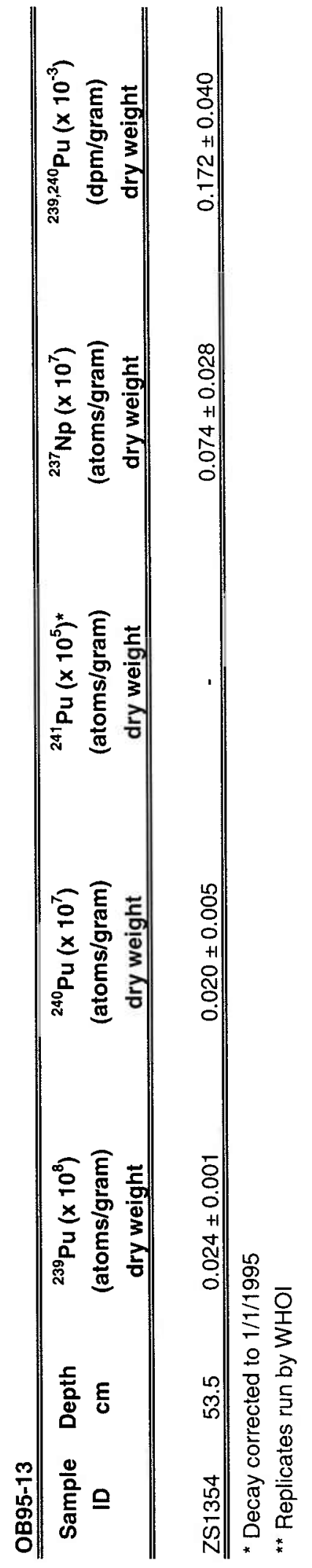


36

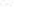

. 


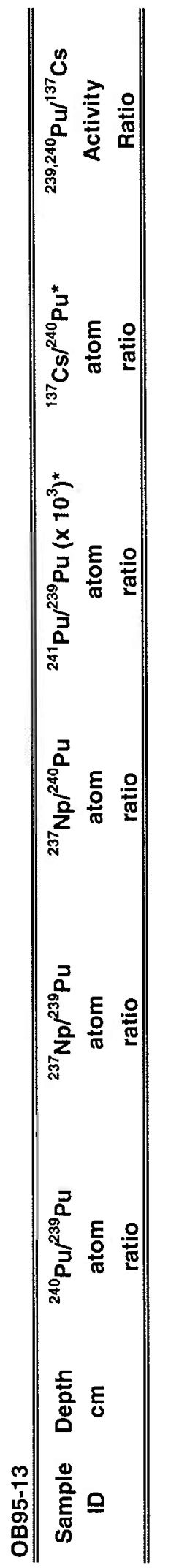

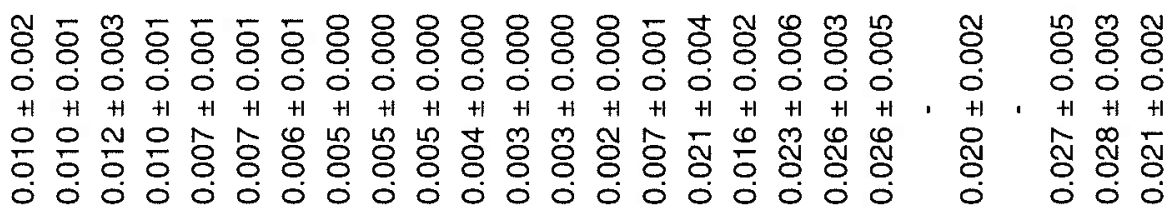

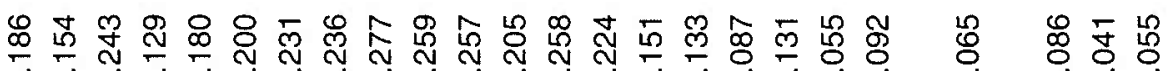

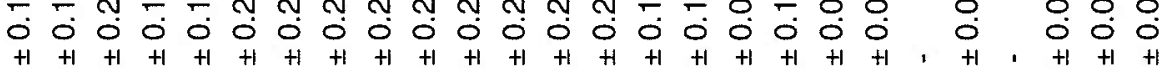
ஸิ

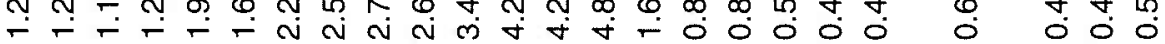

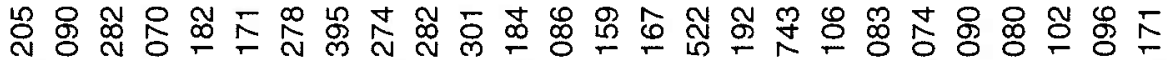

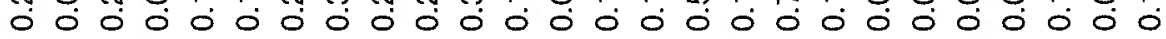
H $+1+1+1+1+H+1+H+1+1+1+1+1+1+1+1+1+1+1+1+1+1+1+1$ 央

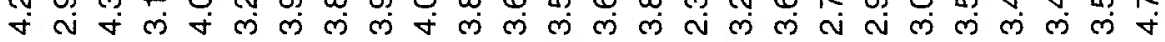

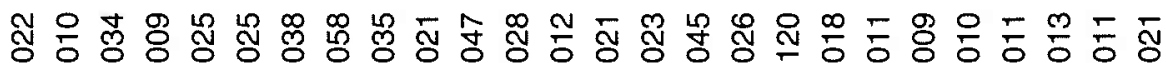

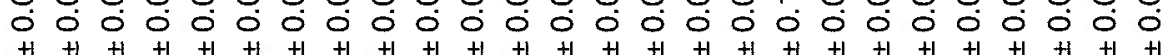

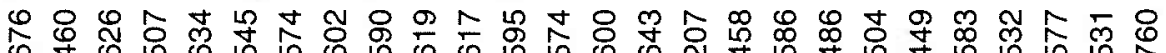

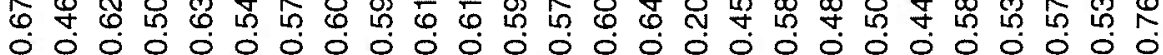

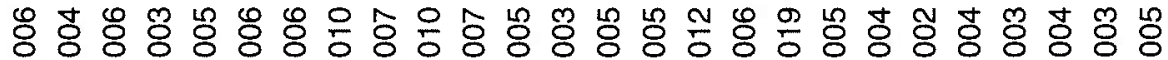

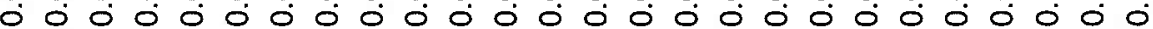
H H H H H H H H H H H H H H H H H H H H H H H H H H

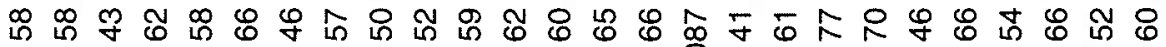
б.

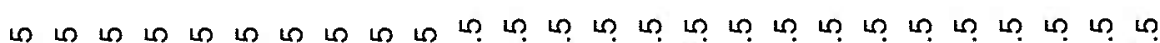
O심

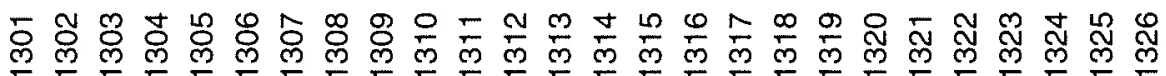
N 


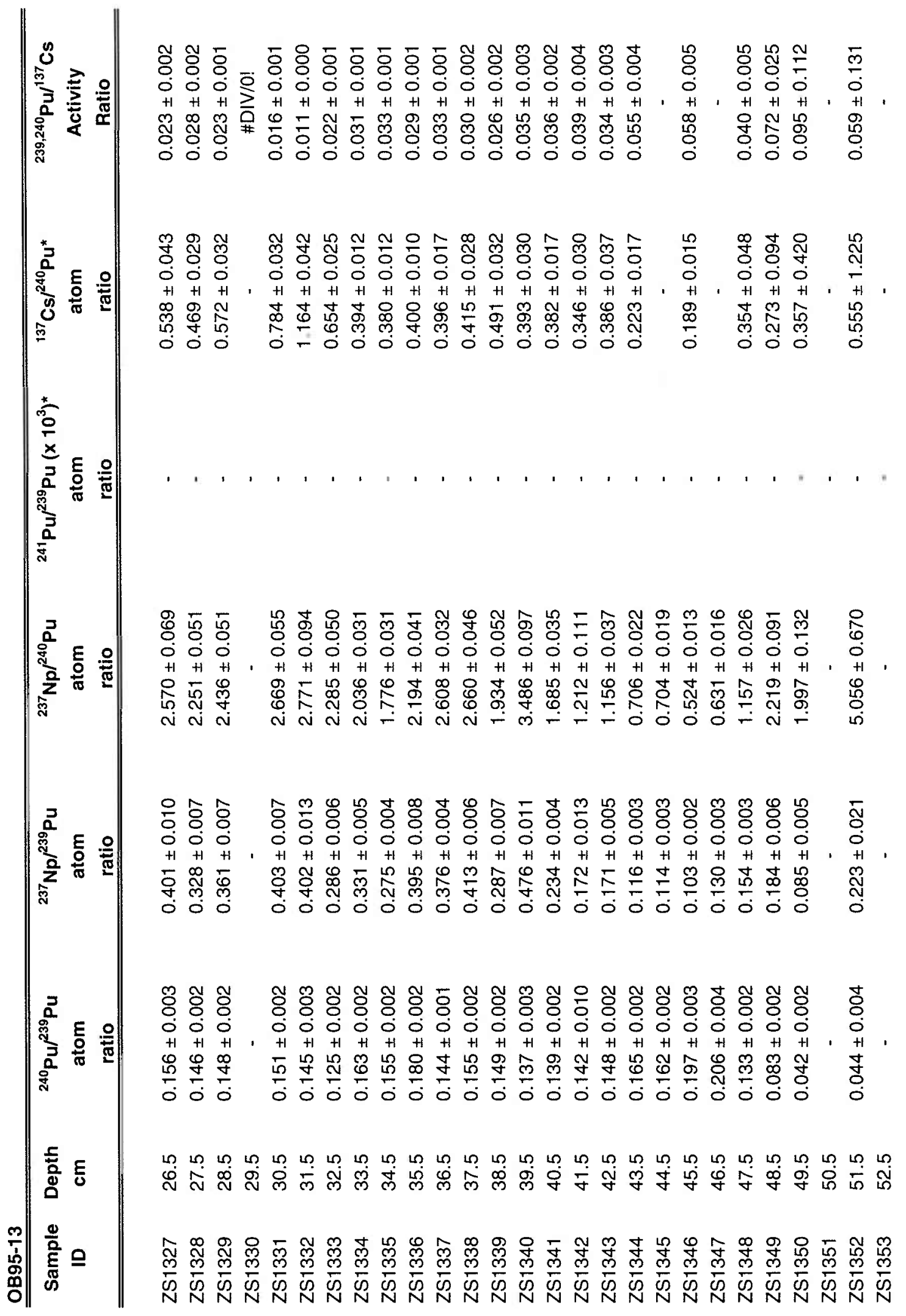




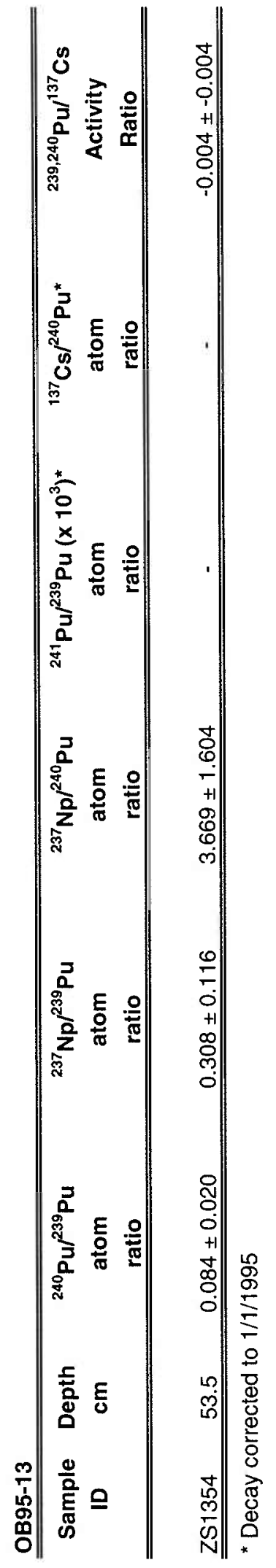


Appendix II

Radionuclide inventories 
Radionuclide inventories for selected time intervals as well as total core inventories are given in Table AII:1. Sayles et al. (1997) observed variable ${ }^{137} \mathrm{Cs}$ inventories in $\mathrm{Ob}$ delta cores and attributed it to sediment focusing, the dominance of sediment composition variables, and possible contributions from local sources. Further isotopic analyses of delta cores as well as those from the upper reaches of the Ob River and its major tributaries also reveal between core variations in the inventories for all radionuclides measured. Due to the numerous different causes of these variations mentioned above, directly comparing radionuclide inventories between cores is problematic.

Comparing the ratios of the different radionuclide inventories however, is quite useful as it mitigates the effects of mineral composition and sediment focusing. Furthermore, as discussed in the Chapter 5, a few of the sediment cores are missing portions of the sedimentary record and thus do not contain complete inventories. Fortunately, the profile features used in radionuclide horizon method provide a means of examining inventory ratios where records are intact. In general, the inventory ratio data yield conclusions similar to those drawn from the higher resolution contaminant records in Chapter 6. One complicating factor with regard to using inventories in this fashion is the effect of a single sample that contains significantly higher contaminant levels (e.g. OB94-10A inventory Total vs. Total* see Table AII:1). 


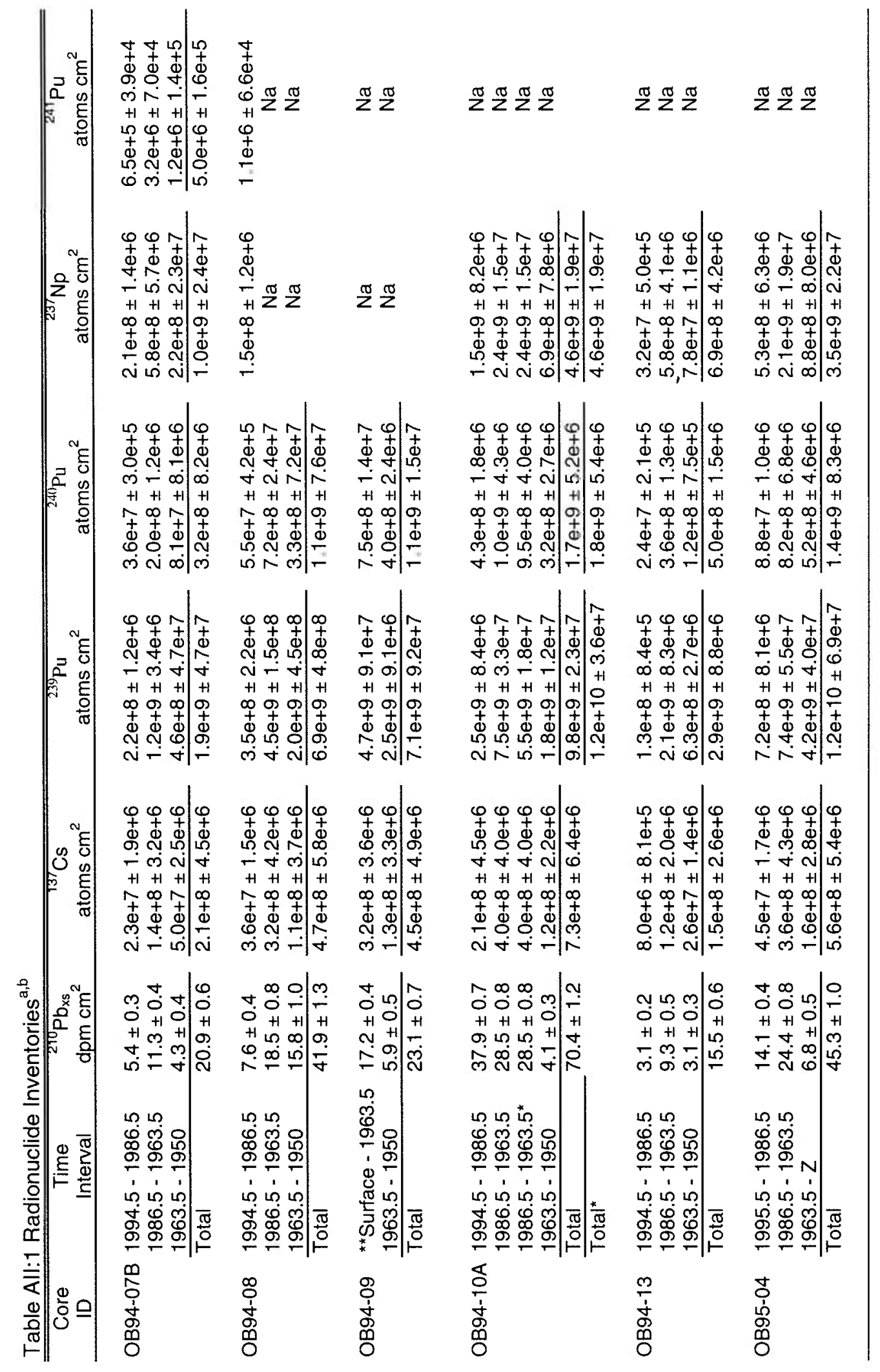




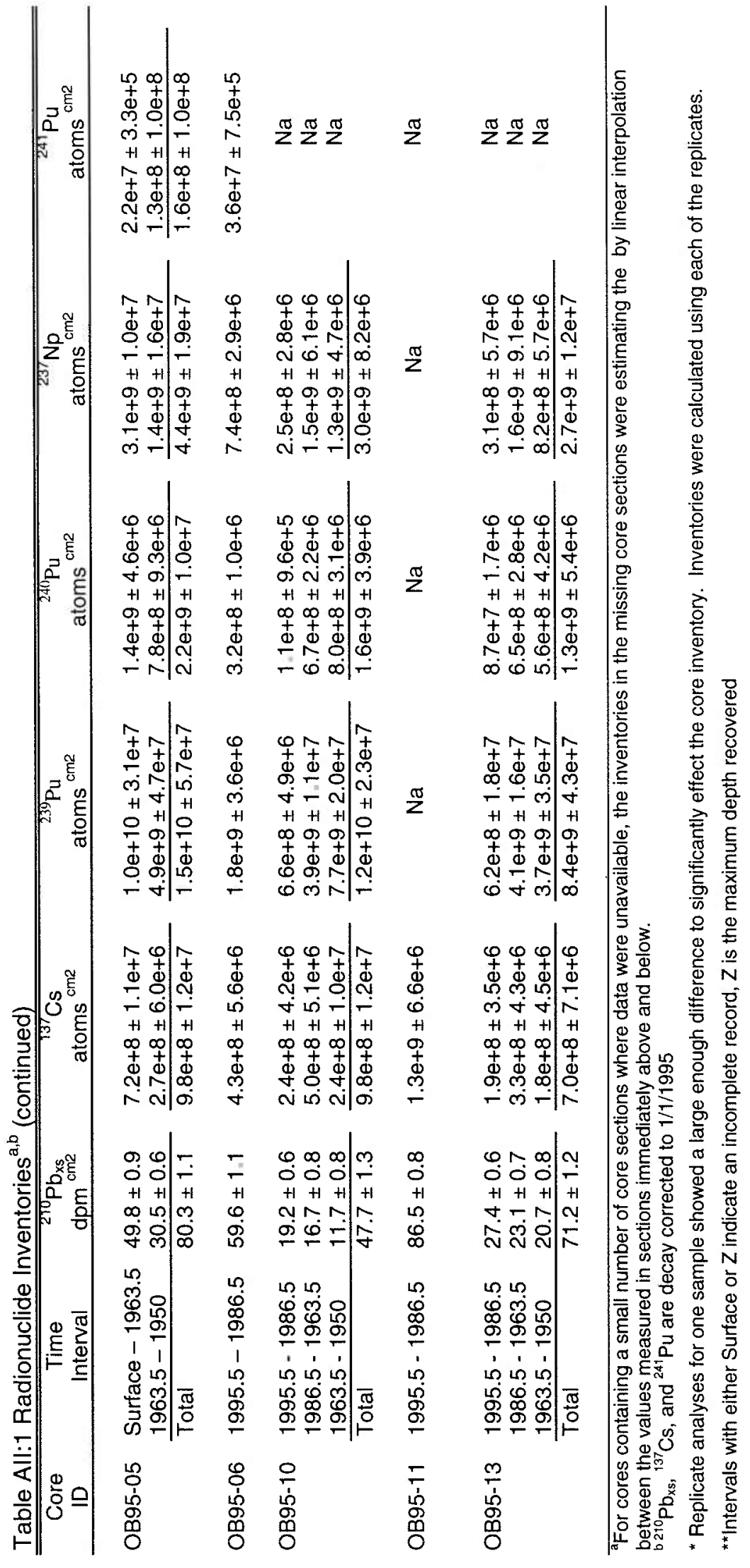


Sediment focusing and possible lithologic effects notwithstanding, a comparison of radionuclide inventories measured in sediment cores from the $\mathrm{Ob}$ region to those measured in soil cores collected at different latitudes in the northern hemisphere is useful as it allows contamination in the $\mathrm{Ob}$ region to be compared to other locations that presumably received contamination from fallout only. Since cores measured by Kelley, Bond, et al. (1998) were collected in the early 1970s, radionuclide inventories for $\mathrm{Ob}$ sediment cores were calculated for sediments with deposition ages between 1950 and 1971. Table AII:2 and Figure AII:1 a to d shows radionuclide inventory comparisons for ${ }^{237} \mathrm{~Np},{ }^{239} \mathrm{Pu},{ }^{240} \mathrm{Pu}$, and ${ }^{137} \mathrm{Cs}$ (note: ${ }^{137} \mathrm{Cs}$ inventories for soil cores were estimated using the global fallout ${ }^{137} \mathrm{Cs} /{ }^{240} \mathrm{Pu}$ ratio of 0.451 ; see Table $2: 3$ for details). With the exception of global fallout inventories measured in Reykjavik, Iceland, and Bergen, Norway, radionuclide inventories appear to be elevated compared to other cores at similar latitudes. Compared to soil cores inventories collected at mid-latitudes however, those measured in Ob sediments are similar, and it can be generally concluded that contaminant levels although elevated are not extreme. 
Table All:2. Comparison of selected radionuclide inventories measured in Ob sediments prior to 1971 to global fallout inventories measured in soils north of $58 \mathrm{~N}$ latitude.

\begin{tabular}{|c|c|c|c|c|c|c|}
\hline Locale & Lat & Lon & $\begin{array}{l}{ }^{237} \mathrm{~Np} \\
\text { atoms } / \mathrm{cm}^{2}\end{array}$ & $\begin{array}{l}{ }^{239} \mathrm{Pu} \\
\text { atoms } / \mathrm{cm}^{2}\end{array}$ & $\begin{array}{l}{ }^{240} \mathrm{Pu} \\
\text { atoms } / \mathrm{cm}^{2}\end{array}$ & $\begin{array}{l}{ }^{\mathrm{B} /} \mathrm{Cs}^{*} \\
\text { atoms } / \mathrm{cm}^{2}\end{array}$ \\
\hline POINT BAI & 71.39 & 156.48 & $4.51 \pm 0.08$ & $8.98 \pm 0.10$ & $1.74 \pm 0.02$ & $0.79 \pm 0.01$ \\
\hline OB94-13 & 69.09 & 76.72 & 0.04 & $21.56 \pm 0.08$ & $3.86=$ & .02 \\
\hline OB94 & 66.82 & 69.47 & $N / A$ & $58.01 \pm 0.91$ & $9.77=$ & \\
\hline 89 & 66.81 & 69.41 & $N / A$ & $50.06 \pm 4.54$ & $8.12 \pm$ & \\
\hline B9 & 66.78 & 70.96 & $20.02 \pm 0.14$ & $51.13 \pm 0.20$ & $8.86 \pm$ & \\
\hline DB94 & 66.67 & 54 & $5.59 \pm 0.24$ & $12.01 \pm 0.47$ & $2.03=$ & 1. \\
\hline ANKS, AK & 64.84 & 147.72 & $10.23 \pm$ & $20.89 \pm$ & $3.73=$ & \\
\hline REYKJAVIK & 64.15 & 21.85 & $25.11 \pm 0.45$ & $52.92 \pm 0.58$ & $9.53 \pm$ & $4.30 \pm$ \\
\hline PALMER, AK & 61.6 & 149.11 & $11.20 \pm 0.29$ & $23.41 \pm 0.41$ & $4.23 \pm$ & \\
\hline OB95-04 & 61.18 & & $17.01 \pm 0.13$ & $92.47 \pm 0.65$ & $10.58 \pm$ & 3.53 \\
\hline OB95-05 & 61.17 & & $35.71 \pm 0.19$ & $124.50 \pm 0.57$ & $18.29 \pm$ & 8.20 \\
\hline BER & 60.38 & 5.33 & $33.50 \pm 0.69$ & $85.70 \pm 1.10$ & $14.89 \pm$ & \\
\hline OSLO & 59.92 & 10.75 & $16.67 \pm$ & $37.30 \pm$ & $6.68=$ & 3.01 \\
\hline WIC & 58.43 & & $15.65=$ & 32 & 5.9 & 2. \\
\hline $\mathrm{OBS}$ & & & $19.09=$ & & 10. & \\
\hline OB & & & $21.79=$ & 101 & 14. & \\
\hline RO & & & $15.71 \pm$ & & & \\
\hline WAI & 55 & & $13.94 \pm$ & 36 & & \\
\hline MUN & 48.13 & 11.57 & $28.50 \pm$ & 00 & 10.5 & \\
\hline PUY & 47.19 & 122.29 & $14.32 \pm$ & 25 & & \\
\hline ISPRA & 45.82 & 8.62 & $30.13 \pm 0.71$ & $0 \pm 1.00$ & 10.5 & \\
\hline ORONC & & & $19.30 \pm$ & 63 & & \\
\hline SAPI & 5 & & $20.45 \pm$ & 47 & 8.3 & $3.75=$ \\
\hline VER & 42.78 & & $28.27 \pm$ & 96 & 10. & $4.59=$ \\
\hline & & & $23.19 \pm$ & & & \\
\hline & & & 27.4 & & 11. & 5 \\
\hline & & & 17. & 59 & 6. & 3. \\
\hline & & & 19.8 & 0 & 44. & 20. \\
\hline MAN & & & $31.64 \pm$ & $0 \pm 1.20$ & & \\
\hline & & 112.33 & $27.20 \pm$ & .50 & 13.3 & .13 \\
\hline & & & $18.29 \pm$ & 62 & & $2.78=$ \\
\hline & 38.35 & 109.15 & $19.33 \pm 0.44$ & $56.31 \pm 0.67$ & $8.46 \pm$ & 3.8 \\
\hline $\mathrm{GA}, \mathrm{CA}$ & 37.84 & 122.13 & $3.13 \pm 0.10$ & $4.91 \pm$ & $0.91 \pm$ & $0.41=$ \\
\hline TUL & 36 & 9 & $25.04 \pm 0.63$ & $51.83 \pm$ & 9.0 & $4.06=$ \\
\hline TEH & 36. & 50.27 & $21.00 \pm$ & 66 & 7.5 & 3.4 \\
\hline & & & $30.00 \pm$ & 7 & 10.8 & 4.5 \\
\hline & & & $17.89 \pm$ & 1 & & $2.88=$ \\
\hline & 34.18 & 118.31 & $6.57 \pm$ & 30 & 2.6 & $1.21 \pm$ \\
\hline & 31.58 & 74.3 & $21.17 \pm 0.63$ & 39 & $7.42 \pm$ & $3.35 \pm$ \\
\hline KINGSVIL & 27.52 & 97.81 & $9.55 \pm 0.42$ & $22.56 \pm 0.42$ & $4.05 \pm$ & $1.83 \pm 0.04$ \\
\hline FORT PIERCE, FL & 27.45 & 80.33 & $12.25 \pm 0.35$ & $25.70 \pm 0.48$ & $4.75 \pm 0.10$ & $2.14 \pm 0.05$ \\
\hline WESLACO, TX & 26.16 & 97.99 & $9.71 \pm 0.24$ & $22.53 \pm 0.38$ & $3.72 \pm 0.07$ & $1.68 \pm 0.03$ \\
\hline CHIENHUA & 25.23 & 121.65 & $10.57 \pm 0.27$ & $19.29 \pm 0.35$ & $3.45 \pm 0.07$ & $1.56 \pm 0.03$ \\
\hline
\end{tabular}

* Radionuclide inventories not shown in figures. 


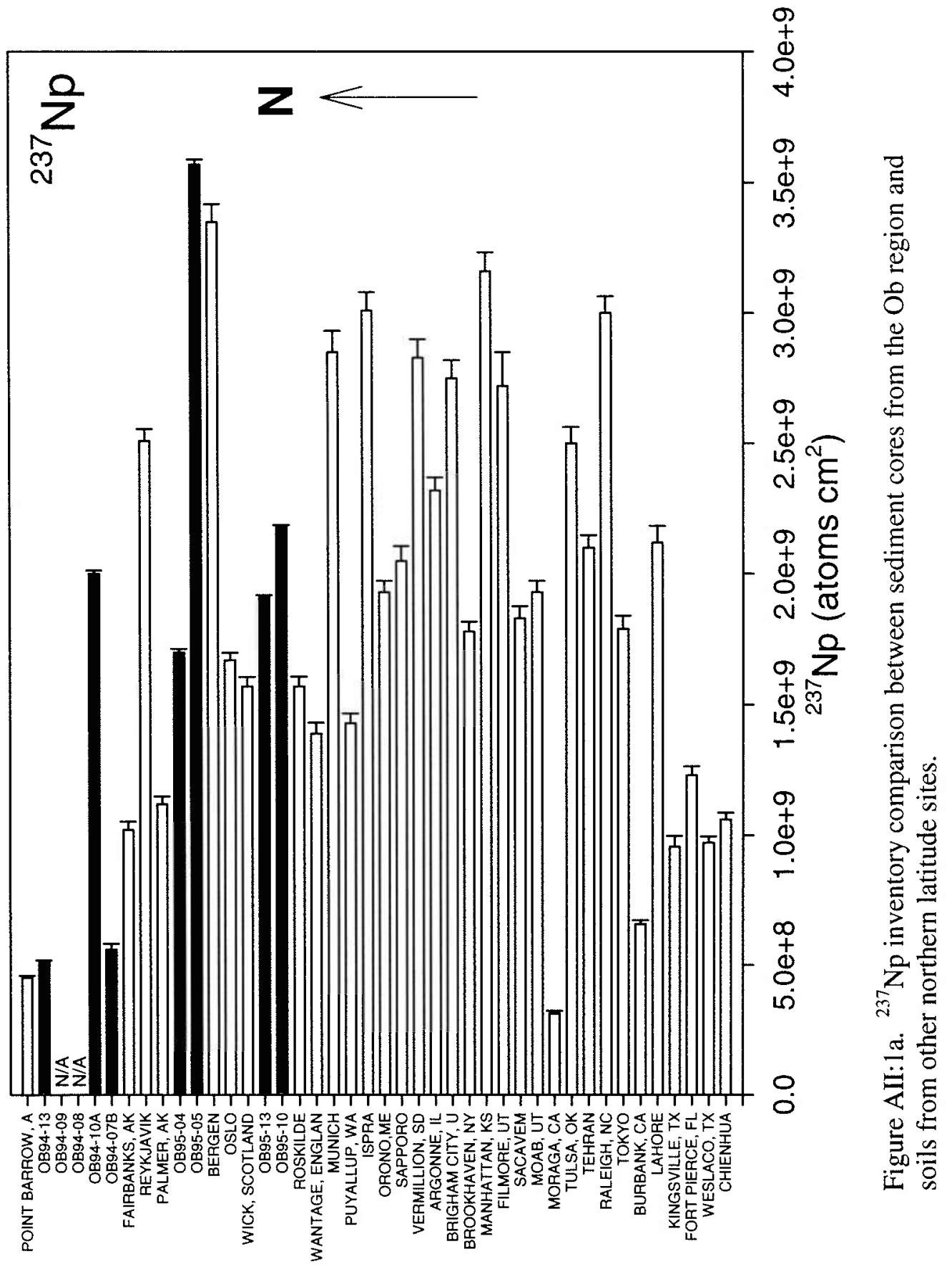




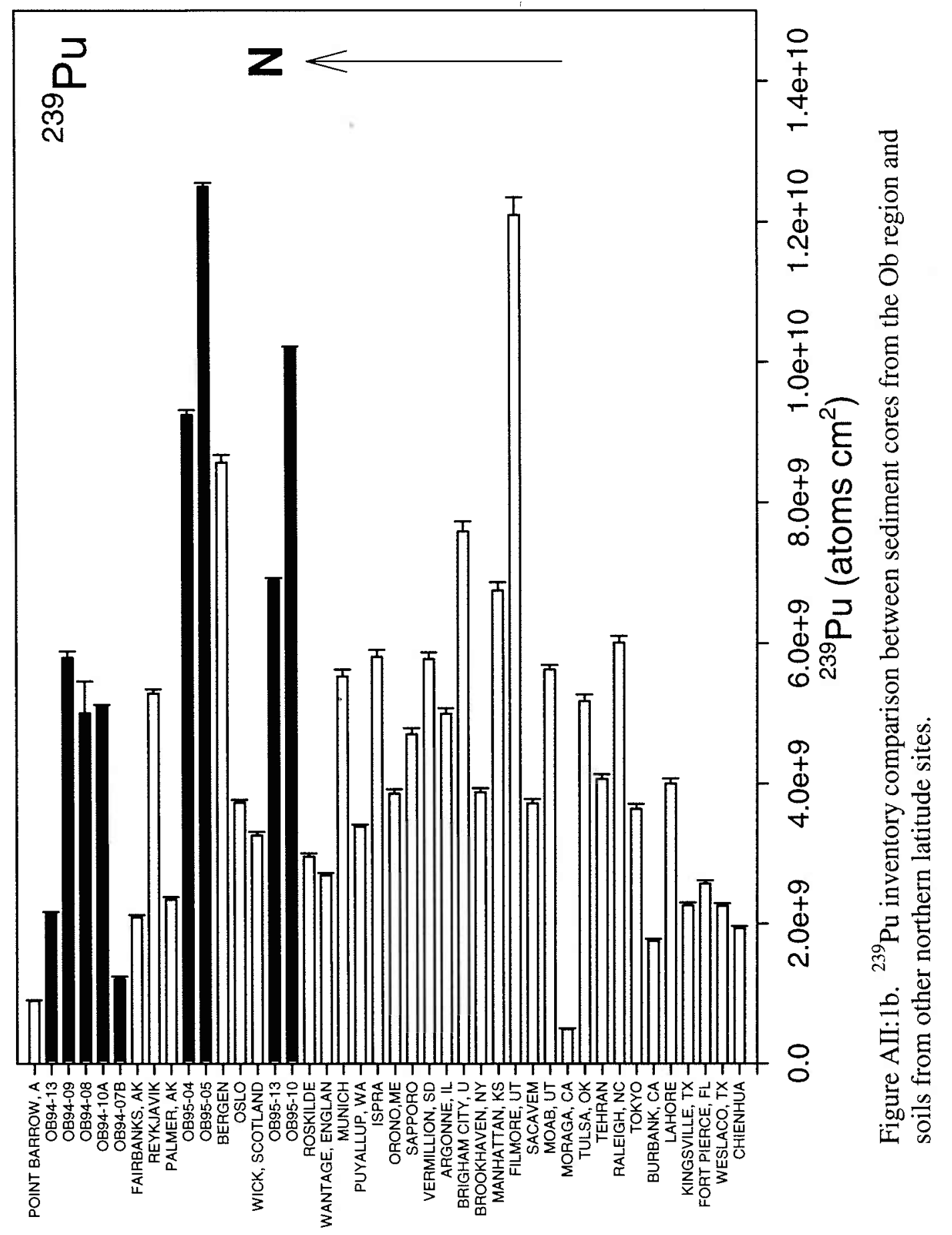




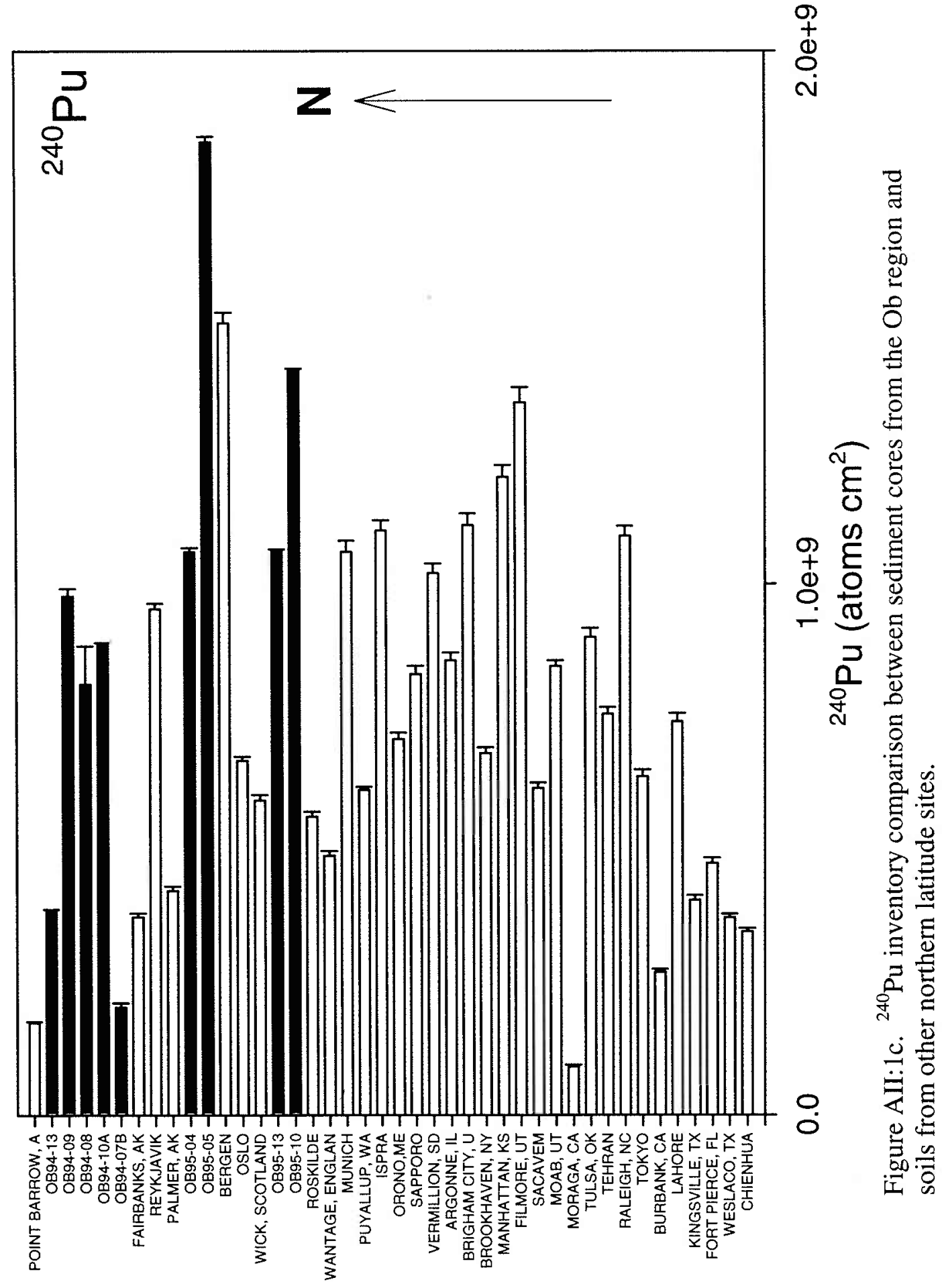




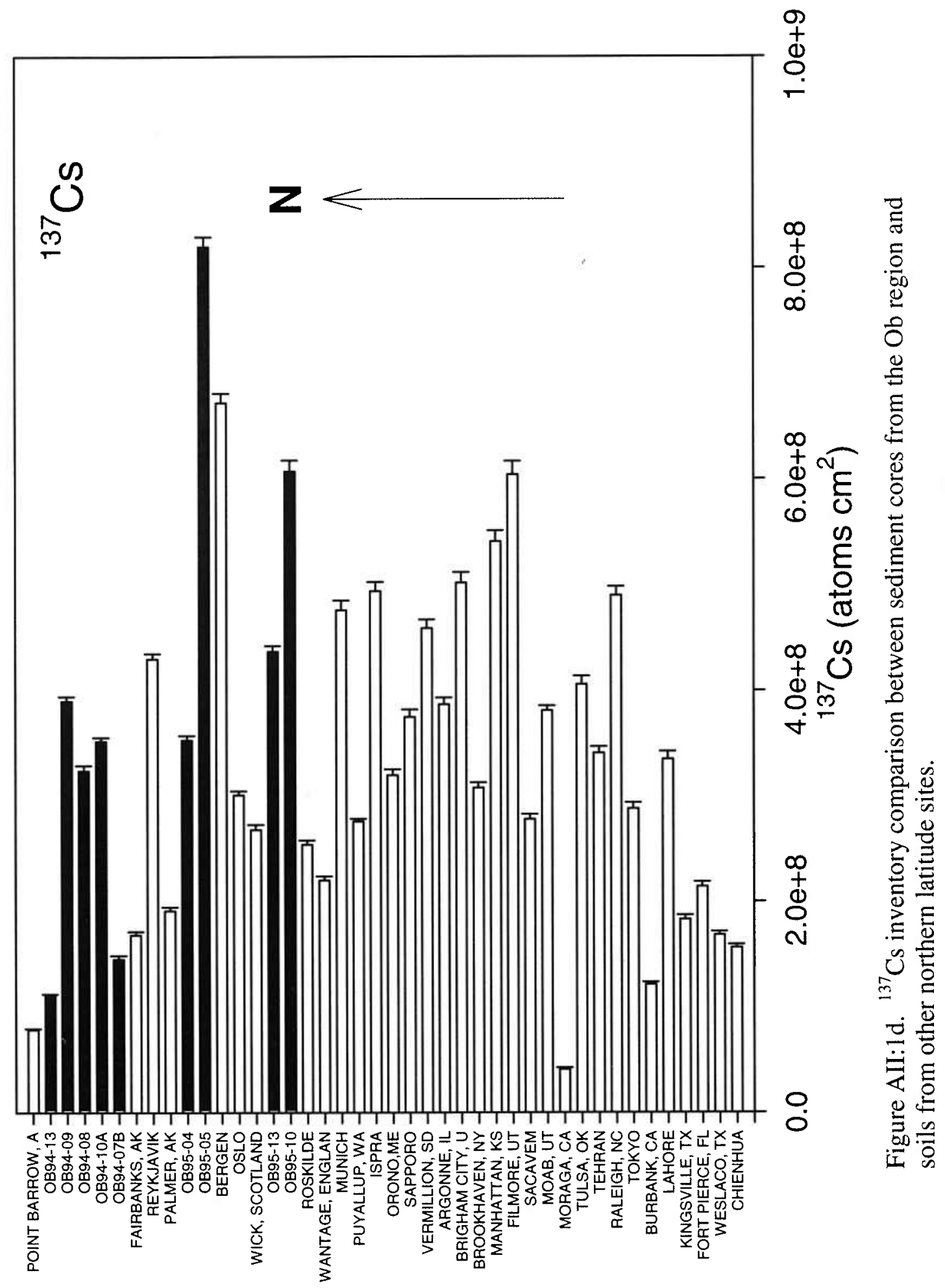

